\title{
Effect of Temperature Variation on the Structural Capacity of a Multi-Span Horizontally Curved Steel I-Girder Bridge
}

Christopher L. Beckett

West Virginia University

Follow this and additional works at: https://researchrepository.wvu.edu/etd

\section{Recommended Citation}

Beckett, Christopher L., "Effect of Temperature Variation on the Structural Capacity of a Multi-Span Horizontally Curved Steel I-Girder Bridge" (2011). Graduate Theses, Dissertations, and Problem Reports. 4691.

https://researchrepository.wvu.edu/etd/4691

This Thesis is protected by copyright and/or related rights. It has been brought to you by the The Research Repository @ WVU with permission from the rights-holder(s). You are free to use this Thesis in any way that is permitted by the copyright and related rights legislation that applies to your use. For other uses you must obtain permission from the rights-holder(s) directly, unless additional rights are indicated by a Creative Commons license in the record and/ or on the work itself. This Thesis has been accepted for inclusion in WVU Graduate Theses, Dissertations, and Problem Reports collection by an authorized administrator of The Research Repository @ WVU. For more information, please contact researchrepository@mail.wvu.edu. 
Effect of Temperature Variation on the Structural Capacity of a MultiSpan Horizontally Curved Steel I-Girder Bridge

\author{
Christopher L. Beckett
}

\author{
Thesis submitted to the \\ College of Engineering and Mineral Resources \\ at West Virginia University \\ in partial fulfillment of the requirements \\ for the degree of
}

\author{
Master of Science \\ in \\ Civil Engineering
}

Dr. Samir N. Shoukry, Ph.D., Chair

Dr. Gergis W. William, Ph.D., P.E.

Dr. David R. Martinelli, Ph.D., P.E.

Dr. Mourad Y. Riad, Ph.D.

Department of Civil and Environmental Engineering

Morgantown, West Virginia

2011

Keywords: Finite Element Modeling, Curved Steel I-Girder Bridges, Bearings, Temperature Load, Thermal Stress, Axial Stress 


\author{
ABSTRACT \\ Effect of Temperature Variation on the Structural Capacity of a \\ Multi-Span Horizontally Curved Steel I-Girder Bridge
}

Christopher L. Beckett

Horizontally curved steel I-girder bridges have become a popular bridge design choice among bridge engineers. The current level of knowledge regarding the design and analysis of curved I-girder bridges under thermal loading is incomplete. The thermal expansion of curved bridges is rather complicated and current standards provide little guidance when designing a bearing plan to prevent the development of thermal stresses and out-of-plane distortional behavior. Thermal stresses, in the form of axial compressive stresses, will develop if thermal expansion is constrained. This study examines the effect of different bearing arrangements on the development of thermal stresses and out-of-plane web distortions in a newly constructed bridge located in West Virginia. Three dimensional finite element modeling and analysis is performed in order to predict bridge response. The research shows that uniform thermal loading significantly increases the magnitude of out-ofplane web distortions. Finite element modeling also shows that very significant levels of thermal stress develop in the curved steel I-girders, consuming a considerable percentage of the bridge's total capacity. The web distortions and thermal stresses will result in major serviceability issues, shortening the life of the structure. However, this behavior is largely eliminated with the implementation of a new bearing arrangement, which removes the constraints from the original bearing plan. 


\section{SUMMARY}

\section{Effect of Temperature Variation on the Structural Capacity of a Multi-Span Horizontally Curved Steel I-Girder Bridge}

Horizontally curved steel I-girder bridges are popular because of its low cost compared to box girder bridge. The current level of knowledge regarding the design and analysis of curved I-girder bridges under thermal loading is incomplete. The thermal expansion of curved bridges is rather complicated and current standards provide little guidance when designing a bearing plan to prevent the development of excessive thermal stresses and out-of-plane web distortion. Thermal stresses, in the form of axial compressive stresses, will develop if thermal expansion is constrained due to inappropriate choice of bearing arrangement.

This study examines the effect of different bearing arrangements on the development of thermal stresses and out-of-plane web distortions in a newly constructed curved I Girder Bridge. The study is conducted using the actual design of a typical 11-spans I-girder bridge developed by a bridge design firm. Three dimensional nonlinear finite element modeling and analysis is performed in order to predict the bridge response to seasonal temperature variations. The model features detailed modeling of all splices, stiffeners, bearings, piers, etc. using shell elements. The model response is validated by comparing the 3DFEcalculated lateral deflection and web distortions with those measured on a typical bridge. The comparison indicates that deformation predicted through finite element modeling is only $27 \%$, on average, of that actually measured in the field. This indicates that the stresses predicted from the model will be a lower estimate of the actual stresses that develop in the bridge structure under similar loading conditions. The deviation between the computational and measured deformation is expected as the model results do not include girder fabrication error, permanent distortion during girder transportation, distortion due to erection errors, initial girder stresses developed at early age due to concrete curing and shrinkage, creep, etc.

The results obtained for the as-built bridge design indicate that temperature loading significantly increases the magnitude of out-of-plane web distortions outside the normal allowable limits in design codes. Excessive thermal compressive stresses develop in the curved steel I-girders, consuming up to 52 percent of the bridge's total structural capacity. The stresses developed in the girder webs exceeded the critical web stresses set forth by AASHTO. Taking in to consideration the contribution of the piers flexibility, the study concludes that curved I-girders should be sized and designed according the AASHTO LRFD provisions to sustain combined axial compression and flexure. The study also recommends that the web slenderness requirement should satisfy the 2003 AASHTO Design Specifications for Curved Bridges.

The curved steel I-girders were not designed strictly according to the AASHTO (2003) Design Specifications for Curved Bridges but rather some provisions that were under development for the next updated versions. This may be a reason for the unusually excessive web and flange distortions leading to significant concern about the short-term serviceability of the bridge. There is need to implement a cost-effective strategy to monitor the growth in permanent deformation of the bridge girders due to continued application of traffic and environmental loads. A new bearing arrangement for the bridge is developed in this work and is shown to largely alleviate the axial stresses and the associated web and flange distortion due to seasonal temperature changes. 


\section{ACKNOWLEDGEMENTS}

I would first like to give my deepest thanks to my research advisor, Dr. Samir Shoukry, for providing me with the opportunity to work closely with his exceptional research team the past 3 years. Thank you for the direction, advice and support you provided throughout my studies at West Virginia University.

Very sincere thanks go to my academic advisor, Dr. Gergis William, for all the help and support you gave me the past few years. Completion of this research would not have been possible without your deep knowledge and willingness to pass this knowledge on to me.

I would especially like to thank Dr. Shoukry, Dr. William, and Dr. Mourad Riad for providing the experimental data used to validate the 3D FE models developed for this research.

Thanks are extended to Dr. Eduardo Sosa and Kevyn McBride for their helpful advice during the development of the finite element models.

I would like to express my appreciation to the West Virginia Division of Highways for their financial support, making this research possible.

A very special thank you goes out to my parents for their on-going support and encouragement throughout my studies. 


\section{TABLE OF CONTENTS}

ABSTRACT

SUMMARY

ACKNOWLEDGEMENTS

TABLE OF CONTENTS

LIST OF FIGURES

LIST OF TABLES

CHAPTER ONE

INTRODUCTION

1.1 BACKGROUND

1.2 PROBLEM STATEMENT

1.3 RESEARCH OBJECTIVES

1.4 THESIS OUTLINE

CHAPTER TWO

LITERATURE REVIEW

2.1 INTRODUCTION

2.2 WEB BEHAVIOR

2.3 OUT-OF-PLANE DISTORTIONS 13

2.4 TRANSVERSE STIFFENERS 14

2.5 LONGITUDINAL STIFFENERS 15

2.6 FLANGE BEHAVIOR 16

2.7 CROSSFRAME SPACING AND BEHAVIOR 17

2.8 CONSTRUCTION ISSUES 19

2.9 FINITE ELEMENT ANALYSIS PARAMETRIC STUDY 22

2.10 THERMAL LOADING BEHAVIOR 24

2.11 AASHTO GUIDE SPECIFICATIONS FOR HORIZONTALLY CURVED STEEL GIRDER HIGHWAY BRIDGES (2003)

2.12 WEST VIRGINIA DIVISION OF HIGHWAYS BRIDGE DESIGN MANUAL (2004) 36

2.13 AISI STEEL BRIDGE BEARING SELECTION AND DESIGN GUIDE 38

2.14 AASHTO/NSBA STEEL BRIDGE COLLABORATION STEEL BRIDGE BEARING DESIGN AND DETAILING GUIDELINES 39

2.15 CONCLUSIONS

CHAPTER THREE

3D FINITE ELEMENT BRIDGE MODEL 43

$\begin{array}{lll}3.1 & \text { INTRODUCTION } & 43\end{array}$

3.2 BRIDGE LAYOUT AND GEOMETRY 43

3.3 SUPERSTRUCTURE ELEMENTS 45

3.4 CROSSFRAMES 49

3.5 FIELD SPLICES 49

3.6 BEARINGS AND BOUNDARY CONDITIONS

3.7 MATERIAL MODEL $\quad 55$

$\begin{array}{ll}3.8 & \text { LOADING } \\ \end{array}$ 
CHAPTER FOUR

OUT-OF-PLANE WEB DISTORTION UNDER_AS-BUILT BEARING

4.1 INTRODUCTION

4.2 AS-BUILT BEARING ARRANGEMENT PLAN 58

4.3 WEB DISTORTION PROFILES 61

4.4 LIVE LOAD EFFECTS

4.5 FE BRIDGE MODEL LINEARITY INVESIGATION 99

4.6 TOPCON IMAGING STATION RESULTS 101

4.7 WEB SLENDERNESS INVESTIGATION 104

$\begin{array}{lll}4.8 & \text { DISCUSSION AND CONCLUSIONS } & 106\end{array}$

CHAPTER FIVE

THERMAL STRESSES UNDER AS-BUILT BEARING ARRANGEMENT 108

$\begin{array}{lll}5.1 & \text { INTRODUCTION } & 108\end{array}$

$\begin{array}{lll}5.2 & \text { EFFECTIVE STRESSES } & 108\end{array}$

5.3 LONGITUDINAL STRESSES 118

$\begin{array}{lll}5.4 & \text { BENDING AND AXIAL STRESSES } & 129\end{array}$

5.5 THERMAL LOADING EFFECTS ON BRIDGE CAPACITY 144

$\begin{array}{lll}5.6 & \text { LIVE LOAD ANALYSIS } & 147\end{array}$

5.7 OUT-OF-PLANE DISTORTION EFFECTS 151

5.8 DISCUSSION AND CONCLUSIONS 153

CHAPTER SIX

OUT-OF-PLANE WEB DISTORTION UNDER_PROPOSED BEARING

ARRANGEMENT 155

6.1 INTRODUCTION 155

6.2 PROPOSED BEARING ARRANGEMENT PLAN 155

6.3 PROPOSED BOUNDARY CONDITIONS LONGITUDINAL WEB PROFILES 157

$\begin{array}{lll}\text { 6.4 DISCUSSION AND CONCLUSIONS } & 170\end{array}$

CHAPTER SEVEN

THERMAL STRESSES UNDER PROPOSED BEARING ARRANGEMENT 171

$\begin{array}{lll}7.1 & \text { INTRODUCTION } & 171\end{array}$

$\begin{array}{lll}7.2 & \text { EFFECTIVE STRESSES } & 171\end{array}$

$\begin{array}{lll}7.3 & \text { LONGITUDINAL STRESSES } & 181\end{array}$

$\begin{array}{lll}7.4 & \text { BENDING AND AXIAL STRESSES } & 191\end{array}$

7.5 NEW BEARING CONDITIONS EFFECT ON BRIDGE CAPACITY 205

$\begin{array}{lll}7.6 & \text { DISCUSSION AND CONCLUSIONS }\end{array}$

CHAPTER EIGHT

EFFECT PIER FLEXIBILITY ON WEB DISTORTIONS AND THERMAL STRESSES

$\begin{array}{lll}\text { 8.1 INTRODUCTION } & 209\end{array}$

8.2 PIER AND BEARING MODELING 209

8.3 EFFECT OF PIER FLEXIBILITY ON WEB DISTORTION 213 
8.4 EFFECT OF PIER FLEXIBILITY ON THERMAL STRESSES 221

8.5 PIER STRESSES DUE TO TEMPERATURE LOADS 236

8.6 DISCUSSION AND CONCLUSIONS 240

CHAPTER NINE

CONCLUSIONS AND FUTURE RESEARCH

$\begin{array}{lll}9.1 & \text { CONCLUSIONS } & 242\end{array}$

9.2 FUTURE RESEARCH 246

$\begin{array}{ll}\text { REFERENCES } & 248\end{array}$

$\begin{array}{ll}\text { APPENDIX A } & 253\end{array}$

$\begin{array}{ll}\text { APPENDIX B } & 262\end{array}$

$\begin{array}{ll}\text { APPENDIX C } & 270\end{array}$

$\begin{array}{ll}\text { APPENDIX D } & 279\end{array}$ 


\section{LIST OF FIGURES}

FIGURE 2.1 CURVED BRIDGE THERMAL EXPANSION 26

FIGURE 2.2 TEMPERATURE DISTRIBUTION FOR THERMAL LOAD 27

FIGURE 2.3 SUTTON CREEK BRIDGE ILLUSTRATION 28

FIGURE 2.4 BEARING LAYOUTS 30

FIGURE 3.1 BRIDGE SPAN CONFIGURATION (UNIT 1) 44

FIGURE 3.2 BRIDGE SPAN CONFIGURATION (UNIT 2) 44

FIGURE 3.3 TYPICAL BRIDGE CROSS-SECTION 45

FIGURE 3.4 MESH TRANSITION NEAR ABUTMENT 2N 47

FIGURE 3.5 MESH TRANSITION (SPAN 8N) 47

FIGURE 3.6 INTERMEDIATE STIFFENERS 48

FIGURE 3.7 BEARING, JACKING, AND AUXILIARY STIFFENERS 48

FIGURE 3.8 FIELD SPLICE DETAILS $\quad 51$

FIGURE 3.9 FIELD SPLICE LOCATIONS $\quad 52$

FIGURE 3.10 BEARING PLATE ILLUSTRATION 53

FIGURE 3.11 BEARING FIXITY CONDITIONS

FIGURE 4.1 AS-BUILT BEARING ARRANGEMENT (UNIT 1) 59

FIGURE 4.2 AS-BUILT BEARING ARRANGEMENT (UNIT 2) 60

FIGURE 4.3 SPAN 1N, OUT-OF-PLANE WEB DEFLECTION DUE TO $\begin{array}{ll}\text { SELF-WEIGHT } & 61\end{array}$

FIGURE 4.4 SPAN 2N, OUT-OF-PLANE WEB DEFLECTION DUE TO SELF-WEIGHT

FIGURE 4.5 SPAN 3N, OUT-OF-PLANE WEB DEFLECTION DUE TO SELF-WEIGHT $\quad 62$

FIGURE 4.6 SPAN 4N, OUT-OF-PLANE WEB DEFLECTION DUE TO SELF-WEIGHT

FIGURE 4.7 SPAN 5N, OUT-OF-PLANE WEB DEFLECTION DUE TO SELF-WEIGHT $\quad 62$

FIGURE 4.8 SPAN 6N, OUT-OF-PLANE WEB DEFLECTION DUE TO SELF-WEIGHT 63

FIGURE 4.9 SPAN 7N, OUT-OF-PLANE WEB DEFLECTION DUE TO SELF-WEIGHT

FIGURE 4.10 SPAN 8N, OUT-OF-PLANE WEB DEFLECTION DUE TO SELF-WEIGHT $\quad 63$

FIGURE 4.11 SPAN 9N, OUT-OF-PLANE WEB DEFLECTION DUE TO SELF-WEIGHT $\quad 64$

FIGURE 4.12 SPAN 10N, OUT-OF-PLANE WEB DEFLECTION DUE TO SELF-WEIGHT $\quad 64$

FIGURE 4.13 SPAN 11N, OUT-OF-PLANE WEB DEFLECTION DUE TO SELF-WEIGHT

FIGURE 4.14 SPAN 12N, OUT-OF-PLANE WEB DEFLECTION DUE TO SELF-WEIGHT

FIGURE 4.15 SPAN 1N, OUT-OF-PLANE WEB DEFLECTION DUE TO TEMP $-60^{\mathrm{O}} \mathrm{F}$ 
FIGURE 4.16 SPAN 2N, OUT-OF-PLANE WEB DEFLECTION DUE TO TEMP $-60^{\circ} \mathrm{F}$

FIGURE 4.17 SPAN 3N, OUT-OF-PLANE WEB DEFLECTION DUE TO TEMP $-60^{\mathrm{O}} \mathrm{F}$

FIGURE 4.18 SPAN 4N, OUT-OF-PLANE WEB DEFLECTION DUE TO TEMP $-60^{\circ} \mathrm{F}$

FIGURE 4.19 SPAN 5N, OUT-OF-PLANE WEB DEFLECTION DUE TO TEMP $-60^{\circ} \mathrm{F}$

FIGURE 4.20 SPAN 6N, OUT-OF-PLANE WEB DEFLECTION DUE TO TEMP $-60^{\circ} \mathrm{F}$

FIGURE 4.21 SPAN 7N, OUT-OF-PLANE WEB DEFLECTION DUE TO TEMP $-60^{\circ} \mathrm{F}$

FIGURE 4.22 SPAN 8N, OUT-OF-PLANE WEB DEFLECTION DUE TO TEMP $-60^{\circ} \mathrm{F}$

FIGURE 4.23 SPAN 9N, OUT-OF-PLANE WEB DEFLECTION DUE TO TEMP $-60^{\circ} \mathrm{F}$

FIGURE 4.24 SPAN 10N, OUT-OF-PLANE WEB DEFLECTION DUE TO TEMP $-60^{\circ} \mathrm{F}$

FIGURE 4.25 SPAN 11N, OUT-OF-PLANE WEB DEFLECTION DUE TO TEMP $-60^{\circ} \mathrm{F}$

FIGURE 4.26 SPAN 12N, OUT-OF-PLANE WEB DEFLECTION DUE TO TEMP $-60^{\circ} \mathrm{F}$

FIGURE 4.27 SPAN 1N, OUT-OF-PLANE WEB DEFLECTION DUE TO TEMP $+60^{\circ} \mathrm{F}$

FIGURE 4.28 SPAN 2N, OUT-OF-PLANE WEB DEFLECTION DUE TO TEMP $+60^{\circ} \mathrm{F}$

FIGURE 4.29 SPAN 3N, OUT-OF-PLANE WEB DEFLECTION DUE TO TEMP $+60^{\circ} \mathrm{F}$

FIGURE 4.30 SPAN 4N, OUT-OF-PLANE WEB DEFLECTION DUE TO TEMP $+60^{\circ} \mathrm{F}$

FIGURE 4.31 SPAN 5N, OUT-OF-PLANE WEB DEFLECTION DUE TO TEMP $+60^{\circ} \mathrm{F}$

FIGURE 4.32 SPAN 6N, OUT-OF-PLANE WEB DEFLECTION DUE TO TEMP $+60^{\circ} \mathrm{F}$

FIGURE 4.33 SPAN 7N, OUT-OF-PLANE WEB DEFLECTION DUE TO TEMP $+60^{\circ} \mathrm{F}$

FIGURE 4.34 SPAN 8N, OUT-OF-PLANE WEB DEFLECTION DUE TO TEMP $+60^{\circ} \mathrm{F}$

FIGURE 4.35 SPAN 9N, OUT-OF-PLANE WEB DEFLECTION DUE TO TEMP $+60^{\circ} \mathrm{F}$

FIGURE 4.36 SPAN 10N, OUT-OF-PLANE WEB DEFLECTION DUE TO TEMP $+60^{\circ} \mathrm{F}$

FIGURE 4.37 SPAN 11N, OUT-OF-PLANE WEB DEFLECTION DUE TO TEMP $+60^{\circ} \mathrm{F}$

FIGURE 4.38 SPAN 12N, OUT-OF-PLANE WEB DEFLECTION DUE TO TEMP $+60^{\circ} \mathrm{F}$ 
FIGURE 4.39 SPAN 1N, OUT-OF-PLANE WEB DEFLECTION DUE TO TEMP $+90^{\circ} \mathrm{F}$

FIGURE 4.40 SPAN 2N, OUT-OF-PLANE WEB DEFLECTION DUE TO $\mathrm{TEMP}+90^{\circ} \mathrm{F}$

FIGURE 4.41 SPAN 3N, OUT-OF-PLANE WEB DEFLECTION DUE TO TEMP $+90^{\circ} \mathrm{F}$

FIGURE 4.42 SPAN 4N, OUT-OF-PLANE WEB DEFLECTION DUE TO TEMP $+90^{\circ} \mathrm{F}$

FIGURE 4.43 SPAN 5N, OUT-OF-PLANE WEB DEFLECTION DUE TO $\mathrm{TEMP}+90^{\circ} \mathrm{F}$

FIGURE 4.44 SPAN 6N, OUT-OF-PLANE WEB DEFLECTION DUE TO $\mathrm{TEMP}+90^{\circ} \mathrm{F}$

FIGURE 4.45 SPAN 7N, OUT-OF-PLANE WEB DEFLECTION DUE TO $\mathrm{TEMP}+90^{\mathrm{O}} \mathrm{F}$

FIGURE 4.46 SPAN 8N, OUT-OF-PLANE WEB DEFLECTION DUE TO TEMP $+90^{\circ} \mathrm{F}$

FIGURE 4.47 SPAN 9N, OUT-OF-PLANE WEB DEFLECTION DUE TO TEMP $+90^{\circ} \mathrm{F}$

FIGURE 4.48 SPAN 10N, OUT-OF-PLANE WEB DEFLECTION DUE TO TEMP $+90^{\circ} \mathrm{F}$

FIGURE 4.49 SPAN 11N, OUT-OF-PLANE WEB DEFLECTION DUE TO TEMP $+90^{\mathrm{O}} \mathrm{F}$

FIGURE 4.50 SPAN 12N, OUT-OF-PLANE WEB DEFLECTION DUE TO TEMP $+90^{\circ} \mathrm{F}$

FIGURE 4.51 AS-BUILT TRANSVERSE WEB PROFILES (UNIT 1)

FIGURE 4.52 AS-BUILT TRANSVERSE WEB PROFILE (UNIT 2)

FIGURE 4.53 I-SECTION BUCKLING MODES

FIGURE 4.54 FE BRIDGE MODEL DISPLACEMENT CONTOURS (SPAN 3N DUE TO $+90^{\circ} \mathrm{F}$ TEMPERATURE LOAD)

FIGURE 4.55 FE BRIDGE MODEL DISPLACEMENT CONTOURS

(SPAN 5N DUE TO $+90^{\circ} \mathrm{F}$ TEMPERATURE LOAD)

FIGURE 4.56 FE MODEL DISPLACEMENT CONTOURS

(PIER 9N AND SPAN 10N DUE TO BRIDGE SELF-WEIGHT)

FIGURE 4.57 FE MODEL DISPLACEMENT CONTOURS

(SPANS 7N AND 8N DUE TO BRIDGE SELF-WEIGHT) 91

FIGURE 4.58 FE MODEL DISPLACEMENT CONTOURS

(SPANS 7N AND 8N DUE TO $+90^{\circ} \mathrm{F}$ TEMPERATURE LOAD)

FIGURE 4.59 FE MODEL DISPLACEMENT CONTOURS (PIER 9N AND SPAN 10N DUE TO $+90^{\circ} \mathrm{F}$ TEMPERATURE LOAD)

FIGURE 4.60 MAXIMUM OUT-OF-PLANE DISTORTION PER SPAN UNDER 94 AS-BUILT BEARING ARRANGEMENT 94

FIGURE 4.61 AASHTO HS20-44 TRUCK LOAD CONFIGURATION 96

FIGURE 4.62 SPAN 8N OUT-OF-PLANE DEFLECTION (LIVE LOAD + SELF-WEIGHT) 97

FIGURE 4.63 SPAN 8N OUT-OF-PLANE DEFLECTION

$\left(\right.$ LIVE LOAD + TEMP $+60^{\circ} \mathrm{F}+$ SELF-WEIGHT) 
FIGURE 4.64 SPAN 8N OUT-OF-PLANE DEFLECTION

(LIVE LOAD + TEMP $+90^{\circ} \mathrm{F}+$ SELF-WEIGHT)

FIGURE 4.65 TRANSVERSE DEFLECTION PROFILE FOR SPAN 8N

A) SELF-WEIGHT + LIVE LOAD

B) TEMP $+60^{\circ} \mathrm{F}+$ LIVE LOAD

C) TEMP $+90^{\circ} \mathrm{F}+$ LIVE LOAD

FIGURE 4.66 TRANSVERSE WEB PROFILE COMPARISONS 100

FIGURE 4.67 OUT-OF-PLANE DISPLACEMENT AT VARIOUS WEB DEPTHS 100

FIGURE 4.68 SPAN 1N TOPCON IMAGING STATION MEASUREMENTS COMPARISON

102

FIGURE 4.69 SPAN 2N TOPCON IMAGING STATION MEASUREMENTS COMPARISON

102

FIGURE 4.70 SPAN 3N TOPCON IMAGING STATION MEASUREMENTS COMPARISON

FIGURE 5.1 AS-BUILT, EFFECTIVE STRESS PROFILES FOR SPAN 7N

FIGURE 5.2 AS-BUILT, EFFECTIVE STRESS PROFILES FOR SPAN 8N

FIGURE 5.3 AS-BUILT, EFFECTIVE STRESS PROFILES FOR SPAN 9N

FIGURE 5.4 AS-BUILT, EFFECTIVE STRESS PROFILES FOR SPAN 10N

110

110

FIGURE 5.5 AS-BUILT, EFFECTIVE STRESS PROFILES FOR SPAN 11N

FIGURE 5.6 AS-BUILT, EFFECTIVE STRESS PROFILES FOR PIER 7N

FIGURE 5.7 AS-BUILT, EFFECTIVE STRESS PROFILES FOR PIER 8N FIGURE 5.8 AS-BUILT, EFFECTIVE STRESS PROFILES FOR PIER 9N

FIGURE 5.9 AS-BUILT, EFFECTIVE STRESS PROFILES FOR PIER 10N

112

112

112

FIGURE 5.10 AS-BUILT, EFFECTIVE STRESS PROFILES FOR PIER 11N

FIGURE 5.11 PIER 7N FE MODEL EFFECTIVE STRESS CONTOUR PLOT $\left(+90^{\circ} \mathrm{F}\right.$ TEMPERATURE LOAD)

114

FIGURE 5.12 PIER 9N FE MODEL EFFECTIVE STRESS CONTOUR PLOT $\left(+90^{\circ} \mathrm{F}\right.$ TEMPERATURE LOAD)

FIGURE 5.13 PIER 2N FE MODEL EFFECTIVE STRESS CONTOUR PLOT $\left(+90^{\circ} \mathrm{F}\right.$ TEMPERATURE LOAD)

FIGURE 5.14 PIER 4N FE MODEL EFFECTIVE STRESS CONTOUR PLOT $\left(+90^{\circ} \mathrm{F}\right.$ TEMPERATURE LOAD)

FIGURE 5.15 FE MODEL EFFECTIVE STRESS CONTOUR PLOTS

$\left(+90^{\circ} \mathrm{F}\right.$ TEMPERATURE LOAD $)$

FIGURE 5.16 AS-BUILT, LONGITUDINAL STRESS PROFILES FOR SPAN 7N 119

FIGURE 5.17 AS-BUILT, LONGITUDINAL STRESS PROFILES FOR SPAN 8N 119

FIGURE 5.18 AS-BUILT, LONGITUDINAL STRESS PROFILES FOR SPAN 9N 119

FIGURE 5.19 AS-BUILT, LONGITUDINAL STRESS PROFILES FOR SPAN 10N 120

FIGURE 5.20 AS-BUILT, LONGITUDINAL STRESS PROFILES FOR SPAN 11N 120

FIGURE 5.21 AS-BUILT, LONGITUDINAL STRESS PROFILES FOR PIER 7N 120

FIGURE 5.22 AS-BUILT, LONGITUDINAL STRESS PROFILES FOR PIER 8N 121

FIGURE 5.23 AS-BUILT, LONGITUDINAL STRESS PROFILES FOR PIER 9N 121

FIGURE 5.24 AS-BUILT, LONGITUDINAL STRESS PROFILES FOR PIER 10N 121

FIGURE 5.25 AS-BUILT, LONGITUDINAL STRESS PROFILES FOR PIER 11N 122

FIGURE 5.26 MAXIMUM LONGITUDINAL STRESS AT MIDSPAN

(POSITIVE MOMENT) 
FIGURE 5.27 MAXIMUM LONGITUDINAL STRESS AT PIERS

(NEGATIVE MOMENT) 124

FIGURE 5.28 DESIGN $F_{C R}$ VS. FE COMPUTED $F_{C R}$ (SPAN LOCATIONS) 126

FIGURE 5.29 DESIGN $F_{C R}$ VS. FE MODEL COMPUTED $F_{C R}$ (PIER LOCATIONS) 127

FIGURE 5.30 FE MODEL LONGITUDINAL STRESS BAND PLOTS FOR UNIT 2 $\left(+90^{\circ} \mathrm{F}\right.$ TEMPERATURE LOAD)

FIGURE 5.31 AS-BUILT, SPAN 7N BENDING AND AXIAL STRESSES UNDER SELF-WEIGHT

FIGURE 5.32 AS-BUILT, SPAN 8N BENDING AND AXIAL STRESSES UNDER SELF-WEIGHT

FIGURE 5.33 AS-BUILT, SPAN 9N BENDING AND AXIAL STRESSES UNDER SELF-WEIGHT

FIGURE 5.34 AS-BUILT, SPAN 10N BENDING AND AXIAL STRESSES UNDER SELF-WEIGHT

FIGURE 5.35 AS-BUILT, SPAN 11N BENDING AND AXIAL STRESSES UNDER SELF-WEIGHT

FIGURE 5.36 AS-BUILT, PIER 7N BENDING AND AXIAL STRESS UNDER SELF-WEIGHT

FIGURE 5.37 AS-BUILT, PIER 8N BENDING AND AXIAL STRESSES UNDER SELF-WEIGHT

FIGURE 5.38 AS-BUILT, PIER 9N BENDING AND AXIAL STRESSES UNDER SELF-WEIGHT

FIGURE 5.39 AS-BUILT, PIER 10N BENDING AND AXIAL STRESSES UNDER SELF-WEIGHT

FIGURE 5.40 AS-BUILT, PIER 11N BENDING AND AXIAL STRESSES UNDER SELF-WEIGHT

FIGURE 5.41 AS-BUILT, SPAN 7N BENDING AND AXIAL STRESSES UNDER TEMP $+90^{\circ} \mathrm{F}$

FIGURE 5.42 AS-BUILT, SPAN 8N BENDING AND AXIAL STRESSES UNDER TEMP $+90^{\circ} \mathrm{F}$

FIGURE 5.43 AS-BUILT, SPAN 9N BENDING AND AXIAL STRESSES UNDER TEMP $+90^{\circ} \mathrm{F}$

FIGURE 5.44 AS-BUILT, SPAN 10N BENDING AND AXIAL STRESSES UNDER TEMP $+90^{\circ} \mathrm{F}$

FIGURE 5.45 AS-BUILT, SPAN 11N BENDING AND AXIAL STRESSES UNDER TEMP $+90^{\circ} \mathrm{F}$

FIGURE 5.46 AS-BUILT, PIER 7N BENDING AND AXIAL STRESSES UNDER TEMP $+90^{\circ} \mathrm{F}$

FIGURE 5.47 AS-BUILT, PIER 8N BENDING AND AXIAL STRESSES UNDER TEMP $+90^{\circ} \mathrm{F}$

FIGURE 5.48 AS-BUILT, PIER 9N BENDING AND AXIAL STRESSES UNDER TEMP $+90^{\circ} \mathrm{F}$

FIGURE 5.49 AS-BUILT, PIER 10N BENDING AND AXIAL STRESSES UNDER TEMP $+90^{\circ} \mathrm{F}$

FIGURE 5.50 AS-BUILT, PIER 11N BENDING AND AXIAL STRESSES UNDER $\mathrm{TEMP}+90^{\circ} \mathrm{F}$ 
FIGURE 5.51 AXIAL STRESS COMPARISON UNDER AS-BUILT BEARING ARRANGEMENT

FIGURE 5.52 AXIAL STRESS COMPARISON UNDER AS-BUILT BEARING ARRANGEMENT

FIGURE 5.53 AXIAL CAPACITY CONSUMED (SPAN LOCATIONS)

FIGURE 5.54 AXIAL CAPACITY CONSUMED (PIER LOCATIONS)

FIGURE 5.55 AS-BUILT, LONGITUDINAL STRESS PROFILE OF PIER 7N DUE TO SELF-WEIGHT + LIVE LOAD

FIGURE 5.56 AS-BUILT, BENDING AND AXIAL STRESS PROFILES AT PIER 7N DUE TO SELF-WEIGHT + LIVE LOAD

FIGURE 5.57 AS-BUILT, LONGITUDINAL STRESS PROFILE OF SPAN 8N DUE TO SELF-WEIGHT + LIVE LOAD

FIGURE 5.58 AS-BUILT, BENDING AND AXIAL STRESS PROFILES AT SPAN 8N DUE TO SELF-WEIGHT + LIVE LOAD

FIGURE 5.59 AS-BUILT, LONGITUDINAL STRESS PROFILE OF PIER 7N DUE TO TEMP $+60^{\circ} \mathrm{F}+$ LIVE LOAD

FIGURE 5.60 AS-BUILT, BENDING AND AXIAL STRESS PROFILES AT PIER 7N DUE TO_TEMP $+60^{\circ} \mathrm{F}+$ LIVE LOAD

FIGURE 5.61 AS-BUILT, LONGITUDINAL STRESS PROFILE OF SPAN 8N DUE TO TEMP $+60^{\circ} \mathrm{F}+$ LIVE LOAD

FIGURE 5.62 AS-BUILT, BENDING AND AXIAL STRESS PROFILES AT SPAN $8 \mathrm{~N}$ DUE TO TEMP $+60^{\circ} \mathrm{F}+$ LIVE LOAD

FIGURE 5.63 AS-BUILT, LONGITUDINAL STRESS PROFILE OF SPAN 8N DUE TO TEMP $+90^{\circ} \mathrm{F}+$ LIVE LOAD

FIGURE 5.64 AS-BUILT, BENDING AND AXIAL STRESS PROFILES AT SPAN 8 N DUE TO TEMP $+90^{\circ} \mathrm{F}+$ LIVE LOAD

FIGURE 6.1 PROPOSED BEARING ARRANGEMENT PLAN (UNIT 2)

FIGURE 6.2 LONGITUDINAL PROFILES COMPARISON OF SPAN 7N DUE TO TEMP $+60^{\circ} \mathrm{F}$

FIGURE 6.3 LONGITUDINAL PROFILES COMPARISON OF SPAN 8N DUE TO TEMP $+60^{\circ} \mathrm{F}$

FIGURE 6.4 LONGITUDINAL PROFILES COMPARISON OF SPAN 9N DUE TO TEMP $+60^{\circ} \mathrm{F}$

FIGURE 6.5 LONGITUDINAL PROFILES COMPARISON OF SPAN 10N DUE TO TEMP $+60^{\circ} \mathrm{F}$

FIGURE 6.6 LONGITUDINAL PROFILES COMPARISON OF SPAN 11N DUE TO TEMP $+60^{\circ} \mathrm{F}$

FIGURE 6.7 LONGITUDINAL PROFILES COMPARISON OF SPAN 12N DUE TO TEMP $+60^{\circ} \mathrm{F}$

FIGURE 6.8 LONGITUDINAL PROFILES COMPARISON OF SPAN 7N DUE TO TEMP $+90^{\circ} \mathrm{F}$

FIGURE 6.9 LONGITUDINAL PROFILES COMPARISON OF SPAN 8N DUE TO TEMP $+90^{\circ} \mathrm{F}$

FIGURE 6.10 LONGITUDINAL PROFILES COMPARISON OF SPAN 9N DUE TO TEMP $+90^{\circ} \mathrm{F}$ 
FIGURE 6.11 LONGITUDINAL PROFILES COMPARISON OF SPAN 10N DUE TO TEMP $+90^{\circ} \mathrm{F}$

FIGURE 6.12 LONGITUDINAL PROFILES COMPARISON OF SPAN 11N DUE TO TEMP $+90^{\circ} \mathrm{F}$

FIGURE 6.13 LONGITUDINAL PROFILES COMPARISON OF SPAN 12N DUE TO TEMP $+90^{\circ} \mathrm{F}$

FIGURE 6.14 COMPARISON OF MAXIMUM LATERAL DISPLACEMENT DUE TO SELF-WEIGHT

FIGURE 6.15 COMPARISON OF MAXIMUM LATERAL DISPLACEMENT DUE TO TEMP $-60^{\circ} \mathrm{F}$

FIGURE 6.16 COMPARISON OF MAXIMUM LATERAL DISPLACEMENT DUE TO TEMP $+60^{\circ} \mathrm{F}$

FIGURE 6.17 COMPARISON OF MAXIMUM LATERAL DISPLACEMENT DUE TO TEMP $+90^{\circ} \mathrm{F}$

FIGURE 6.18 TRANSVERSE WEB PROFILE COMPARISONS UNDER $-60^{\circ} \mathrm{F}$ TEMPERATURE LOAD

FIGURE 6.19 TRANSVERSE WEB PROFILE COMPARISONS UNDER $+60^{\circ} \mathrm{F}$ TEMPERATURE LOAD

FIGURE 6.20 TRANSVERSE WEB PROFILE COMPARISONS UNDER $+90^{\circ} \mathrm{F}$ TEMPERATURE LOAD

FIGURE 7.1 NEW BEARINGS, EFFECTIVE STRESS PROFIELS FOR SPAN 7N FIGURE 7.2 NEW BEARINGS, EFFECTIVE STRESS PROFILES FOR SPAN 8N

FIGURE 7.5 NEW BEARINGS, EFFECTIVE STRESS PROFILES FOR SPAN 11N 173 FIGURE 7.6 AS-BUILT - NEW BEARINGS EFF. STRESS COMPARISON UNDER SELF-WEIGHT (SPANS)

FIGURE 7.7 AS-BUILT - NEW BEARINGS EFF. STRESS COMPARISON UNDER TEMP $-60^{\circ} \mathrm{F}$ (SPANS)

FIGURE 7.8 AS-BUILT - NEW BEARINGS EFF. STRESS COMPARISON UNDER TEMP $+60^{\circ} \mathrm{F}$ (SPANS)

FIGURE 7.9 AS-BUILT - NEW BEARINGS EFF. STRESS COMPARISON UNDER TEMP $+90^{\circ} \mathrm{F}$ (SPANS)

FIGURE 7.10 NEW BEARINGS, EFFECTIVE STRESS PROFILES FOR PIER 7N 176

FIGURE 7.11 NEW BEARINGS, EFFECTIVE STRESS PROFILES FOR PIER 8N 176

FIGURE 7.12 NEW BEARINGS, EFFECTIVE STRESS PROFILES FOR PIER 9N 176

FIGURE 7.13 NEW BEARINGS, EFFECTIVE STRESS PROFILES FOR PIER 10N 177

FIGURE 7.14 NEW BEARINGS, EFFECTIVE STRESS PROFILES FOR PIER 11N 177

FIGURE 7.15 AS-BUILT - NEW BEARINGS EFF. STRESS COMPARISON UNDER SELF-WEIGHT (PIERS)

FIGURE 7.16 AS-BUILT - NEW BEARINGS EFF. STRESS COMPARISON UNDER TEMP $-60^{\circ} \mathrm{F}$ (PIERS)

FIGURE 7.17 AS-BUILT - NEW BEARINGS EFF. STRESS COMPARISON UNDER TEMP $+60^{\circ} \mathrm{F}$ (PIERS)

FIGURE 7.18 AS-BUILT - NEW BEARINGS EFF. STRESS COMPARISON UNDER TEMP $+90^{\circ} \mathrm{F}$ (PIERS) 
FIGURE 7.19 GIRDER 1N, FE MODEL EFFECTIVE STRESS CONTOUR PLOT 180

$\left(+90^{\circ} \mathrm{F}\right.$ TEMPERATURE LOAD, NEW BEARINGS) 180

FIGURE 7.20 GIRDER 1N, ABUTMENT 2N FE MODEL EFFECTIVE STRESS

CONTOUR PLOT $\left(+90^{\circ} \mathrm{F}\right.$ TEMPERATURE LOAD, NEW BEARINGS) 180

FIGURE 7.21 NEW BEARINGS, LONGITUDINAL STRESS PROFILES FOR SPAN 7N

FIGURE 7.22 NEW BEARINGS, LONGITUDINAL STRESS PROFILES FOR SPAN 8N

FIGURE 7.23 NEW BEARINGS, LONGITUDINAL STRESS PROFILES FOR SPAN 9N

FIGURE 7.24 NEW BEARINGS, LONGITUDINAL STRESS PROFILES FOR SPAN 10N

FIGURE 7.25 NEW BEARINGS, LONGITUDINAL STRESS PROFILES FOR SPAN 11N

FIGURE 7.26 AS-BUILT - NEW BEARINGS LONG. STRESS COMPARISON UNDER SELF-WEIGHT (SPANS)

FIGURE 7.27 AS-BUILT - NEW BEARINGS LONG. STRESS COMPARISON UNDER TEMP $+60^{\circ} \mathrm{F}$ (SPANS)

FIGURE 7.28 AS-BUILT - NEW BEARINGS LONG. STRESS COMPARISON UNDER TEMP $+90^{\circ} \mathrm{F}$ (SPANS)

FIGURE 7.29 NEW BEARINGS, LONGITUDINAL STRESS PROFILES FOR PIER 7N

FIGURE 7.30 NEW BEARINGS, LONGITUDINAL STRESS PROFILES FOR PIER 8N

FIGURE 7.31 NEW BEARINGS, LONGITUDINAL STRESS PROFILES FOR PIER 9N

FIGURE 7.32 NEW BEARINGS, LONGITUDINAL STRESS PROFILES FOR PIER 10N

FIGURE 7.33 NEW BEARINGS, LONGITUDINAL STRESS PROFILES FOR PIER $11 \mathrm{~N}$

FIGURE 7.34 AS-BUILT - NEW BEARINGS LONG. STRESS COMPARISON UNDER SELF-WEIGHT (PIERS)

FIGURE 7.35 AS-BUILT - NEW BEARINGS LONG. STRESS COMPARISON UNDER TEMP $+60^{\circ} \mathrm{F}$ (PIERS)

FIGURE 7.36 AS-BUILT - NEW BEARINGS LONG. STRESS COMPARISON UNDER TEMP $+90^{\circ} \mathrm{F}$ (PIERS)

FIGURE 7.37 FE MODEL LONGITUDINAL STRESS BAND PLOTS FOR UNIT 2 UNDER PROPOSED BEARING ARRANGEMENT $\left(+90^{\circ} \mathrm{F}\right.$ TEMPERATURE LOAD)

FIGURE 7.38 NEW BEARINGS, SPAN 7N BENDING AND AXIAL STRESSES UNDER TEMP $+60^{\circ} \mathrm{F}$

FIGURE 7.39 NEW BEARINGS, SPAN 8N BENDING AND AXIAL STRESSES UNDER TEMP $+60^{\circ} \mathrm{F}$

FIGURE 7.40 NEW BEARINGS, SPAN 9N BENDING AND AXIAL STRESSES UNDER TEMP $+60^{\circ} \mathrm{F}$

FIGURE 7.41 NEW BEARINGS, SPAN 10N BENDING AND AXIAL STRESSES UNDER TEMP $+60^{\circ} \mathrm{F}$ 
FIGURE 7.42 NEW BEARINGS, SPAN 11N BENDING AND AXIAL STRESSES UNDER TEMP $+60^{\circ} \mathrm{F}$

FIGURE 7.43 NEW BEARINGS, PIER 7N BENDING AND AXIAL STRESSES UNDER TEMP $+60^{\circ} \mathrm{F}$

FIGURE 7.44 NEW BEARINGS, PIER 8N BENDING AND AXIAL STRESSES UNDER TEMP $+60^{\circ} \mathrm{F}$

FIGURE 7.45 NEW BEARINGS, PIER 9N BENDING AND AXIAL STRESSES UNDER TEMP $+60^{\circ} \mathrm{F}$

FIGURE 7.46 NEW BEARINGS, PIER 10N BENDING AND AXIAL STRESSES UNDER TEMP $+60^{\circ} \mathrm{F}$

FIGURE 7.47 NEW BEARINGS, PIER 11N BENDING AND AXIAL STRESSES UNDER TEMP $+60^{\circ} \mathrm{F}$

FIGURE 7.48 AS-BUILT - NEW BEARINGS, AXIAL STRESS COMPARISON UNDER TEMP $+60^{\circ} \mathrm{F}$ (SPANS)

FIGURE 7.49 AS-BUILT - NEW BEARINGS, AXIAL STRESS COMPARISON UNDER TEMP $+60^{\circ} \mathrm{F}$ (PIERS)

FIGURE 7.50 NEW BEARINGS, SPAN 7N BENDING AND AXIAL STRESSES UNDER TEMP $+90^{\circ} \mathrm{F}$

FIGURE 7.51 NEW BEARINGS, SPAN 8N BENDING AND AXIAL STRESSES UNDER TEMP $+90^{\circ} \mathrm{F}$

FIGURE 7.52 NEW BEARINGS, SPAN 9N BENDING AND AXIAL STRESSES UNDER TEMP $+90^{\circ} \mathrm{F}$

FIGURE 7.53 NEW BEARINGS, SPAN 10N BENDING AND AXIAL STRESSES UNDER TEMP $+90^{\circ} \mathrm{F}$

FIGURE 7.54 NEW BEARINGS, SPAN 11N BENDING AND AXIAL STRESSES UNDER TEMP $+90^{\circ} \mathrm{F}$

FIGURE 7.55 NEW BEARINGS, PIER 7N BENDING AND AXIAL STRESSES UNDER TEMP $+90^{\circ} \mathrm{F}$

FIGURE 7.56 NEW BEARINGS, PIER 8N BENDING AND AXIAL STRESSES UNDER TEMP $+90^{\circ} \mathrm{F}$

FIGURE 7.57 NEW BEARINGS, PIER 9N BENDING AND AXIAL STRESSES UNDER TEMP $+90^{\circ} \mathrm{F}$

FIGURE 7.58 NEW BEARINGS, PIER 10N BENDING AND AXIAL STRESSES UNDER TEMP $+90^{\circ} \mathrm{F}$

FIGURE 7.59 NEW BEARINGS, PIER 11N BENDING AND AXIAL STRESSES UNDER TEMP $+90^{\circ} \mathrm{F}$

FIGURE 7.60 AS-BUILT - NEW BEARINGS, AXIAL STRESS COMPARISON UNDER TEMP $+90^{\circ} \mathrm{F}$ (SPANS)

FIGURE 7.61 AS-BUILT - NEW BEARINGS, AXIAL STRESS COMPARISON UNDER TEMP $+90^{\circ} \mathrm{F}$ (PIERS)

FIGURE 7.62 NEW BEARINGS, AXIAL STRESS DUE TO TEMPERATURE LOADS (SPANS)

FIGURE 7.63 NEW BEARINGS, AXIAL STRESS DUE TO TEMPERATURE LOADS (PIERS)

FIGURE 7.64 AXIAL CAPACITY COMPARISON UNDER SELF-WEIGHT (SPANS) 202 FIGURE 7.65 AXIAL CAPACITY COMPARISON UNDER SELF-WEIGHT (PIERS) 203 FIGURE 7.66 AXIAL CAPACITY COMPARISON UNDER TEMP $+60^{\circ} \mathrm{F}$ (SPANS) 203 
FIGURE 7.67 AXIAL CAPACITY COMPARISON UNDER TEMP $+60^{\circ} \mathrm{F}$ (PIERS) 203

FIGURE 7.68 AXIAL CAPACITY COMPARISON UNDER TEMP $+90^{\circ} \mathrm{F}$ (SPANS) 204

FIGURE 7.69 AXIAL CAPACITY COMPARISON UNDER TEMP $+90^{\circ} \mathrm{F}$ (PIERS) 204

FIGURE 7.70 AS-BUILT - NEW BEARINGS, TOTAL CAPACITY COMPARISON (TEMP $+60^{\circ} \mathrm{F}$, SPANS)

206

FIGURE 7.71 AS-BUILT - NEW BEARINGS, TOTAL CAPACITY COMPARISON (TEMP $+60^{\circ} \mathrm{F}$, PIERS)

FIGURE 7.72 AS-BUILT - NEW BEARINGS, TOTAL CAPACITY COMPARISON (TEMP $+90^{\circ} \mathrm{F}$, SPANS)

206

207

FIGURE 7.73 AS-BUILT - NEW BEARINGS, TOTAL CAPACITY COMPARISON $\left(\right.$ TEMP $+90^{\circ} \mathrm{F}$, PIERS)

FIGURE 8.1 UNIT 2 FE MODEL WITH PIERS (ISO-VIEW 1) 210

FIGURE 8.2 UNIT 2 FE MODEL WITH PIERS (ISO-VIEW 2) 211

FIGURE 8.3 PIER 6N, PIER CAP MESH 212

FIGURE 8.4 PIER 7N, PIER CAP MESH AND SPRING ELEMENTS 212

FIGURE 8.5 SPAN 7N, LONG. PROFILE COMPARISON WITH ADDITION OF PIERS (SELF-WEIGHT)

213

FIGURE 8.6 SPAN 8N, LONG. PROFILE COMPARISON WITH ADDITION OF PIERS (SELF-WEIGHT)

FIGURE 8.7 SPAN 9N, LONG. PROFILE COMPARISON WITH ADDITION OF PIERS (SELF-WEIGHT)

214

FIGURE 8.8 SPAN 10N, LONG. PROFILE COMPARISON WITH ADDITION OF PIERS (SELF-WEIGHT)

214

FIGURE 8.9 SPAN 11N, LONG. PROFILE COMPARISON WITH ADDITION OF PIERS (SELF-WEIGHT)

FIGURE 8.10 SPAN 12N, LONG. PROFILE COMPARISON WITH ADDITION OF PIERS (SELF-WEIGHT)

FIGURE 8.11 SPAN 7N, LONG. PROFILE COMPARISON WITH ADDITION OF PIERS (TEMP $+60^{\circ} \mathrm{F}$ )

FIGURE 8.12 SPAN 8N, LONG. PROFILE COMPARISON WITH ADDITION OF PIERS (TEMP $+60^{\circ} \mathrm{F}$ )

216

FIGURE 8.13 SPAN 9N, LONG. PROFILE COMPARISON WITH ADDITION OF PIERS (TEMP $+60^{\circ} \mathrm{F}$ )

FIGURE 8.14 SPAN 10N, LONG. PROFILE COMPARISON WITH ADDITION OF PIERS (TEMP $\left.+60^{\circ} \mathrm{F}\right)$

216

FIGURE 8.15 SPAN 11N, LONG. PROFILE COMPARISON WITH ADDITION OF PIERS (TEMP $+60^{\circ} \mathrm{F}$ )

FIGURE 8.16 SPAN 12N, LONG. PROFILE COMPARISON WITH ADDITION OF PIERS (TEMP $+60^{\circ} \mathrm{F}$ )

FIGURE 8.17 SPAN 7N, LONG. PROFILE COMPARISON WITH ADDITION OF PIERS (TEMP $+90^{\circ} \mathrm{F}$ )

217

FIGURE 8.18 SPAN 8N, LONG. PROFILE COMPARISON WITH ADDITION OF PIERS (TEMP $+90^{\circ} \mathrm{F}$ )

FIGURE 8.19 SPAN 9N, LONG. PROFILE COMPARISON WITH ADDITION OF PIERS (TEMP $\left.+90^{\circ} \mathrm{F}\right)$ 
FIGURE 8.20 SPAN 10N, LONG. PROFILE COMPARISON WITH ADDITION OF PIERS (TEMP $+90^{\circ} \mathrm{F}$ )

FIGURE 8.21 SPAN 11N, LONG. PROFILE COMPARISON WITH ADDITION OF PIERS (TEMP $+90^{\circ} \mathrm{F}$ )

FIGURE 8.22 SPAN 12N, LONG. PROFILE COMPARISON WITH ADDITION OF PIERS (TEMP $+90^{\circ} \mathrm{F}$ )

FIGURE 8.23 MAXIMUM OUT-OF-PLANE WEB DISTORTION COMPARISON WITH PIERS MODELED (TEMP $+60^{\circ} \mathrm{F}$ )

FIGURE 8.24 MAXIMUM OUT-OF-PLANE WEB DISTORTION COMPARISON WITH PIERS MODELED (TEMP $+90^{\circ} \mathrm{F}$ )

FIGURE 8.25 SPAN 7N, EFFECTIVE STRESS COMPARISON WITH ADDITION OF PIERS (TEMP $+90^{\circ} \mathrm{F}$ )

FIGURE 8.26 SPAN 8N, EFFECTIVE STRESS COMPARISON WITH ADDITION OF PIERS (TEMP $+90^{\circ} \mathrm{F}$ )

FIGURE 8.27 SPAN 9N, EFFECTIVE STRESS COMPARISON WITH ADDITION OF PIERS (TEMP $+90^{\circ} \mathrm{F}$ )

FIGURE 8.28 SPAN 10N, EFFECTIVE STRESS COMPARISON WITH ADDITION OF PIERS (TEMP $+90^{\circ} \mathrm{F}$ )

FIGURE 8.29 SPAN 11N, EFFECTIVE STRESS COMPARISON WITH ADDITION OF PIERS (TEMP $+90^{\circ} \mathrm{F}$ )

FIGURE 8.30 PIER 7N, EFFECTIVE STRESS COMPARISON WITH ADDITION OF PIERS (TEMP $+90^{\circ} \mathrm{F}$ )

FIGURE 8.31 PIER 8N, EFFECTIVE STRESS COMPARISON WITH ADDITION OF PIERS $\left(\right.$ TEMP $\left.+90^{\circ} \mathrm{F}\right)$

FIGURE 8.32 PIER 9N, EFFECTIVE STRESS COMPARISON WITH ADDITION OF PIERS (TEMP $\left.+90^{\circ} \mathrm{F}\right)$

FIGURE 8.33 PIER 10N, EFFECTIVE STRESS COMPARISON WITH ADDITION OF PIERS (TEMP $+90^{\circ} \mathrm{F}$ )

FIGURE 8.34 PIER 11N, EFFECTIVE STRESS COMPARISON WITH ADDITION OF PIERS (TEMP $+90^{\circ} \mathrm{F}$ )

FIGURE 8.35 MAXIMUM WEB EFFECT STRESS COMPARISONS NEAR MIDSPANS WITH PIERS MODELED $\left(\right.$ TEMP $+90^{\circ} \mathrm{F}$ )

FIGURE 8.36 MAXIMUM WEB EFFECT STRESS COMPARISONS AT PIER CENTERLINES WITH PIERS MODELED $\left(\right.$ TEMP $\left.+90^{\circ} \mathrm{F}\right)$

FIGURE 8.37 SPAN 7N, LONGITUDINAL STRESS COMPARISON WITH ADDITION OF PIERS (TEMP $+90^{\circ} \mathrm{F}$ )

FIGURE 8.38 SPAN 8N, LONGITUDINAL STRESS COMPARISON WITH ADDITION OF PIERS (TEMP $+90^{\circ} \mathrm{F}$ )

FIGURE 8.39 SPAN 9N, LONGITUDINAL STRESS COMPARISON WITH ADDITION OF PIERS (TEMP $+90^{\circ} \mathrm{F}$ )

FIGURE 8.40 SPAN 10N, LONGITUDINAL STRESS COMPARISON WITH ADDITION OF PIERS (TEMP $+90^{\circ} \mathrm{F}$ )

FIGURE 8.41 SPAN 11N, LONGITUDINAL STRESS COMPARISON WITH ADDITION OF PIERS (TEMP $+90^{\circ} \mathrm{F}$ )

FIGURE 8.42 PIER 7N, LONGITUDINAL STRESS COMPARISON WITH ADDITION OF PIERS (TEMP $+90^{\circ} \mathrm{F}$ ) 
FIGURE 8.43 PIER 8N, LONGITUDINAL STRESS COMPARISON WITH ADDITION

OF PIERS (TEMP $+90^{\circ} \mathrm{F}$ ) 228

FIGURE 8.44 PIER 9N, LONGITUDINAL STRESS COMPARISON WITH ADDITION OF PIERS (TEMP $+90^{\circ} \mathrm{F}$ ) 228

FIGURE 8.45 PIER 10N, LONGITUDINAL STRESS COMPARISON WITH ADDITION OF PIERS (TEMP $+90^{\circ} \mathrm{F}$ ) 229

FIGURE 8.46 PIER 11N, LONGITUDINAL STRESS COMPARISON WITH ADDITION OF PIERS (TEMP $+90^{\circ} \mathrm{F}$ ) 229

FIGURE 8.47 MAXIMUM WEB LONGITUDINAL STRESS COMPARISONS NEAR MIDSPANS WITH PIER MODELED (TEMP $+90^{\circ} \mathrm{F}$ ) 229

FIGURE 8.48 MAXIMUM WEB LONGITUDINAL STRESS COMPARISONS AT PIER CENTERLINES WITH PIERS MODELED (TEMP $+90^{\circ} \mathrm{F}$ ) 230

FIGURE 8.49 FE MODEL LONGITUDINAL STRESS BAND PLOTS FOR UNIT 2 WITH ADDITION OF PIERS $\left(+90^{\circ} \mathrm{F}\right.$ TEMPERATURE LOAD) 231

FIGURE 8.50 AXIAL STRESS COMPARISONS NEAR MIDSPANS WITH PIERS MODELED_(TEMP $\left.+90^{\circ} \mathrm{F}\right)$

FIGURE 8.51 AXIAL STRESS COMPARISONS AT PIER CENTERLINES WITH PIERS MODELED (TEMP $+90^{\circ} \mathrm{F}$ ) 232

FIGURE 8.52 AXIAL CAPACITY COMPARISON NEAR MIDSPANS WITH PIERS MODELED_(TEMP $+90^{\circ} \mathrm{F}$ ) 233

FIGURE 8.53 AXIAL CAPACITY COMPARISON AT PIER CENTERLINES WITH PIERS MODELE_(TEMP $\left.+90^{\circ} \mathrm{F}\right)$

FIGURE 8.54 TOTAL CAPACITY COMPARISON NEAR MIDSPANS WITH PIERS MODELED_(TEMP $+90^{\circ} \mathrm{F}$ ) 235

FIGURE 8.55 TOTAL CAPACITY COMPARISON AT PIER CENTERLINES WITH PIERS MODELED (TEMP $\left.+90^{\circ} \mathrm{F}\right)$

FIGURE 8.56 EFFECTIVE STRESS IN PIER 8N PIER CAP DUE TO TEMP $+90^{\circ} \mathrm{F}$ LOAD CASE

FIGURE 8.57 EFFECTIVE STRESS IN PIER 9N PIER CAP DUE TO TEMP $+90^{\circ} \mathrm{F}$ LOAD CASE

FIGURE 8.58 EFFECTIVE STRESS IN PIER 10N PIER CAP DUE TO TEMP $+90^{\circ} \mathrm{F}$ LOAD CASE

238

FIGURE 8.59 PIER BENDING MOMENTS (PIERS 7N-9N)

239

FIGURE 8.60 PIER TORSIONAL MOMENTS (PIERS 6N-11N)

239

FIGURE A.1 SPAN 7N, GIRDER 3N LONGITUDINAL WEB PROFILE (SELF-WEIGHT)

FIGURE A.2 SPAN 8N, GIRDER 3N LONGITUDINAL WEB PROFILE (SELF-WEIGHT)

FIGURE A.3 SPAN 9N, GIRDER 3N LONGITUDINAL WEB PROFILE (SELF-WEIGHT)

FIGURE A.4 SPAN 10N, GIRDER 3N LONGITUDINAL WEB PROFILE (SELF-WEIGHT)

FIGURE A.5 SPAN 11N, GIRDER 3N LONGITUDINAL WEB PROFILE (SELF-WEIGHT) 
FIGURE A.6 SPAN 12N, GIRDER 3N LONGITUDINAL WEB PROFILE (SELF-WEIGHT) 255

FIGURE A.7 SPAN 8N, GIRDER 3N LONGITUDINAL WEB PROFILE (TEMP $-60^{\circ} \mathrm{F}$ ) 255

FIGURE A.8 SPAN 7N, GIRDER 3N LONGITUDINAL WEB PROFILE (TEMP $-60^{\circ} \mathrm{F}$ )

FIGURE A.9 SPAN 9N, GIRDER 3N LONGITUDINAL WEB PROFILE (TEMP $-60^{\circ} \mathrm{F}$ )

FIGURE A.10 SPAN 10N, GIRDER 3N LONGITUDINAL WEB PROFILE (TEMP $-60^{\circ} \mathrm{F}$ )

FIGURE A.11 SPAN 11N, GIRDER 3N LONGITUDINAL WEB PROFILE (TEMP $-60^{\circ} \mathrm{F}$ )

FIGURE A.12 SPAN 12N, GIRDER 3N LONGITUDINAL WEB PROFILE (TEMP $-60^{\circ} \mathrm{F}$ )

FIGURE A.13 SPAN 7N, GIRDER 3N LONGITUDINAL WEB PROFILE $\left(\mathrm{TEMP}+60^{\circ} \mathrm{F}\right)$

FIGURE A.14 SPAN 8N, GIRDER 3N LONGITUDINAL WEB PROFILE $\left(\mathrm{TEMP}+60^{\circ} \mathrm{F}\right)$

FIGURE A.15 SPAN 9N, GIRDER 3N LONGITUDINAL WEB PROFILE $\left(\mathrm{TEMP}+60^{\circ} \mathrm{F}\right)$

FIGURE A.16 SPAN 10N, GIRDER 3N LONGITUDINAL WEB PROFILE $\left(\mathrm{TEMP}+60^{\circ} \mathrm{F}\right)$

FIGURE A.17 SPAN 11N, GIRDER 3N LONGITUDINAL WEB PROFILE $\left(\mathrm{TEMP}+60^{\circ} \mathrm{F}\right)$

FIGURE A.18 SPAN 12N, GIRDER 3N LONGITUDINAL WEB PROFILE $\left(\mathrm{TEMP}+60^{\circ} \mathrm{F}\right)$

FIGURE A.19 SPAN 7N, GIRDER 3N LONGITUDINAL WEB PROFILE $\left(\right.$ TEMP $\left.+90^{\circ} \mathrm{F}\right)$

FIGURE A.20 SPAN 8N, GIRDER 3N LONGITUDINAL WEB PROFILE $\left(\mathrm{TEMP}+90^{\circ} \mathrm{F}\right)$

FIGURE A.21 SPAN 9N, GIRDER 3N LONGITUDINAL WEB PROFILE $\left(\mathrm{TEMP}+90^{\circ} \mathrm{F}\right)$

FIGURE A.22 SPAN 10N, GIRDER 3N LONGITUDINAL WEB PROFILE $\left(\mathrm{TEMP}+90^{\circ} \mathrm{F}\right)$

FIGURE A.23 SPAN 11N, GIRDER 3N LONGITUDINAL WEB PROFILE $\left(\mathrm{TEMP}+90^{\circ} \mathrm{F}\right)$

FIGURE A.24 SPAN 12N, GIRDER 3N LONGITUDINAL WEB PROFILE $\left(\mathrm{TEMP}+90^{\circ} \mathrm{F}\right)$

FIGURE B.1 PIER 7N, BENDING AND AXIAL STRESS PROFILES (TEMP -60 ${ }^{\circ} \mathrm{F}$ ) 262 FIGURE B.2 PIER 8N, BENDING AND AXIAL STRESS PROFILES (TEMP $-60^{\circ} \mathrm{F}$ ) 262 FIGURE B.3 PIER 9N, BENDING AND AXIAL STRESS PROFILES (TEMP -60 ${ }^{\circ} \mathrm{F}$ ) 263 FIGURE B.4 PIER 10N, BENDING AND AXIAL STRESS PROFILES (TEMP -60 $\left.{ }^{\circ} \mathrm{F}\right) 263$ FIGURE B.5 PIER 11N, BENDING AND AXIAL STRESS PROFILES (TEMP $\left.-60^{\circ} \mathrm{F}\right) 263$ FIGURE B.6 SPAN 7N, BENDING AND AXIAL STRESS PROFILES (TEMP -60 $60^{\circ}$ F) 264 FIGURE B.7 SPAN 8N, BENDING AND AXIAL STRESS PROFILES (TEMP - $60^{\circ} \mathrm{F}$ ) 264 FIGURE B.8 SPAN 9N, BENDING AND AXIAL STRESS PROFILES (TEMP -60 F) 264 
FIGURE B.9 SPAN 10N, BENDING AND AXIAL STRESS PROFILES (TEMP $-60^{\circ} \mathrm{F}$ ) 265 FIGURE B.10 SPAN 11N, BENDING AND AXIAL STRESS PROFILES

(TEMP -60 ${ }^{\circ} \mathrm{F}$ ) 265

FIGURE B. 11 PIER 7N, BENDING AND AXIAL STRESS PROFILES (TEMP $\left.+60^{\circ} \mathrm{F}\right) 266$

FIGURE B.12 PIER 8N, BENDING AND AXIAL STRESS PROFILES (TEMP $+60^{\circ} \mathrm{F}$ ) 266

FIGURE B.13 PIER 9N, BENDING AND AXIAL STRESS PROFILES (TEMP $\left.+60^{\circ} \mathrm{F}\right) 266$

FIGURE B.14 PIER 10N, BENDING AND AXIAL STRESS PROFILES

$\left(\right.$ TEMP $\left.+60^{\circ} \mathrm{F}\right)$

FIGURE B.15 PIER 11N, BENDING AND AXIAL STRESS PROFILES

$\left(\right.$ TEMP $\left.+60^{\circ} \mathrm{F}\right)$

FIGURE B.16 SPAN 7N, BENDING AND AXIAL STRESS PROFILES

$\left(\right.$ TEMP $\left.+60^{\circ} \mathrm{F}\right) \quad 268$

FIGURE B.17 SPAN 8N, BENDING AND AXIAL STRESS PROFILES $\left(\right.$ TEMP $\left.+60^{\circ} \mathrm{F}\right) \quad 268$

FIGURE B.18 SPAN 9N, BENDING AND AXIAL STRESS PROFILES $\left(\mathrm{TEMP}+60^{\circ} \mathrm{F}\right) \quad 268$

FIGURE B.19 SPAN 10N, BENDING AND AXIAL STRESS PROFILES $\left(\right.$ TEMP $\left.+60^{\circ} \mathrm{F}\right) \quad 269$

FIGURE B.20 SPAN 11N, BENDING AND AXIAL STRESS PROFILES $\left(\mathrm{TEMP}+60^{\circ} \mathrm{F}\right) \quad 269$

FIGURE C.1 LONGITUDINAL PROFILES COMPARISON OF SPAN 7N DUE TO SELF-WEIGHT 270

FIGURE C.2 LONGITUDINAL PROFILES COMPARISON OF SPAN 8N DUE TO SELF-WEIGHT

FIGURE C.3 LONGITUDINAL PROFILES COMPARISON OF SPAN 9N DUE TO SELF-WEIGHT

FIGURE C.4 LONGITUDINAL PROFILES COMPARISON OF SPAN 10N DUE TO SELF-WEIGHT

FIGURE C.5 LONGITUDINAL PROFILES COMPARISON OF SPAN 11N DUE TO

SELF-WEIGHT 271

FIGURE C.6 LONGITUDINAL PROFILES COMPARISON OF SPAN 12N DUE TO SELF-WEIGHT 272

FIGURE C.7 LONGITUDINAL PROFILES COMPARISON OF SPAN 7N DUE TO TEMP $-60^{\circ} \mathrm{F}$

FIGURE C.8 LONGITUDINAL PROFILES COMPARISON OF SPAN 8N DUE TO TEMP $-60^{\circ} \mathrm{F}$

FIGURE C.9 LONGITUDINAL PROFILES COMPARISON OF SPAN 9N DUE TO TEMP $-60^{\circ} \mathrm{F}$

FIGURE C.10 LONGITUDINAL PROFILES COMPARISON OF SPAN 10N DUE TO TEMP $-60^{\circ} \mathrm{F}$

FIGURE C.11 LONGITUDINAL PROFILES COMPARISON OF SPAN 11N DUE TO TEMP $-60^{\circ} \mathrm{F}$

FIGURE C.12 LONGITUDINAL PROFILES COMPARISON OF SPAN 12N DUE TO TEMP $-60^{\circ} \mathrm{F}$

FIGURE C.13 LONGITUDINAL PROFILES COMPARISON OF SPAN 7N DUE TO TEMP $+60^{\circ} \mathrm{F}$ 
FIGURE C.14 LONGITUDINAL PROFILES COMPARISON OF SPAN 8N DUE TO TEMP $+60^{\circ} \mathrm{F}$

FIGURE C.15 LONGITUDINAL PROFILES COMPARISON OF SPAN 9N DUE TO TEMP $+60^{\circ} \mathrm{F}$

FIGURE C.16 LONGITUDINAL PROFILES COMPARISON OF SPAN 10N DUE TO TEMP $+60^{\circ} \mathrm{F}$

FIGURE C.17 LONGITUDINAL PROFILES COMPARISON OF SPAN 11N DUE TO TEMP $+60^{\circ} \mathrm{F}$

FIGURE C.18 LONGITUDINAL PROFILES COMPARISON OF SPAN 12N DUE TO TEMP $+60^{\circ} \mathrm{F}$

FIGURE C.19 LONGITUDINAL PROFILES COMPARISON OF SPAN 7N DUE TO TEMP $+90^{\circ} \mathrm{F}$

FIGURE C.20 LONGITUDINAL PROFILES COMPARISON OF SPAN 8N DUE TO TEMP $+90^{\circ} \mathrm{F}$

FIGURE C.21 LONGITUDINAL PROFILES COMPARISON OF SPAN 9N DUE TO TEMP $+90^{\circ} \mathrm{F}$

FIGURE C.22 LONGITUDINAL PROFILES COMPARISON OF SPAN 10N DUE TO TEMP $+90^{\circ} \mathrm{F}$

FIGURE C.23 LONGITUDINAL PROFILES COMPARISON OF SPAN 11N DUE TO TEMP $+90^{\circ} \mathrm{F}$

FIGURE C.24 LONGITUDINAL PROFILES COMPARISON OF SPAN 12N DUE TO TEMP $+90^{\circ} \mathrm{F}$

FIGURE D.1 PIER 7N, BENDING AND AXIAL STRESS PROFILES (SELF-WEIGHT)

FIGURE D.2 PIER 8N, BENDING AND AXIAL STRESS PROFILES (SELF-WEIGHT)

FIGURE D.3 PIER 9N, BENDING AND AXIAL STRESS PROFILES (SELF-WEIGHT)

FIGURE D.4 PIER 10N, BENDING AND AXIAL STRESS PROFILES (SELF-WEIGHT)

FIGURE D.5 PIER 11N, BENDING AND AXIAL STRESS PROFILES (SELF-WEIGHT)

FIGURE D.6 SPAN 7N, BENDING AND AXIAL STRESS PROFILES (SELF-WEIGHT)

FIGURE D.7 SPAN 8N, BENDING AND AXIAL STRESS PROFILES (SELF-WEIGHT)

FIGURE D.8 SPAN 9N, BENDING AND AXIAL STRESS PROFILES (SELF-WEIGHT)

FIGURE D.9 SPAN 10N, BENDING AND AXIAL STRESS PROFILES (SELF-WEIGHT)

FIGURE D.10 SPAN 11N, BENDING AND AXIAL STRESS PROFILES (SELF-WEIGHT) 282 FIGURE D.11 PIER 7N, BENDING AND AXIAL STRESS PROFILES (TEMP - $\left.60^{\circ} \mathrm{F}\right) 283$ FIGURE D.12 PIER 8N, BENDING AND AXIAL STRESS PROFILES (TEMP -60 $\left.{ }^{\circ} \mathrm{F}\right) 283$ FIGURE D.13 PIER 9N, BENDING AND AXIAL STRESS PROFILES (TEMP -60 $\left.{ }^{\circ} \mathrm{F}\right) 283$ 
FIGURE D.14 PIER 10N, BENDING AND AXIAL STRESS PROFILES (TEMP $-60^{\circ} \mathrm{F}$ )

FIGURE D.15 PIER 11N, BENDING AND AXIAL STRESS PROFILES (TEMP $-60^{\circ} \mathrm{F}$ )

FIGURE D.16 SPAN 7N, BENDING AND AXIAL STRESS PROFILES (TEMP $-60^{\circ} \mathrm{F}$ )

FIGURE D.17 SPAN 8N, BENDING AND AXIAL STRESS PROFILES (TEMP $-60^{\circ} \mathrm{F}$ )

FIGURE D.18 SPAN 9N, BENDING AND AXIAL STRESS PROFILES (TEMP $-60^{\circ} \mathrm{F}$ )

FIGURE D.19 SPAN 10N, BENDING AND AXIAL STRESS PROFILES (TEMP $-60^{\circ} \mathrm{F}$ )

FIGURE D.20 SPAN 11N, BENDING AND AXIAL STRESS PROFILES (TEMP $-60^{\circ} \mathrm{F}$ ) 


\section{LIST OF TABLES}

TABLE 3.1 BEARING FIXITY CONDITIONS 53

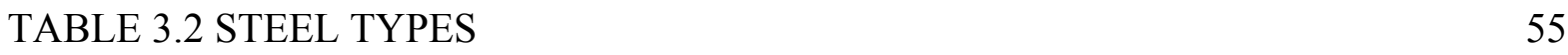

TABLE 3.3 MATERIAL PROPERTIES 56

TABLE 4.1 BRIDGE WELDING CODE DIMENSIONAL TOLERANCES 86

TABLE 4.2 FE MODEL OUT-OF-FLATNESS RESULTS

TABLE 4.3 WEB SLENDERNESS VALUES 104

TABLE 4.4 TRANSVERSE STIFFENER SPACING 105

TABLE 5.1 BRIDGE GIRDER CAPACITY ANALYSIS $\left(+60^{\circ} \mathrm{F}\right) \quad 142$

TABLE 5.2 BRIDGE GIRDER CAPACITY ANALYSIS $\left(+90^{\circ} \mathrm{F}\right)$

TABLE 7.1 BRIDGE GIRDER CAPACITY ANALYSIS (NEW BEARINGS, $\left.+60^{\circ} \mathrm{F}\right) \quad 205$

TABLE 7.2 BRIDGE GIRDER CAPACITY ANALYSIS (NEW BEARINGS, $\left.+90^{\circ} \mathrm{F}\right) 205$

TABLE 8.1 BRIDGE GIRDER CAPACITY ANALYSIS WITH PIERS ADDED

$\begin{array}{ll}\text { TEMP }+90^{\circ} \mathrm{F} & 236\end{array}$ 


\section{CHAPTER ONE}

\section{INTRODUCTION}

\subsection{BACKGROUND}

According to the AASHTO LRFD Bridge Design Specifications (AASHTO 2007) and AASHTO Guide Specifications for Horizontally Curved Steel Girder Highway Bridges (AASHTO 2003), I-shaped plate girder members are primarily designed to carry only stresses produced by flexural forces. During design, axial forces are considered very small in comparison to flexural forces, and are therefore neglected.

Due to environmental temperature fluctuations, the steel girder members undergo thermal expansion and contraction. If not properly accounted for, this thermal movement can become constrained, inhibiting expansion and contraction of the bridge. Constraints to bridge expansion can cause axial compressive girder stresses (McBride, 2005). These additional axial stresses will affect bridge capacity. This is especially true for horizontally curved steel girder bridge structures. Unlike straight girder bridges that expand and contract solely along their longitudinal axis, curved girder bridges expand and contract radially as well when exposed to changing thermal conditions. Therefore, axial stresses cannot be fully relieved simply by allowing the structure to expand along the longitudinal axis. Radial expansion and contraction must also be accommodated, therefore complicating the design.

Eliminating thermal stresses in a straight girder bridge is accomplished by employing free and guided bridge bearings, allowing the full range of thermal movement in the structure. However, minimizing thermal stresses in a curved girder bridge is a much more complicated, if not impossible, task because of the multi-axis translation. The bridge design engineer is left with the task of designing a bearing arrangement plan that successfully allows 
the predicted thermal translation of the bridge without imparting additional stresses on the structure. AASHTO (2003) states that when a curved structure changes temperature uniformly, thermal forces are minimized by orientating guided bearing devices on rays emanating from the nearest fixed point (bearing). This is the only suggestion AASHTO (2003) puts forward to aid bridge designers when it comes to devising a bearing arrangement design for curved girder bridges. Thus, creating a bearing plan for a curved bridge is a subjective design issue, left mostly to the discretion and expertise of the design engineer.

Bearing devices can be 1) fixed, allowing no translation, 2) guided, allowing translation in only one direction, or 3) free, allowing translation in any direction. A welldesigned bearing arrangement will integrate guided and free expansion bearings to allow as much thermal expansion as possible. If restrained from expansion by fixed bearings or by misaligned expansion bearings, thermal stresses will develop due to uniform temperature loads. These thermal stresses, primarily axial stresses, will ultimately reduce the flexural load-carrying capacity of a bridge girder. Currently, bridge designers do not consider axial forces when designing a steel girder member, neglecting their effects and designing only for flexural loads.

Web distortion is also an issue that may affect the load-carrying capacity of curved steel I-girders. Several theoretical and analytical research studies have shown that the flexural capacity is negatively influenced by out-of-plane web distortion (White and Jung, 2007 and Kala et al., 2005). It is well known that researchers have developed strength reduction equations taking into account initial geometric imperfections of the web plate prior to loading. However, the majority of these reduction equations fail to consider that state of stress leading to the imperfection. Under certain scenarios, these stresses may be "locked in" 
the structure, rendering the reduction equations inaccurate, overestimating the ultimate capacity of the member.

\subsection{PROBLEM STATEMENT}

Thermal loading on horizontally curved steel girder bridges is not intensely dealt with in current design specifications. AASHTO (2003) states that the impact of thermal loading is negligible when aligning expansion bearings in a chordal manner from a fixed point on the bridge. However, the guideline assumes uniform temperature changes throughout the structure, which past and current studies have proven is an incorrect assumption. Also, the guideline fails to recognize that curved girder members expand and contract along two axes when subjected to thermal loads, making the movement of a curved structure a complicated design challenge.

The effect of bearing selection and alignment for horizontally curved steel girder bridges needs to be investigated. If not fully accommodated by the bridge bearings, the thermal expansion of the bridge will result in an accumulation of thermal stresses, not accounted for during bridge design. These thermal stresses, when combined with flexural loads, can create capacity and stability issues within a bridge. Since the thermal stresses are not considered during design, the ultimate design capacity of the structure may be exceeded when exposed to thermal loading in addition to design loads. The influence of thermal stresses on the bridge's structural capacity is studied. Lastly, out-of-plane web distortions can have a significant impact on girder capacity as well. The contribution of temperature loads to out-of-plane web distortions has not been previously investigated, and the exact amount of reduction in structural capacity due to web distortions is not fully known. 
Dr. Samir Shoukry and his research recently completed field inspections of a newly constructed horizontally curved steel I-girder bridge. Shortly after construction, severe outof-plane web distortions were noticed. After reviewing the bridge design plans, it was determined that the bearing arrangement selected for the bridge included numerous fixed bearing devices that may responsible for the out-of-plane web distortions. A 3D finite element model is constructed to determine the magnitude of thermal stress levels and out-ofplane distortion that develop in the bridge under the current bearing plan.

\subsection{RESEARCH OBJECTIVES}

The main objective of this thesis is to investigate the effects of thermal loading and bearing selection on the out-of-plane distortion and thermal stress response of the selected bridge. The following objectives will be completed to achieve this objective:

1. Develop a detailed 3D finite element bridge model of the entire superstructure of the bridge, which accurately replicates the behavior of the study bridge.

2. Investigate the effect that temperature increases have on out-of-plane web distortion and thermal stress levels under the as-built bearing arrangement. Determine the magnitude of the axial stress throughout the bridge.

3. Investigate the effects of live load in conjunction with thermal loading under the as-built bearing arrangement.

4. Propose a new bearing arrangement to be implemented on the bridge. This new arrangement should reduce out-of-plane web distortions and thermal stress levels in the steel I-girders when the structure is subjected to thermal loading. 
5. Investigate and compare the structural capacity of the bridge under each bearing arrangement in order to determine if the new bearings will increase its structural integrity.

6. Investigate the effect of pier flexibility on out-of-plane web distortion and thermal stresses due to temperature loading.

\subsection{THESIS OUTLINE}

Presented in the following chapters is the methodology used to carry out this research. An outline of this research methodology is as follows:

Chapter Two includes a thorough literature review on the behavior and design of horizontally curved steel I-girder bridges. Topics related to web, flange, stiffener and crossframe behavior and design are included. Also included is a section discussing the various issues that arise during construction of curved bridges and a section presenting the results of a lengthy FE parametric study on curved steel I-girders. An extensive literature review discussing the thermal behavior of curved bridges is completed. Lastly, several design specifications are studied with the focus of extracting all information related to 1) the design of curved bridges under thermal loading and 2) bearing design and selection.

Chapter Three presents a detailed description of the 3D finite element bridge model developed for this research study. Included is a description of bridge geometry and layout, structural components, field splices, material models, boundary conditions, and loading.

Chapter Four investigates the out-of-plane web distortion observed on the bridge under the as-built bearing arrangement. Longitudinal and transverse web profiles are created using data obtained from the FE bridge model and compared to the web buckling deformations observed and measured in the field. The effect of AASHTO live loading is also 
examined. Lastly, web slenderness and transverse stiffener spacing are studied to determine their role regarding out-of-plane web distortion.

Chapter Five investigates thermal stress levels in the steel I-girders due to thermal and live loading under the as-built bearing arrangement. The analysis in this chapter relies solely on data obtained using the FE bridge model. Effective and longitudinal stress profiles are generated for several locations throughout the structure. The longitudinal stress profiles are further analyzed to determine the magnitude of axial stress developed in the girders. A discussion on out-of-plane distortion and residual axial stress is included to establish their effect on girder capacity. Results from the FE model conclude that, under the current bearing arrangement, axial stresses are not negligible as assumed during bridge design.

Chapter Six proposes a new bearing arrangement plan to be implemented on the bridge. The new bearing plan employs as many free and guided bearings as possible, replacing the numerous fixed bearings, in order to allow the structure to expand and contract freely and without restraint. The out-of-plane web distortion investigated in chapter four is significantly reduced, as expected, when the new bearing arrangement is applied.

Chapter Seven investigates the thermal stress levels in the structure with the newly designed bearing arrangement applied in chapter six. The magnitude of thermal stresses is significantly reduced compared to the as-built bearing arrangement. However, axial stresses still persist in the structure, and could still have a significant impact on bridge capacity and stability.

Chapter Eight investigates the effect of pier flexibility bridge response. It is found that while axial stresses decreases, bending stresses increase negatively influencing bridge behavior. Also, out-of-plane web distortions increase when pier flexibility is included. 
The conclusions and recommendations developed during the study are given in Chapter Nine. 


\section{CHAPTER TWO}

\section{LITERATURE REVIEW}

\subsection{INTRODUCTION}

The Federal Highway Administration (FHWA) created the Consortium of University Research Teams (CURT) in 1969 with the goal of developing design specifications for horizontally curved bridges. In 1992, the FHWA began the Curved Steel Bridge Research Project (CSBRP) to improve upon the guidelines and specifications developed by CURT research using actual experimental data. These two initiatives are well-known for their respective efforts in providing research and creating guidelines and specifications in the areas structural design and analysis, and construction behavior for curved girder bridges.

However, currently, the amount of research and literature focusing on the behavior of curved I-girder bridges under thermal (temperature) load is rather incomplete. Equally lacking is a considerable amount of literature discussing the influence of out-of-plane web distortions on the structural capacity of curved I-girder bridges.

Several studies have been completed discussing the displacement behavior of curved bridges; however, these studies have been performed on relatively small structures. With modern curved bridges routinely being designed with several long spans, there is a need for more research into the thermal behavior of curved bridges, especially for large, multi-span structures.

This literature review presents some of the work performed by previous researchers on various topics of horizontally curved bridge behavior and design. The AASHTO Guide Specifications for Horizontally Curved Steel Girder Highway Bridges (2003), the West 
Virginia Division of Highways (WVDOH) Bridge Design Manual (2004), AASHTO/NSBA

Steel Bridge Bearing Design and Detailing Guidelines (2004), and the AISI Steel Bridge

Bearing Selection and Design Guide are thoroughly reviewed to obtain a clear understanding of how current bridge designs account for thermal movement.

\subsection{WEB BEHAVIOR}

In I-shape plate girders, the primary responsibilities of the web panel is to sustain the relative distance between the tension and compression flanges when subjected to flexure and to carry shear forces that develop in the I-girders. Therefore, a plate girder's web may be, by design, quite slender. In the design of a straight girder, slenderness ratios $\left(d / t_{w}\right)$ and stiffener (transverse and longitudinal) requirements are rooted mainly in buckling issues. In curved Igirders, bifurcation buckling behavior is eliminated when compared to comparable straight girders. In the case of curved I-girders, nonlinear bulging of the web is of more concern (Davidson et al. 2000).

The introduction of curvature to a plate girder immediately complicates its design and behavior. Warping of the cross section and transverse displacement (bulging) of the web are both attributed to girder curvature. The transverse displacement of a curved web due to a bending moment (flexure) creates plate bending (through-thickness) stresses (Davidson et al. 1999). Curvature also causes membrane stresses in the web panel to become nonlinear, decreasing the flexural capacity of the girder by increasing flange normal stresses. Also, with the addition of curvature the longitudinal stress distribution due to bending becomes highly nonlinear through the depth of the web. 


\subsubsection{Web- Bending}

Culver et al. (1972) conducted a theoretical study into the bending behavior of cylindrical web panels of curved plate girders with transverse stiffeners. A simple physical model was used to obtain web bending stresses (through-thickness) and yield moment reduction due to curvature. The study presented the following web slenderness ratio for use in the AASHTO Guide Specifications for Horizontally Curved Bridges (1993):

$$
\frac{d}{t_{w}} \leq \frac{35000}{\sqrt{F y}}\left[1-8.6\left(\frac{2 a}{R}\right)+34\left(\frac{2 a}{R}\right)^{2}\right]
$$

where $2 \mathrm{a}$ is the span length, and $\mathrm{R}$ is the radius. This equation may be compared to the web slenderness limit in AASHTO (2003):

$$
\frac{D}{t_{w}} \leq 100
$$

for a girder having a radius less than $700 \mathrm{ft}$ and

$$
\frac{D}{t_{w}} \leq 100+0.038(R-700) \leq 150
$$

for girders with a radius larger than $700 \mathrm{ft}$.

Davidson and Yoo (2002) conducted an in-depth investigation into the finite displacement behavior of curved I-girder web panels under bending and developed strength reduction equations for application in the design of curved plate girder webs. It was also shown that web slenderness has profound effects on buckling strength, and transverse displacement. Using the lateral pressure analogy developed by Davidson et al. (1999), it was shown that the maximum transverse deflection (bulging) can be approximated by the equation:

$$
\delta_{\max }=\frac{\alpha h_{c}^{4} \sigma_{m} 12\left(1-v^{2}\right)}{E t^{2} R}
$$


where $\alpha$ is a constant that depends on the location of the measured deflection and aspect ratio, $h_{c}$ is the height of the web in compression, and $\sigma_{m}$ is the stress at the flange/web interface due to vertical bending moment. The corresponding plate bending stress can by approximated by:

$$
M_{b \theta}=\frac{\beta h_{c}^{2} t \sigma_{m}}{R}
$$

where $\beta$ is a constant depending on the location of the measured bending moment and aspect ratio and $h_{c}$ is the height of web in compression. Based on maximum transverse web displacement, the web slenderness could be expressed by multiplying an equivalent straight girder ratio by reduction factor $R_{d}$ :

$$
\begin{aligned}
& {\left[\frac{D}{t_{w}}\right]_{\text {curved }} \leq\left[\frac{D}{t_{w}}\right]_{\text {straight }} R_{d}} \\
& R_{d}=0.185 \sqrt{\frac{R}{D}} \leq 1.0
\end{aligned}
$$

Yielding of the web panel should also be prevented when considering the web slenderness ratio. In lieu of this, the web slenderness could also be expressed by the following equations, where $R_{s}$ is the curvature reduction based on stress issues:

$$
\begin{gathered}
{\left[\frac{D}{t_{w}}\right]_{\text {curved }} \leq\left[\frac{D}{t_{w}}\right]_{\text {straight }} R_{s}} \\
R_{s}=\sqrt{\frac{1}{\psi_{w}}} \\
\psi_{w}=\sqrt{1+0.161\left(\frac{D_{c}}{t_{w}}\right)\left(\frac{D_{c}}{R}\right)+0.128\left(\frac{D_{c}}{t_{w}}\right)^{2}\left(\frac{D_{c}}{R}\right)^{2}}\left[1+1.5\left(\frac{D_{c}}{R}\right)^{0.5}\right]
\end{gathered}
$$

where $D_{c}$ is the depth of web in compression, $t_{w}$ is the web thickness, and $\mathrm{R}$ is the radius of curvature of the web panel. 


\subsubsection{Web-Shear}

CURT (Consortium of University Research Team project) researchers found that the post-buckling strength of curved I-girders decreases with an increasing curvature. Lee et al. (1996) suggested that shear buckling coefficients determined for straight web panels can be used for strength calculations of curved web panels. Lee and Yoo (1999) subjected curved web panels to pure shear loading in order to analyze their ultimate strength behavior, concluding that curved web panels are able to develop significant post-buckling strength, and behave similarly to comparable straight girders. Also, since torsional moments are carried mostly by lateral flange bending, torsional stresses should not greatly affect curved web panels when subjected to vertical shear forces.

\subsubsection{Web - Combined Loading}

Abdel-Sayed (1973) was one of the first to study the behavior of curved I-girder webs under combined bending and shear. It was demonstrated that, except in the case of pure shear, lateral web displacement is more significant than web buckling. Also, it was concluded that the elastic critical load for curved web panels is larger than comparable straight girder panels.

Davidson et al. (2000) studied the buckling and finite displacement behavior of curved web panels subjected to combined bending and shear, considering details that AbdelSayed (1973) did not, such as torsional rigidity of the flanges. The investigation demonstrated that under combined bending and shear the critical load of curved web panels is similar to that of straight girder webs. Also, transverse displacement increased under combined loading compared to flexural loading alone. However, the transverse displacement due to combined loading decreased with increased curvature. 


\subsection{OUT-OF-PLANE DISTORTIONS}

Bradford (1988) used energy methods to study the distortional buckling of elasticallyrestrained monosymmetric I-section beams. Results indicated that singly-symmetric straight I-sections with thin webs and with the smaller flange in compression are susceptible to buckling strength reductions if web distortion is significant. The study also demonstrated that the elastic critical moment of an I-section member increases as the torsional restraint of the tension flange increases. Along with this, the effects of web distortion become severe, causing substantial twisting of the compression flange.

Kala et al. (2005) performed a numerical analysis to examine the influence of web distortion on the ultimate load bearing capacity of a straight steel I-girder member. Initial imperfections and several other factors such modulus of elasticity, web thickness, and web yield strength were taken into account to determine their influence on the ultimate load bearing capacity of a straight I-girder. The initial out-of-plane imperfection was modeled by a one half-wave sine function with variable amplitude along both the normal and longitudinal axes. Results from this study showed that the magnitude of initial web imperfections have a negative effect on the ultimate load carrying capacity of a steel plate girder. However, web thickness, web yield strength, upper flange thickness, and upper flange yield strength all have greater influence on a girder's ultimate capacity.

White and Jung (2007) used a theoretical analysis to determine the effects of web distortion on the buckling strength of braced, straight steel I-girder members. It concluded that lateral buckling strength decreases significantly due to web distortions, but also found that if maximum stiffener spacing is satisfactory throughout an unbraced length of an Isection, the effects of web distortion are reduced. They also note that several I-section members suffered significant decreases in lateral buckling strengths due to web distortion, 
even with $D_{w} / t_{w}$ values near 90, which is a relatively favorable value. Goodier and Barton (1944) found that the influence of web distortions in a thin web is significant in the vicinity of a fixed support.

\subsection{TRANSVERSE STIFFENERS}

In AASHTO (1998), the design of transverse stiffeners for straight I-girders is based upon two principles. AASHTO (2003) suggests using stiffeners based on research by Yoo (1996) that transverse stiffeners aid in maintaining the cross-section shape of curved girders, thereby reducing out-of-plane web distortion.

First, an area requirement relies on web post-buckling stresses being carried by transverse stiffeners, and second, a moment of inertia (rigidity) requirement. As for curved girders, AASHTO (2003) transverse stiffener design equations are based exclusively on the moment of inertia requirement of AASHTO (1998) (Kim et al., 2007). Transverse stiffener width-tothickness ratio and moment of inertia are given in Equations 2.11 and 2.12 respectively.

$$
\begin{gathered}
\frac{b_{s}}{t_{s}} \leq 0.48 \sqrt{\frac{E}{F_{y}}} \\
I_{t s}=d_{o} t_{w}^{3} J
\end{gathered}
$$

Where $b_{s}$ is the stiffener width, $t_{s}$ is the stiffener thickness, $d_{\mathrm{o}}$ is the distance between stiffeners, and $t_{w}$ is the web thickness. The parameter $J$ is defined in Article 6.5 of AASHTO (2003).

Mariani et al. (1973) developed a relationship between the buckling strength of curved web panels and stiffener rigidity in order to produce design requirements for transverse stiffeners. To achieve the proper stiffener rigidity, the web panel was loaded until 
buckling occurred between stiffeners. The results showed that transverse stiffener rigidity

for curved webs is lower when compared to straight web panels. The following equation was suggested to determine stiffener rigidity requirements for curved web panels:

A nonlinear finite element parametric study by Kim et al. (2007) was performed with the following varying parameters: web slenderness $\left(d / t_{w}\right)$, web panel aspect ratio $\left(d_{0} / d\right)$, curvature, and stiffener yield strength and width-to-thickness ratio. The study suggested that lateral bending of the web panel, not axial loading, is a more significant factor when analyzing transverse stiffener behavior and the development of post-buckling shear strength. Therefore, the design of transverse stiffeners should be based on providing sufficient strength and bending stiffness, and not rely solely on area or axial force requirements.

\subsection{LONGITUDINAL STIFFENERS}

In the design of relatively deep plate girders, longitudinal stiffeners are included to increase the overall strength of the girder. When used on straight girders, the main purpose of a longitudinal stiffener is to minimize lateral deflection of the web due to vertical bending forces. The primary intention of using longitudinal stiffeners on curved girders is similar, minimizing the nonlinear transverse displacement of the web. Plate bending stresses are also greatly reduced by inclusion of these stiffeners. AASHTO (2003) states that the required rigidity of longitudinal stiffeners is greater for curved webs due to its warping not seen in straight girders. The following equation, imposing a minimum moment of inertia for longitudinal stiffeners, while the width-to-thickness ratio shall satisfy the same ratio as transverse stiffeners:

$$
I_{l s} \geq D t_{w}^{3}\left(2.4 a^{2}-0.13\right) \beta
$$


where $\mathrm{a}$ is the aspect ratio of the web panel $\left(d_{0} / D\right)$ and $\beta$ depends on a factor $\mathrm{Z}$ defined in Article 6.5, and on which side of the web with respect to the center of curvature the stiffener is attached.

Davidson et al. (2000) studied the affects of longitudinal stiffeners on curved I-girder web panels. Part of this study focused on the nonlinear finite-displacement of curved web panels with longitudinal stiffeners and compared the results to web panels without stiffeners. Deflection amplification factors for Von Mises stresses at the flange/web interface were calculated, and it was concluded that the restraint provided by the longitudinal stiffener(s) decreases this amplification. It was concluded that there is a reduction in bending strength of unstiffened curved web panels compared to straight panels with a single longitudinal stiffener.

\subsection{FLANGE BEHAVIOR}

According to Madhavan and Davidson (2009), the effect of horizontal curvature on the local buckling of compression flanges is fully understood. Curved I-girders undergo longitudinal axis bending as well as bifurcation. These actions, when combined, lead to normal and warping stresses within the compression flange, decreasing its ultimate buckling strength. Also, curved I-girders may experience large torsional moments, lateral bending, and irregular eccentricities which can complicate the design and analysis of compression flanges. Research by Davidson and Yoo (1996) demonstrated that web rotational resistance and warping are the main factors affecting local flange buckling of curved steel I-girders. Madhavan and Davidson (2009) investigated the effect of curvature on the flexural resistance of curved steel I-girders. Flange buckling resistance was evaluated using theoretical and analytical models. The models included the effects of a stress gradient across 
the width of the flange plate, and the rotational resistance supplied by the web. It is demonstrated that the "one-third rule", applied without regard to flange slenderness, as utilized in AASHTO (2007) does not accurately predict load-carrying capacity. The "onethird rule" is a unified approach where the factor $f_{1} / 3$ is implemented to account for lateral bending of the flange.

Results from Madhavan and Davidson (2009) showed the flange compactness limit used for the design of straight steel I-girders is acceptable for use in the design of curved steel I-girders. Also, the "one-third rule" as given in AASHTO (2007) is suitable for curved, compact sections. Lastly, inelastic buckling was shown to be inconsequential in practical designs scenarios.

\subsection{CROSSFRAME SPACING AND BEHAVIOR}

Unlike a straight girder bridge, a curved girder system contains an inherent torsional instability, which requires adequate restraint to ensure the overall system stability. In a straight girder bridge, the crossframes prevent premature lateral buckling, but in a curved bridge they must restrain the internal warping of each girder in the system. Crossframe spacing design is intended mainly to control warping stresses and maintain overall structural

integrity (Davidson and Yoo 2003). Therefore, in a curved girder bridge, the crossframes act as primary load carrying members, and hence must be designed as such. Several studies have been performed to develop proper equations to determine the appropriate crossframe spacing. In AASHTO (2003) suggests crossframes spacing $l$ is taken as the following equation:

$$
l=\sqrt{\frac{5}{36} r_{\sigma} R b_{f}}
$$


where $r_{\sigma}$ is the desired bending stress ratio $\left(f_{l} / f_{b}\right), \mathrm{R}$ is the radius of the girder, and $b_{f}$ is the flange width. Crossframe spacing shall never exceed $30 \mathrm{ft}$, and if curvature effects are neglected, spacing shall not exceed $25 \mathrm{ft}$.

Yoo and Littrell (1986) developed full-scale finite element models of various curved bridge designs using SAP (1977) to perform a parametric study in order to formulate an empirical design equation for crossframe spacing. Bridge length, radius of curvature, and unbraced girder length were varied during the study. The results of the study provided the following equation that could be used to approximate crossframe spacing for curved steel Igirder bridges:

$$
\text { Spacing }=\frac{L}{N}=L\left[-\ln \left(\frac{F_{w s} R}{18.890 L}\right)\right]^{-1.3364}
$$

where $L / N$ is the crossframe spacing, $F_{\text {ws }}$ is the ratio of maximum warping stress of a curved girder to the maximum bending stress of a comparable straight girder, $L$ is the span length, and $R$ is the radius of curvature. It was concluded that if not adequately braced, a curved Igirder cross-section will warp under dead and live load; however, cross bracing beyond three girders does not greatly affect normal bending stresses.

Davidson et al. (1996) employed a finite element model to expand upon Yoo and Littrell (1986) and develop an equation for crossframe spacing. The following equations were produced for warping-to-bending stress ratio and maximum crossframe spacing respectively:

$$
\begin{gathered}
F_{w s}=7.788\left(\frac{L^{1.947}}{R b_{f}}\right) e^{-N^{0.659}} \\
S_{\max }=\frac{L}{N}=L\left[-\ln \left(\frac{F_{w s} R b_{f}}{6.108 L^{2}}\right)\right]^{-1.52}
\end{gathered}
$$


where $L$ and $R$ are in feet, and $b_{f}$ is in inches. Results from the study showed improvement over the equation presented by Yoo and Littrell (1986).

Davidson et al. (1996) also formulated a crossframe spacing equation treating the curved girder flange as a continuous beam on rigid supports, represented by the crossframes. Using the lateral-section modulus for a rectangular flange, the lateral-flange bending moment due to a virtual lateral load, and the warping stress, the crossframe spacing can be written as:

$$
l=\left(\frac{5}{3} F_{w s} R b_{f}\right)^{1 / 2}
$$

with crossframe spacing $l$ giving similar results to previous equations (2.16 and 2.17).

\subsection{CONSTRUCTION ISSUES}

It is well documented, especially through field observation, that the construction of horizontally curved steel I-girder bridges is more intricate than the construction of comparable straight girder bridges. During the construction of curved bridges, certain problems may develop that are not experienced during the construction of straight bridges. Unexpected displacements, stress conditions and girder instabilities can plague curved bridge erection. An example of this is the inherent behavior of a single curved girder to want to rotate and translate under self-weight due to its center of gravity not being coplanar with the web (Howell and Earls, 2007).

Grubb et al. (1996) discusses many issues relating to the fabrication, construction and erection of horizontally curved steel girder bridges. It was noted that eccentric construction loads may cause deflections and twist in the cross-section of curved I-girders if not adequately braced against torsion force effects. Lateral stability of individual girders is a 
major concern during the erection process, given that a single curved girder resting freely on two piers is unstable unless adequately supported against natural torsional moments.

Calculating the appropriate lifting points of a curved girder requires more thought than a straight girder because the center of gravity is not in the same plane as the web. When erecting and lifting curved I-girders, it is advantageous to preassemble a pair of parallel girders connected with intact crossframes. Doing so creates the lateral stability not found when erecting individual girders.

A major concern during the construction process of curved I-girder bridges is the effect of web plumbness. When girders are designed to be web-plumb at one load condition, while crossframes and other supporting members are fabricated to be web-plumb at another load condition, detailing inconsistencies can arise (Chavel and Earls, 2003). These detailing may be significant if bridge components must be forced into alignment, creating unaccounted for stress conditions in the girders and an out-of-plumb web. Further research is needed in order to determine the loss of bridge capacity due to girder webs being out-of-plumb (Howell and Earls, 2007).

Howell and Earls (2007) used nonlinear finite element analysis to investigate the effects of web out-of-plumbness on flange tip stresses, vertical and lateral deflections, crosssectional distortion, and crossframe behavior. Five varying degrees of web out-of-plumbness are considered. To complete the FEM analysis, a three-span continuous structure consisting of six concentric curved steel I-girders was created using ADINA software. Three critical regions were chosen to assess the effects of web out-of-plumbness: two positive moment regions (midspans) and one negative moment region (over a support).

It was also found that in one of the positive moment regions, the bottom flange outside tip von Mises stress increases with increasing degrees of web out-of-plumbness. This 
increase in von Mises stress increases within a cross-sectional slice of the bridge, as the radius of each girder becomes smaller. This increase in stress is partly due to flexural normal stresses increasing as the web out-of-plumbness increases the eccentricity between the elastic neutral axis and the flange tip under consideration. As for top flange tip stresses, the von Mises stress decreases, with the innermost girder experiencing the largest stress decrease. Similar to the behavior in the bottom flange, this decrease in stress is partly due to the decreasing eccentricity between the top flange tip and elastic neutral axis due to the out-ofplumb condition and smaller compressive flexural normal stress.

In the negative moment region, increasing out-of-plumbness tends to decrease bottom flange outer tip stresses. This behavior is more distinct as the radius of curvature decreases within a cross-section. The decrease in flange tip stresses at the outside bottom flange tip signifies lateral flange bending behavior. As the out-of-plumb degree increases at the pier, the result seems to encourage a stress reversal due to the effects of a nonuniform torsion. In the top flange, stress in the negative moment region increases with increasing out-ofplumbness. This effect is greater for girders having a smaller radius of curvature. The increase in von Mises stresses in the negative moment region of the top flange is likely caused by higher levels of cross-sectional twisting in this region. The twisting of the crosssection helps relieve top flange bending stresses, unlike in the bottom flange.

Results show that, under gravity load alone, deflection of the bottom web-flange interface decreases with increasing web out-of-plumbness, indicating distortion of the crosssection. In the positive moment regions, lateral deflections increase with increasing out-ofplumbness. For girders with a smaller radius of curvature, bottom flange lateral deflections are more sensitive to out-of-plumbness than girders of larger radii. When considering top flange lateral deflections, girders of varying radii seem to be affected similarly by out-of- 
plumb conditions. Cross-frame behavior was shown to be significantly affected by out-ofplumbness. The torsional rigidity in a curved bridge, due to differing span lengths, greatly affects the demands on cross-frames as bay location varies.

\subsection{FINITE ELEMENT ANALYSIS PARAMETRIC STUDY}

Davidson et al. (1996) implemented finite element methods to develop detailed models of horizontally curved I-girders connected by crossframes. The models were used to perform a parametric study investigating the effect of several parameters on bending and warping stresses in curved I-girder systems. The parameters investigated were crossframe spacing, span length, girder depth, number of girders, flange width, girder spacing, and curvature.

First, an increase in span length results in increased warping stresses of the girder cross-section. Second, except for sharper degrees of curvature, a change in the depth of a curved girder system produces a similar effect to that of a straight girder system. That is to say, the variation of bending stresses of curved girders is similar to straight girders with respect to girder depth. It was found that the increased warping stress due to increased girder depth is not a concern for practical curved bridge design situations. For curved bridges with small curvature, the effect of adding girders to the system resulted in insignificant changes to bending and warping stresses. As curvature increased, the act of adding girders to the system seemed to lessen the effects of curvature. Lateral and torsional stiffness of the system increased as the number of girders increased, as expected. Increasing the spacing between girders of a curved girder system produced similar results to that of adding girders; the overall lateral and torsional stiffness increased. It was concluded that the effects of girder spacing and the number of girders in cross-section are not a concern for the development of a 
preliminary design equation for crossframe spacing. Flange width has no effect on bending stress in a curved system other than the typical effects noticed in straight girder systems. 


\subsection{THERMAL LOADING BEHAVIOR}

The topic of bearing selection and evaluation for horizontally curved steel I-girder bridges has not been highly researched. This is especially true for curved bridge behavior and movement due to thermal loading. Field observations have established that curved bridges tend to move in both radial and longitudinal directions. Large horizontal forces can be produced if these movements are not accommodated properly. Radial movements due to temperature variations are not carefully considered during the design of curved I-girder bridges. However, these movements are a very important aspect of bridge behavior.

In the design of horizontally curved bridges, a combination of fixed and expansion mechanical bearings is implemented in order to alleviate the stresses imparted into the structure through mechanical and environmental loads. However, if not properly designed for, these loads will cause movement (translations and rotations) of the structure, which can lead to structural failures.

Thatcher (1967) published the first paper extensively studying the design and fabrication of horizontally curved steel I-girders. The study details two areas: fabrication methods, such as heat curving, and design considerations, including lateral bracing and expansion (bridge movements) due to uniform temperature change and load application. The study considers a two-span continuous curved bridge structure with two I-girders in crosssection under two different bearing configurations. First, the fixed bearings are located at an abutment, while the expansion bearings are located at the middle pier and second abutment. The second configuration has the fixed bearings located at the middle pier and expansion bearings at the abutments. In a curved bridge, the theoretical line of movement of a bridge expansion bearing due to temperature change is along a chord line between that bearing and the nearest fixed bearing. Also, in continuous span structures, relative misalignment between 
the expansion ends of the span and the abutment may be minimized if the fixed bearings are located at an interior pier, while placing the expansion devices at the abutments.

Thatcher (1967) stated that girders tend to rotate at bearing points due to the application of loads, and that the axis of the hinges at the bearing points should theoretically be perpendicular to the tangent of the curve at that point, i.e. radial. A slight change in length of the girder will take place along this tangent. It was concluded that in curved girder expansion devices, the theoretical planes of movement are angular to one another, and that the movement and angular relationship need to be considered very carefully when designing curved structures.

Moorty and Roeder (1990) discussed the issue of thermal movement in curved steel girder bridges. When designing curved bridges, some engineers adjust the bearings and expansion joints to permit tangential movement, while other engineers, believing movement is uniform in a curved segment, place the bearings and expansion joints on a chordal alignment from a point of fixity. Chordal and tangential bearing movements are demonstrated below in Figure 2.1. However, focus is usually placed solely on longitudinal movements and at the expense of the proper analysis of the radial displacement. It was confirmed through field observations that some thermal movements of curved bridges are not tangential or chordal. Rather, movement takes place in a pure radial direction and may be of the same magnitude as chordal or tangential displacements. 


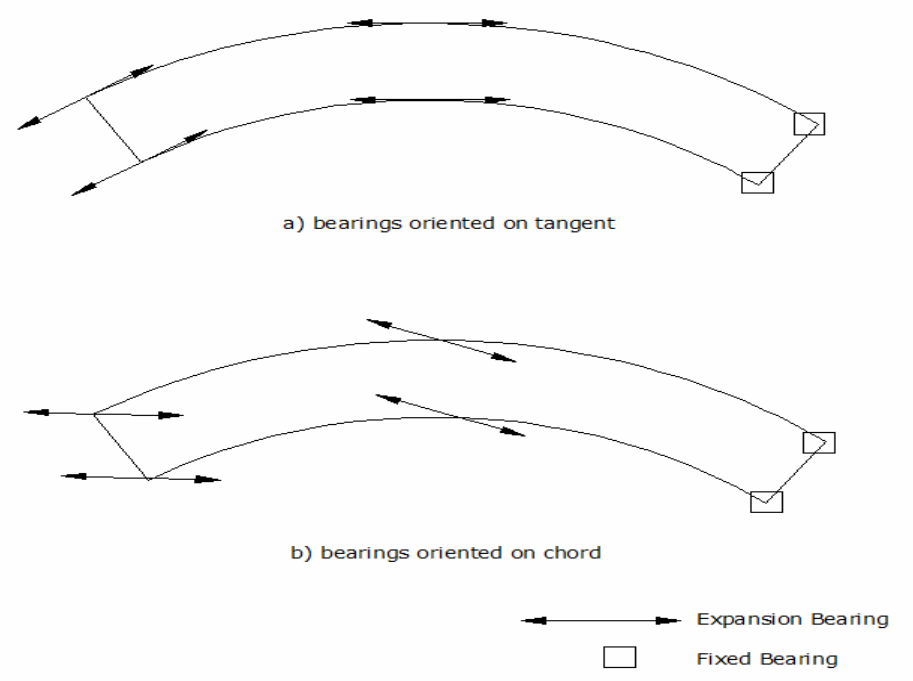

Figure 2.1 Curved Bridge Thermal Expansion. (From Moorty and Roeder (1990))

A second article by Moorty and Roeder (1990) discusses the inspection of the Sutton Creek Bridge in Montana. The structure is a sharply curved three-span continuous steel girder bridge with rocker bearings placed tangentially on the arc. An inspection in 1988 revealed that the bearings were in considerably good condition, having moved very little. Instead, the movement was accommodated by bending of the piers. It was also noticed that some bearings uplifted approximately 0.25 in on hotter days shortly after construction. Preliminary results indicated that the radial displacements were comparable to tangential displacements. These radial displacements seem to increase as the internal tangential resistance of the expansion bearing increased. The preliminary results indicated that pier flexibility plays an important role in the thermal movements of curved bridges. A detailed analysis of bridge-pier behavior is discussed by Moulton (1983). Due to differential radial displacements, a number of curved bridges in the US have experienced locked finger joints leading to substantial damage. Guideways for bearings have also experienced moderate damage or suffered misalignment problems as a result of these radial movements. A computer model study performed by Moorty and Roeder (1990) suggested that if a curved 
bridge is modeled as a line element with uniform temperature and fixity at one location, then movement at free supports will be on a chord from the fixed point to the support in question. A study considering a three-span, four girder system showed that the fixed bearings located on the piers experienced considerable displacements. It was concluded that radial displacements, when aligning the bearings on a chord, were slightly larger than displacements when expansion is in the tangential direction. It was concluded that guiding devices must be exceptionally strong, or piers and supporting elements must be relatively flexible if all damage from thermal movements is to be avoided.

In Moorty and Roeder (1992), a theoretical method for predicting bridge temperatures and the resulting behavior is presented. This paper is a follow-up to work presented previously in Moorty and Roeder (1990) and it intended to improve the understanding of thermal movements in bridges. Their paper includes thermal-structural analysis calculations to determine the effect of various parameters, a computer model to analyze bridge movements, and a field study of the Sutton Creek Bridge located in Montana. For the analyses, a temperature distribution similar to Figure 2.2 was used as the thermal load. The model had an angle of curvature of $40^{\circ}$ and span length of $600 \mathrm{ft}$. The three-span, four girder structure had fixed pin bearings at one abutment and expansion bearings the all other supports. The effect of bearing orientation and location of fixity was the focus of their study.

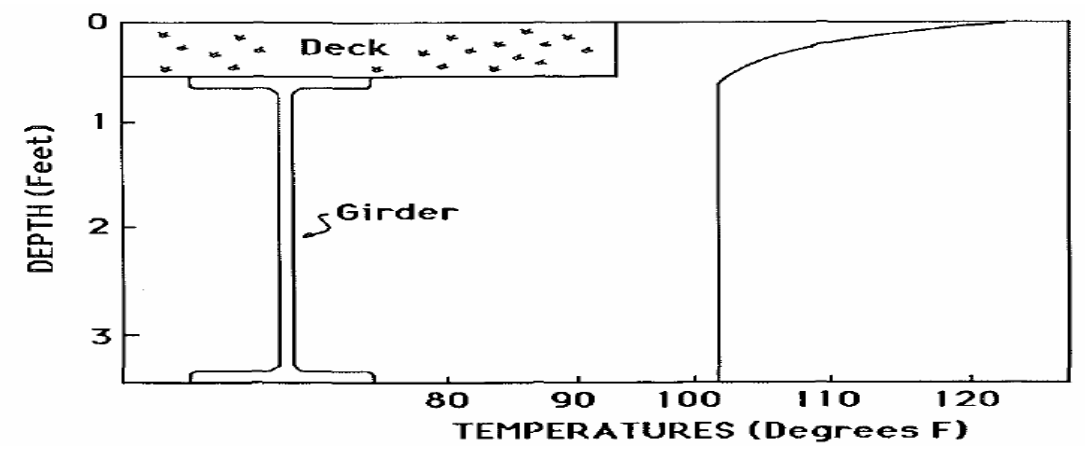

Figure 2.2 Temperature Distribution for Thermal Load. (From Moorty and Roeder (1992)) 
Their first analysis, guided bearings allowing tangential movement, yielded significant radial displacements at the center of the bridge, accommodated the piers, which experienced some tangential movement as well. As for bearings oriented along a chord, the results were nearly similar to the tangential displacements. The displacements at the expansion bearings are practically along a chord from the fixed point, as intended. This leads to the conclusion that a chordal bearing orientation is a better choice when the fixed point is at a rigid support. When not at a rigid support, pier flexibility complicates the behavior, causing movements to stray from chordal. In this situation, elastomeric or unguided sliding bearings would be a better alternative. It was also concluded that radial displacements increase with an increase in the angle of curvature $(\mathrm{L} / \mathrm{R})$, where $\mathrm{R}$ is the girder radius and $\mathrm{L}$ is the arc length.

The Sutton Creek Bridge used for the field test is a three-span, continuous steel girder structure with a total span length of $657.5 \mathrm{ft}$. and a has a radius of $881.5 \mathrm{ft}$. Three spans are continuous, while a fourth span is simply supported. The bridge bearing layout and rough geometry is shown in Figure 2.3.

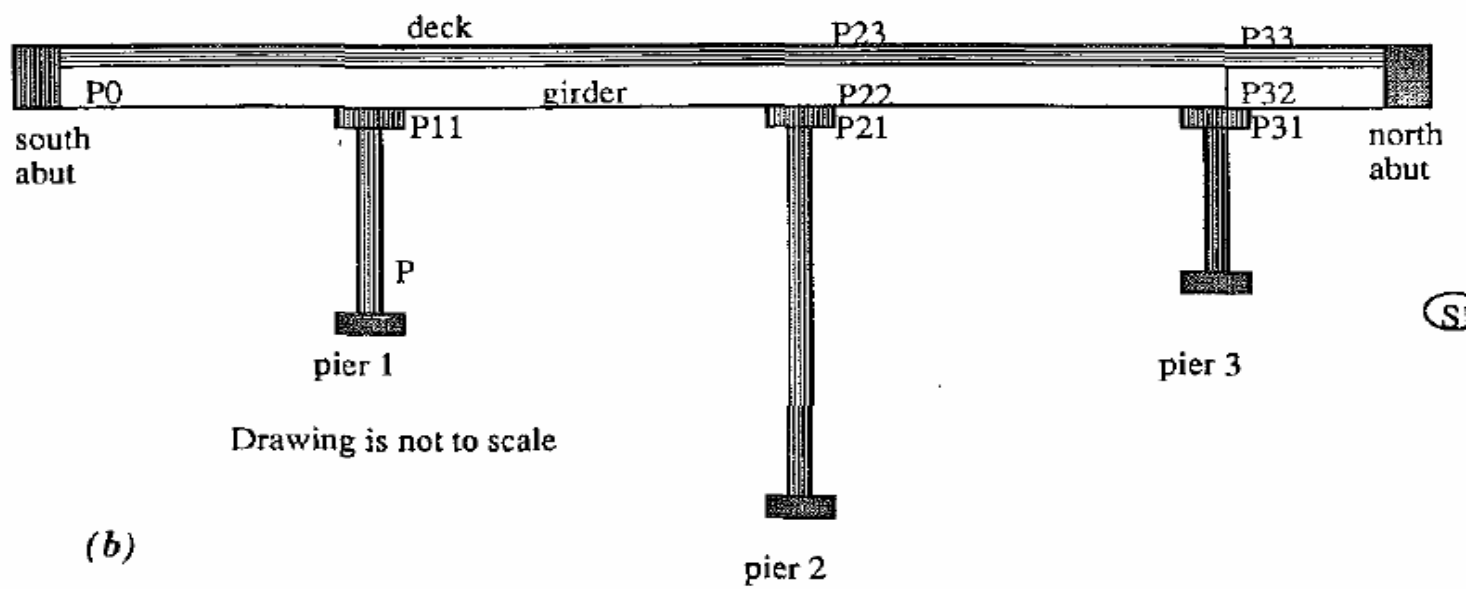

Figure 2.3 Sutton Creek Bridge Illustration (Taken from Moorty and Roeder (1992)) 
At the north abutment and pier 1 the girders are on fixed pin bearings. Rocker bearings are located at piers 2 and 3 and at the south abutment. All bearings are oriented tangential to the curve of the bridge. Expansion joints are placed at the abutments and at pier 3.

Moorty and Roeder (1992) offer several conclusions and recommendations for the design and analysis of curved bridges. Tangential and radial movements of curved bridges are impacted by the relative stiffness of the bridge, including bearings and substructure elements. Piers occasionally accommodate bridge movements. If the bearing orientation is set along a chord from a point of fixity, it is recommended that that point be located at a rigid support. Orientation is less predictable if this fixed point is located at a pier or other flexible support. An increase in bearing and expansion joint resistance leads to higher radial displacements and radial stresses in curved bridges, thus, maintenance becomes increasingly important. Due to the theoretical applications of integral construction, radial movements may be increased in these types of structures. Lastly, one-dimensional analysis is adequate for obtaining temperature distributions in a structurally composite bridge.

A large-scale study aimed at developing new guidelines for the design of horizontally curved steel bridges was performed by Zureick et al. (2000) for the Federal Highway Administration (FHWA). The study consisted of experimental and analytical (3DFE) models to investigate the forces incurred in cross-frame members of curved bridges. The models consisted of a single span, three-girder structure. Radial restraints were applied at each support of the center girder, and tangential restraint at one support of the center girder. The bearings were assumed to be mounted on rigid supports. 
Samaan et al. (2002) investigated the positioning of bearings on a continuous curved spread-box steel girder bridge. The focus of this study was to compare the chord method of bearing orientation with the tangential method. To examine the structure response due to temperature variations, prototype bridges were subjected to the following temperature conditions: uniform temperatures of $46^{\circ} \mathrm{C}$ and $-18^{\circ} \mathrm{C}$, and a temperature gradient for the section with $45^{\circ} \mathrm{C}$ at the top of the concrete deck slab, decreasing linearly to $15^{\circ} \mathrm{C}$ at the bottom of the slab and remaining constant through the depth of the steel section. The study consisted of six different bearing arrangement schemes shown in Figure 2.4.
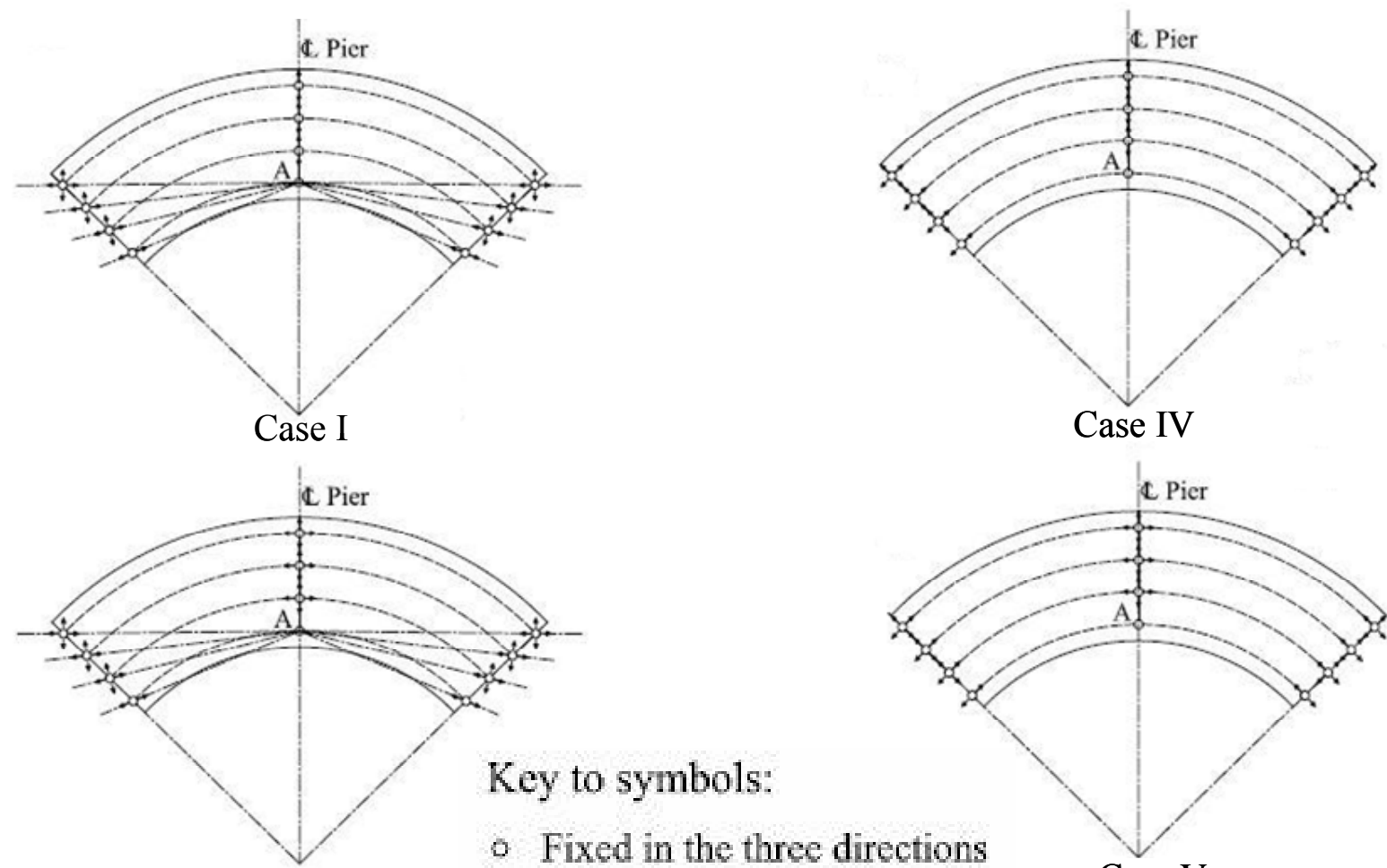

Case II

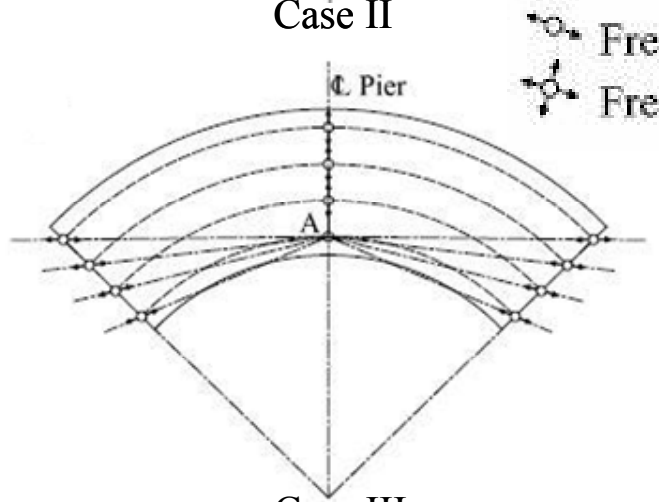

Case III

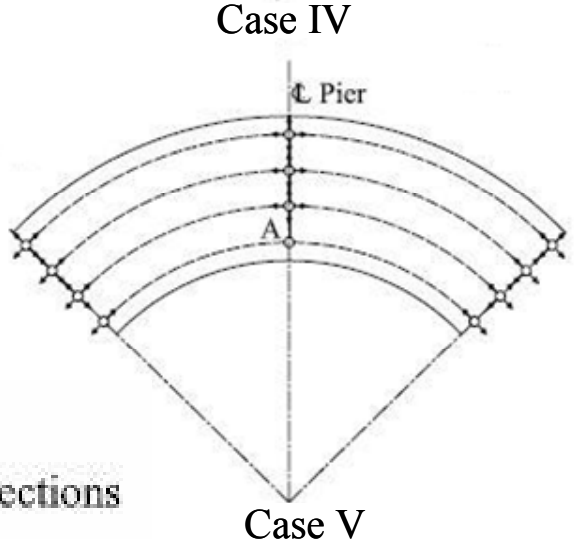

Key to symbols:

- Fixed in the three directions

. Free in one direction

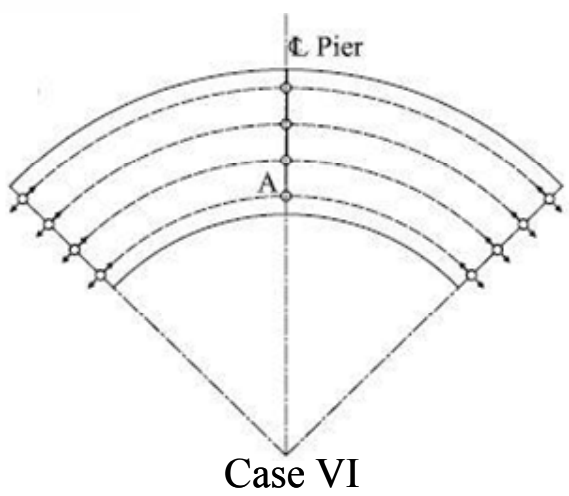

Figure 2.4 Bearing layouts (From Samaan et al. (2002)) 
The investigation by Samaan et al. (2002) produced several conclusions. First, concerning the dead and live loading, bearing type case VI significantly influences radial reactions. The distribution factors for stresses due to dead load remain unaffected by the support conditions, regardless of the span length. However, bearing case type III does influence tangential reactions, whereas VI augments the radial reactions for both span lengths (40m and $80 \mathrm{~m})$. For this case, distribution factors for stresses and reactions increase with span length. Also, maximum positive and negative live load stresses are not significantly affected by the bearing schemes studied. As for thermal loading, radial reactions and stress distribution factors for cases IV, V, and VI (tangential method) are much larger than for cases I, II, and III (the chord method). When a thermal gradient is present, stresses are not significantly influenced by the boundary conditions impose by any of the bearing schemes studied. However, VI does influence radial reaction. Bearing type VI gives rise to very high stresses and reactions. Results from thermal loading indicate higher stresses in the $40 \mathrm{~m}$ span bridges, where the radius of curvature is smaller. Several recommendations are presented.

Bearing type VI (tangential translation only) should be avoided. This type of support gives rise to large reactions and stresses due to dead, live and thermal loads. Bearing type cases I, III, and IV produce values for stresses, reactions, and frequencies that are consistent and nominal. It is recommended that bearing type case IV be used for curved continuous spread-box girder bridges, since the bearings in this case would be simple to arrange and install while keeping the correct orientation along the curved profile of the bridge.

Kim et al. (2005) created a three-dimensional finite element model to examine the effect of bearing orientation and alignment on live load analysis. The study bridge is a simple 2-steel-box girder curved bridge with a span length of $50 \mathrm{~m}$ and radius of curvature of $150 \mathrm{~m}$. The vehicle model used for live load is modeled after 5-axle tractor-trailers and has 
the same properties of the design vehicle load specified in the Korean Highway Bridge Design Specifications (2005).

On curved box-girder structures, the bearings are varied by orientation (chordal or tangential) and by positioning (centered under the box girder or centered under the outer flange of the box girder). Due to specific curvature, bearing orientation on a curved bridge may take on chorded (radial from a fixed position) or tangential direction. Generally, the arrangement of the bearing in a tangential direction is most suitable for bridges of constant curvature; whereas chordal oriented bearings are applied to all types of bridges having constant and/or variable curvature. After running finite element solution, the following conclusions were made.

First, in a curved bridge, rolling motion has a much greater effect on support reaction than does displacement. Longitudinal reactions are very small when the bearing is installed at the outer web compared to much larger reactions when installed in the middle of the lower flange. Second, when the bearing is installed at the outer web, changes in horizontal reactions caused by superelevation and bearing arrangement are not significant. However, when the bearing is installed at the middle of the lower flange, radial and longitudinal reactions increase significantly as superelevation increases. Therefore, as superelevation increases, so to do the horizontal reactions at the bearings. Third, no significant difference is observed in the radial reactions when comparing chordal and tangential bearing orientations. However a chordal arrangement does seem to moderately increase the longitudinal reaction at a bearing. Lastly, it is proven that broadening the distance between the supports of a curved bridge will bring more favorable results.

Baber and Lydzinski (2008) used finite element analysis to investigate the dynamic response of the Wolf Creek Bridge in Bland Country, VA. The bridge is a three-span 
structure, with four steel plate girders in cross section, and a radius of curvature of $260 \mathrm{ft}$. Baber and Lydzinski used the following bearing layout for a model with rigid piers: simply pinned supports at the piers and tangential roller supports at the abutments. Their model showed that the entire superstructure undergoes approximate rigid body rotation about the center of curvature. 


\subsection{AASHTO GUIDE SPECIFICATIONS FOR HORIZONTALLY CURVED STEEL GIRDER HIGHWAY BRIDGES (2003)}

A review of AASHTO (2003) codes pertaining to the treatment of temperature change, and the design and selection of bearings for curved bridge structures is presented here. The appropriate codes are listed as they appear in AASHTO (2003).

- $\quad$ Article 3.6 Thermal Loads - Load effects in the superstructure shall be determined for uniform temperature changes as specified in AASHTO (2004) Article 3.16. A uniform temperature difference of $25^{\circ} \mathrm{F}$ between the deck and girders will be considered when the deck width is less than one-fifth the longest span. The load effects due to the temperature differential shall be added to the effects due to temperature changes specified in AASHTO (2004) Article 3.16.

- $\quad$ Article C3.6 - Wide bridges are particularly prone to large lateral thermal forces because the bridge expands radially as well as longitudinally.

- $\quad$ Article C3.6 - Orienting bearing guides toward a "fixed point" and allowing the bridge to move freely along rays emanating from the fixed point causes thermal forces in the superstructure to be zero if the structure changes temperature uniformly. However, there are other load conditions that may affect decisions regarding bearing orientation.

- $\quad$ Article 8.2.1 Vertical Forces - Supports shall be designed to resist vertical forces due to factored construction loads and factored design loads specified in AASHTO (2004) Table 3.22.1A. 
- $\quad$ Article 8.2.2 Horizontal Forces - Supports shall be designed to resist longitudinal and transverse forces due to factored construction loads and the factored design loads specified in AASHTO (2004) Table 3.22.1A.

- $\quad$ Article 8.2.3 Shear Forces - Adequate shear connection shall be provided between the girders and the substructure to transmit shear forces from the girder to integral piers or abutments.

- $\quad$ Article 8.3 Movements - Bearings shall be designed to accommodate forces due to factored loads as specified. Bearings shall be designed to permit translations due to the temperature changes in the superstructure specified in Article 3.6. Bearings shall be designed to accommodate computed rotations about the tangential axis and about the radial axis of the girder. Rotations that occur during construction shall be considered in determining the design-rotation capacity of the bearing.

- $\quad$ Article C8.3 - Thermal forces are minimized when bearings are oriented such that they permit free translation along rays emanating from a single point. With bearings arranged to permit such movement along these rays, there will be no thermal forces generated when the superstructure temperature changes uniformly. Any other orientation of the bearings will induce thermal forces into the superstructure and substructure.

- $\quad$ Article C8.3 - A variety of bearings are appropriate for use on curved girder bridges. When the required translations, rotations and reactions that bearings must accommodate are known, bearings can be selected to provide the necessary freedom and restraint in an economical manner. 


\subsection{WEST VIRGINIA DIVISION OF HIGHWAYS BRIDGE DESIGN MANUAL (2004)}

This section presents the code(s) pertaining to the treatment of temperature change, and the design and selection of bearings for horizontally curved bridges as given in the WVDOH Bridge Design Manual. The Governing Specifications (AASHTO Guide Specs) refer to AASHTO (2004), while Curved Girder Specs refer to AASHTO (2003). Only codes and specifications pertaining to design or selection of bearings for horizontally curved bridges are discussed.

- $\quad$ 2.5.1 Curved Bridges Design Considerations - Bridge Designers are cautioned to design curved structures for all relevant forces as specified in the Governing Specifications, even if girders are straight and deck is curved.

- $\quad$ 3.1.4.1.6 Force Effects due to Temperature - For force effects due to temperature change, the temperature range for bridges designed in West Virginia shall be $-30^{\circ} \mathrm{F}$ to $120^{\circ} \mathrm{F}$ for steel or aluminum superstructures.

- $\quad$ 3.3.10 Steel Curved Girder Bridges - The effects of temperature change on curved bridges must be considered. Thermal movements must be allowed in directions radiating from the fixed supports. Whenever multiple fixed supports are utilized, or when guided expansion bearings are not oriented to satisfy provisions of the Curved Girder Specifications, a thermal analysis of the superstructure is required. A thermal analysis will also be required for complex and irregular framing arrangements. 
- $\quad$ 3.6 Bearings - All bridge bearing designs shall be in accordance with the Governing Specifications. Elastomeric bearings are preferred for most span arrangements. Polytetrafluorethylene (PTFE or Teflon) expansion bearing assemblies or pot bearings may be used when span lengths, curvature, or load limits for the standard elastomeric pads are exceeded.

- $\quad$ 3.6.1 Bearing Design Criteria - Combinations of load, rotation and translation anticipated during construction shall be incorporated into the design of the bearings with allowance for construction tolerances and variation of temperature at installation.

Section 3.6.1 Bearing Design Criteria, also discusses the possibility and control of "locked-in" stresses resulting from the construction process. With respect to temperature issues, the bridge designer must design the bearings for additional movement and rotation during construction that includes sufficient tolerances for: temperature variation at installation (from an assumed ambient temperature), or prescribe the installation temperature for the bearings, which will be incorporated into their design. It is stated that the bearings must resist lateral forces due to thermal expansion and contraction. 


\subsection{AISI STEEL BRIDGE BEARING SELECTION AND DESIGN GUIDE}

The AISI Steel Bridge Bearing Selection and Design Guide consists of two main parts. Part I discusses the selection of steel bridge bearings, while Part II is a design guide for steel bridge bearings. Part II is further divided into three sections: Section 1, General Design Requirements, Section 2, Special Design Requirements for Different Bearing Types, and Section 3, Construction, Installation and Attachment Details. Only codes and specifications pertaining to design or selection of bearings for horizontally curved bridges are discussed.

\section{Part I - Steel Bridge Bearing Section Guide}

The direction and magnitude of applied loads, translations and rotations should be defined in accordance with appropriate AASHTO LRFD Bridge Design Specifications. Those specifications include loads, translations and rotations due to dead load, live load, thermal load, etc. After defining the design requirements, any bearing type satisfying those requirements may be selected for design. Select an appropriate bearing type meeting all design requirements for the lowest overall cost. Selection of a bearing is not based solely on cost, but should be based on other practical limits as well, such as ease of access for inspection, maintenance and possible replacement. The final selection of a bearing should be the bearing system with the lowest combined initial and maintenance costs meeting all appropriate AASHTO LFRD Bridge Design Specifications requirements.

\section{Part II - Steel Bridqe Bearing Design Guide and Commentary}

Once a bearing type is chosen, superstructure geometry has no affect on bearing design. The design of the actual bearing device is similar for straight and curved bridges. 


\subsection{AASHTO/NSBA STEEL BRIDGE COLLABORATION - STEEL BRIDGE BEARING DESIGN AND DETAILING GUIDELINES}

The Steel Bridge Bearing Design and Detailing Guidelines present the design and detailing of three widely-used types of bridge bearings: elastomeric bearings, high load multi-rotational bearings (HLMR) and steel bearings. The type of elastomeric bearings discussed is steel reinforced elastomeric pads, while pot, disc, and spherical bearings are included under HLMR bearing types.

The document includes many guidelines based on provisions of the AASHTO design and construction specifications, and is to be used as a supplemental tool. In the event that future AASHTO specifications may be in conflict with the guidelines presented, in which case, the new AASHTO specifications shall take precedence. Only codes and specifications pertaining to design or selection of bearings for horizontally curved bridges are discussed.

\section{Section 1 Elastomeric Bearings}

- 1.4.1.1 Bearing Shapes - Elastomeric bearings can either be round or rectangular. Round Bearings are recommended for curved and larger skewed bridges since they can accommodate movement and rotations in multiple directions.

- 1.4.1.2 Design Rotation and Movements - The bearings should be designed for all longitudinal and lateral movements.

\section{Section 2 High Load Multi-Rotational Bearings}

- 2.4.1 Design Rotation and Movements - The bearings should be designed for all longitudinal and lateral movements. 


\section{Section 3 Steel Bearings}

Steel bearings are limited to fixed bearing designs that do not undergo any translational movements. Therefore, they should only be considered for fixed bearing types.

The AASHTO specifications outline requirements for the calculation of bridge movements due to temperature changes. Therefore, this supplemental guideline recommends a similar bearing orientation when designing a horizontally curved bridge. Bearing devices should be designed to expand along a chord that runs from the point of zero movement (e.g. fixed bearing) to the bearing device under consideration (expansion bearing). Stiffness of substructure elements (piers, abutments, etc.) may have an affect on thermal movement, and should therefore be considered in design. Other than the details given above, bearing design is the same for straight and curved bridges. 


\subsection{DISCUSSION and CONCLUSIONS}

While conducting this literature review, it became apparent that the current state of the art is lacking research pertaining the behavior of curved steel I-girders under thermal loading. Strength-reduction equations have been developed to compare curved girders to comparable straight girders, under certain boundary conditions and temperature loads, significant thermal stresses may develop. Consequently, current strength-reduction equations may still over-estimate the a curved girder's capacity because residual thermal stresses are not included in the development of the reduction equations. As well, the affect that thermal loading has on out-of-plane web distortions has not been thoroughly investigated.

Davidson and Yoo (2002) produced an equation to approximate the magnitude of transverse web deflection (bulging) due to bending in curved I-girder web panels. White and Jung (2007) discussed the effect of web distortions on the buckling strength of straight steel I-girders, which found that web distortions may cause a reduction in lateral buckling strength. Kala et al. (2005) found that the ultimate load-carrying capacity of a straight steel plate girder is negatively affected by initial out-of-plane web imperfections. However, web thickness and yield strength among other factors affect capacity to a greater extent than do initial imperfections in the web.

After a thorough review of AASHTO, WVDOH, AASHTO/NSBA, and AISI design codes, it is safe to conclude that designing a horizontally curved bridge structure for temperature changes is a relatively straightforward procedure. AASHTO (2003), using suggestions from several research studies states that orienting guided expansion bearings on a ray emanating from the fixed point will minimize the accumulation of thermal stresses. This is identical to recommendations made in the AASHTO/NSBA guidelines. Due to the fact that expansion is required on curved bridges, a high load multi-rotational (HLMR) bearing 
satisfying design requirements (load, translation, rotation, etc.) may be employed.

Elastomeric bearings are not suggested because they may lack appropriate translational functionality.

When designing the actual bearing devices, no deviation exists between design for straight and curved bridges. The manner in which the bearing translates may differ between straight and curved bridges; nonetheless, expansion will always occur along a straight line. Once a bearing type is selected, girder geometry is no longer considered in its design. 


\section{CHAPTER THREE}

\section{D FINITE ELEMENT BRIDGE MODEL}

\subsection{INTRODUCTION}

This chapter details and describes the development of the nonlinear three-dimensional finite element model created using ADINA 8.6.1 (Bathe 2009) to predict the behavior a horizontally curved steel I-girder bridge selected for this research study. Presented are details regarding superstructure modeling, material constitutive modeling, boundary conditions, loading and several other features. The main goal of the FE model is to accurately predict the effects of thermal loading and varying boundary conditions on the outof-plane web distortion and thermal stress levels in the bridge.

\subsection{BRIDGE LAYOUT AND GEOMETRY}

The horizontally curved steel I-girder bridge selected for this research study is a twelve span continuous bridge structure roughly $2,211 \mathrm{ft}$ along roadway centerline with an expansion joint installed near the center of the structure (at Pier 6N). This expansion joint divides the structure into two separate units (Unit 1 and Unit 2). The radius of the curve in Span $1 \mathrm{~N}$ varies from 1,546 ft. until the structure become tangential near Pier $3 \mathrm{~N}$. A second curve with a radius of 1,672 ft begins near the midspan of Span 5N. Figures 3.1 and 3.2 the span configuration for Unit 1 and Unit 2 respectively. 


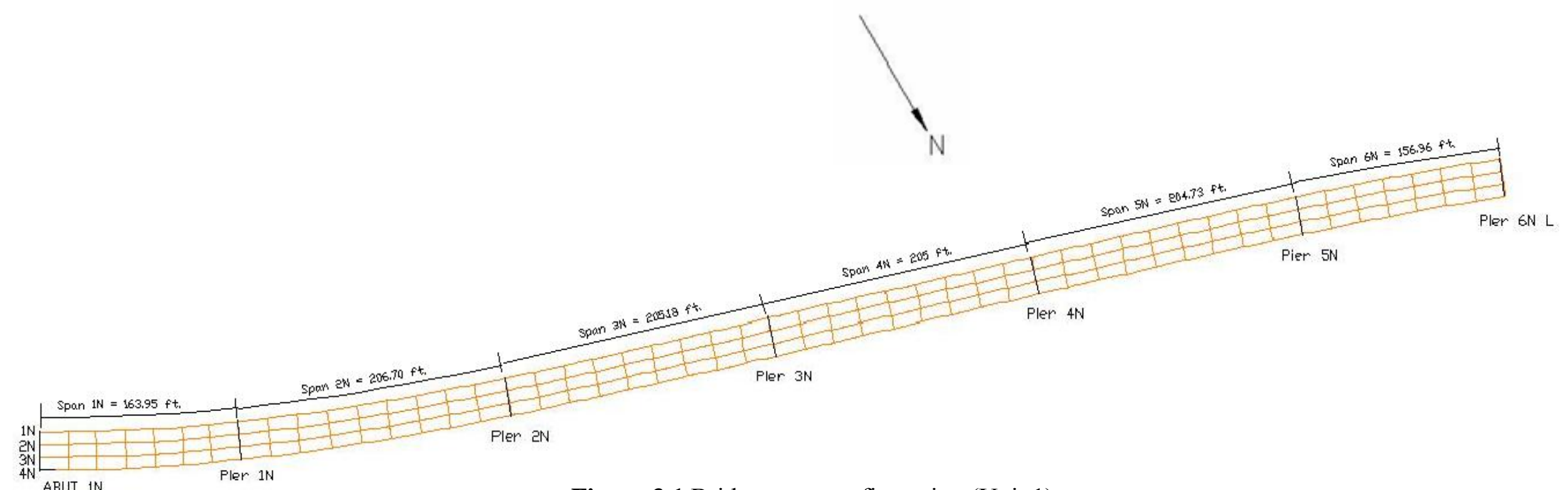

Figure 3.1 Bridge span configuration (Unit 1)

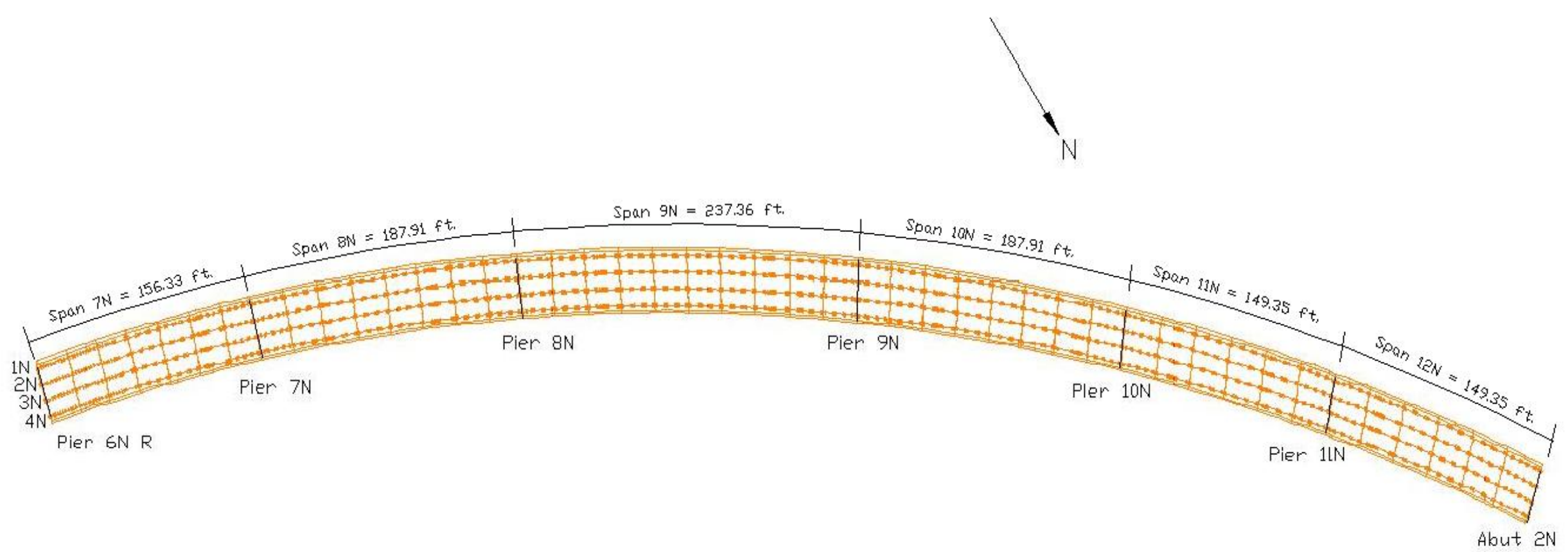

Figure 3.2 Bridge span configuration (Unit 2) 


\subsection{SUPERSTRUCTURE ELEMENTS}

Each unit has four welded steel plate I-girders in cross-section. The four girders of Unit 1, Spans $1 \mathrm{~N}-6 \mathrm{~N}$, have a constant web depth of 78 in. with a web thickness varying from $0.5625 \mathrm{in}$. in positive moment regions to $0.625 \mathrm{in}$. in negative moment regions (over the pier supports). Unit 2 utilizes variable depth girders. Spans $7 \mathrm{~N}, 11 \mathrm{~N}$, and $12 \mathrm{~N}$ have a constant web depth of $78 \mathrm{in.}$ The web depth of Span $8 \mathrm{~N}$ is 78 in. until a field splice is encountered, where the depth transitions to 99 in. at a second field splice and remains constant over Pier $8 \mathrm{~N}$ and through Span $9 \mathrm{~N}$. The web depth of Span $10 \mathrm{~N}$ is 99 in. until the first field splice, where the depth transitions to $78 \mathrm{in}$. at the second field splice and for the remaining span length. The top and bottom flanges are of variable thickness depending upon location in the positive or negative moment regions of the continuous spans. A typical cross-section showing the four welded plate girders and k-type crossframe members is presented in Figure 3.3.

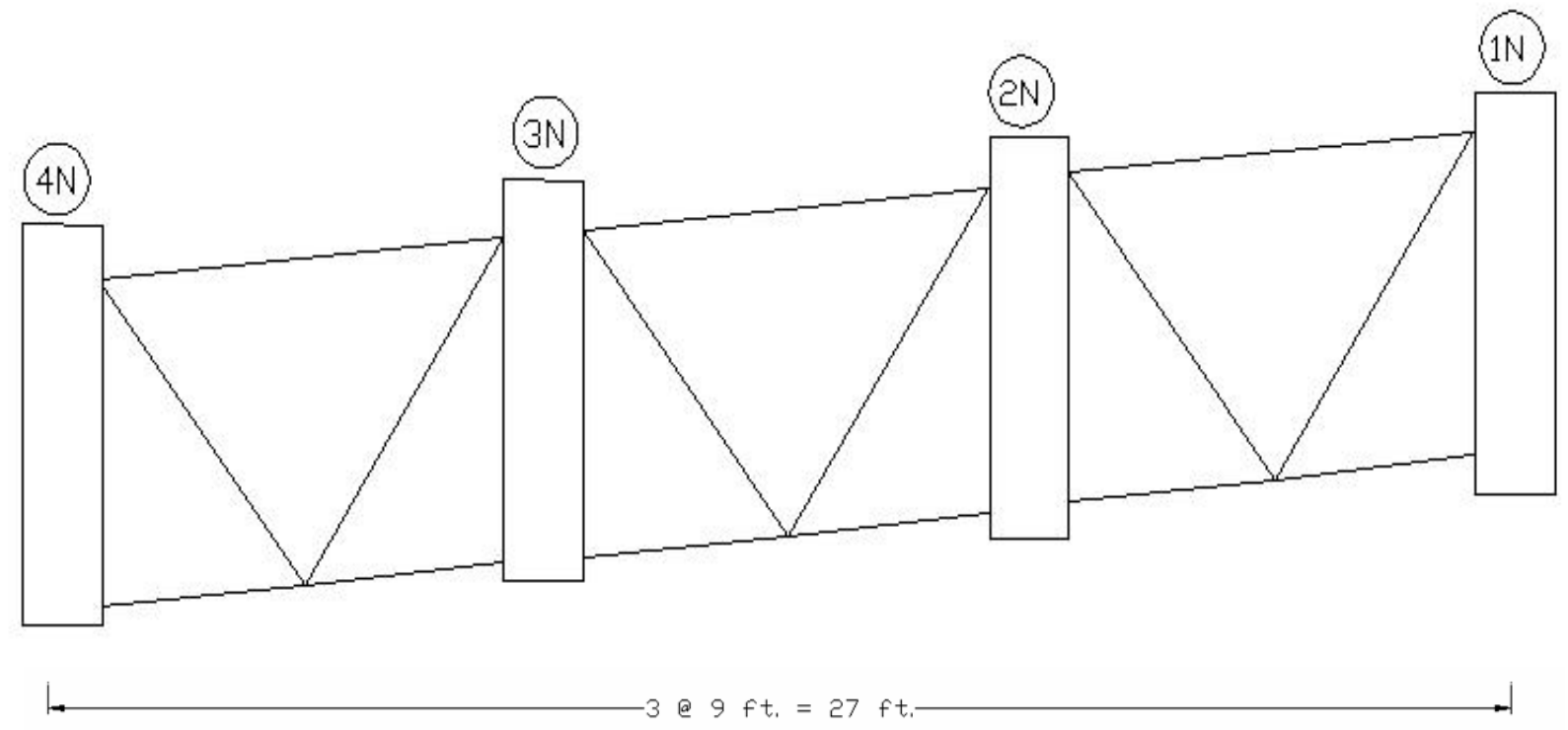

Figure 3.3 Typical Bridge Cross-Section 
Including crossframe connection plates, various size transverse stiffeners are installed throughout the structure. At the piers, bearing and jacking stiffeners are welded through the full depth of the girder. Also included at the piers are 24" auxillary stiffeners, welded six inches from the bearing stiffener on either side of the pier centerline. A higher number of transverse web stiffeners are implemented in the negative moment region, most likely for the purpose of carrying shear forces. Aside from a few locations, the crossframe connection plates are the only transverse web stiffeners utilized in the positive moment regions of bridge.

All steel components making up the bridge superstructure including girder webs, flanges, bearing stiffeners, jacking stiffeners, auxiliary stiffeners, intermediate stiffeners, and crossframe connection plates are modeled using four node shell elements. The 8.5 in. thick concrete deck was modeled using 3-layered shell elements. The reason for employing layered shell elements for the deck is to consider the bottom and top layers of steel reinforcement. Element size varies from 6" x 6" $\left(36\right.$ in $\left.^{2}\right)$ at midspan between piers, to $2 " \mathrm{x}$ 2" $\left(4 \mathrm{in}^{2}\right)$ at the piers and near the abutments. The 4 in $^{2}$ element sizes extend out from each pier to include the field splices on either side. The mesh transitions from 6" to 2" elements in regions surrounding the piers and near the abutments to ensure accurate solutions in these areas. This meshing technique was chosen in order to produce the most accurate results in areas that were deemed more significant for the purpose of this study, while also considering computing time. A total of 1,826,806 elements were created. Figures 3.4 and 3.5 show the size transition of the FE mesh. Figures 3.6 and 3.7 show the various types of stiffeners utilized throughout the bridge. 


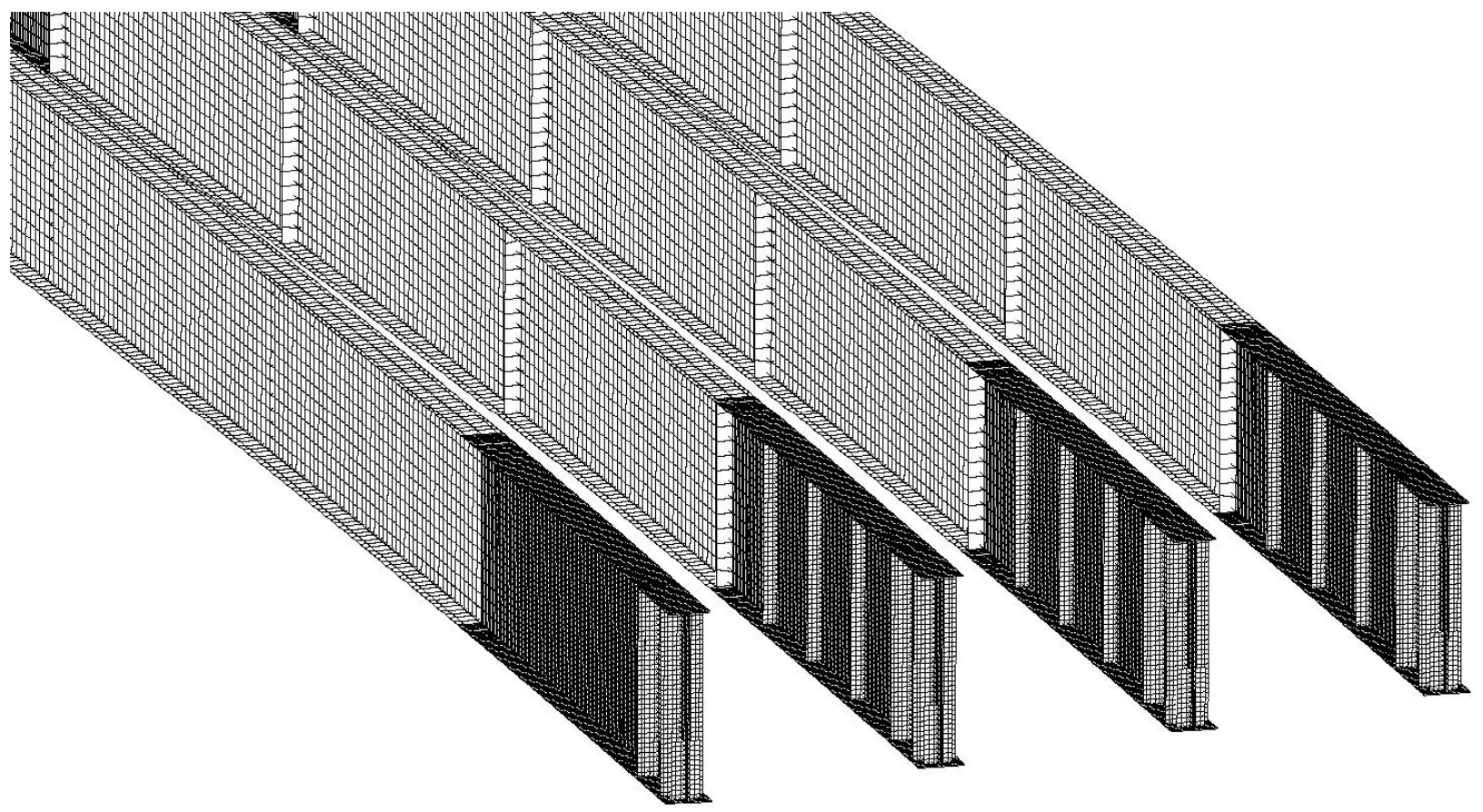

Figure 3.4 Mesh Transition Near Abutment 2N

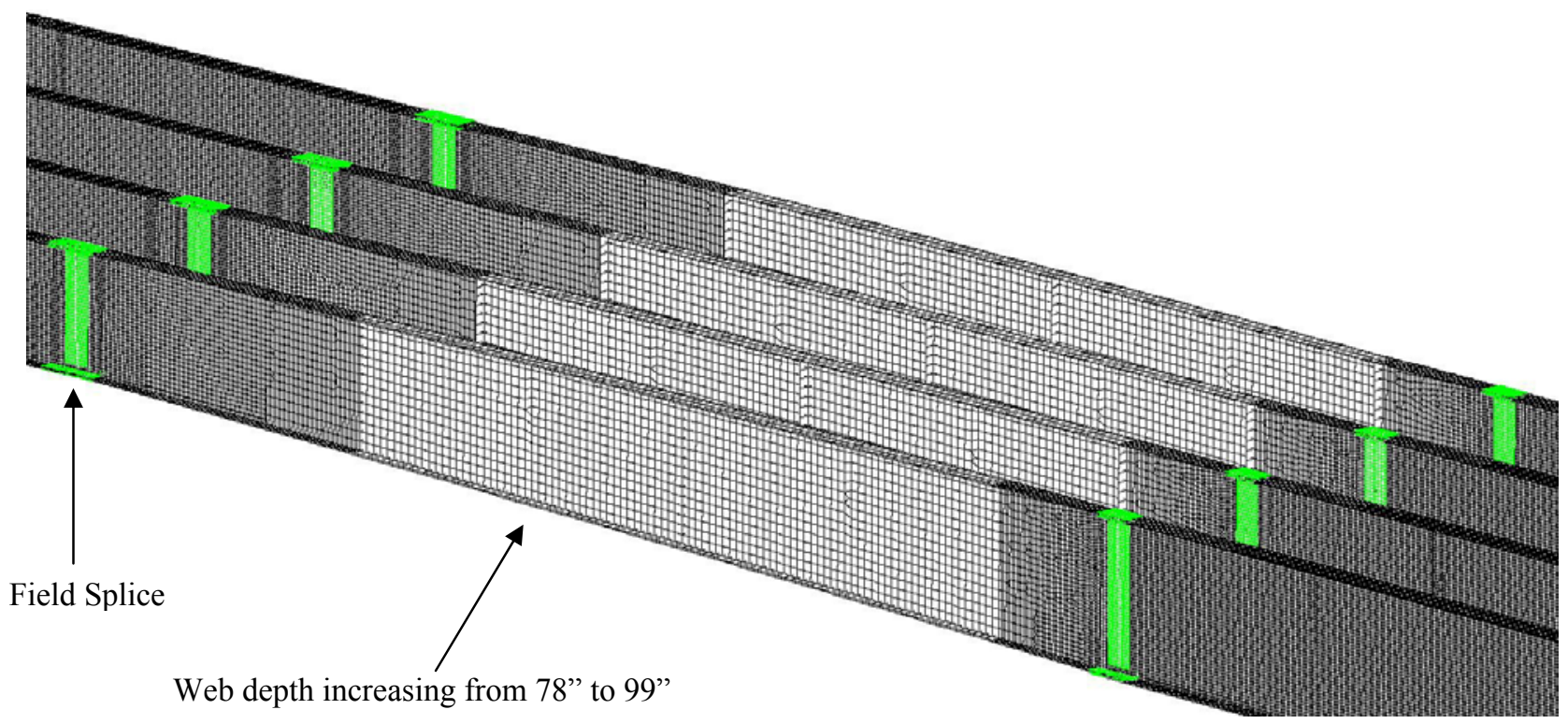

Figure 3.5 Mesh Transition (Span 8N) 


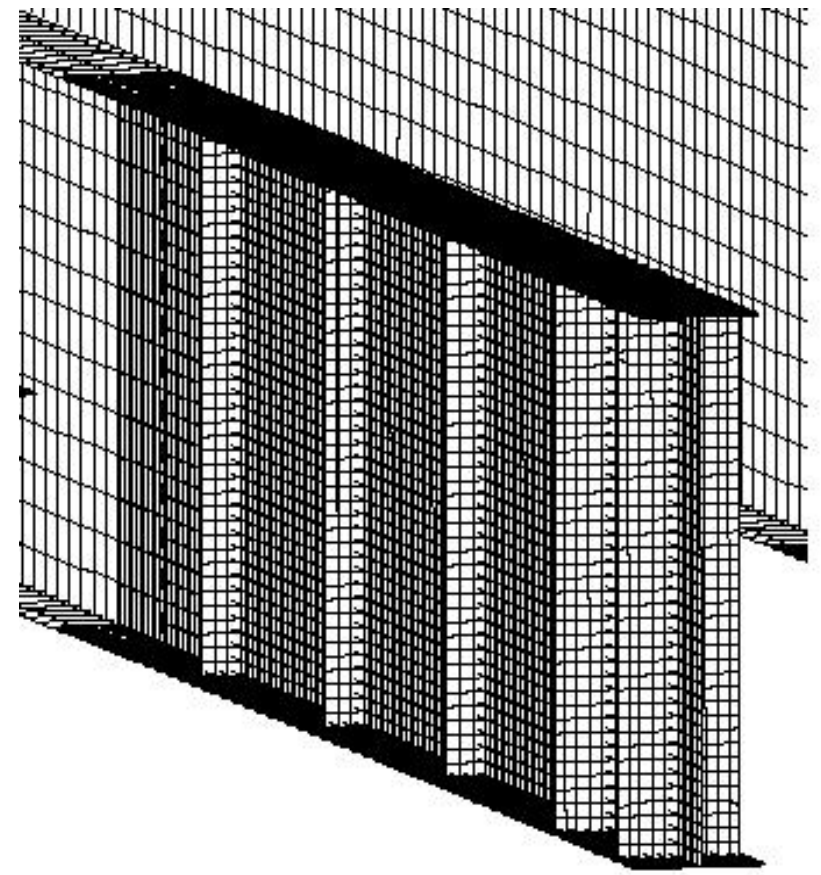

Figure 3.6 Intermediate Stiffeners

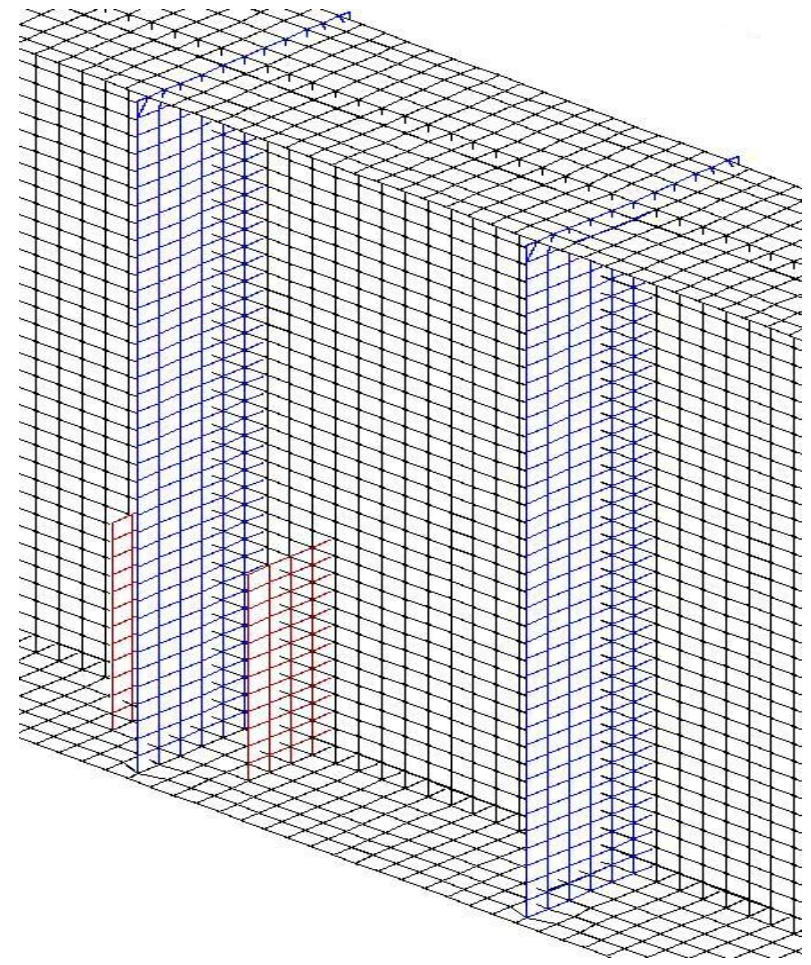

Figure 3.7 Bearing, Jacking, and Auxiliary Stiffeners 


\subsection{CROSSFRAMES}

Crossframe members play an important role in the behavior and response of curved girder bridges. Unlike in straight bridges, the crossframes of curved bridges are designed as primary load-bearing members because they are responsible for resisting the torsional moments inherent to a curved structure.

The crossframes in this study were modeled using Hermitian beam elements. On this structure, the majority of crossframe members are WT sections, including WT5 x 15 and WT6 $\times 25$ shapes. A W $12 \times 50$ section is also used, but is only used at Pier $6 \mathrm{~N}$ and the abutments. For each shape, the cross-sectional area, torsional and local moments of inertia were inputted into ADINA. All section properties were extracted from the AISC Steel Construction Manual $13^{\text {th }}$ Edition. Due to all crossframe members being modeled as 2-noded beam elements, the connection of the crossframe member to the connection plate is through a simple shared-node connection. In reality a certain number of structural steel bolts or welds connect the WT shape member to the connection plate. Also, the horizontal and diagonal crossframe members would be bolted or welded to a gusset plate. These simplifications were made in order to minimize the time needed to construct the FE model. All beam elements are 5 in. in length. The model has a total of 9,867 Hermitian beam elements.

\subsection{FIELD SPLICES}

A unique feature implemented during the FE modeling was the detail given to the bolted field splices used in the structure. Field splices are employed mainly to meet transportation allowances. In order to transport a girder to the construction site for erection, it must meet certain size tolerances to be permitted clearance on highways. Due to these size constraints, the girders are manufactured in sections to be erected and bolted together at the 
field splice locations. However, at these field splice locations, discontinuity is introduced to the structure. The field splices were modeled by creating a 0.25 in. gap (discontinuity) where instructed on the bridge design plans. The various field splice plates would be modeled to the dimensions listed in the design plans.

Referencing closely the design drawings, the plates used for the top and bottom flanges and the web were modeled as precise as possible. The dimensions of the plates are exactly as provided in the design drawings. Geometric surfaces representing the plates were created and offset from the web or flange by using the following formula:

$$
d_{\text {offset }}=\frac{t_{\text {web/flange }}}{2}+\frac{t_{\text {plate }}}{2}
$$

Using this formula ensured the centroids of the girder component and splice plate would be the correct distance apart. As for connecting the splice plates to the web or flange, in ADINA the rigid links constraint option was used to act as the structural bolts that are used on the actual structure. The accurate modeling of structural bolts is a very time consuming task, especially given the number of bolts present in the structure. Using the rigid links option made this task as expeditious as possible. The rigid links are created at the nodal level, connecting one node on the girder shell to one node on the splice plate shell element. Using this method, the multiple rows of bolts at each splice could be modeled relatively quickly. The girders and splice plates were modeled so that nodes generated on the girders line up vertically with nodes generated on the splice plates. This simulates the alignment needed for a bolt to be inserted through each plate and fitted with a nut. When generating the rigid links, certain parameters are selected to control the behavior of the so-called slave nodes (nodes on the splice plates). Master nodes (nodes on the girder) determine what 
displacements, forces, etc. are imparted to the slave nodes. In the FE model, it was specified that forcing the nodes on the splice plates to experience the same displacements as the girder nodes is an accurate assumption to make. An example illustration of the splice plates and rigid links taken from the FE model is shown in Figure 3.8. The bridge has 20 field splices per girder, totaling 80 field splices in all. Field splice locations for Unit 2, outlined in green, are shown in Figure 3.9. The concrete deck, modeled with shell elements, is connected to the top flange in a similar manner.
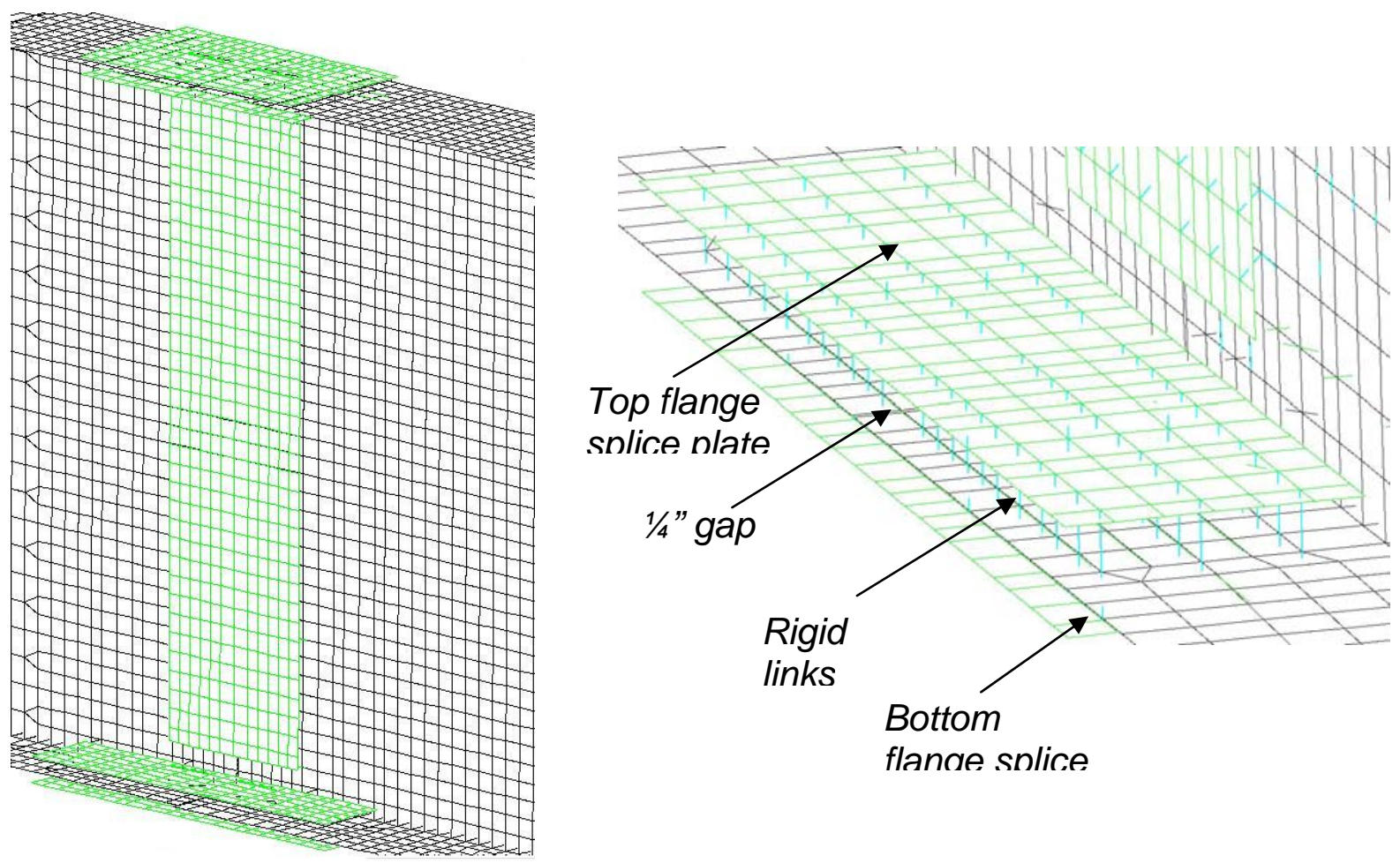

Figure 3.8 Field Splice Details 


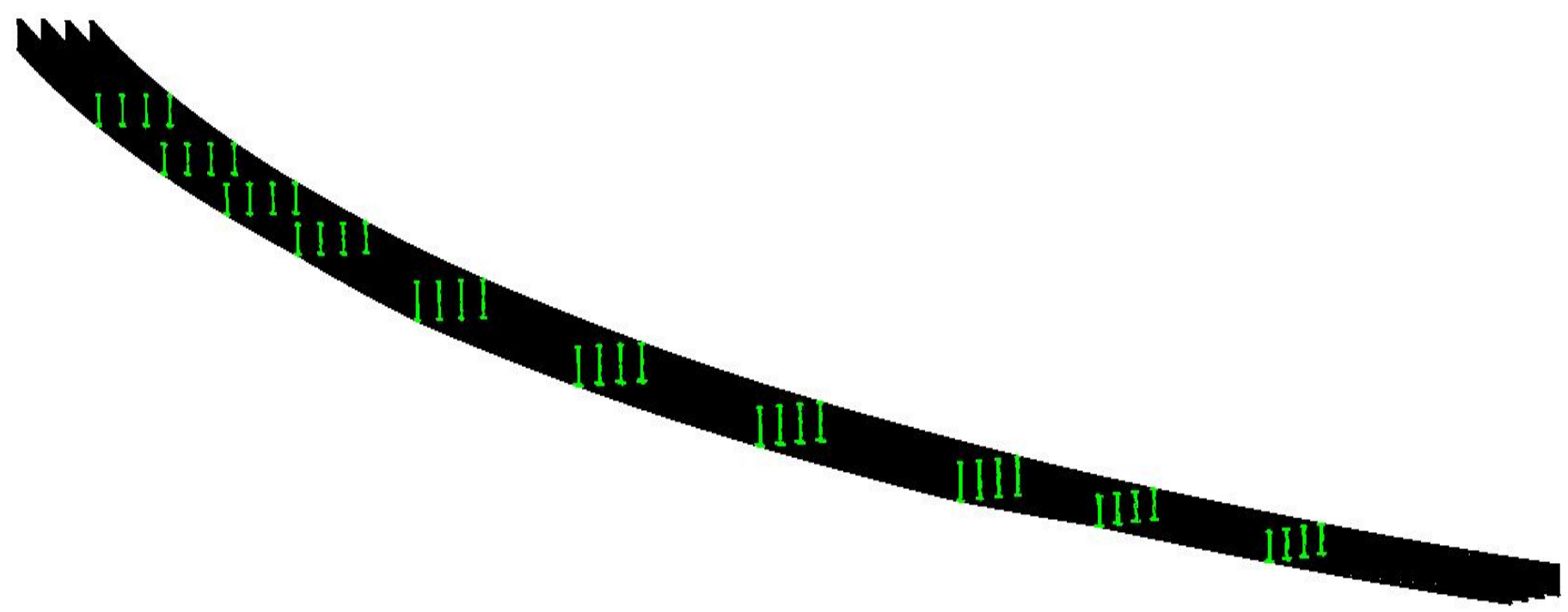

Figure 3.9 Field Splice Locations

\subsection{BEARINGS AND BOUNDARY CONDITIONS}

Modeling the bridge bearings was relatively straightforward. The bridge has a total of 56 bearings, four at each pier and the abutments. A combination of fixed, guided, and free bearings are employed on this structure. The exact bearing layout is presented later in Chapter Four. In reality each of these bearings is fixed to the girder by welding the bottom flange to the bearing's sole plate. To represent the welded sole plate, the shell elements making up the bottom flange at pier locations were increased in thickness by 1 in. compared to surrounding elements. These elements with increased thickness extend 12 in. on each side of the pier centerline and are the full width of the bottom flange. This concept is shown in Figure 3.10, where the bearing plate surfaces are outlined in black. Actual bearing components were not modeled; therefore some aspects of bearing behavior, such as friction forces, are not ignored. 


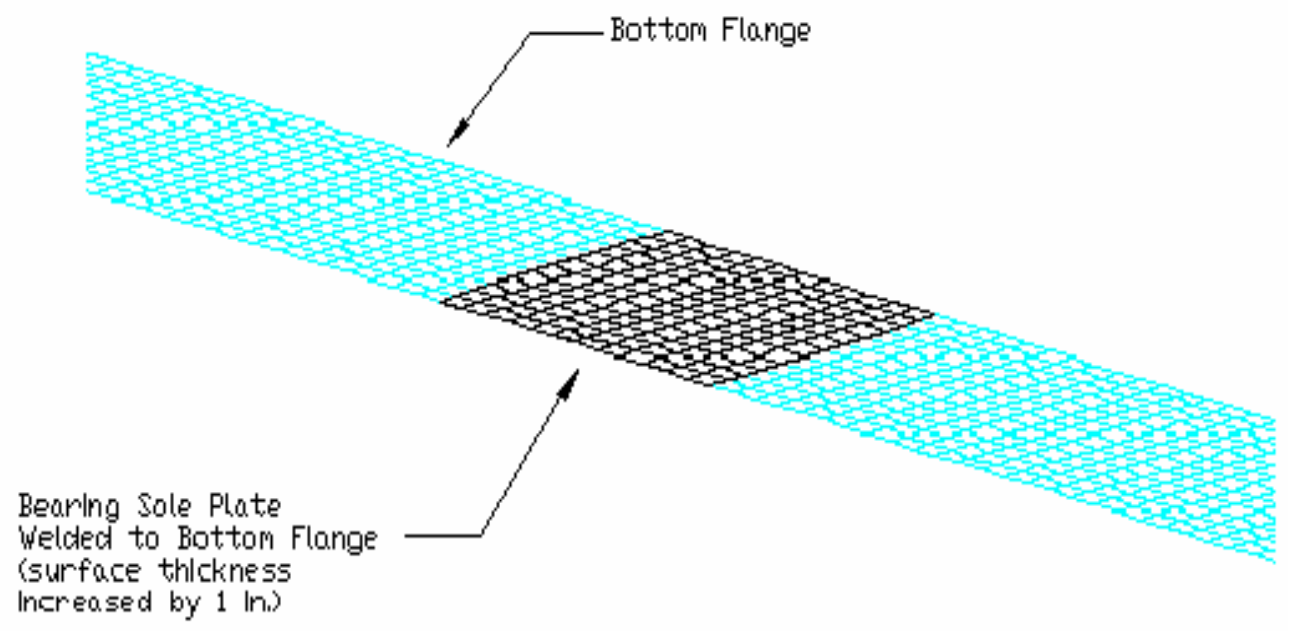

Figure 3.10 Bearing Plate Illustration

The boundary conditions in ADINA were applied in accordance with the bearing arrangement key plan provided in the design drawings. Boundary condition fixities were applied to the surfaces representing the bearings using the skew systems command in ADINA. Doing so prescribed the fixity to each node generated on the surfaces and removed the possibility of any relative displacement among different areas of the bearing surface. Listed below in Table 3.1 are the fixity conditions assigned to each bearing type used on the bridge.

Table 3.1 Bearing Fixity Conditions

\section{DIRECTION}

\begin{tabular}{|c|c|c|c|}
\cline { 2 - 4 } \multicolumn{1}{c}{$\begin{array}{c}\text { Bearing Type } \\
\text { (Fixity) }\end{array}$} & TRANSVERSE & LONGITUDINAL & VERTICAL \\
\hline FIXED & fixed & fixed & fixed \\
\hline $\begin{array}{c}\text { LONGITUDINALLY } \\
\text { GUIDED }\end{array}$ & fixed & free & fixed \\
\hline FREE & free & free & fixed \\
\hline
\end{tabular}


The fixed bearings allow zero displacement in all directions. Longitudinally -guided bearings prevent movement in the transverse direction, permitting girder translation only along an axis perpendicular to the transverse direction. As per AASHTO recommendations, girder movement at these longitudinally-guided bearings is oriented on chords passing through the nearest fixed bearing location. Free bearings permit movement in both the transverse and longitudinal directions, while all three bearing types allow girder rotation about any axis.

To accomplish correctly modeling the longitudinally-guided boundary condition, each bearing was assigned its own coordinate system (ADINA skew system command) so that the longitudinal axis was correctly aligned on a chord oriented toward the nearest fixed bearing. The local axes for a portion of one guided bearing are shown in Figure 3.11. It is also shown that the prescribed boundary condition is applied to each node of the mesh representing the bearing plate.

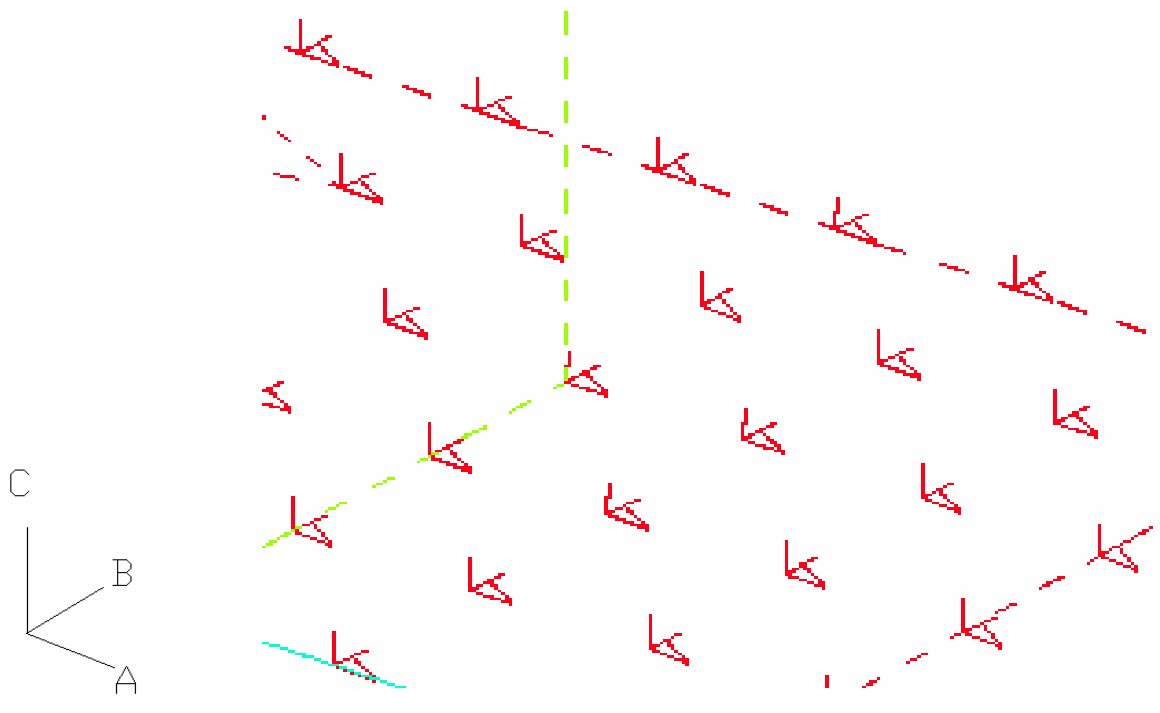

Figure 3.11 Bearing Fixity Conditions 


\subsection{MATERIAL MODEL}

This section describes the material models used for the FE bridge model. A bilinear elastic-plastic material with isotropic hardening was used to model all girder components. A material model that could develop strain hardening and exhibit plastic behavior was chosen because field observations determined that several areas of the bridge have undergone plastic deformations and material yielding.

No failure criterion was defined in this study, therefore an elastic isotropic material model was assumed for the 8.5 in. thick concrete deck. All material properties are presented in Table 3.3. As seen in the table, two different types of steel are present in the structure. HPS 70W is a high-performance steel with a yield stress of $70 \mathrm{ksi}$. The girder web and flanges are made of this type of steel in regions of negative bending moment. Grade 50W-T2 is a structural steel used throughout the rest of the bridge. A summary of the type of steel and location as used in the FE model is given in Table 3.2.

Table 3.2 Steel Types

\begin{tabular}{|c|c|}
\hline $\begin{array}{c}\text { GIRDER } \\
\text { COMPONENT }\end{array}$ & $\begin{array}{c}\text { TYPE OF } \\
\text { STEEL }\end{array}$ \\
\hline WEB/FLANGES & $\begin{array}{c}\text { HPS 70W (piers) } \\
\text { Grade 50W-T2 (midspan) }\end{array}$ \\
\hline STIFFENERS & Grade 50W-T2 \\
\hline $\begin{array}{c}\text { CROSSFRAME } \\
\text { CONNCECTION } \\
\text { PLATES }\end{array}$ & Grade 50W-T2 \\
\hline $\begin{array}{c}\text { CROSSFRAME } \\
\text { MEMBERS }\end{array}$ & Grade 50W-T2 \\
\hline \begin{tabular}{c} 
SPLICE PLATES \\
\hline
\end{tabular}
\end{tabular}


Table 3.3 Material Properties

STEEL

\begin{tabular}{|l|c|c|c|}
\hline & $\begin{array}{c}\text { HPS 70W } \\
\text { (elastic-plastic) }\end{array}$ & $\begin{array}{c}\text { Grade 50W-T2 } \\
\text { (elastic-plastic) }\end{array}$ & $\begin{array}{c}\text { Grade 50W-T2 } \\
\text { (elastic) }\end{array}$ \\
\hline Modulus of Elasticity (psi) & $30 \times 10^{6}$ & $30 \times 10^{6}$ & $30 \times 10^{6}$ \\
\hline Poisson's Ratio & 0.3 & 0.3 & 0.3 \\
\hline Unit Weight $\left(\right.$ Ib/in $^{3}$ ) & 0.286 & 0.286 & 0.286 \\
\hline Coefficient of Thermal Expansion $\left(/^{\circ} \mathbf{F}\right)$ & $6.5 \times 10^{-6}$ & $6.5 \times 10^{-6}$ & $6.5 \times 10^{-6}$ \\
\hline Initial Yield Stress (psi) & 70,000 & 50,000 & \\
\hline Strain Hardening Modulus (psi) & $500 \times 10^{3}$ & $500 \times 10^{3}$ & \\
\hline
\end{tabular}

\section{CONCRETE}

\begin{tabular}{|l|c|}
\hline Modulus of Elasticity (psi) & $4.5 \times 10^{6}$ \\
\hline Poisson's Ratio & 0.2 \\
\hline Unit Weight $\left({\left.\mathrm{Ib} / \mathrm{in}^{3}\right)}^{3}\right)$ & 0.0868 \\
\hline Coefficient of Thermal Expansion $\left(/^{\circ} \mathrm{F}\right)$ & $5.5 \times 10^{-6}$ \\
\hline
\end{tabular}

\subsection{LOADING}

Three uniform temperature loads, $-60^{\circ} \mathrm{F},+60^{\circ} \mathrm{F}$, and $+90^{\circ} \mathrm{F}$ were separately applied to the FE model, as well was the self-weight gravity load. The temperature loads were selected in order to cover a wide range of possible temperature variations the actual bridge may experience and also to determine at what temperature critical behavior occurs. All applied temperature loads represent departure from a certain ambient installation temperature specified in design guidelines. The longitudinally-guided bearing devices are then designed to permit expansion or contraction of the girders when the temperature increases or decreases with respect to that ambient temperature. The ambient temperature for this model is $0^{\circ} \mathrm{F}$, therefore a temperature load of $+90^{\circ} \mathrm{F}$ represents a uniform $90^{\circ} \mathrm{F}$ increase in temperature. 


\section{CHAPTER FOUR}

\section{OUT-OF-PLANE WEB DISTORTION UNDER AS-BUILT BEARING ARRANGEMENT}

\subsection{INTRODUCTION}

Large magnitudes of out-of-plane web distortion were observed on the study bridge during field inspections. This out-of-plane web behavior is not isolated to one region of the structure; rather it is prevalent throughout the entire bridge. While it is well known that steel I-girders maintain a certain level of postbuckling strength after initial buckling, large out-ofplane distortions will negatively influence the ultimate structural capacity of a steel I-girder (White and Jung 2007, Kala et al. 2005).

This chapter investigates the web behavior observed in the bridge's curved steel Igirders, and seeks to accurately quantify the deformations by utilizing the detailed FE bridge model. Four load conditions were studied: bridge self-weight alone, and temperature loads of $-60^{\circ} \mathrm{F},+60^{\circ} \mathrm{F}$ and $+90^{\circ} \mathrm{F}$. Longitudinal web profiles of the entire length of Girder $4 \mathrm{~N}$ and transverse cross-section profiles at several locations on the bridge were created using data obtained from the FE model. AASHTO design live load is added to the bridge to determine its effect on out-of-plane web distortion. Lastly, using the TOPCON Imaging Station laser scanning instrument, the web distortion of Girder $4 \mathrm{~N}$, Spans $1 \mathrm{~N}$ to $3 \mathrm{~N}$ was measured is compared to the results obtained from the FE model. The results of the laser scanning instrument serves as a validation tool for the 3D FE bridge model. 


\subsection{AS-BUILT BEARING ARRANGEMENT PLAN}

When reviewing the bearing arrangement key plan included in the bridge design drawings, a key area of concern is the implementation of numerous fully fixed bearing devices. The bearing arrangement calls for the use of numerous fully fixed bearing devices to be employed at three consecutive piers in two separate locations. The use of so many consecutive fixed bearings imparts a high level of constraint to the structure. When subjected to thermal loads, this constraint will inhibit the thermal expansion of the structure, resulting in possible unexpected deformations. This chapter utilizes the FE bridge model to study the behavior of the bridge under several thermal loads. Figure 4.2 presents the bearing arrangement plan for the bridge as it was designed. 


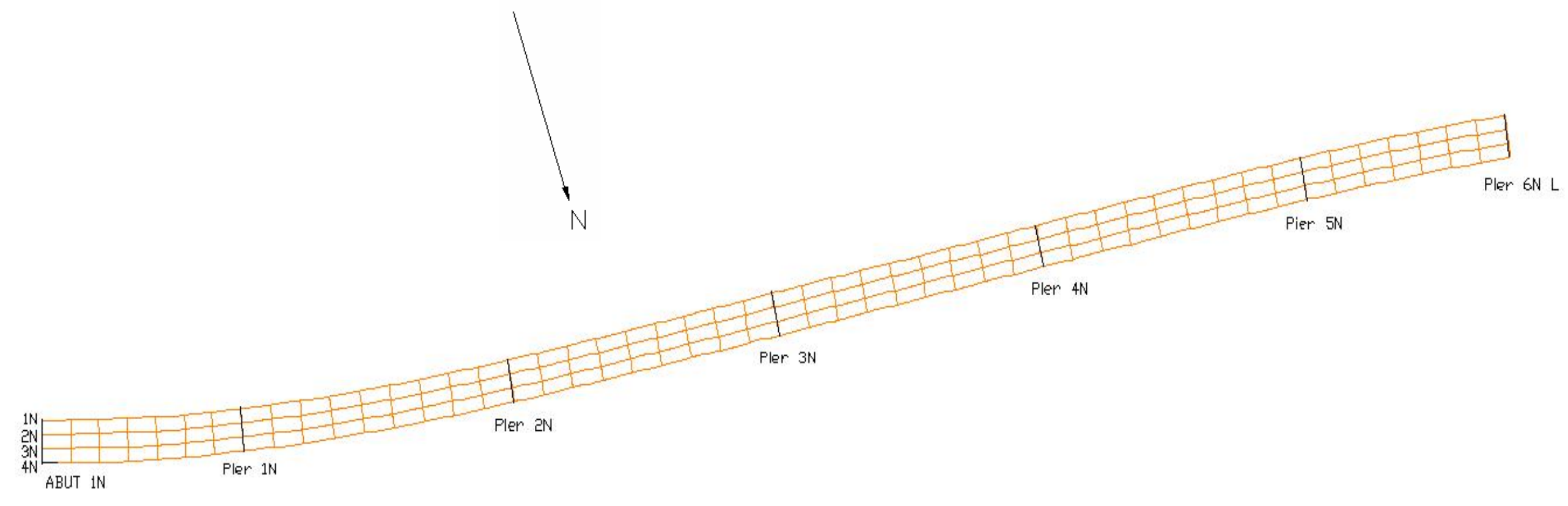

\begin{tabular}{c|c|c|c|c|c|c|c} 
Girder & Abutment 1N & Pier 1N & Pier 2N & Pier 3N & Pier 4N & Pier 5N & Pier 6N L \\
\hline $\mathbf{1 N}$ & FREE & FREE & FIXED & FIXED & FIXED & FIXED & FREE \\
$\mathbf{2 N}$ & GUIDED & GUIDED & FIXED & FIXED & FIXED & FIXED \\
$\mathbf{3 N}$ & GUIDED & GUIDED & FIXED & FIXED & FIXED & FIXED \\
$\mathbf{4 N}$ & FREE & FREE & FIXED & FIXED & FIXED & GUIDED \\
& & & & FIXED
\end{tabular}

Figure 4.1 As-Built Bearing Arrangement (Unit 1) 


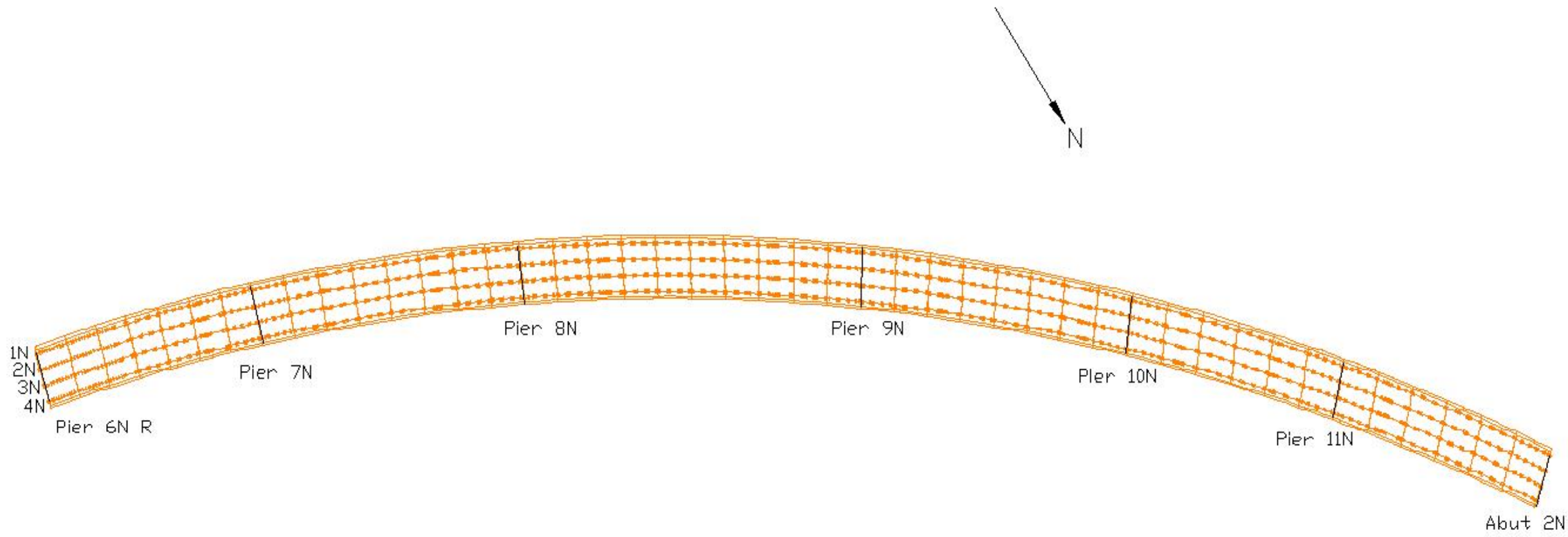

\begin{tabular}{c|c|c|c|c|c|c|c} 
Girder & Pier 6N R & Pier 7N & Pier 8N & Pier 9N & Pier 10N & Pier 11N & Abutment 2N \\
\hline $\mathbf{1 N}$ & FREE & FIXED & FIXED & FIXED & FREE & FREE \\
$\mathbf{2 N}$ & GUIDED & FIXED & FIXED & FIXED & GUIDED & GUIDED \\
$\mathbf{3 N}$ & GUIDED & FIXED & FIXED & FIXED & GUIDED & GUIDED & GUIDED \\
$\mathbf{4 N}$ & FREE & FIXED & FIXED & FIXED & FREE & FREE
\end{tabular}

Figure 4.2 As-Built Bearing Arrangement (Unit 2) 


\subsection{LONGITUDINAL WEB PROFILES}

This section details the out-of-plane web distortion produced by the FE bridge model for an exterior girder (Girder 4N). Figures 4.4 through 4.15 show the out-of-plane web distortion (horizontal profiles) for all twelve spans. Nodal displacements were recorded as near to the web centroid as possible, depending on the geometry of the computer-generated FE mesh. Horizontal profiles for an interior girder (Girder $3 \mathrm{~N}$ ) are given in Appendix A.

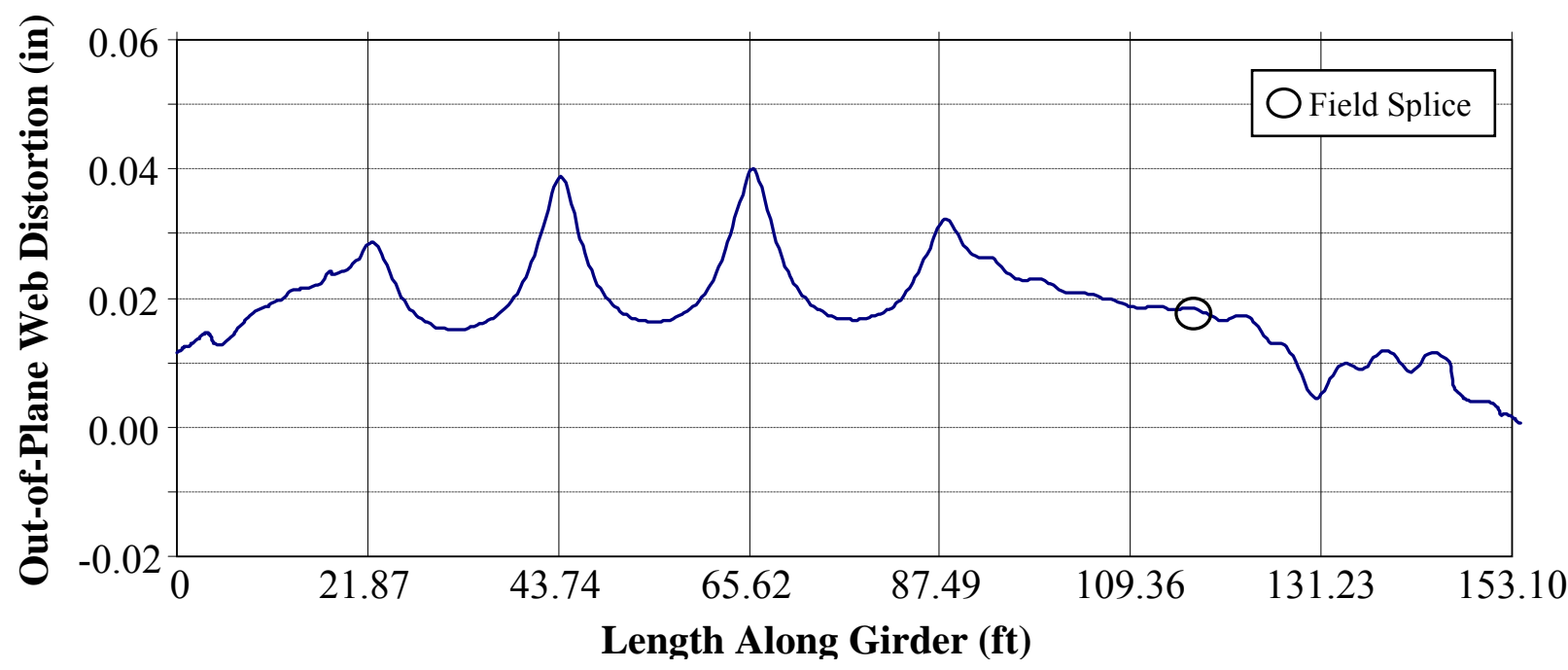

Figure 4.3 Span 1N, Out-of-Plane Web Deflection Due to Self-Weight

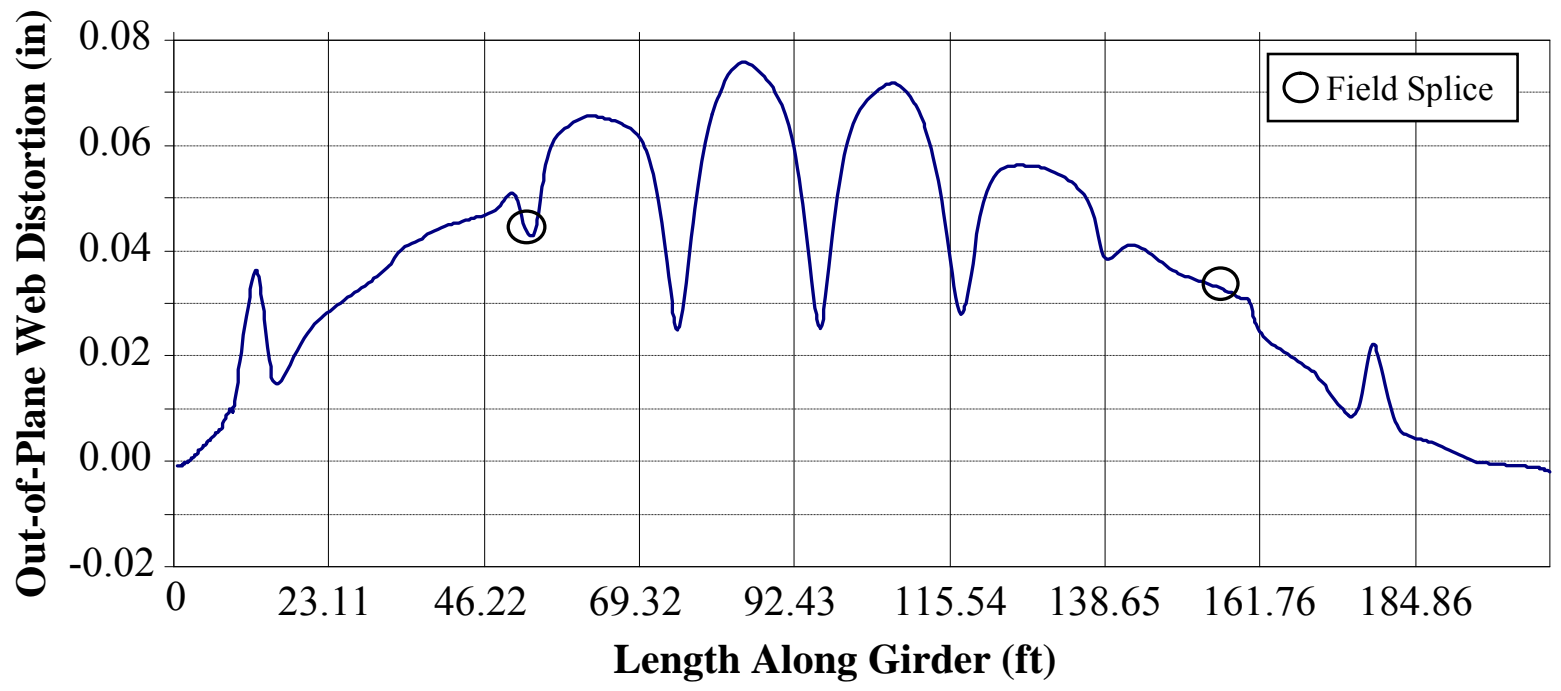

Figure 4.4 Span 2N, Out-of-Plane Web Deflection Due to Self-Weight 


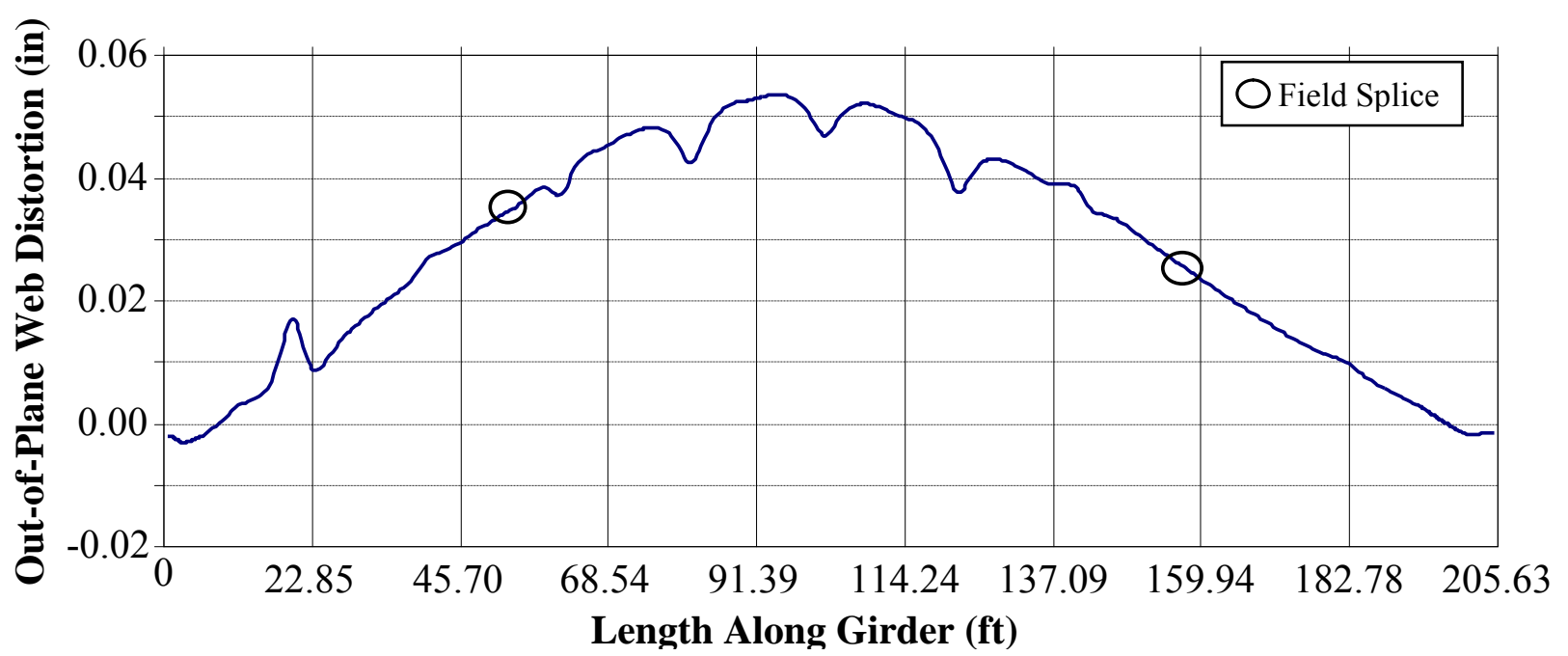

Figure 4.5 Span 3N, Out-of-Plane Web Deflection Due to Self-Weight

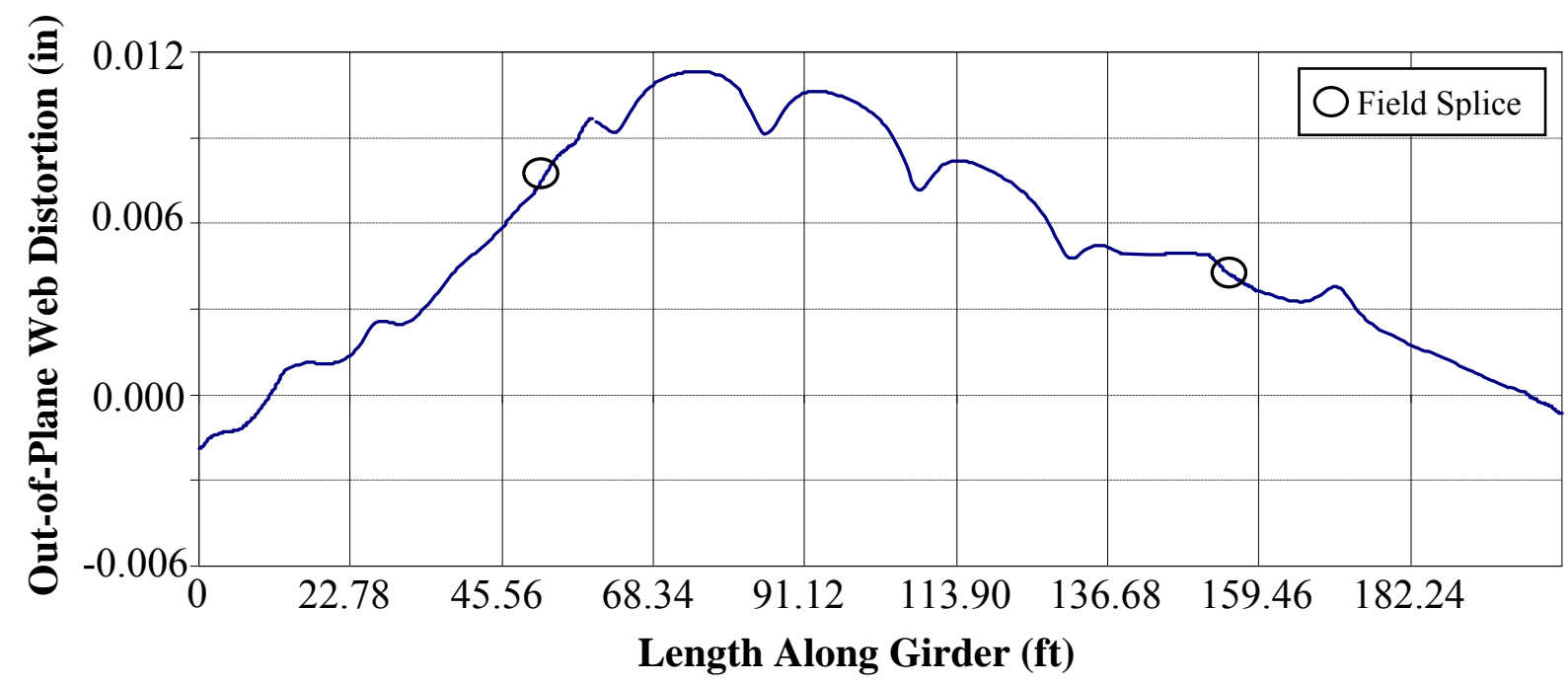

Figure 4.6 Span 4N, Out-of-Plane Web Deflection Due to Self-Weight

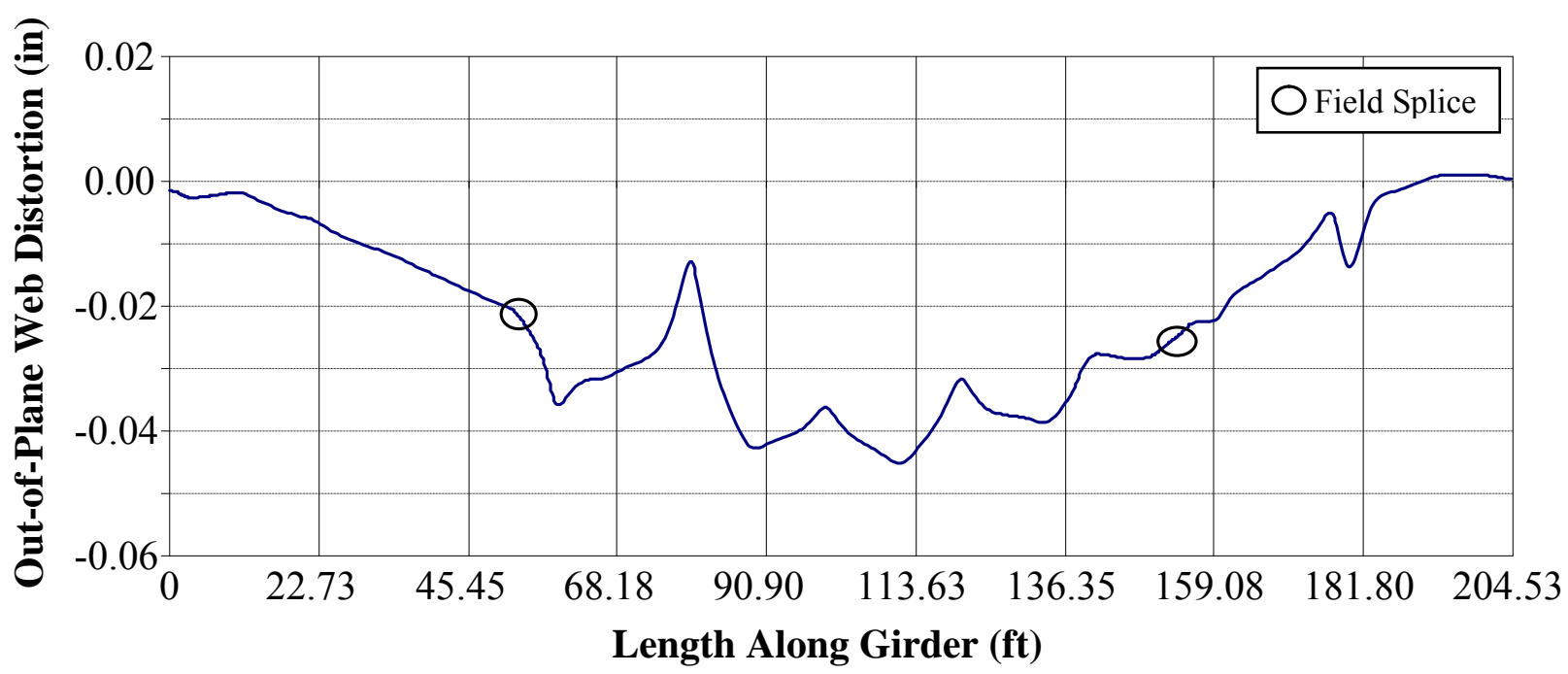

Figure 4.7 Span 5N, Out-of-Plane Web Deflection Due to Self-Weight 


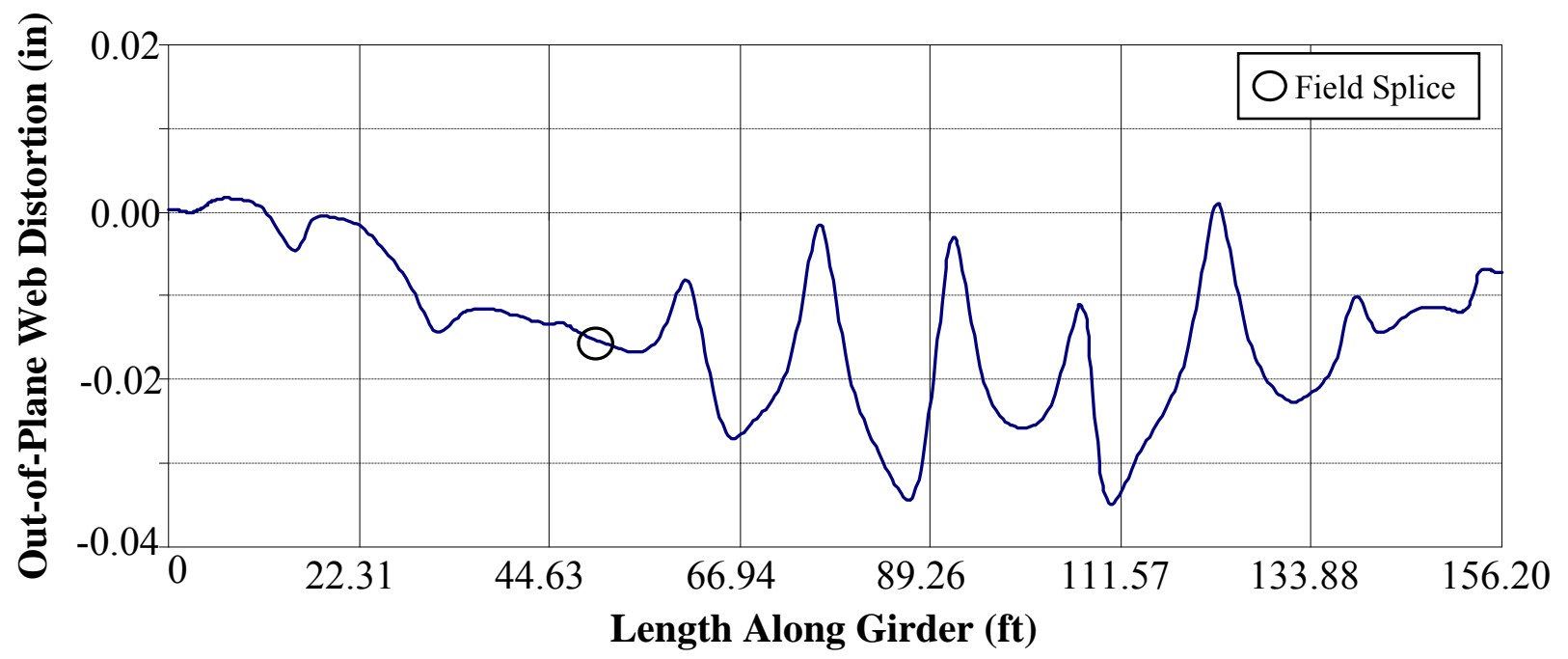

Figure 4.8 Span 6N, Out-of-Plane Web Deflection Due to Self-Weight

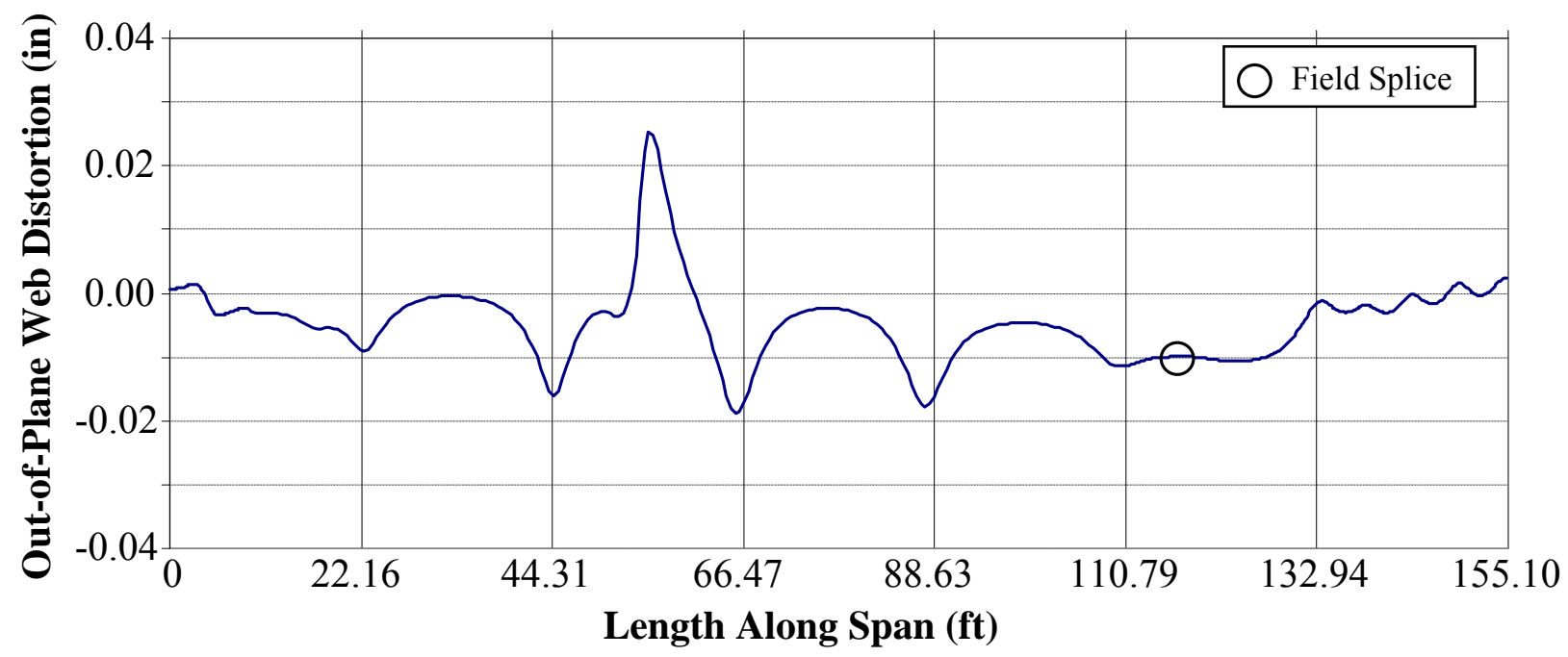

Figure 4.9 Span 7N, Out-of-Plane Web Deflection Due to Self-Weight

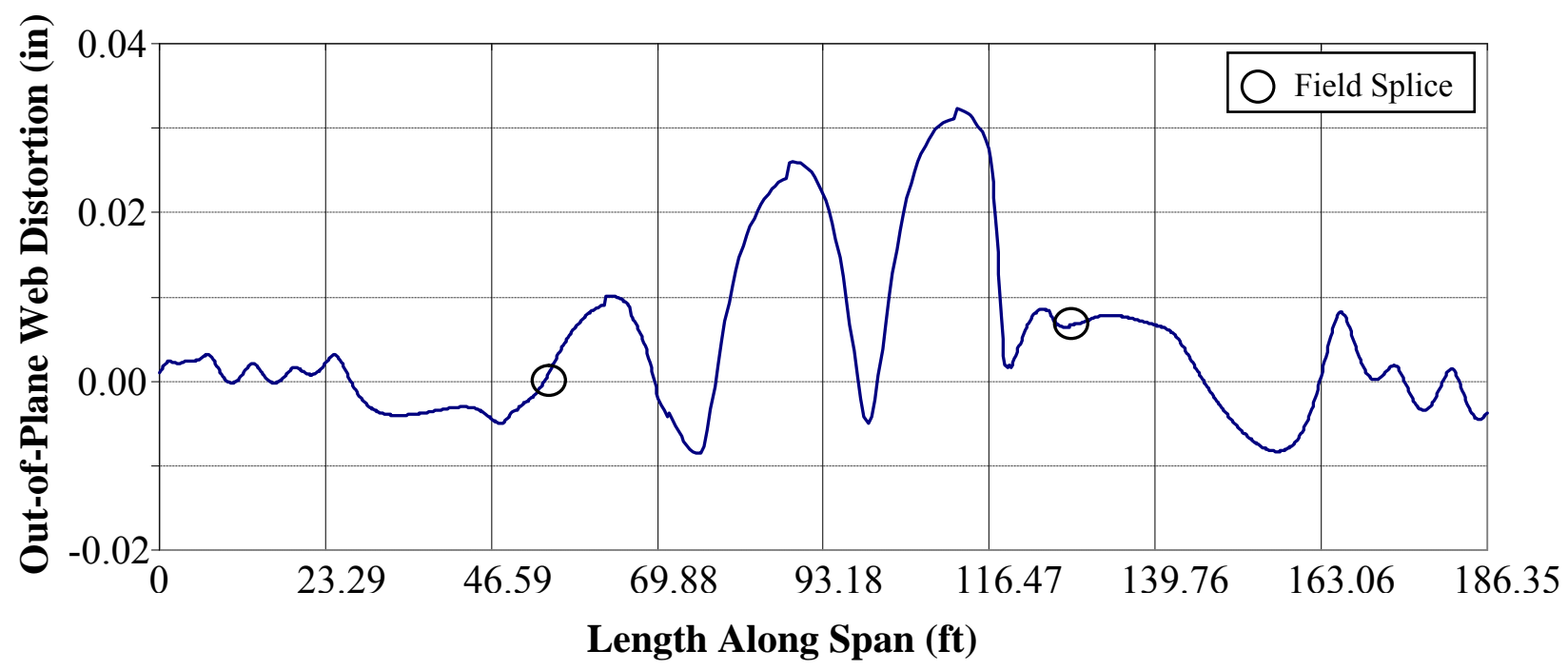

Figure 4.10 Span 8N, Out-of-Plane Web Deflection Due to Self-Weight 


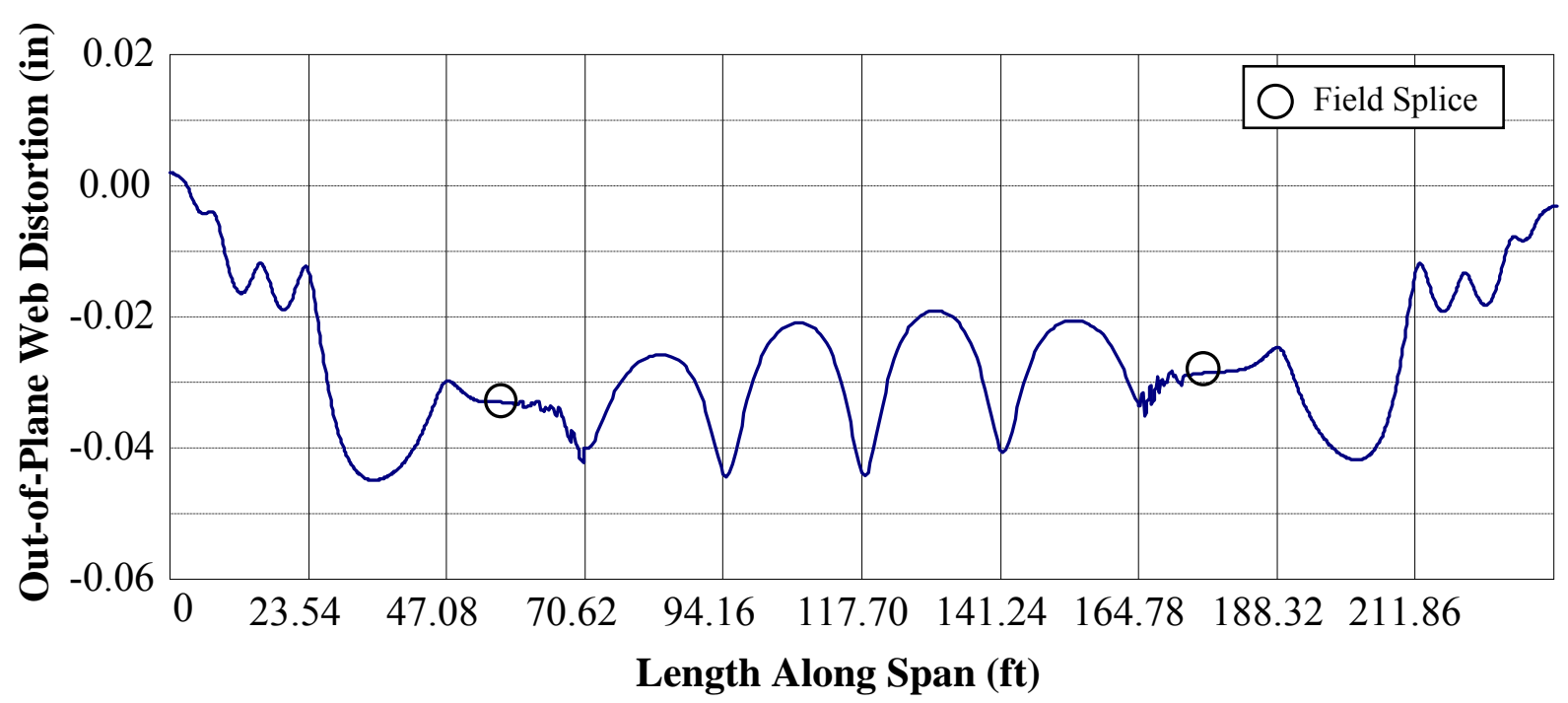

Figure 4.11 Span 9N, Out-of-Plane Web Deflection Due to Self-Weight

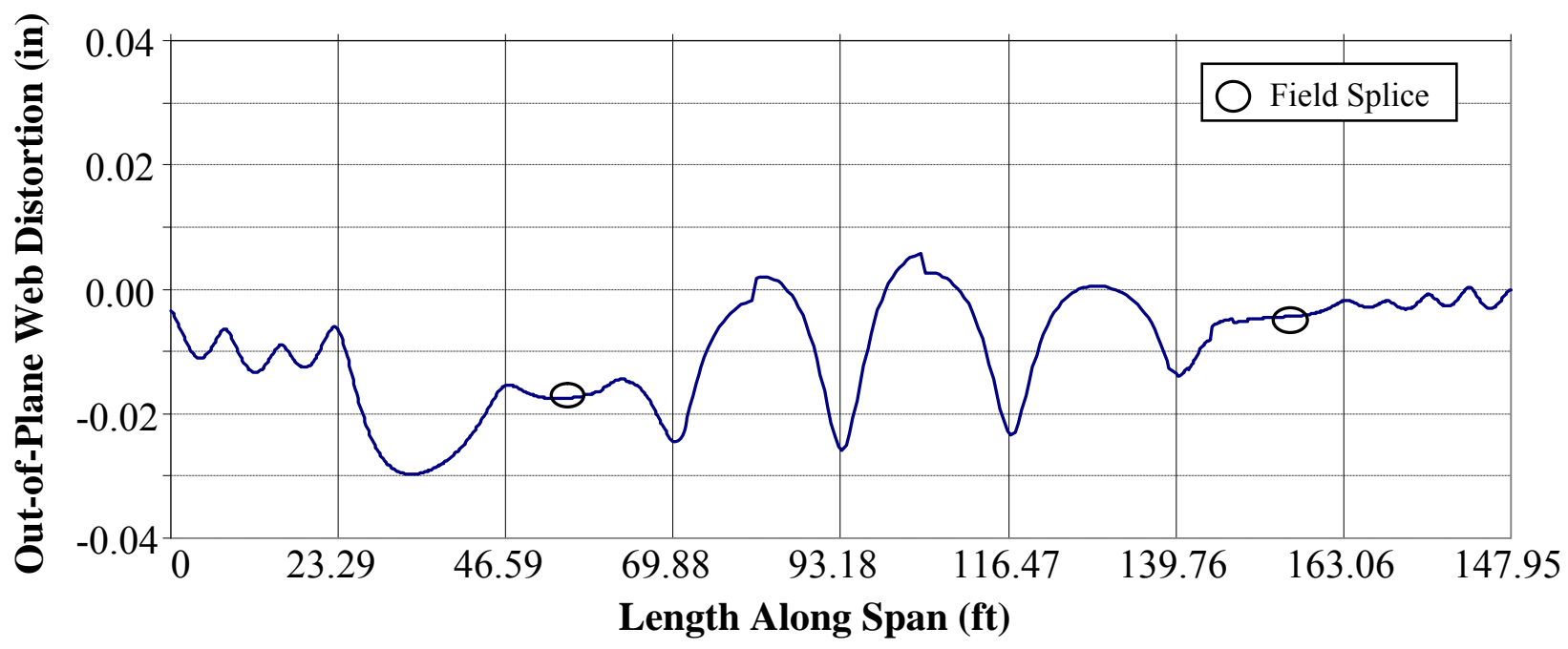

Figure 4.12 Span 10N, Out-of-Plane Web Deflection Due to Self-Weight

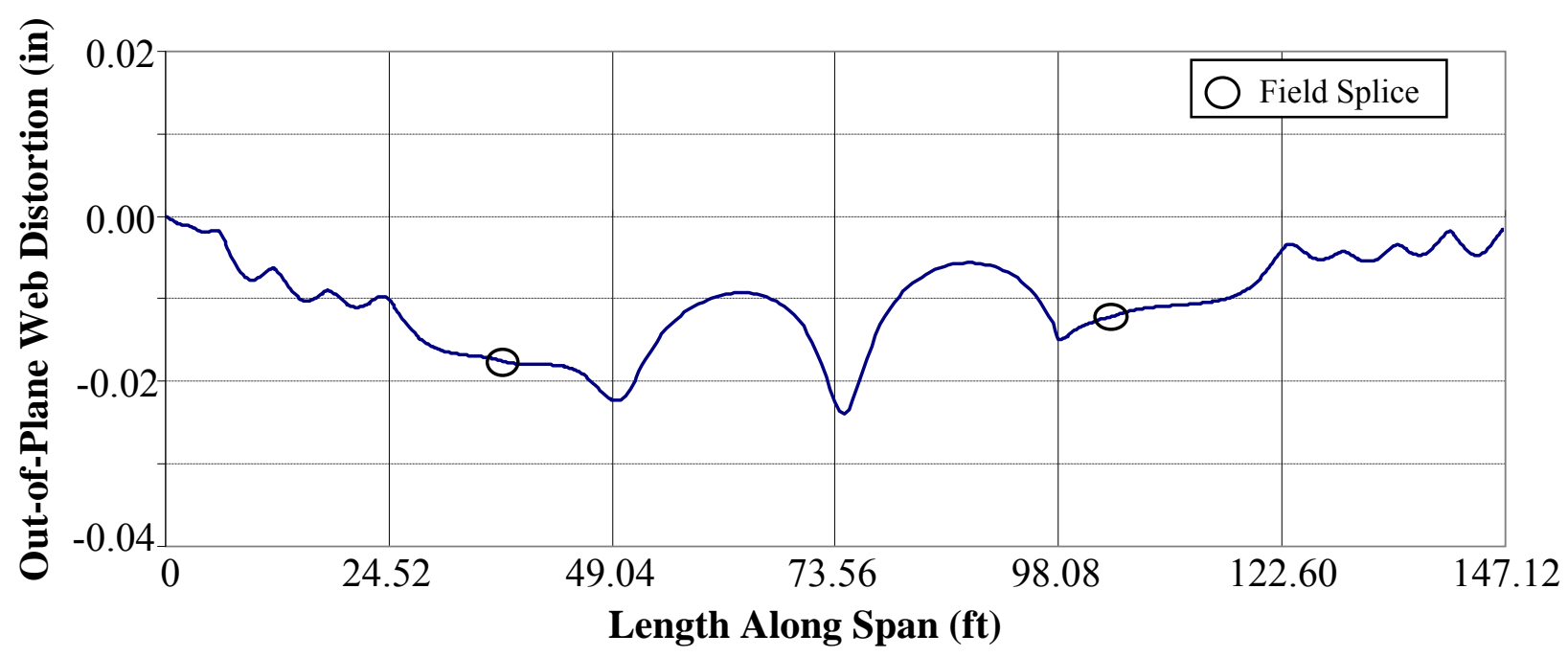

Figure 4.13 Span 11N, Out-of-Plane Web Deflection Due to Self-Weight 


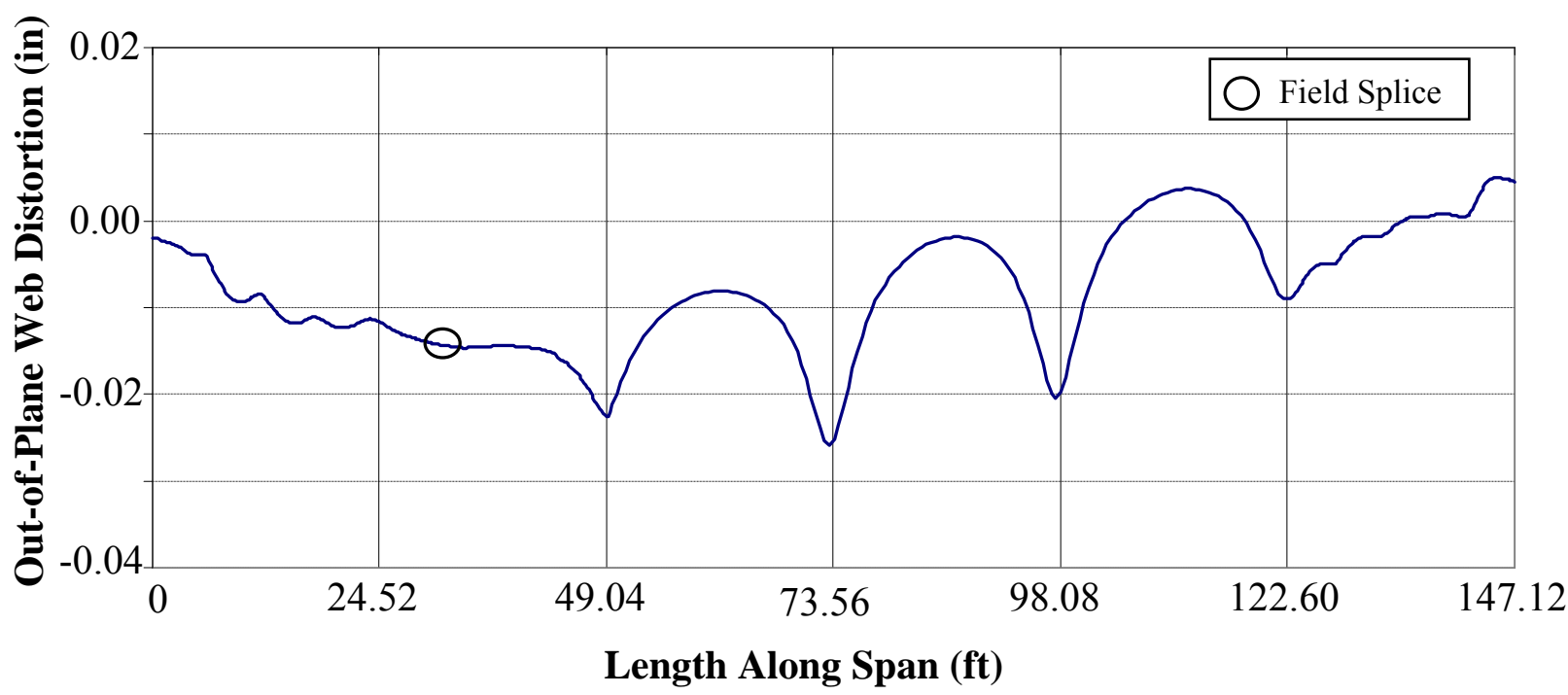

Figure 4.14 Span 12N, Out-of-Plane Web Deflection Due to Self-Weight

The web distortion profiles extracted from the FE model show that under bridge selfweight, significant out-of-plane web distortion is occurring throughout the entire structure. The maximum out-of-plane web deflection under bridge self-weight is $0.075 \mathrm{in}$., which occurs near the midspan of Span $2 \mathrm{~N}$. The average maximum displacement throughout the twelve spans is approximately $0.035 \mathrm{in}$. It is important to recognize that the profiles shown above were produced without any lateral or temperature force effects applied. For this reason, Figures 4.4 through 4.15 are undergoing a certain level of web buckling due to flexural forces, which is specified and discussed in AASHTO LRFD design specifications Article C6.10.1.9.1.

According to Article C6.10.1.9.1, during numerous experimental tests, web plate bending deformations and concurrent transverse displacements can develop due to initial web out-of-flatness or other initial geometric imperfections in steel I-girder webs. Due this behavior being a load-deflection action, AASHTO (2007) controls this out-of-plane deformation by limiting the stress in the web to a certain critical value; the web bendbuckling resistance. While not discussed here, stress considerations resulting from the outof-plane deformations in Figures 4.4 through 4.14 is treated thoroughly in Chapter Five. The 
FE model has shown that web distortions have developed in the bridge due only to girder self-weight and bridge deck dead load, but may not be overly influential when discussing bridge capacity. Since such a response is produced without consideration of design live loads, lateral loading, or thermal loading, web slenderness and transverse stiffener spacing will be investigated as well. The FE results produced from the application of the temperature loads are shown in Figures 4.15-4.26, Figures 4.27-4.38, and Figures 4.39-4.50 respectively.

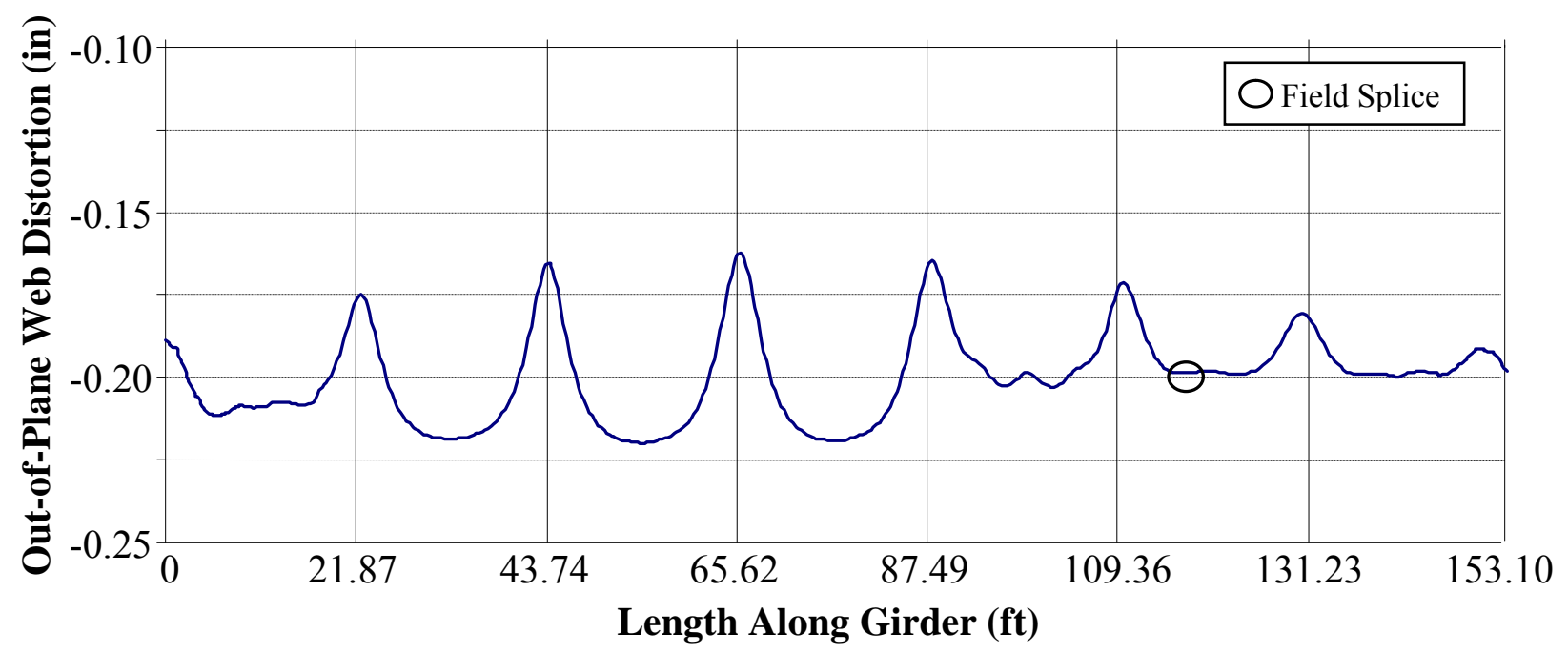

Figure 4.15 Span 1N, Out-of-Plane Web Deflection Due to Temp $-60^{\circ} \mathrm{F}$

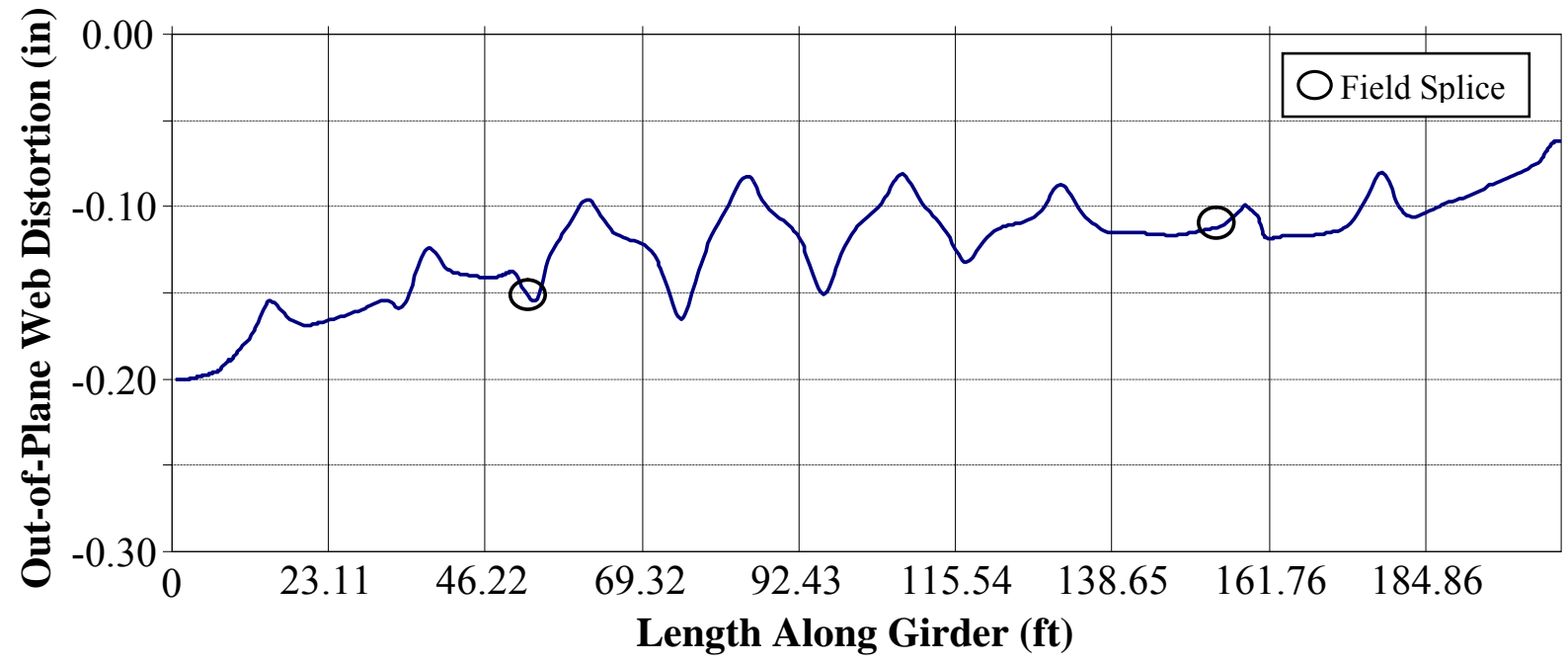

Figure 4.16 Span 2N, Out-of-Plane Web Deflection Due to Temp $-60^{\circ} \mathrm{F}$ 


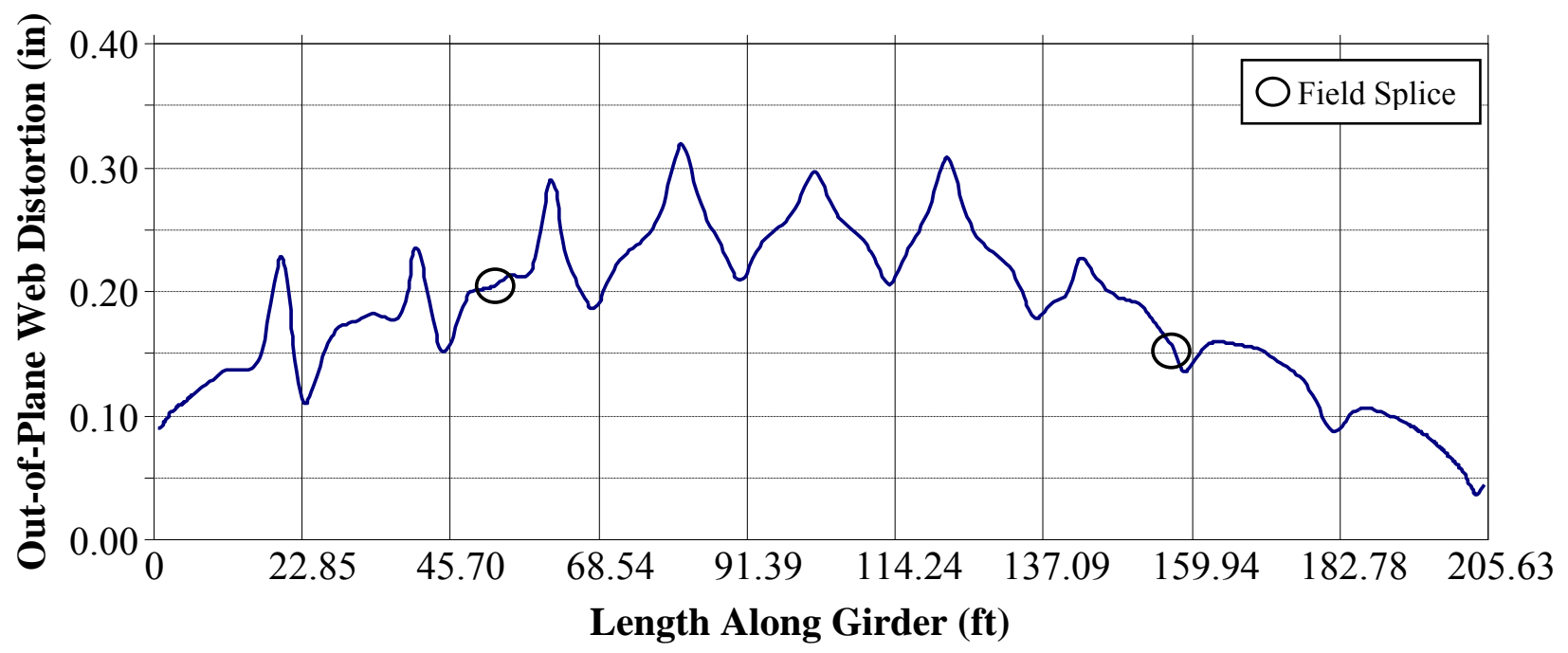

Figure 4.17 Span 3N, Out-of-Plane Web Deflection Due to Temp $-60^{\circ} \mathrm{F}$

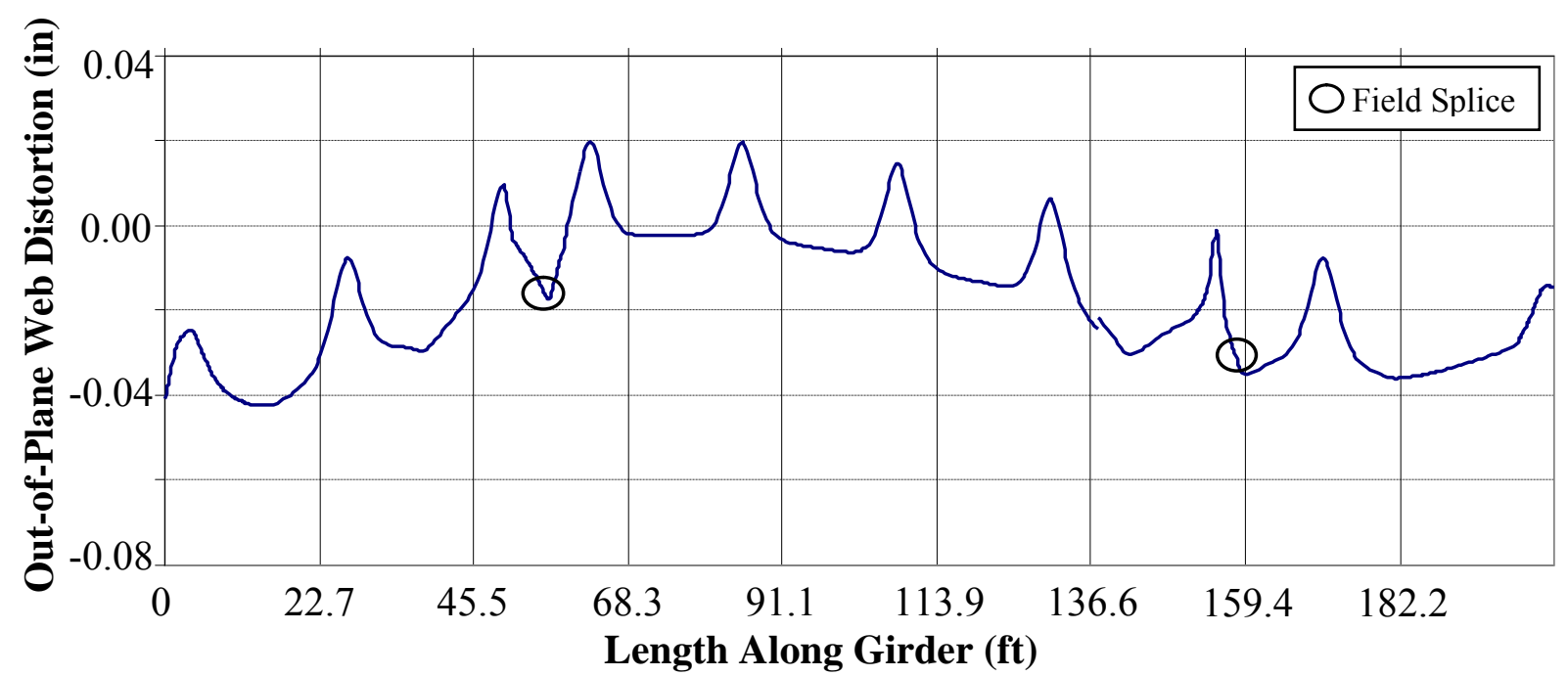

Figure 4.18 Span 4N, Out-of-Plane Web Deflection Due to Temp $-60^{\circ} \mathrm{F}$

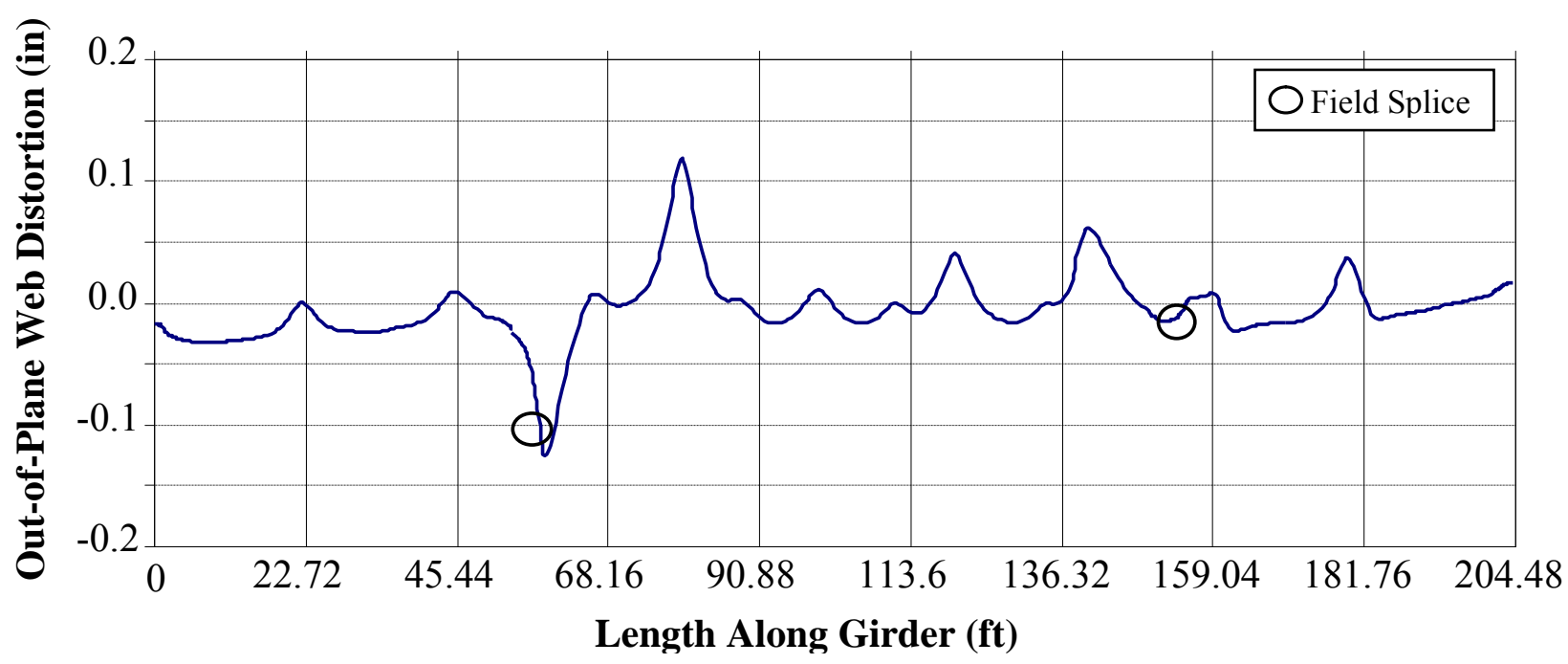

Figure 4.19 Span 5N, Out-of-Plane Web Deflection Due to Temp - $60^{\circ} \mathrm{F}$ 


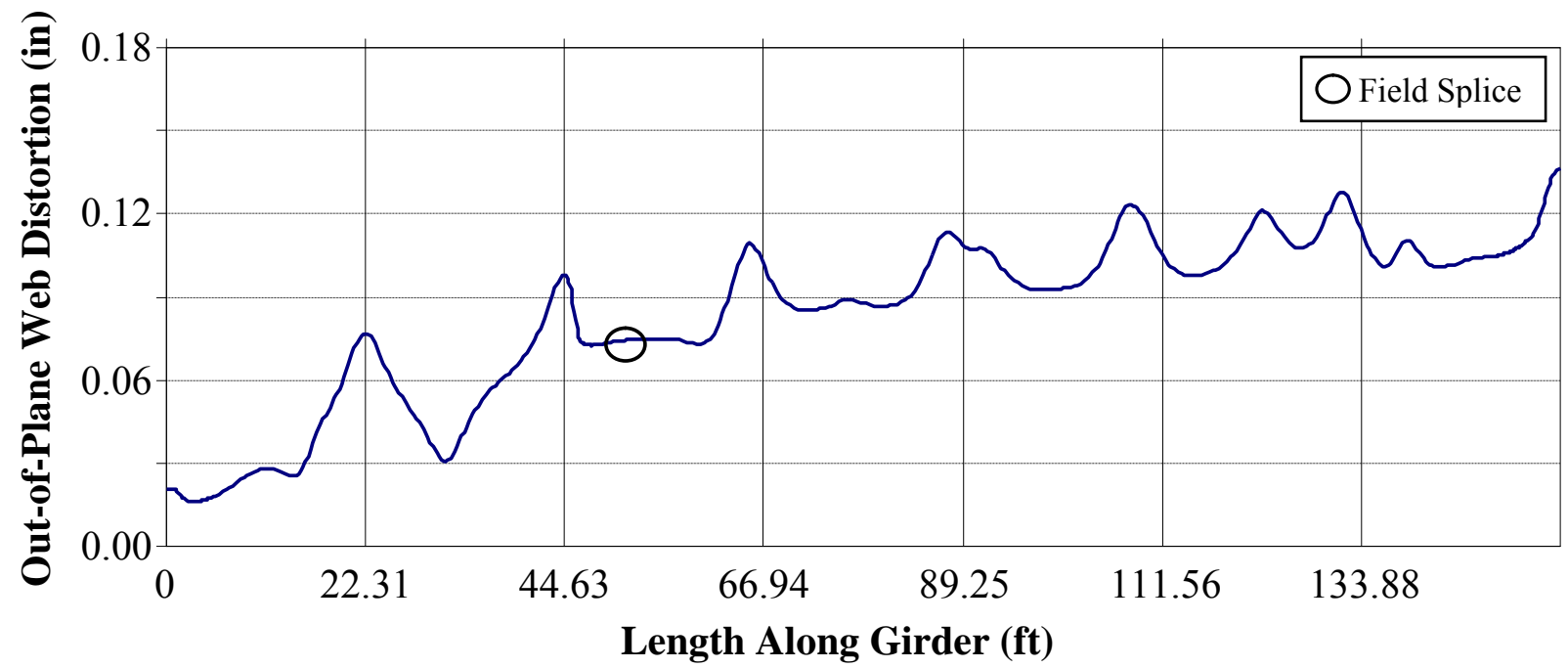

Figure 4.20 Span 6N, Out-of-Plane Web Deflection Due to Temp $-60^{\circ} \mathrm{F}$

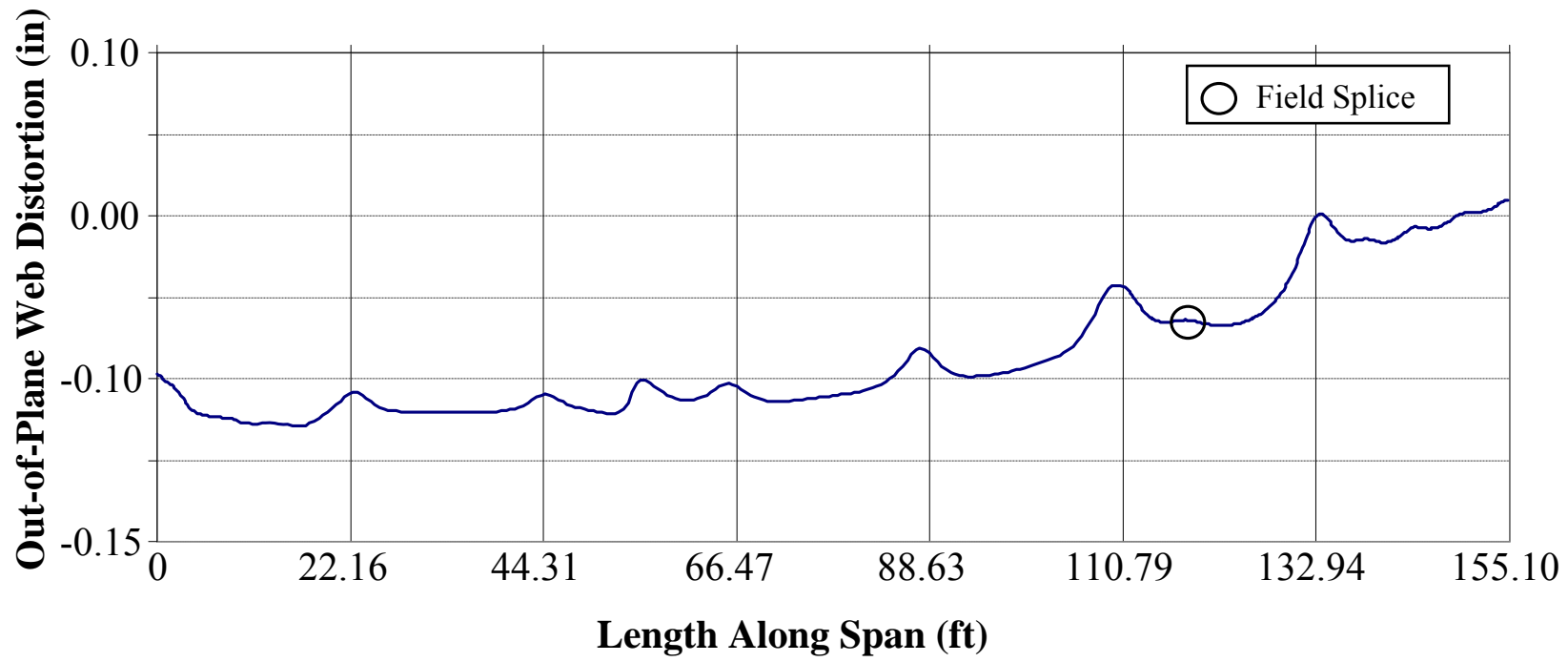

Figure 4.21 Span 7N, Out-of-Plane Web Deflection Due to Temp $-60^{\circ} \mathrm{F}$

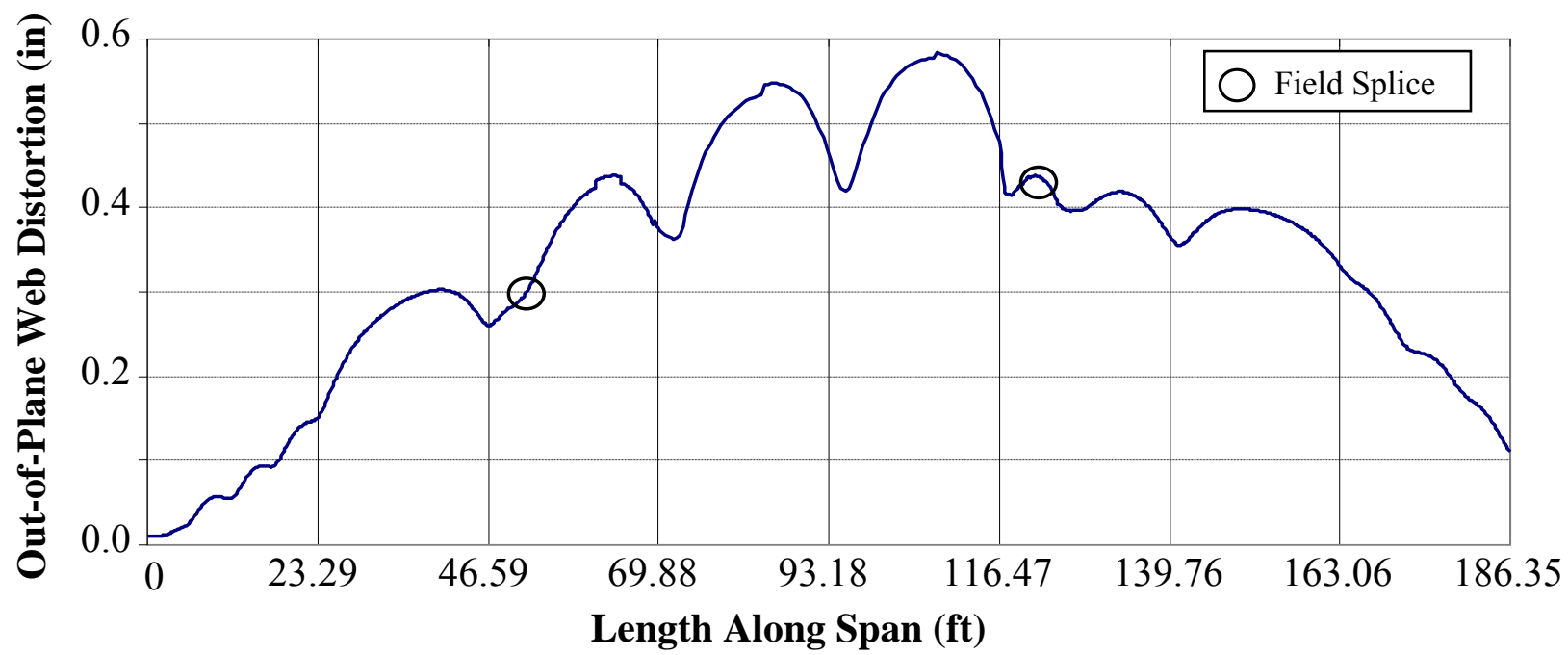

Figure 4.22 Span 8N, Out-of-Plane Web Deflection Due to Temp $-60^{\circ} \mathrm{F}$ 


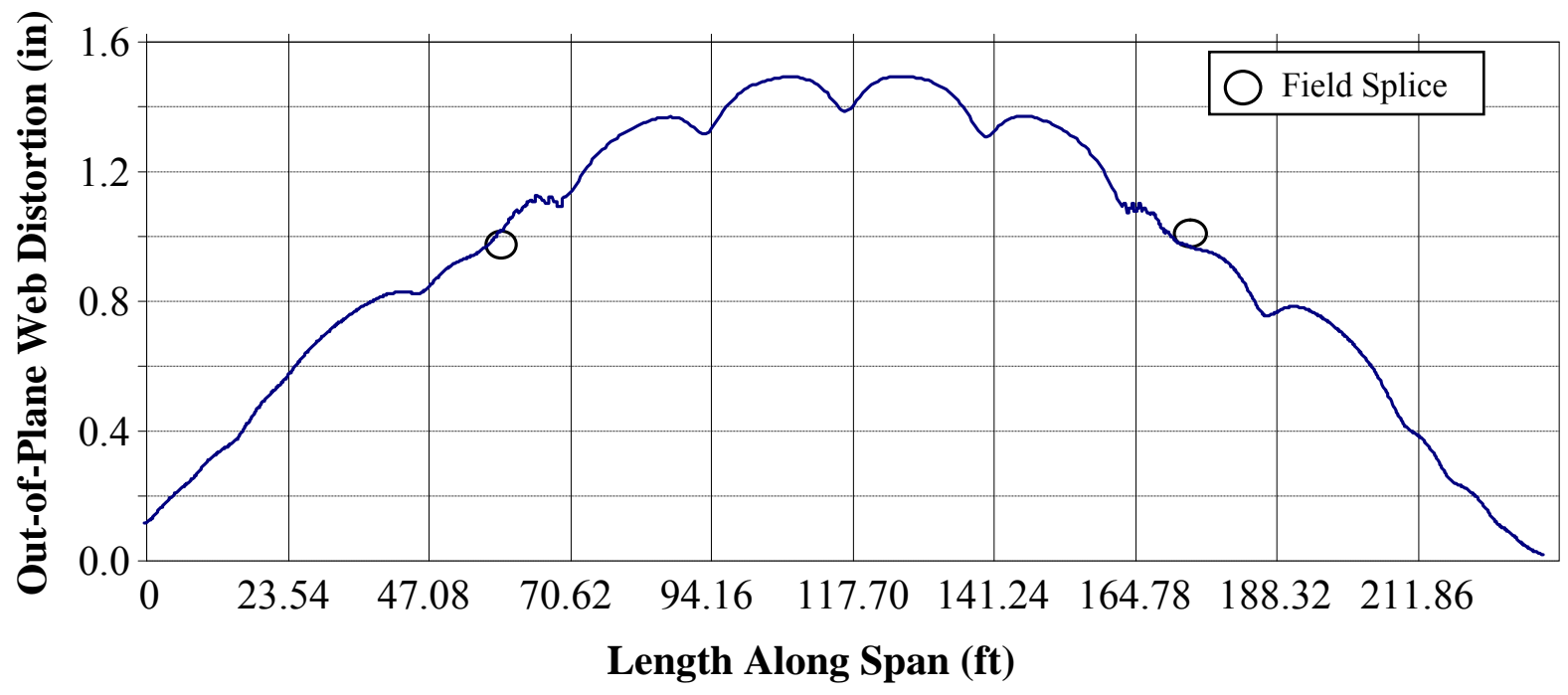

Figure 4.23 Span 9N, Out-of-Plane Web Deflection Due to Temp $-60^{\circ} \mathrm{F}$

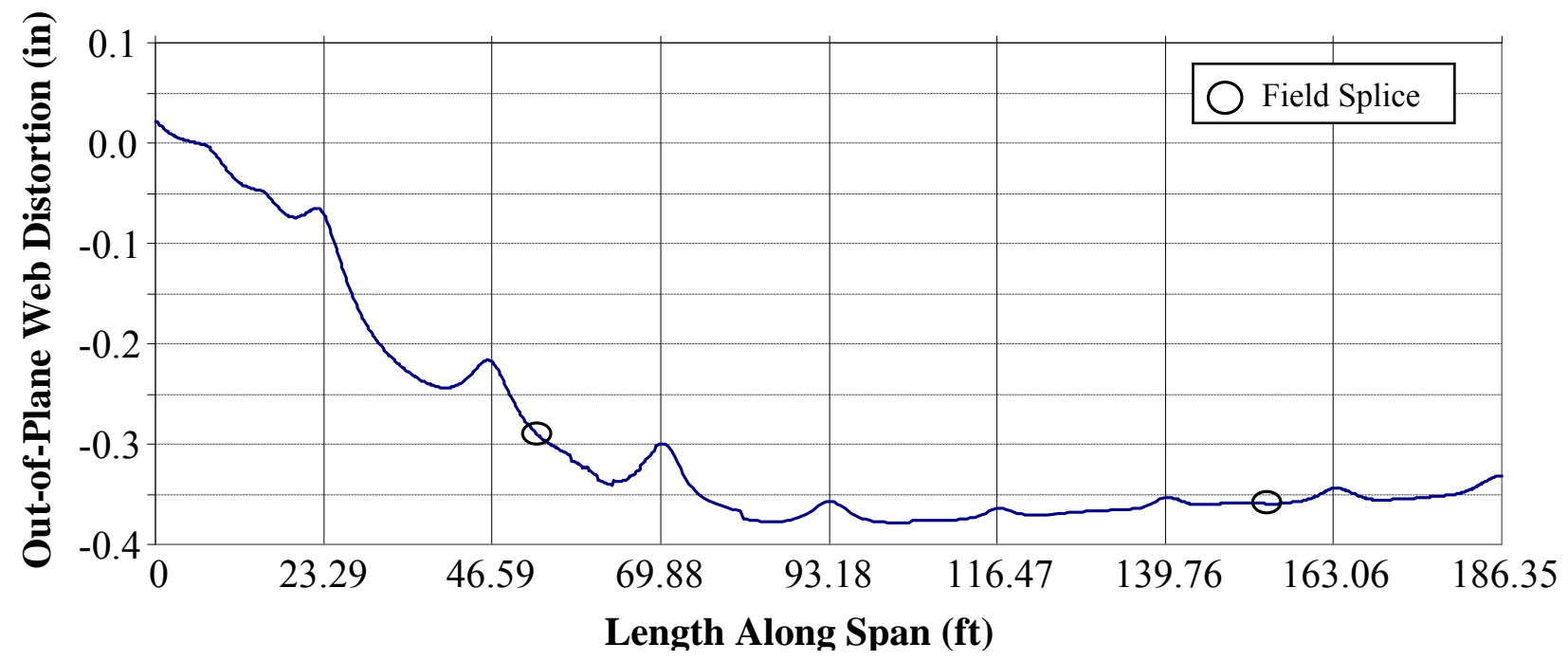

Figure 4.24 Span 10N, Out-of-Plane Web Deflection Due to Temp $-60^{\circ} \mathrm{F}$

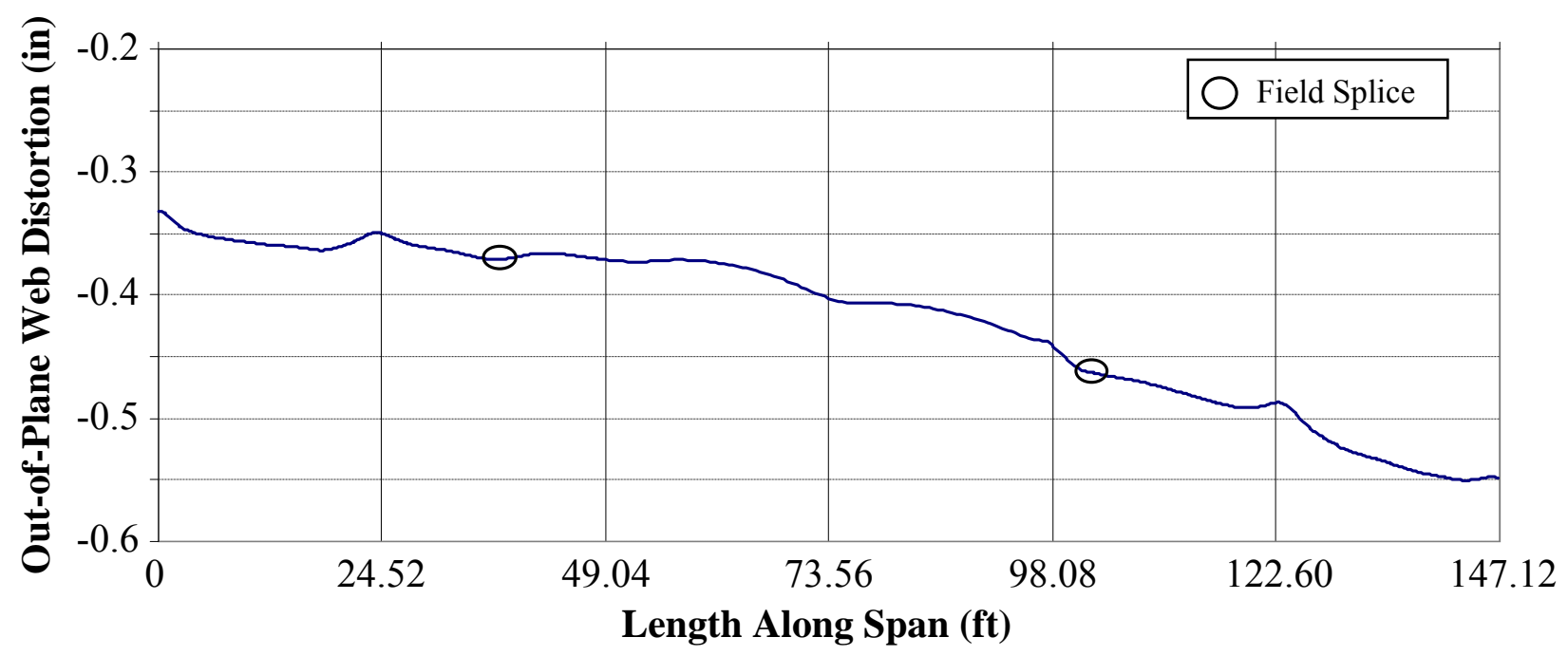

Figure 4.25 Span 11N, Out-of-Plane Web Deflection Due to Temp $-60^{\circ} \mathrm{F}$ 


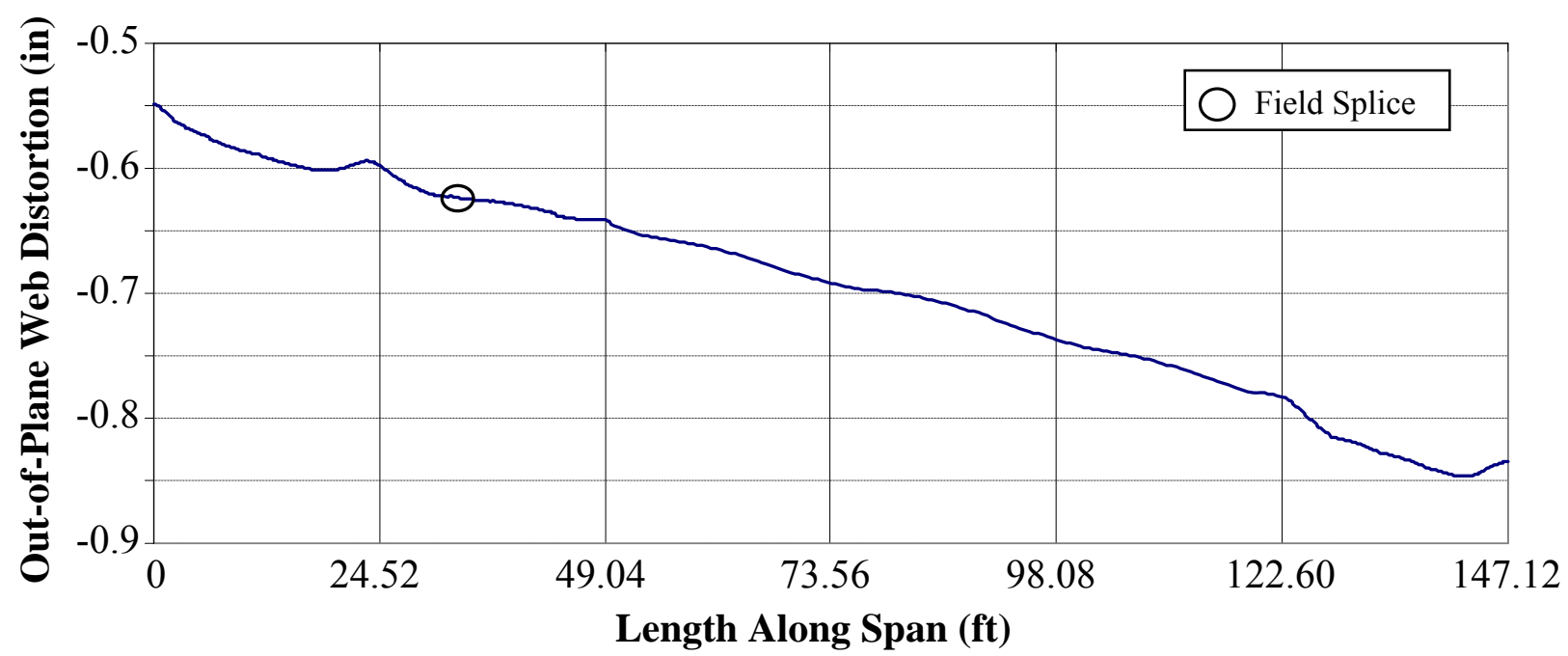

Figure 4.26 Span 12N, Out-of-Plane Web Deflection Due to Temp $-60^{\circ} \mathrm{F}$

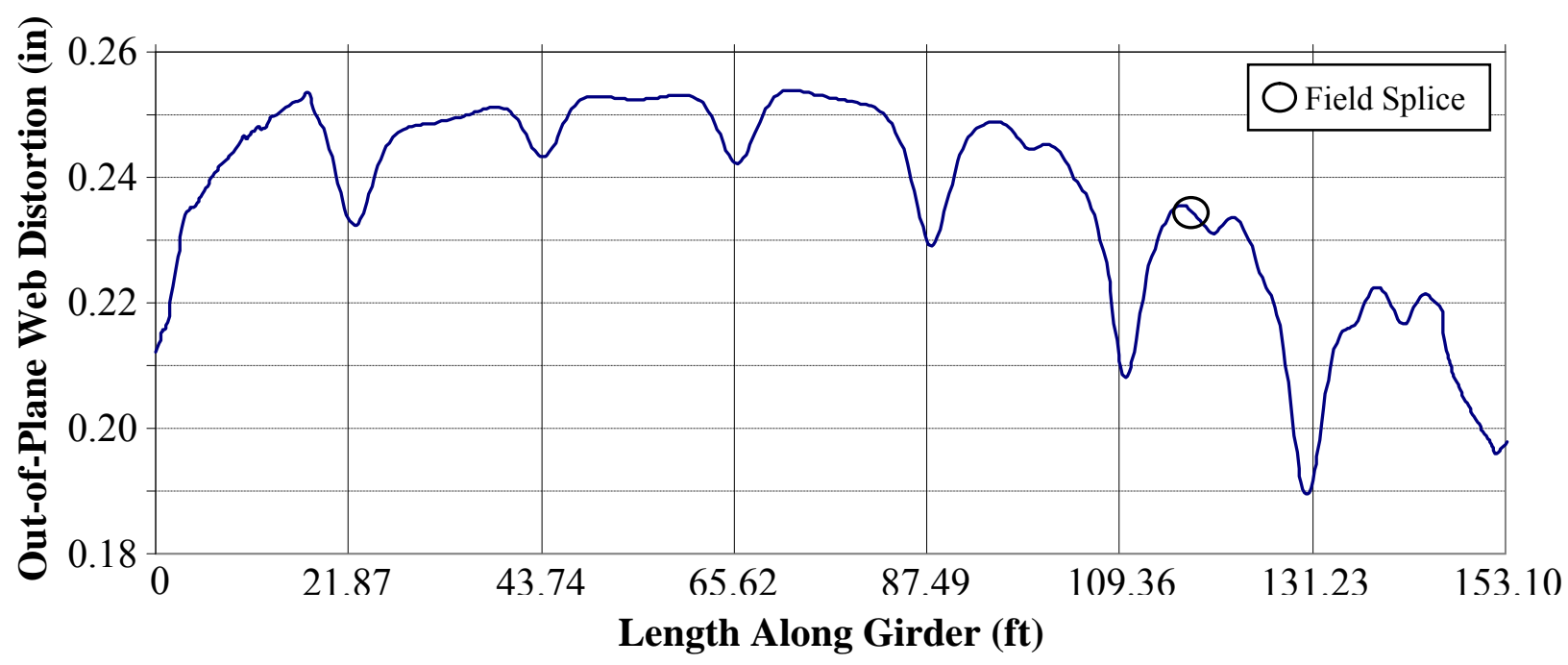

Figure 4.27 Span 1N, Out-of-Plane Web Deflection Due to Temp $+60^{\circ} \mathrm{F}$

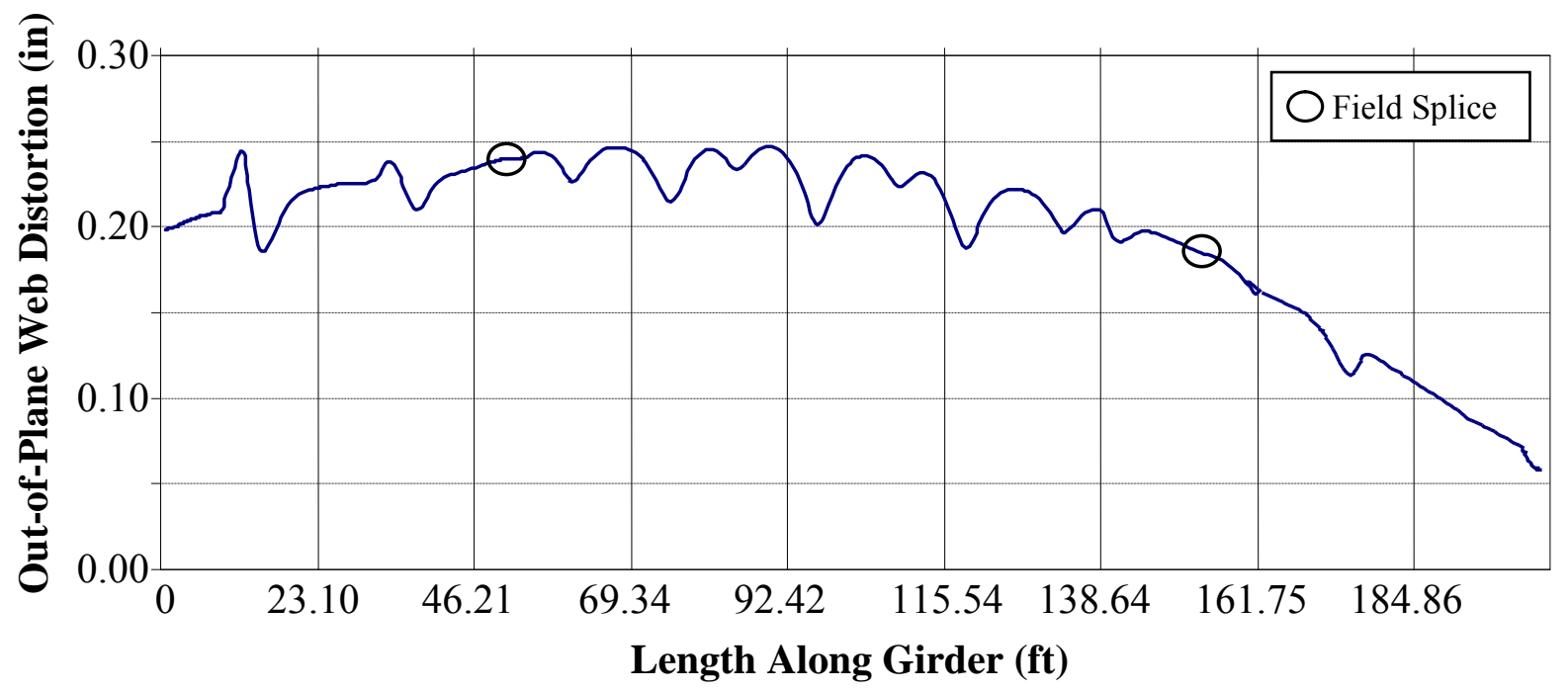

Figure 4.28 Span 2N, Out-of-Plane Web Deflection Due to Temp $+60^{\circ} \mathrm{F}$ 


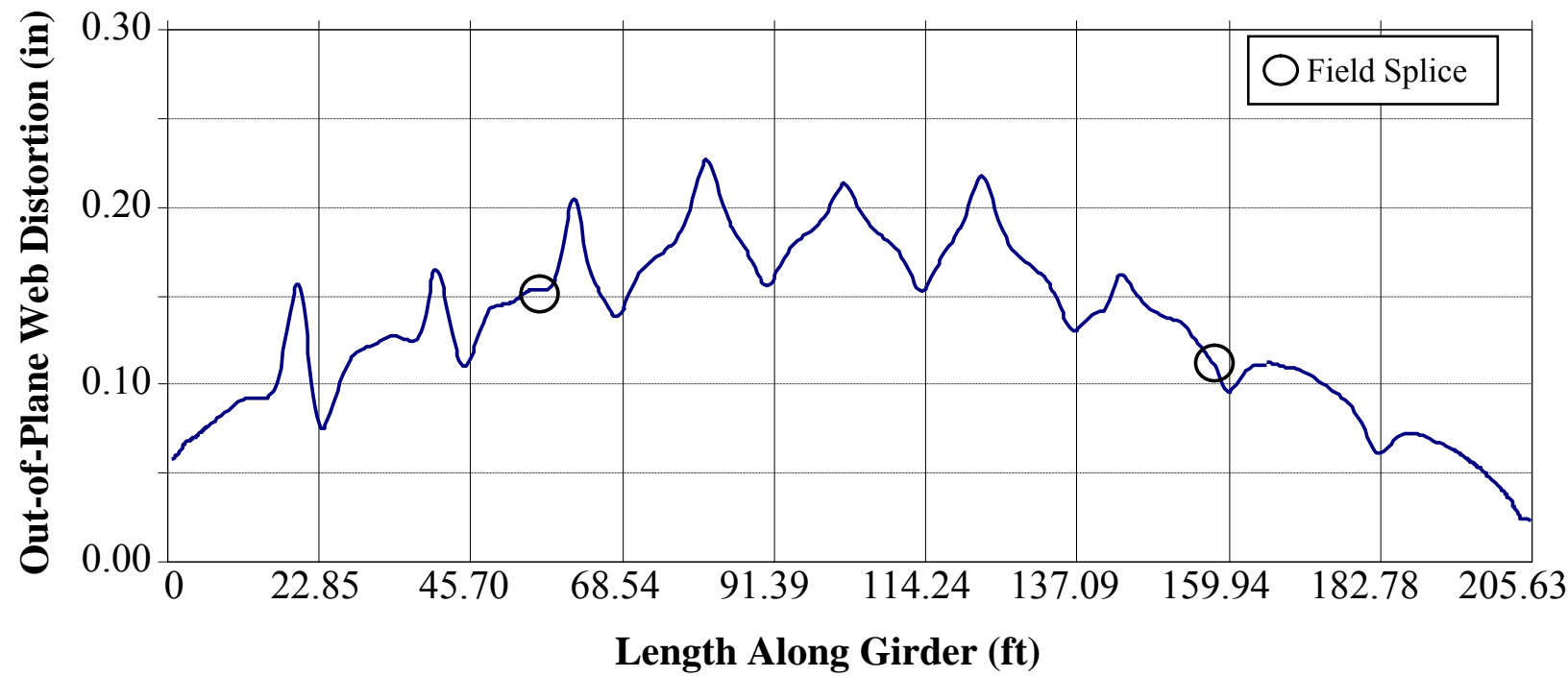

Figure 4.29 Span 3N, Out-of-Plane Web Deflection Due to Temp $+60^{\circ} \mathrm{F}$

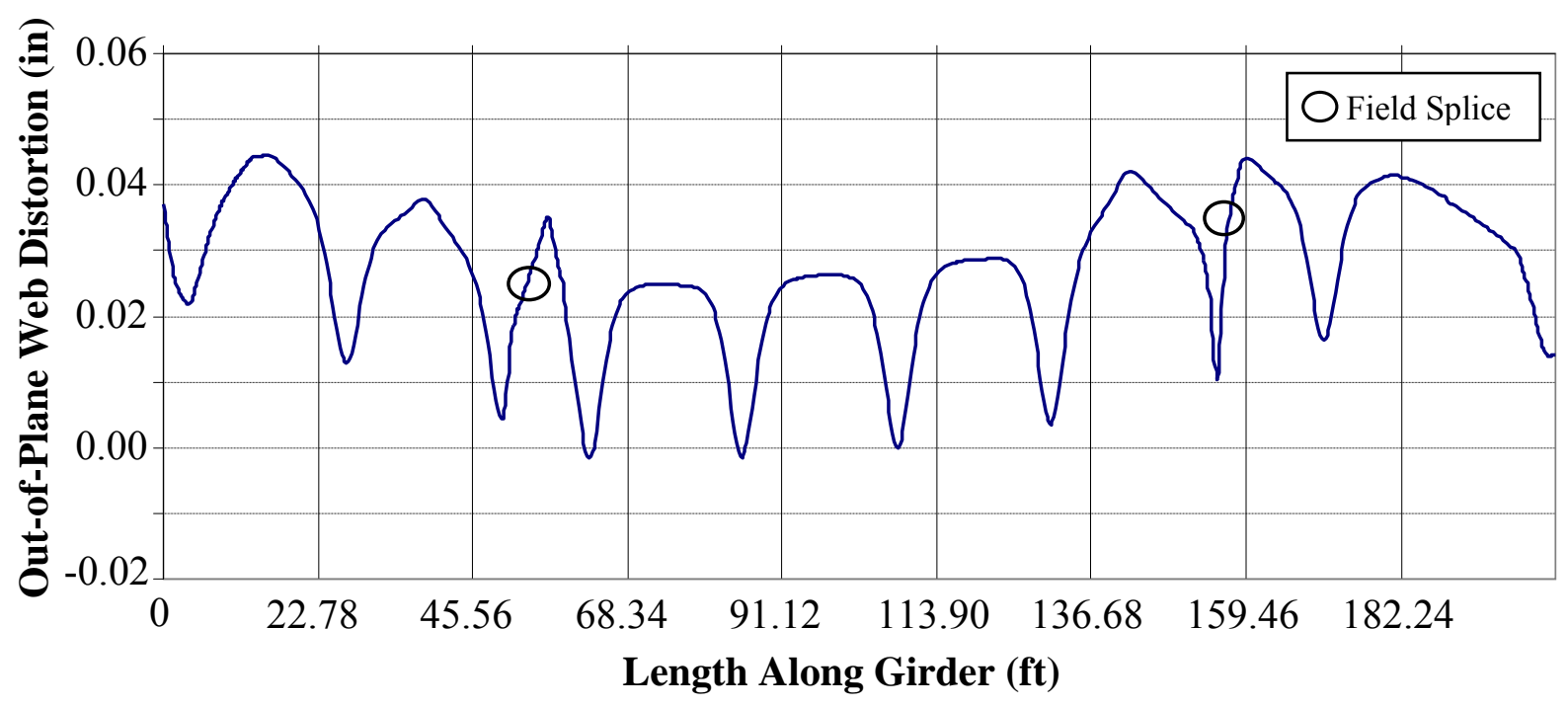

Figure 4.30 Span 4N, Out-of-Plane Web Deflection Due to Temp $+60^{\circ} \mathrm{F}$

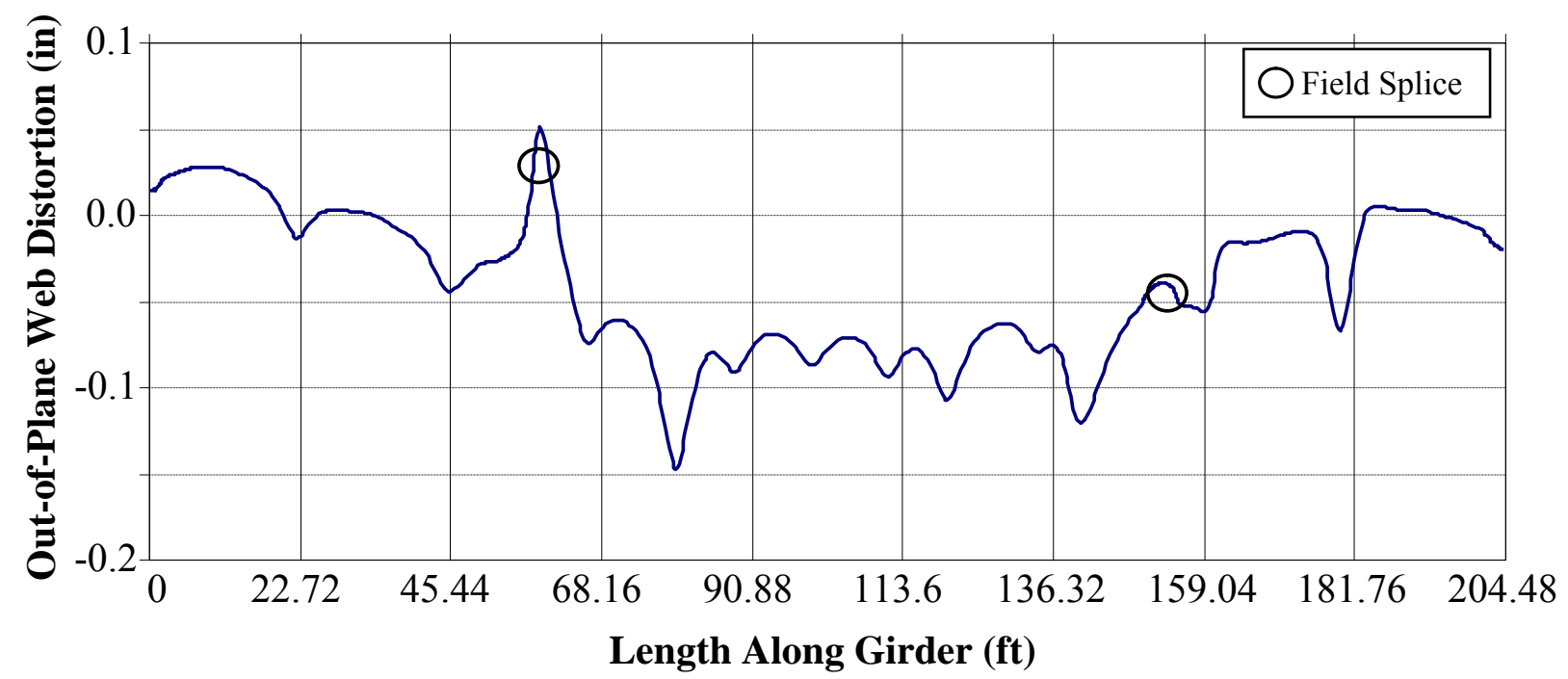

Figure 4.31 Span 5N, Out-of-Plane Web Deflection Due to Temp $+60^{\circ} \mathrm{F}$ 


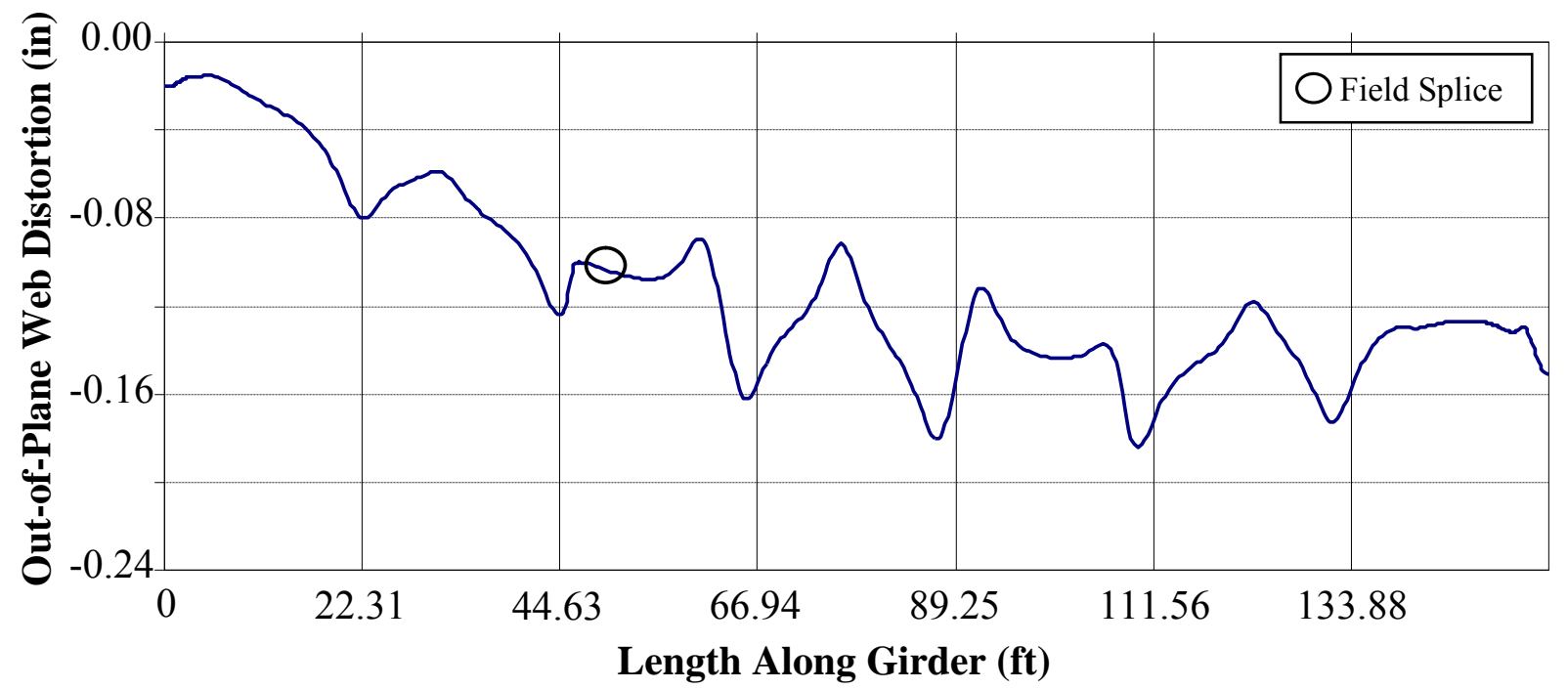

Figure 4.32 Span 6N, Out-of-Plane Web Deflection Due to Temp $+60^{\circ} \mathrm{F}$

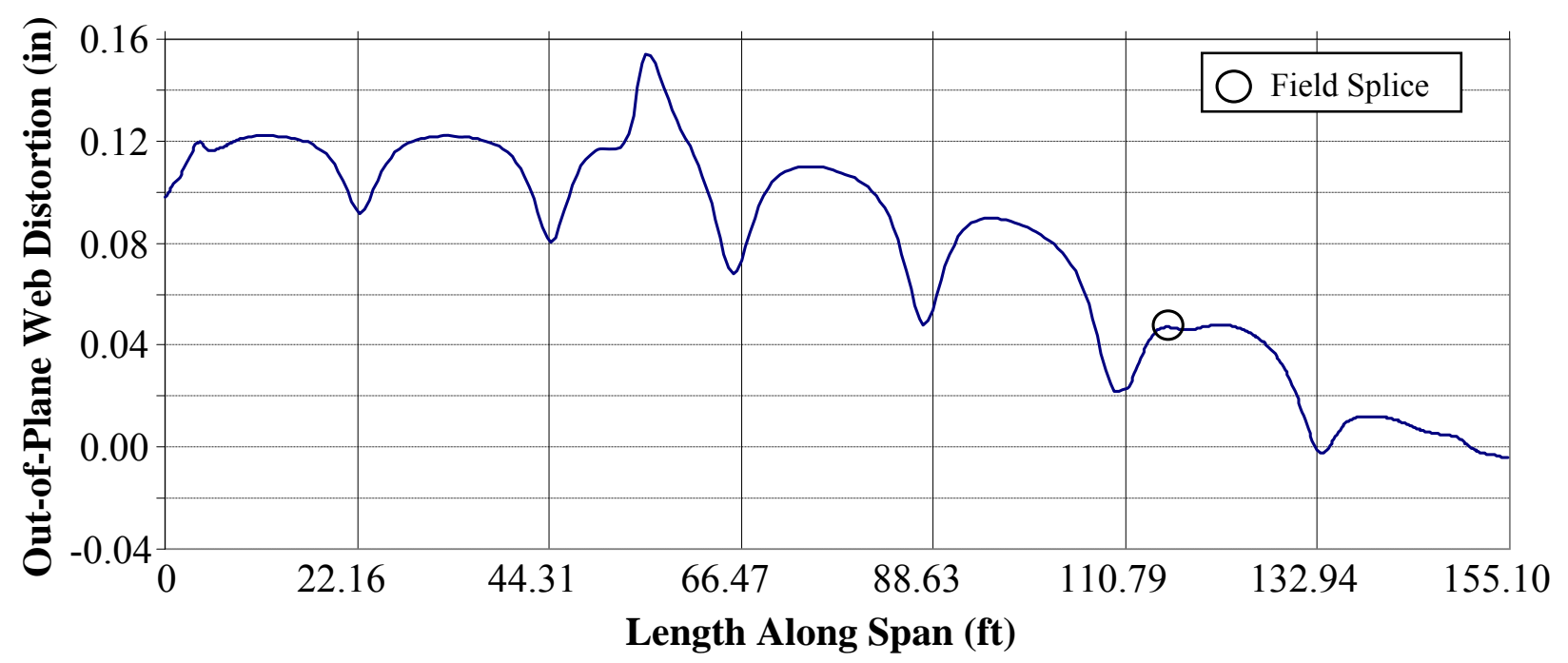

Figure 4.33 Span 7N. Out-of-Plane Web Deflection Due to Temp $+60^{\circ} \mathrm{F}$

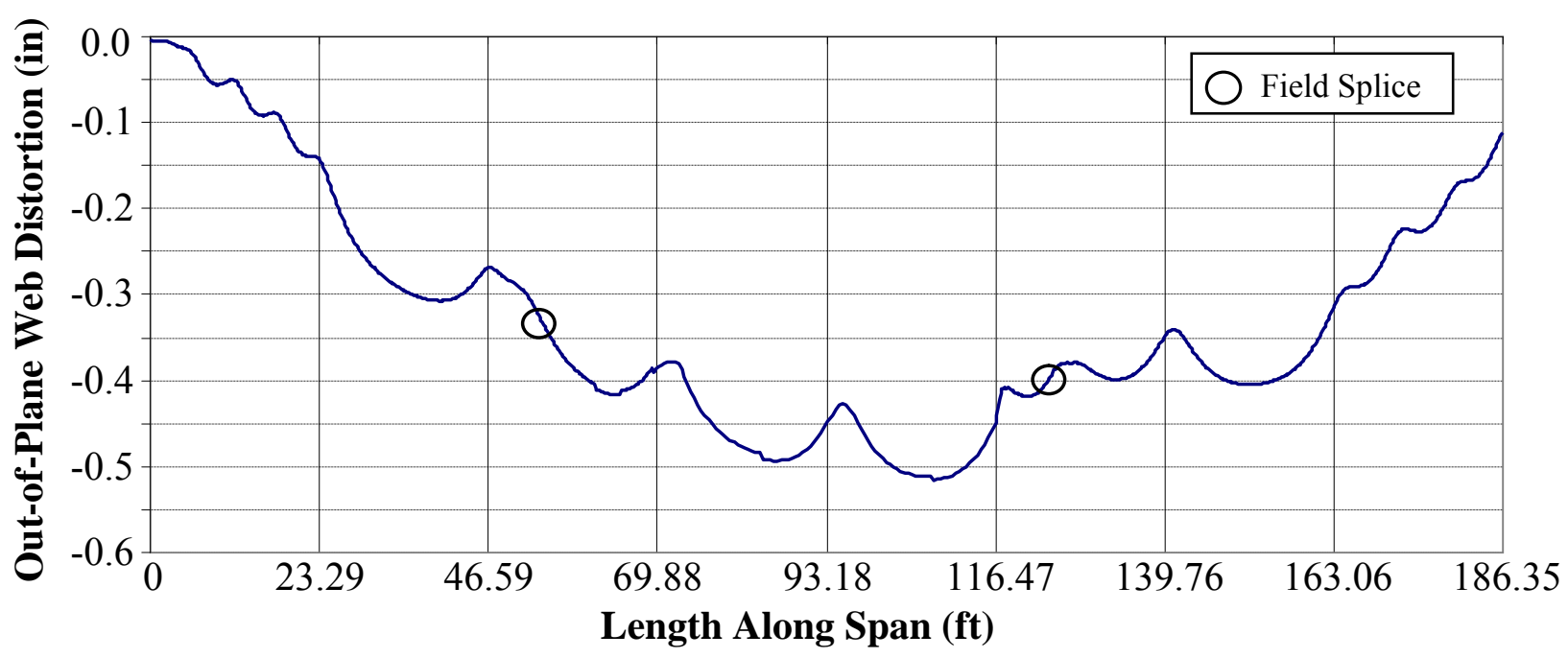

Figure 4.34 Span 8N, Out-of-Plane Web Deflection Due to Temp $+60^{\circ} \mathrm{F}$ 


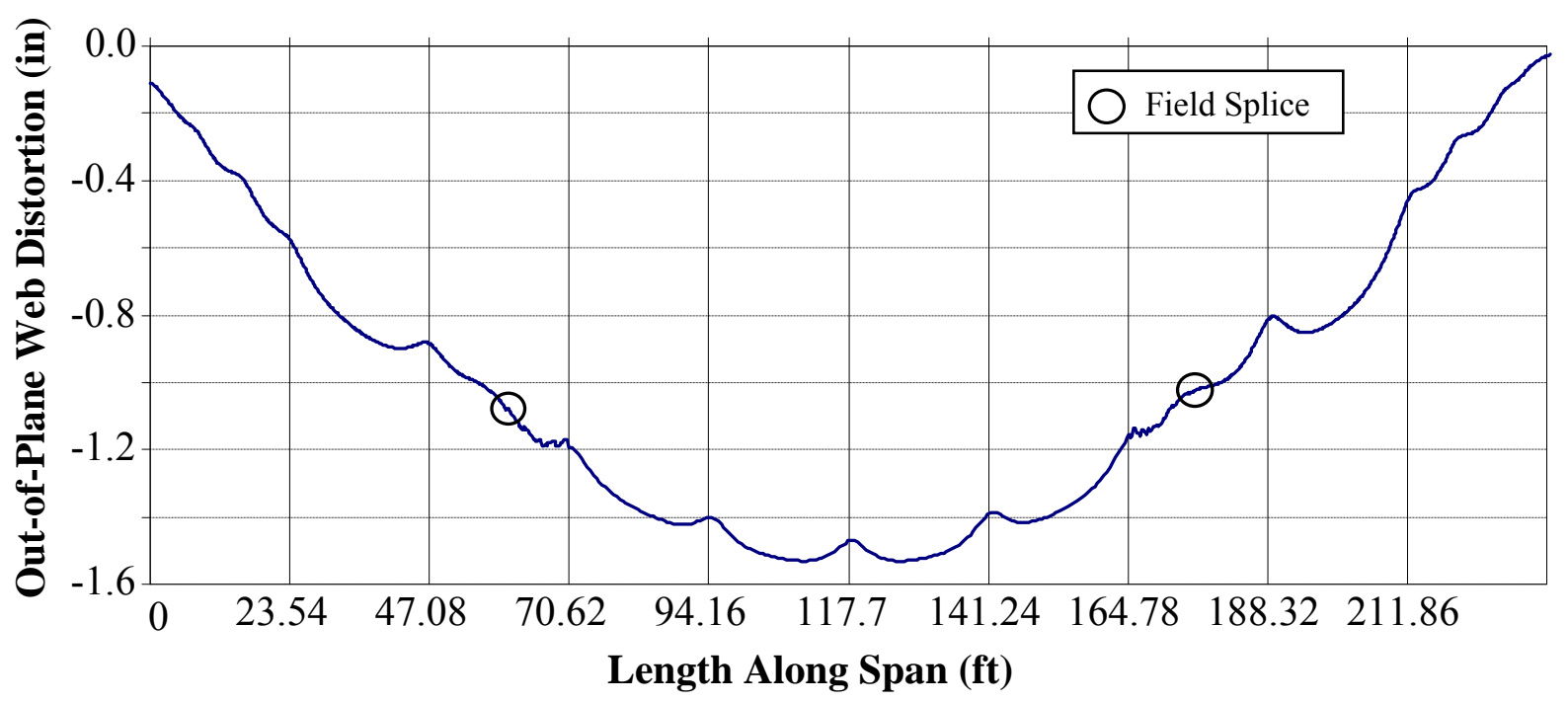

Figure 4.35 Span 9N, Out-of-Plane Web Deflection Due to Temp $+60^{\circ} \mathrm{F}$

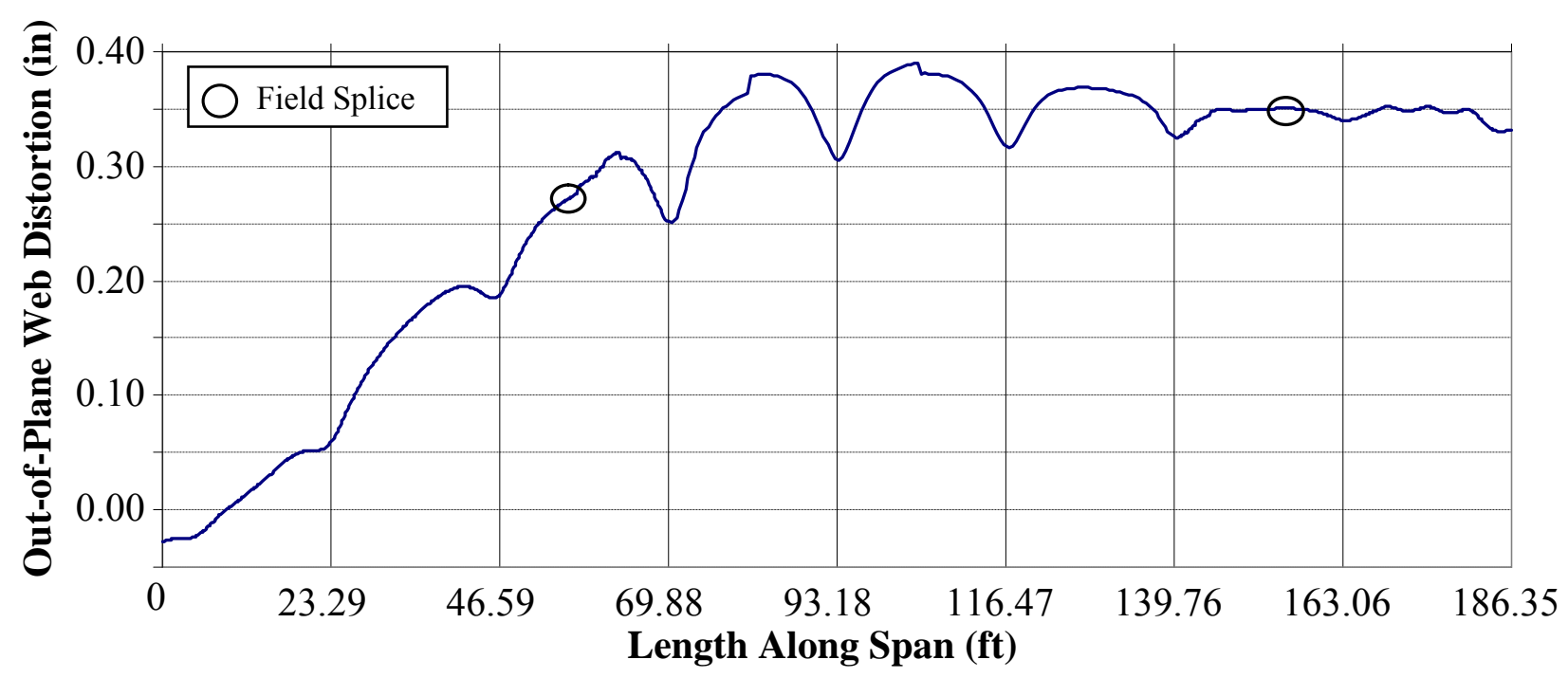

Figure 4.36 Span 10N, Out-of-Plane Web Deflection Due to Temp $+60^{\circ} \mathrm{F}$

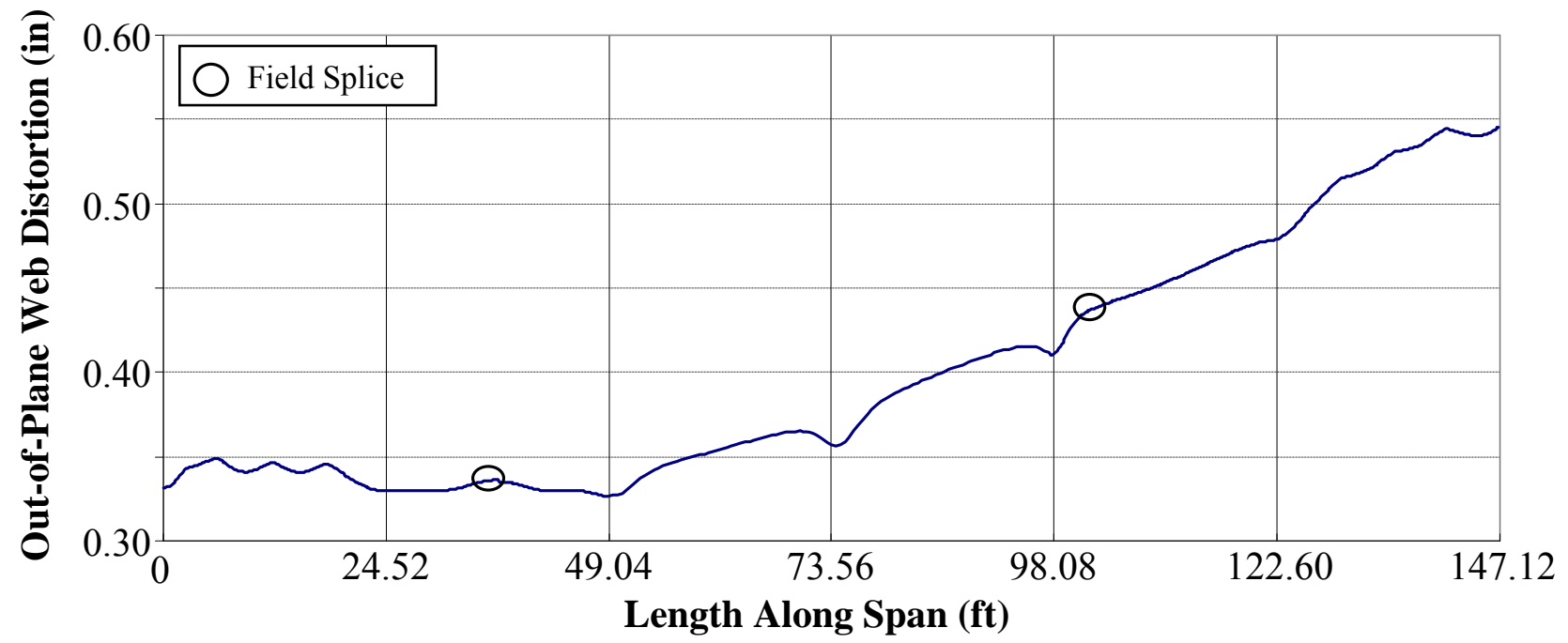

Figure 4.37 Span 11N, Out-of-Plane Web Deflection Due to Temp $+60^{\circ} \mathrm{F}$ 


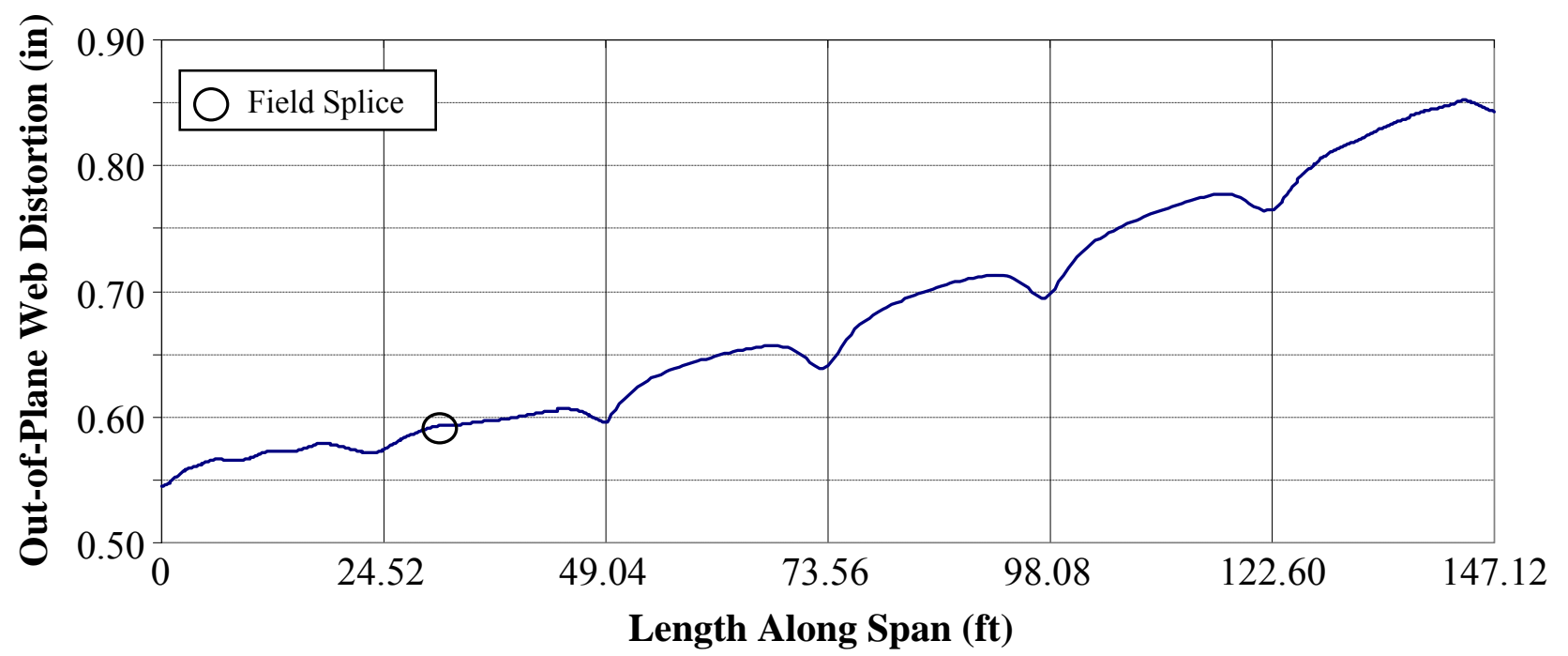

Figure 4.38 Span 12N, Out-of-Plane Web Deflection Due to Temp $+60^{\circ} \mathrm{F}$

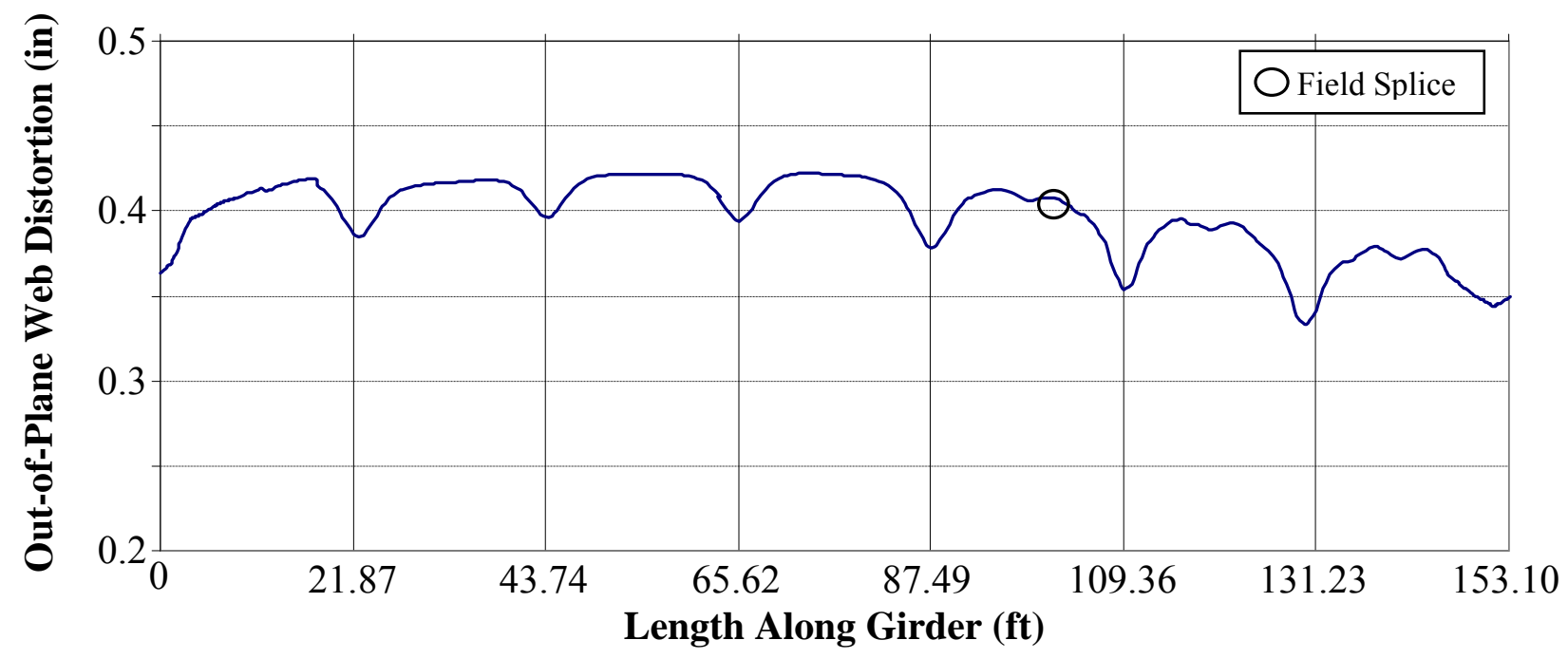

Figure 4.39 Span 1N, Out-of-Plane Web Deflection Due to Temp $+90^{\circ} \mathrm{F}$

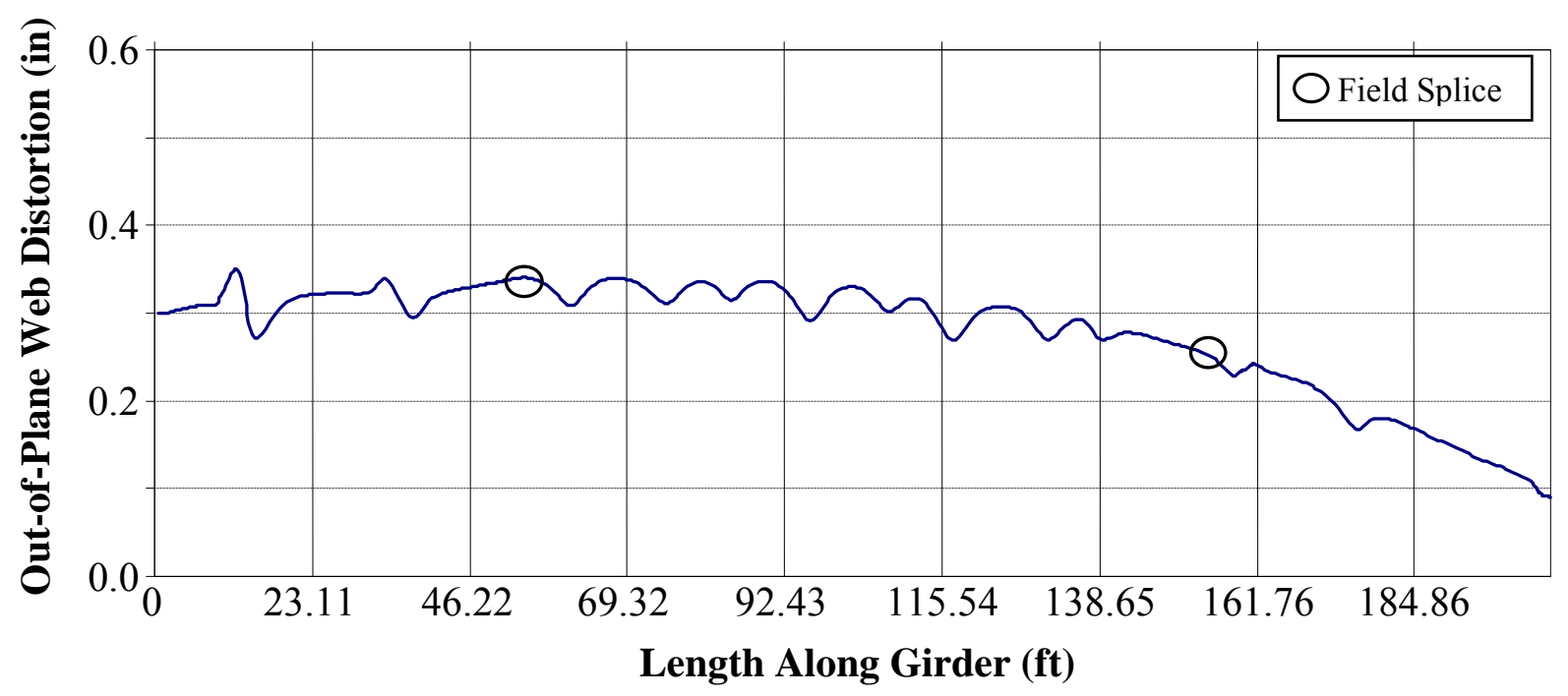

Figure 4.40 Span 2N, Out-of-Plane Web Deflection Due to Temp $+90^{\circ} \mathrm{F}$ 


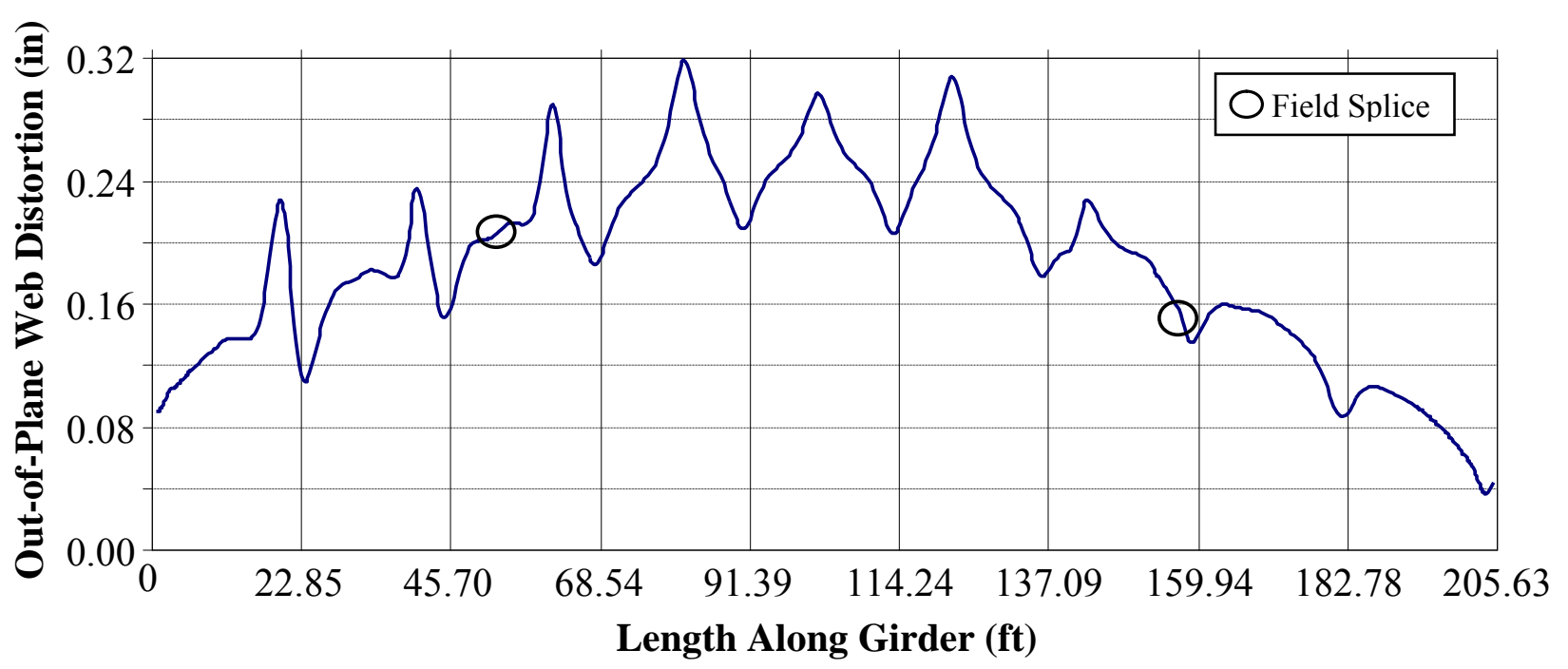

Figure 4.41 Span 3N, Out-of-Plane Web Deflection Due to Temp $+90^{\circ} \mathrm{F}$

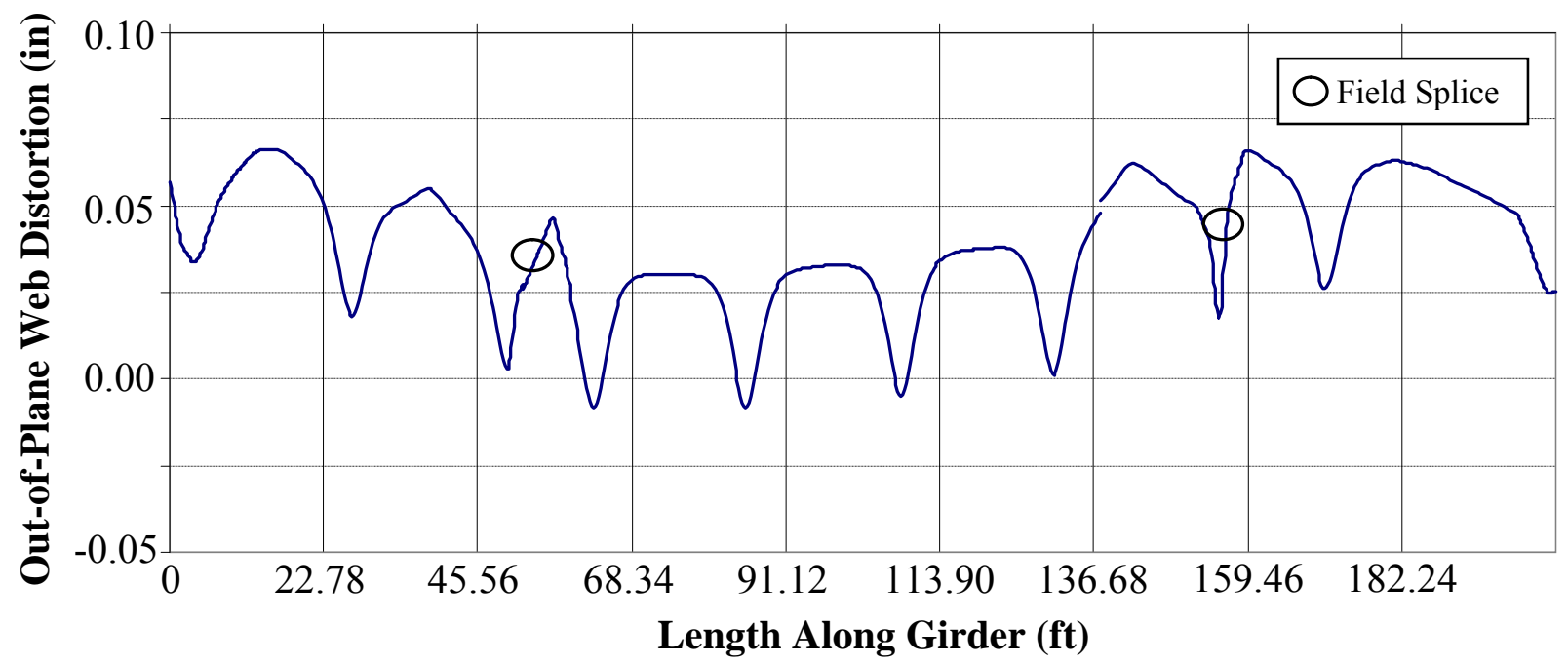

Figure 4.42 Span 4N, Out-of-Plane Web Deflection Due to Temp $+90^{\circ} \mathrm{F}$

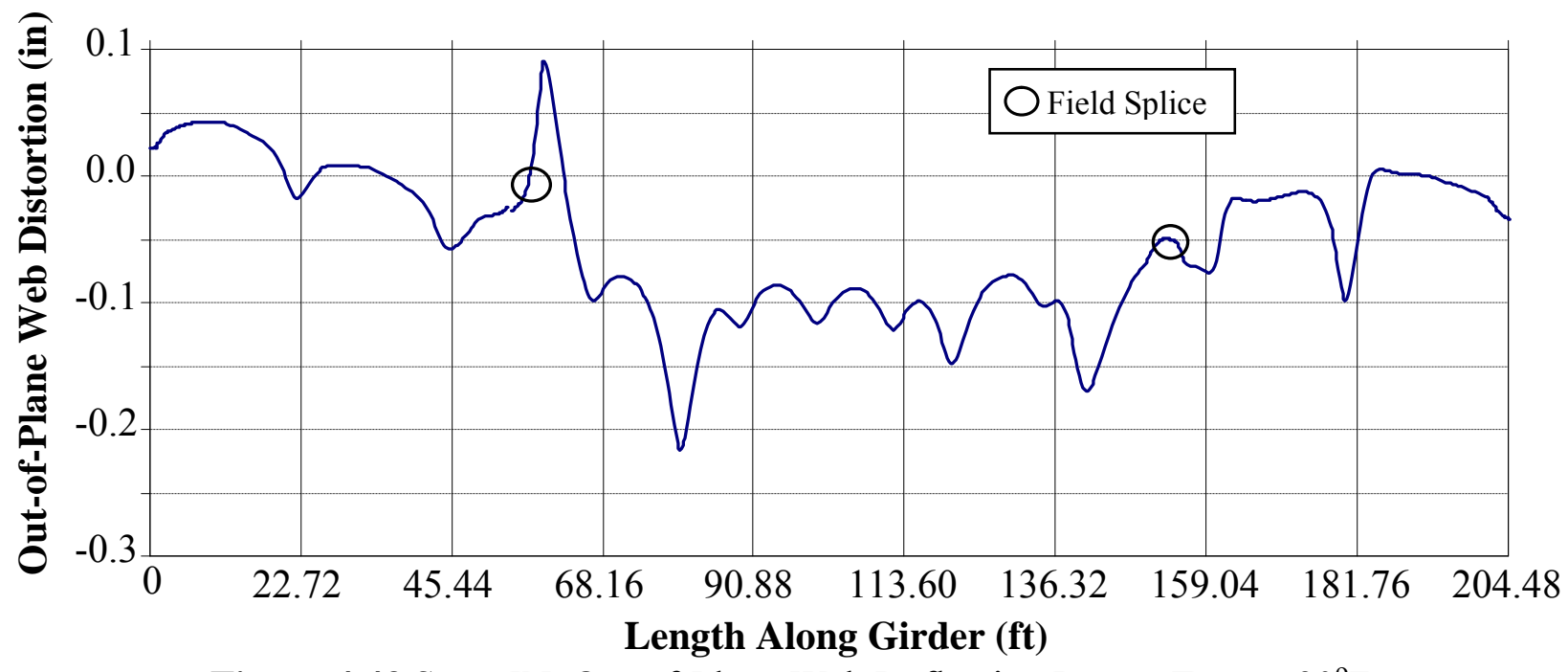

Figure 4.43 Span 5N, Out-of-Plane Web Deflection Due to Temp $+90^{\circ} \mathrm{F}$ 


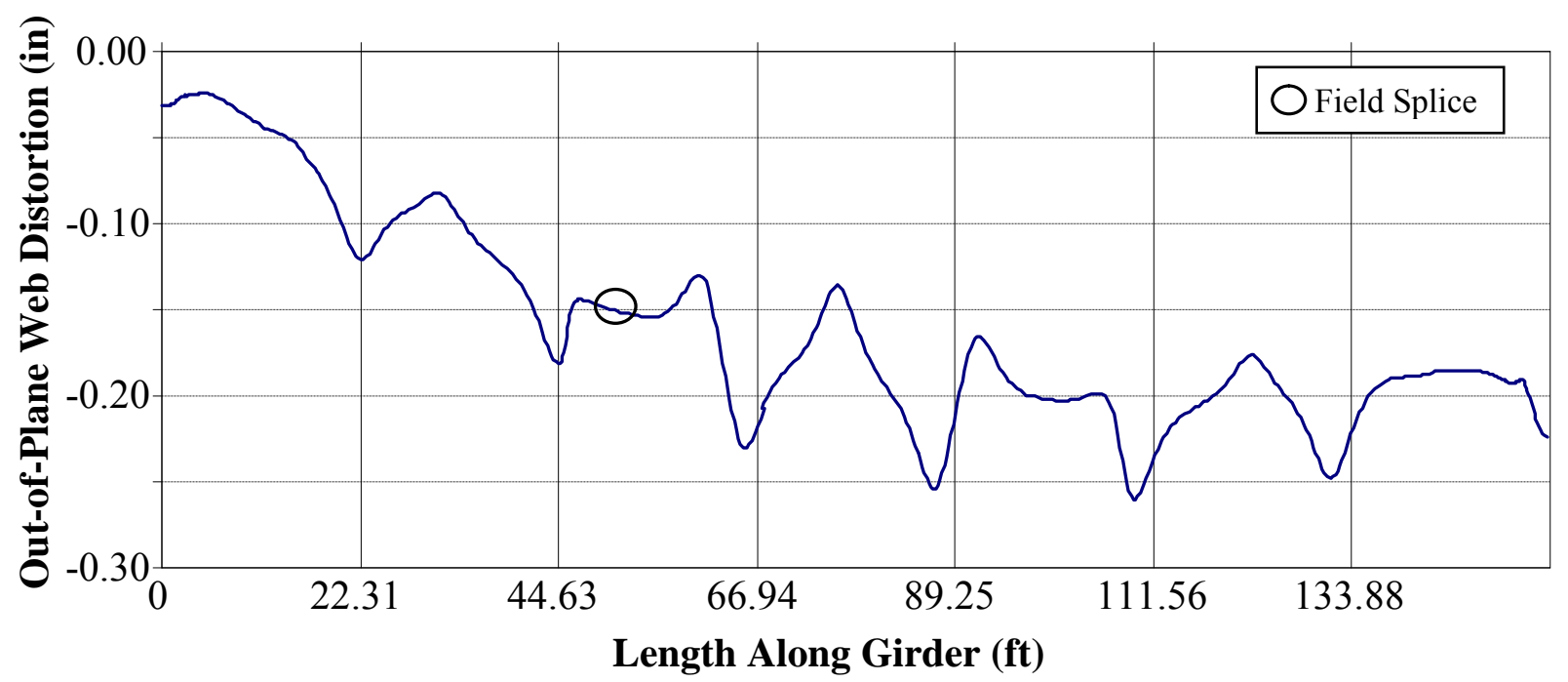

Figure 4.44 Span 6N, Out-of-Plane Web Deflection Due to Temp $+90^{\circ} \mathrm{F}$

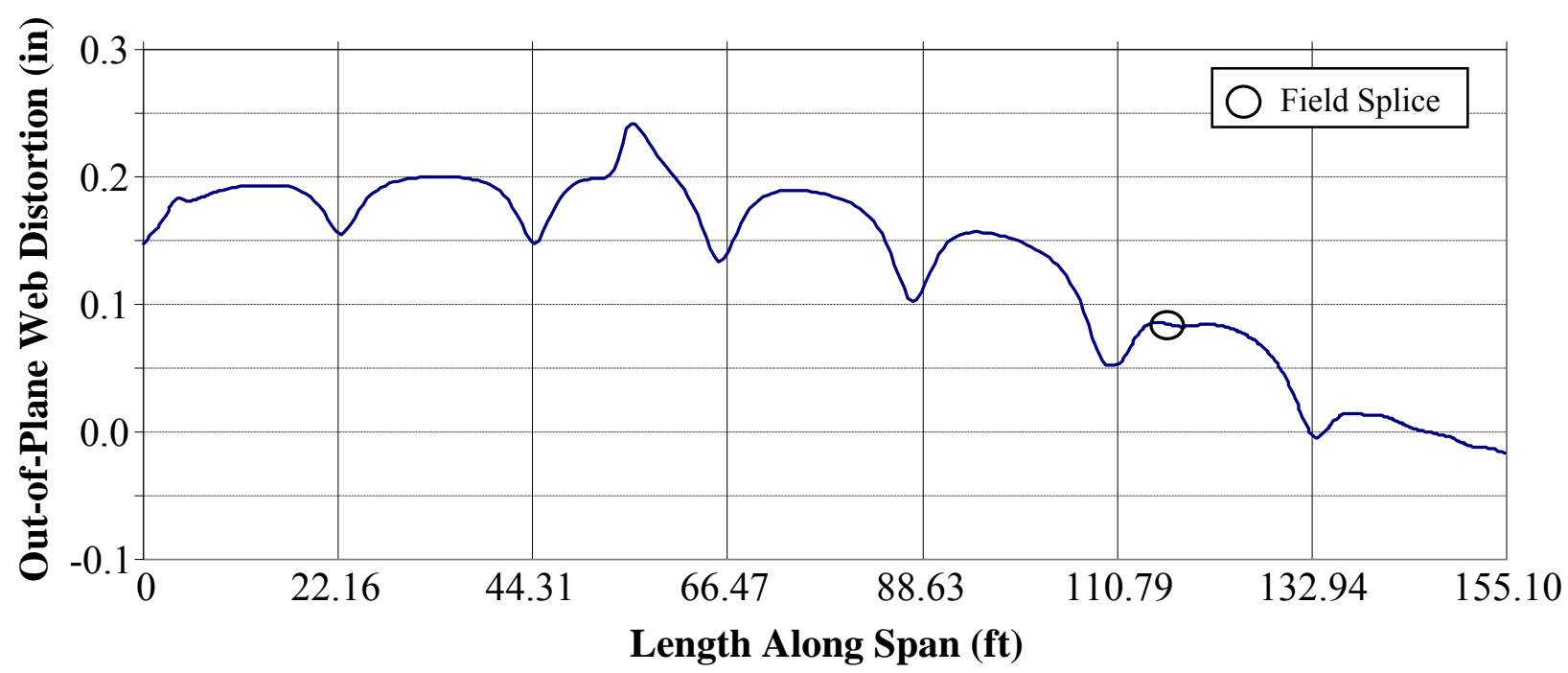

Figure 4.45 Span 7N, Out-of-Plane Web Deflection Due to Temp $+90^{\circ} \mathrm{F}$

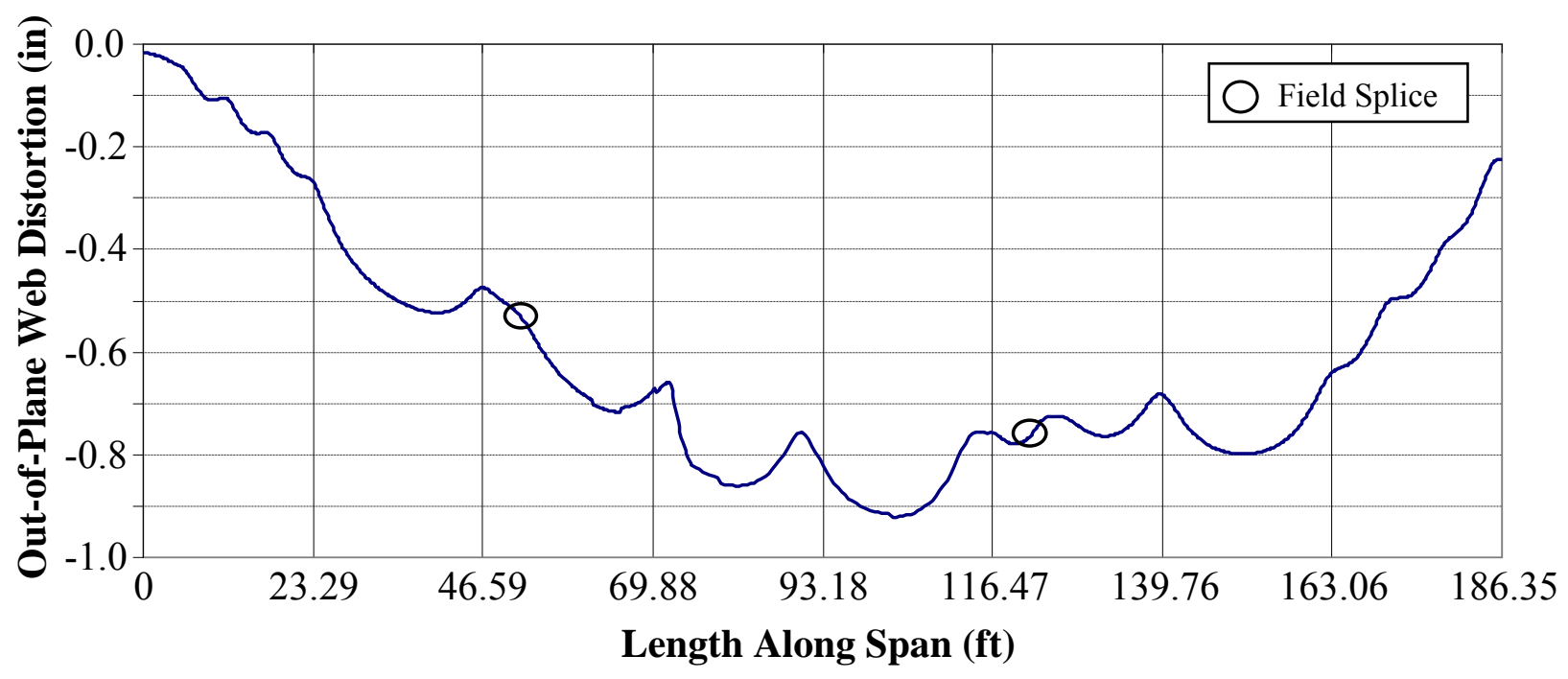

Figure 4.46 Span 8N, Out-of-Plane Web Deflection Due to Temp $+90^{\circ} \mathrm{F}$ 


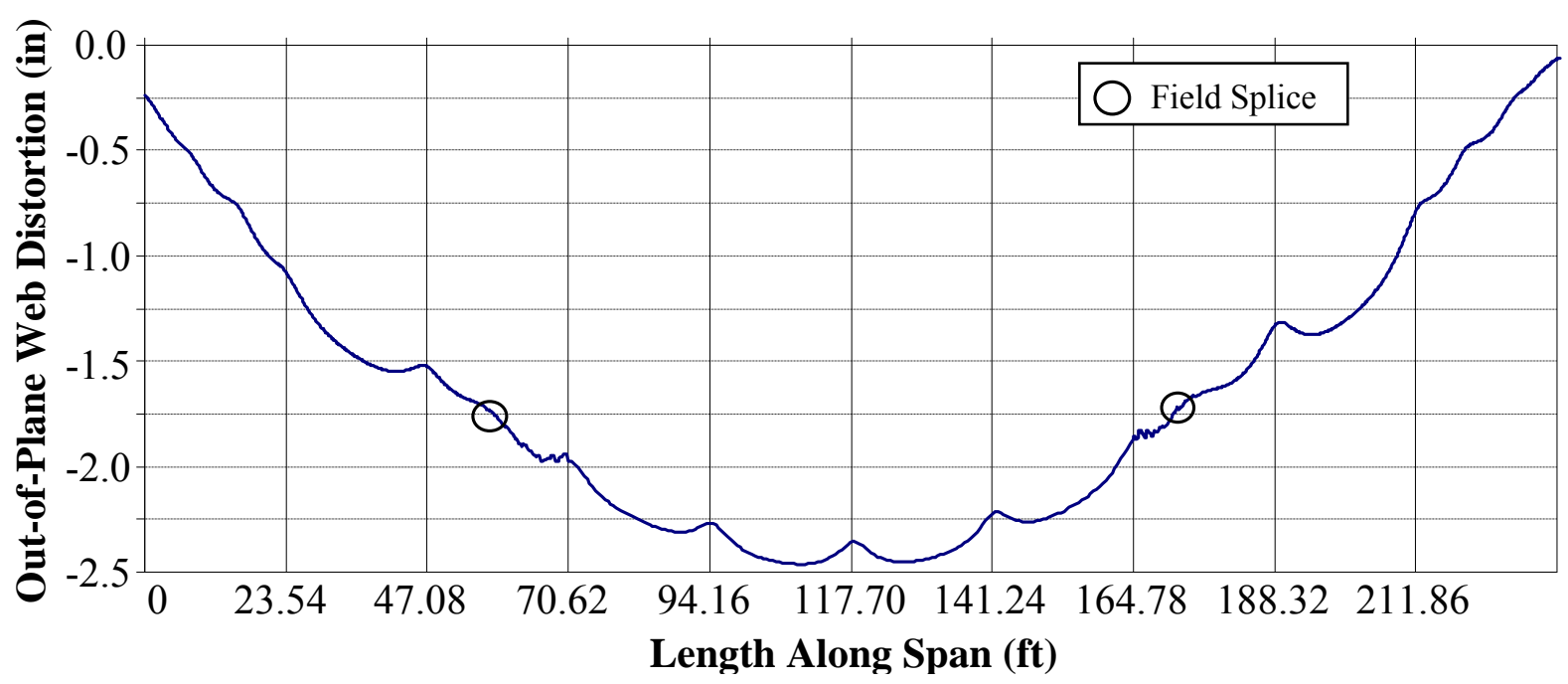

Figure 4.47 Span 9N, Out-of-Plane Web Deflection Due to Temp $+90^{\circ} \mathrm{F}$

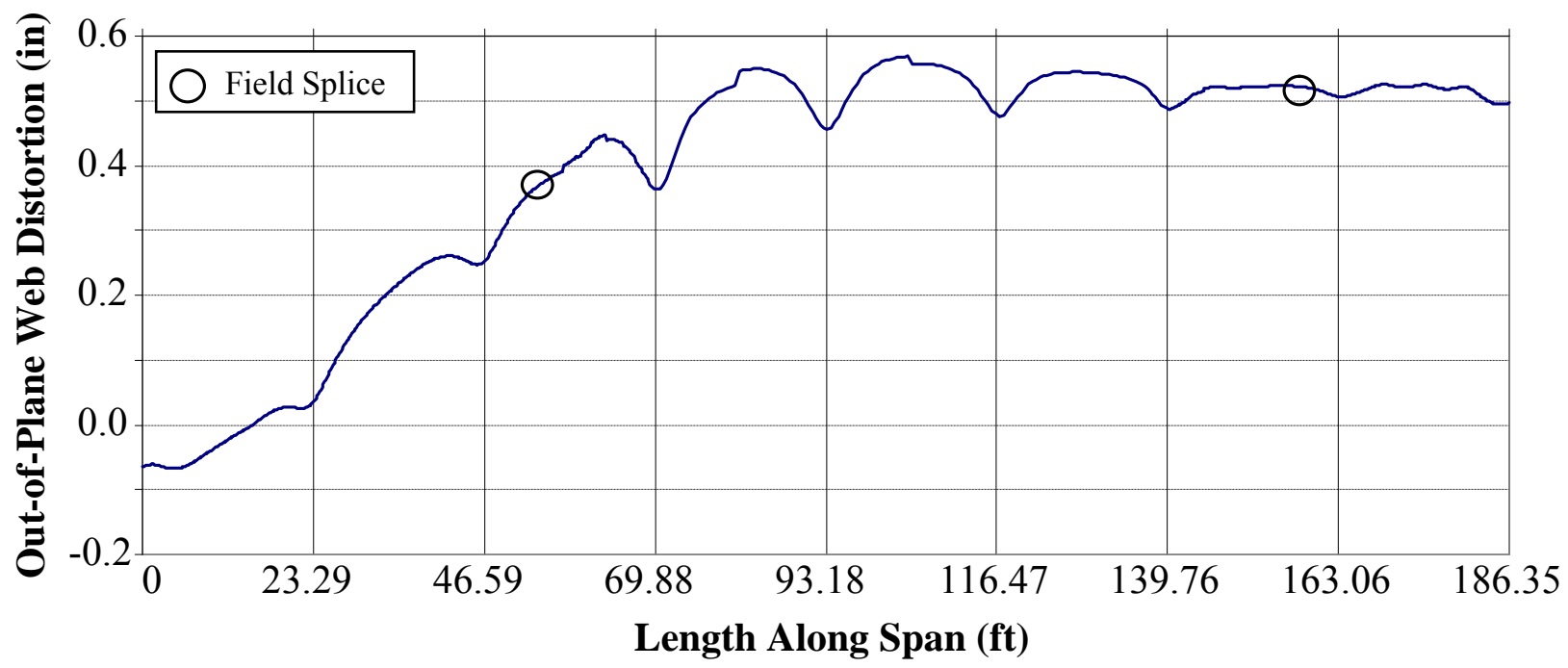

Figure 4.48 Span 10N, Out-of-Plane Web Deflection Due to Temp $+90^{\circ} \mathrm{F}$

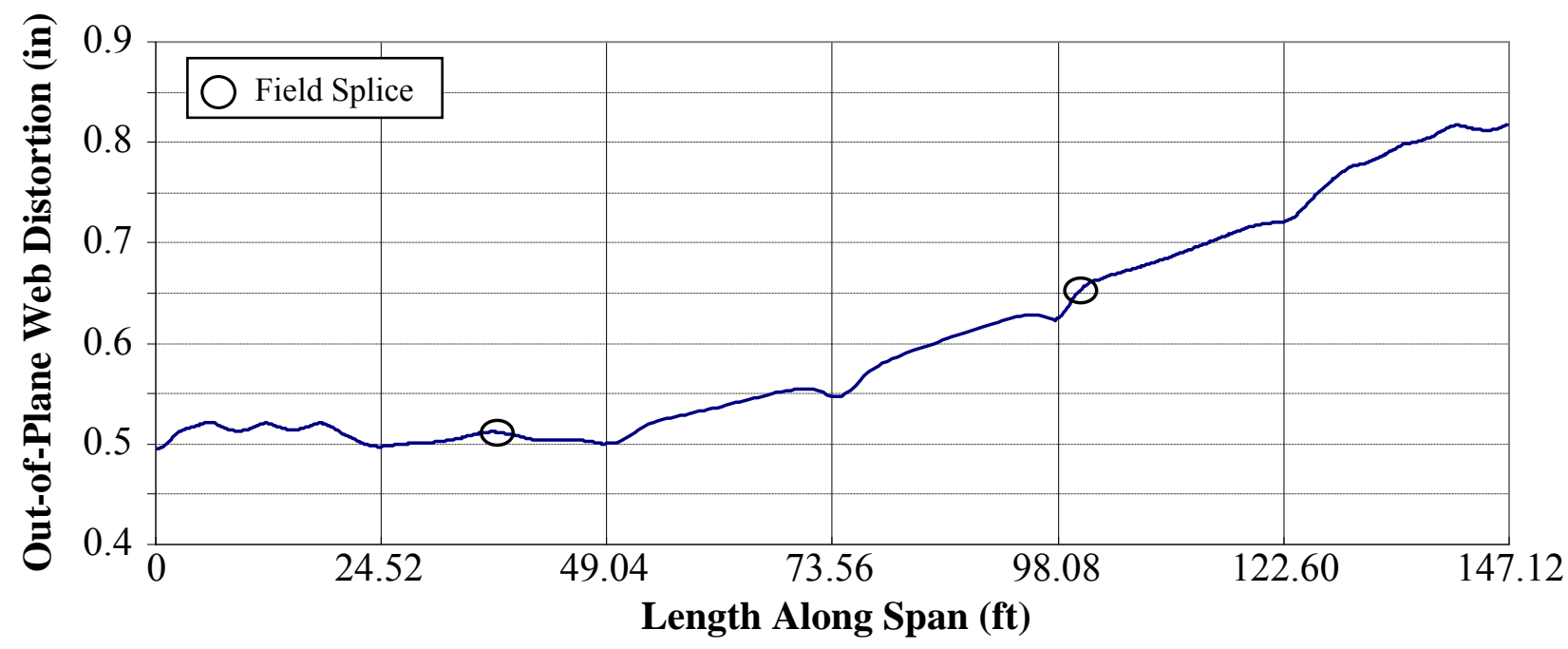

Figure 4.49 Span 11N, Out-of-Plane Web Deflection Due to Temp $+90^{\circ} \mathrm{F}$ 


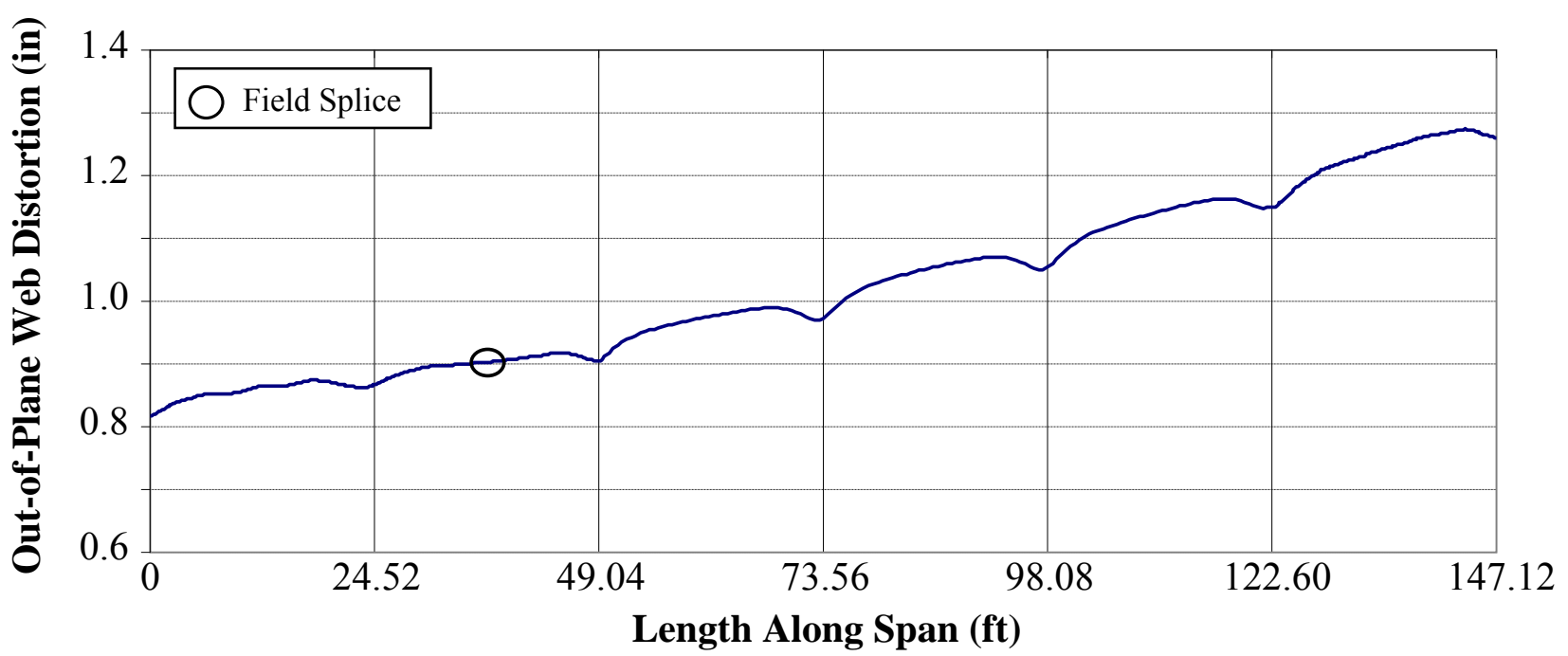

Figure 4.50 Span 12N, Out-of-Plane Web Deflection Due to Temp $+90^{\circ} \mathrm{F}$

When comparing the out-of-plane web deflection plots due to bridge self-weight with the plots produced when a temperature load is present shows that out-of-plane web displacement is highly affected by the application of uniform temperature loads. The largest increases in out-of-plane web displacement are produced in the spans implementing fully fixed bearings at the piers (Spans $3 \mathrm{~N}, 4 \mathrm{~N}, 5 \mathrm{~N}, 8 \mathrm{~N}, 9 \mathrm{~N}$ ). Spans that are free to translate at one or both piers experience increased out-of-plane displacement as well, but values are less than in the previously mentioned spans.

With the uniform temperature loads of $-/+60^{\circ} \mathrm{F}$ applied to the FE model, the behavior of the bridge becomes very noticeable. Most apparent is the increase in the magnitude of out-of-plane web displacements. The FE model produces web displacements very similar in magnitude for each load case. Span 9N shows the largest overall out-of-plane deflection, with a maximum displacement of roughly 1.5 in. near midspan for each load cases. As seen in Figures 4.15-4.38, when studying each span's displacement behavior individually, the magnitude of web displacement is almost identical throughout much of the bridge for the $60^{\circ} \mathrm{F}$ and $+60^{\circ} \mathrm{F}$ loads, with the magnitude of displacements being just slightly larger under 
the $+60^{\circ} \mathrm{F}$ load. The average maximum out-of-plane web displacement is approximately 0.427 in. under the $+60^{\circ} \mathrm{F}$ load, while the $-60^{\circ} \mathrm{F}$ temperature produces an average maximum web displacement of .409 in., only a $4 \%$ difference.

When subjected to the largest temperature load of $+90^{\circ} \mathrm{F}$, out-of-plane web displacements increase significantly over those recorded under the $-/+60^{\circ} \mathrm{F}$ temperature loads. Comparing the self-weight and $+90^{\circ} \mathrm{F}$ loadings specifically, an increase in out-ofplane web displacement of approximately $1,000 \%$ is seen in several spans. The largest outof-plane displacement of 2.5 in. is produced in Span 9N, similar the other load conditions. As with the $-60^{\circ} \mathrm{F}$ and $+60^{\circ} \mathrm{F}$ temperature loads, the fixed spans experience the largest magnitudes of out-of-plane web displacement. Horizontal web profiles similar to Figures 4.4-4.50 were created for an interior girder (Girder $3 \mathrm{~N}$ ) in order to compare the effect of free and guided bearing devices on out-of-plane web displacements. The profiles for Girder 3N, guided bearings, are presented in Appendix A, but show no marked difference in web behavior.

Figures 4.51 and 4.52 present transverse web displacement profiles of several locations throughout the bridge due to the temperature loads. These transverse (vertical) profiles present a clearer understanding of the web buckling behavior, as opposed to only the lateral displacements seen in the horizontal profiles (Figures 4.4-4.50). The horizontal profiles only show the out-of-plane deflection at a single particular depth in the girder webs. Hence, more analysis is needed to thoroughly examine the out-of-plane web distortion. In Figures 4.51-4.52, transverse displacements are shown through the depth of a girder web plate. The displacements are recorded occur primarly in the radial direction (perpendicular to the girder axis), with a datum of 0.00 in. representing a perfectly vertical web plate without any out-of-plane deflection. 


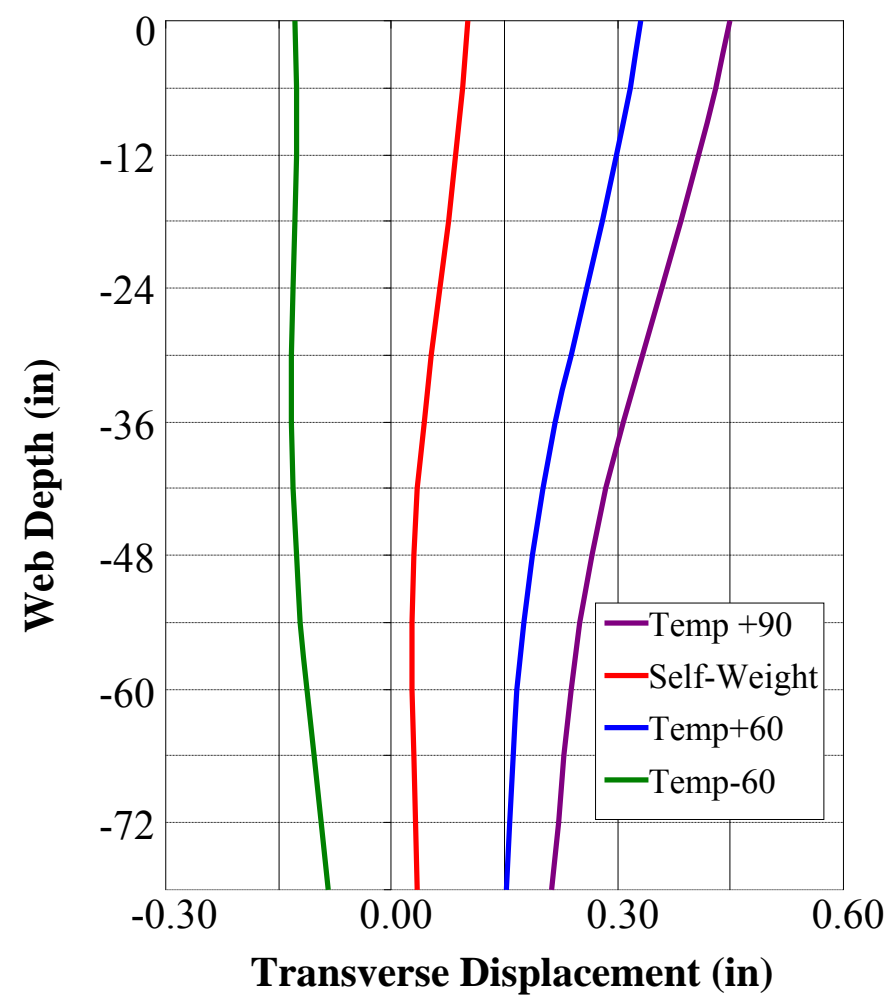

(a) Span $2 \mathrm{~N}$, Girder $4 \mathrm{~N}$

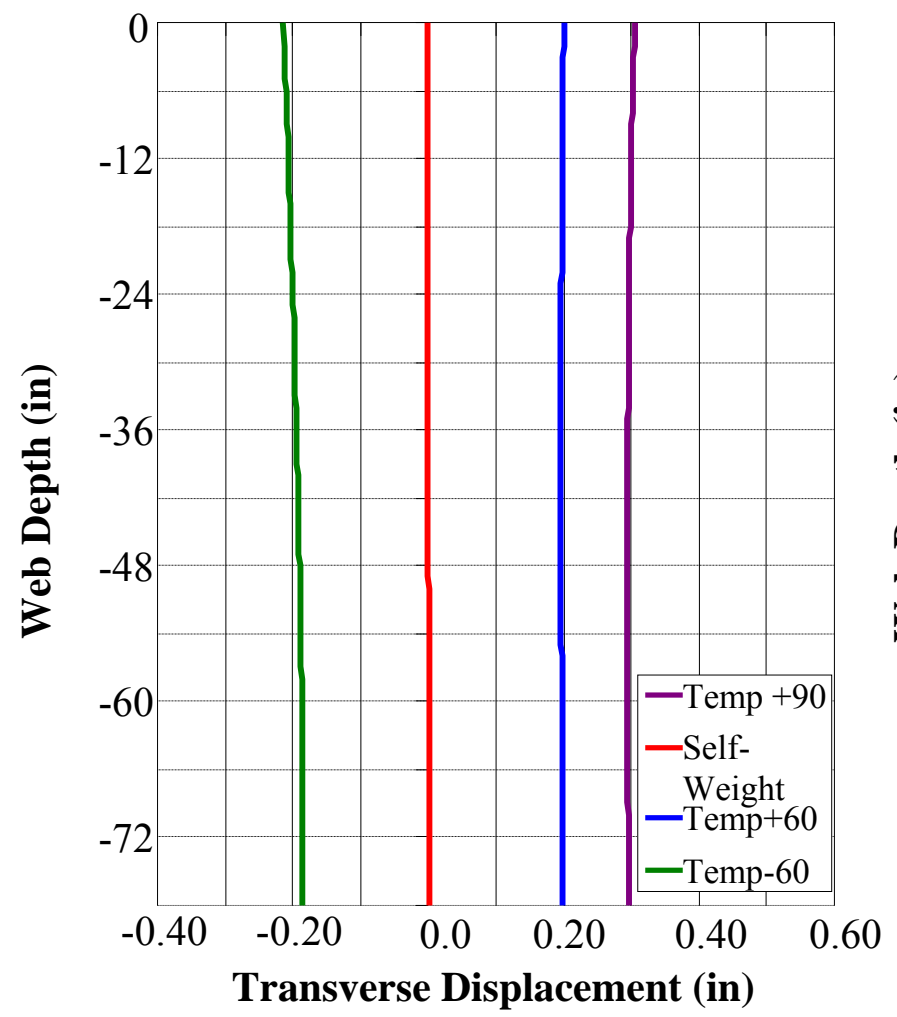

(c) Pier $1 \mathrm{~N}$, Girder $4 \mathrm{~N}$

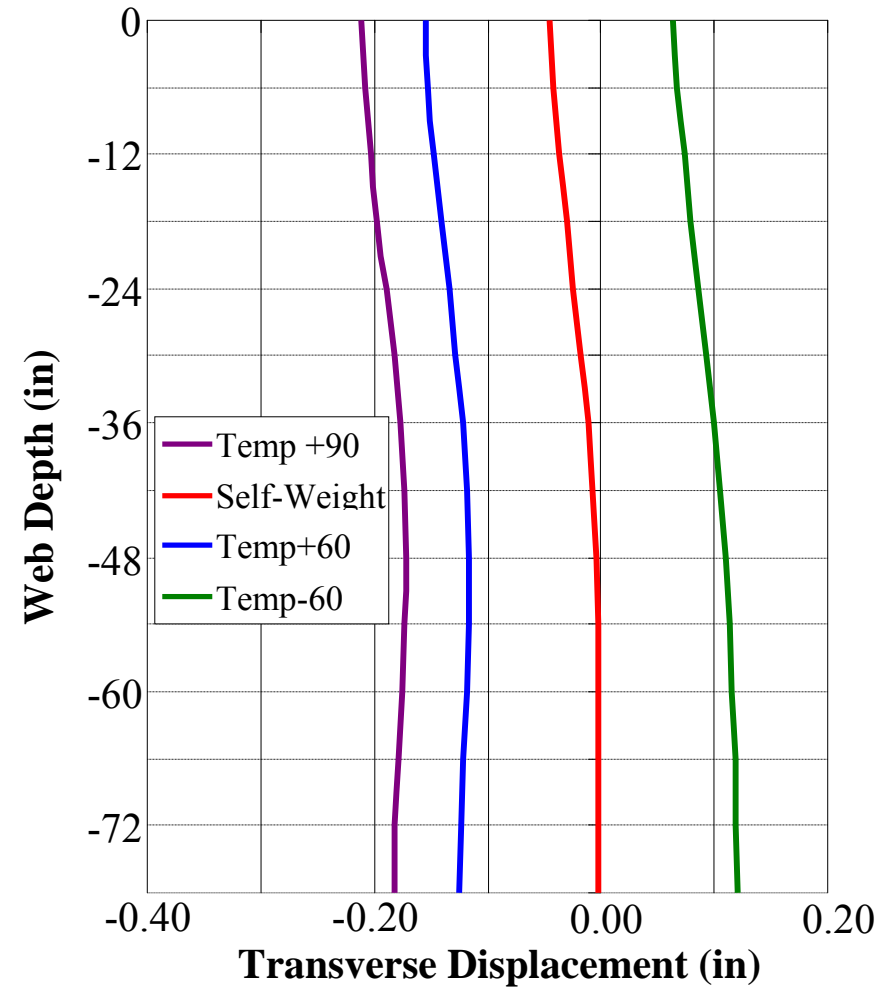

(b) Span 6N, Girder 4N

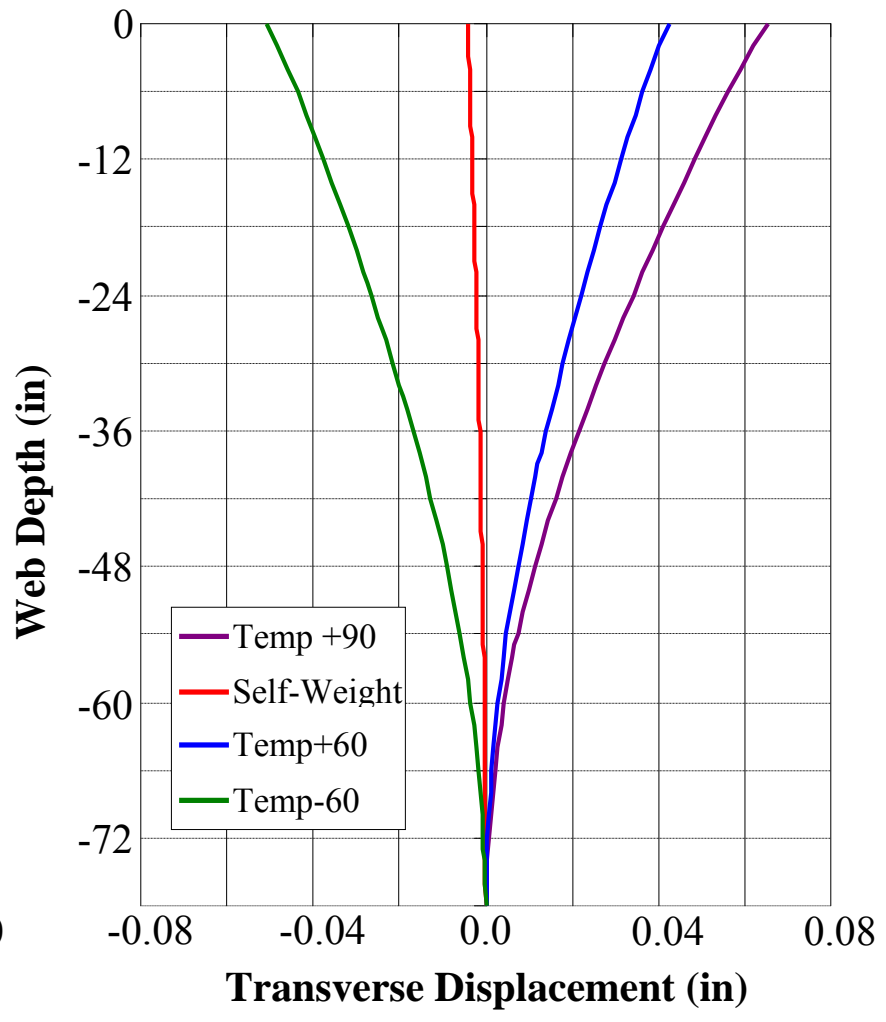

(d) Pier 4N, Girder 4N

Figure 4.51 As-Built Transverse Web Profiles (Unit 1) 


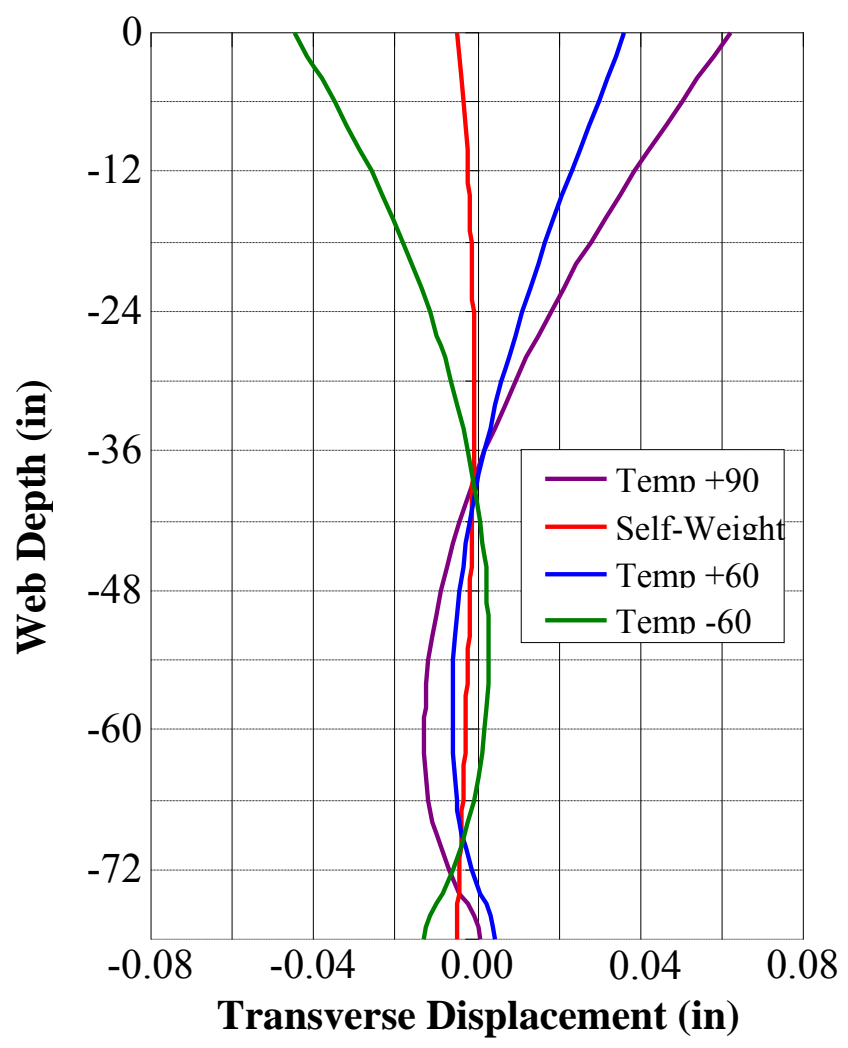

(a) Span $7 \mathrm{~N}$, Girder $4 \mathrm{~N}$

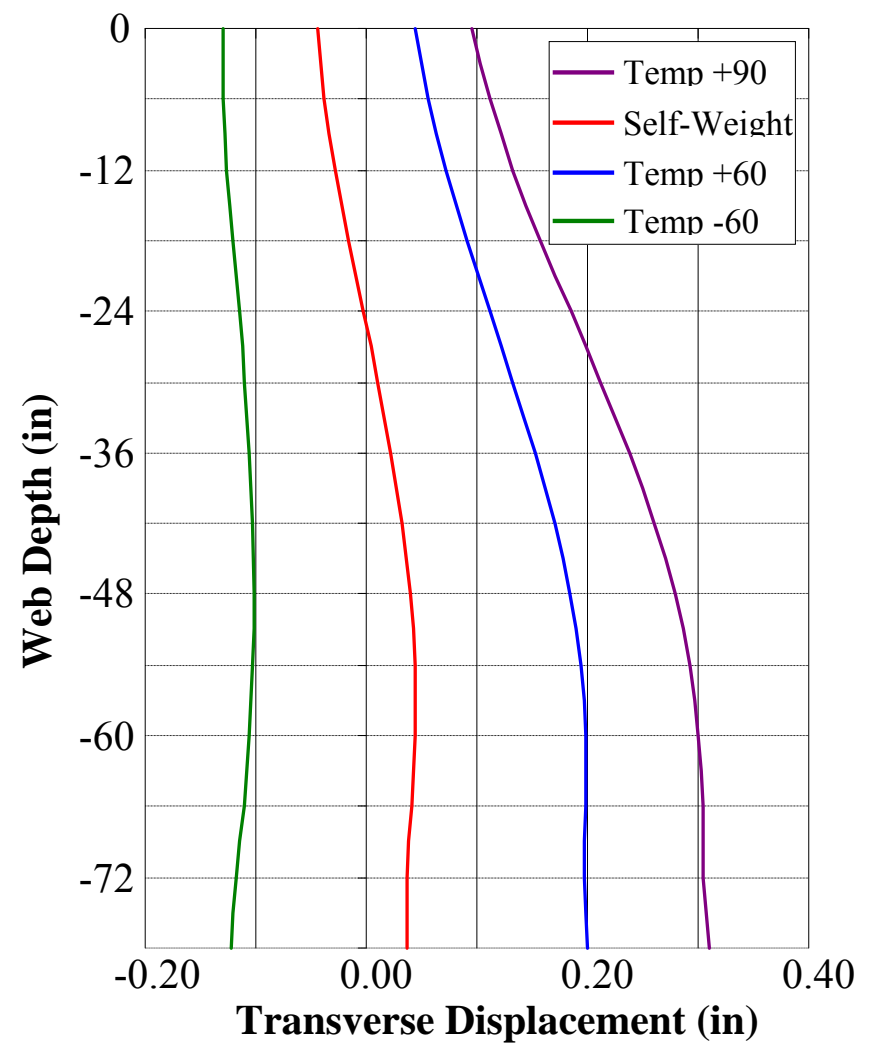

(c) Span $8 \mathrm{~N}$, Girder $4 \mathrm{~N}$

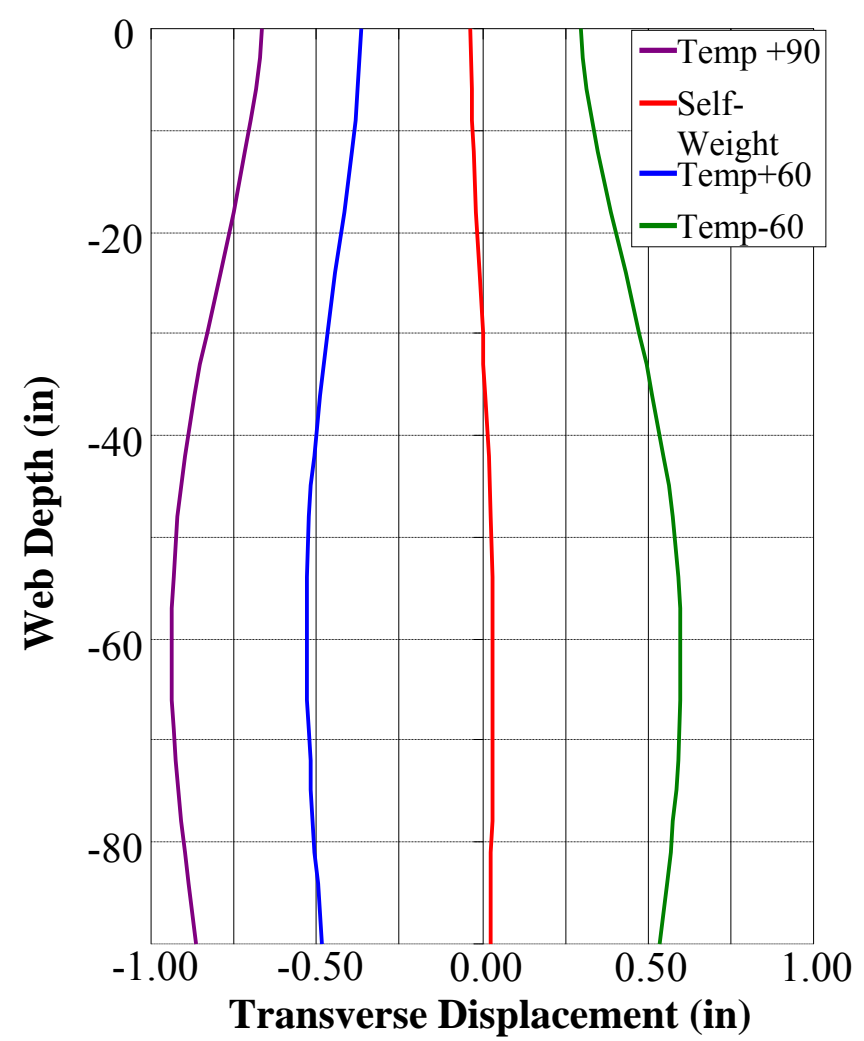

(b) Span $7 \mathrm{~N}$, Girder $1 \mathrm{~N}$

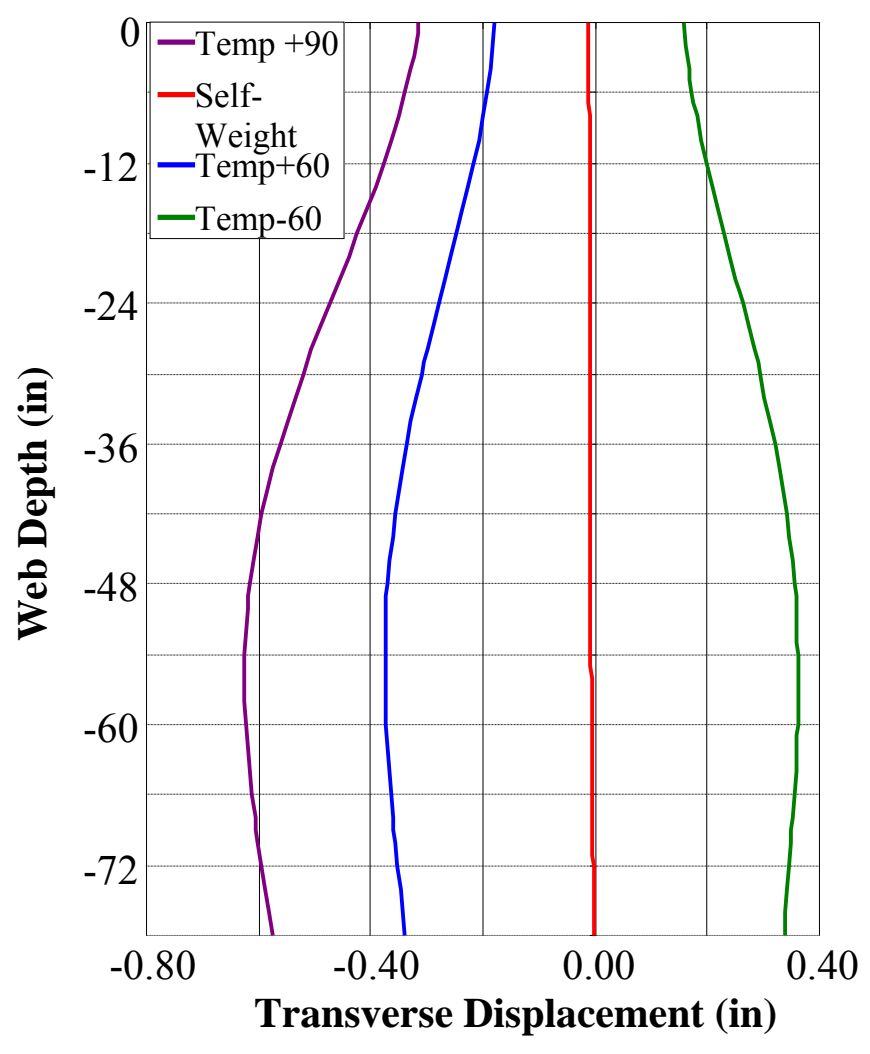

(d) Span 8N, Girder 1N 


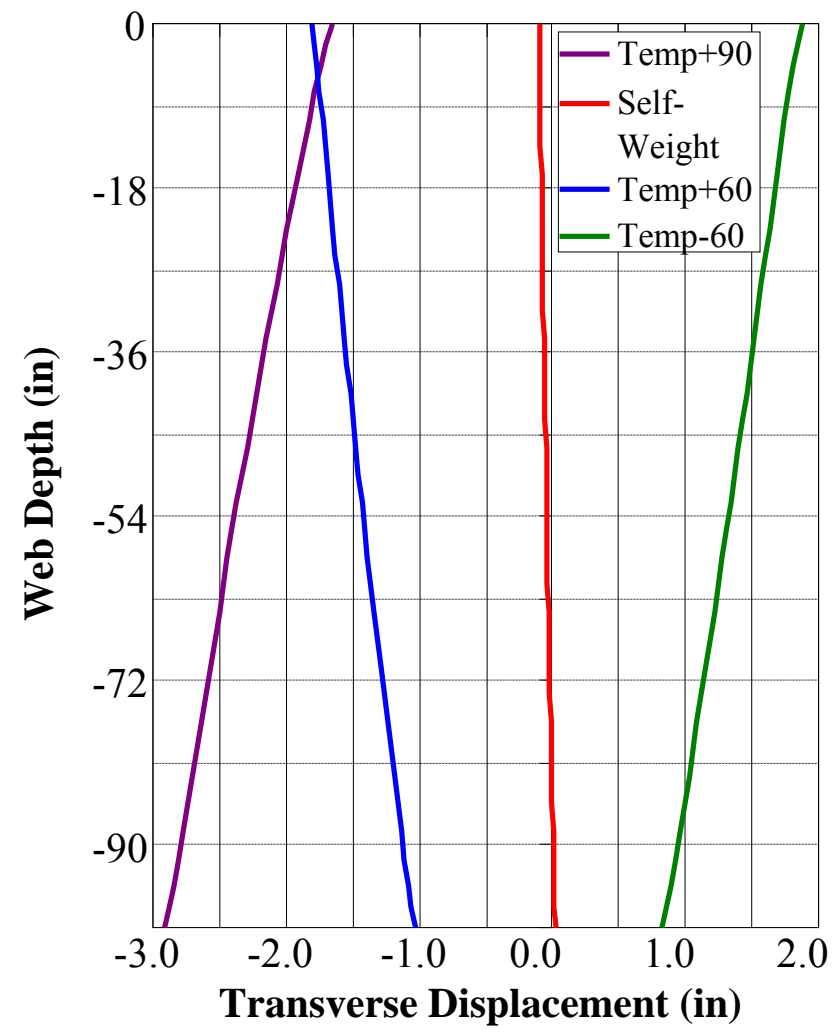

(e) Span 9N, Girder 4N

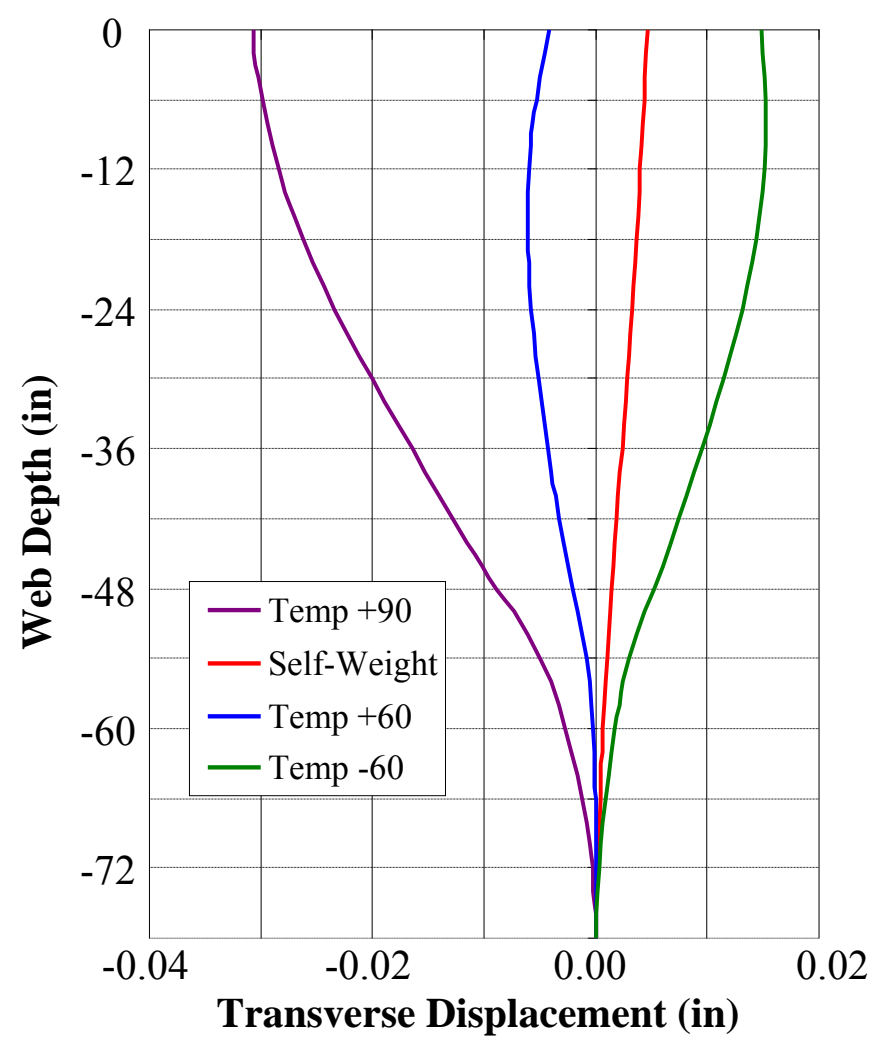

(g) Pier 7N, Girder 4N

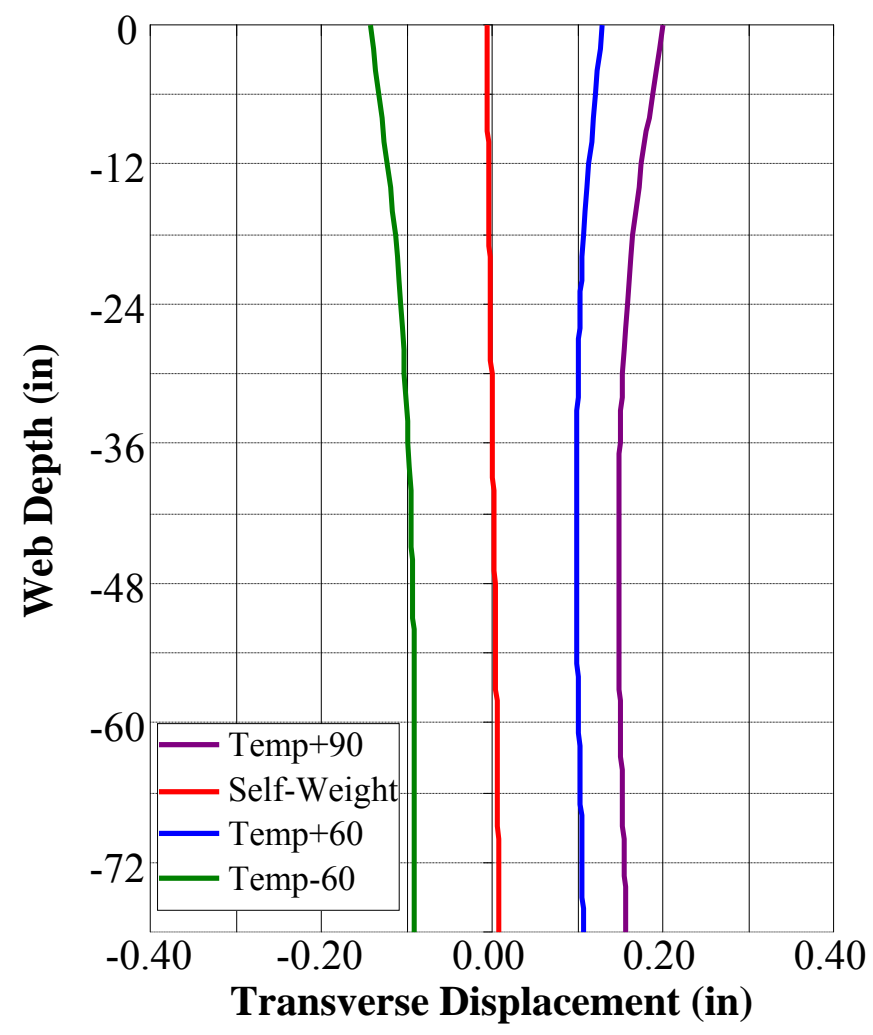

(f) Pier $6 \mathrm{~N}$, Girder $4 \mathrm{~N}$

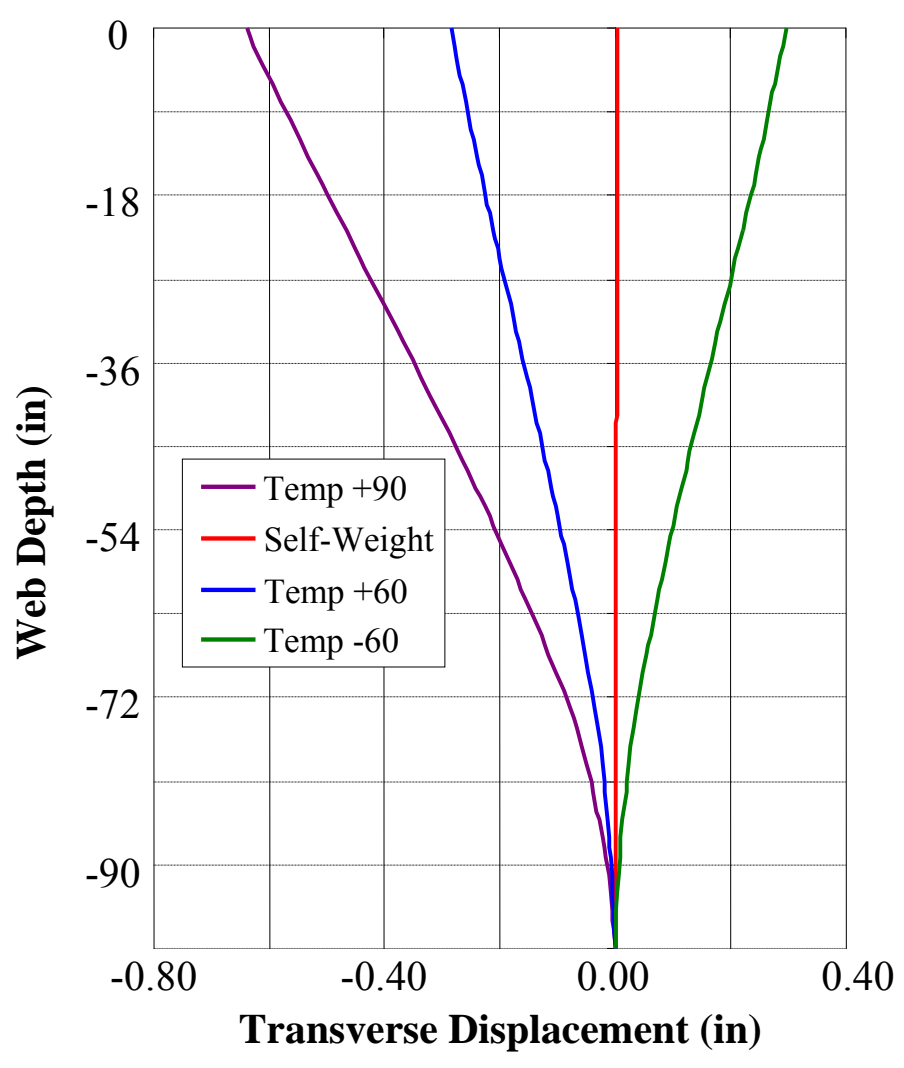

(h) Pier $8 \mathrm{~N}$, Girder $4 \mathrm{~N}$ 


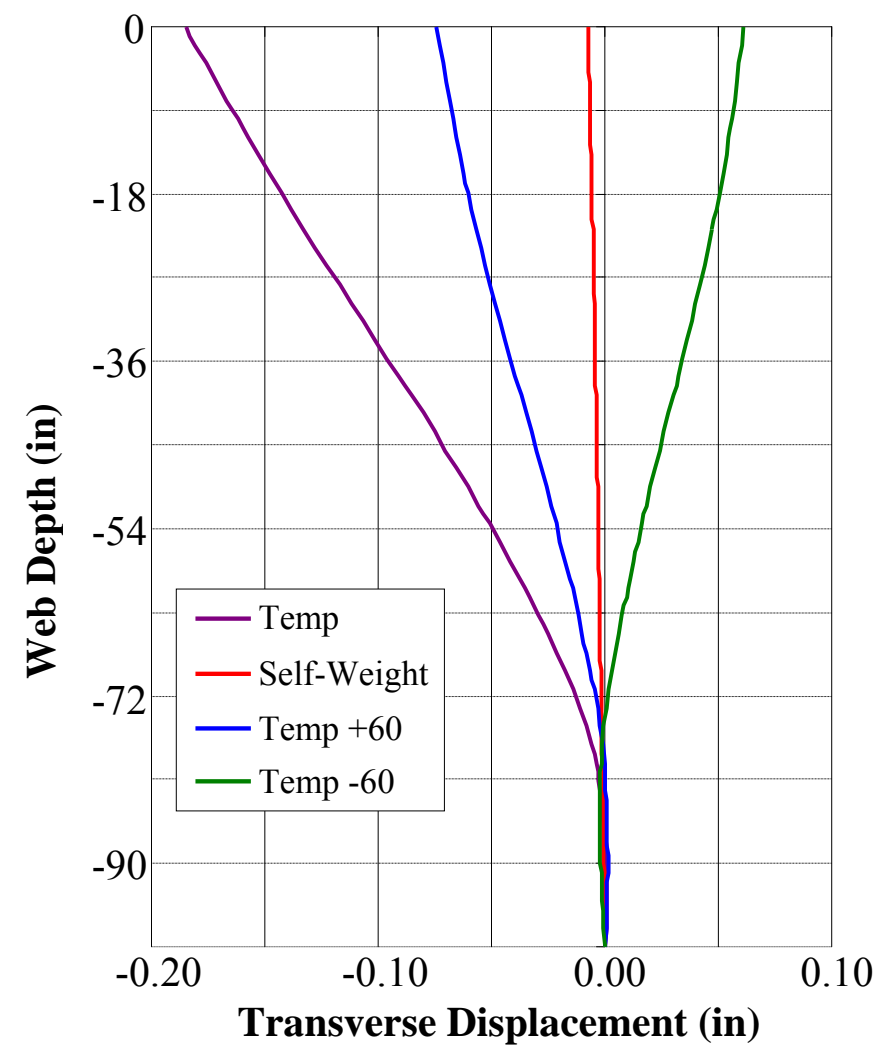

(i) Pier 9N, Girder 4N

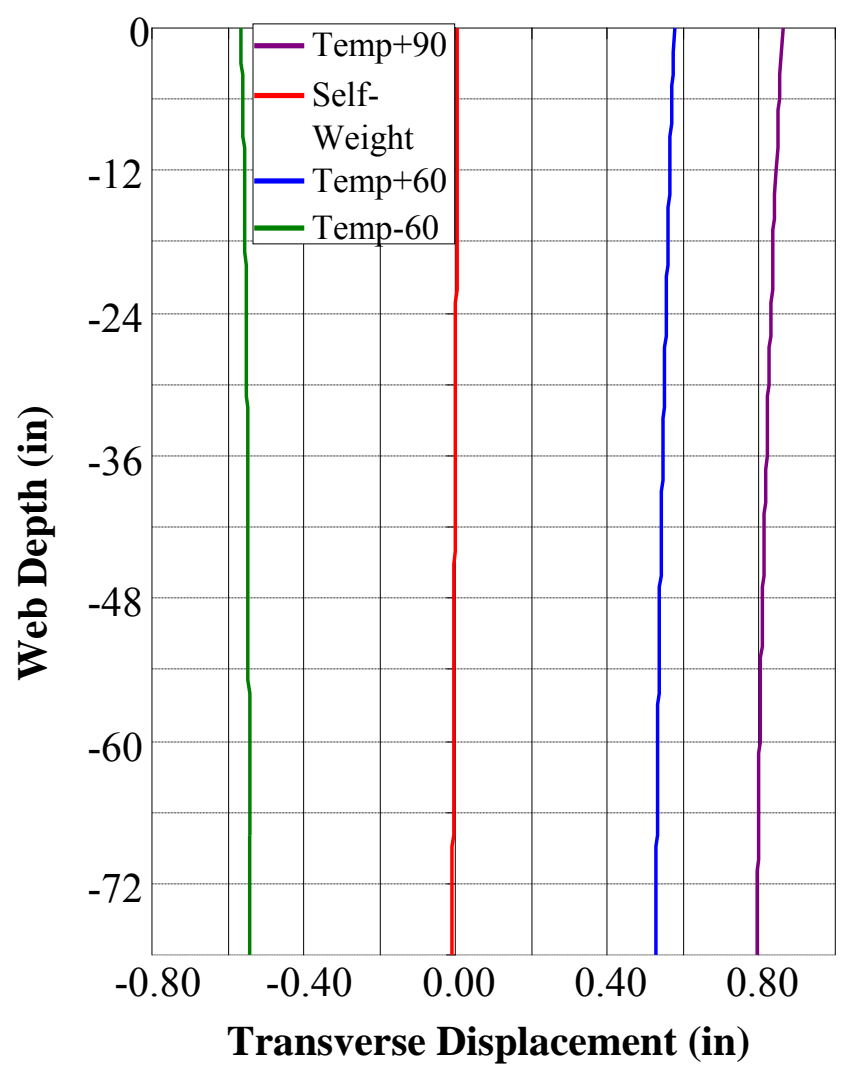

(k) Pier $11 \mathrm{~N}$, Girder $4 \mathrm{~N}$
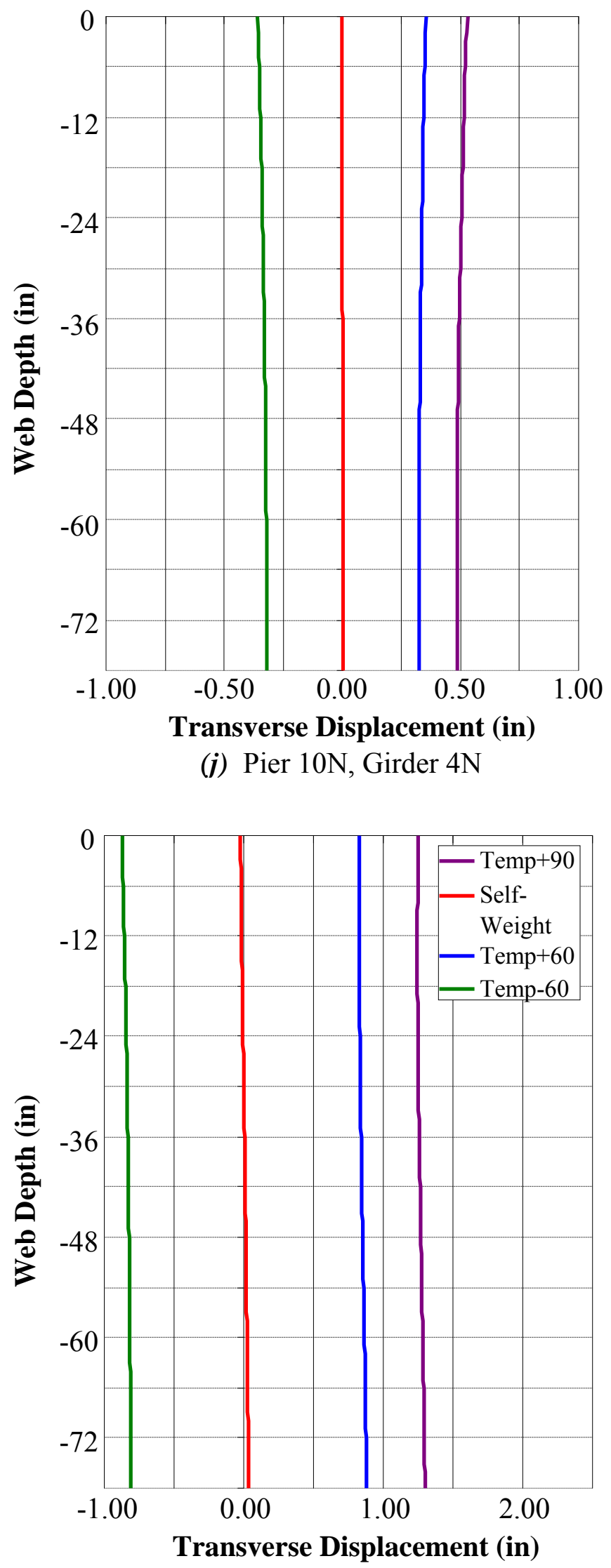

(l) Abut 2N, Girder 4N

Figure 4.52 As-Built Transverse Web Profile (Unit 2) 
Figures 4.51 and 4.52 present a more detailed understanding of the out-of-plane web distortion produced by the FE model. At Pier $8 \mathrm{~N}$ (Figure $4.52 \mathrm{~h}$ ), the difference in displacement between the top and bottom of the web is approximately 0.65 in. Pier $9 \mathrm{~N}$ (Figure 4.52i) shows a difference of 0.19 in. between the upper and lower edges of the web plate. While investigated in Chapter five, stresses in these areas are expected to be quite large. The profiles at Piers $8 \mathrm{~N}$ and $9 \mathrm{~N}$ are excellent examples of how the fixed bearings are contributing to web distortions. Piers $10 \mathrm{~N}$ and $11 \mathrm{~N}$, and Abutment $2 \mathrm{~N}$ (Figure 4.52j-1) show only lateral translation, with insignificant differential displacement between the top and bottom of the web plate.

At the cross-section examined in Span $7 \mathrm{~N}$, out-of-plane deflection is 0.032 in. due to the bridge self-weight alone; whereas a deflection of $0.34 \mathrm{in.} \mathrm{occurs} \mathrm{due} \mathrm{to} \mathrm{the} \mathrm{bridge} \mathrm{self-}$ weight combined with the applied temperature load of $+90^{\circ} \mathrm{F}$, resulting in an increase of over $1,000 \%$. Larger increases in deflection are calculated in Span $8 \mathrm{~N}$, which is one of two spans fully restrained from translation at its piers. Under the $+90^{\circ} \mathrm{F}$ temperature load, out-of-plane displacement increases $2,875 \%$ for the cross-section near the midspan of Span $8 \mathrm{~N}$. Portions of Span $10 \mathrm{~N}$ experience similar increases in transverse displacement.

When studying the vertical web profiles for the locations near the midspans (Figure 4.52a-e), it is clearly seen that lateral-distortional web buckling has occurred. Figure $4.51 \mathrm{a}-\mathrm{b}$ (Spans $2 \mathrm{~N}$ and $6 \mathrm{~N}$ ) and Figure 4.52a-d (Spans $7 \mathrm{~N}$ and $8 \mathrm{~N}$ ) are all perfect illustration of lateral-distortional buckling. Lateral-distortional web buckling occurs when an I-girder web has rotated and translated laterally (lateral-torsional buckling), while simultaneously undergoing distortion (local buckling) of the cross-section. Figure 4.53 shows three buckling modes of an I-section. Lateral-distortional buckling is a combination of lateral-torsional and local web buckling. 


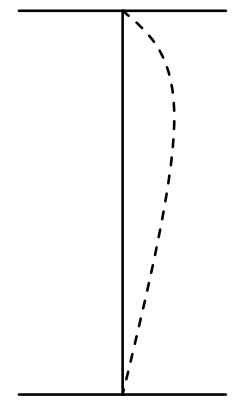

(a) local web buckling

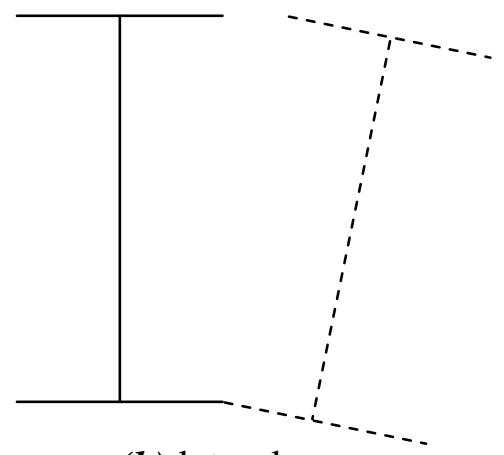

(b) lateral buckling

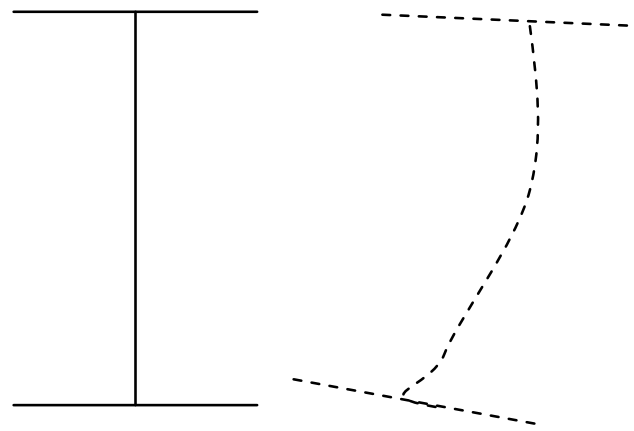

(c) distortional buckling

Figure 4.53 I-section Buckling Modes

As seen in Figures 4.51 and 4.52, not only does the entire cross-section displace laterally and twist, the web also shows some distortion (S-shape). The transverse (vertical) profiles show the true extent of the web buckling that develops throughout the bridge as a result of the self-weight and uniform temperature loads. White and June (2007) point out that, generally, steel design standards define the flexural resistance of a steel I-section based on local and lateral-torsional buckling modes, whereas lateral-distortional buckling is not considered, mainly due to the lack of closed-form solutions. The transverse profiles here have shown that small magnitudes of lateral-distortional buckling have developed in the bridge girders due only to bridge self-weight. When subjected to uniform temperature loads, the magnitude of this buckling increases dramatically. This increased buckling will affect the flexural capacity of the girders. Bradford (1992) found that distortional buckling will occur at significantly lower load than lateral-torsional buckling. This means that while a girder may be satisfactory against lateral-torsional buckling, distortional buckling failure may occur at load levels not considered during design.

Currently, AASHTO has not developed specifications pertaining directly to out-ofplane web distortions and their effect on the structural capacity of curved steel I-girders. However, the AASHTO/AWS Bridge Welding Code (2008) does provide specifications to 
control plate girder web out-of-flatness during shop work (e.g. welding). Section 3.5 of the Bridge Welding Code (2008) sets forth maximum values for web out-of-flatness for welded structural members of steel bridges. Measurements of out-of-flatness are based on depth-tothickness ratios $(D / t w)$ and web panel dimensions. Table 4.1 lists the dimensional tolerances for allowable variations from flatness for girder web plates, where $D$ is the web depth, $t$ is the web thickness, and $\mathrm{d}$ is the least panel dimension. The least panel dimension, $\mathrm{d}$, is equal to the lesser of the web depth and spacing between stiffeners. If no intermediate stiffeners are present, maximum out-of-flatness variation is taken as $D / 150$.

Table 4.1 Bridge Welding Code Dimensional Tolerances

Intermediate stiffeners on both sides of web:

\begin{tabular}{|c|c|c|}
\hline Position & Range & Maximum Variation \\
\hline Interior Girders & $D / t<150$ & $\mathrm{~d} / 115$ \\
\hline & $D / t<150$ & $\mathrm{~d} / 92$ \\
\hline Fascia (Exterior) Girders & $D / t<150$ & $\mathrm{~d} / 130$ \\
\hline & $D / t<150$ & $\mathrm{~d} / 105$ \\
\hline
\end{tabular}

Intermediate stiffeners on only one side of web:

\begin{tabular}{|c|c|c|}
\hline Position & Range & Maximum Variation \\
\hline Interior Girders & $D / t<100$ & $\mathrm{~d} / 100$ \\
\hline Fascia (Exterior) Girders & $D / t<100$ & $\mathrm{~d} / 67$ \\
\hline & $D / t<100$ & $\mathrm{~d} / 120$ \\
\hline
\end{tabular}


Web distortions produced by the FE model are compared to the values shown in Table 4.1 for several locations throughout the bridge. Results are presented in Table 4.2, which shows that the web distortion at each location examined is within maximum flatness variation specifications as given in the Bridge Welding Code (2008).

Table 4.2 FE Model Out-of-Flatness Results

\begin{tabular}{|c|c|c|c|c|}
\hline Location & Girder Location & Range & Maximum Variation & FE Out-of-Flatness \\
\hline Span 2N & Exterior (4N) & $D / t>100$ & $D / 150=0.52$ in. & 0.25 in. \\
\hline Span 6N & Exterior $(4 \mathrm{~N})$ & $D / t>100$ & $D / 150=0.52$ in. & 0.02 in. \\
\hline Span 7N & Exterior $(1 \mathrm{~N})$ & $D / t>100$ & $D / 150=0.52$ in. & 0.21 in. \\
\hline Span 7N & Exterior $(4 \mathrm{~N})$ & $D / t>100$ & $D / 150=0.52$ in. & 0.07 in. \\
\hline Span 8N & Exterior $(1 \mathrm{~N})$ & $D / t>100$ & $D / 150=0.52$ in. & 0.35 in. \\
\hline Span 8N & Exterior $(4 \mathrm{~N})$ & $D / t<100$ & $D / 150=0.52$ in. & 0.31 in. \\
\hline Pier 4N & Exterior $(4 \mathrm{~N})$ & $D / t<150$ & $\mathrm{~d} / 130=0.60$ in. & 0.065 in. \\
\hline Pier 8N & Exterior $(1 \mathrm{~N})$ & $D / t<150$ & $\mathrm{~d} / 130=.728$ in. & 0.62 in. \\
\hline
\end{tabular}

As stated previously, a discussion on out-of-flatness and geometric imperfections is provided in Article C6.10.1.9.1. The information in this article discusses only observations where the application of load is in the vertical plane. For the case of the bridge studied here, the application of temperature loads more than tripled the magnitude of web distortion seen under bridge self-weight. This finding suggests that significant web distortions can develop due to increasing temperature loads, while studies by Kala et al. (2005) and White and Jung (2007) concluded that web distortions do negatively influence girder capacity. However, determining the exact level of strength reduction in is beyond the scope of this work. 
Figures 4.54-4.59 show displacement contour plots and deformed shapes produced by the FE bridge model for several areas of the FE model under the self-weight and $+90^{\circ} \mathrm{F}$ load cases. The extent of the web buckling is very clear in these figures.
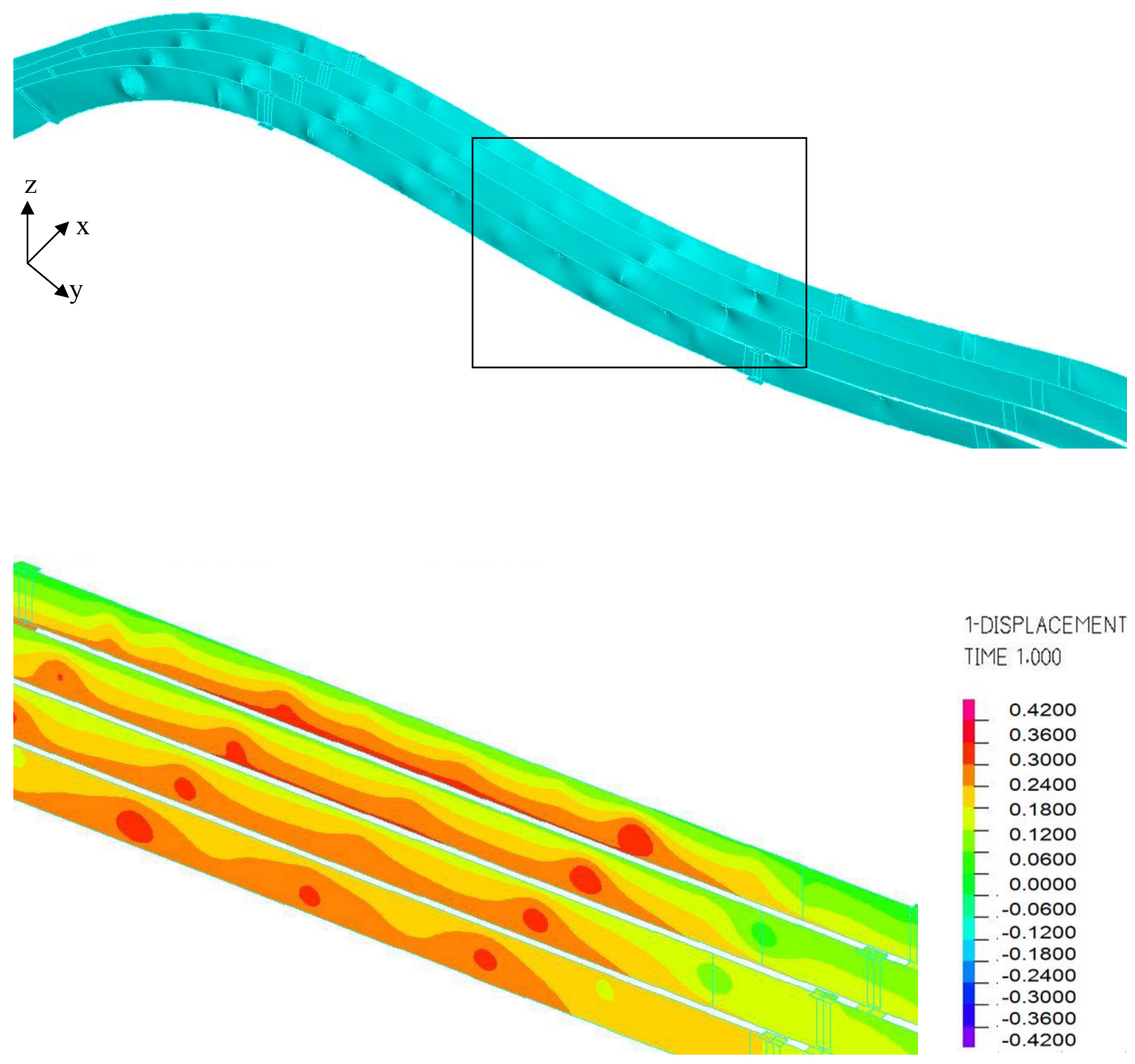

1-DISPLACEMENT TIME 1.000

0.4200

0.3600

$-0.3000$

$-0.2400$

$-0.1800$

$-0.1200$

$-0.0600$

0.0000

$-0.0600$

$-0.1200$

$-0.1800$

$-0.2400$

$-0.3000$

$-0.3600$

$-0.4200$

Figure 4.54 FE Bridge Model Displacement Contours (Span $3 \mathrm{~N}$ due to $+90^{\circ} \mathrm{F}$ Temperature Load) 


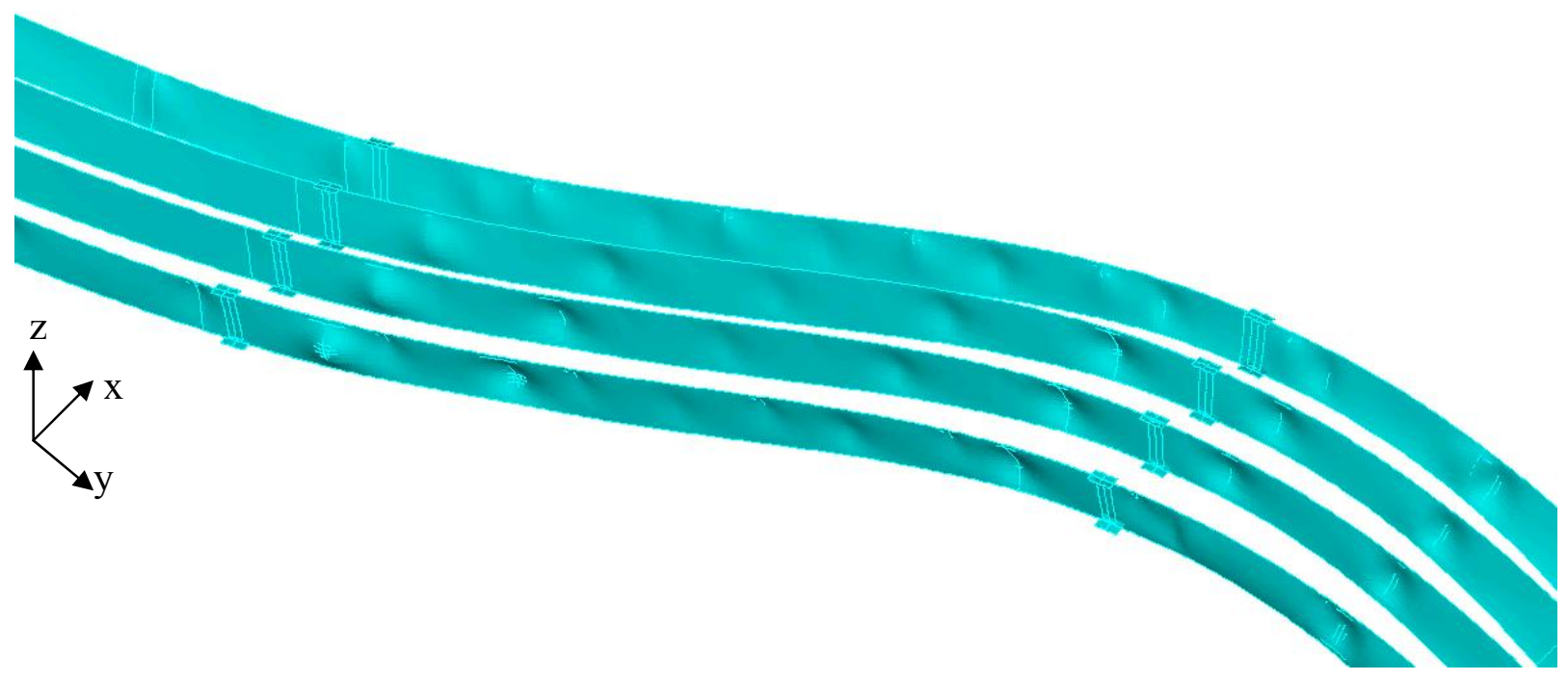

1-DISPLACEMENT

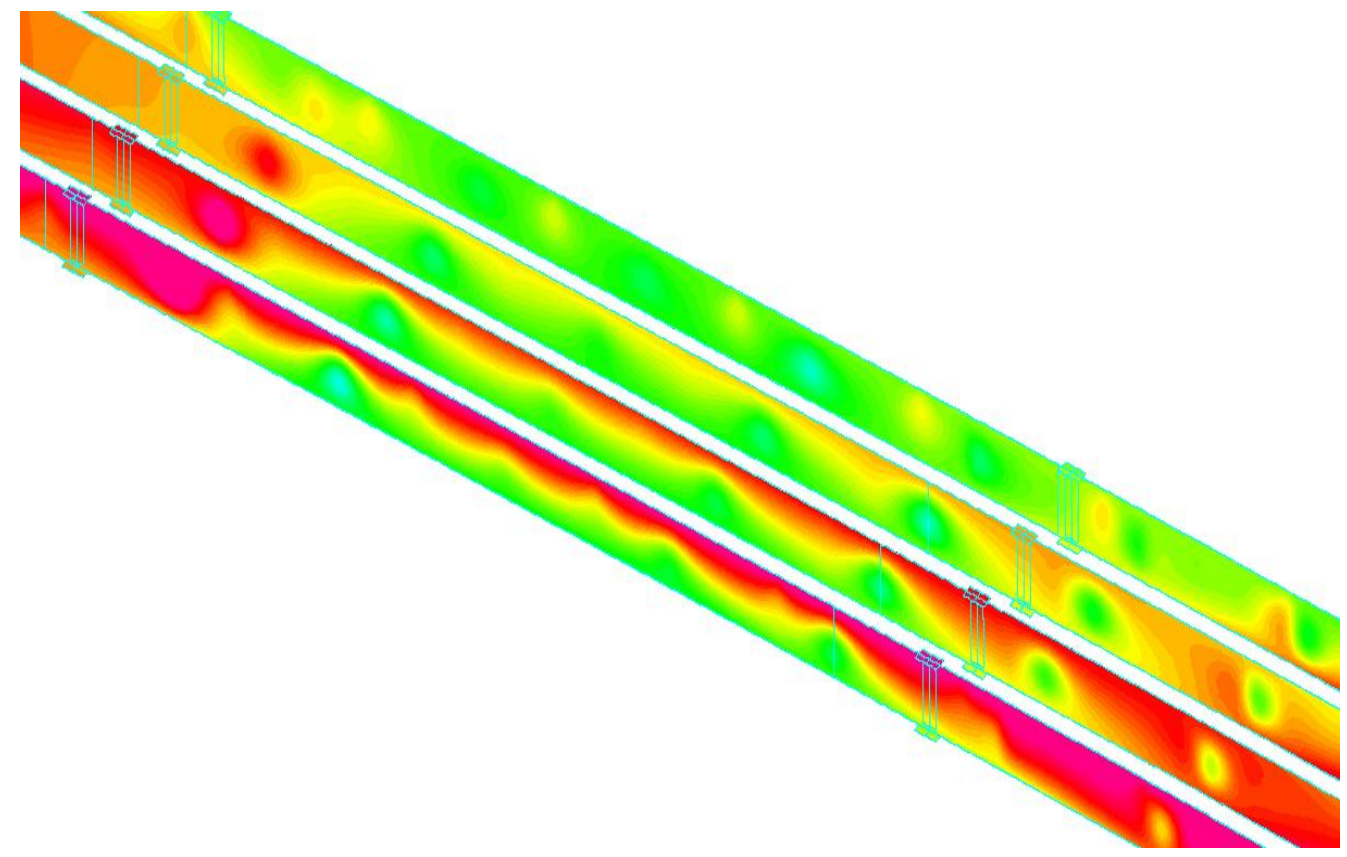

TIME 1.000

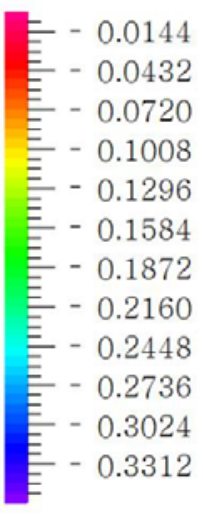

Figure 4.55 FE Bridge Model Displacement Contours (Span $5 \mathrm{~N}$ due to $+90^{\circ} \mathrm{F}$ Temperature Load) 

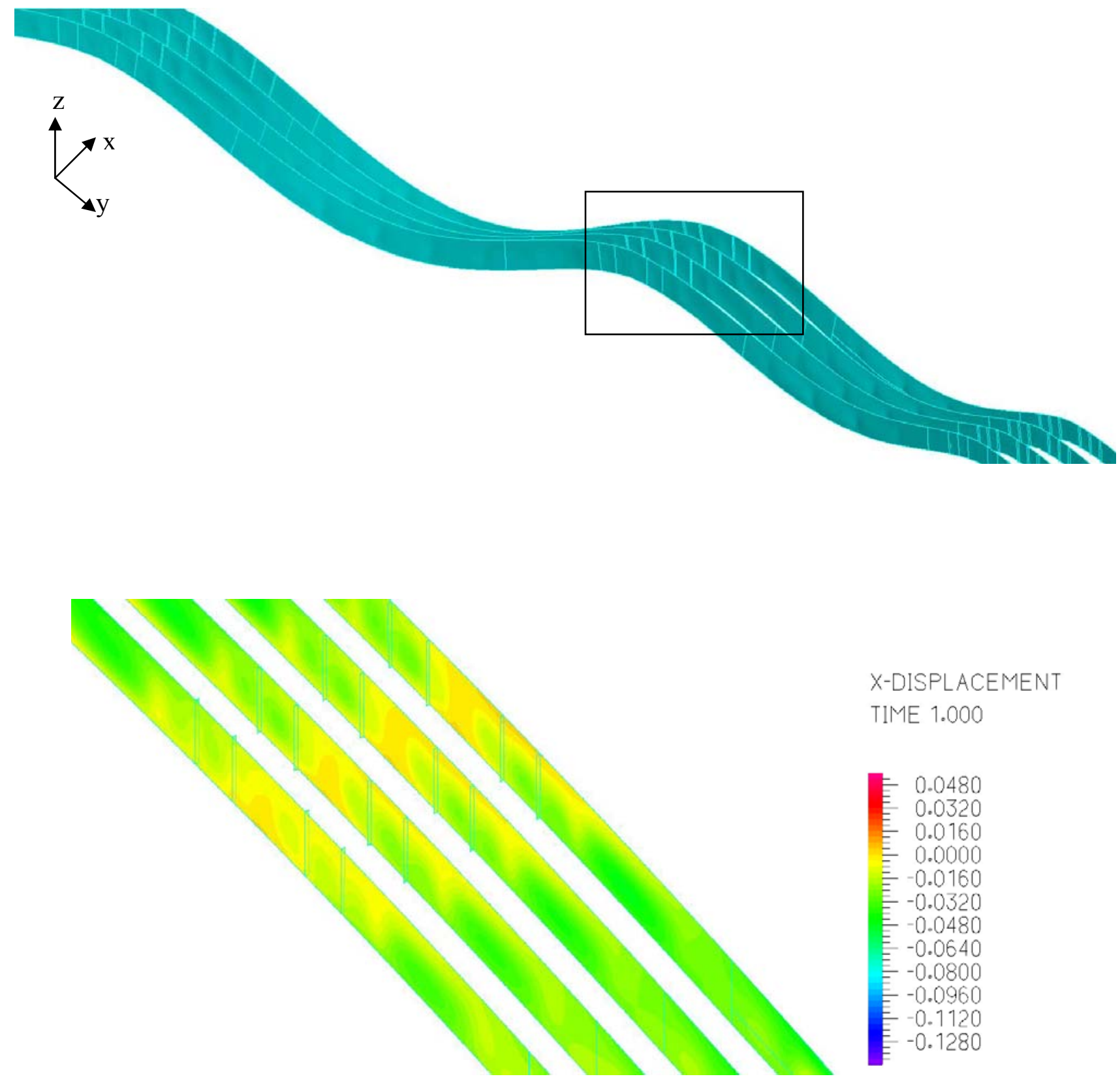

Figure 4.56 FE Model Displacement Contours (Pier 9N and Span 10N due to Bridge Self-Weight) 

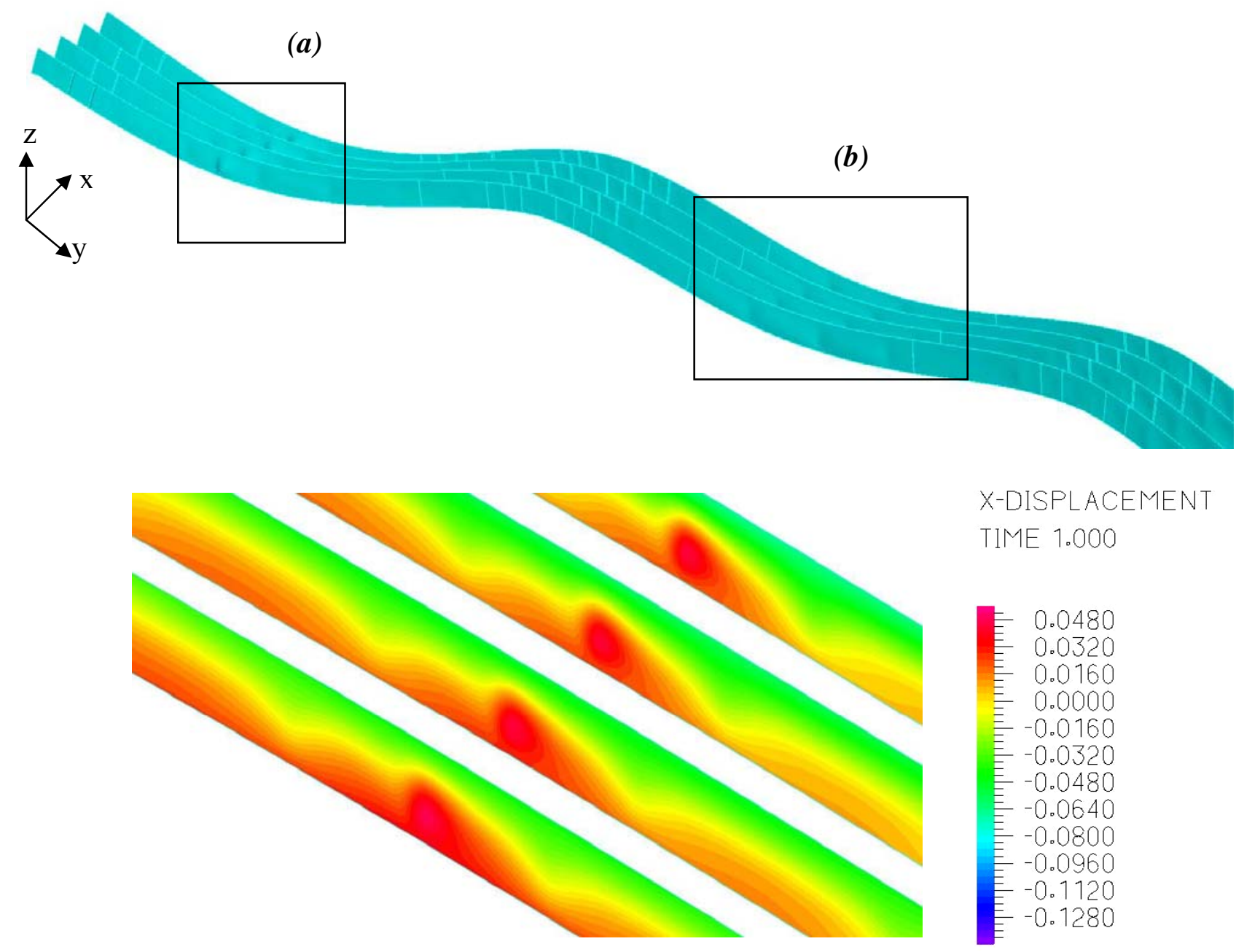

(a) Span 7N, FE model transverse displacement contours

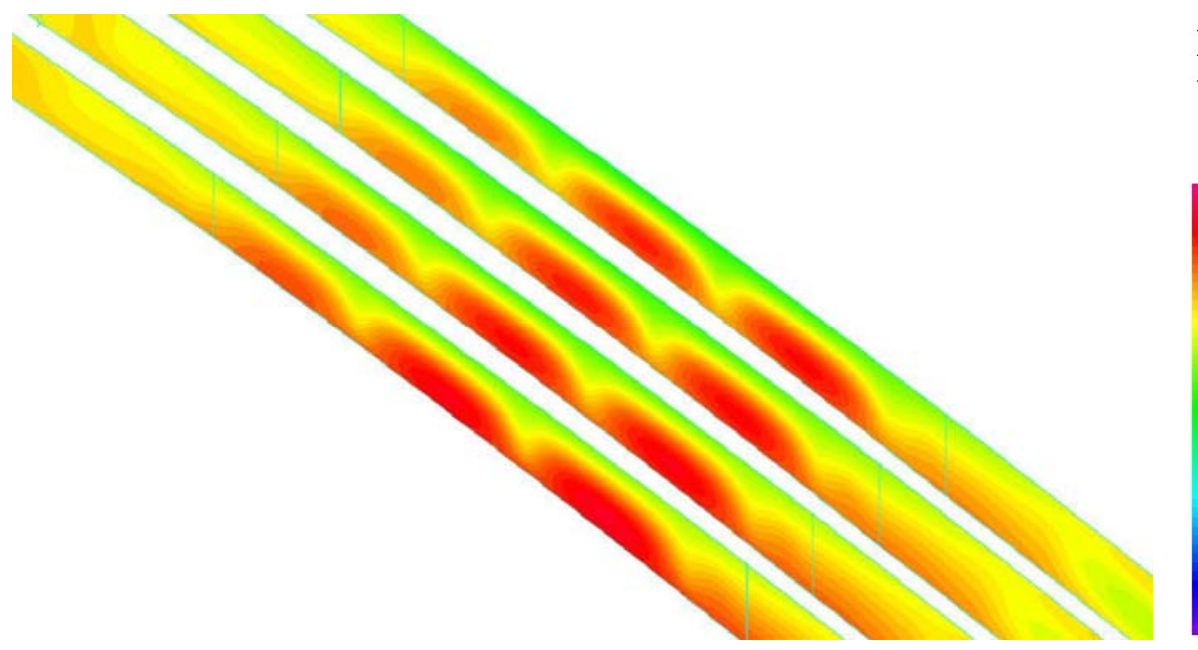

(b) Span $8 \mathrm{~N}$, FE model transverse displacement contours

Figure 4.57 FE Model Displacement Contours (Spans 7N and 8N due to Bridge Self-Weight) 


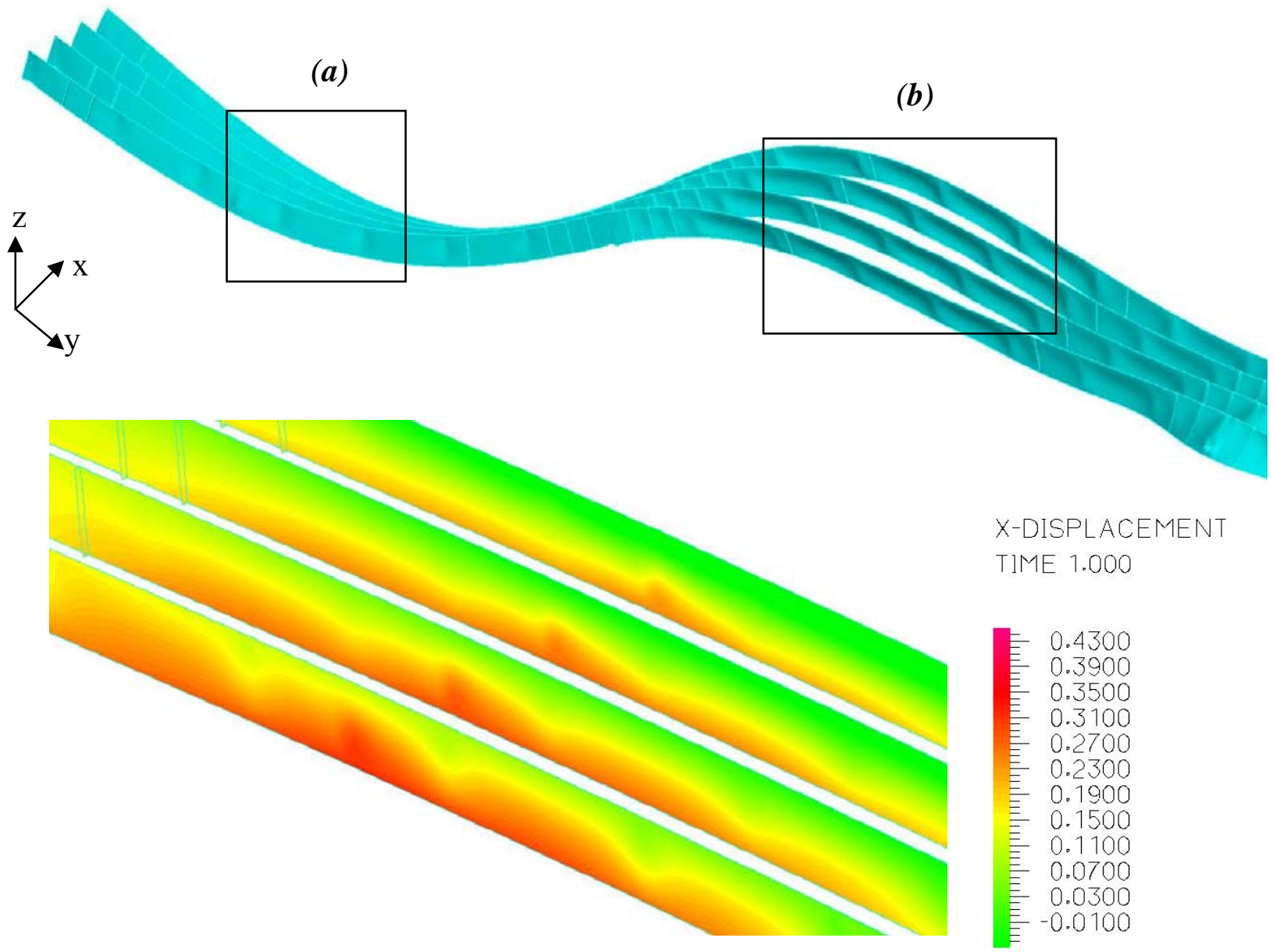

(a) Span 7N, FE model transverse displacement contours

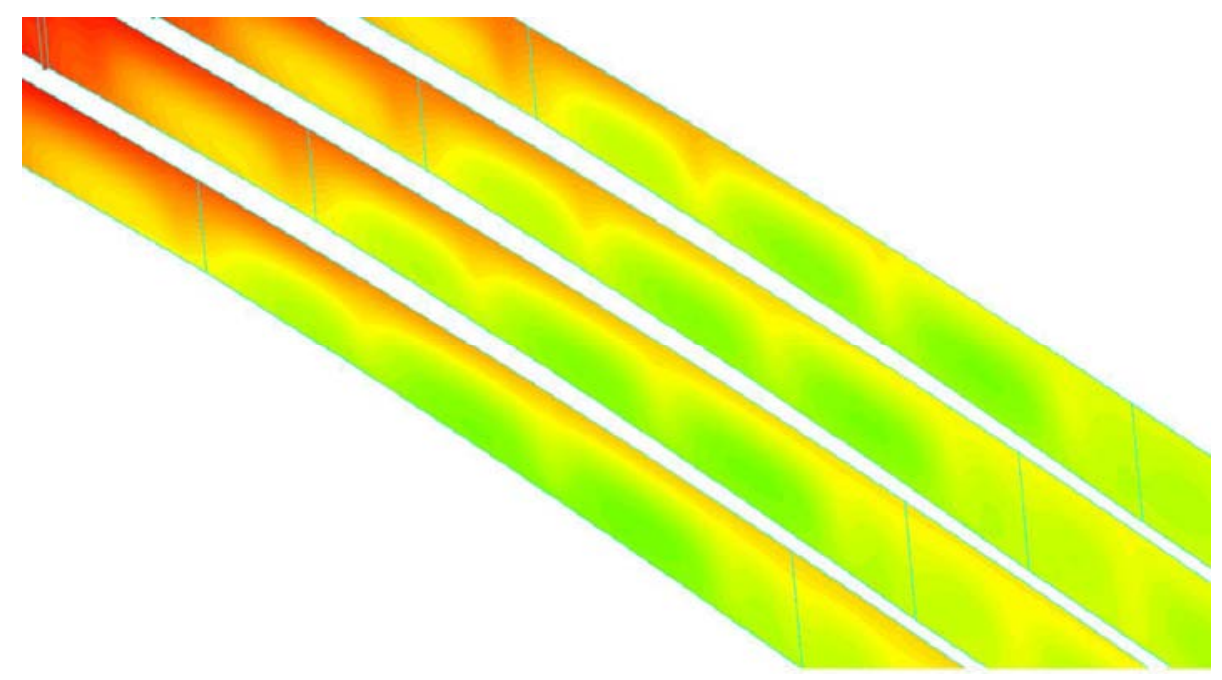

$X$-DISPLACEMENT TIME 1.000

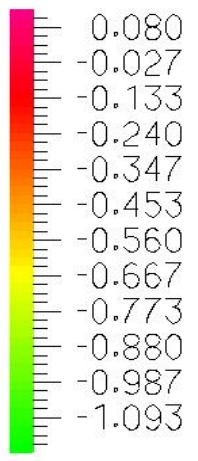

(b) Span $8 \mathrm{~N}$, FE model transverse displacement contours

Figure 4.58 FE Model Displacement Contours (Spans $7 \mathrm{~N}$ and $8 \mathrm{~N}$ due to $+90^{\circ} \mathrm{F}$ Temperature Load) 

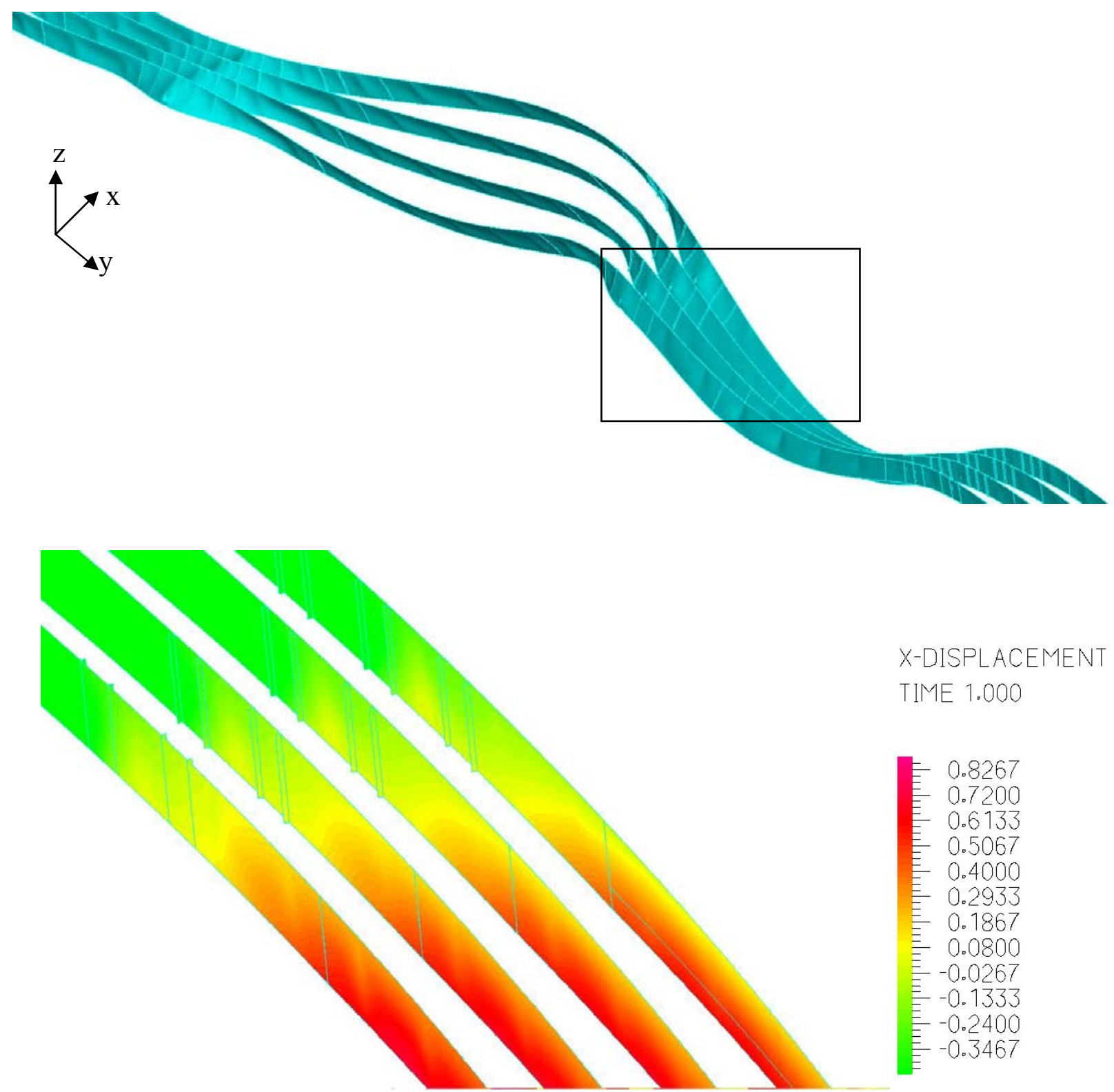

X-DISPLACEMENT

TIME 1.000

0.8267

0.7200

0.6133

0.5067

$=0.4000$

0.2933

0.1867

0.0800

$-0.0267$

E -0.1333

$-0.2400$

$-0.3467$

Figure 4.59 FE Model Displacement Contours (Pier 9N and Span $10 \mathrm{~N}$ due to $+90^{\circ} \mathrm{F}$ Temperature Load) 
Figure 4.60 compares the maximum out-of-plane deflection for each span under each load case. This plot excellently shows how temperature loads affect the response of the FE bridge model. It is clearly seen that Span 9N produces the largest out-of-plane deflection. The temperature loads considered here are very reasonable loads that the bridge may experience in the field. The magnitude of out-of-plane distortions produced by the FE model may have serious implications on girder strength and stability, especially when all other load conditions are considered, most notably design live load.
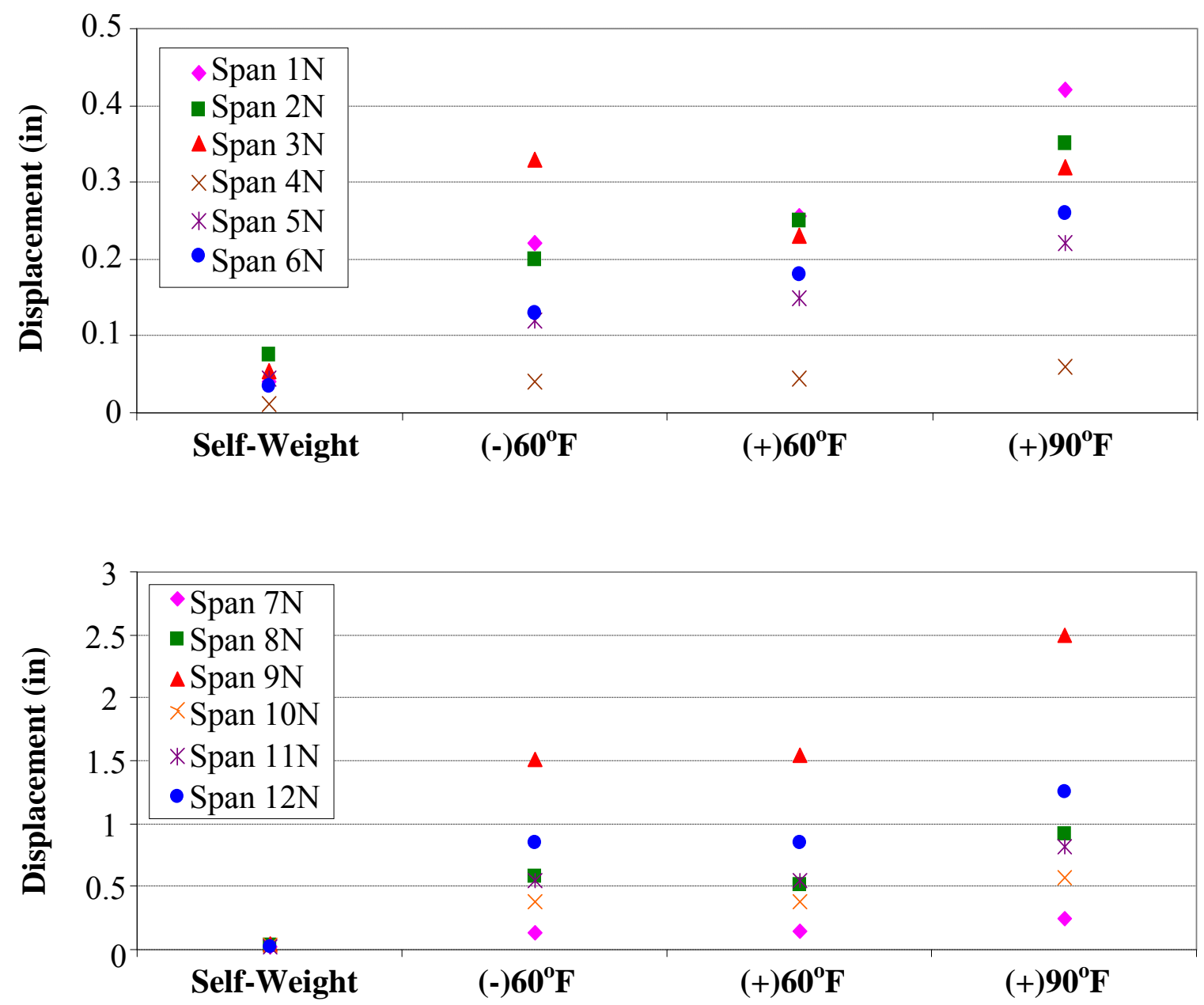

Figure 4.60 Maximum Out-of-Plane Distortion per Span Under As-Built Bearing Arrangement 


\subsection{LIVE LOAD EFFECTS}

In this section, a static live load is added to the bridge self-weight and thermal loading cases previously investigated in order to determine the effects of live loading on the out-ofplane distortion of the bridge girders. For this study, live load experiments could not be performed on the actual structure, therefore, the effect of design live load will be investigated by applying the live load to the FE bridge model. The out-of-plane distortion due to temperature forces have already been shown to be quite large. If these deformations are increased by the addition of live loading, strength and stability issues will become even more significant.

The live load used for this study is the AASHTO HL-93 design live load. The AASHTO HL-93 consists of the AASHTO HS20-44 standard truck load with the addition of a 0.64 klf uniformly distributed lane load added as specified in Section 3.6.1.2 of AASHTO (2007). Figure 4.61 illustrates the layout and wheel load values of the AASHTO HS20-44 design truck. The magnitude of the wheel loads shown in Figure 4.61 do not include the dynamic load allowance of $33 \%$ as specified in Section 3.6.2 of AASHTO (2007). Using influence line theory, the AASHTO truck load and design lane loads are applied to maximize its effect near the midspan of Span $8 \mathrm{~N}$ (the same cross-section as studied in Section 4.3). The design live load is applied in conjunction with the temperature load of $+60^{\circ} \mathrm{F}$ and by itself (design live load and bridge self-weight only) to determine full effect of the live load. 

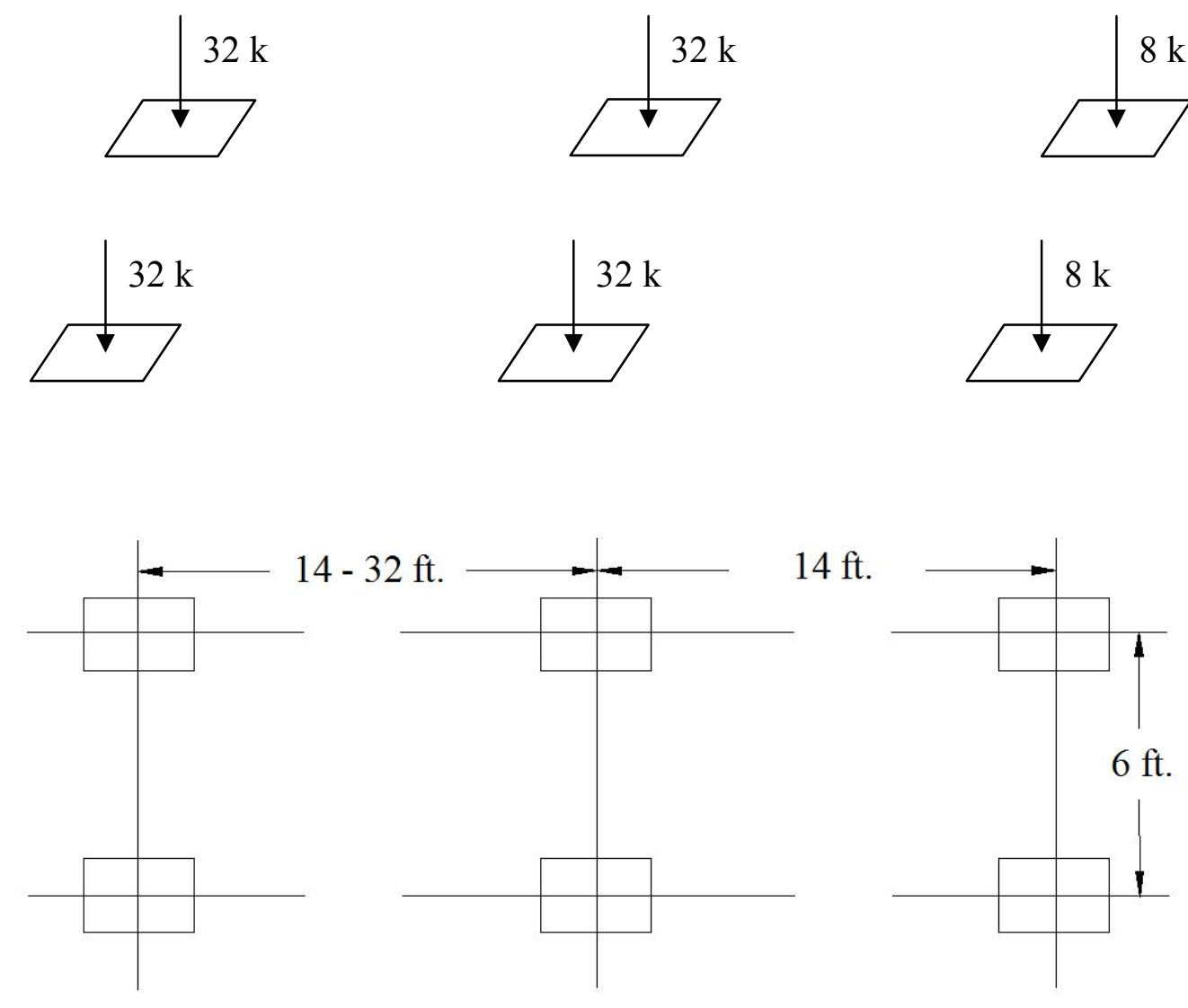

Figure 4.61 AASHTO HS20-44 Truck Load Configuration

Figure 4.62 shows the horizontal profile for Span $8 \mathrm{~N}$ of Girder $4 \mathrm{~N}$ (exterior girder) due to bridge self-weight and the design live load. Figures 4.63 and 4.64 show the horizontal profiles for Span $8 \mathrm{~N}$ of Girder $4 \mathrm{~N}$ (exterior girder) due to bridge self-weight, temperature loads, and design live load. As seen below, the addition of the design live load increases the magnitude of out-of-plane web displacement throughout the entire span. When added to bridge self-weight, the design live load increases the out-of-plane displacement at midspan increased from roughly 0 in. to $0.31 \mathrm{in}$. Maximum out-of-plane displacement in Span $8 \mathrm{~N}$ is roughly $0.90 \mathrm{in}$. under the $+90^{\circ} \mathrm{F}$ temperature load alone. With the addition of the design live load, this increases to over 1.0 in., an increase of $11 \%$. The maximum out-of-plane displacement increase from $0.50 \mathrm{in}$. to $0.70 \mathrm{in}$., an increase of $40 \%$, when live load is added to the $+60^{\circ} \mathrm{F}$ temperature load. 


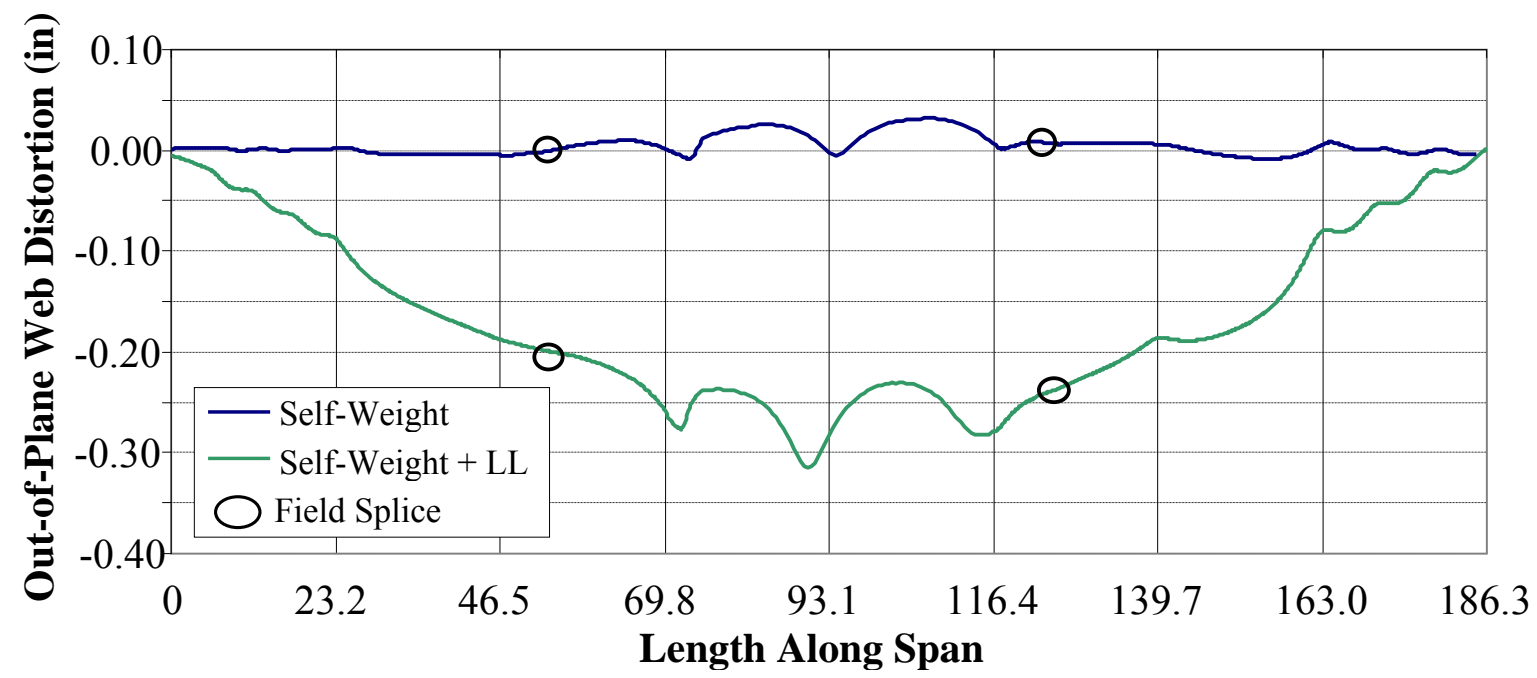

Figure 4.62 Span 8N Out-of-Plane Deflection (Live Load + Self-Weight)

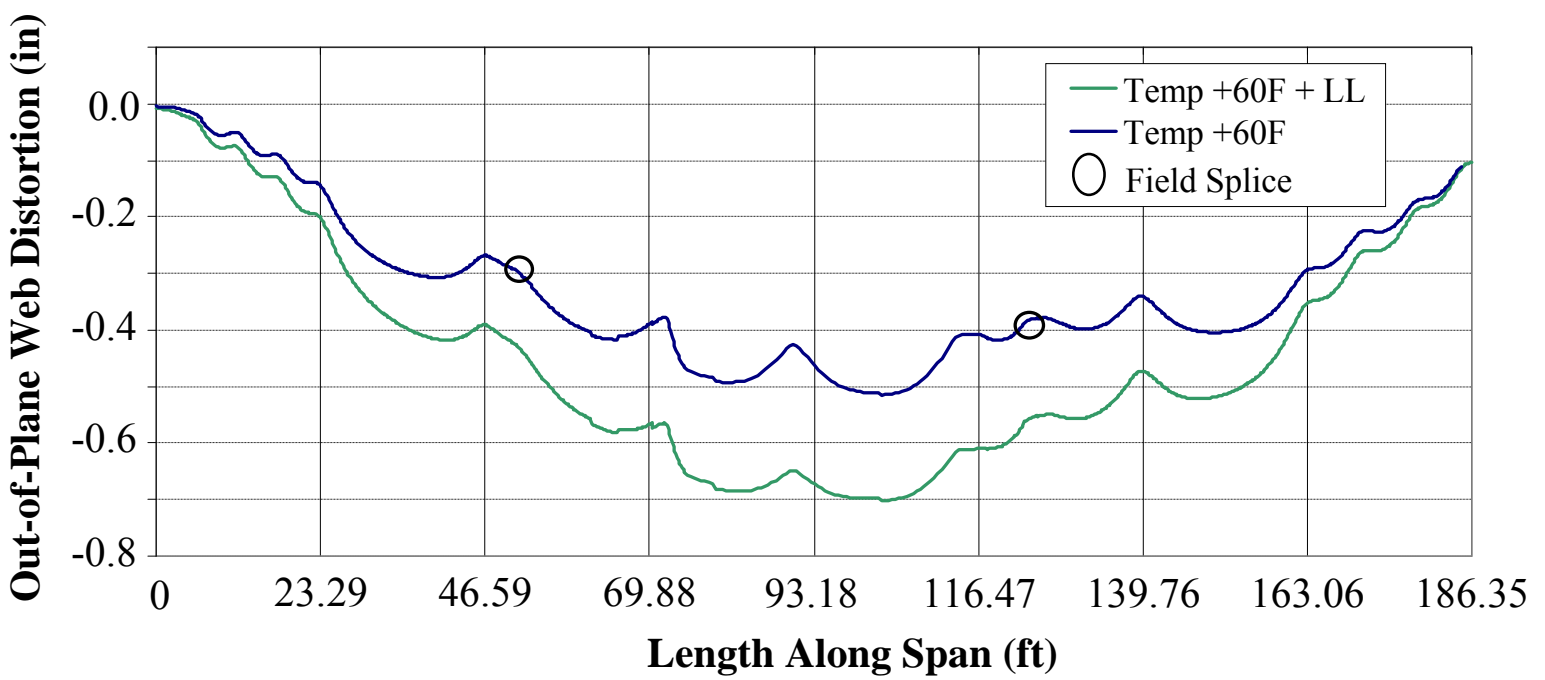

Figure 4.63 Span 8N Out-of-Plane Deflection (Live Load + Temp $+60^{\circ} \mathrm{F}+$ Self-Weight)

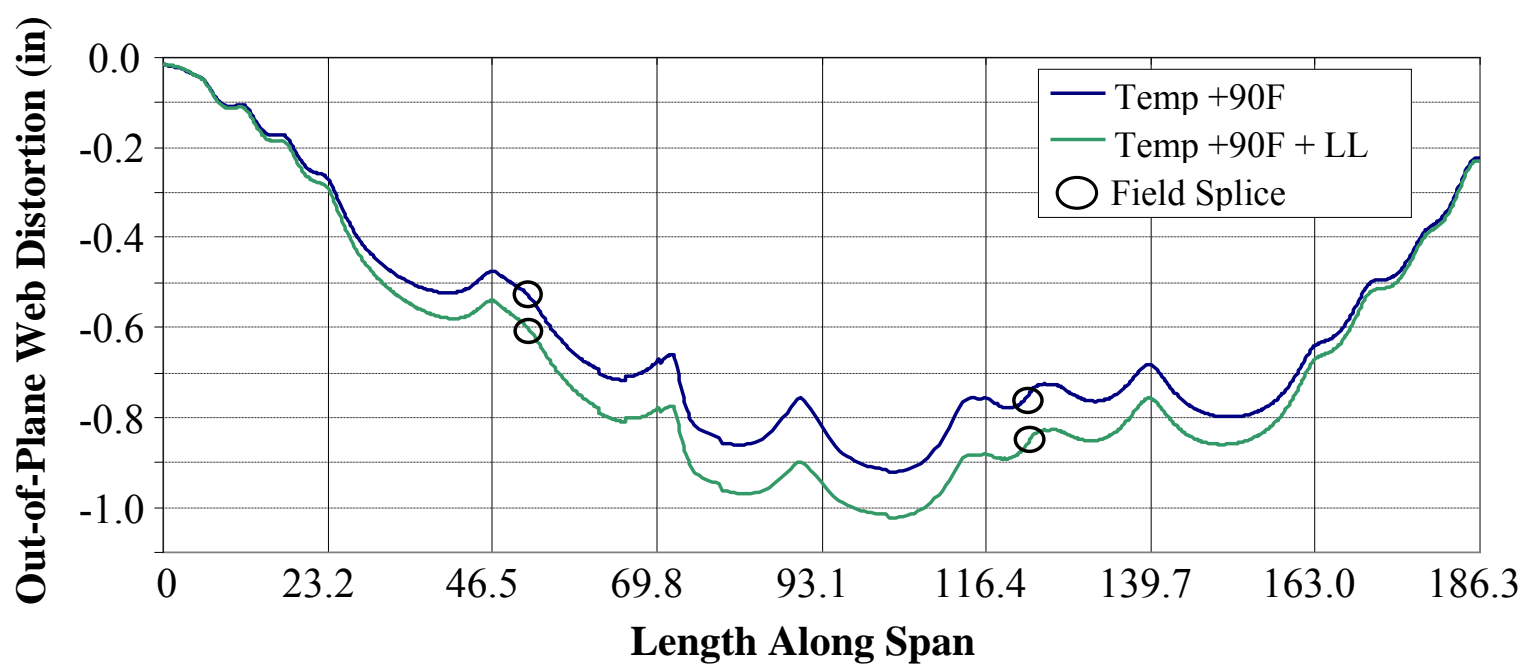

Figure 4.64 Span 8N Out-of-Plane Deflection (Live Load + Temp $+90^{\circ} \mathrm{F}+$ Self-Weight) 


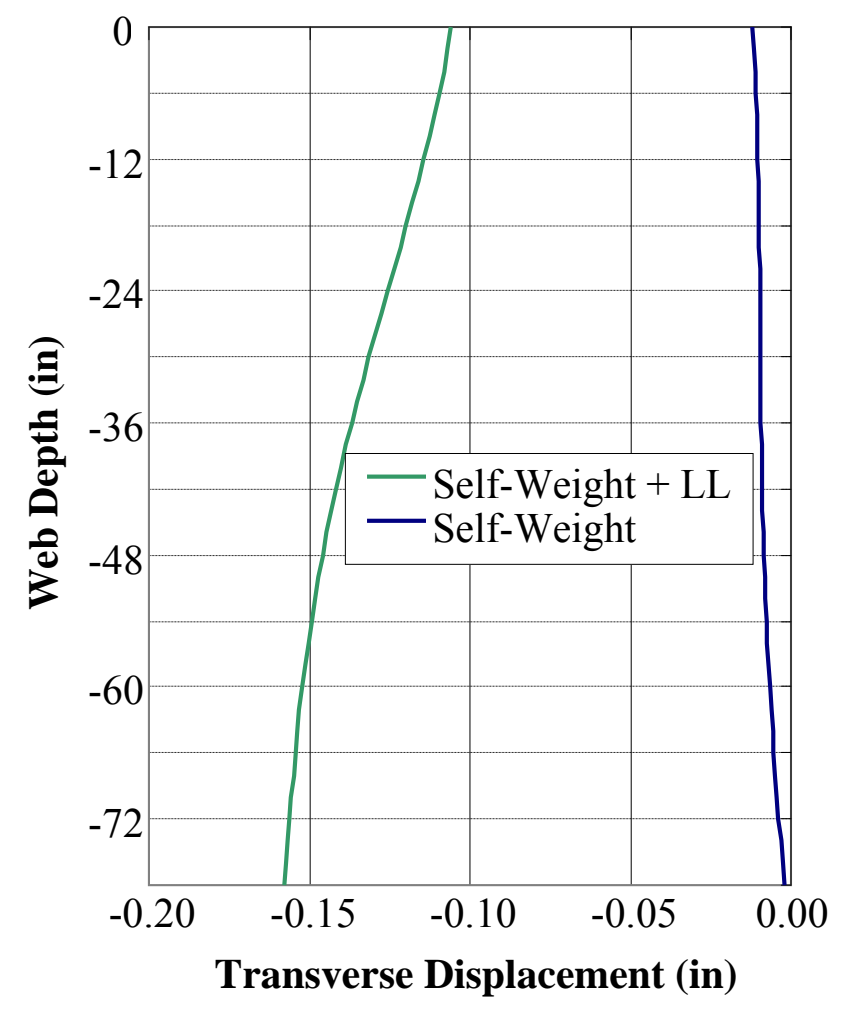

(a) Self-Weight load case

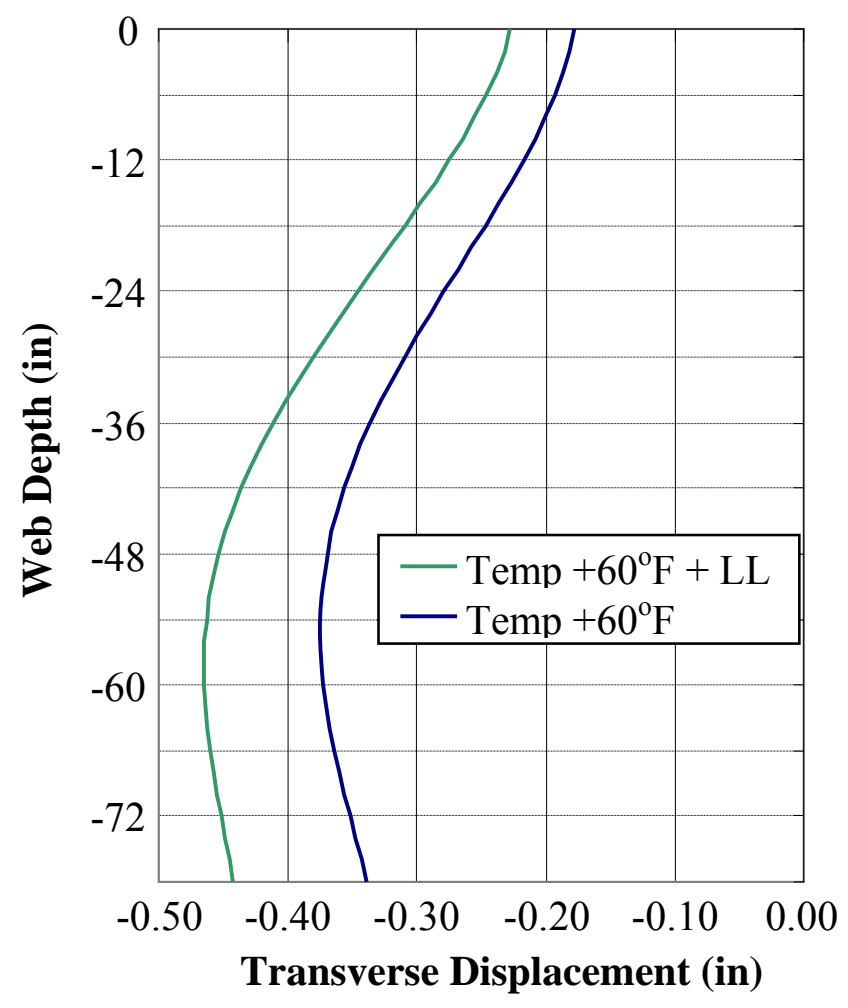

(b) Temp $+60^{\circ} \mathrm{F}$ load case

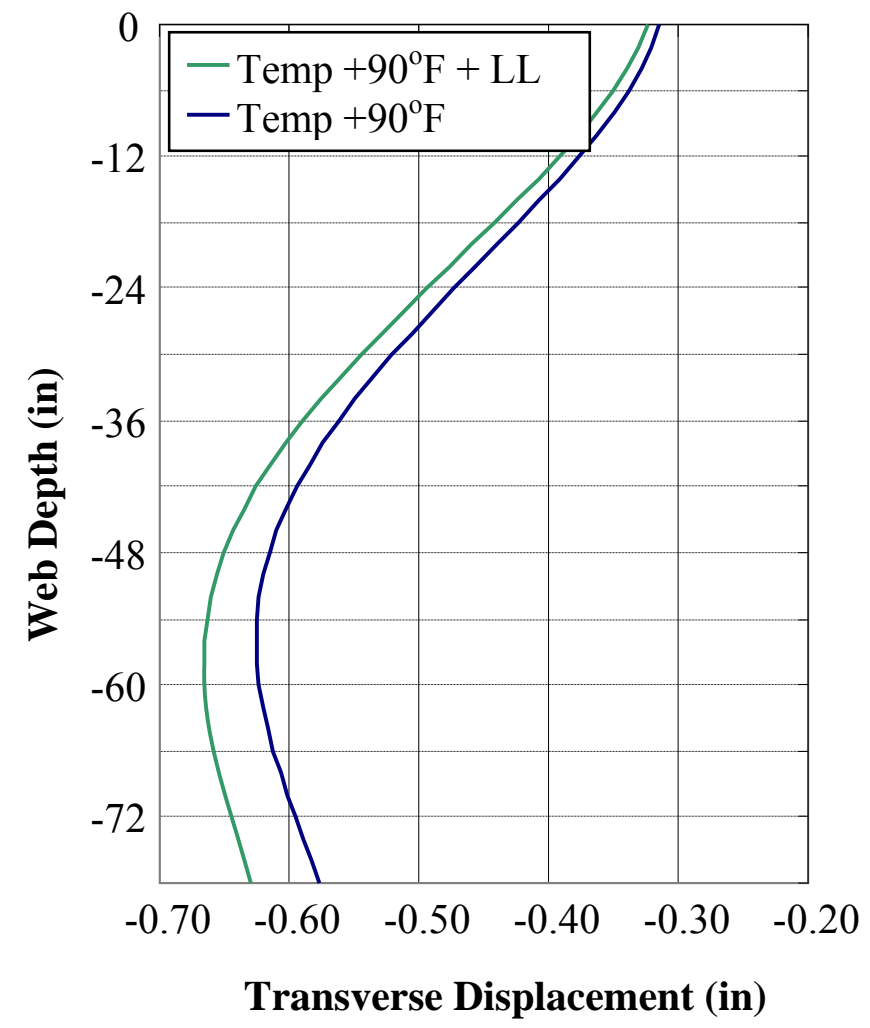

(c) Temp $+90^{\circ} \mathrm{F}$ load case

Figure 4.65 Transverse Deflection Profile for Span $8 \mathrm{~N}$ a) Self-Weight with Live Load b) Temp $+60^{\circ} \mathrm{F}$ with Live Load c) Temp $+90^{\circ} \mathrm{F}+$ Live Load 
Figure 4.65 shows the transverse profiles for the cross-section in Span $8 \mathrm{~N}$ under the temperature loads and with design live loaded added. Out-of-plane distortions increased for each load case. The magnitude of distortion increased the most for self-weight load case (Figure 4.65a). The maximum out-of-plane displacement increased from 0.02 in. to 0.16 in. For the $+60^{\circ} \mathrm{F}$ and $+90^{\circ} \mathrm{F}$ load cases (Figure 4.65b-c), maximum out-of-plane displacement increased $21 \%$ and $7 \%$ respectively. Figures $4.62-4.65$ suggest that the addition of static design live load has a larger effect on the magnitude o out-of-plane distortion as the applied uniform temperature approaches $0^{\circ} \mathrm{F}$.

\subsection{FE BRIDGE MODEL LINEARITY INVESIGATION}

A short investigation into the linearity of the structure was completed in order to establish a relationship between the magnitude of out-of-plane distortion and temperature load. A series of temperature loads ranging from $-60^{\circ} \mathrm{F}$ to $+90^{\circ} \mathrm{F}$ was applied to the $\mathrm{FE}$ model. A web deflection profile at a cross-section near midspan of Span $7 \mathrm{~N}$ was constructed for each separate temperature load case as shown in Figure 4.66. The values from the transverse profiles were plotted to determine the nature of the relationship between load and deflection, shown in Figure 4.67. Two critical pieces of information were discovered during this study. First, it was found that the FE model produces a linear load-deflection curve for temperatures ranging from $-60^{\circ} \mathrm{F}$ to $+60^{\circ} \mathrm{F}$. At a temperature load magnitude of $60^{\circ} \mathrm{F}$, the slope of the curve decreases, but remains linear up to $+90^{\circ} \mathrm{F}$. 


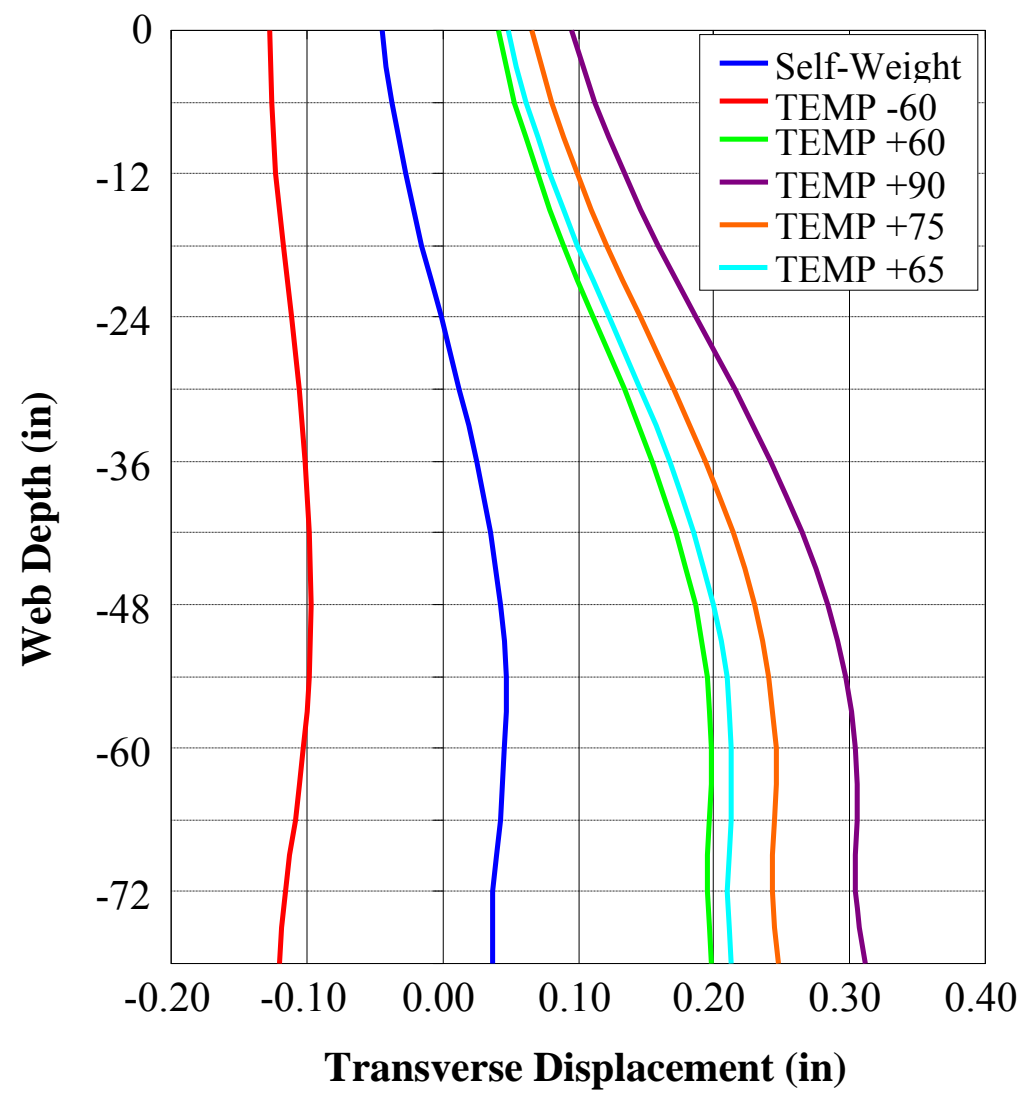

Figure 4.66 Transverse Web Profile Comparisons

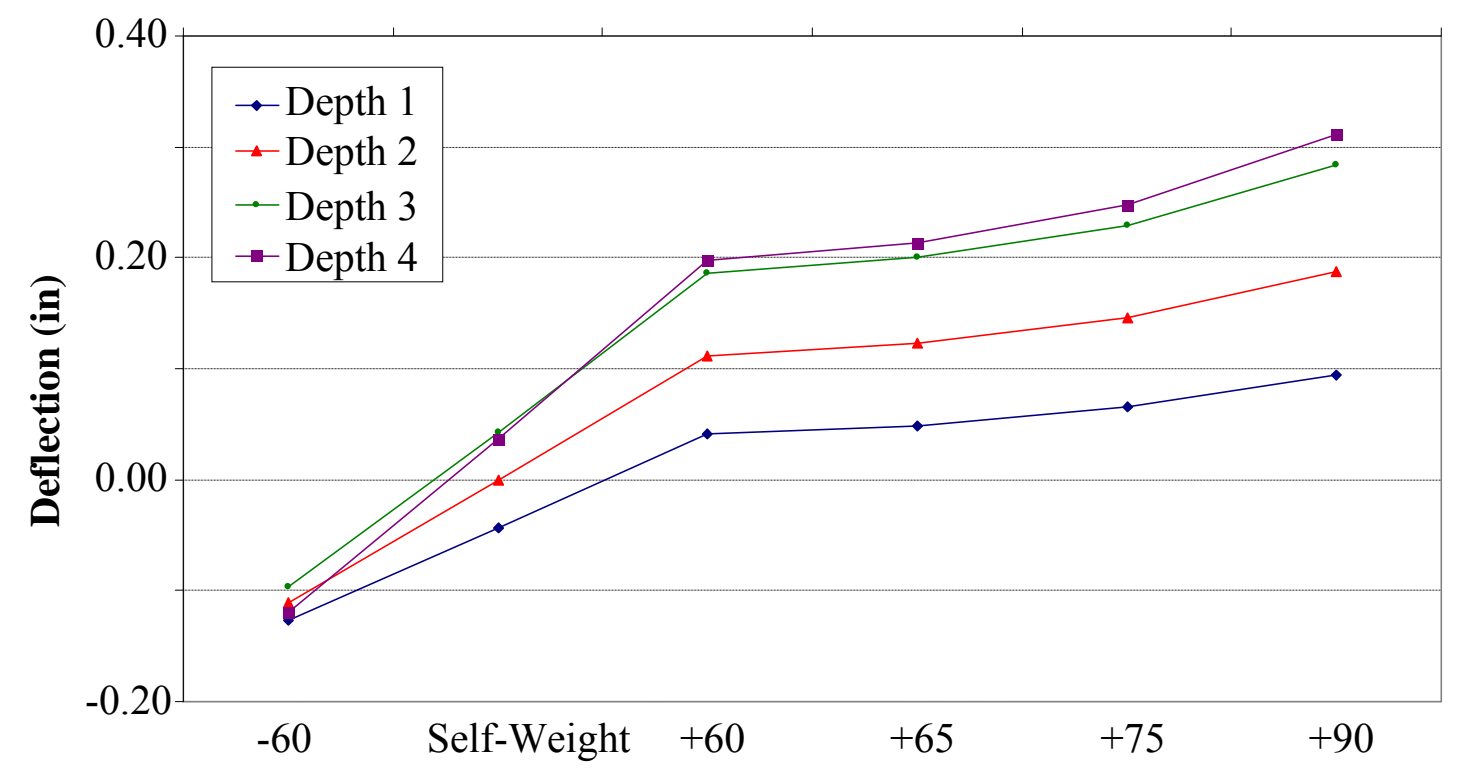

Figure 4.67 Out-of-Plane Displacement at Various Web Depths 


\subsection{TOPCON IMAGING STATION RESULTS}

This section discusses the results from the TOPCON Imaging Station laser scan performed during a field inspection of the bridge. The laser scanning instrument was employed to quantify the out-of-plane web distortion of Spans $1 \mathrm{~N}, 2 \mathrm{~N}$ and $3 \mathrm{~N}$ of Girder $4 \mathrm{~N}$. The measurements produced by the scan are also used as a validation tool for the results generated by the FE bridge model. The measurements recorded by the TOPCON Imaging Station were manipulated into the graphs presented in Figures 4.68-4.70 using MATLAB software. The measured web distortions observed on the actual structure, represented by the individual points, are shown very well. Also included on the charts is a profile of lateral web deflection of the center of the web produced by the FE model when subjected to the $+90^{\circ} \mathrm{F}$ temperature load, and a profile representing the geometry of the girder centerline as designed, in the absence of any web distortion.

When compared to one another, the FE model profiles and laser measurements produce comparable results for lateral displacement. However, the FE model profiles in these figures do not show the extent of local web buckling. This behavior is measured by the Imaging Station measurements. In Figures 4.68-4.70, the thickness of the bandwidth represents the differential displacement between the top and bottom of the girder web. According to Figures 5.68-4.70, the FE model results under-estimate the actual magnitude the experimentally measured web distortions. Therefore, based on lateral displacement comparisons, the FE model created for this research study likely produces conservative predictions for the actual response of the bridge. 


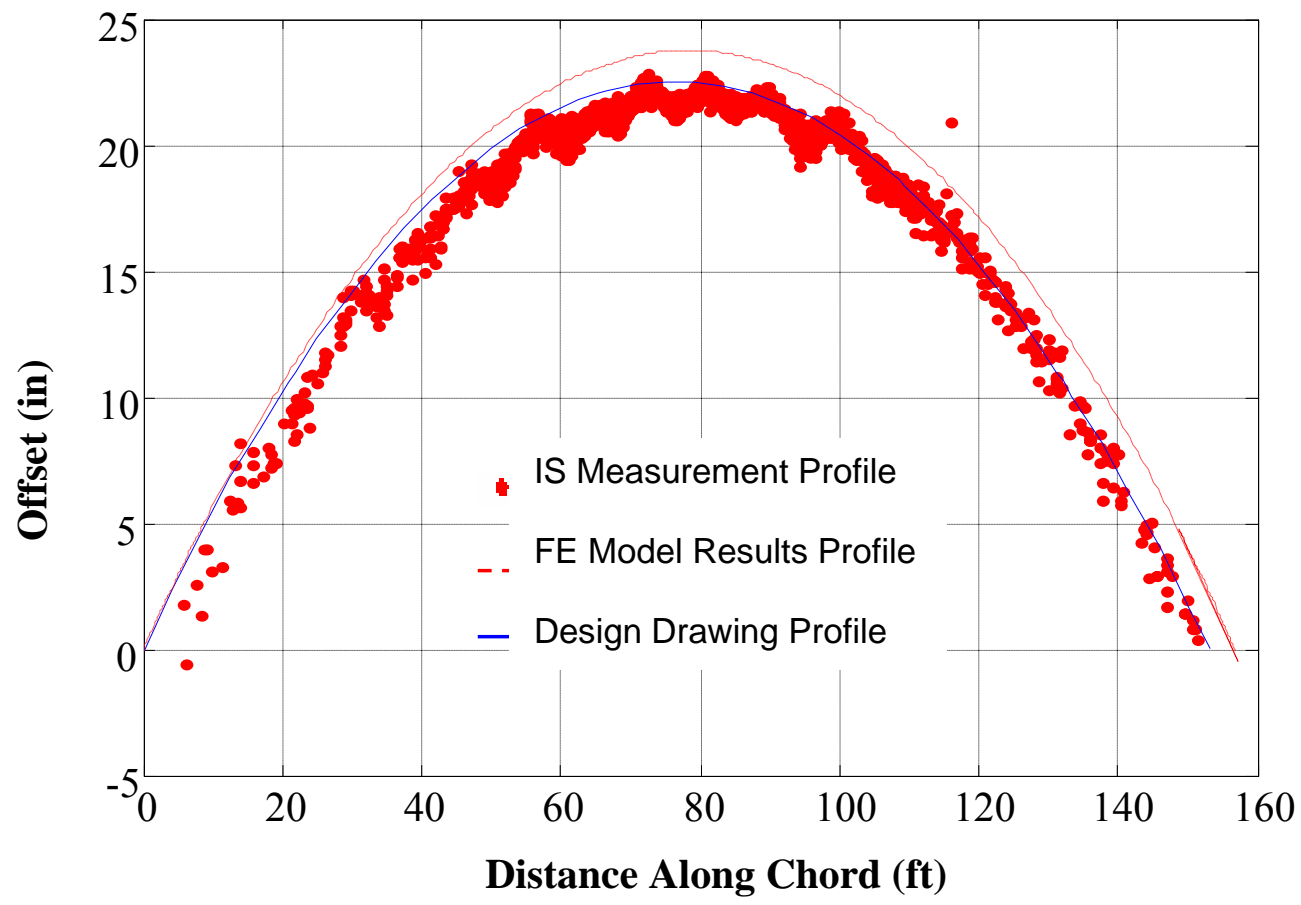

Figure 4.68 Span 1N TOPCON Imaging Station Measurements Comparison

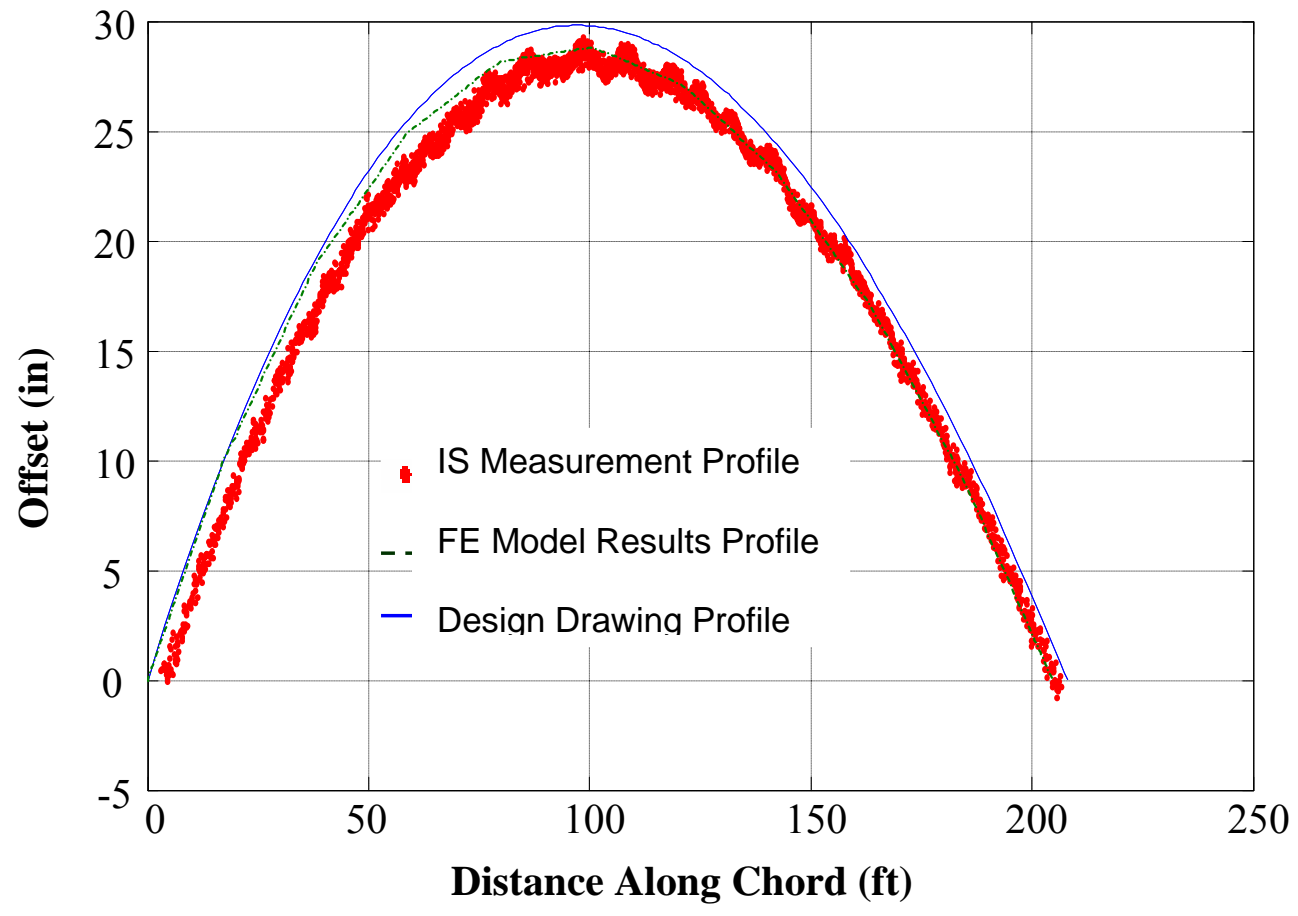

Figure 4.69 Span 2N TOPCON Imaging Station Measurements Comparison 


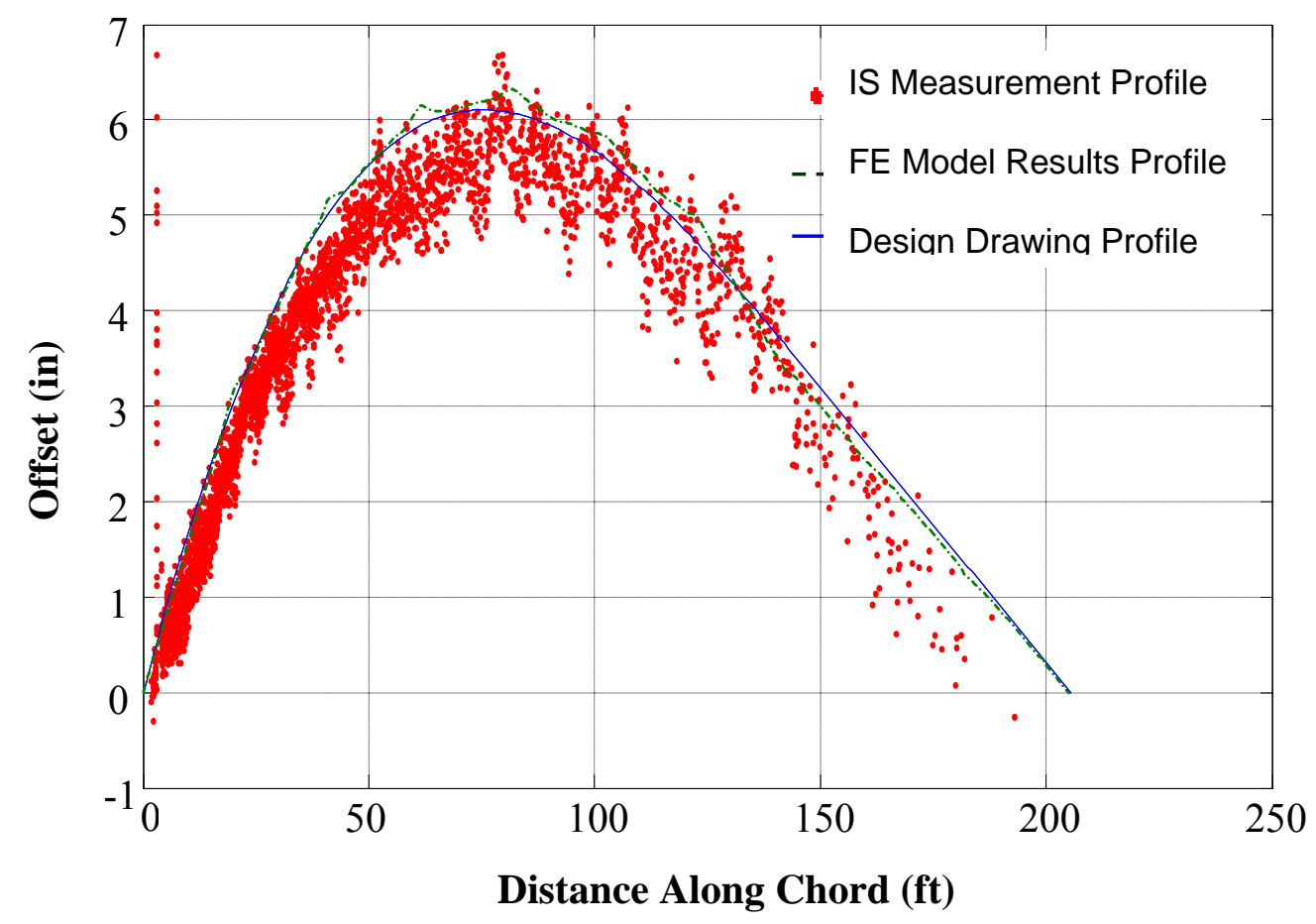

Figure 4.70 Span 3N TOPCON Imaging Station Measurements Comparison 


\subsection{WEB SLENDERNESS INVESTIGATION}

After thoroughly reviewing the provided design drawings of the bridge and analyzing the web distortion results, web slenderness values and transverse stiffener spacing of the girders was checked against AAHSTO (2003) specifications. In the predominantly negative moment regions of the bridge, over the pier supports, transverse stiffeners are provided in accordance with AASHTO (2003) requirements. However, in the mainly positive moment regions (between field splice connections) transverse stiffeners are mostly absent, except for two specific locations in Spans $7 \mathrm{~N}$ and 12N. Thus, web slenderness values and transverse stiffener spacing was investigated as part of this study based upon the level of web buckling shown in the FE model.

First, web slenderness, $\mathrm{D} / \mathrm{t}_{\mathrm{w}}$, was calculated for the midspan region for Spans $7 \mathrm{~N}-12 \mathrm{~N}$ and compared to the appropriate requirement per AASHTO (2003) Article 6.2.

$$
\frac{D}{t_{w}} \leq 100+0.038(R-700) \leq 150
$$

The web slenderness, $\mathrm{D} / \mathrm{t}_{\mathrm{w}}$, and the values produced by Equation 4.1 are shown in Table 4.3. A variable depth (78"-99") web plate is used in Spans $8 \mathrm{~N}$ and $10 \mathrm{~N}$, therefore the web depth where the web slenderness ratio is first exceeded is used for calculation in Equation 4.1.

Table 4.3 Web Slenderness Values

GIRDER 1N (R=1645.375 ft.)

\begin{tabular}{lccccc}
\hline & D (in) & tw (in) & D/tw & $\mathbf{1 0 0 + 0 . 0 3 8 ( R - 7 0 0 )}$ & Maximum D/tw \\
Span 7N & 78 & 0.5625 & 138.67 & 135.92 & 150 \\
Span 8N & 93.5 & 0.6875 & 136.00 & 135.92 & 150 \\
Span 9N & 99 & 0.6875 & 144.00 & 135.92 & 150 \\
Span 10N & 93.5 & 0.6875 & 136.00 & 135.92 & 150 \\
Span 11N & 78 & 0.5625 & 138.67 & 135.92 & 150 \\
Span 12N & 78 & 0.5625 & 138.67 & 135.92 & 150
\end{tabular}


AASHTO (2003) Article 6.3 cites a study by Yoo (1996) finding that there is evidence suggesting transverse stiffeners assist in maintaining the cross-section shape of a curved steel I-girder. Therefore, where stiffeners are no longer required for shear effects, AASHTO (2003) recommends they be provided to help retain cross-section shape if web slenderness exceeds maximum slenderness values. As seen in Table 4.3, in all six spans analyzed, maximum web slenderness is exceeded and transverse stiffeners should be provided in the design and spaced at a distance $\left(\mathrm{d}_{0}\right)$ as given in AASHTO (2003) Article 6.3.

$$
d_{0}=[1.0+0.00154(R-700)] D \leq 3 D
$$

Table 4.4 Transverse Stiffener Spacing

GIRDER 1N (R=1645.375 ft.)

\begin{tabular}{lcccccc}
\hline & D (in) & tw (in) & D/tw & d0(in) & 3D (in) & $\begin{array}{c}\text { Connection } \\
\text { plate spacing (in) }\end{array}$ \\
Span 7N & 78 & 0.5625 & 138.67 & 191.558 & 234 & 270.125 \\
Span 8N & 93.5 & 0.6875 & 136.00 & 229.625 & 280.5 & 284.203 \\
Span 9N & 99 & 0.6875 & 144.00 & 243.132 & 297 & 287.1875 \\
Span 10N & 93.5 & 0.6875 & 136.00 & 229.625 & 280.5 & 284.203 \\
Span 11N & 78 & 0.5625 & 138.67 & 191.558 & 234 & 299.167 \\
Span 12N & 78 & 0.5625 & 138.67 & 191.558 & 234 & 299.167
\end{tabular}

Required transverse stiffener spacing $\left(\mathrm{d}_{0}\right)$ is given in 4.4 , along with the maximum allowable stiffener spacing (3D). Also shown is the spacing of crossframe connection plates, considered here as transverse stiffeners. As seen in Table 4.4, the actual spacing of transverse stiffeners in positive moment regions is significantly greater than AASHTO (2003) requirements. The maximum stiffener spacing allowable, 3D, is not met in five of the six spans studied (maximum allowable spacing for Span $9 \mathrm{~N}$ is greater than the spacing of the connection plates). White and Jung (2007) found that if the maximum stiffener spacing is satisfactory throughout an unbraced length of girder, web distortion effects will be reduced. 
They also note that in several members in their study suffered significant decreases in lateral buckling strengths due to web distortion, even when transverse stiffeners are no longer required for shear support. A study by Yoo (1996) showed that the addition of transverse stiffeners may increase the bending capacity of curved steel I-girder webs.

According to this investigation, web slenderness and transverse stiffener spacing of the bridge are in violation of the requirements given in AASHTO (2003) Articles 6.2 and 6.3. The magnitude of web buckling and transverse web displacement seen in the positive moment regions of the FE model may be a result of these violations. The same analysis was completed for the regions over the pier supports. At these locations, web slenderness values and transverse stiffener spacing are well within AASHTO (2003) requirements. Even so, Davidson and Yoo (2002) found that web plate design should be based upon web elastic buckling, transverse (bulging) displacement and maximum stress. While web elastic buckling and transverse displacement are significant design issues, as seen in this section, it was concluded that maximum web stress would ultimately govern web slenderness values. Stresses produced in the girders are studied in detail in Chapter Five.

\subsection{DISCUSSION AND CONLUSIONS}

It is apparent from the web distortion profiles constructed in this chapter that when subjected to uniform temperature loads, the FE bridge model produces very significant outof-plane web distortions in the steel I-girders. Three buckling modes are observed on the bridge: local web buckling, lateral-torsional buckling, and distortional buckling. Even under bridge self-weight alone, web buckling and out-of-plane distortion is produced over the entire structure. Under increasing temperature loads, this behavior is amplified significantly, and according to literature, will affect the structural capacity of the bridge. The extent of 
web distortion found in the chapter, will certainly give rise to serviceability issues. This is especially true for the case of distortional buckling, as AASHTO has set forth no guidelines concerning this buckling mode, and its affects are not greatly understood.

The out-of-plane web distortions and web buckling observed on the bridge may be due to a combination of factors including web slenderness issues, insufficient transverse stiffener spacing, web bend-buckling, initial geometric imperfections in the web, or a simple under design of bridge components. Also, some distortion of the girders may occur during girder fabrication, erection and transportation. However, the true extent of distortions due to any of these procedures cannot be fully known. 


\section{CHAPTER FIVE}

\section{THERMAL STRESSES UNDER AS-BUILT BEARING ARRANGEMENT}

\subsection{INTRODUCTION}

Expansion bearing devices are typically implemented in order to allow the structure to expand and contract under temperature fluctuations; however, a poorly designed bearing arrangement may not fully accommodate this expansion, leading to the development of thermal stresses. McBride (2005) showed that this constraint to thermal expansion will lead to the development of axial compressive stresses. The unexpected axial stresses could complicate bridge behavior, introducing stability and reducing the structural capacity of a bridge. This chapter will investigate the affect of thermal loading on the stresses developed in the steel bridge girders under the current bearing arrangement. According to Davidson and Yoo (2002), maximum stresses are the most important aspect of girder web design; therefore the effect of thermal loading on the web plates is a very important issue.

Effective stresses are analyzed to establish the overall state of stress in the FE model. Longitudinal stress profiles are used to calculate the critical web stress at several crosssections throughout the FE model. The effect of axial stress on the strength and behavior of the girders is investigated. Lastly, AASHTO live load is added to the bridge in conjunction with the dead load and temperature load to investigate the effects of temperature change when a static live load is present.

\subsection{EFFECTIVE STRESSES}

This section investigates effect stress levels produced in the FE bridge model with the current bearing arrangement applied. Data obtained from the model is used to construct 
stress profiles through the entire depth of the web at certain cross-sections. Ten locations were selected from throughout Spans $7 \mathrm{~N}-11 \mathrm{~N}$ for stress analysis during this study. Included are four cross-sections in the positive moment regions, near the midspans of Spans $7 \mathrm{~N}, 8 \mathrm{~N}$, $10 \mathrm{~N}$ and $11 \mathrm{~N}$ in Girder $4 \mathrm{~N}$. A cross-section nearer to midspan, but in the negative moment region is analyzed in Span 9N. Cross-sections over the centerline of each pier, Piers $7 \mathrm{~N}$ $11 \mathrm{~N}$, on Girder $1 \mathrm{~N}$ are also analyzed. Stress profiles are created at each cross-section, for each load case. Figures 5.1-5.5 present effective stress profiles for cross-sections near the midspan of Spans $7 \mathrm{~N}-11 \mathrm{~N}$.

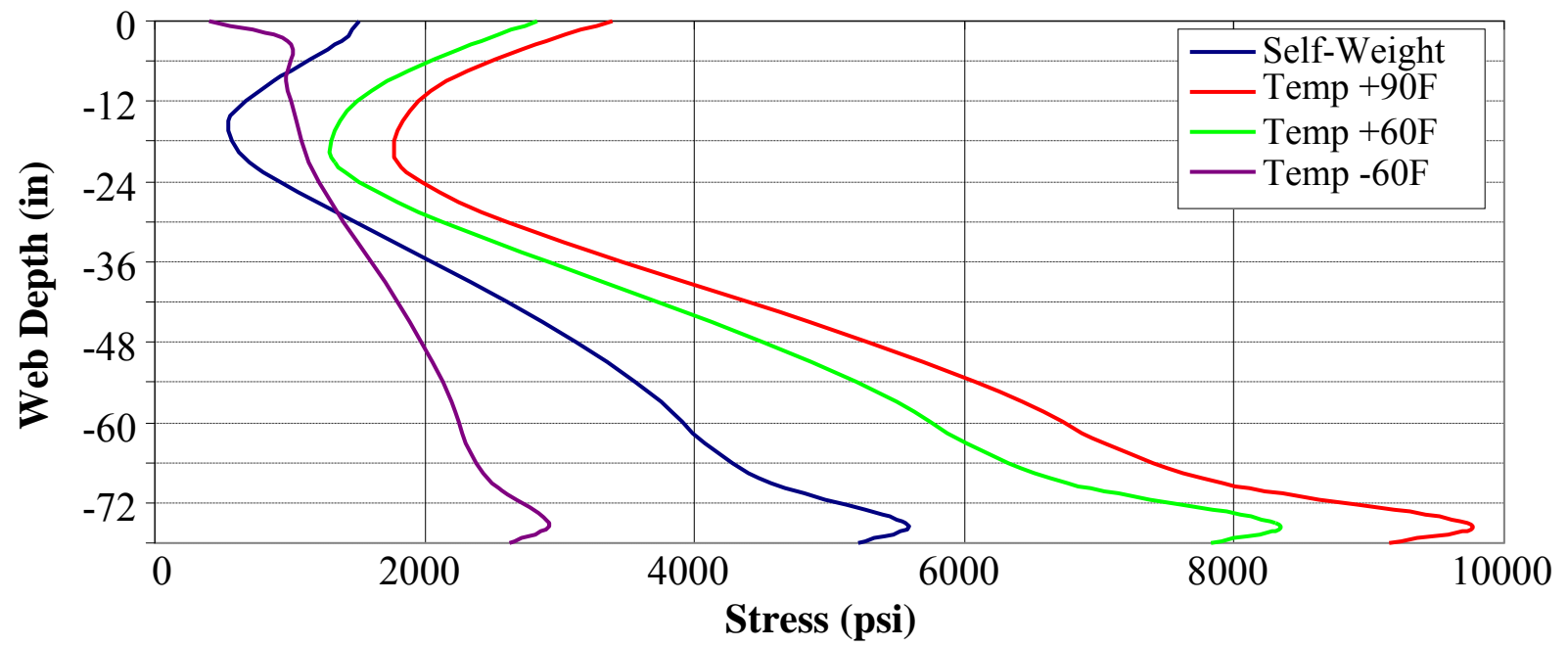

Figure 5.1 As-Built, Effective Stress Profiles for Span 7N

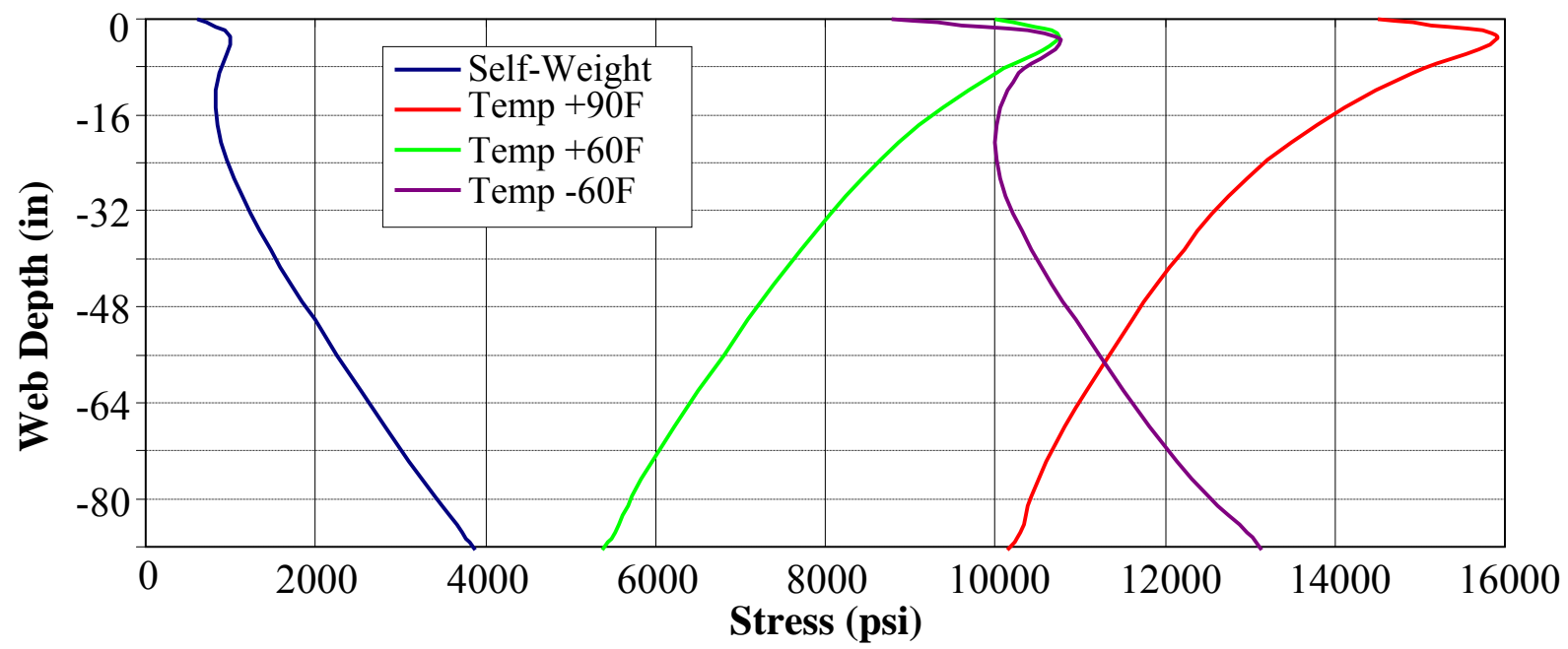

Figure 5.2 As-Built, Effective Stress Profiles for Span 8N 


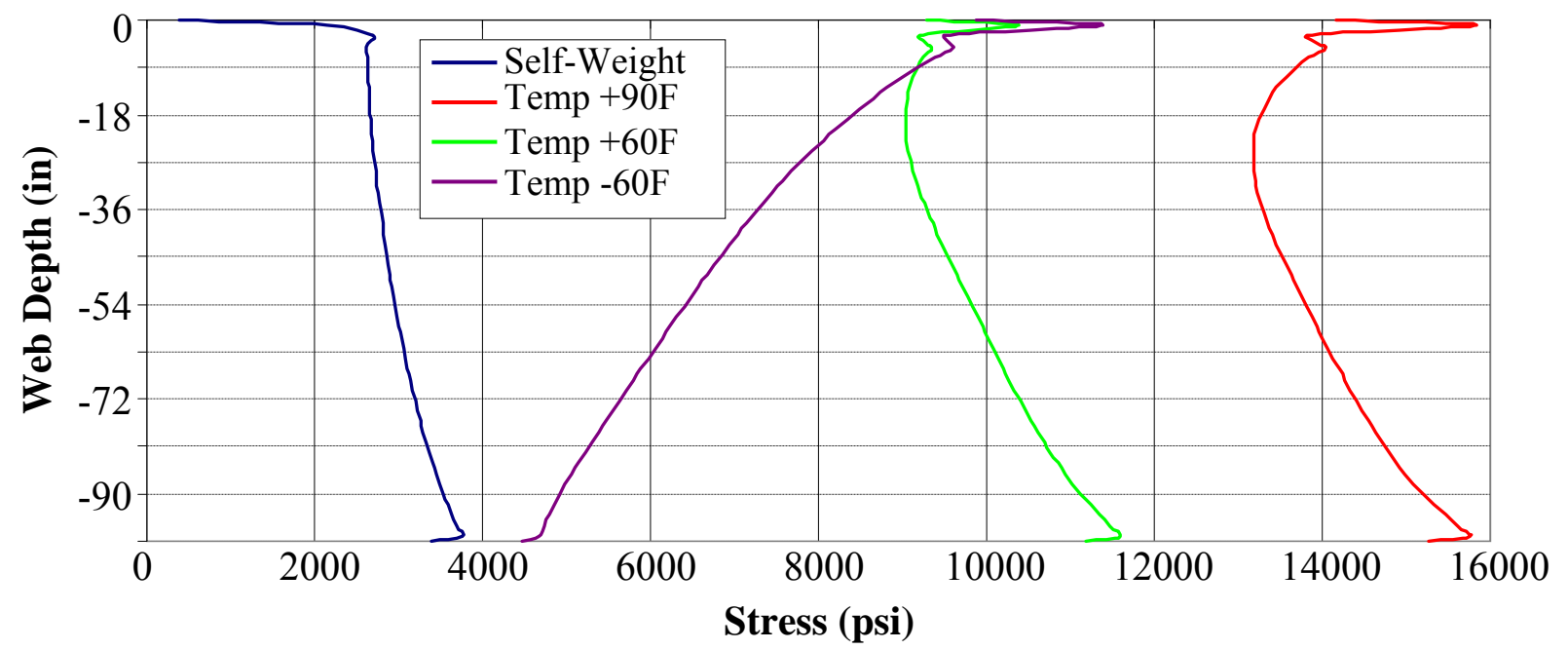

Figure 5.3 As-Built, Effective Stress Profiles for Span 9N

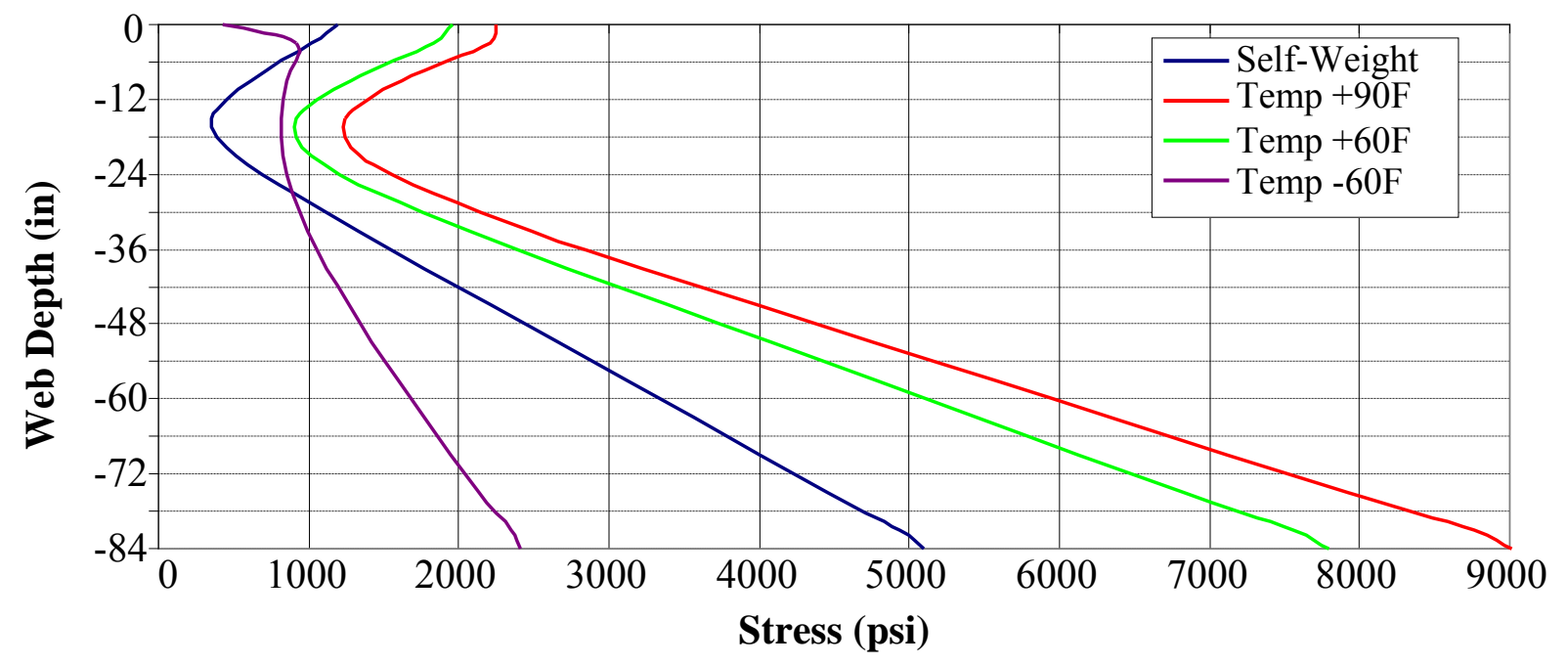

Figure 5.4 As-Built, Effective Stress Profiles for Span 10N

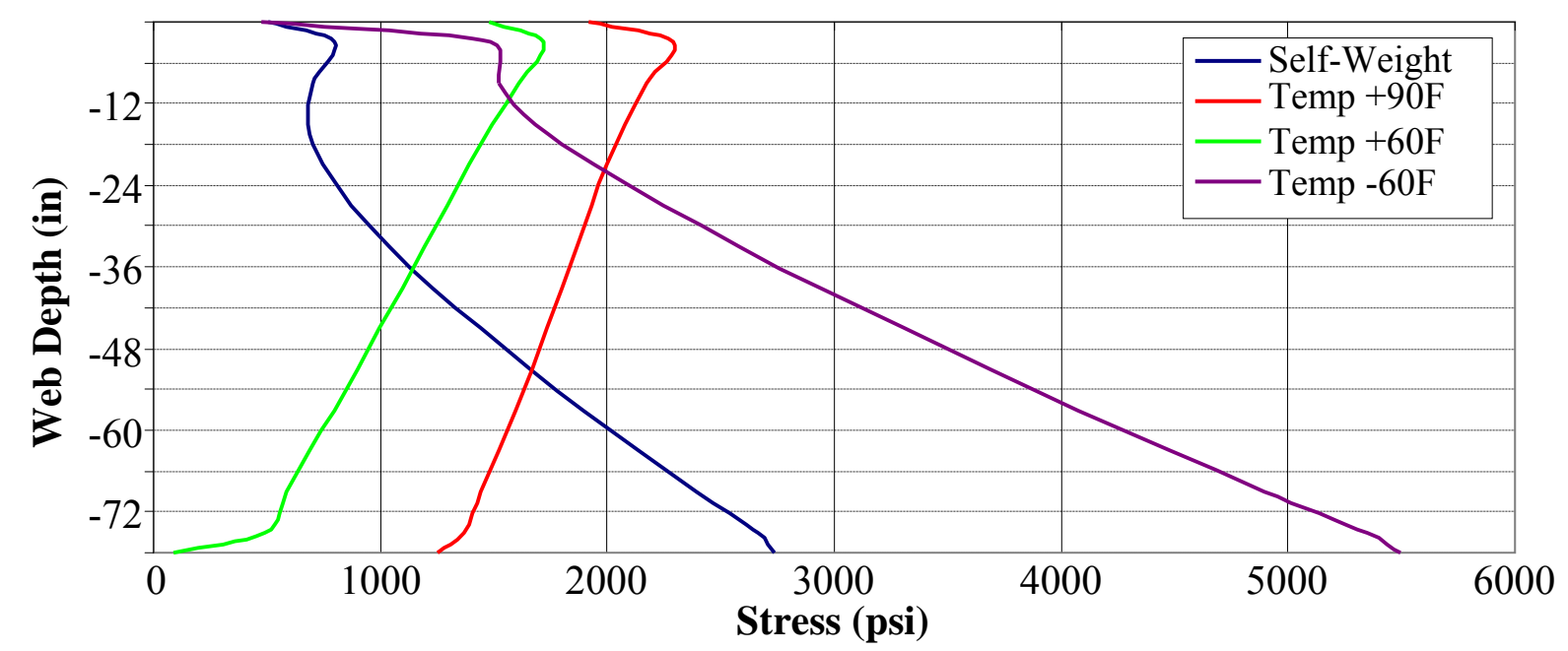

Figure 5.5 As-Built, Effective Stress Profiles for Span 11N 
The effective stress profiles presented in Figures 5.1-5.5 indicate that the effective stress in the steel girders due to the $+90^{\circ} \mathrm{F}$ thermal loading approach a maximum of value 16 ksi for locations in the positive moment region of Span $8 \mathrm{~N}$ and negative moment region of Span 9N. According to these stress profiles, the application of a uniform temperature load significantly increases stress levels in the bridge. For the locations examined, an average stress increase of approximately $6 \mathrm{ksi}$ is attributed to the maximum temperature load $\left(+90^{\circ} \mathrm{F}\right)$.

Figures 5.6-5.10 present the effective stress profiles for several of the piers locations of Spans $7 \mathrm{~N}-11 \mathrm{~N}$ on Girder 1N. Stresses at the piers are very important, because the stresses are transmitted to substructure elements (i.e. bearings, pier caps, anchor bolts).

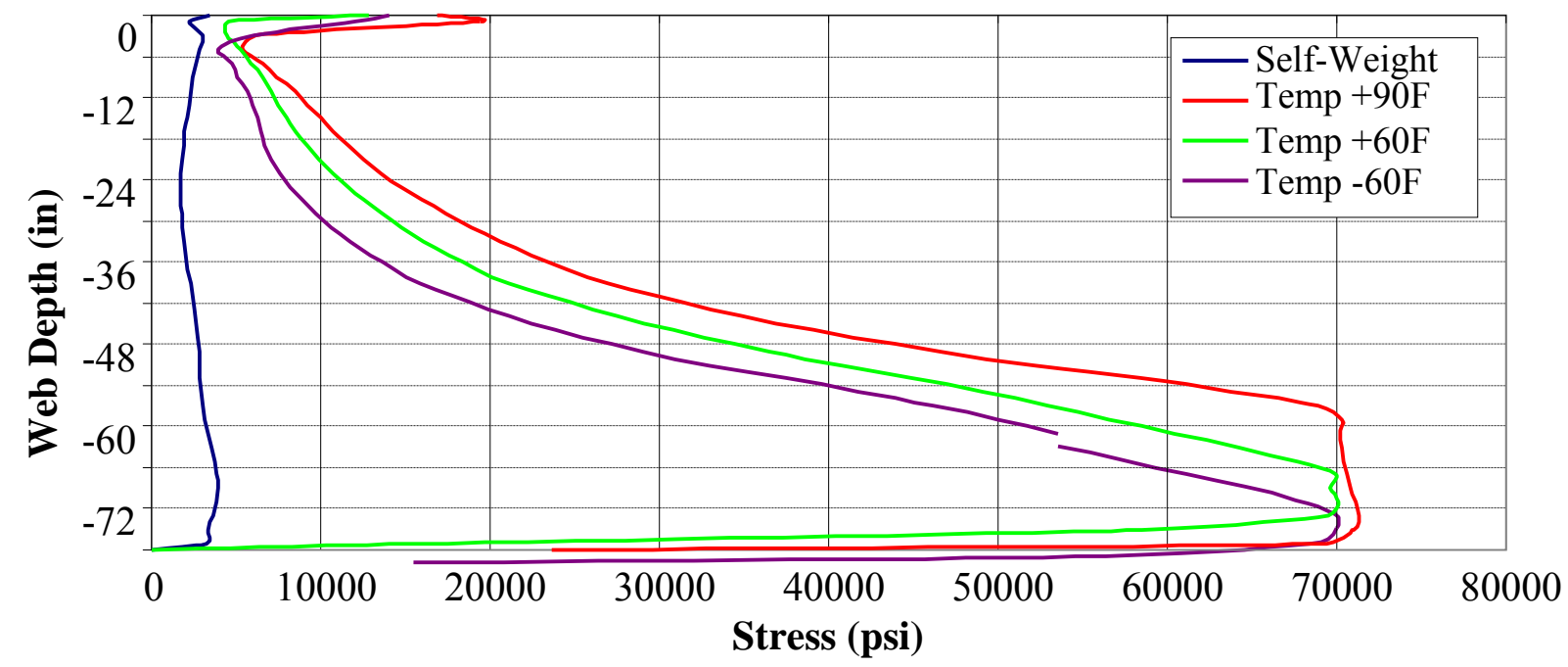

Figure 5.6 As-Built, Effective Stress Profiles for Pier 7N 


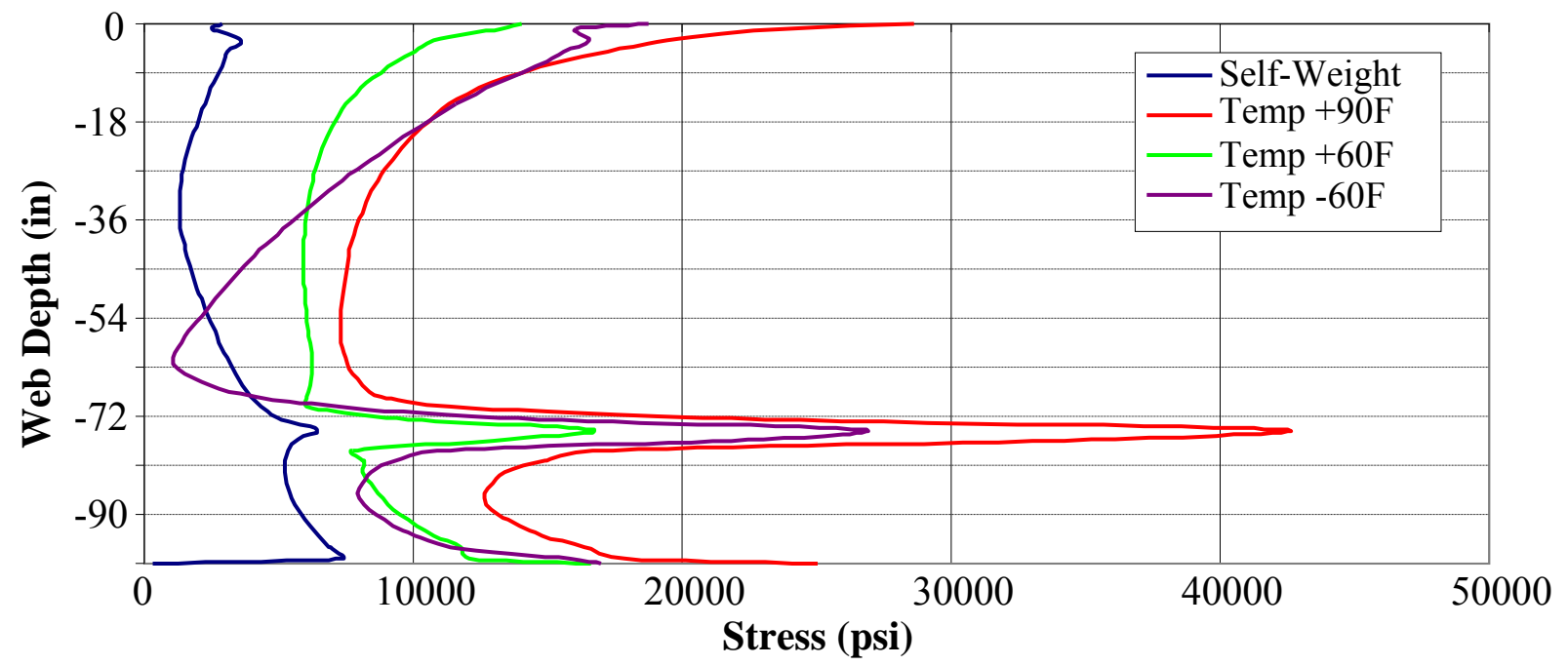

Figure 5.7 As-Built, Effective Stress Profiles for Pier 8N

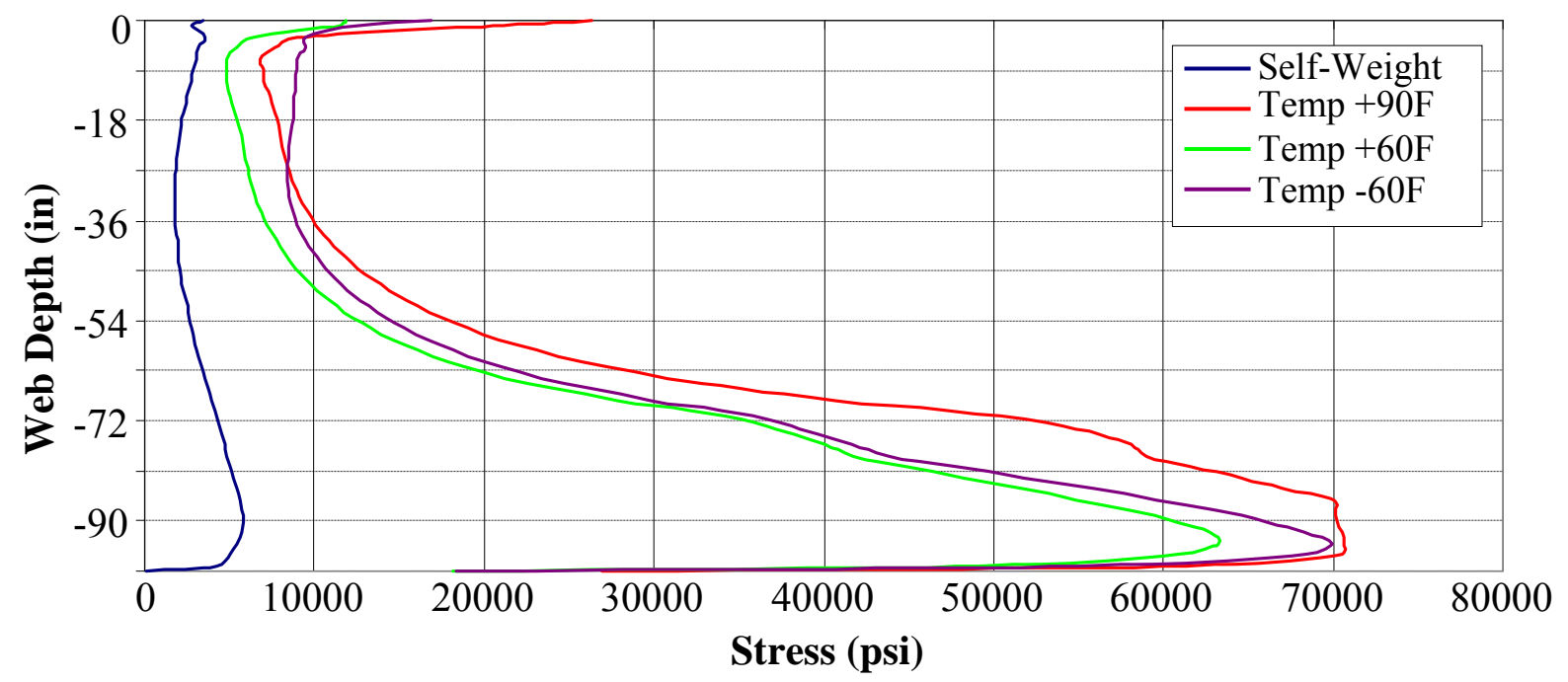

Figure 5.8 As-Built, Effective Stress Profiles for Pier 9N

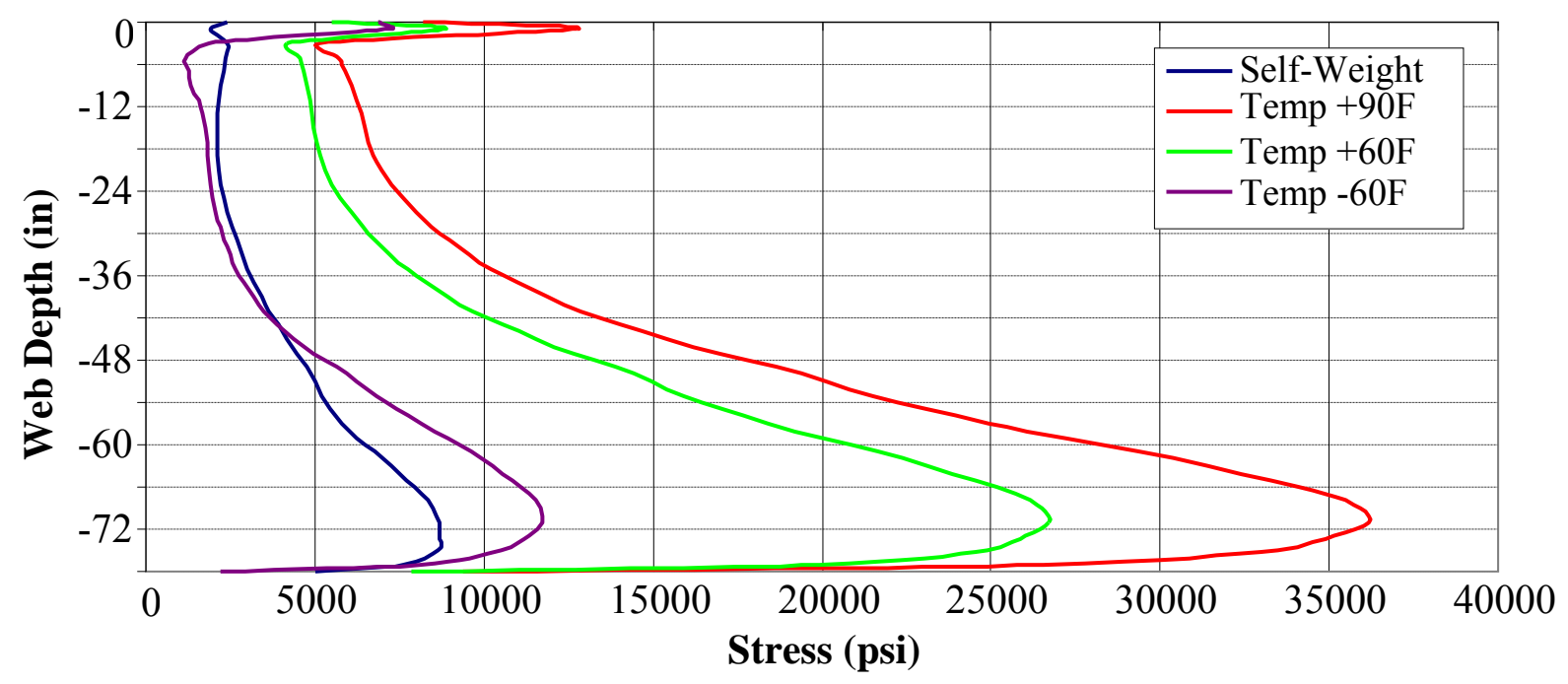

Figure 5.9 As-Built, Effective Stress Profiles for Pier 10N 


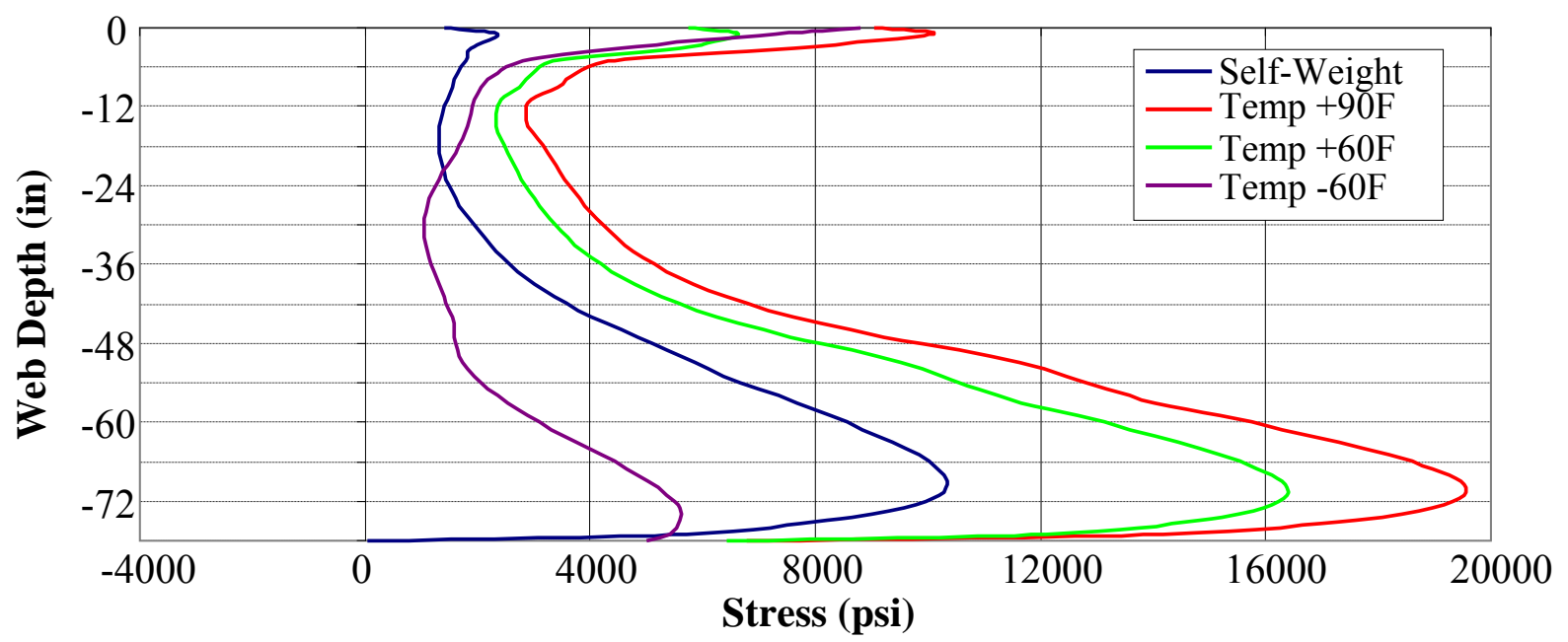

Figure 5.10 As-Built, Effective Stress Profiles for Pier 11N

Figures 5.6-5.10 reveal that, under thermal loading, stress at the piers is significantly larger than near midspan. The effective stress at Pier $7 \mathrm{~N}$ and $9 \mathrm{~N}$ is up to $450 \%$ larger than the maximum effective stress produced near the midspan of Spans $8 \mathrm{~N}$ and $9 \mathrm{~N}$. The plots shown in Figure 5.6 and 5.8 show that effective stress levels due to thermal loading at Piers $7 \mathrm{~N}$ and $9 \mathrm{~N}$ exceed the yield strength (70ksi) of the HPS 70W steel I-girders. Stress levels in these areas reach roughly $72 \mathrm{ksi}$. This indicates that areas in the vicinity of these fixed bearings have yielded, and begun exhibiting plastic behavior even under the lower temperature loads of $+/-60^{\circ} \mathrm{F}$. Stresses at Piers $10 \mathrm{~N}$ and $11 \mathrm{~N}$, Figures 5.9 and 5.10, are less than $40 \mathrm{ksi}$. It is apparent that the magnitude of stress is highest at piers where fixed bearings are implemented, suggesting that the restraint provided by this bearing type is responsible for large levels of thermal stress.

Effective stress contour plots produced by the FE model for Piers $7 \mathrm{~N}$ and $9 \mathrm{~N}$ of Girder 1N are presented in Figures 5.11 and 5.12 respectively. Figures 5.13 and 5.14 show FE model effective stress plots for Piers $2 \mathrm{~N}$ and $4 \mathrm{~N}$. Areas of the web plate directly above the fixed bearings have surpassed the yield strength of the steel $(70 \mathrm{ksi})$. At Piers $2 \mathrm{~N}$ and $4 \mathrm{~N}$, effective stress levels approach $60 \mathrm{ksi}$, well below the girder's $70 \mathrm{ksi}$ yield strength. After 
analyzing the FE contour plots and the stress profiles, it is evident that the 24 " high auxiliary stiffeners installed at each pier are playing a critical role in the stress distribution at the supports. These stiffeners, welded on each side of the bearing stiffener, are creating large stress concentrations at all bearing support locations, with larger stress concentrations occurring at fixed bearings.

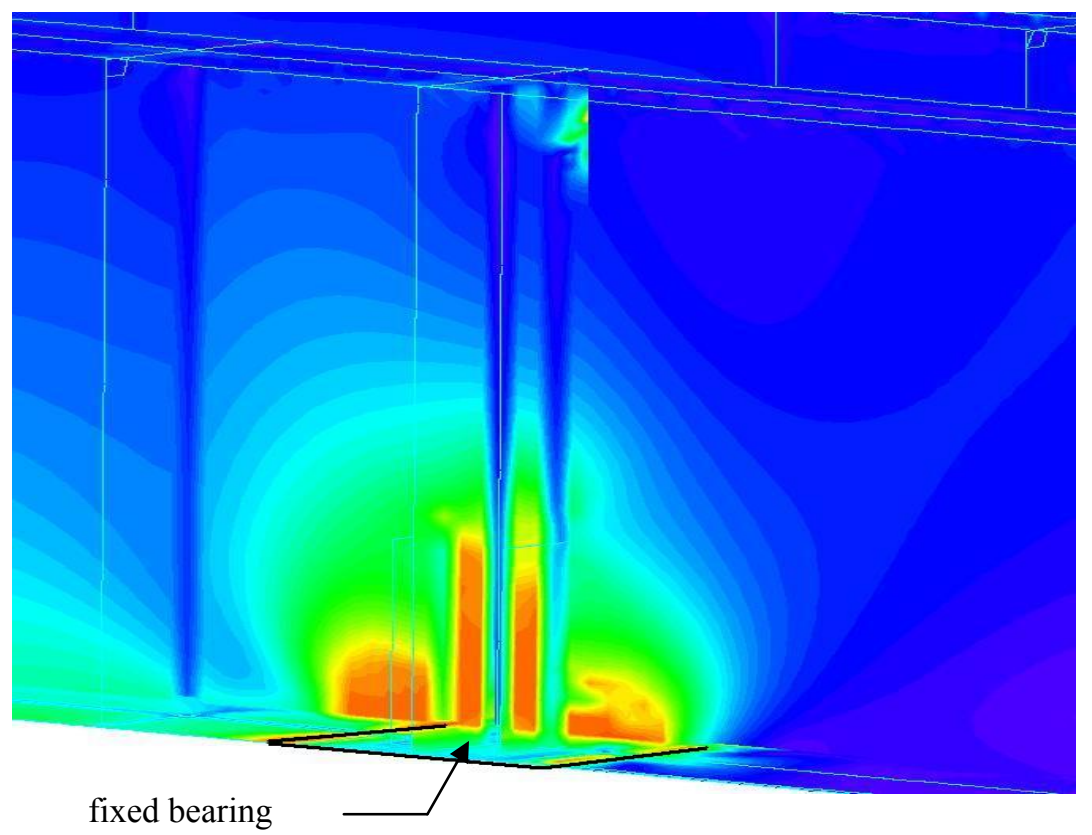

fixed bearing

5400 .

Figure 5.11 Pier 7N FE Model Effective Stress Contour Plot $\left(+90^{\circ} \mathrm{F}\right.$ Temperature Load)

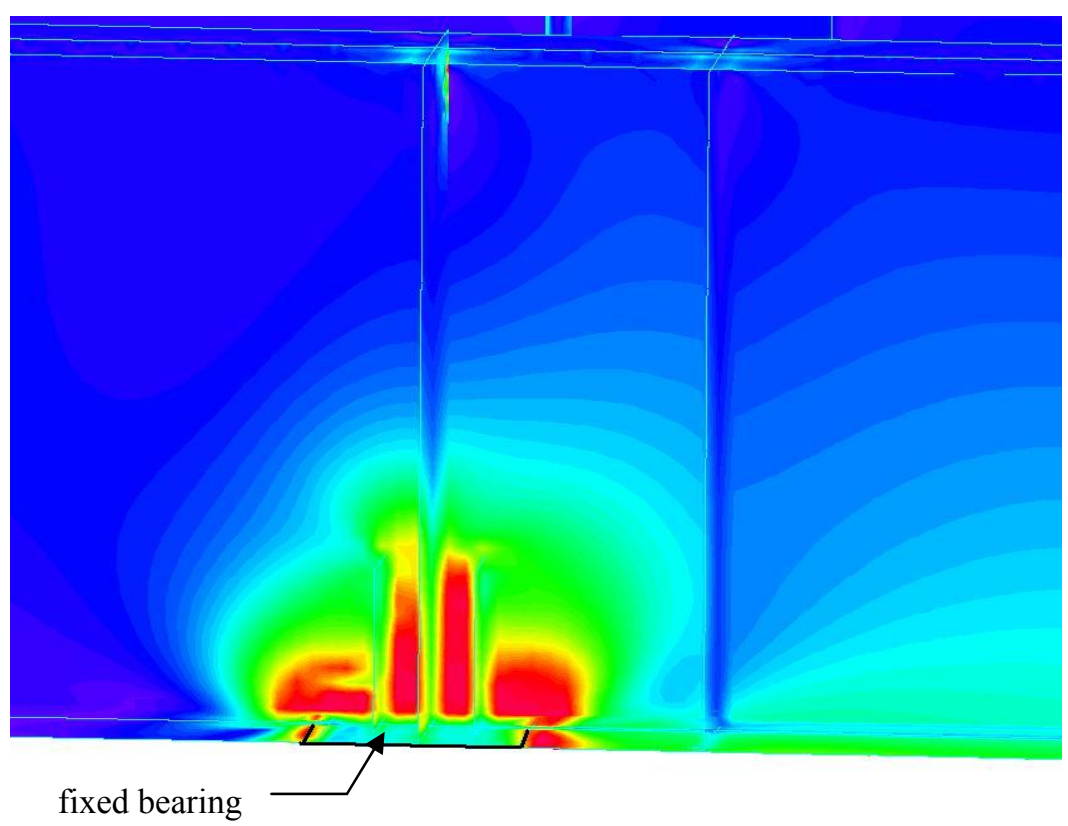

Figure 5.12 Pier 9N FE Model Effective Stress Contour Plot $\left(+90^{\circ} \mathrm{F}\right.$ Temperature Load) 


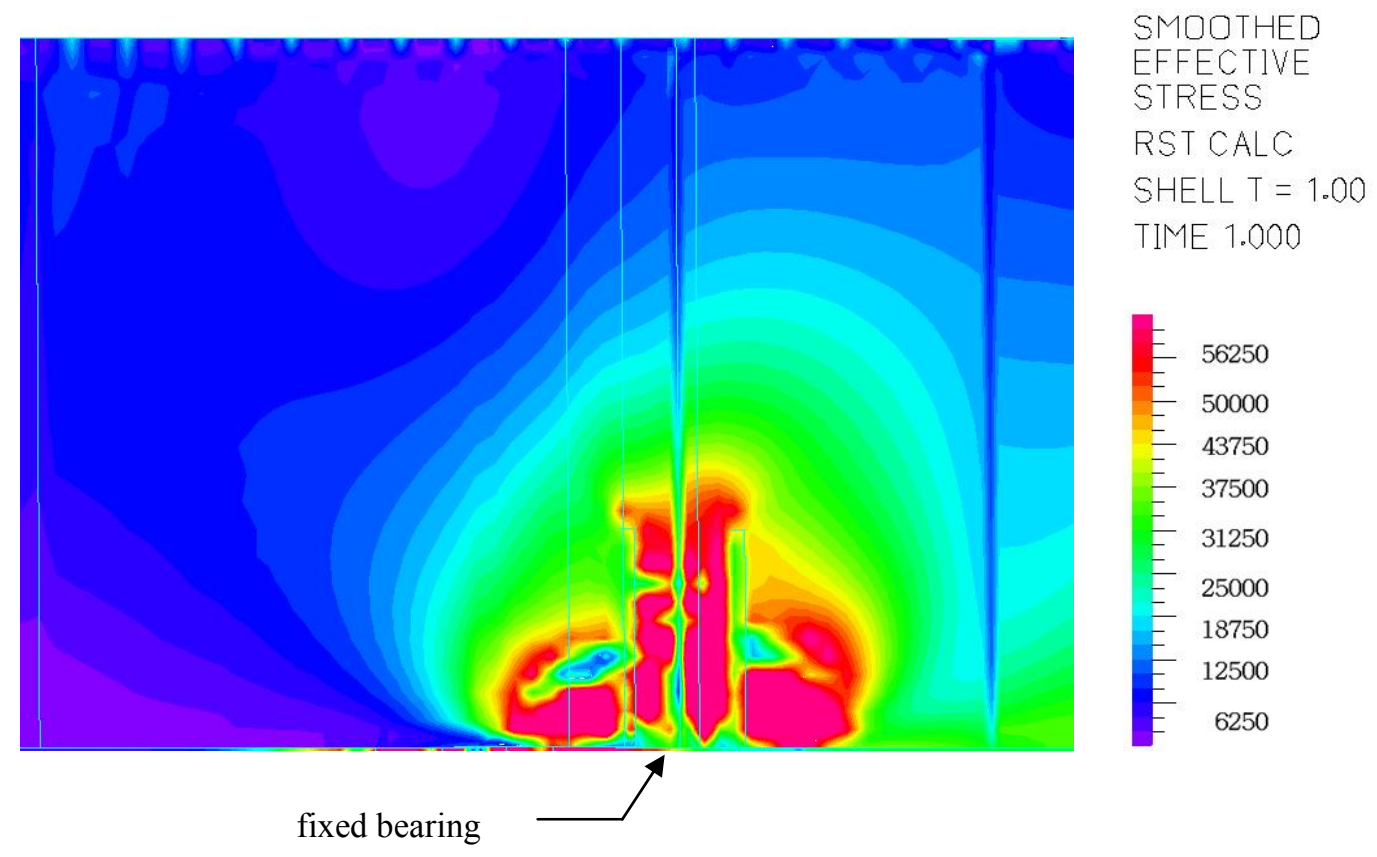

Figure 5.13 Pier 2N FE Model Effective Stress Contour Plot $\left(+90^{\circ} \mathrm{F}\right.$ Temperature Load)

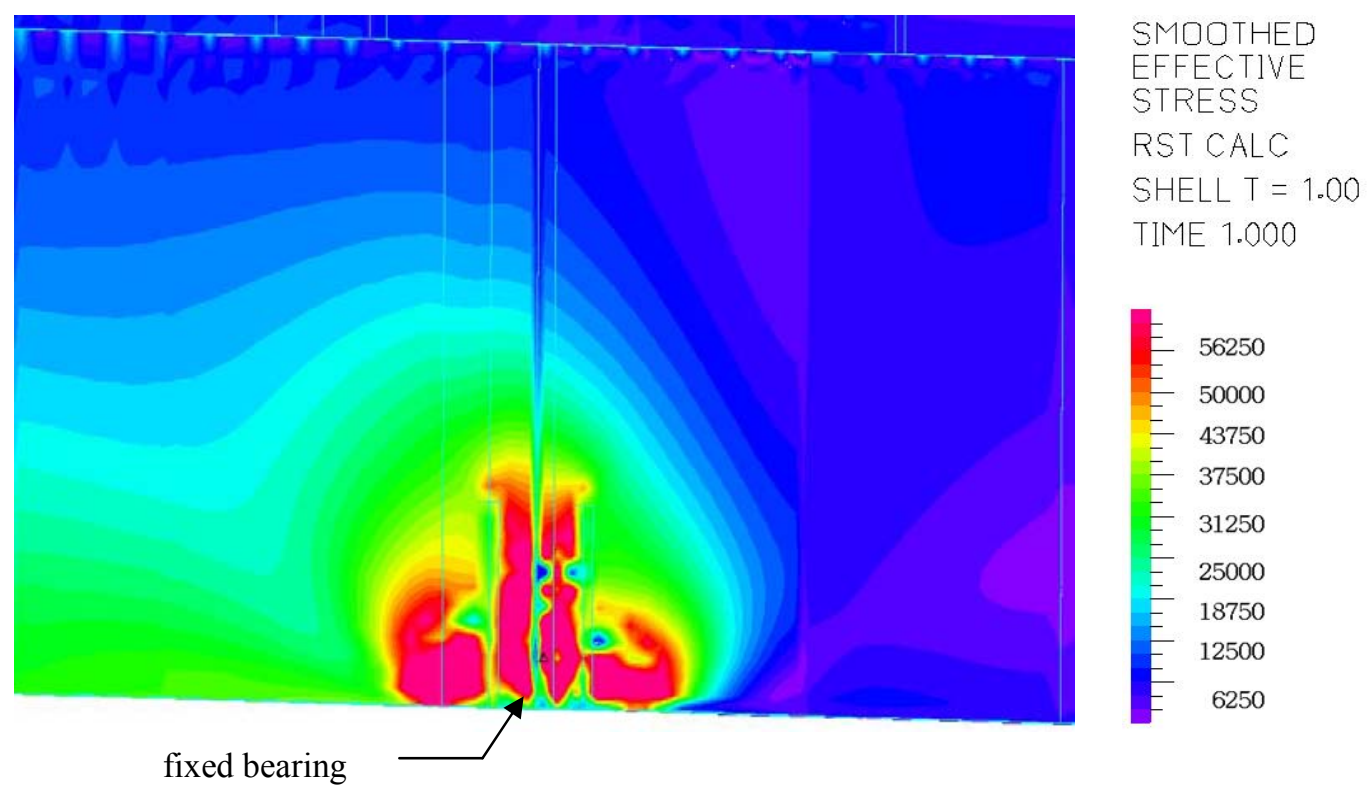

Figure 5.14 Pier 4N FE Model Effective Stress Contour Plot $\left(+90^{\circ}\right.$ F Temperature Load) 


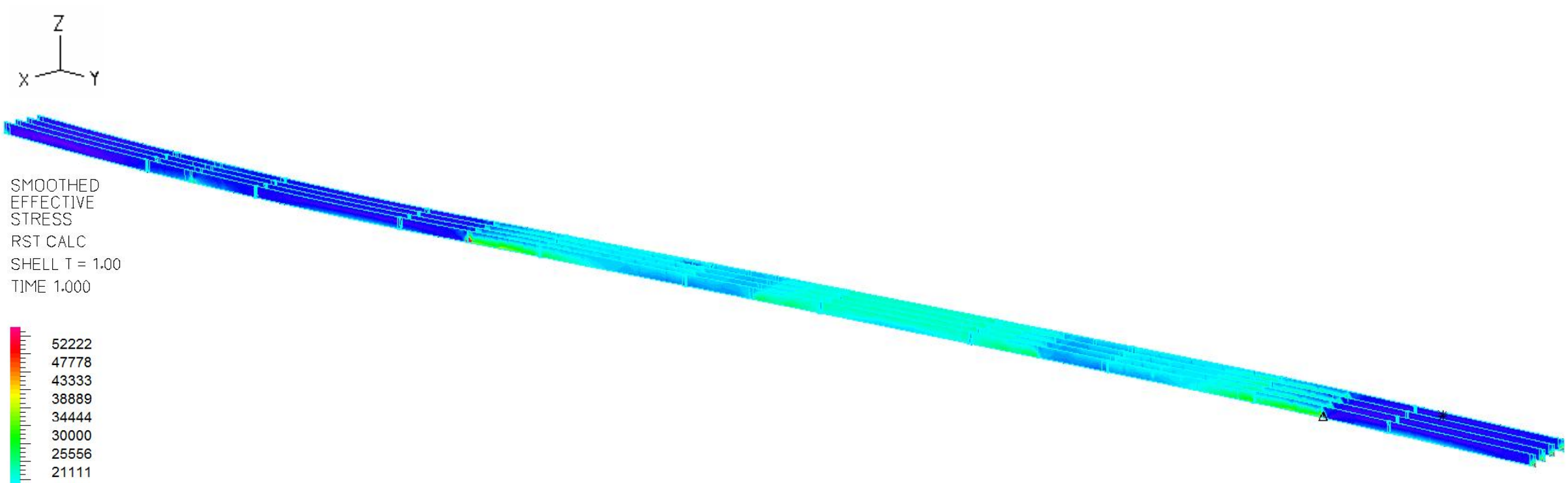

(a) Unit 1 (Spans 1N-6N)
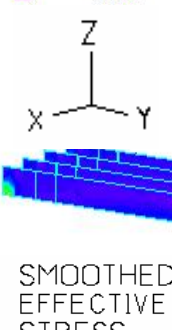

EFFECTIVE

STRESS

RST CALC

SHELL T $=1.00$

TIME 1.000

$$
\begin{aligned}
& 75200 . \\
& 68800 \text {. } \\
& 56000 \\
& 49600 \text {. } \\
& 43200 \text {. } \\
& \text { E } 36800 \text {. } \\
& \text { E } 368000 \text {. } \\
& 30400 \text {. } \\
& 24000 . \\
& 17600 \text {. } \\
& 11200 . \\
& 4800 \text {. }
\end{aligned}
$$$$
\text { (b) Unit } 2(\text { Span } 7 \mathrm{~N}-12 \mathrm{~N})
$$

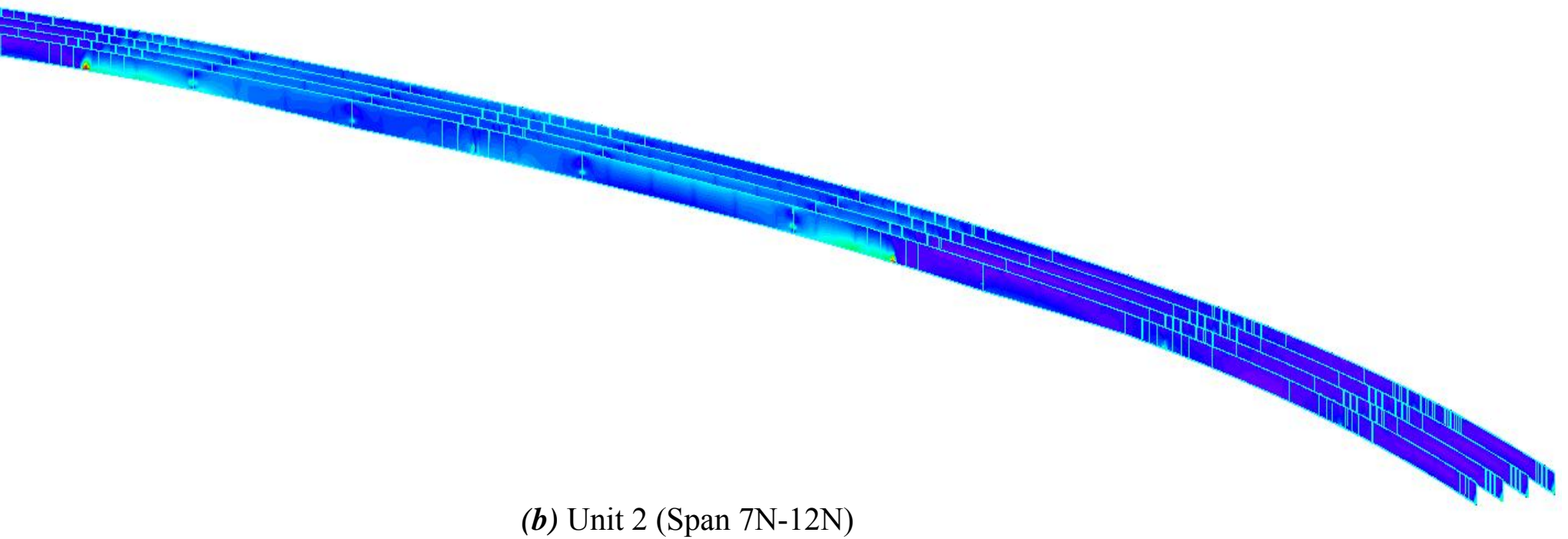

Figure 5.15 FE Model Effective Stress Contour Plots $\left(+90^{\circ} \mathrm{F}\right.$ Temperature Load) 
The FE model contour plots in Figure 5.15 show that effective stress levels are nearly $100 \%$ higher in fully restrained spans (fixed bearings at both supports) than in the other spans, which employ expansion bearings at the pier locations. Spans $4 \mathrm{~N}$ and $5 \mathrm{~N}$ show approximate stresses of nearly $25 \mathrm{ksi}$ while the free spans produce maximum effective stresses of only $13 \mathrm{ksi}$. Similar results are produced in Spans 8N and 9N, where effective stresses are around are $30 \mathrm{ksi}$ throughout. Spans $7 \mathrm{~N}$ and $10 \mathrm{~N}-12 \mathrm{~N}$ show that stresses are, on average, approximately $10 \mathrm{ksi}$ or less.

The current bearing arrangement implements fixed bearings at Piers $3 \mathrm{~N}-5 \mathrm{~N}$ and Piers 7N-9N. Further investigation of Figure 5.15 reveals that a particular stress pattern has developed in the FE model. Higher magnitudes of stress are produced on the side of the pier centerline where fixed bearings are implemented at the next pier. For example, let's consider Spans $9 \mathrm{~N}$ and $10 \mathrm{~N}$. Span $9 \mathrm{~N}$ has fixed bearings at both supports (Piers $8 \mathrm{~N}$ and $9 \mathrm{~N}$ ), while Span $10 \mathrm{~N}$ is only fixed at Pier $9 \mathrm{~N}$. Stresses are much larger in Span $9 \mathrm{~N}$ as opposed to span $10 \mathrm{~N}$. The same pattern emerges for Spans $3 \mathrm{~N}-5 \mathrm{~N}$. This analysis leads to the conclusion that the fixed bearings are responsible for the large magnitudes of thermal stress produced in the bridge. 


\subsection{LONGITUDINAL STRESSES}

Longitudinal stresses are composed of both bending and axial stresses. Bending stresses are a result of flexural loads (bridge self-weight dead load and design live load). Axial stresses, if present, will mainly be the result of the thermal loading. During the design of steel girder bridges only forces due to flexural loads are considered, while axial stresses are mostly neglected. However, McBride (2005) showed that constrained thermal expansion on a steel girder bridge can lead to the development of significant levels of temperature induced axial stress.

Due to the as-built bearing arrangement of the study bridge not allowing the full thermal expansion of the structure, considerable levels of axial stress may have developed in the girders raising concerns regarding the structural capacity of the bridge girders. If axial stresses are not zero, as assumed during design, the strength of the girder may not be adequate to resist both the flexural design loads and unforeseen axial loads.

Depending on load conditions, material response, etc., bending stress is either linear or nonlinear though the girder cross-section. Axial stress, on the other hand, is uniform throughout the cross-section. This uniform axial stress on a cross-section is easily calculated from the longitudinal stress profile by multiplying the total stress by the cross-sectional area. The result is the magnitude of the uniform axial stress. Figures 5.16-5.24 present longitudinal stress profiles for positive moment regions near midspans of Spans $7 \mathrm{~N}, 8 \mathrm{~N}$, $10 \mathrm{~N}$, and $11 \mathrm{~N}$ and negative moment regions of Piers $7 \mathrm{~N}$ to $11 \mathrm{~N}$ and Span $9 \mathrm{~N}$. From these longitudinal profiles, axial stresses will be isolated to in order to determine whether or not temperature loading can lead to the development of large axial stresses. 


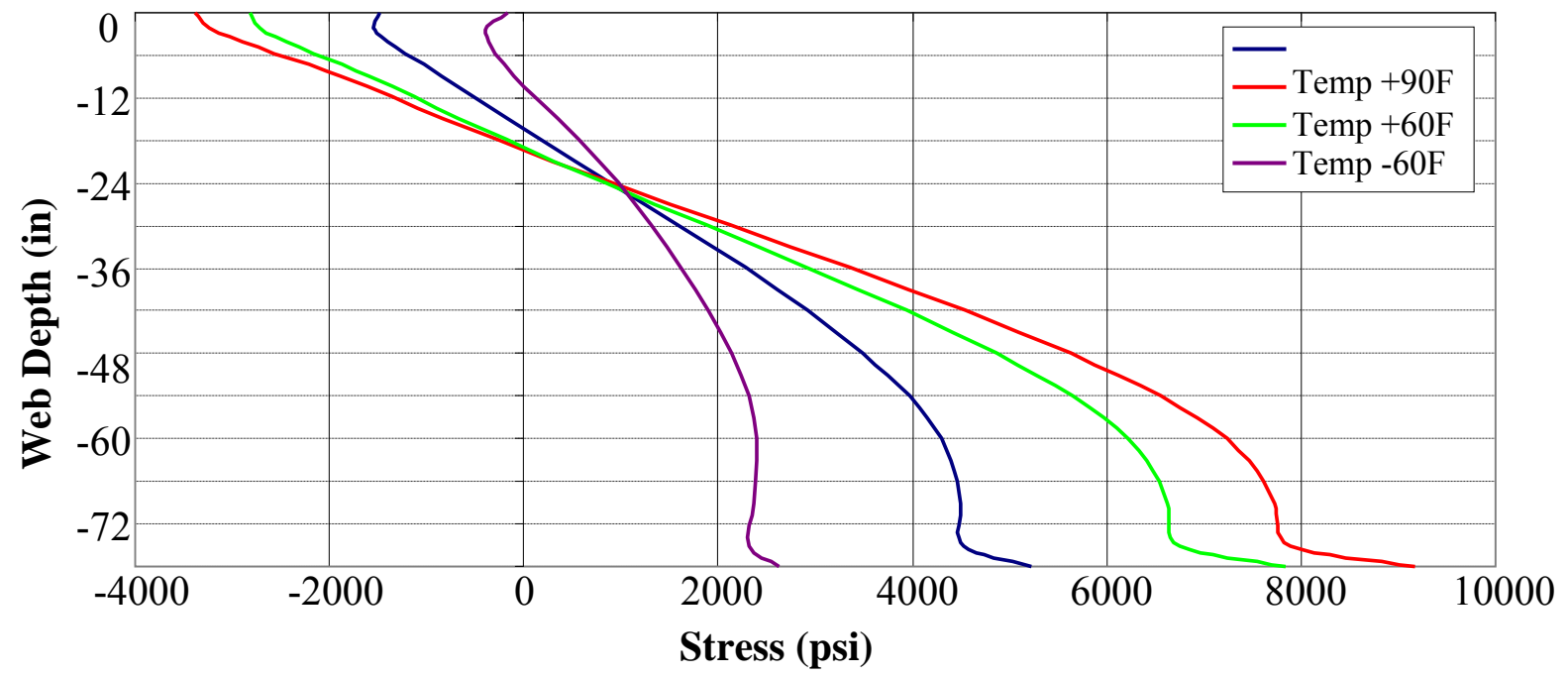

Figure 5.16 As-Built, Longitudinal Stress Profiles for Span 7N

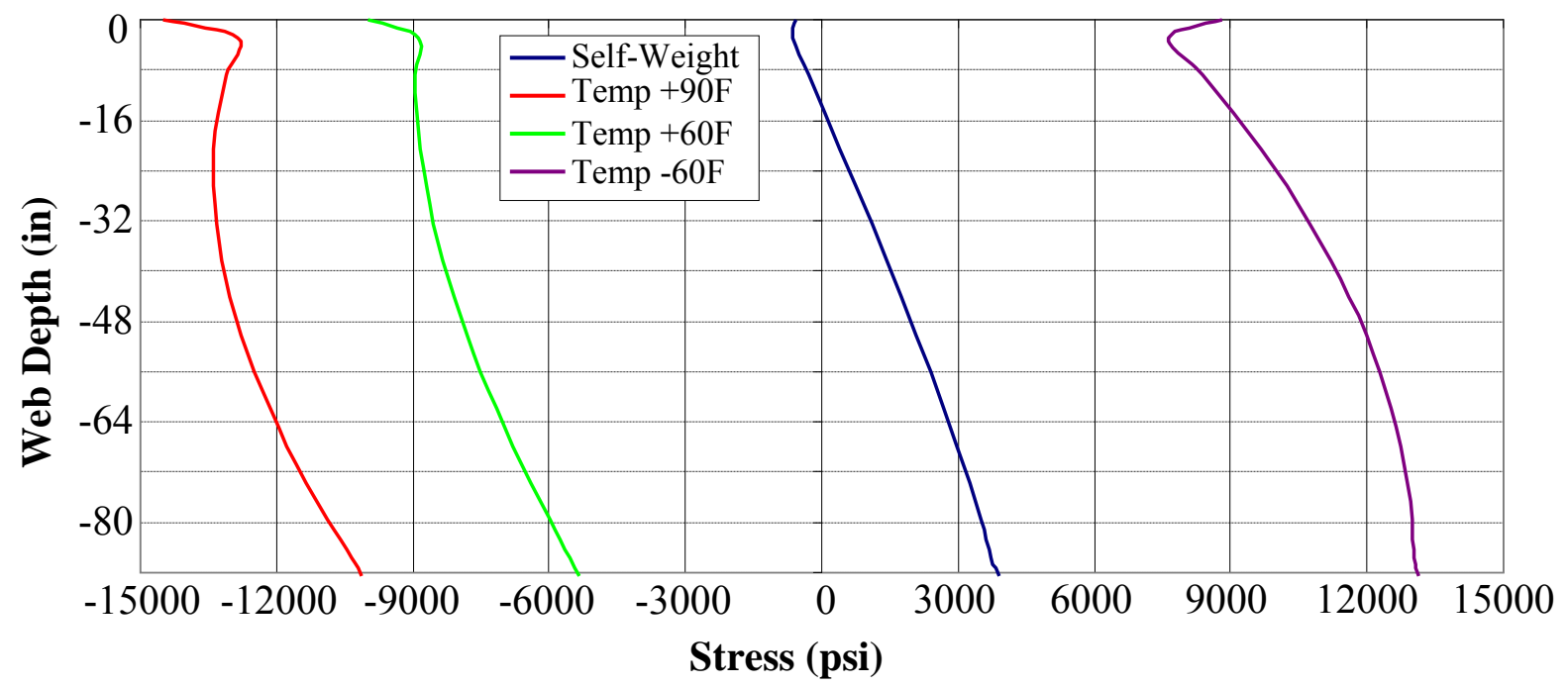

Figure 5.17 As-Built, Longitudinal Stress Profiles for Span 8N

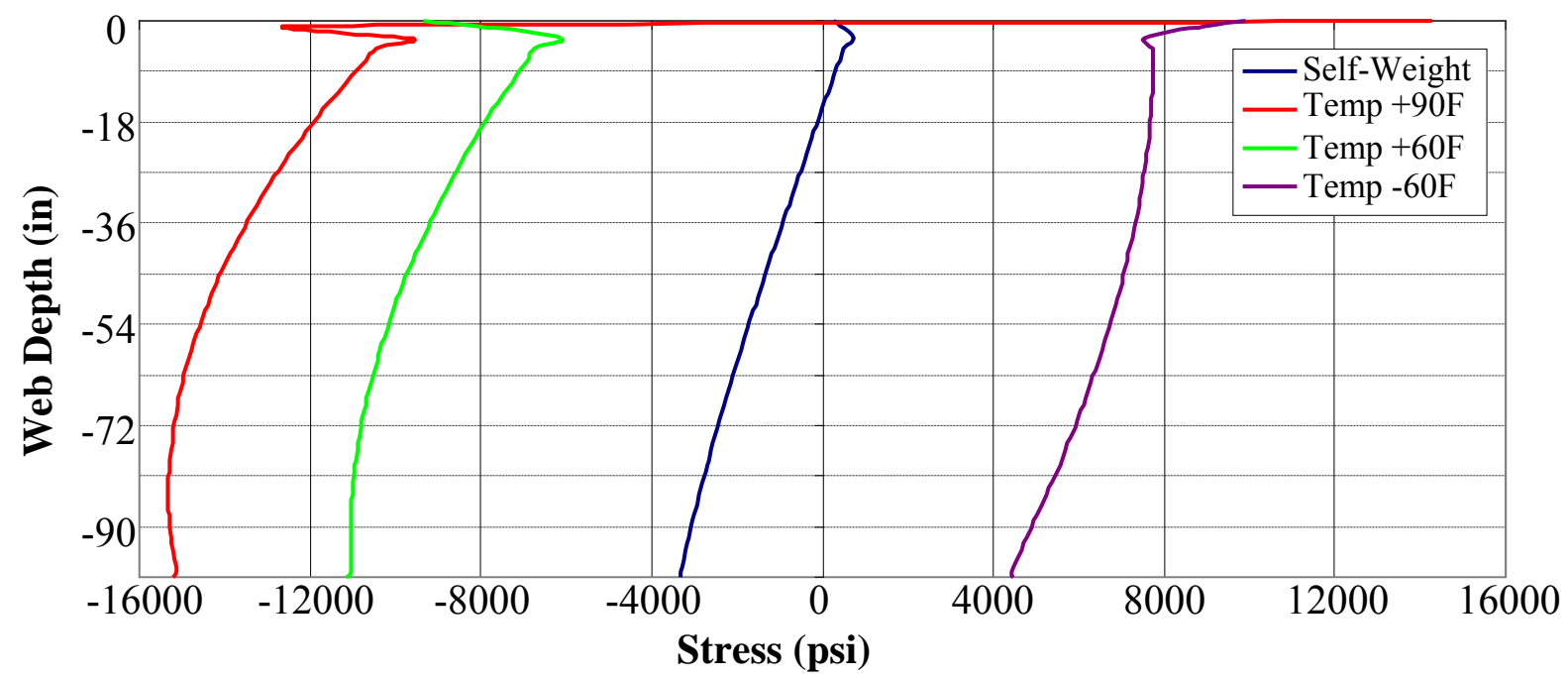

Figure 5.18 As-Built, Longitudinal Stress Profiles for Span 9N 


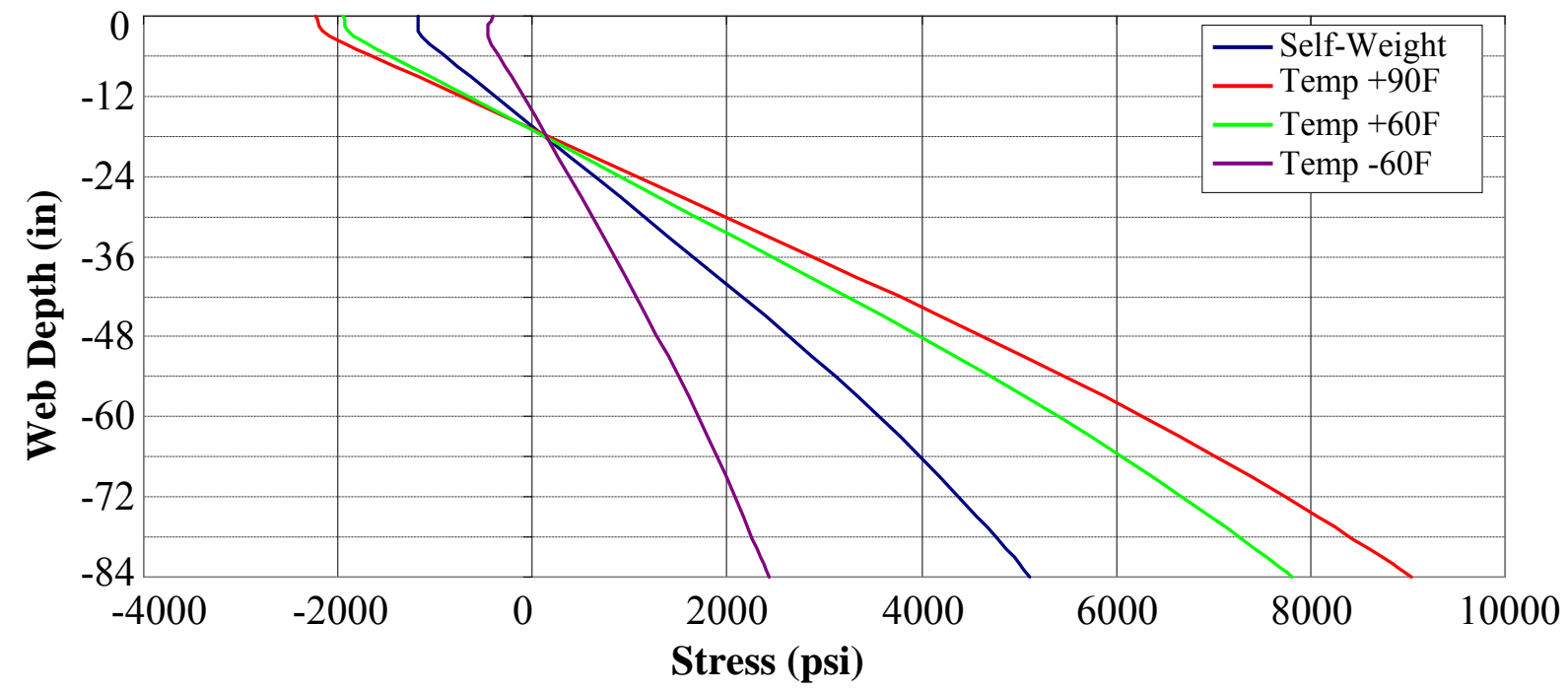

Figure 5.19 As-Built, Longitudinal Stress Profiles for Span 10N

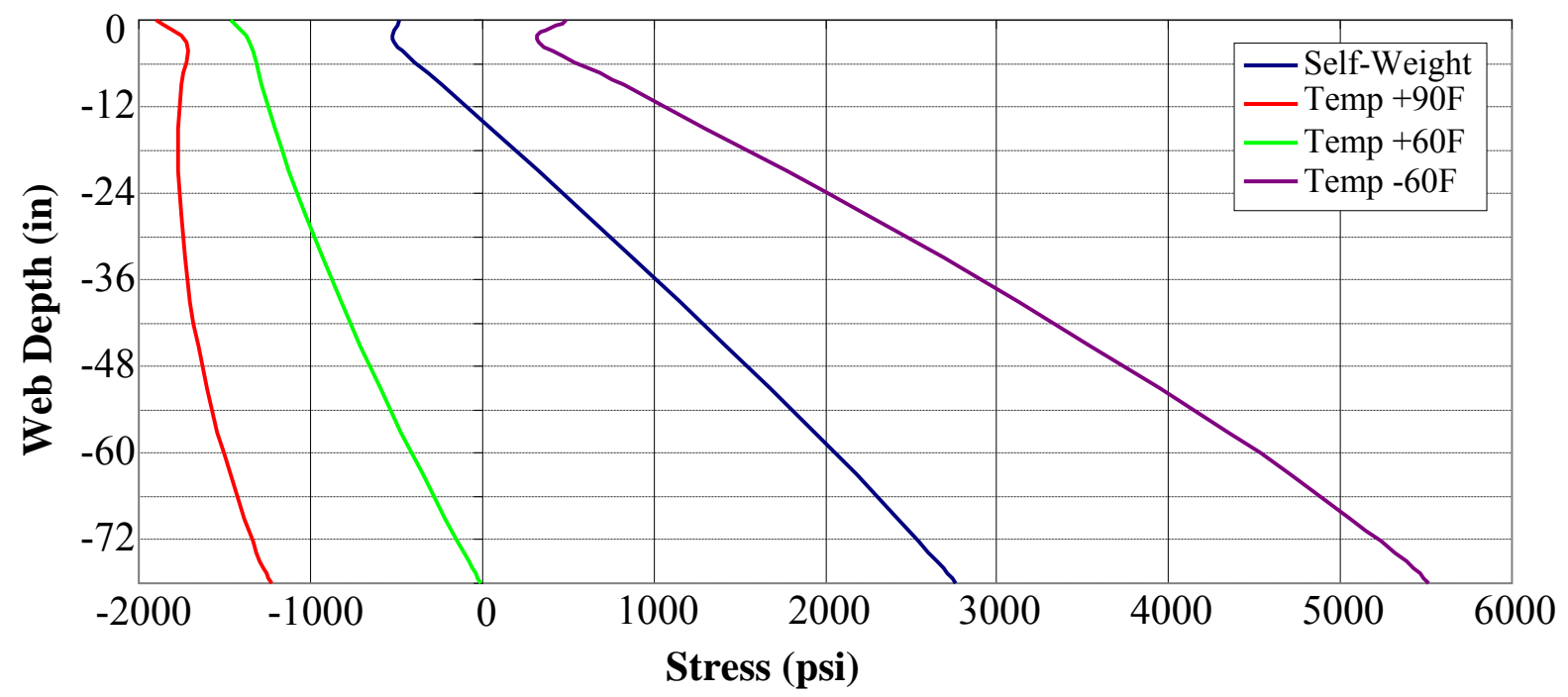

Figure 5.20 As-Built, Longitudinal Stress Profiles for Span 11N

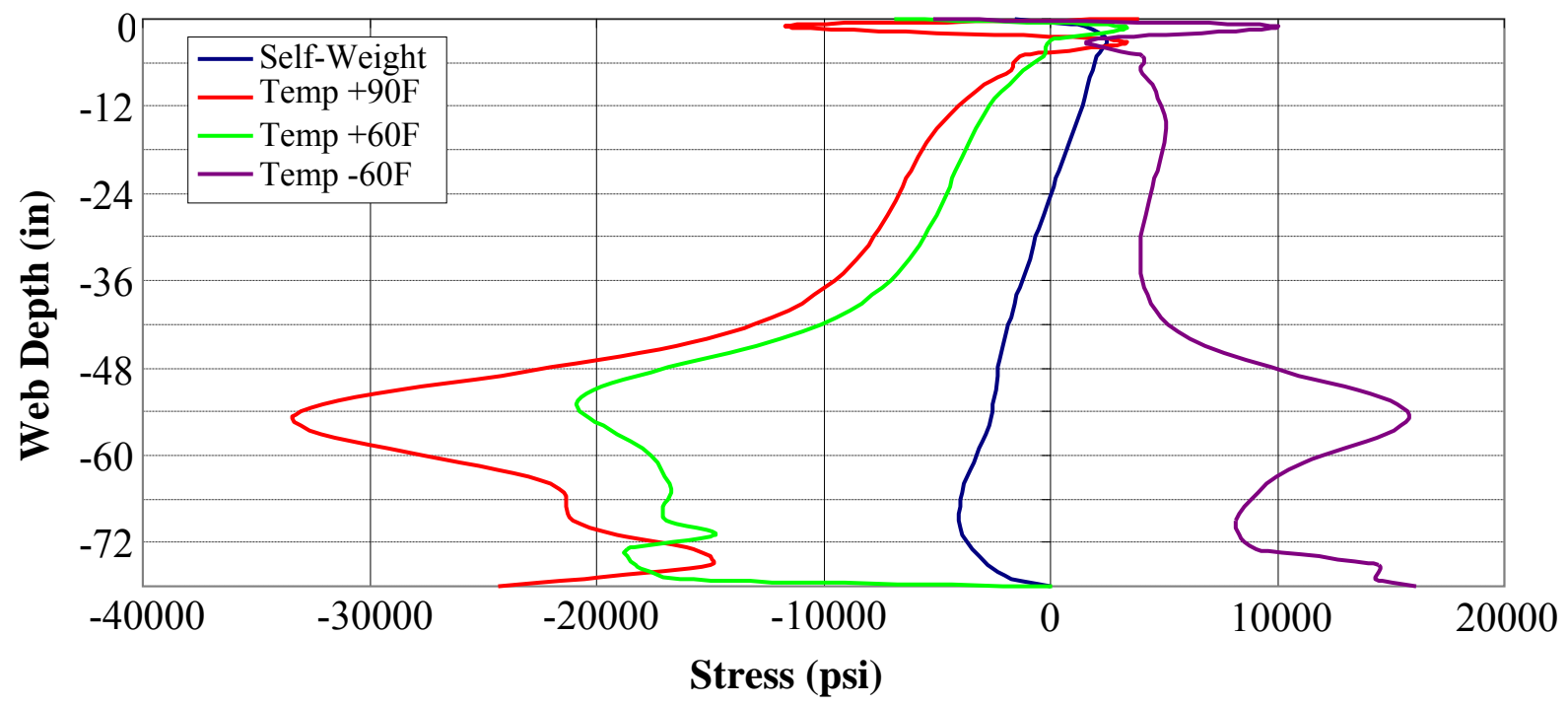

Figure 5.21 As-Built, Longitudinal Stress Profiles for Pier 7N 


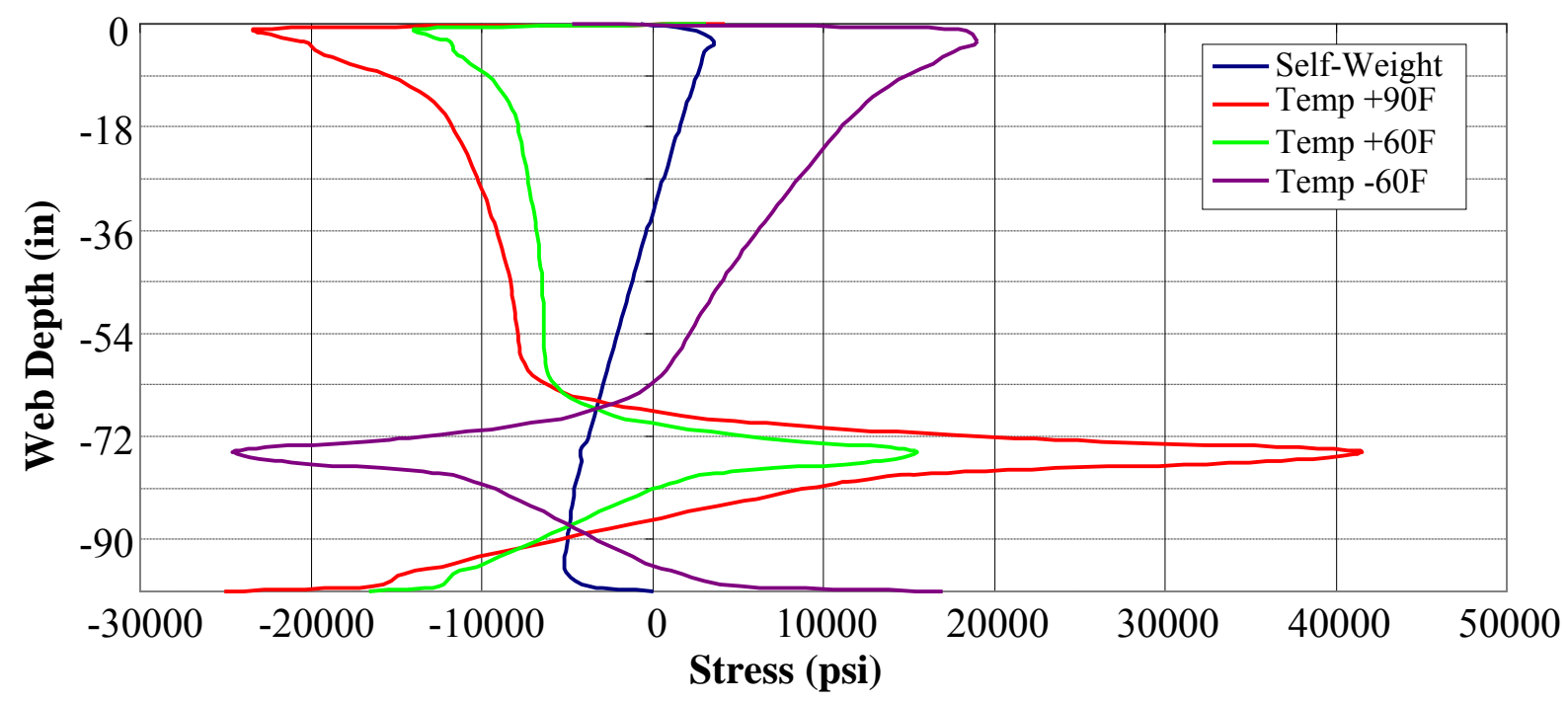

Figure 5.22 As-Built, Longitudinal Stress Profiles for Pier 8N

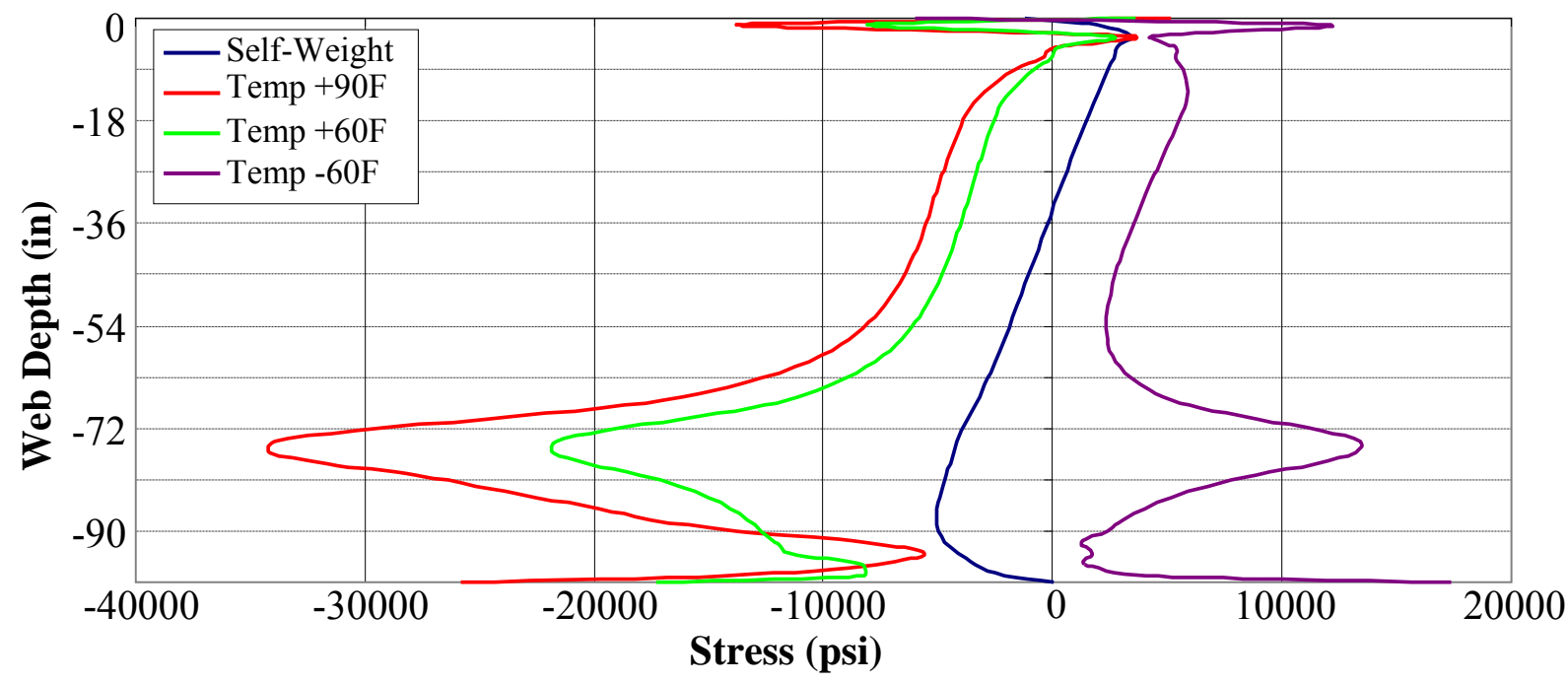

Figure 5.23 As-Built, Longitudinal Stress Profiles for Pier 9N

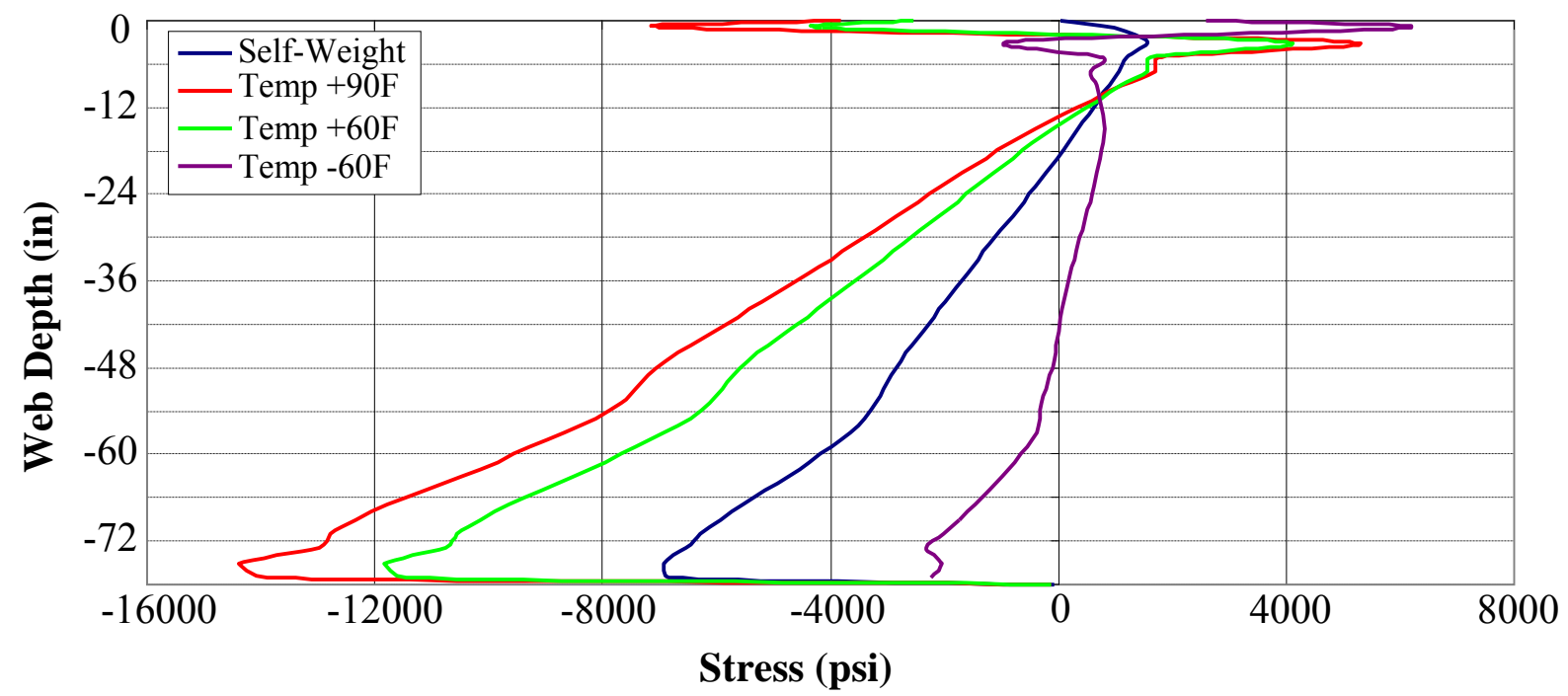

Figure 5.24 As-Built, Longitudinal Stress Profiles for Pier 10N 


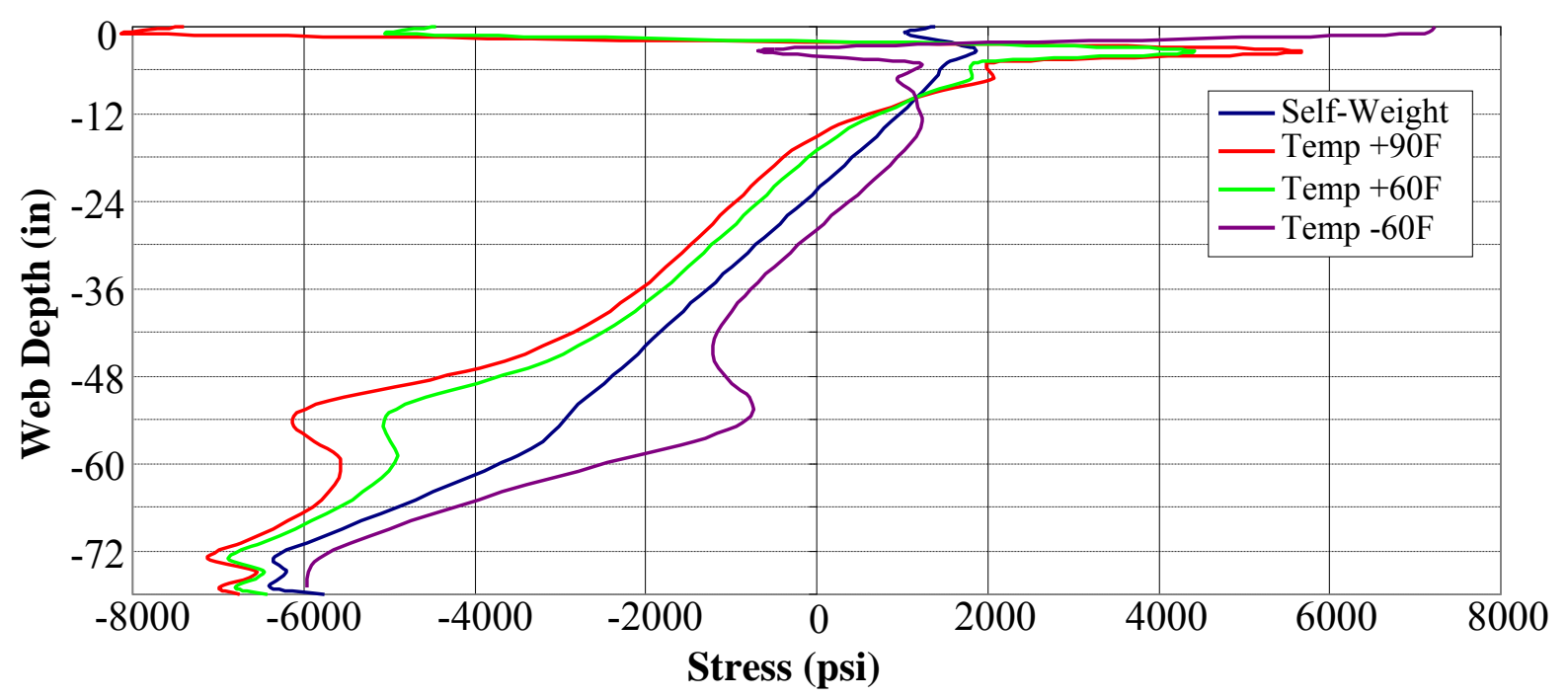

Figure 5.25 As-Built, Longitudinal Stress Profiles for Pier 11N

Figures 5.17 and 5.18 show significant increases in longitudinal stress in Spans 8N and $9 \mathrm{~N}$ due to temperature loading. These two spans are fully restrained from thermal expansion at Piers $7 \mathrm{~N}, 8 \mathrm{~N}$, and $9 \mathrm{~N}$. In Span $8 \mathrm{~N}$, maximum longitudinal compressive stress increases from $500 \mathrm{psi}$ under bridge self-weight to near $14 \mathrm{ksi}$ when the $+90^{\circ} \mathrm{F}$ temperature load is applied. A $400 \%$ increase in longitudinal compressive stress is produced in Span 9N. Also, the full cross-section near midspan of Spans $8 \mathrm{~N}$ and $9 \mathrm{~N}$ are under compression. Clearly, the axial stress component has increased dramatically due to the applied temperature loads, as no additional flexural loads other than bridge self-weight are present. The increase in axial stress has occurred in part because of the constraint within the bridge supplied by the numerous fully fixed bearing devices.

Figures 5.21-5.25 show longitudinal stress profiles due each load case for crosssections in the negative moment regions of Girder $1 \mathrm{~N}$, directly above the pier supports. Piers $7 \mathrm{~N}$ through $11 \mathrm{~N}$ are included in this analysis. Longitudinal stress at the support locations shows the same behavior as the midspan locations investigated in Figures 5.16-5.20. However, the increase in longitudinal stress at the bearing locations is much higher in magnitude than in the positive moment regions. Longitudinal compressive stress at Piers $7 \mathrm{~N}$, 
$8 \mathrm{~N}$, and $9 \mathrm{~N}$ is approximately $34 \mathrm{ksi}, 40 \mathrm{ksi}$, and $35 \mathrm{ksi}$ respectively. Under bridge selfweight, longitudinal stress is roughly $5 \mathrm{ksi}$ at these same piers. The yield strength of the steel at these locations is $70 \mathrm{ksi}$, therefore the longitudinal stress is approximately $50 \%$ of the yield strength of the steel due to the $+90^{\circ} \mathrm{F}$ temperature load.

Piers $7 \mathrm{~N}, 8 \mathrm{~N}$, and $9 \mathrm{~N}$, all fully restrained by fixed bearings, experience the largest increases in longitudinal stress. The piers with expansion bearings installed, Piers $10 \mathrm{~N}$ and $11 \mathrm{~N}$, develop significantly lower levels stress. As in the previous case, the axial component of longitudinal stress must be responsible for the dramatic stress increases at the piers, as no additional flexural loads were applied. The larger increase longitudinal stress at these locations is not unexpected. The cross-sections examined in the positive moment regions, near midspan, are allowed a certain level of deflection under temperature loading, which will help relieve some of the thermal stresses. However, at the fixed bearings, the cross-section is almost fully restrained, allowing minimal displacement of the structure under temperature loading, and leading to an accumulation of thermal stress.

The web plates of steel I-girders, mainly responsible for carrying shear force, are not typically analyzed for flexural loads. When considering steel I-girder web plates under flexure, web bend-buckling resistance is calculated. Bend-buckling may occur when a slender web plate is subjected to bending forces. The bending forces cause the development of longitudinally compressive stresses that may lead to web buckling. For this study, any additional compressive forces in the web plates not attributed to bridge self-weight will be a result of thermal loading.

In AASHTO (2003) and AASHTO (2007), web bend-buckling behavior limits the critical longitudinal stress in web panels to values determined by Equation 5.1, the nominal web bend-buckling resistance $F_{c r}$. 


$$
\begin{aligned}
F_{c r} & =\frac{0.9 E k}{\left(\frac{D}{t_{w}}\right)^{2}} \leq F_{y} \\
& -k=\text { bend-buckling coefficient }=7.2\left(\mathrm{D} / \mathrm{D}_{\mathrm{c}}\right)^{2}
\end{aligned}
$$

Equation 5.1 becomes very important to this investigation. Axial forces are typically neglected during the design of most bridge structures due to the belief that the expansion bearings will alleviate the majority of axial force effects resulting from thermal movement. Consequently, if large axial forces do arise in a structure, perhaps due to an ill-designed bearing arrangement, those forces will increase compressive longitudinal stresses. The longitudinal stresses from Figures 5.16-5.25 are now compared to critical web stress values in Figures 5.26 and 5.27

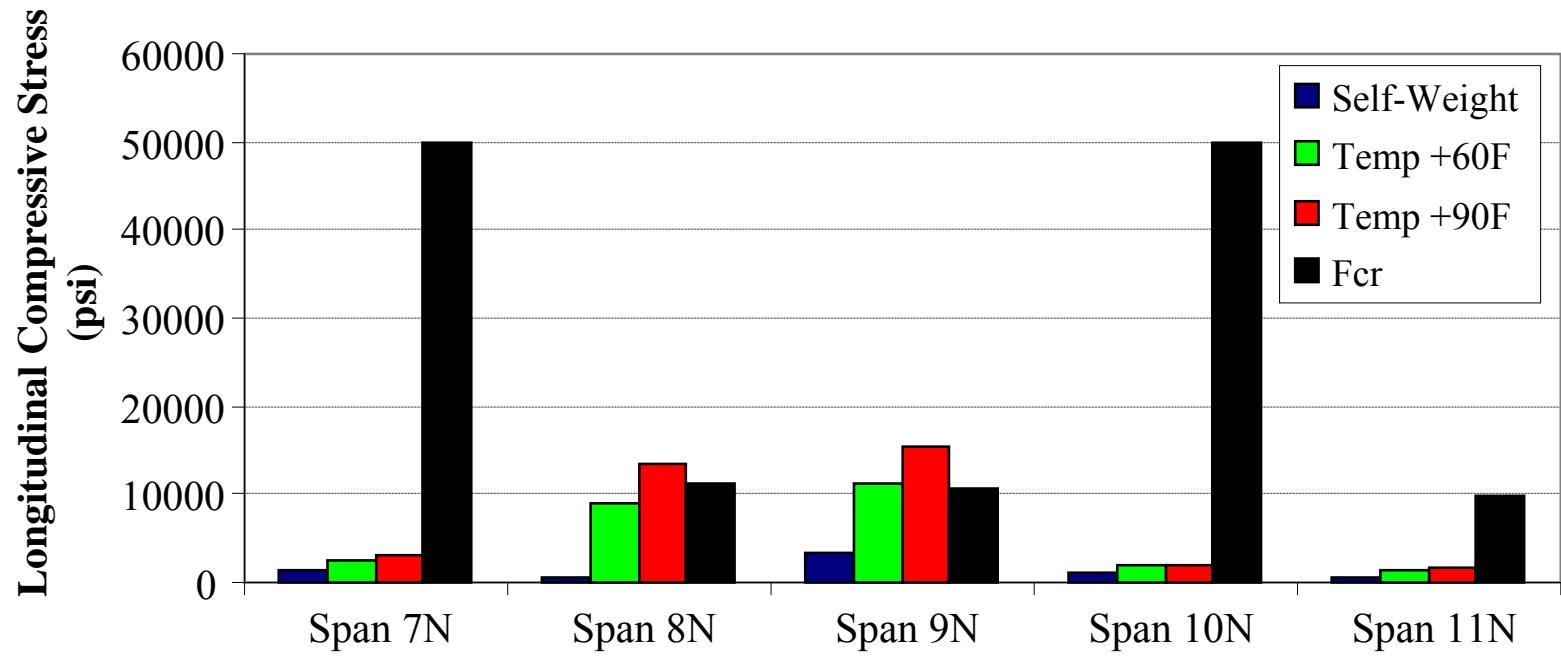

Figure 5.26 Maximum Longitudinal Stress at Midspan (Positive Moment)

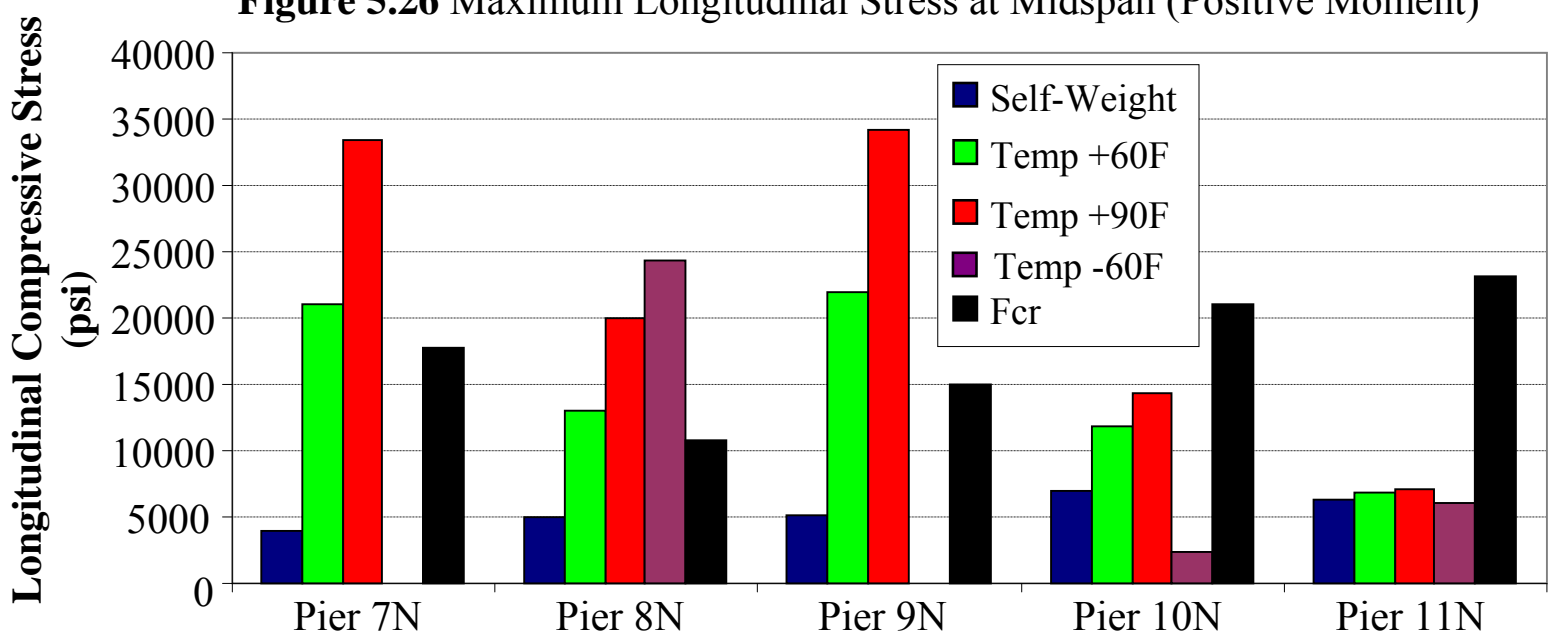

Figure 5.27 Maximum Longitudinal Stress at Piers (Negative Moment) 
The web bend-buckling coefficient, $k$, is dependent upon the depth of the web plate under compression. This is where the discrepancy in the critical stress, $F_{c r}$, values develops. Spans $7 \mathrm{~N}$ and $10 \mathrm{~N}$ are under positive flexure forces and have neutral axes located very near the top of the web and therefore very little of the web is under longitudinal compression. Hence, $F_{c r}$ is taken as the yield stress at these locations. In Spans $8 \mathrm{~N}, 9 \mathrm{~N}$ and $11 \mathrm{~N}$ the entire cross-section is under compression and Equation 5.1 yields much smaller values for critical web stress. The fact that Spans $8 \mathrm{~N}$ and $9 \mathrm{~N}$ are under compression is not unexpected. The boundary conditions at Piers $7 \mathrm{~N}$ through $9 \mathrm{~N}$ do not allow the thermal expansion of the steel girders, and large axial stresses have developed due to the applied temperature loads. As seen from Figure 5.26, in Spans $8 \mathrm{~N}$ and 9N, the compressive longitudinal stress from temperature load exceeds the $F_{c r}$ value calculated for the web at the respective cross-sections. A compressive stress is produced in Span $11 \mathrm{~N}$, leaning towards the hypothesis that the expansion bearings at Pier $11 \mathrm{~N}$ are restraining the thermal expansion of the bridge, resulting in an accumulation of axial compressive stress in the span.

There are significant concerns after comparing the critical stress, $F_{c r}$, to the compressive longitudinal stresses obtained from the FE bridge model at the pier support locations. The compressive longitudinal stresses due to the temperature loads at Piers $7 \mathrm{~N}-9 \mathrm{~N}$ are considerably larger than $F_{c r}$. Stresses produced by the $+90^{\circ} \mathrm{F}$ temperature load are well above the critical stress limit, more than $100 \%$ greater at Pier $9 \mathrm{~N}$ and roughly $100 \%$ greater at Piers $7 \mathrm{~N}$ and $8 \mathrm{~N}$. The temperature load of $+60^{\circ} \mathrm{F}$, a moderate temperature load, produces stresses in excess of $F_{c r}$, leaving open the possibility of the critical stress being surpassed due to even lower magnitude temperature loads. 
Overall, longitudinal stress at the support locations is substantially larger than near the midspan. Also, longitudinal compressive stress is highest at Spans $8 \mathrm{~N}$ and $9 \mathrm{~N}$, and at Piers 7N-9N. Spans $8 \mathrm{~N}$ and $9 \mathrm{~N}$ are fully restrained against thermal expansion by Piers $7 \mathrm{~N}-$ $9 \mathrm{~N}$. Spans $7 \mathrm{~N}, 10 \mathrm{~N}$ and $11 \mathrm{~N}$ show much lower levels of longitudinal stress, meaning that the expansion bearings at Piers $6 \mathrm{~N}, 10 \mathrm{~N}$ and $11 \mathrm{~N}$ permitting thermal expansion of the bridge. The higher levels of stress in Spans $8 \mathrm{~N}$ and 9N, and at Piers 7N-9N make certain the fact that the current bearing arrangement is not allowing the fully thermal expansion of the structure due to temperature variations.

Figures 5.28-5.29 show exactly how the increase in longitudinal stress due to thermal loading affects the critical web stress. The figures compare $F_{c r}$ values calculated from the FE model (with temperature) and the design drawings (design loads only). The reduction in critical web stress values is very apparent. Thermal stresses were considered minimal during design, therefore were neglected. However, Figures 5.28-5.29 show that girder capacity is reduced significantly due to thermal loading.

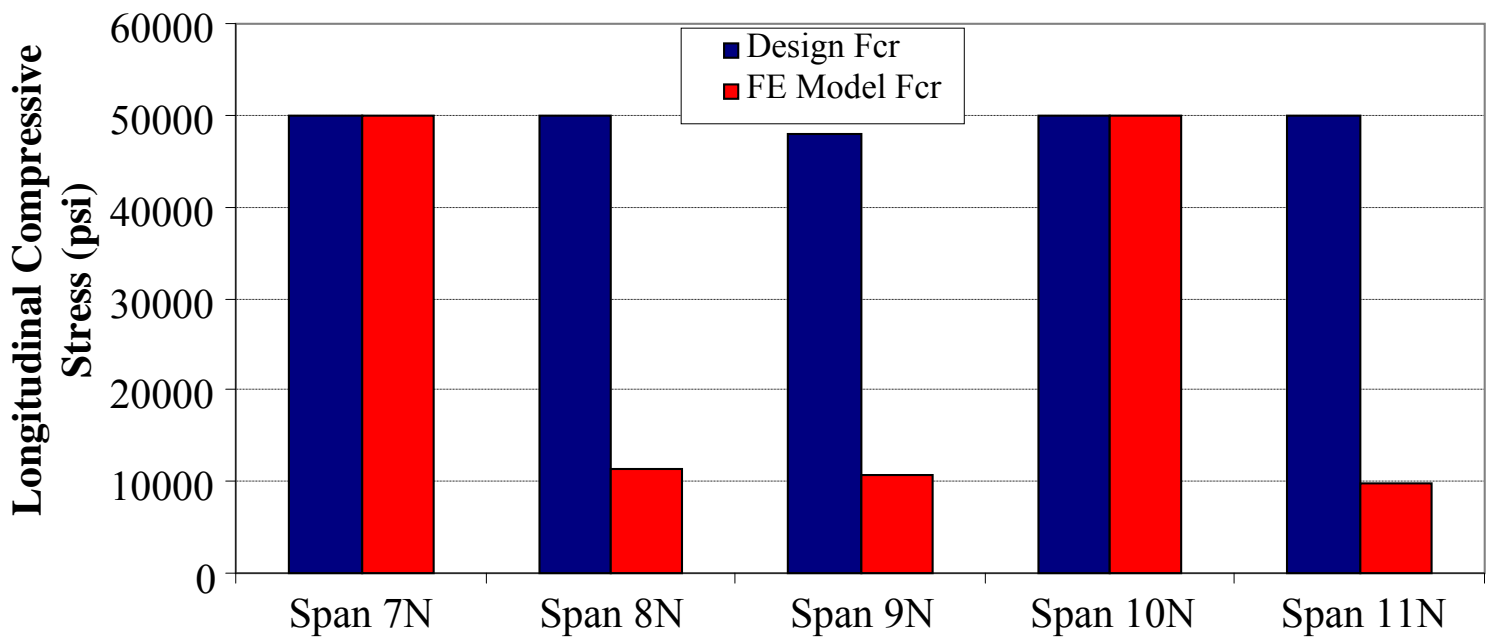

Figure 5.28 Design $F_{c r}$ vs. FE Computed $F_{c r}$ (Span Locations) 


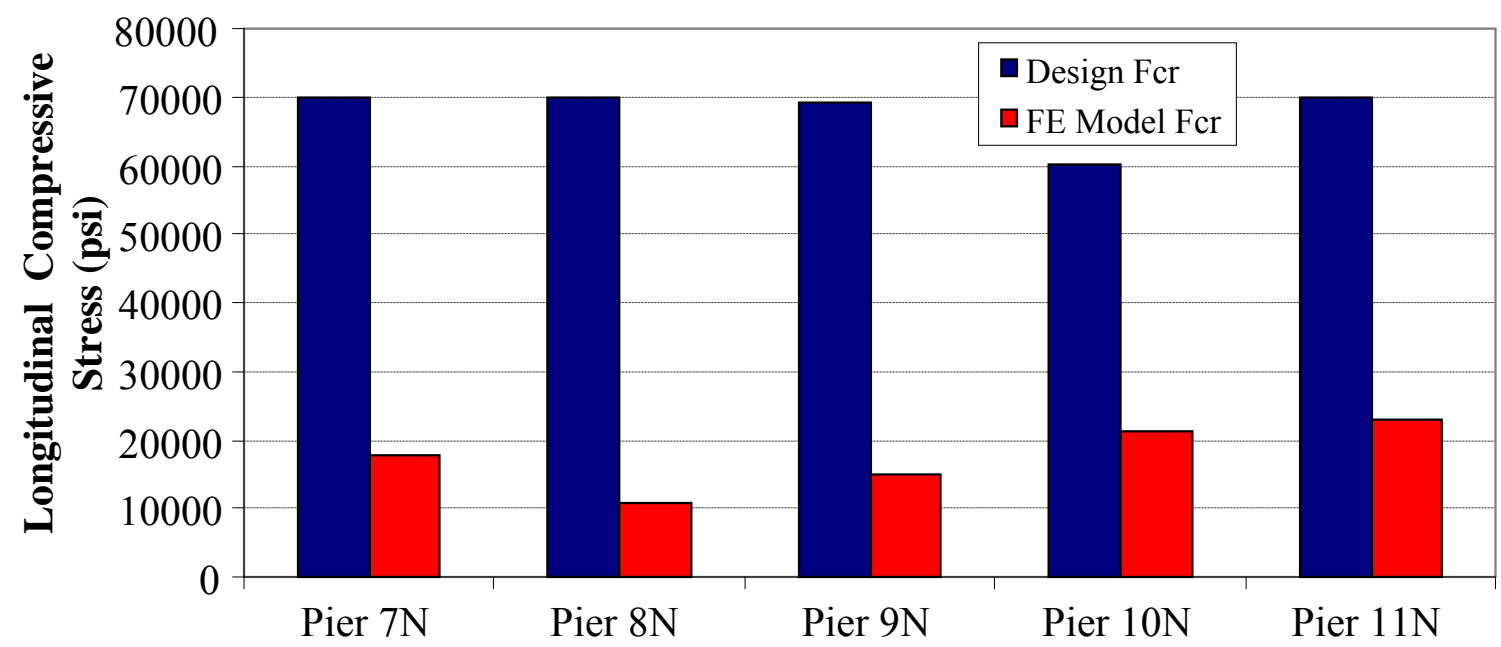

Figure 5.29 Design $F_{c r}$ vs. FE Model Computed $F_{c r}($ Pier Locations)

Significant reductions in $F_{c r}$ are recorded at each pier location. An average decrease in $F_{c r}$ of approximately $70-75 \%$ occurs. This means that a $70-75 \%$ reduction in capacity results by application of the $+90^{\circ} \mathrm{F}$ temperature load. This reduction in capacity is not accounted for during the design of a bridge, because thermal stresses are typically assumed to be near zero, so the above affects would not be considered. Similar results are produced near the midspan of Spans $8 \mathrm{~N}, 9 \mathrm{~N}$, and $11 \mathrm{~N}$.

Longitudinal stress band plots extracted from the FE model for the $+90^{\circ} \mathrm{F}$ temperature load case are presented in Figure 5.30. Easily noticed is the discrepancy in stress values among Spans $7 \mathrm{~N}-12 \mathrm{~N}$. Spans $8 \mathrm{~N}$ and 9N develop significantly larger magnitudes of longitudinal stress than the other spans due to the fixed bearing conditions at Piers $7 \mathrm{~N}, 8 \mathrm{~N}$ and $9 \mathrm{~N}$. In Span $8 \mathrm{~N}$ and $9 \mathrm{~N}$, the magnitude of longitudinal compressive stress is approximately 20 ksi throughout, whereas Spans $7 \mathrm{~N}, 10 \mathrm{~N}, 11 \mathrm{~N}$ and $12 \mathrm{~N}$ are well under a 10 ksi, mainly in tension. Clearly, the bearing arrangement currently employed on the bridge is causing a significant accumulation of thermal stress in a large portion of the structure. 

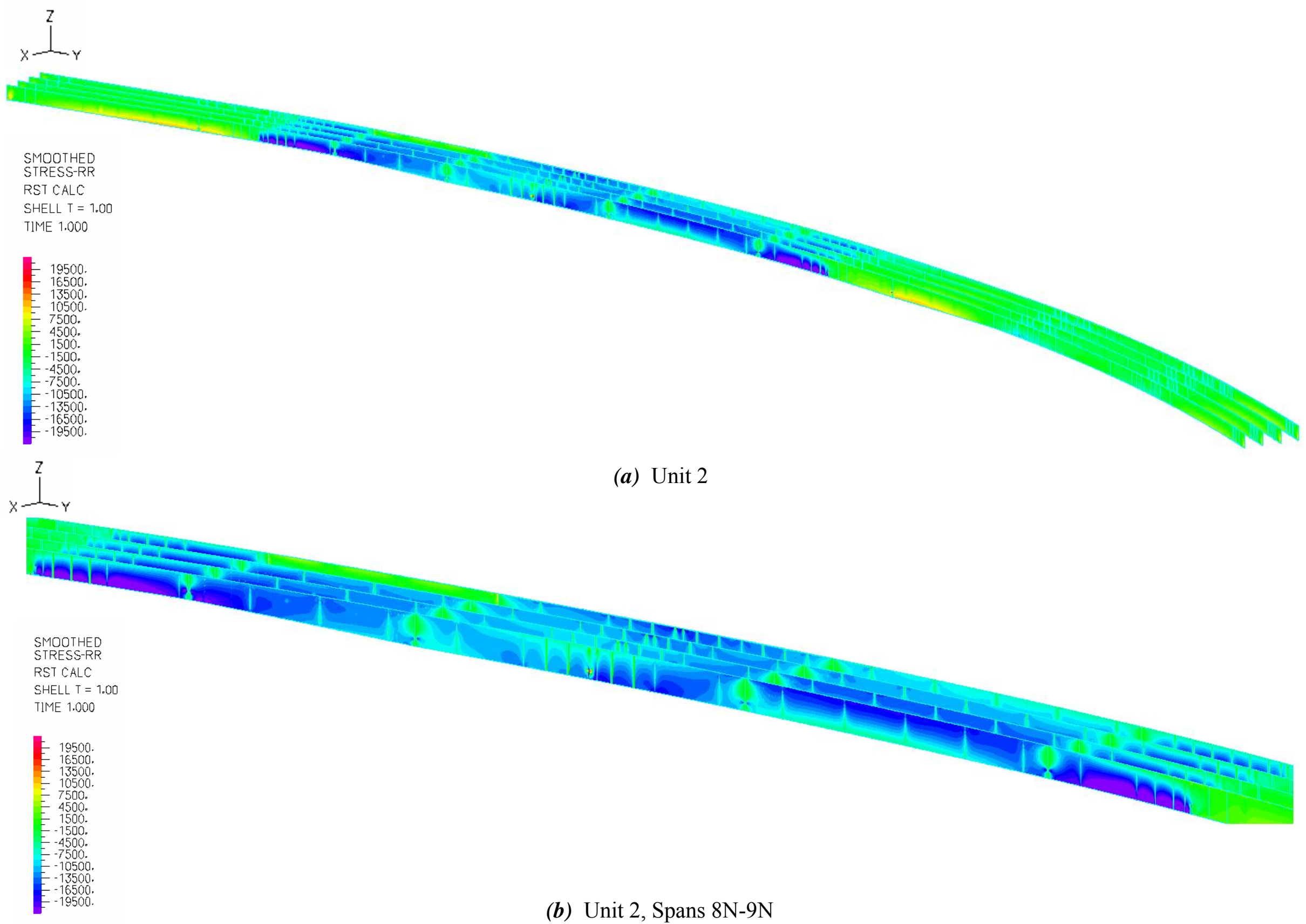

(a) Unit 2

(b) Unit 2, Spans $8 \mathrm{~N}-9 \mathrm{~N}$

Figure 5.30 FE Model Longitudinal Stress Band Plots for Unit $2\left(+90^{\circ} \mathrm{F}\right.$ Temperature Load) 


\subsection{BENDING AND AXIAL STRESSES}

In this section, the longitudinal stress profiles in Figures 5.16-5.25 are decomposed into their bending and axial stress components in order to determine the magnitude of axial stress on each cross-section. Typical bridge design methods assume thermal stresses are minimized by use of expansion bearings. Therefore, bridge design loads are predominantly flexural loads, not accounting for large axial force effects. The thermal stresses produced by the FE model are mainly axial stresses caused by constrained thermal expansion. If axial stresses are large enough, structural capacity can be negatively influenced, and the steel Igirders may be shown to be under-designed and unable to carry additional stresses (i.e. live loads).

The following compression member equations from AASHTO (2007) were used to calculate the compressive resistance of the steel I-girders. The girders were treated as pure compression members for this analysis, with an unbraced length $(l)$ being equal to the distance between cross-frame connection plates. The factored compressive resistance of the member was calculated using Equations 5.2-5.4.

$$
\begin{gathered}
P_{n}=0.66^{\lambda} F_{y} A_{s} \\
P_{r}=\phi P_{n}
\end{gathered}
$$

- $\phi_{\mathrm{c}}-$ resistance factor for compression $=0.90$

$$
\lambda=\left(\frac{K l}{r_{s} \pi}\right)^{2} \frac{F_{y}}{E}
$$

- $K$ - effective length factor

- $r$-radius of gyration of the member

- $E$ - modulus of elasticity

- $F_{y}$ - yield stress 
Figures 5.31-5.50 show the longitudinal stress profiles from Figures 5.16-5.25 decomposed into bending and axial stress components. The uniform axial stress is represented by the vertical line, while bending moment is the linear (or nonlinear) graph. Included here are the self-weight and $+90^{\circ} \mathrm{F}$ load cases. Similar charts of the $-/+60^{\circ} \mathrm{F}$ temperature load cases is provided in Appendix A.

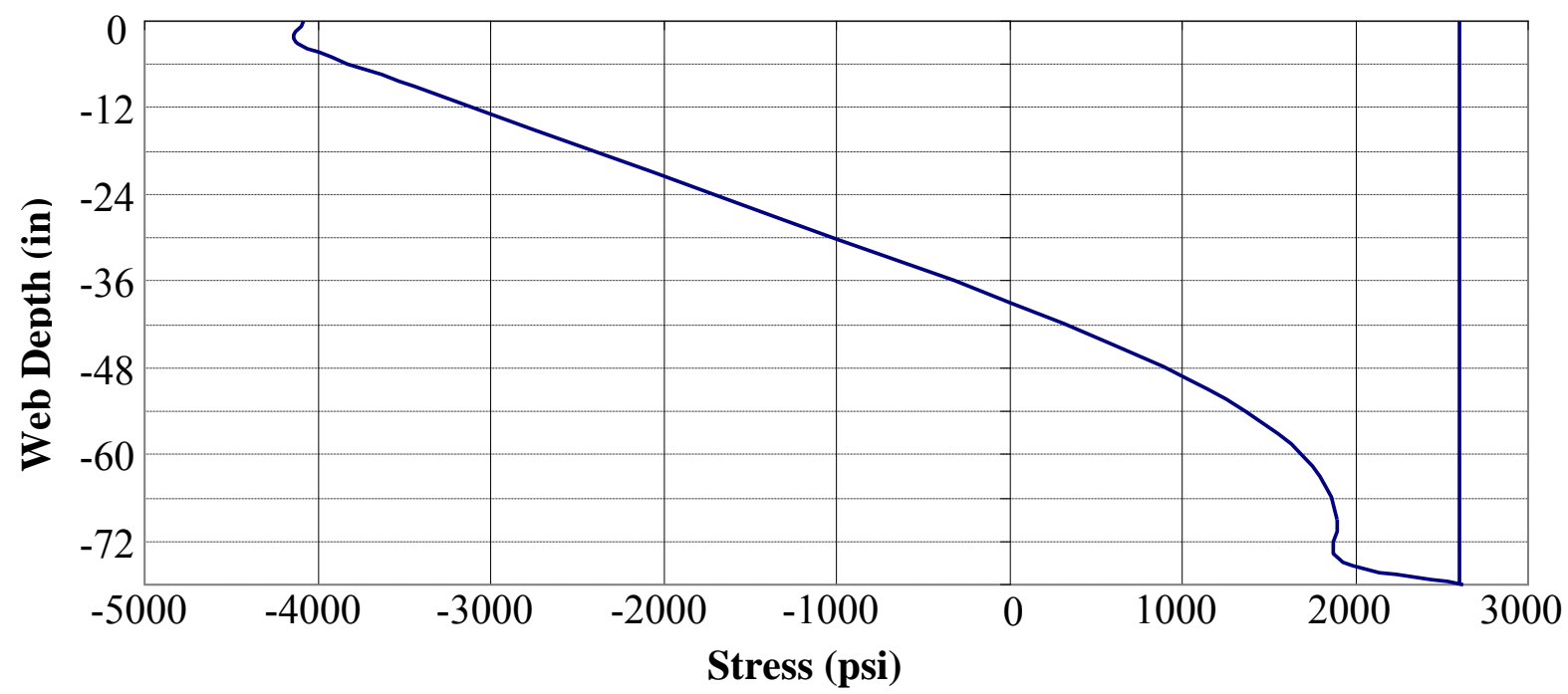

Figure 5.31 As-Built, Span 7N Bending and Axial Stresses Under Self-Weight

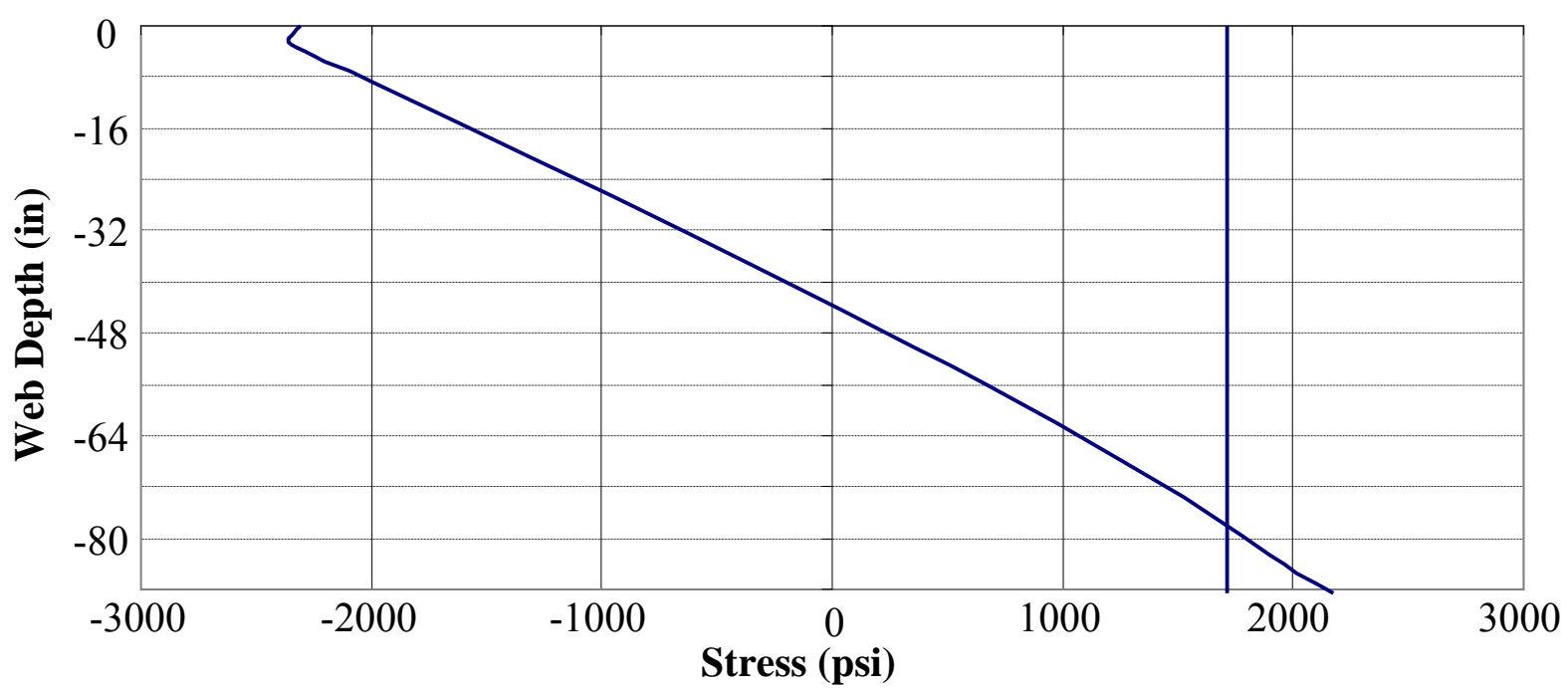

Figure 5.32 As-Built, Span 8N Bending and Axial Stresses Under Self-Weight 


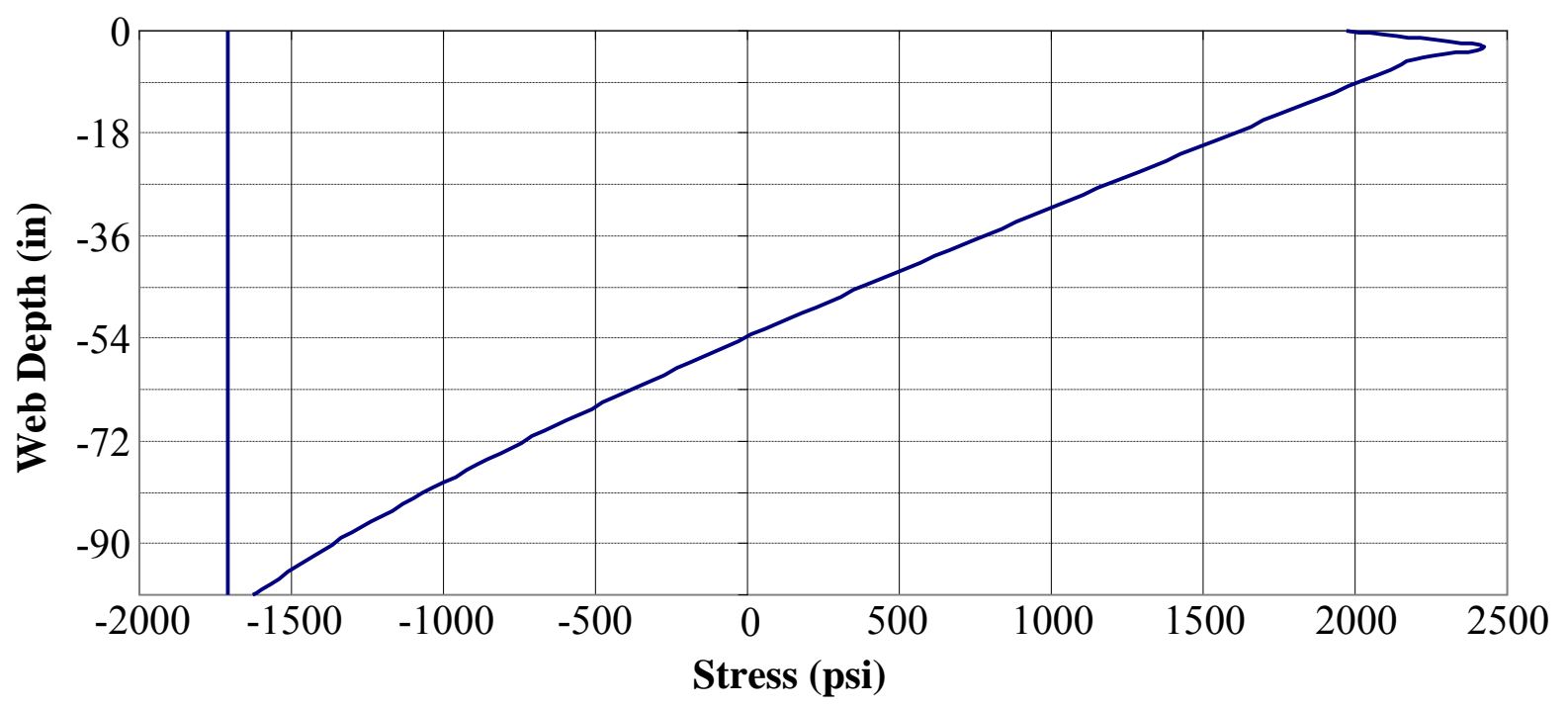

Figure 5.33 As-Built, Span 9N Bending and Axial Stresses Under Self-Weight

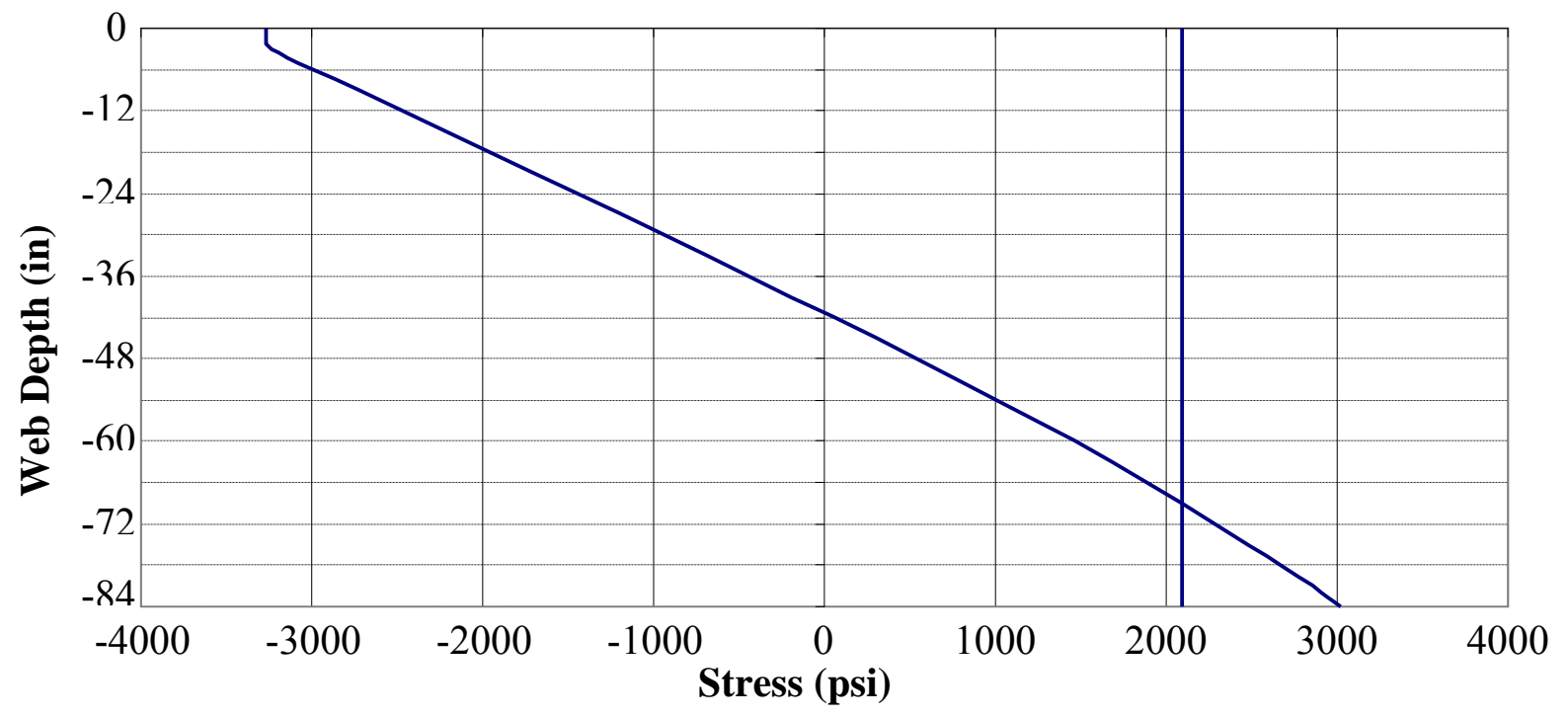

Figure 5.34 As-Built, Span 10N Bending and Axial Stresses Under Self-Weight

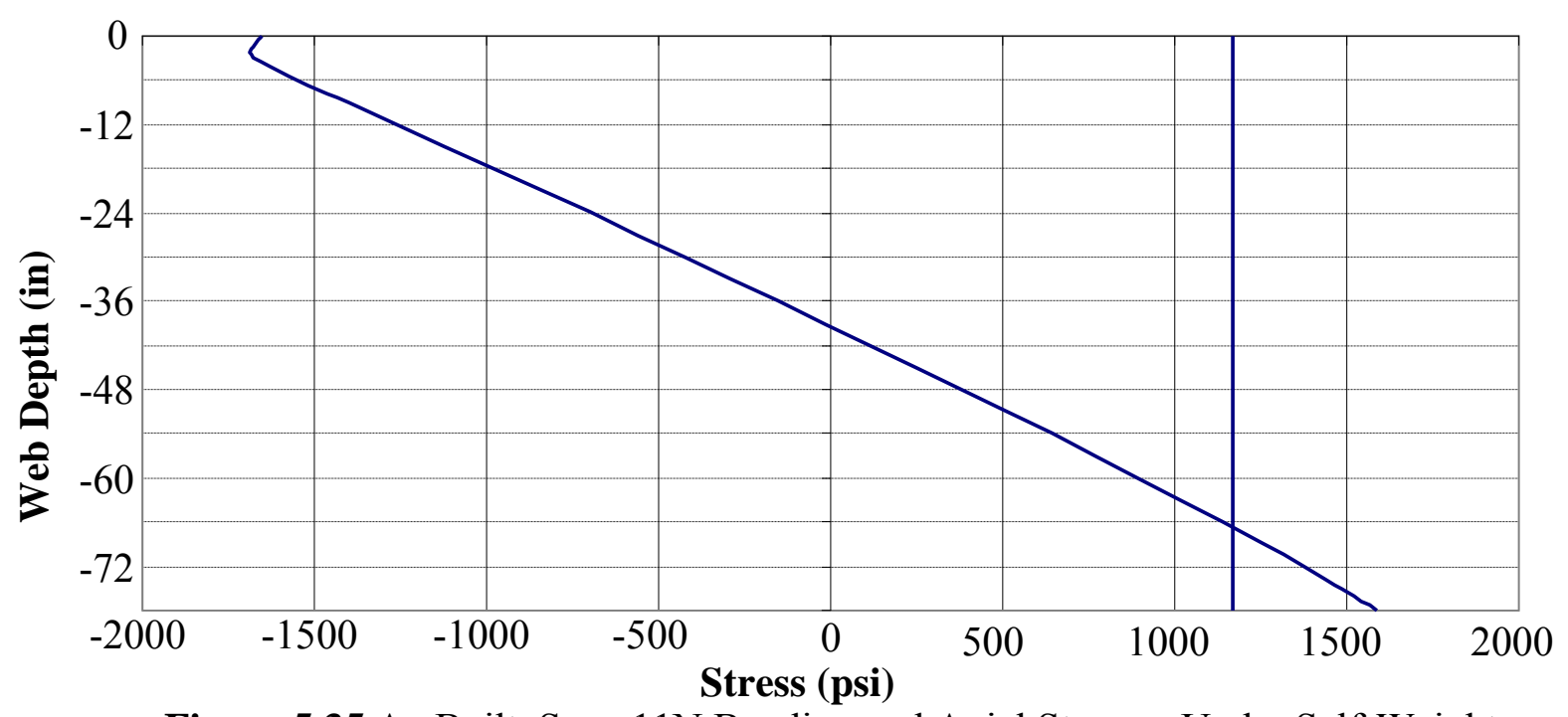

Figure 5.35 As-Built, Span 11N Bending and Axial Stresses Under Self-Weight 


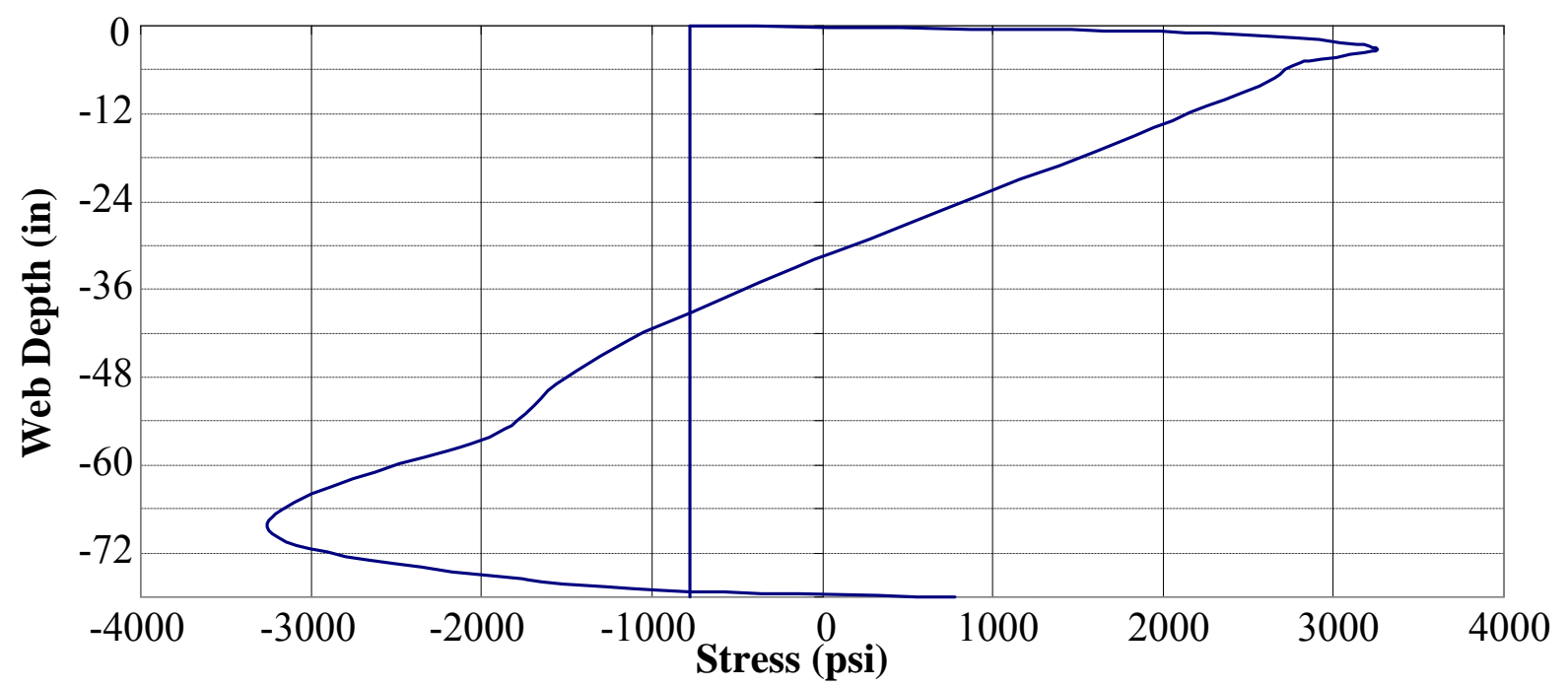

Figure 5.36 As-Built, Pier 7N Bending and Axial Stress Under Self-Weight

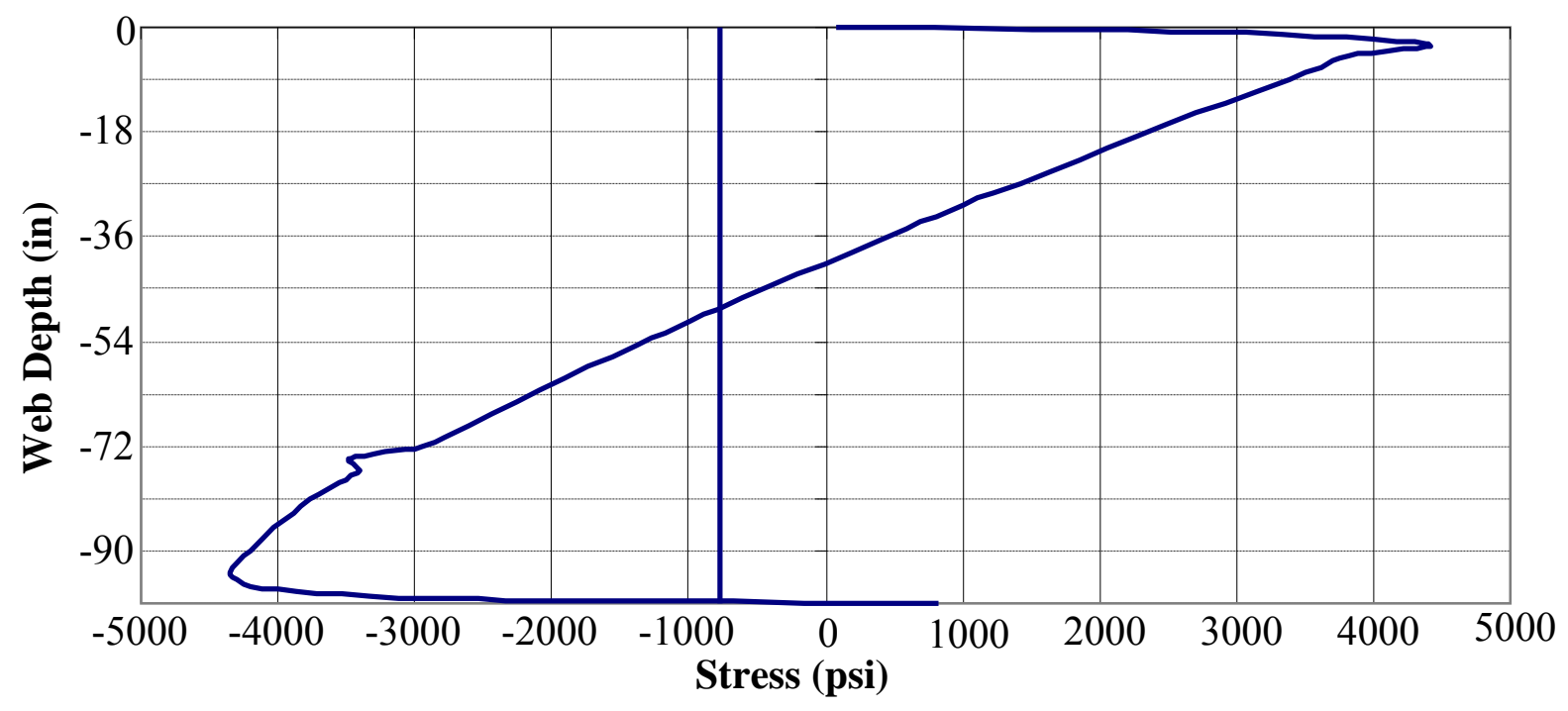

Figure 5.37 As-Built, Pier 8N Bending and Axial Stresses Under Self-Weight

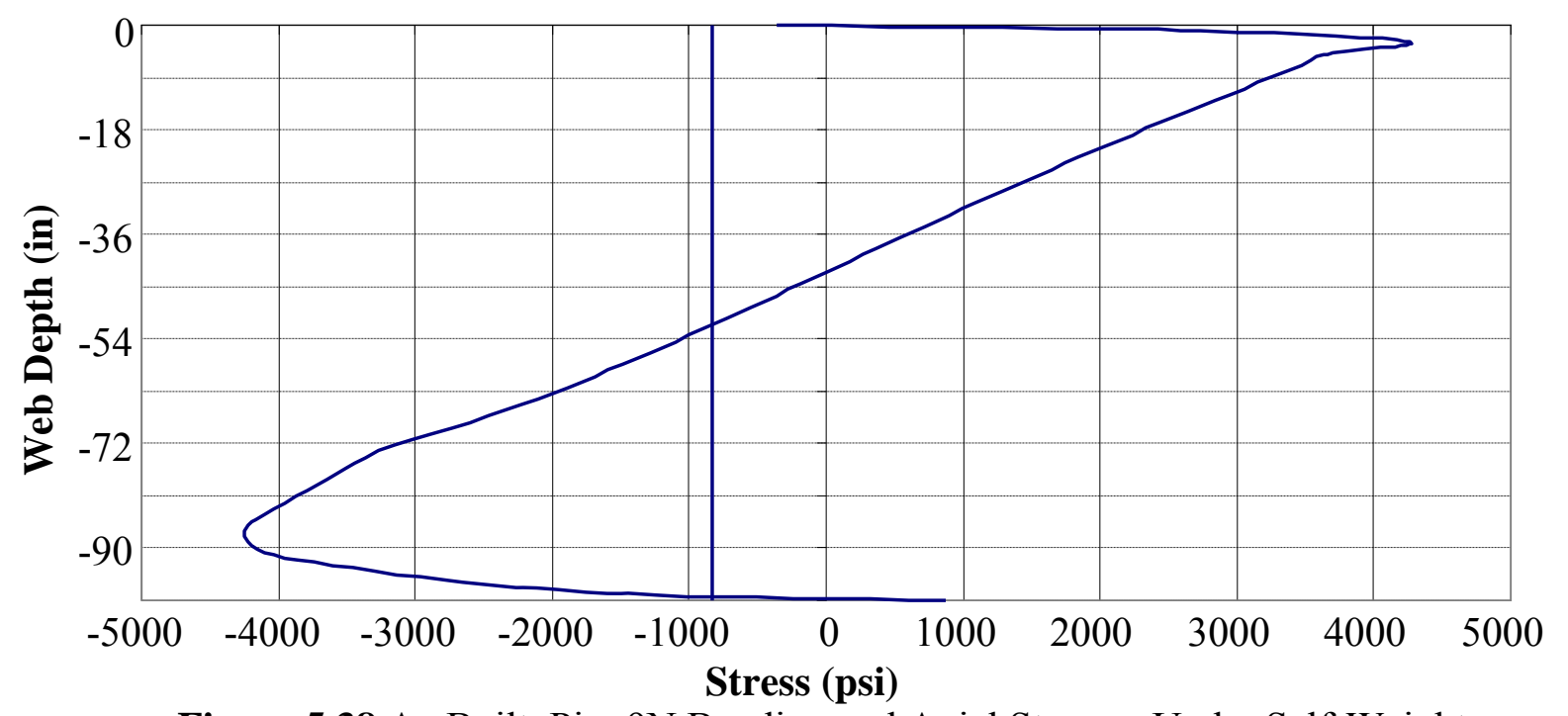

Figure 5.38 As-Built, Pier 9N Bending and Axial Stresses Under Self-Weight 


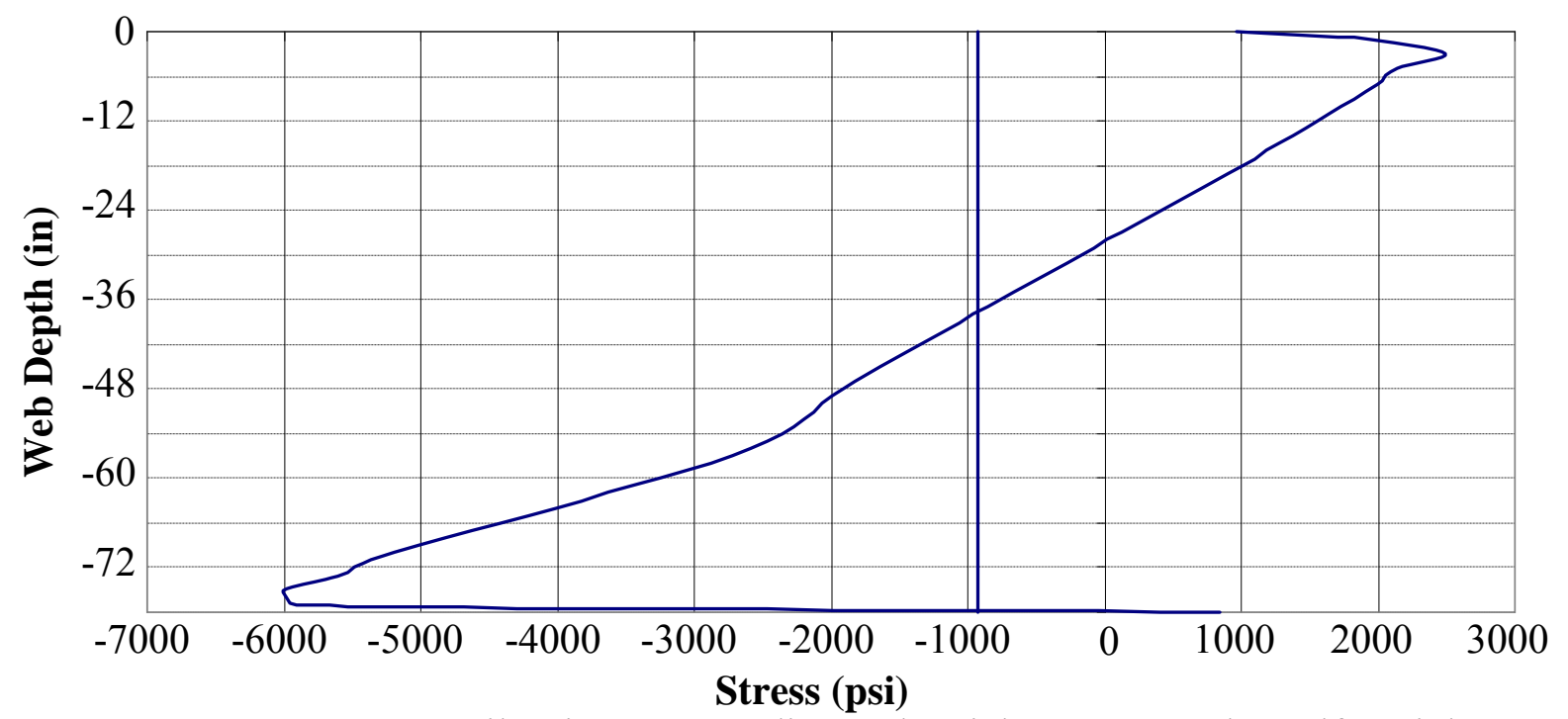

Figure 5.39 As-Built, Pier 10N Bending and Axial Stresses Under Self-Weight

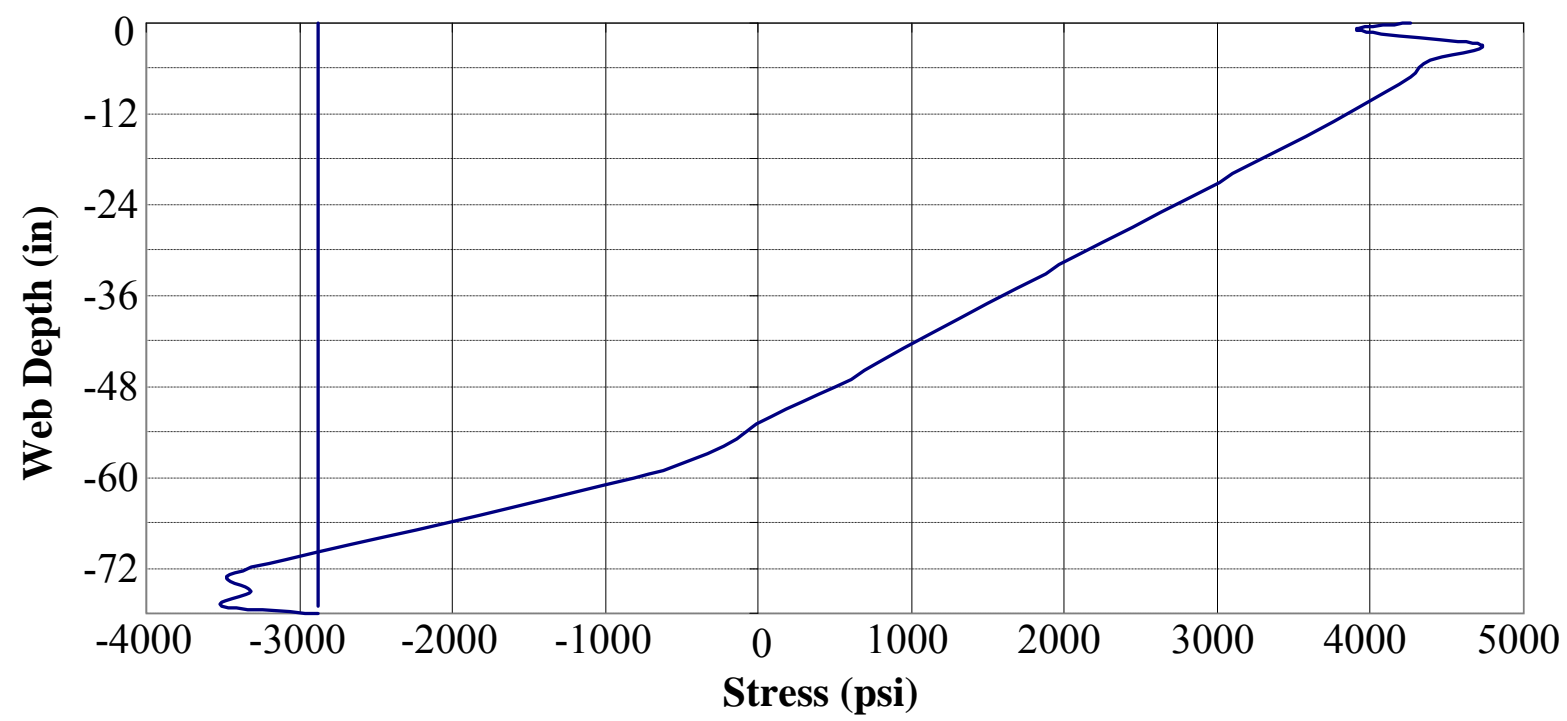

Figure 5.40 As-Built, Pier 11N Bending and Axial Stresses Under Self-Weight

As expected, under self-weight dead load the positive moment regions of the girders develop a constant axial tensile stress, while pier locations develop a constant axial compressive stress. Examining Figures 5.31-5.40, it is seen that constant axial stress of approximately 1-2 ksi psi develop at each cross-section under bridge self-weight. The largest bending stresses, though less than $6 \mathrm{ksi}$, occur at the support locations. 


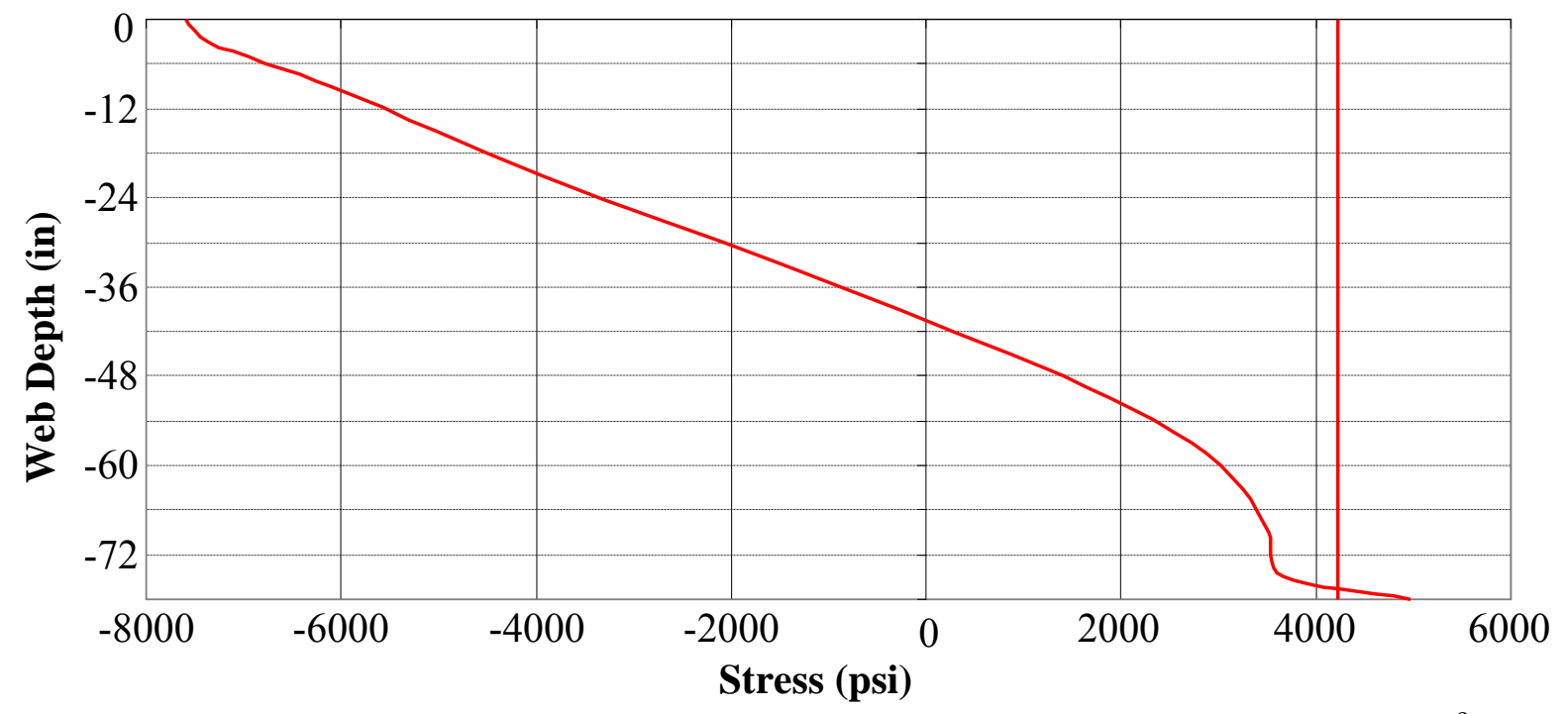

Figure 5.41 As-Built, Span $7 \mathrm{~N}$ Bending and Axial Stresses Under Temp $+90^{\circ} \mathrm{F}$

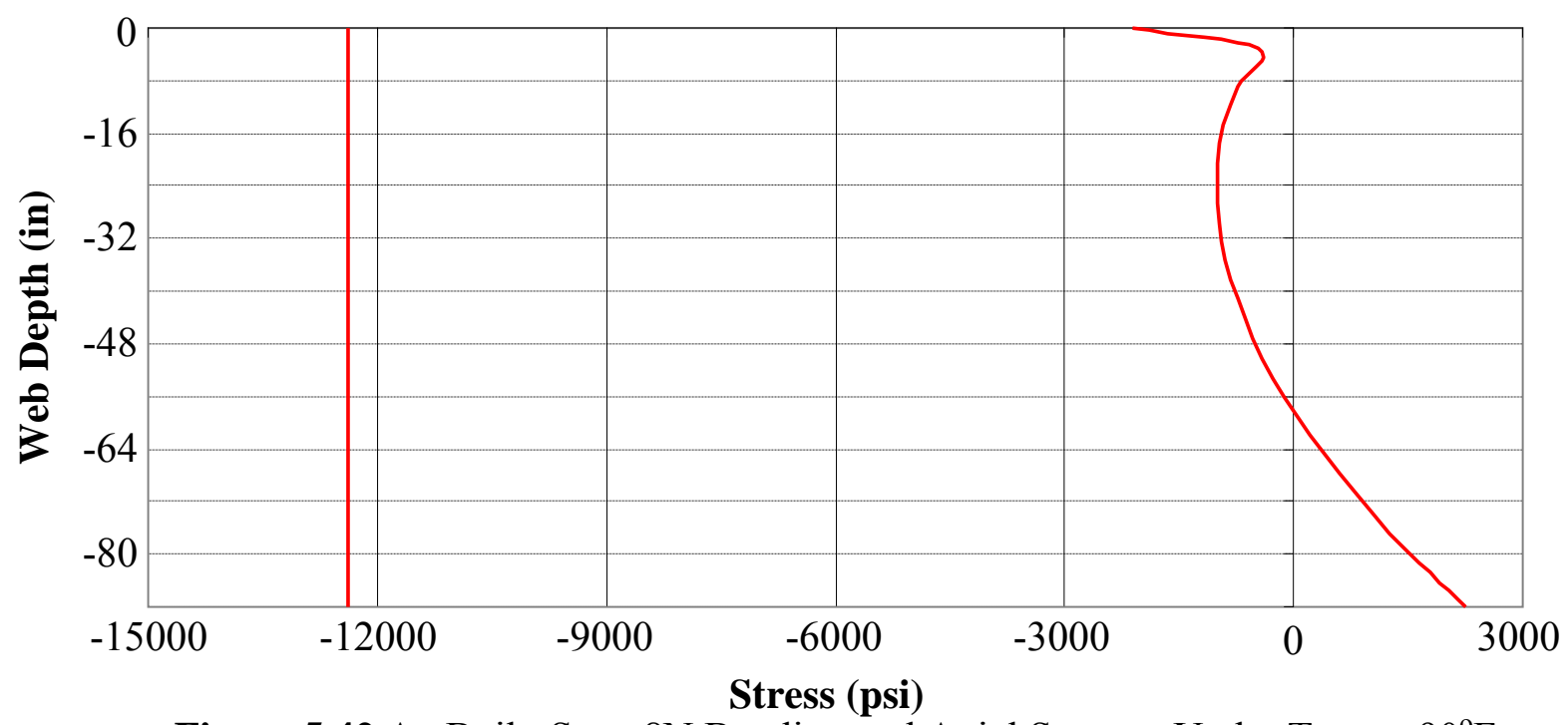

Figure 5.42 As-Built, Span $8 \mathrm{~N}$ Bending and Axial Stresses Under Temp $+90^{\circ} \mathrm{F}$

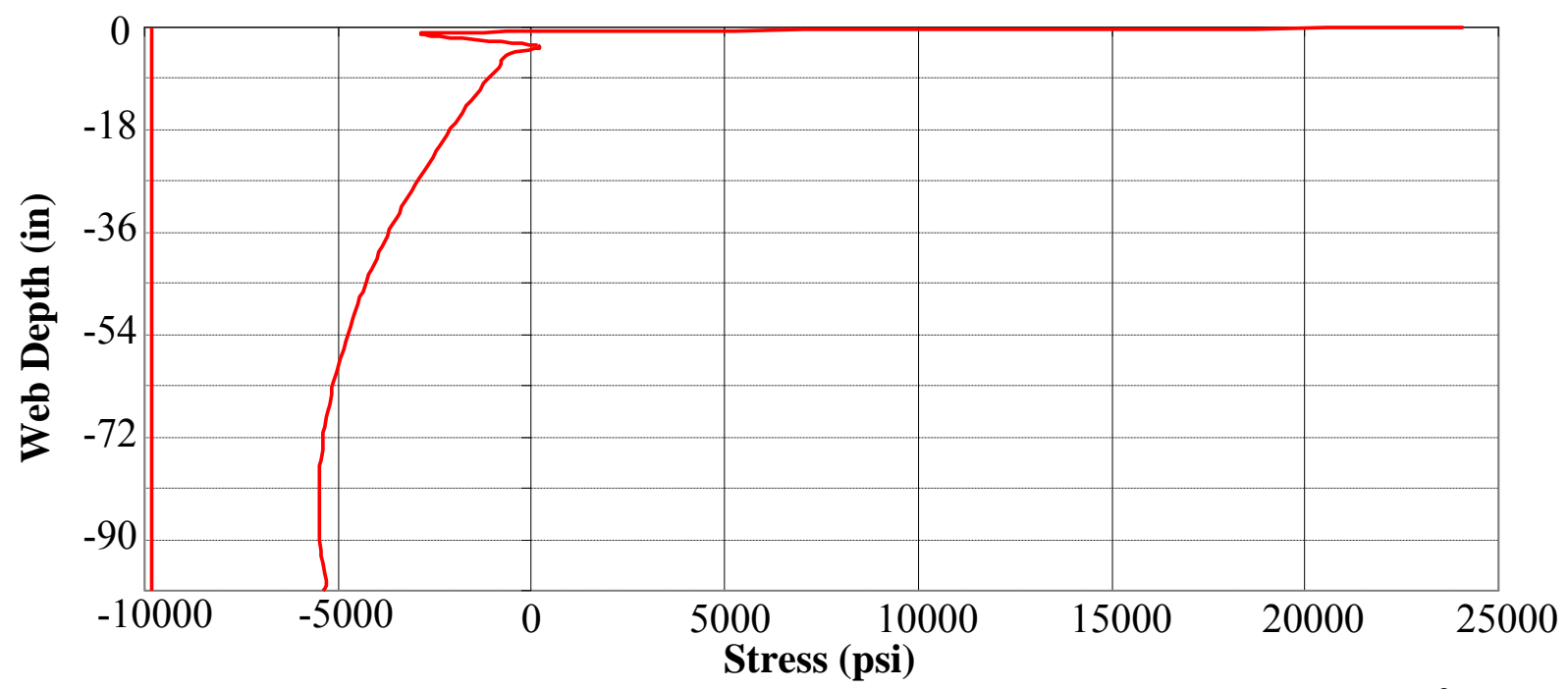

Figure 5.43 As-Built, Span 9N Bending and Axial Stresses Under Temp $+90^{\circ} \mathrm{F}$ 


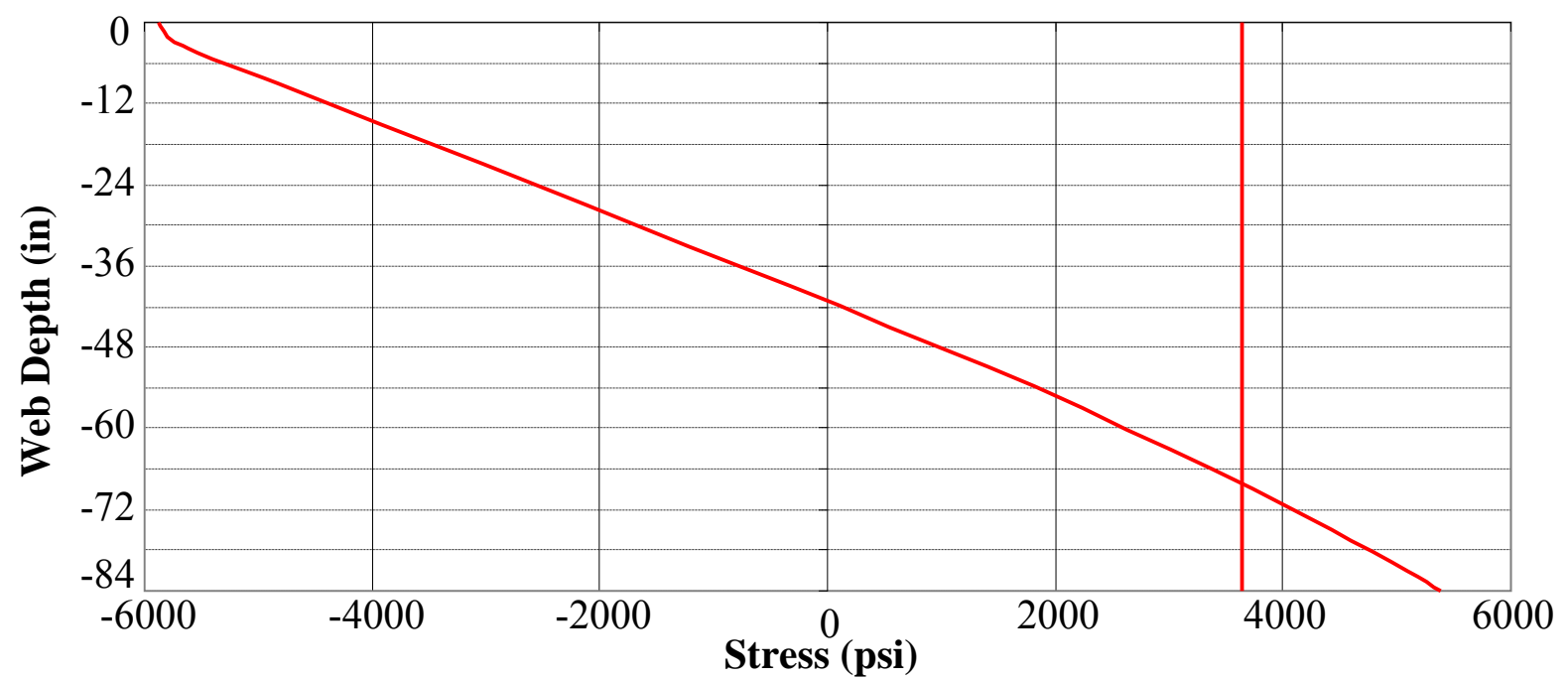

Figure 5.44 As-Built, Span 10N Bending and Axial Stresses Under Temp $+90^{\circ} \mathrm{F}$

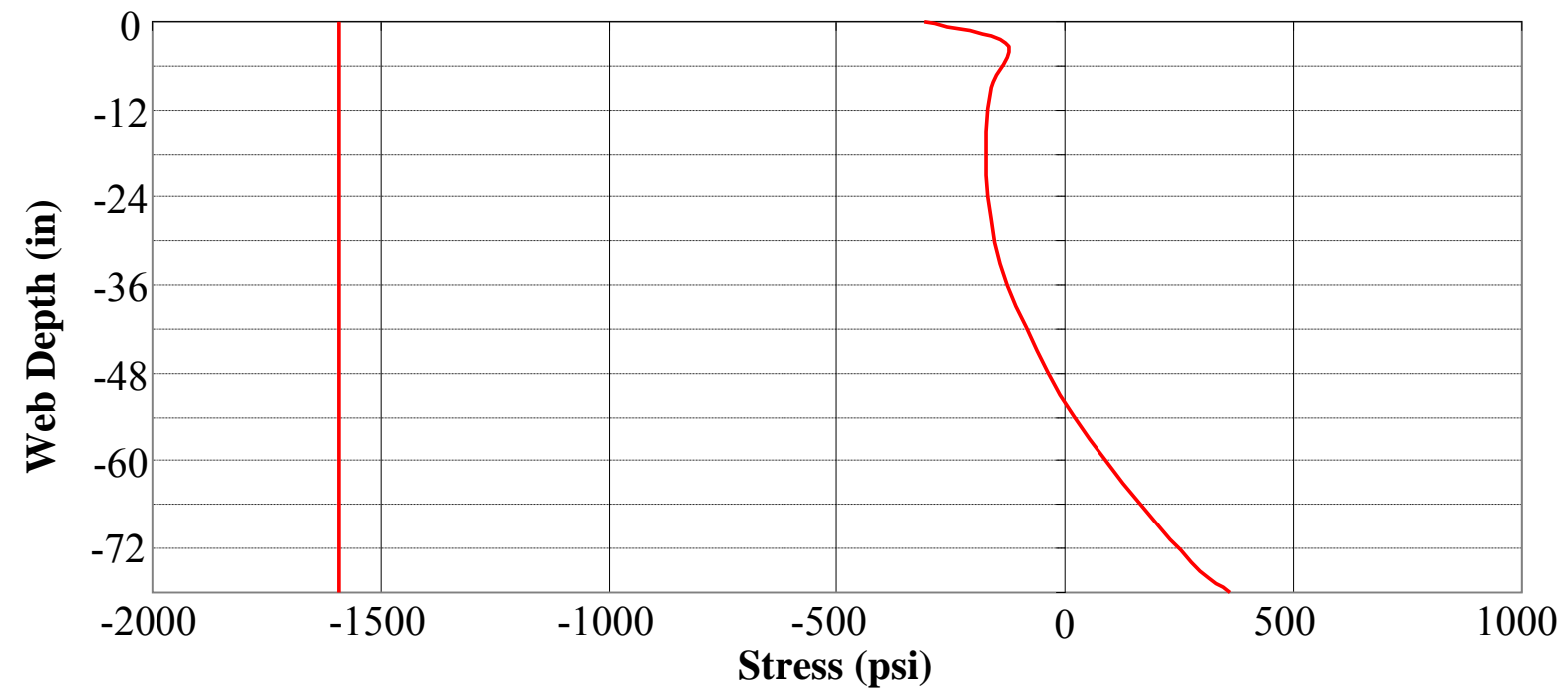

Figure 5.45 As-Built, Span 11N Bending and Axial Stresses Under Temp $+90^{\circ} \mathrm{F}$

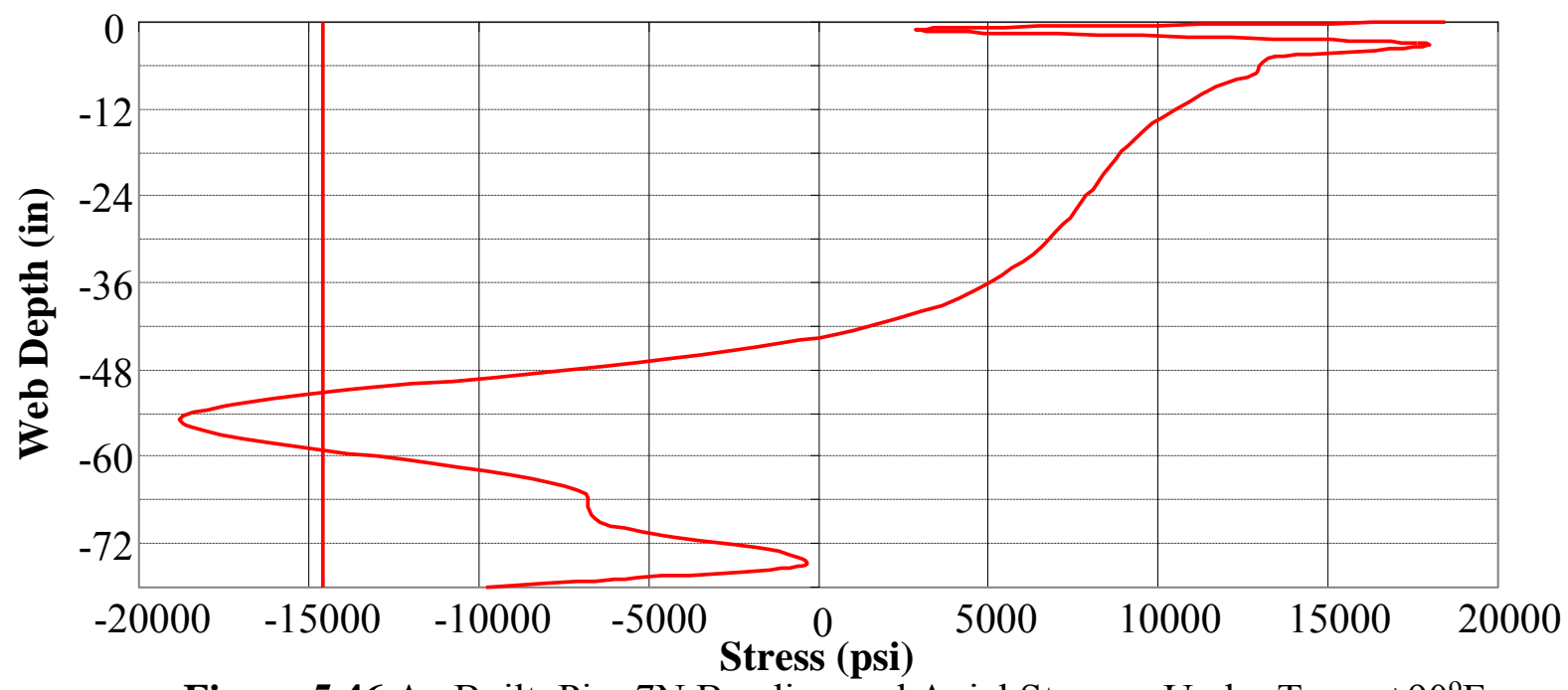

Figure 5.46 As-Built, Pier 7N Bending and Axial Stresses Under Temp $+90^{\circ} \mathrm{F}$ 


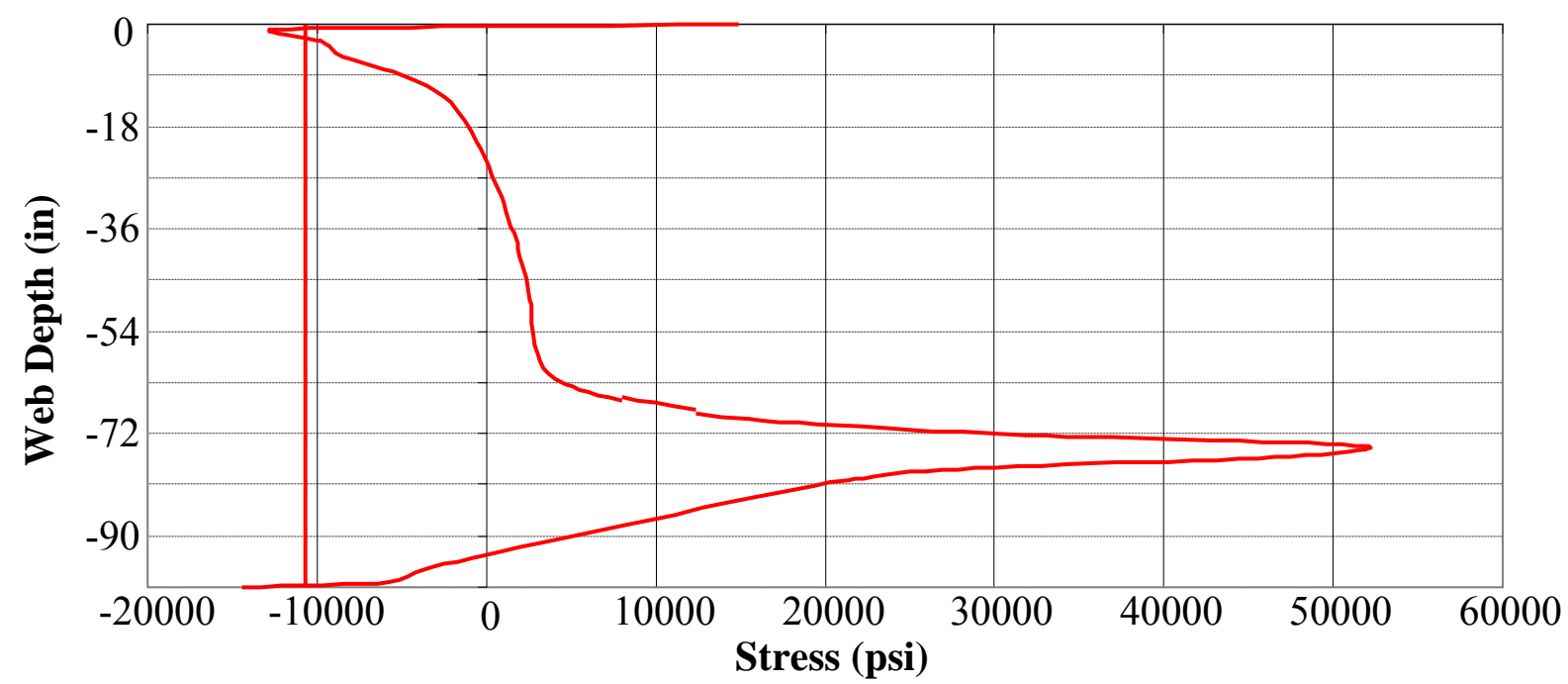

Figure 5.47 As-Built, Pier $8 \mathrm{~N}$ Bending and Axial Stresses Under Temp $+90^{\circ} \mathrm{F}$

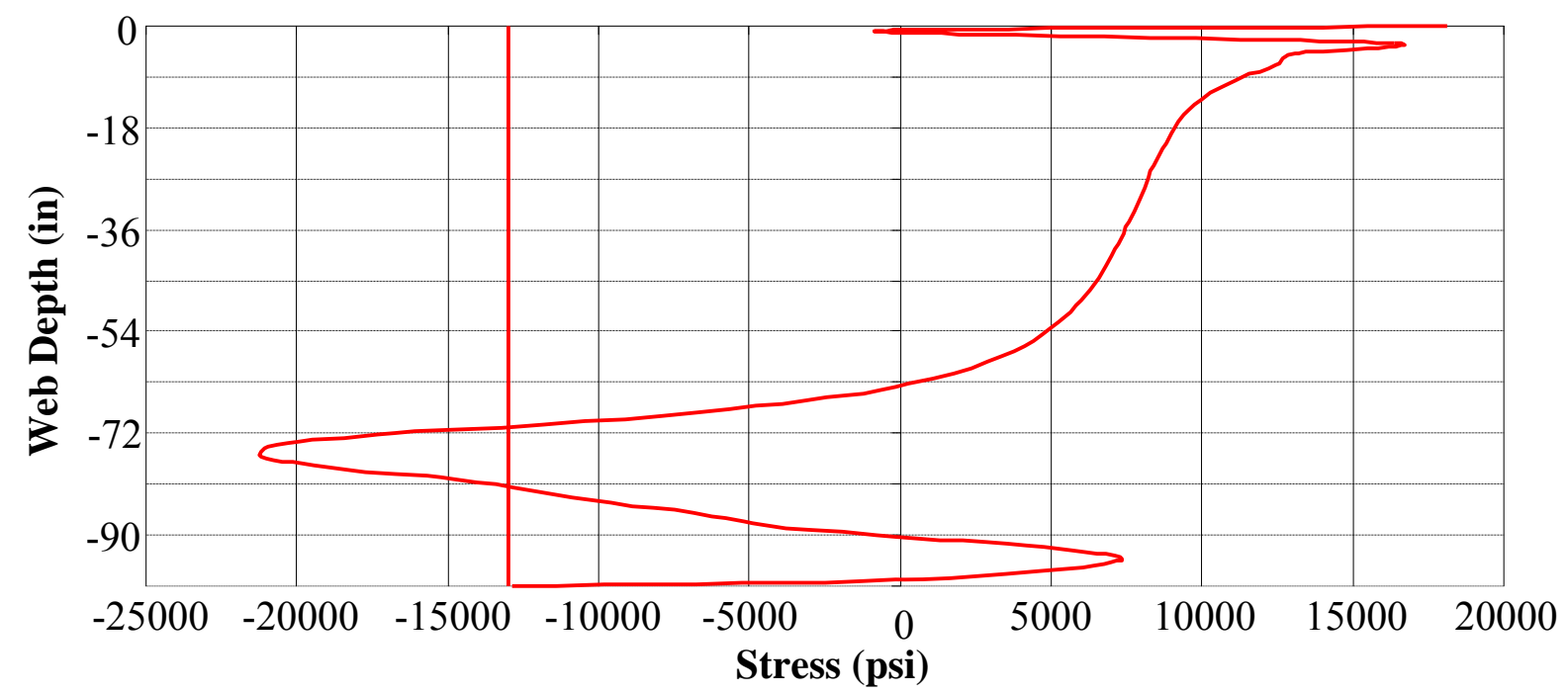

Figure 5.48 As-Built, Pier 9N Bending and Axial Stresses Under Temp $+90^{\circ} \mathrm{F}$

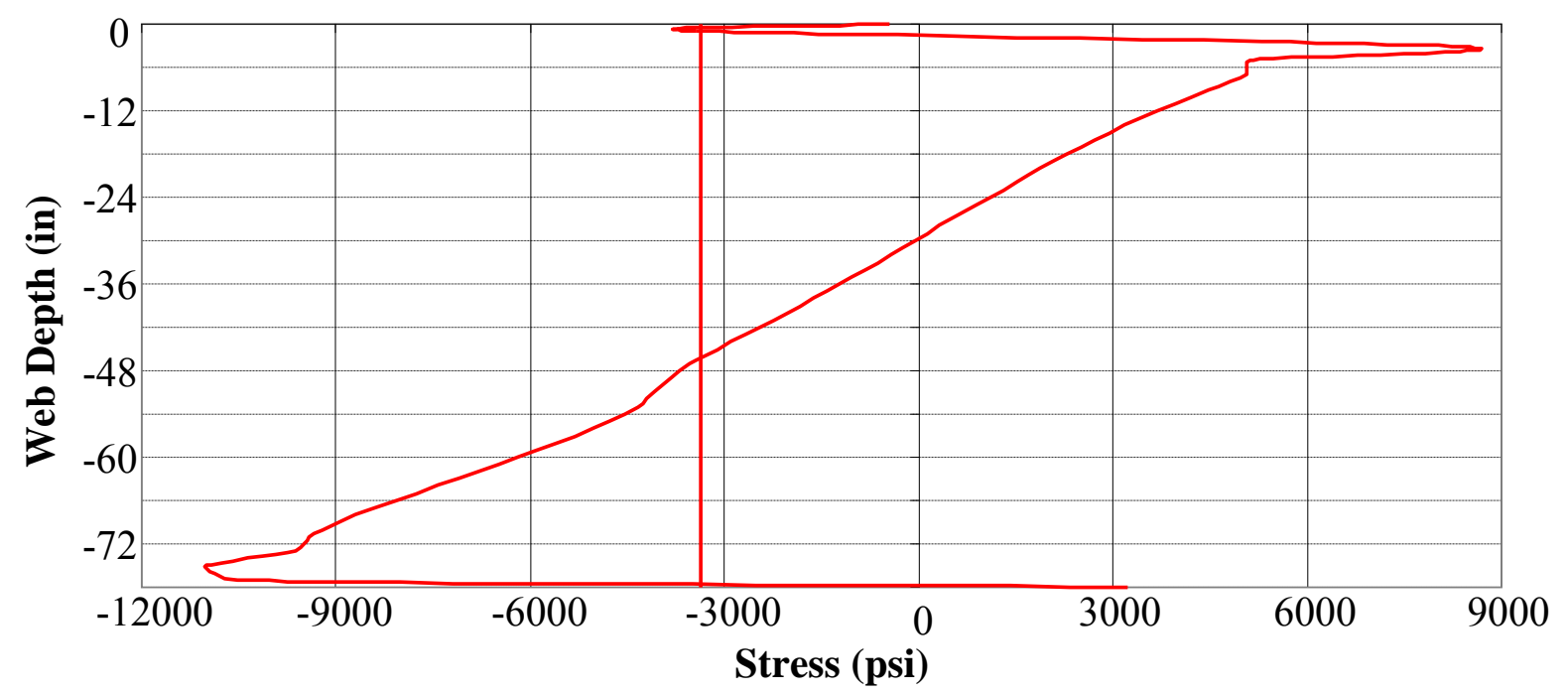

Figure 5.49 As-Built, Pier 10N Bending and Axial Stresses Under Temp $+90^{\circ} \mathrm{F}$ 


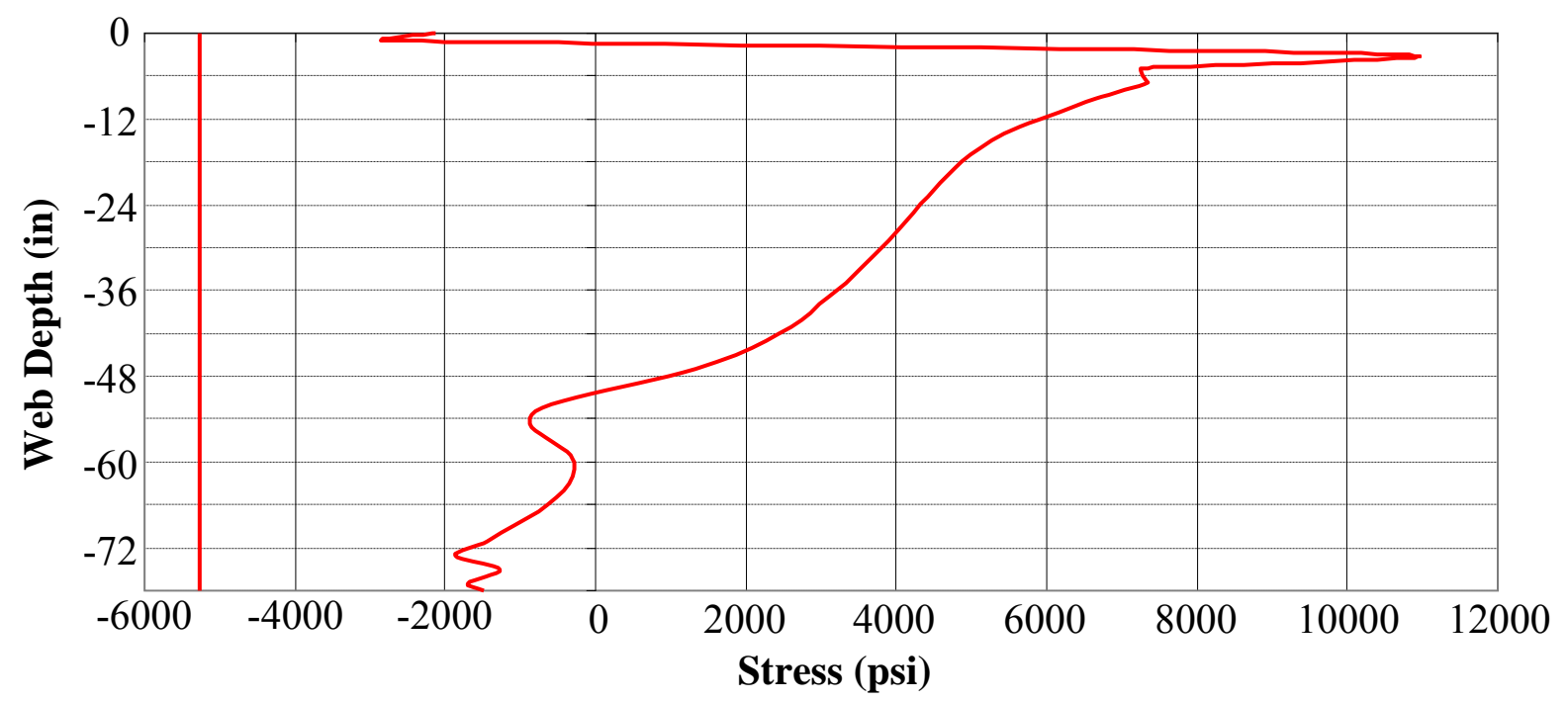

Figure 5.50 As-Built, Pier 11N Bending and Axial Stresses Under Temp $+90^{\circ} \mathrm{F}$

Figures 5.41-5.50 present bending and axial stress profiles for the $+90^{\circ} \mathrm{F}$ load case. When comparing the profiles for bridge self-weight and $+90^{\circ} \mathrm{F}$, large increases in axial stress are very apparent. The largest increases in axial stress occur as anticipated. Spans $8 \mathrm{~N}$ and $9 \mathrm{~N}$ are fully restrained from movement at their piers; therefore under the thermal loading these spans develop a higher magnitude of axial stress than the other spans. Span $8 \mathrm{~N}$ experiences a tensile stress of $1.7 \mathrm{ksi}$ due to bridge self-weight alone. When the temperature load is applied, a compressive stress of $12.4 \mathrm{ksi}$ is produced. The same behavior occurs in Span 9N, with compressive stresses increasing from 1.7 ksi under bridge self-weight to 9.8 ksi due to temperature load. Piers $7 \mathrm{~N}$ and $8 \mathrm{~N}$ experience compressive stresses of over $12 \mathrm{ksi}$, with Pier $7 \mathrm{~N}$ recording a compressive stress of nearly $15 \mathrm{ksi}$ due to the $+90^{\circ} \mathrm{F}$ temperature load. Piers $10 \mathrm{~N}$ and $11 \mathrm{~N}$ develop compressive stresses of $3.5 \mathrm{ksi}$ and $5.5 \mathrm{ksi}$ respectively. It is now apparent that even the free and guided bearings employed on the structure are providing a certain amount of restraint against thermal movement. This explains why axial stress increases in Spans $7 \mathrm{~N}, 10 \mathrm{~N}$, and $11 \mathrm{~N}$ when the bridge is subjected to thermal loading. 
Bending and axial stress profiles for each cross-section under $-/+60^{\circ} \mathrm{F}$ temperature loads are presented in Appendix B. A tensile stress develops in each midspan as a result of the $-60^{\circ} \mathrm{F}$ temperature load. A maximum tensile stress of approximately 4 ksi occurs in Span 8 N. Results are as expected in Spans $8 \mathrm{~N}$ and $9 \mathrm{~N}$, due to fully constrained thermal contraction of the girders causing the development of tensile stresses. As for the pier locations, Pier $11 \mathrm{~N}$ is the only cross-section not to develop tensile stresses. Compressive stresses were recorded at this location. These results strengthen the point that the free and guided bearings on the bridge are allowing some level of thermal stress to develop.

Under the $+60^{\circ} \mathrm{F}$ temperature load, behavior similar to the $+90^{\circ} \mathrm{F}$ load occurs. Spans $8 \mathrm{~N}, 9 \mathrm{~N}$ and $11 \mathrm{~N}$ develop axial compressive stresses, while in Spans $7 \mathrm{~N}$ and $10 \mathrm{~N}$ a tensile stress is produced. A maximum compressive stress of $10 \mathrm{ksi}$ is recorded in Span $9 \mathrm{~N}$ with a stress of 7.7 ksi produced in Span 8N. Each pier location develops a significant compressive stress. Pier $7 \mathrm{~N}$ experiences the largest stress, at $10 \mathrm{ksi}$. Piers $8 \mathrm{~N}$ and $9 \mathrm{~N}$ develop compressive stresses of $8 \mathrm{ksi}$ and $9 \mathrm{ksi}$ respectively. Lastly, the compressive stresses recorded at Piers $10 \mathrm{~N}$ and $11 \mathrm{~N}$ further reinforce the assumption that the free and guided bearings meant to relieve thermal stresses are actually providing a significant level of restraint.

Figures 5.51 and 5.52 provide a summary of the axial stress values recorded at each cross-section, under each load case. The compressive axial stress values from Figures 5.49 and 5.50 were used to calculate compressive-resistance ratios for each cross-section. The ratios show what percentage of the girders' compressive resistance capacity is consumed by thermal stresses. 


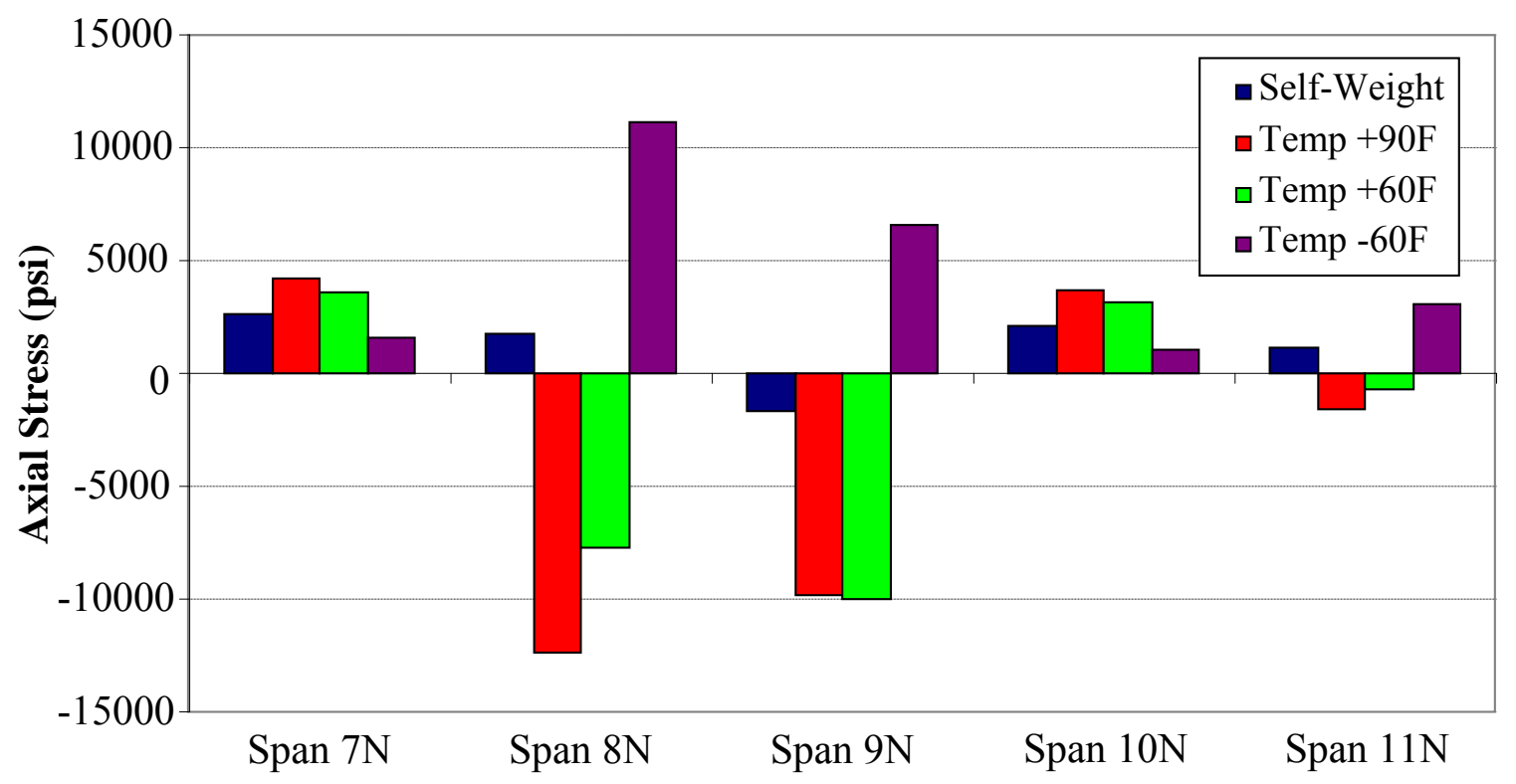

Figure 5.51 Axial Stress Comparison Under As-Built Bearing Arrangement (Span locations)

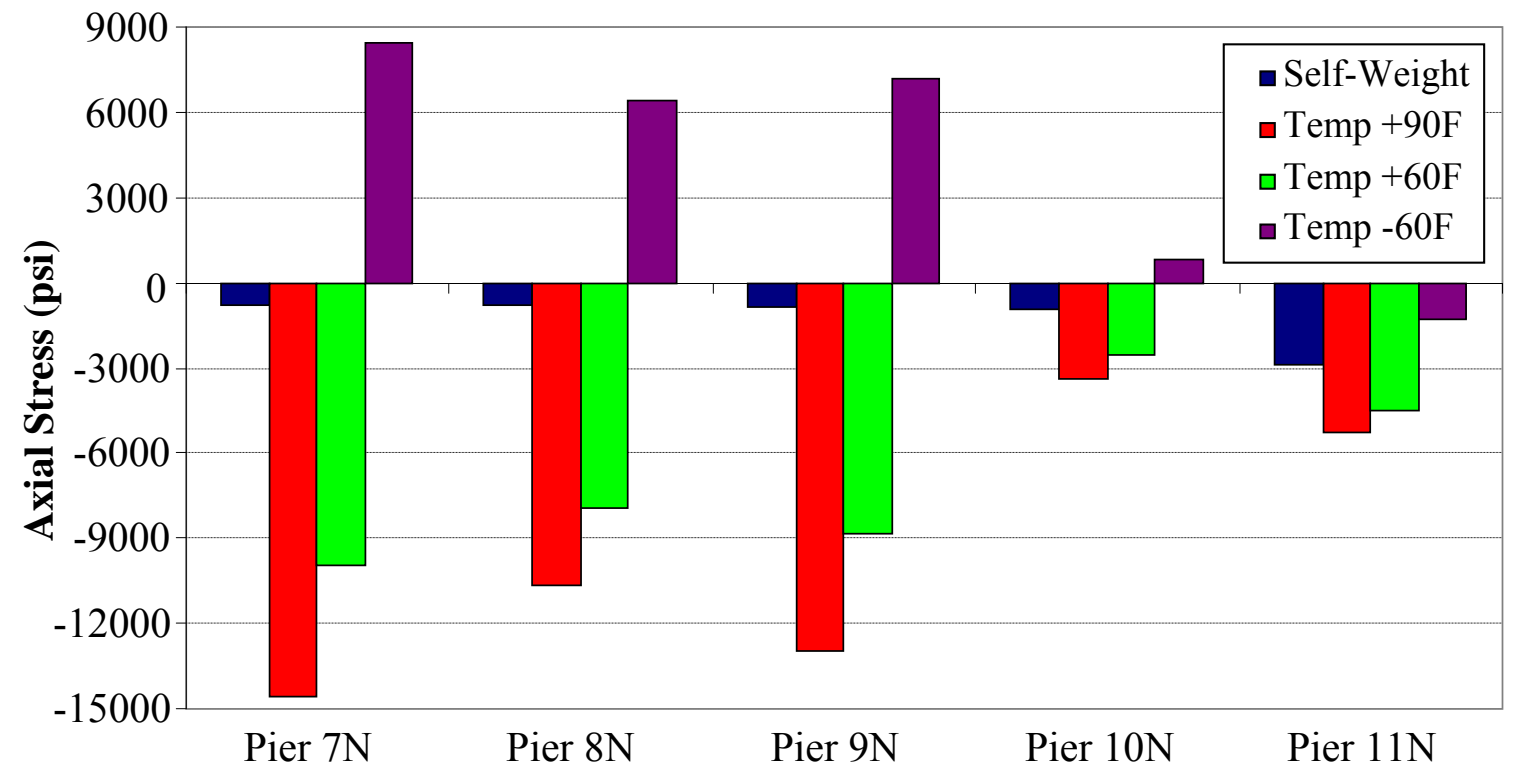

Figure 5.52 Axial Stress Comparison Under As-Built Bearing Arrangement (Pier locations) 
Figures 5.51 and 5.52 show the distinct variation in axial stress among all four load cases (bridge self-weight, $-60^{\circ} \mathrm{F},+60^{\circ} \mathrm{F}$, and $+90^{\circ} \mathrm{F}$ temperature loads). Several conclusions are able to be drawn from these two figures. First, from Figure 5.51 it is easily noticed that Spans $8 \mathrm{~N}$ and $9 \mathrm{~N}$ develop very significant magnitudes of compressive stress under the $+60^{\circ} \mathrm{F}$ and $+90^{\circ} \mathrm{F}$ temperature loads. The largest tensile stress produced by the FE model is approximately $11 \mathrm{ksi}$ near the midspan of Span $8 \mathrm{~N}$. According to Figure 5.52, the axial stresses produced at the support locations are greater in magnitude than locations near midspan. Piers $7 \mathrm{~N}, 8 \mathrm{~N}$, and $9 \mathrm{~N}$ develop large compressive stresses due to the $+60^{\circ} \mathrm{F}$ and $+90^{\circ} \mathrm{F}$ temperature loads. Tensile stresses near $9 \mathrm{ksi}$ are produced under the $-60^{\circ} \mathrm{F}$ temperature load.

Using Equations 5.2-5.5, a percentage was calculated by comparing the axial stress produced by the FE model to the factored resistance provided by the girder as calculated using AASHTO (2007) compression member equations. Figures 5.53 and 5.54 summarize the results comparing the FE model axial stress results to the calculated factored compressive resistance.

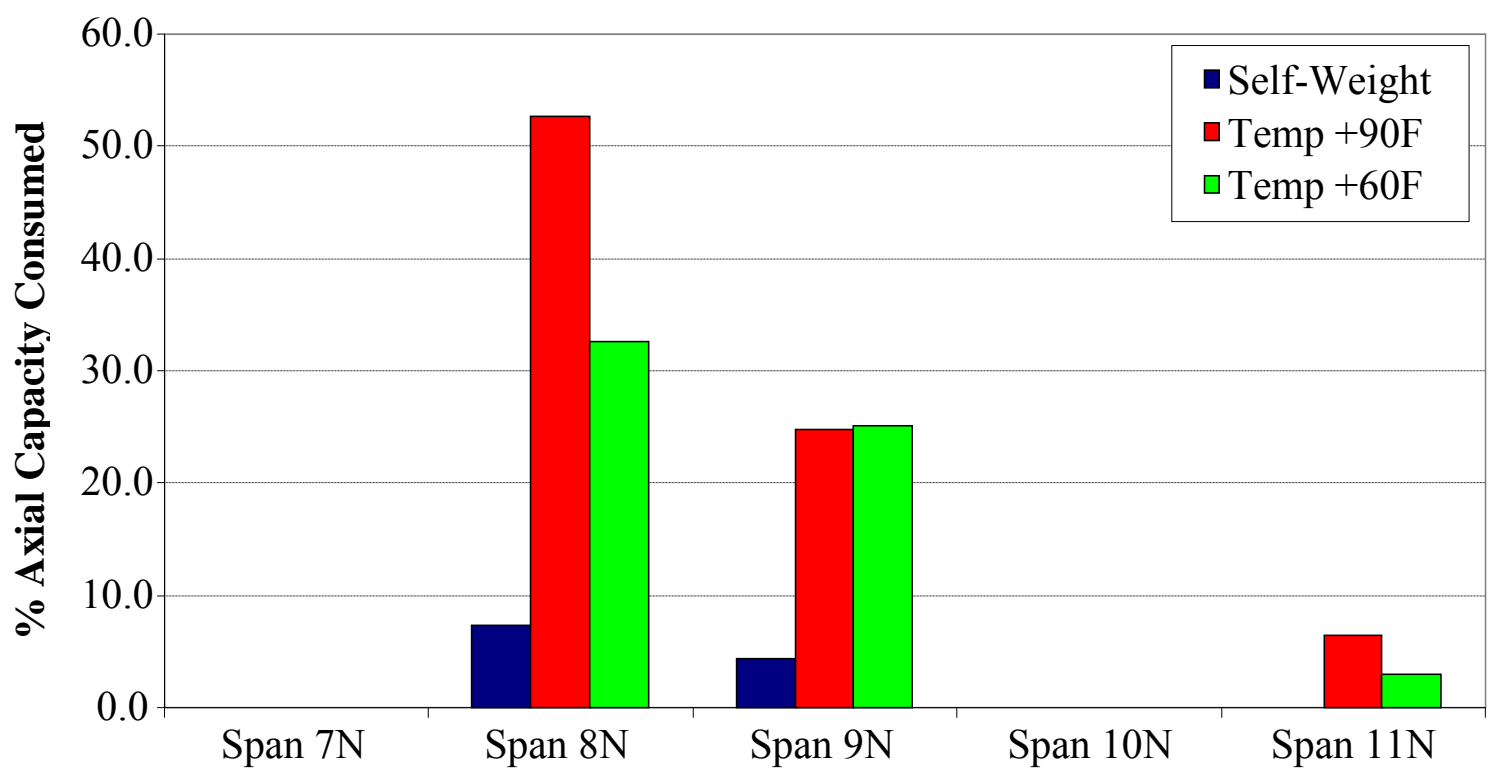

Figure 5.53 Axial Capacity Consumed (Span locations) 


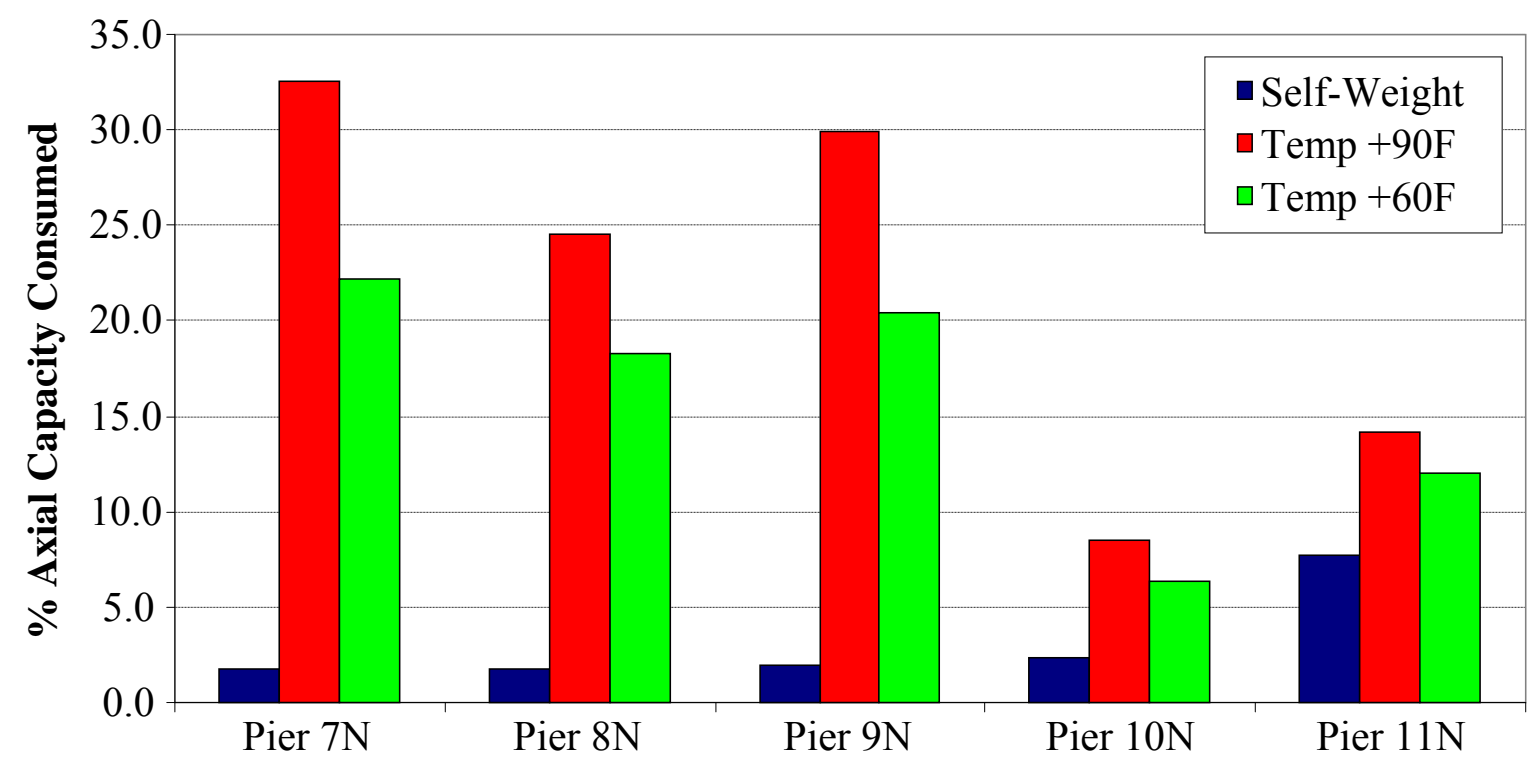

Figure 5.54 Axial Capacity Consumed (Pier locations)

Under the $+90^{\circ} \mathrm{F}$ temperature load applied, the axial stress in Span $8 \mathrm{~N}$ reaches approximately $52 \%$ of the calculated factored compressive resistance of the girder. At Piers $7 \mathrm{~N}, 8 \mathrm{~N}$ and $9 \mathrm{~N}$, axial stress reaches approximately $25-33 \%$ of the girder's factored compressive resistance. Tensile stress is produced in Spans $7 \mathrm{~N}$ and 10N. Piers $10 \mathrm{~N}$ and $11 \mathrm{~N}$, where free and guided bearings are installed, the ratios reach $8.5 \%$ and $14 \%$ respectively. Figures 5.51-5.54 provide excellent evidence that axial forces cannot be neglected on this bridge. The current bearing arrangement does not relieve thermal stresses as it should. With the combined effects of the restraining bearing arrangement and positive $(+)$ temperature loads resulting in axial compression, stresses exceed $30 \%$ of the girders total axial capacity, with one cross-section showing a compressive stress exceeding $50 \%$ of capacity. These stresses will have major implications on the ultimate load-carrying capacity of the bridge girders. 


\subsection{THERMAL LOADING EFFECTS ON BRIDGE GIRDER CAPACITY}

The effect of the thermal stresses on bridge capacity is investigated in this section.

The total capacity of a steel girder web plate can be represented by the relationship shown in Equation 5.5.

$$
\frac{\sigma_{\text {axial }}}{\sigma_{\text {allowable(axial) }}}+\frac{\sigma_{\text {benidng }}}{F_{c r}} \leq 1.0
$$

In Equation 5.5, which represents a structural capacity ratio, $F_{c r}$ represents the maximum allowable bending stress of a web plate without longitudinal stiffeners as defined in AASHTO (2003) Article 6.2.1. The maximum allowable axial stress is determined from Equations 5.2-5.4. In Equation 5.5, this value is the compressive resistance. Maximum bending and axial stress values from the stress profiles were used in order to determine capacity ratios. If the capacity ratio in Equation 5.5 is greater than 1.0, the girder's allowable capacity has been exceeded, and it may be considered unstable. Using Equation 5.2 through 5.5, each cross-section analyzed in previous sections will be investigated to determine the stability of the girder under thermal load. Tables 5.1 and 5.2 present the results produced by Equation 5.5 for two load cases $\left(+60^{\circ} \mathrm{F}\right.$ and $\left.+90^{\circ} \mathrm{F}\right)$ at the cross-sections at each cross-section.

Table 5.1 Bridge Girder Capacity Analysis $\left(+60^{\circ} \mathrm{F}\right)$

\begin{tabular}{|c|c|c|c|c|c|c|c|}
\hline & $\begin{array}{l}\sigma_{\text {axial }} \\
(p s i)\end{array}$ & $\begin{array}{c}\sigma_{\text {axial allowable }} \\
\text { (psi) }\end{array}$ & $\sigma_{\text {axial/axial allowable }}$ & $\begin{array}{c}\sigma_{\text {bending }} \\
\text { (psi) }\end{array}$ & $\begin{array}{c}\sigma_{\text {bending allowable }} \\
\text { (psi) }\end{array}$ & $\sigma_{\text {bending/bending allowable }}$ & ratio \\
\hline Span $7 \mathrm{~N}$ & & & & 6288 & 50000 & 0.126 & 0.126 \\
\hline Span 8N & 7680 & 23516 & 0.327 & 1251 & 11340.5 & 0.110 & 0.437 \\
\hline Span $9 \mathbf{N}$ & 9960 & 39574 & 0.252 & 1100 & 11340.5 & 0.097 & 0.349 \\
\hline Span $10 \mathrm{~N}$ & & & & 4975 & 50000 & 0.100 & 0.100 \\
\hline Span 11N & 743 & 24911 & 0.030 & 611 & 9773 & 0.063 & 0.092 \\
\hline Pier $7 \mathrm{~N}$ & 9934 & 44733 & 0.222 & 10944 & 17700 & 0.618 & 0.840 \\
\hline Pier 8N & 7920 & 43357 & 0.183 & 5917 & 10785 & 0.549 & 0.731 \\
\hline Pier 9N & 8863 & 43453 & 0.204 & 12918 & 14953 & 0.864 & 1.068 \\
\hline Pier $10 \mathrm{~N}$ & 2522 & 39760 & 0.063 & 9304 & 21064 & 0.442 & 0.505 \\
\hline Pier $11 \mathrm{~N}$ & 4476 & 37225 & 0.120 & 2331 & 23118 & 0.101 & 0.221 \\
\hline
\end{tabular}


The capacity ratios presented in Table 5.1 , for the $+60^{\circ} \mathrm{F}$ load case, show that the midspan cross-sections analyzed are satisfactory. The structural capacity ratio is much less than 1.0. However, concerns arise when evaluating the cross-sections at the pier support locations. The capacity ratio at Pier $9 \mathrm{~N}$ is greater than 1.0 , while the ratio at Piers $7 \mathrm{~N}$ and $8 \mathrm{~N}$ $73 \%$ and $84 \%$ respectively. The axial component of Equation 5.5 is roughly $20 \%$ for the three pier support locations mentioned; however the bending stress component is the major contributor to the capacity ratio. The axial stress component of the locations in Spans $8 \mathrm{~N}$ and $9 \mathrm{~N}$ is around $30 \%$. Table 5.2 presents the capacity ratios for the $+90^{\circ} \mathrm{F}$ temperature load.

Table 5.2 Bridge Girder Capacity Analysis $\left(+90^{\circ} \mathrm{F}\right)$

\begin{tabular}{|c|c|c|c|c|c|c|c|}
\hline & $\begin{array}{l}\sigma_{\text {axial }} \\
(p s i)\end{array}$ & $\begin{array}{c}\sigma_{\text {axial allowable }} \\
\text { (psi) }\end{array}$ & $\sigma_{\text {axial/axial allowable }}$ & $\begin{array}{c}\sigma_{\text {bending }} \\
\text { (psi) }\end{array}$ & $\begin{array}{c}\sigma_{\text {bending allowable }} \\
(\mathrm{psi})\end{array}$ & $\sigma_{\text {bending/bending allowable }}$ & ratio \\
\hline Span 7N & & & & 7350 & 50000 & 0.147 & 0.147 \\
\hline Span $8 \mathrm{~N}$ & 12377 & 23516 & 0.526 & 1002 & 11340.5 & 0.088 & 0.615 \\
\hline Span 9N & 9818 & 39574 & 0.248 & 5500 & 11340.5 & 0.485 & 0.733 \\
\hline Span $10 \mathrm{~N}$ & & & & 5374 & 50000 & 0.107 & 0.107 \\
\hline Span $11 \mathrm{~N}$ & 1592 & 24911 & 0.064 & 176 & 9773 & 0.018 & 0.082 \\
\hline Pier $7 \mathrm{~N}$ & 14573 & 44733 & 0.326 & 18825 & 17700 & 1.064 & 1.389 \\
\hline Pier 8N & 10651 & 43357 & 0.246 & 12489 & 10785 & 1.158 & 1.404 \\
\hline Pier 9N & 12983 & 43453 & 0.299 & 21195 & 14953 & 1.417 & 1.716 \\
\hline Pier 10N & 3362 & 39760 & 0.085 & 11038 & 21064 & 0.524 & 0.609 \\
\hline Pier 11N & 5279 & 37225 & 0.142 & 2783 & 23118 & 0.120 & 0.262 \\
\hline
\end{tabular}

The ratios calculated in Table 5.2 show that the cross-sections at Pier $7 \mathrm{~N}, 8 \mathrm{~N}$, and $9 \mathrm{~N}$ have exceeded the total capacity of the girder. Again, the bending stress component is the dominant term. The bending capacity portion of the overall capacity ratio is actually greater than 1.0 . For these pier locations, the axial stress ratio is roughly $30 \%$. For the midspan locations, all capacity ratios are less than 1.0; however the axial capacity component for Spans $8 \mathrm{~N}$ and $9 \mathrm{~N}$ are $52 \%$ and $25 \%$ respectively.

The capacity ratios calculated using Equation 5.5 and presented in Tables 5.2 and 5.3 show that several locations in the FE bridge model develop bending and axial stresses that cause the total stress state in the girders to surpass its total capacity. This behavior mainly 
occurs in the negative moment regions over the pier supports. At these locations, the bending stress component is the dominant term, while axial stress consumes between $25-50 \%$ of the girders' capacity. At several locations, the compressive axial stress ratio exceeds $18 \%$ under the $+60^{\circ} \mathrm{F}$ and $+90^{\circ} \mathrm{F}$ load cases. According to these results, substantial thermal (axial) stresses have developed in the plate girders. The development of the large thermal stresses can be attributed, mostly, to the restraining nature of the current bearing arrangement. The current arrangement implements too many fully fixed bearings, which do not aid in relieving thermal stresses. These thermal stresses, typically neglected during the design process, are shown here to have a very significant impact on structural capacity. 


\subsection{LIVE LOAD ANALYSIS}

In this section, AASHTO design live load introduced in chapter four is again applied to the FE bridge model in order to investigate bridge behavior due to the combination of live load and temperature effects. Typical bridge designs loads are live loads, mainly resulting in flexural stresses. As shown in the previous sections, axial stresses have developed in the FE bridge model due to thermal loading, and the addition of live loads may create even greater concerns regarding bridge capacity. The AASHTO HL-93 live load is applied to the FE model to determine the level of stress generated due to combined load effects. Longitudinal stresses, as well as bending and axial stresses, are obtained for the cross-section near the midspan of Span $8 \mathrm{~N}$ and at Pier $7 \mathrm{~N}$ under bridge self-weight and the $+60^{\circ} \mathrm{F}$ temperature load cases are presented in Figures 5.55-5.62.

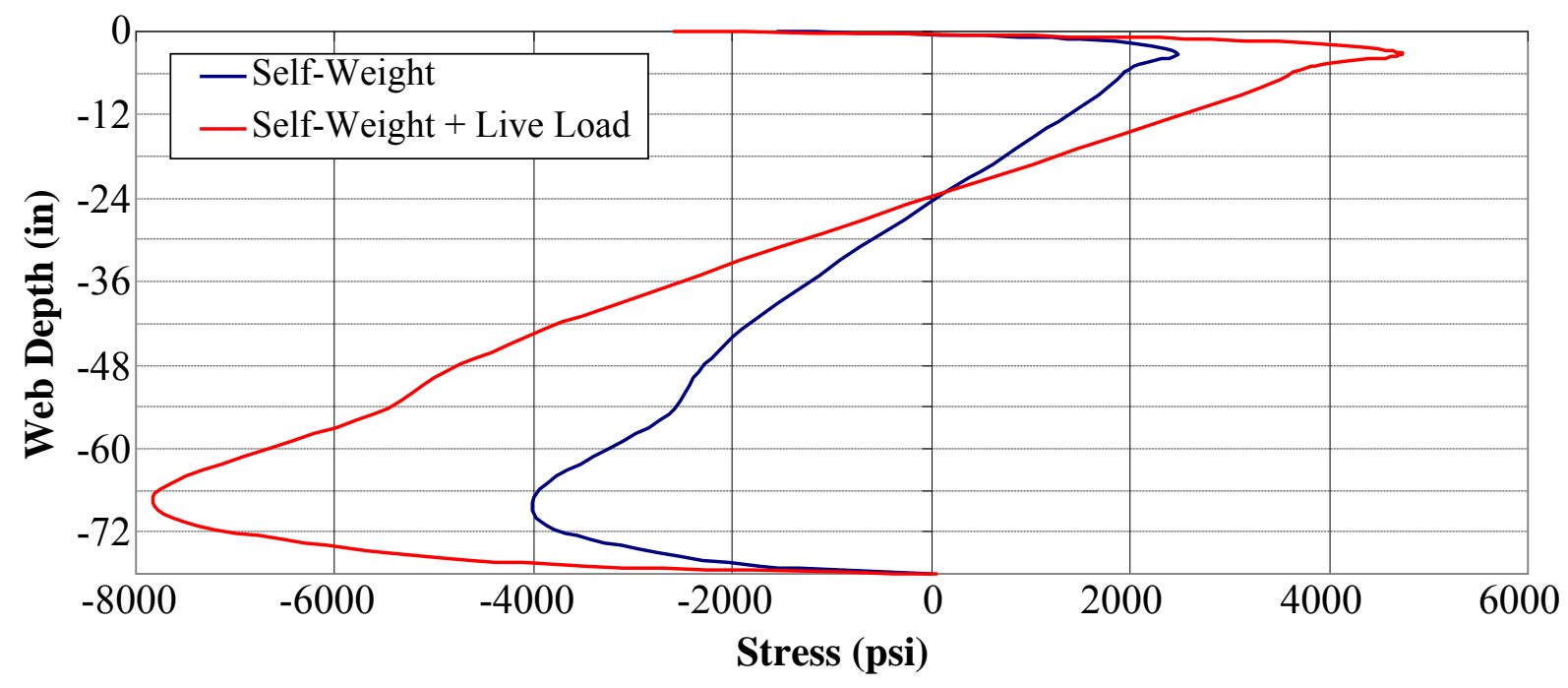

Figure 5.55 As-Built, Longitudinal Stress Profile of Pier 7N Due to Self-Weight + Live Load 


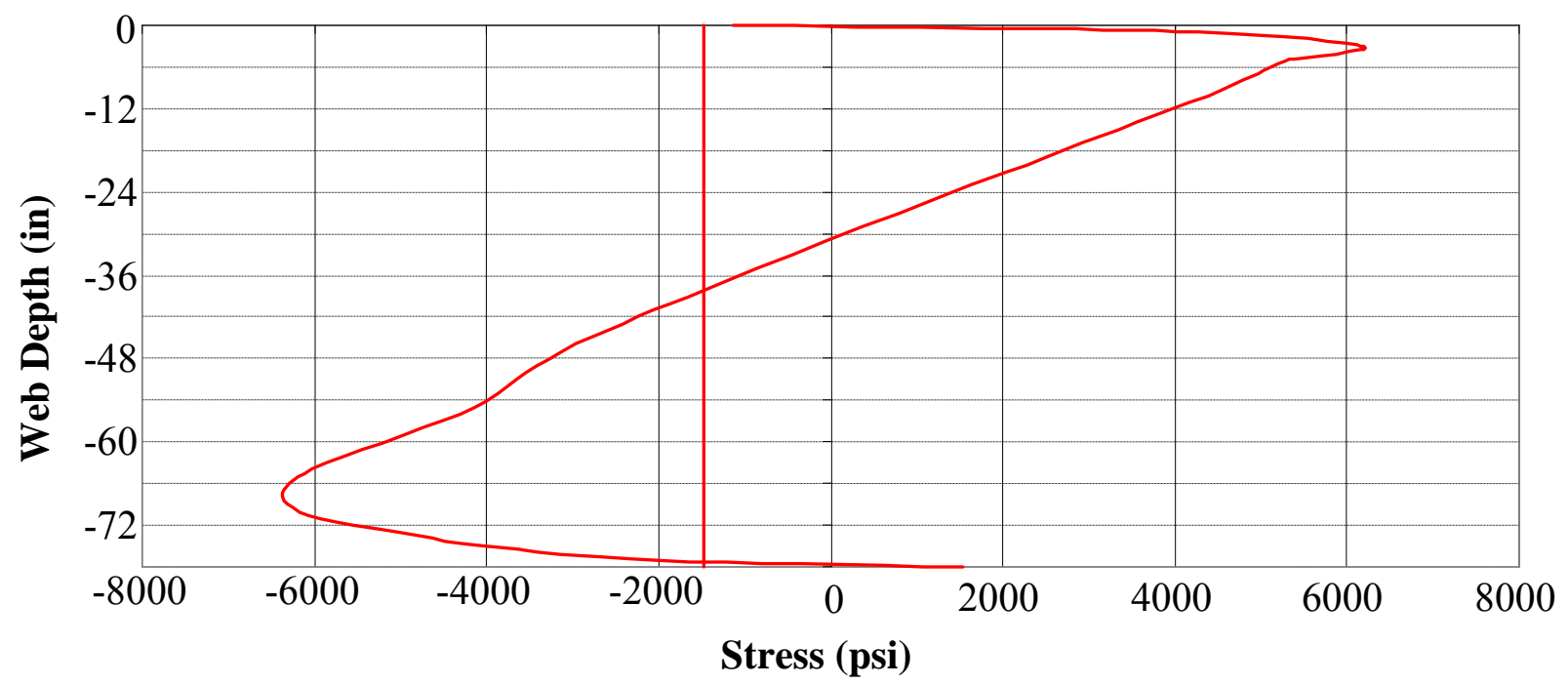

Figure 5.56 As-Built, Bending and Axial Stress Profiles at Pier 7N Due to Self-Weight + Live Load

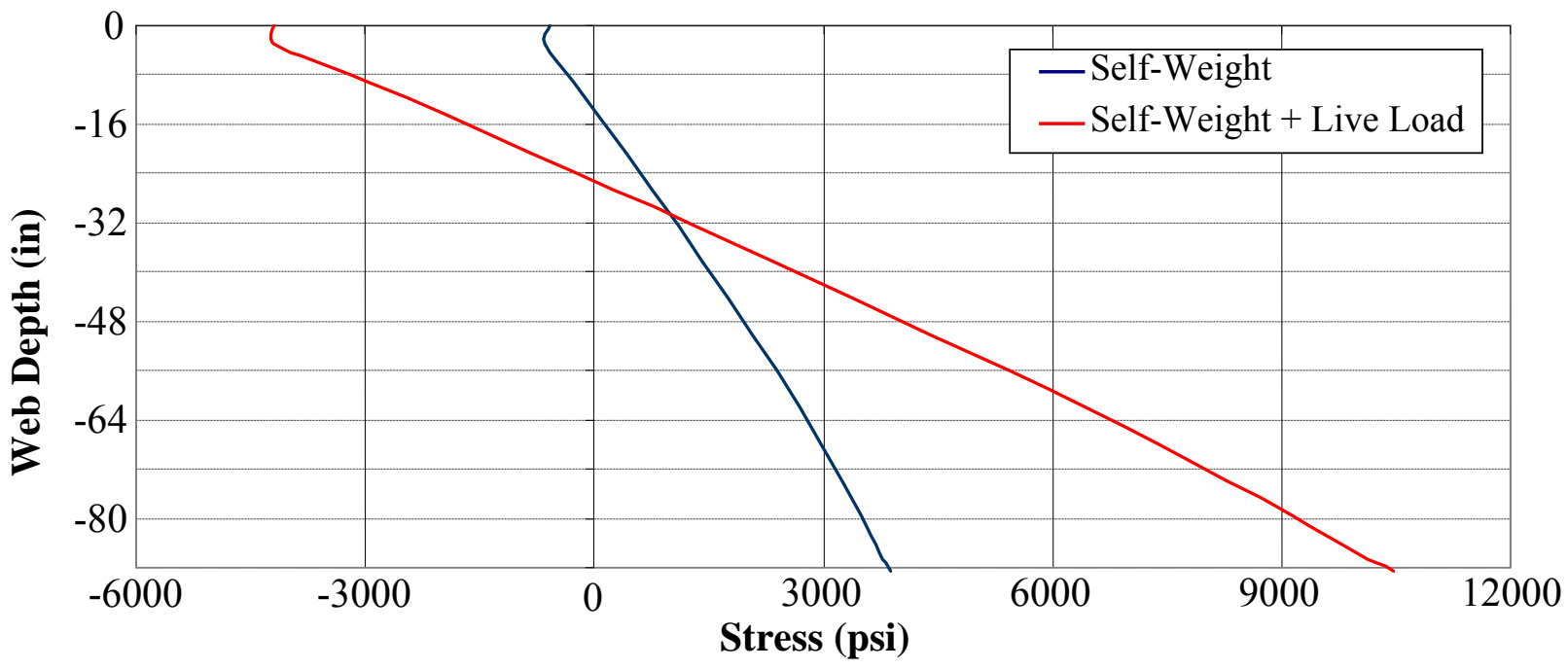

Figure 5.57 As-Built, Longitudinal Stress Profile of Span 8N Due to Self-Weight + Live Load 


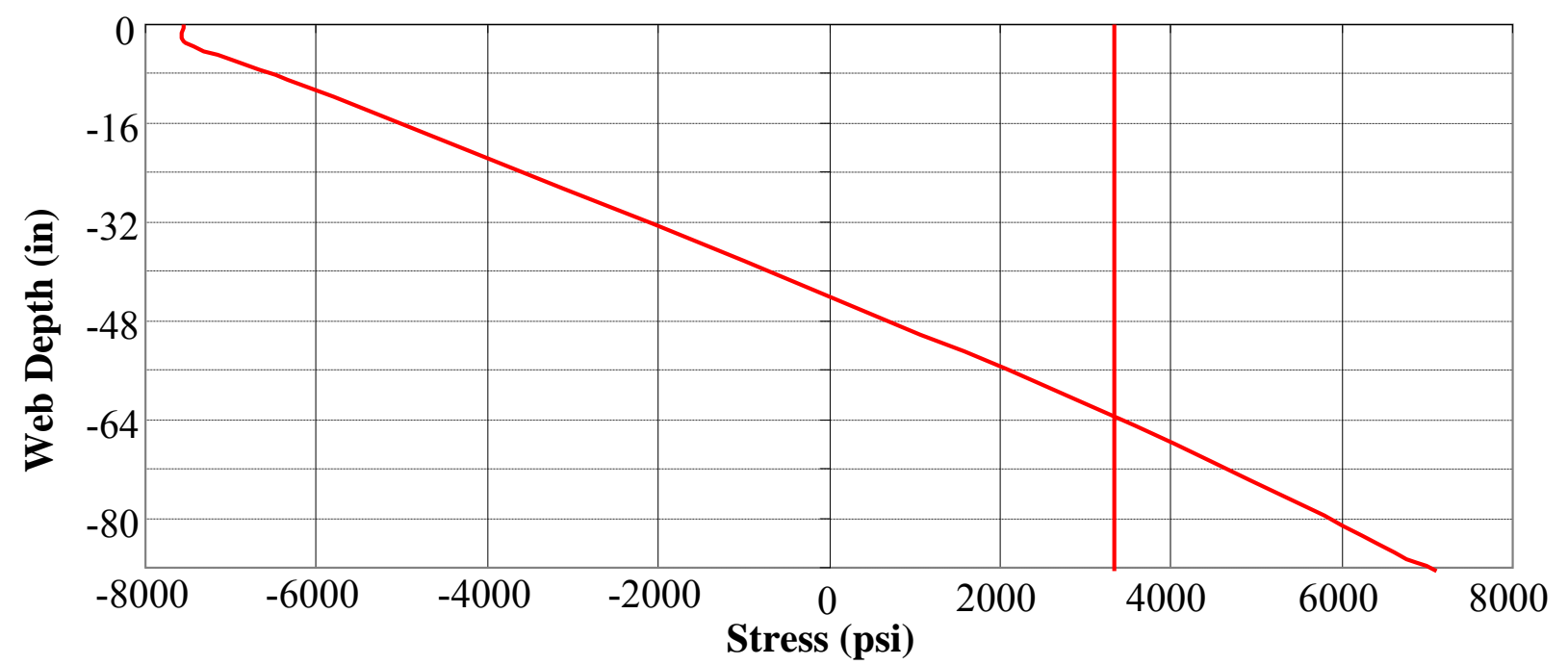

Figure 5.58 As-Built, Bending and Axial Stress Profiles at Span 8N Due to Self-Weight + Live Load

When including live load in addition to bridge self-weight, the increase in stress levels in Span 8N and at Pier 7N occur as expected. Longitudinal stress increases approximately $60 \%$ at Pier $7 \mathrm{~N}$, from 5 ksi to near 8 ksi. In Span $8 \mathrm{~N}$, a $162 \%$ increase in longitudinal stress occurs. As seen from Figures 5.56 and 5.58, it is bending stress that experiences an increase in magnitude. Figures 5.55-5.58 ensure that the FE model is reacting accurately to the additional live load. Figures 5.59-5.62 show the results of the addition of live load to the $\mathrm{FE}$ model subjected to the $+60^{\circ} \mathrm{F}$ temperature load.

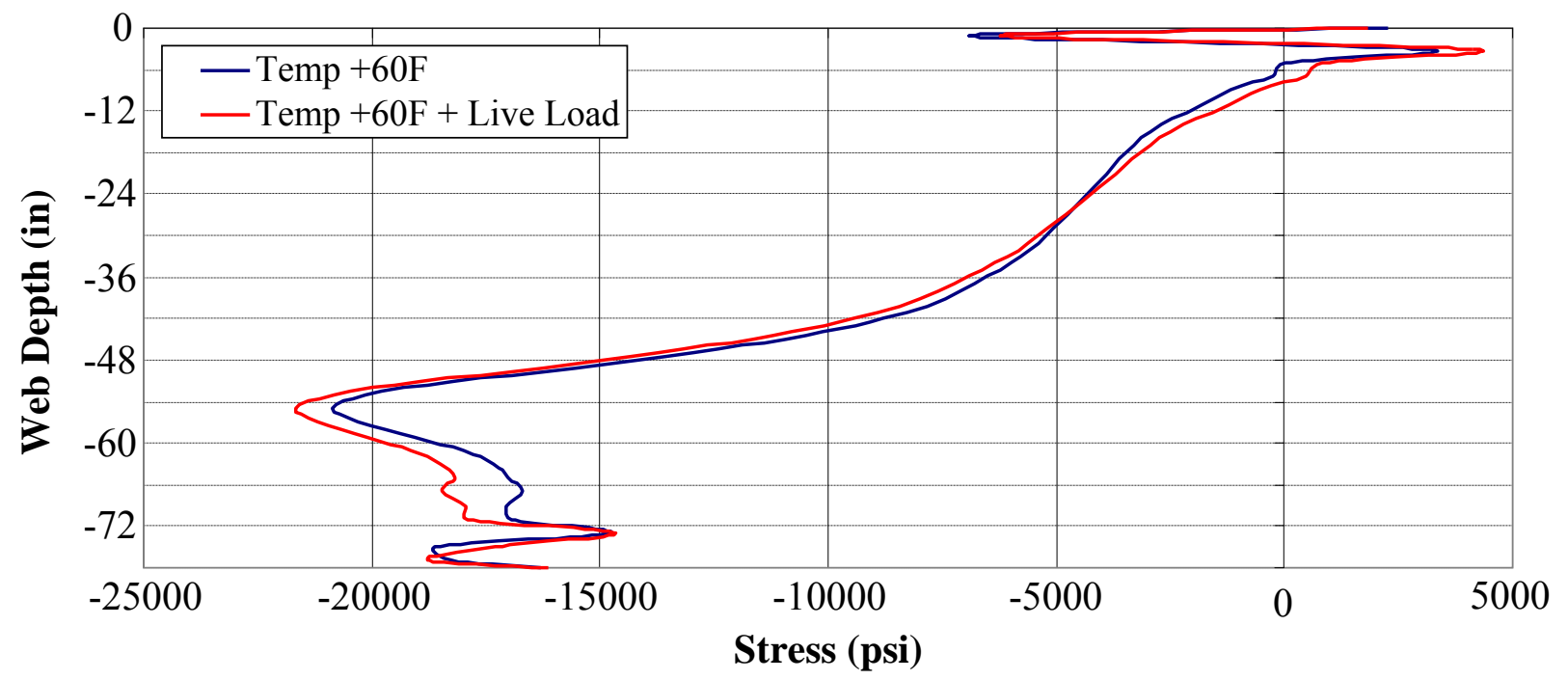

Figure 5.59 As-Built, Longitudinal Stress Profile of Pier $7 \mathrm{~N}$ Due to Temp $+60^{\circ} \mathrm{F}+$ Live Load 


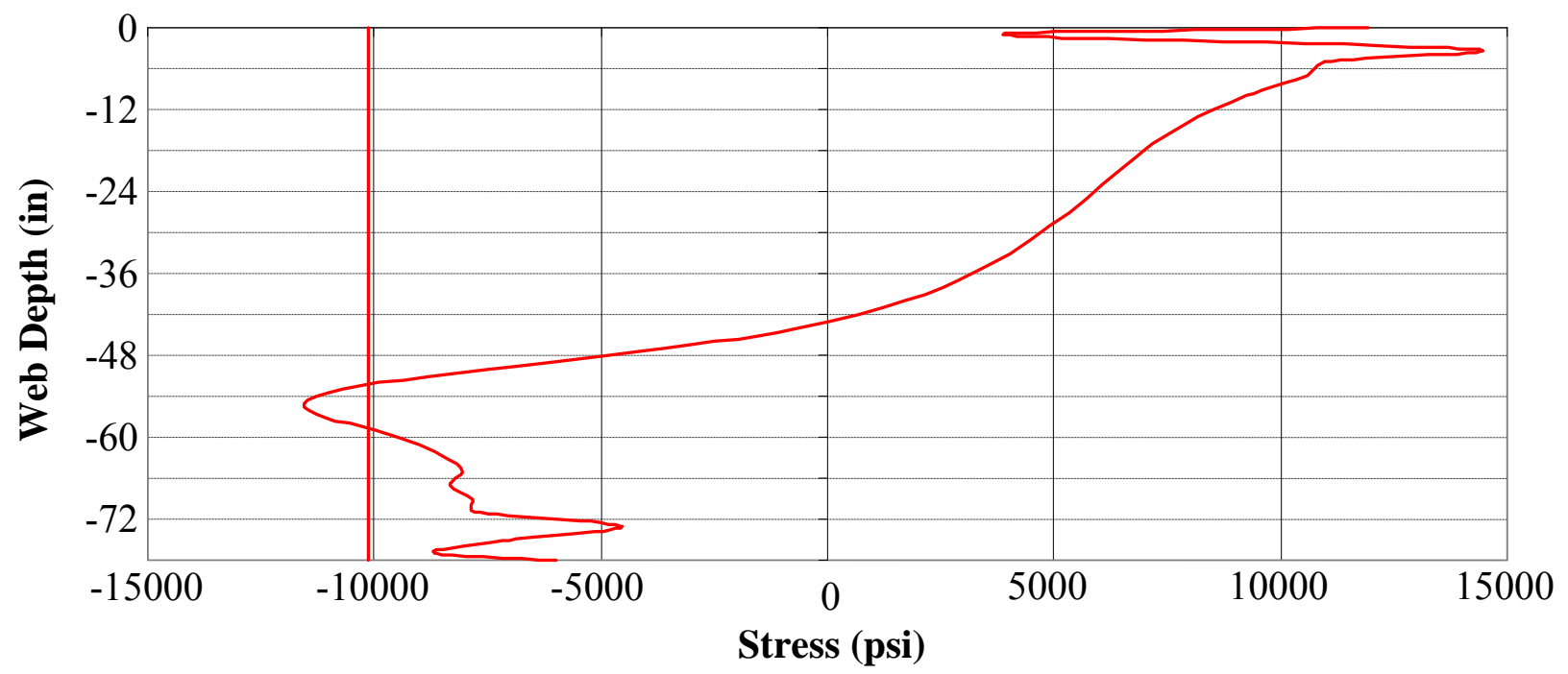

Figure 5.60 As-Built, Bending and Axial Stress Profiles at Pier 7N Due to Temp $+60^{\circ} \mathrm{F}+$ Live Load

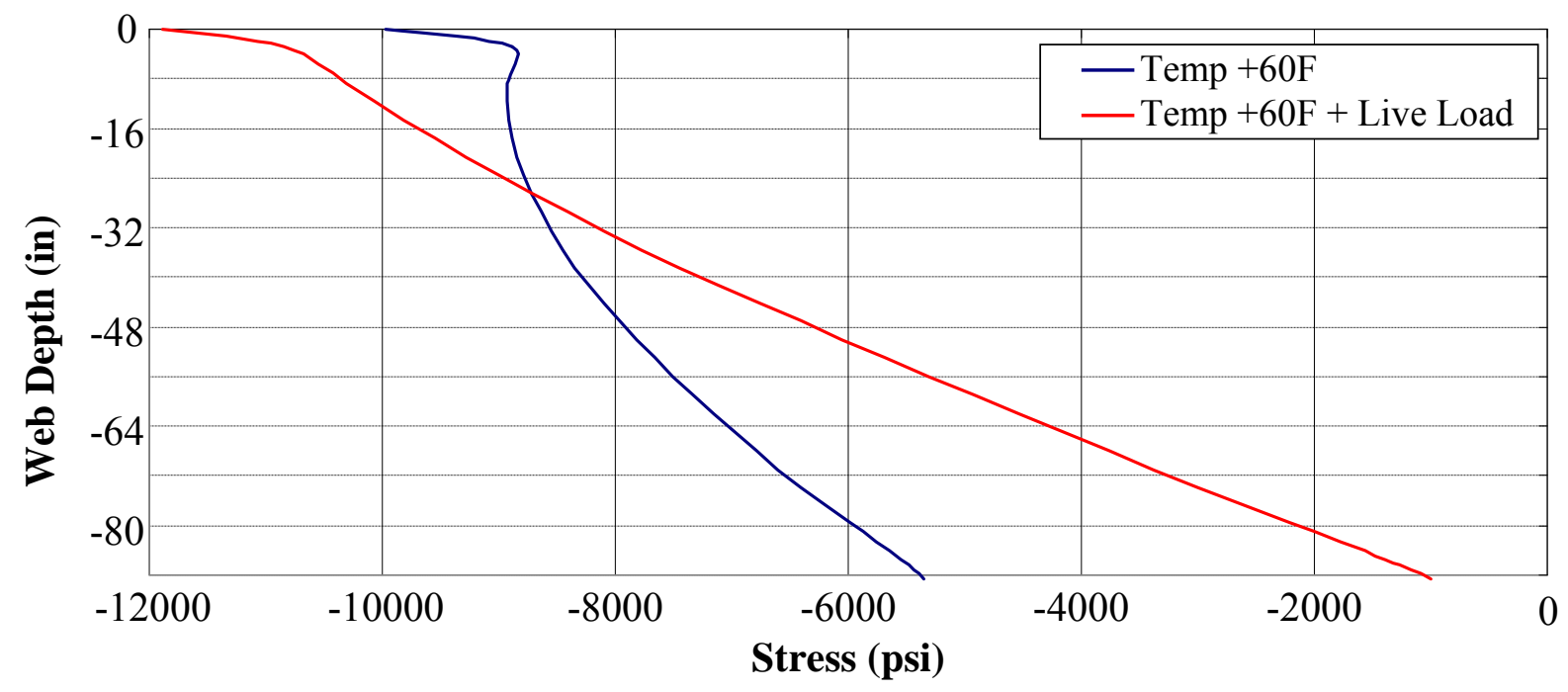

Figure 5.61 As-Built, Longitudinal Stress Profile of Span $8 \mathrm{~N}$ Due to Temp $+60^{\circ} \mathrm{F}+$ Live Load 


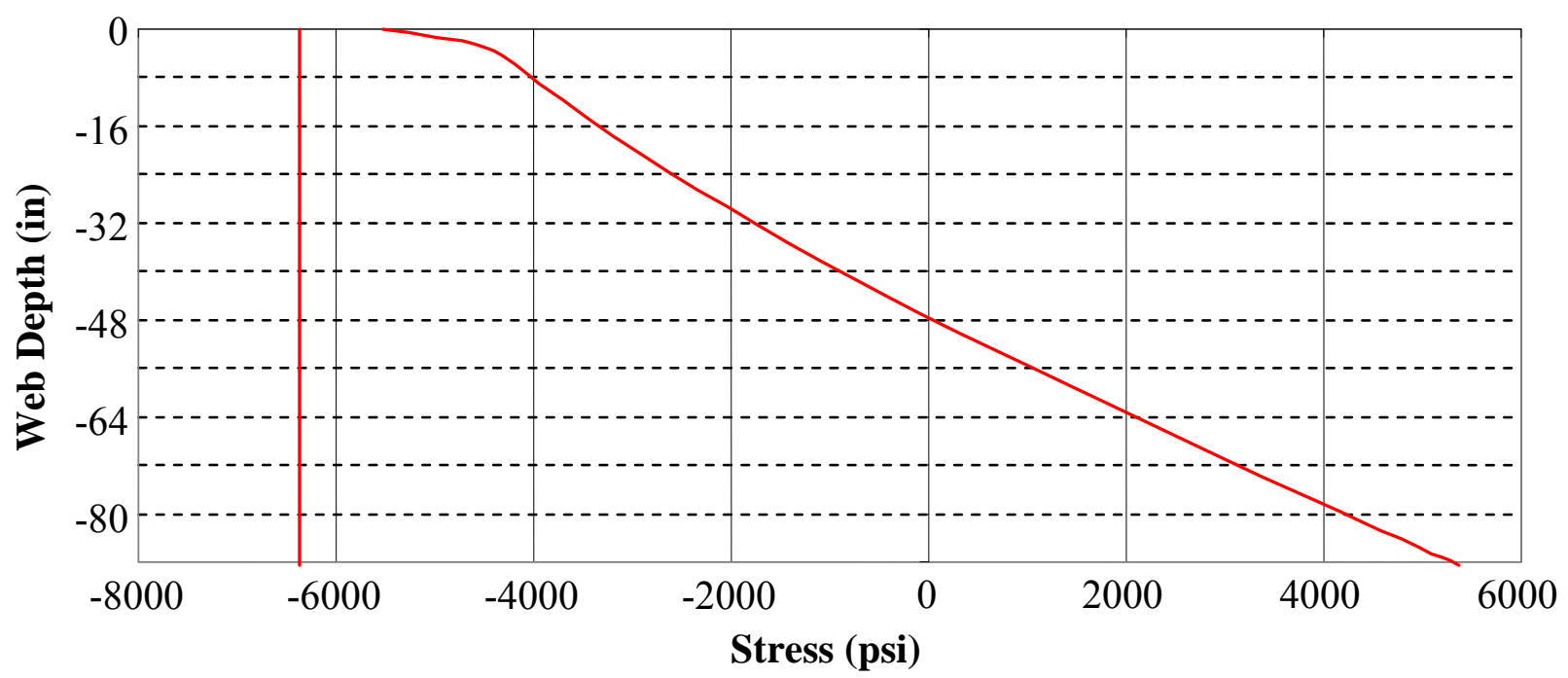

Figure 5.62 As-Built, Bending and Axial Stress Profiles at Span 8N Due to Temp $+60^{\circ} \mathrm{F}+$ Live Load

Figures 5.59-5.62 show that adding the live load to the FE model, in conjunction with the $+60^{\circ} \mathrm{F}$ temperature load, increased compressive stresses near the top of the girder, while compressive stress near the bottom of the girder decreased. However, the entire crosssection is still under compression. In Span $8 \mathrm{~N}$, axial compressive stress decreased from near $8 \mathrm{ksi}$ to $6.5 \mathrm{ksi}$ when the live load was added. Bending stresses, as expected, increased, from around $2 \mathrm{ksi}$ to $5.5 \mathrm{ksi}$. As for the location at Pier $7 \mathrm{~N}$, minimal changes were seen in longitudinal, bending, and axial stress levels.

Figures 5.63 and 5.64 show stress profiles near the midspan of Span $8 \mathrm{~N}$ obtained when the live load is added to the $+90^{\circ} \mathrm{F}$ temperature load. Overall, compressive longitudinal stress decreased through the depth of the cross-section. Bending stresses increased with the addition of live load, from around $3 \mathrm{ksi}$ to $4.5 \mathrm{ksi}$, while axial compressive stress decreased from over 12 ksi to approximately $10.5 \mathrm{ksi}$. 


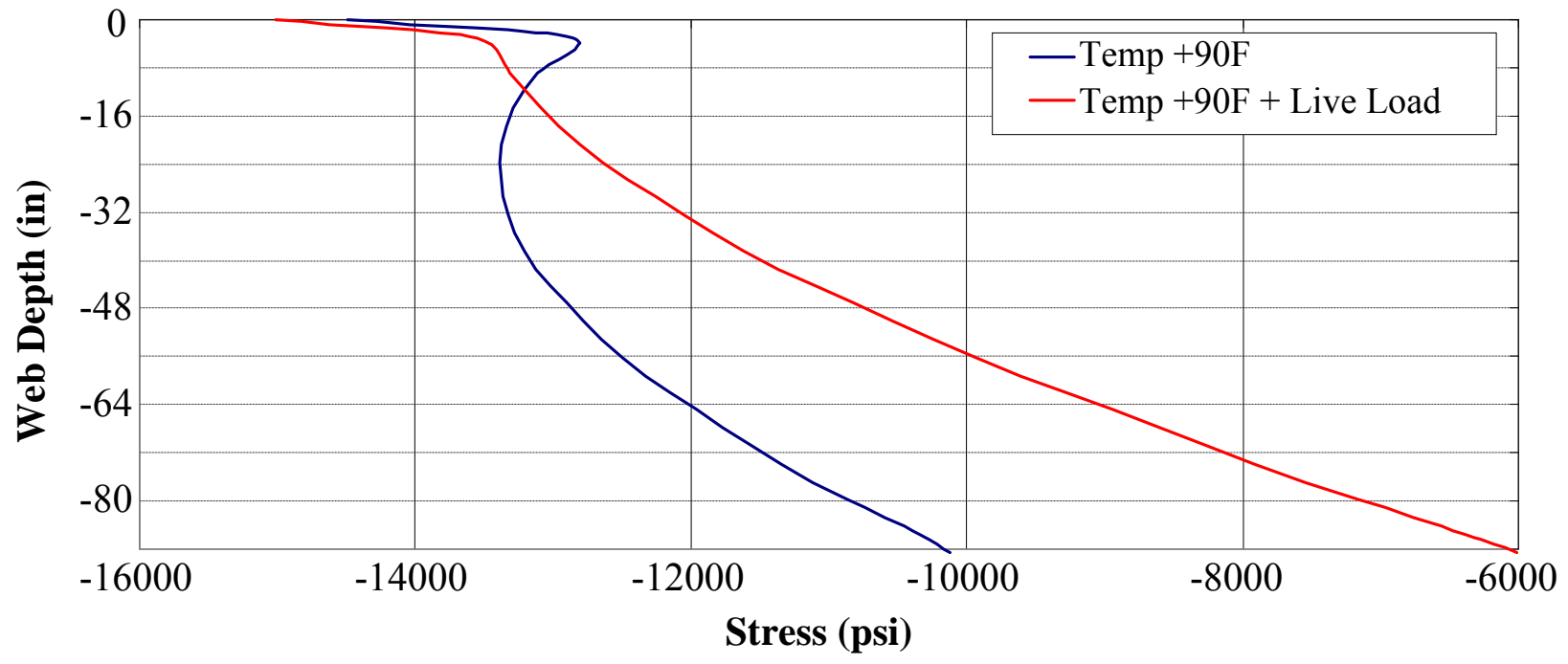

Figure 5.63 As-Built, Longitudinal Stress Profile of Span $8 \mathrm{~N}$ Due to Temp $+90^{\circ} \mathrm{F}+$ Live Load

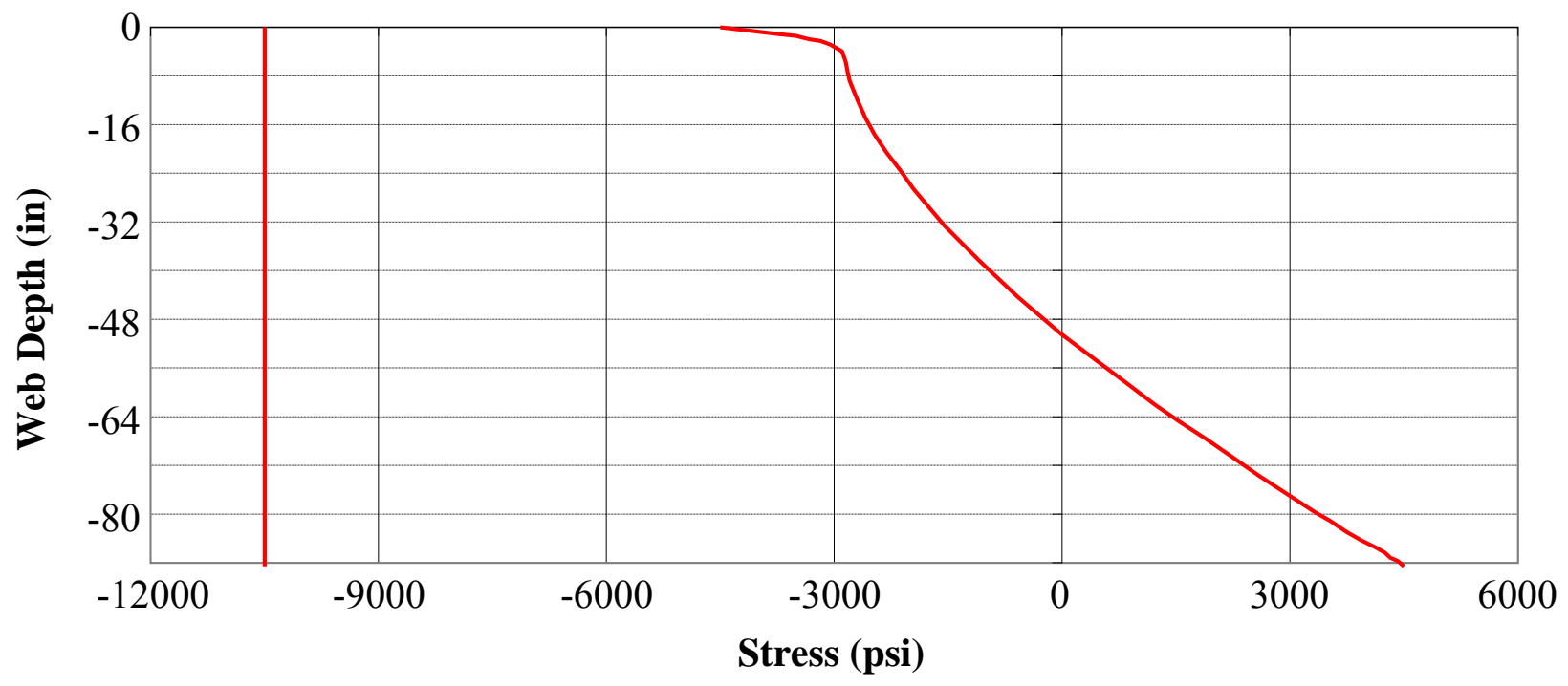

Figure 5.64 As-Built, Bending and Axial Stress Profiles at Span 8N Due to Temp $+90^{\circ} \mathrm{F}+$ Live Load 
The investigation into the inclusion of live load effects to the effects from temperature loading have shown that significant changes in bridge behavior did not occur . Overall, when the live load was added to the temperature load cases, the girders experienced a modest reduction in axial compressive stress, while bending stresses increased in the areas near midspan. When calculating the total capacity of a girder it should be noted that while the axial stress has decreased, the increase in bending stresses may have an offsetting effect and neither an improvement nor decline in girder performance is capacity or stability is determined. After analyzing the stress profiles, it seems that the axial compressive stress due to the temperature loads has an affect similar to behaviors seen by pre-stressing concrete members. This is substantiated by comparing the bending stress profiles from the bridge self-weight and temperature load cases. Bending stresses when temperature load is excluded are $40 \%$ higher than the cases where temperature load is applied.

\subsection{OUT-OF-PLANE DISTORTION EFFECTS}

Several theoretical and experimental studies have been published examining the effect of out-of-plane distortion on the ultimate strength capacity of steel plate girders. From these studies, bending strength reduction and predictor equations have been developed taking into account the initial distortions (or imperfections) in a girder's web. However, many of these laboratory tests, theoretical, and analytical models, such as in Kala et al. (2005), fail to taken into account residual, or "locked in", stresses that may exist within the girder. The nature of the stress that produced the initial imperfection in the web is ignored. Finite element modeling results from Chapter Four and section 5.5 and 5.6 show large out-of-plane distortions and large axial compressive stresses develop due to bridge self-weight and applied uniform temperature loads. In this case, the initial web distortions are magnified by the 
development of compressive stresses, which are "locked in" the structure due to the bearing conditions. Results show that these unexpected "locked in" axial stresses can consume up to $30 \%$ of a girder's ultimate capacity, a behavior not considered during the design process.

The omission of residual stresses in the formulation of strength reduction equations will have a significant impact on the theoretical strength of a girder if those equations are utilized during design.

Web out-of-plumbness can also have a significant effect on initial out-of-plane distortion and residual stresses in a girder. Web out-of-plumbness is a problem that arises during the erection and construction of a curved girder bridge due to inconsistent detailing practices (discussed in Section 2.8). Howell and Earls (2007) indicated that with increasing levels of web out-of-plumbness, cross-sectional distortion may occur under girder dead load, and that lateral deflections increase with out-of-plumbness in positive moment regions. Locked in stresses develop during construction, when bridge erectors force out-of-plumb members into position, further influencing initial web distortions. As shown in this study, the out-of-plane distortion produced by the bridge dead load is magnified considerably by the application of uniform thermal loading.

The cause of the web distortions on the bridge studied for this research is difficult to isolate. However, steel erection and web out-of-plumbness was not considered in the FE bridge model. This makes it difficult to conclude whether or not those issues were involved in the web distortion seen in the girders. Nevertheless, out-of-plumbness may play a role, but without consulting the contractor it is impossible to know whether it was an issue when constructing the actual bridge. 


\subsection{DISCUSSION AND CONCLUSIONS}

The FE bridge model used for this investigation was subjected to several different uniform temperature loads. When reviewing the design drawings for the bridge, it is readily apparent that the number of fully fixed bearing devices would not allow expansion of the steel I-girders when subjected to these uniform thermal loadings. Free and guided bearing devices are employed at only a few locations in an attempt to accommodate the thermal expansion of the structure. It was found that under the current bearing arrangement, significant levels of axial compressive stress develop throughout the bridge. Also, the magnitude of temperature induced axial compressive stresses is comparable to, and actually exceeds that of bending stresses.

The impact of the axial stresses is best illustrated when calculating the total capacity ratio of the girder. Depending on the location within the structure, axial compressive stress consumes between $20 \%$ and $52 \%$ of the girder's overall capacity, leaving a much lower percentage of capacity available for flexural load resistance. The addition of the AASHTO HL-93 live load results in a modest decrease in axial compressive stresses, however, the increase in bending stress offsets any effect that may have on the overall state of stress in the girder.

The design of the web plate of welded steel I-girders is based upon a critical web stress that is permitted by design code to be less than web yield strength. Longitudinal compressive stresses are required to be less than this critical web stress, $F_{c r}$. It was shown that the application of thermal loading on this bridge reduces the critical web stress. The development of significant levels of axial compressive stress due to thermal loading is not accounted for during design procedures, and their addition to longitudinal stresses caused by design loads will result in web stresses well in excess of the $F_{c r}$ limit. 
Lastly, residual stresses from distortions caused by girder fabrication, erection or transportation errors are not included in this investigation. Residual stresses resulting from any of these errors would also negatively affect bridge capacity. Therefore, the predictions made by the FE model likely underestimate the true state of stress in the curved steel Igirders. 


\section{CHAPTER SIX}

\section{OUT-OF-PLANE WEB DISTORTION UNDER PROPOSED BEARING ARRANGEMENT}

\subsection{INTRODUCTION}

Chapter Four detailed the out-of-plane web distortion of the bridge girders as produced by the FE model under the current bearing arrangement. The FE bridge model showed that with the as-built bearing arrangement, the out-of-plane distortion is magnified substantially when the bridge is subjected to increasing thermal loads. In this chapter, a new bearing arrangement, designed to allow a much greater level of thermal expansion, is implemented on the FE bridge model. The new bearing arrangement will remove the numerous fixed bearings and employ more free and guided expansion bearings throughout the bridge.

\subsection{PROPOSED BEARING ARRANGEMENT PLAN}

Figures 6.1 presents the proposed bearing arrangement plans for the bridge model. Pier $9 \mathrm{~N}$ is the only support location to employ fully fixed bearings. At Piers $7 \mathrm{~N}$ and $8 \mathrm{~N}$, fixed bearings have been replaced with free and guided expansion bearings similar to the devices found at Piers $6 \mathrm{~N}, 10 \mathrm{~N}, 11 \mathrm{~N}$, and Abutment $2 \mathrm{~N}$. The guided bearings implemented for this proposed bearing arrangement is oriented as suggested by AASHTO (2003) and various pieces of literature. It is predicted that this bearing arrangement will result is significantly smaller lateral displacement, local web buckling, and thermal stresses by better accommodating the thermal movement of the steel girders. 


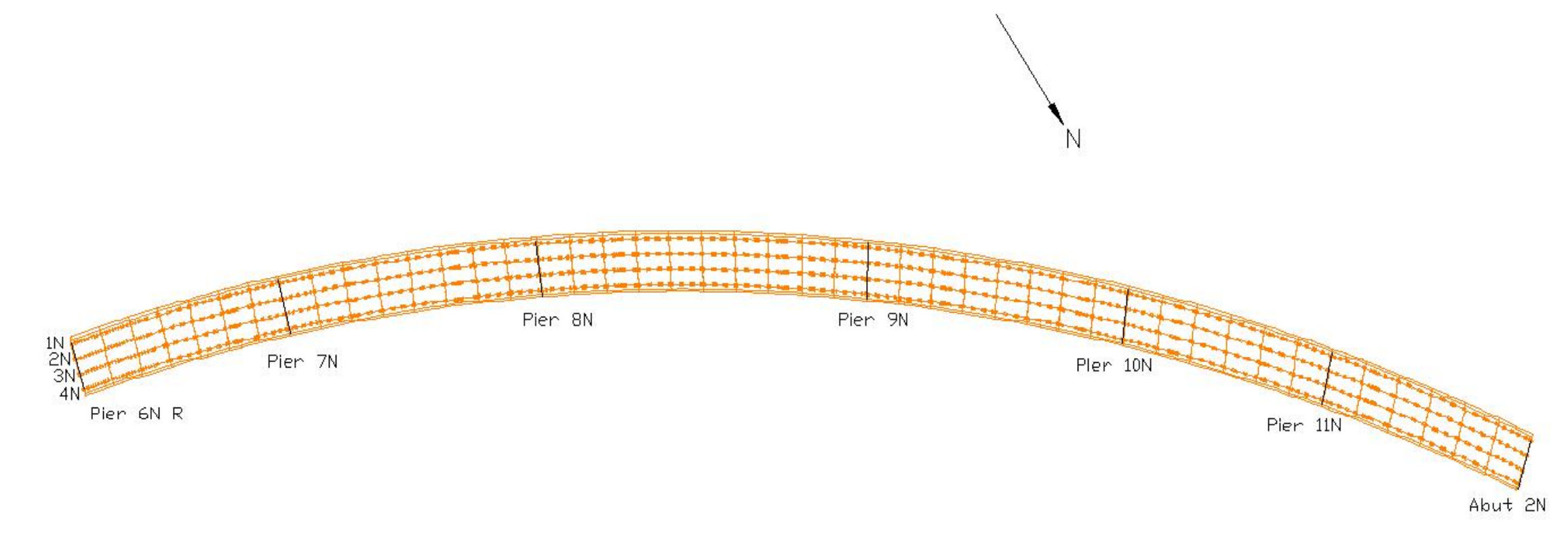

\begin{tabular}{|c|c|c|c|c|c|c|c|}
\hline Girder & Pier 6N R & Pier 7N & Pier $8 \mathrm{~N}$ & Pier 9N & Pier $10 \mathrm{~N}$ & Pier 11N & Abutment $2 \mathrm{~N}$ \\
\hline $1 \mathrm{~N}$ & FREE & FREE & FREE & FIXED & FREE & FREE & FREE \\
\hline $2 \mathrm{~N}$ & GUIDED & GUIDED & GUIDED & FIXED & GUIDED & GUIDED & GUIDED \\
\hline $3 N$ & GUIDED & GUIDED & GUIDED & FIXED & GUIDED & GUIDED & GUIDED \\
\hline $4 N$ & FREE & FREE & FREE & FIXED & FREE & FREE & FREE \\
\hline
\end{tabular}

Figure 6.1 Proposed Bearing Arrangement Plan (Unit 2) 


\subsection{PROPOSED BOUNDARY CONDITIONS - LONGITUDINAL WEB PROFILES}

This section presents longitudinal web profile comparisons between the as-built and proposed bearing arrangements. Figures 6.2-6.13 compare the longitudinal web distortion profiles of each bearing arrangement of Girder $4 \mathrm{~N}$ for the $+60^{\circ} \mathrm{F}$ and $+90^{\circ} \mathrm{F}$ temperature loads. Profile comparisons for the self-weight and $-60^{\circ} \mathrm{F}$ load cases are included in Appendix $\mathrm{C}$, as well as comparisons for all load cases of Girder 3N.

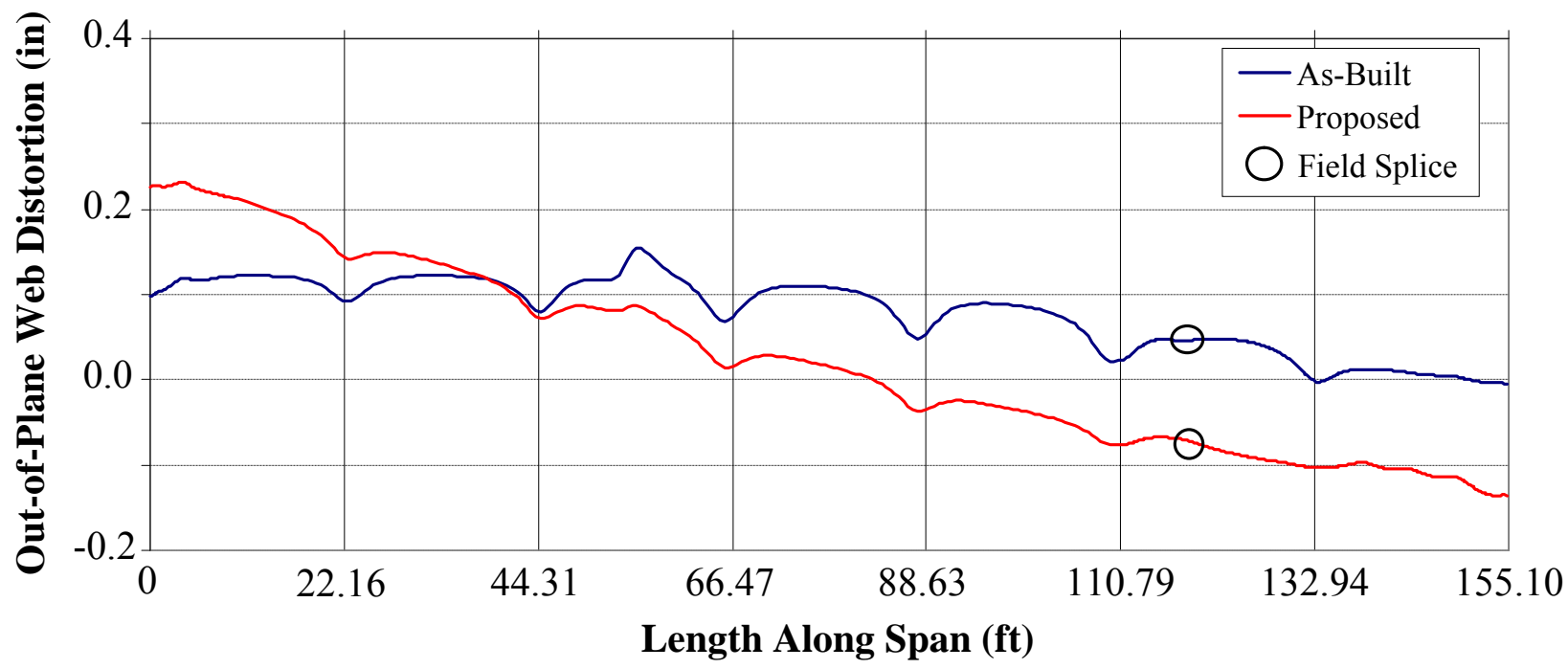

Figure 6.2 Longitudinal Profiles Comparison of Span $7 \mathrm{~N}$ Due to Temp $+60^{\circ} \mathrm{F}$

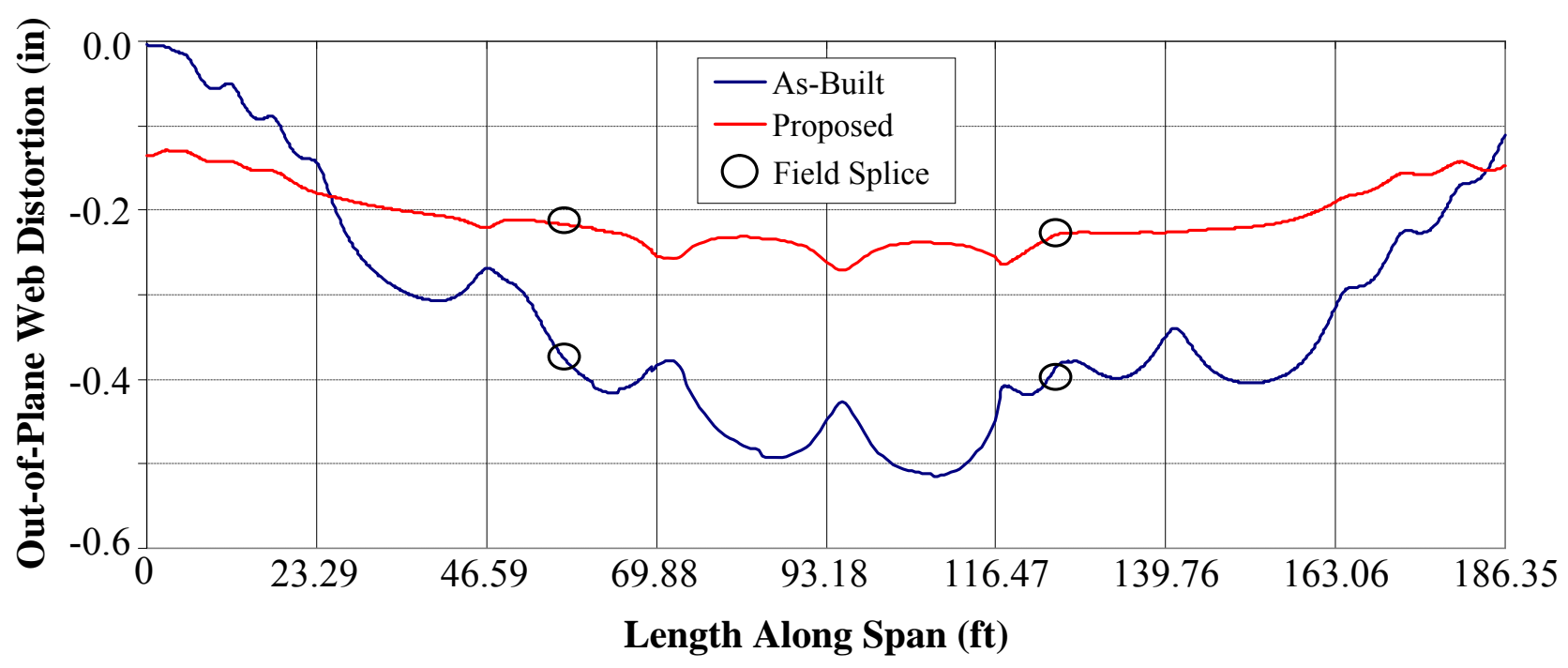

Figure 6.3 Longitudinal Profiles Comparison of Span $8 \mathrm{~N}$ Due to Temp $+60^{\circ} \mathrm{F}$ 


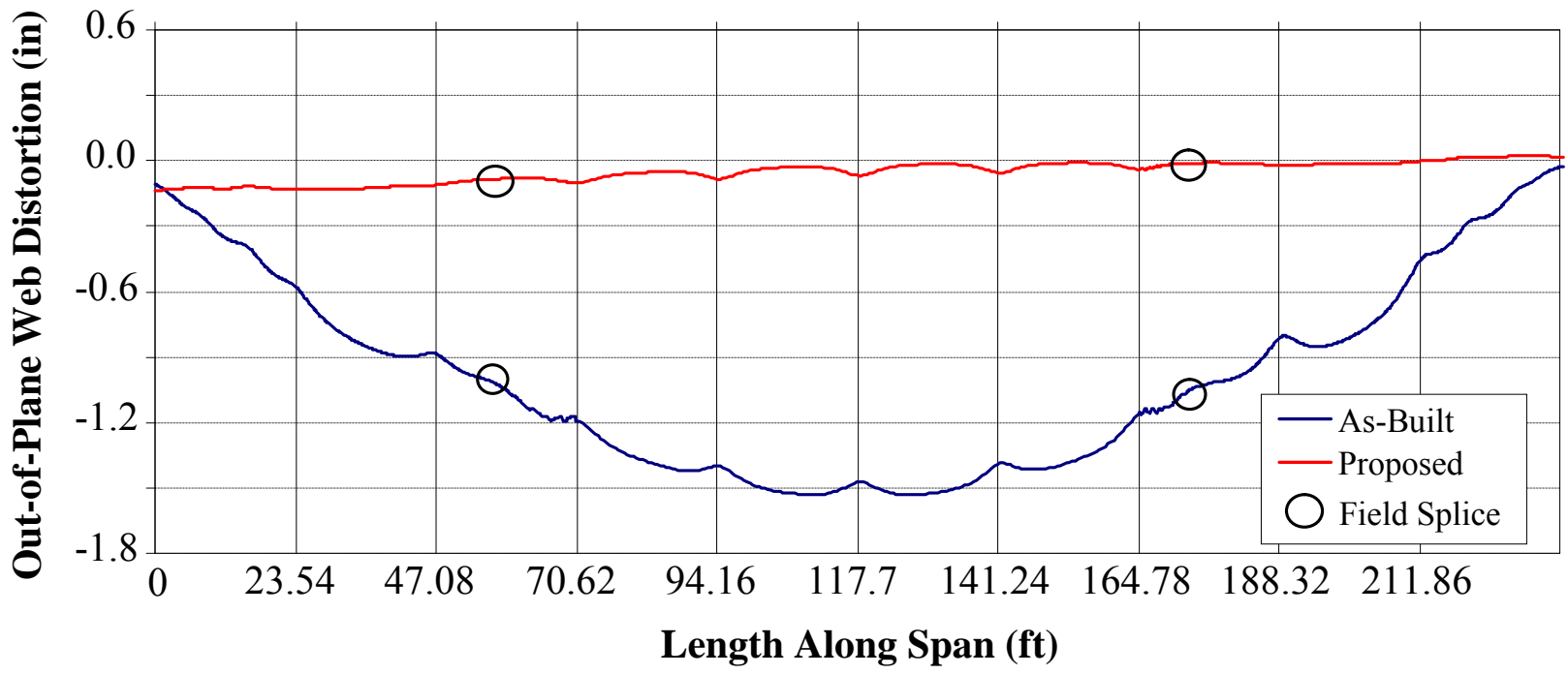

Figure 6.4 Longitudinal Profiles Comparison of Span 9N Due to Temp $+60^{\circ} \mathrm{F}$

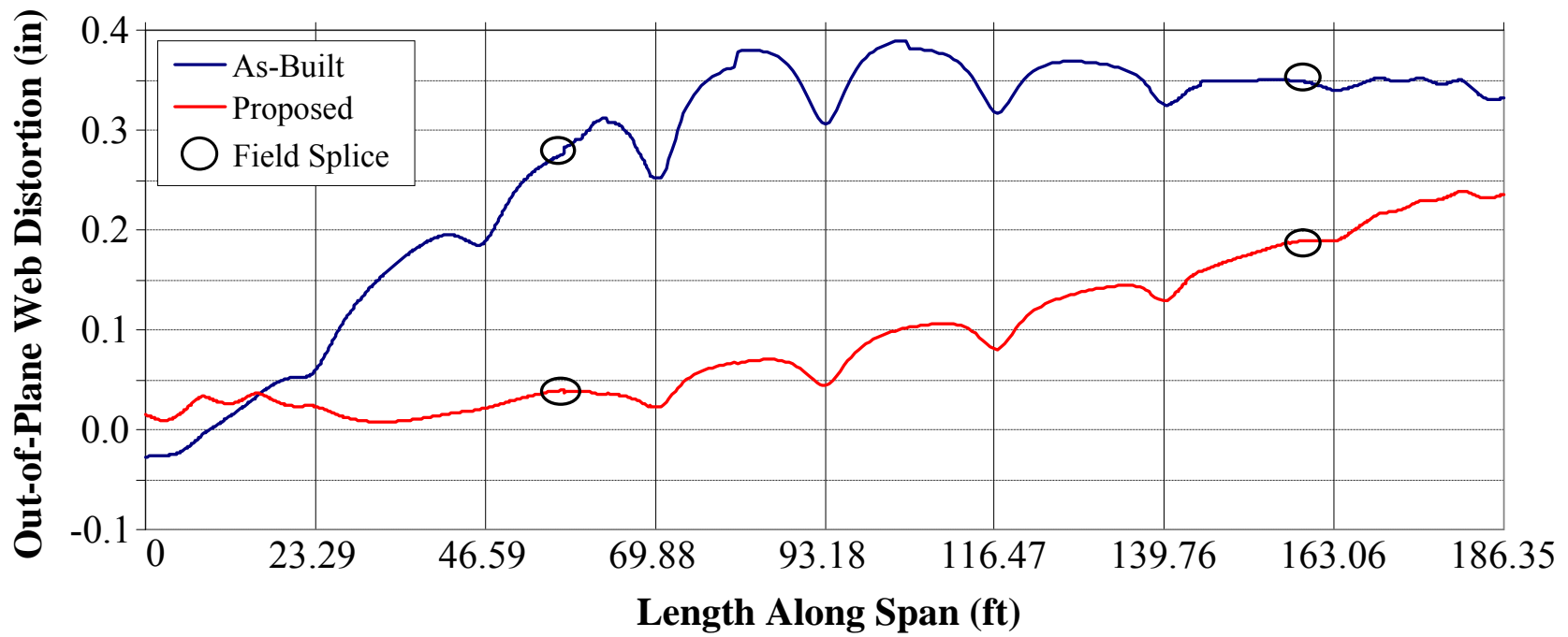

Figure 6.5 Longitudinal Profiles Comparison of Span 10N Due to Temp $+60^{\circ} \mathrm{F}$

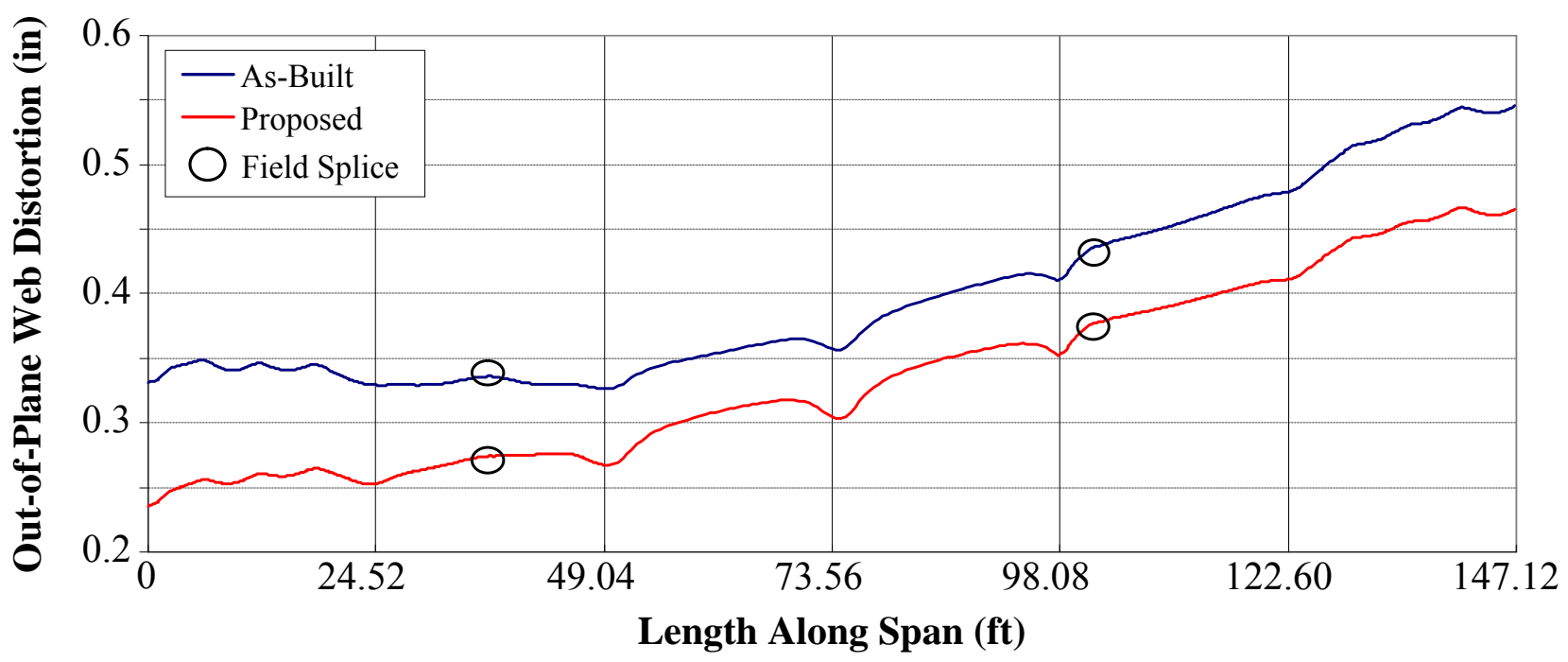

Figure 6.6 Longitudinal Profiles Comparison of Span 11N Due to Temp $+60^{\circ} \mathrm{F}$ 


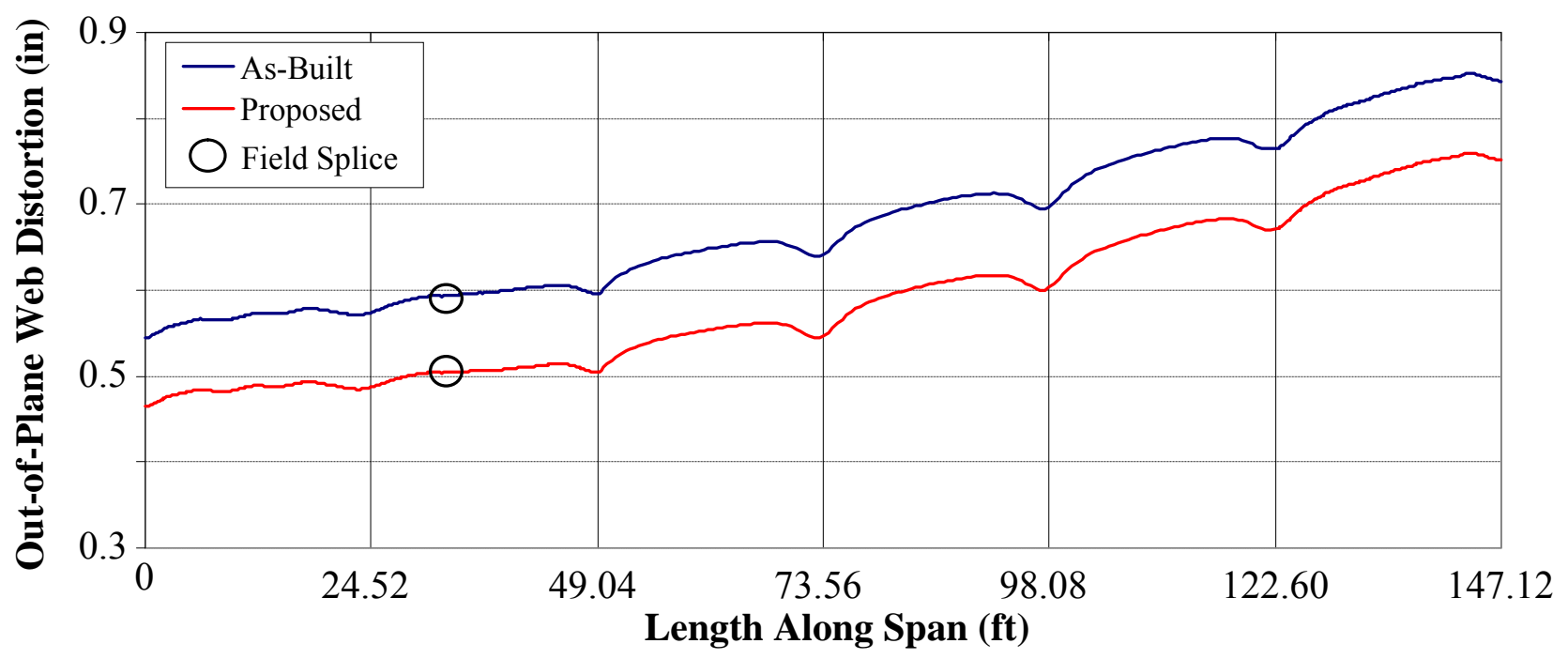

Figure 6.7 Longitudinal Profiles Comparison of Span $12 \mathrm{~N}$ Due to Temp $+60^{\circ} \mathrm{F}$

The magnitude of out-of-plane web distortion produced by the $+60^{\circ} \mathrm{F}$ temperature load is greatly reduced under the proposed bearing arrangement. This is especially evident in Spans $7 \mathrm{~N}-10 \mathrm{~N}$, which under the new bearing plan, better accommodates thermal movements due to the change in support conditions from fixed to expansion bearings. The reduction in the magnitude of lateral buckling is very apparent. The largest lateral displacement of approximately 1.5 in. recorded at the midspan of Span $9 \mathrm{~N}$ under the as-built bearing arrangement, decreases to $0.025 \mathrm{in}$. under the new bearing conditions, a decrease of $98 \%$. Similar results are produced in Spans $7 \mathrm{~N}, 8 \mathrm{~N}$, and 10N, although the decrease in lateral buckling is not quite as large. Spans $11 \mathrm{~N}$ and $12 \mathrm{~N}$ experience smaller magnitudes of lateral displacement when compared to the as-built bearing plan, on the order of a $20-25 \%$. Similar results are seen for the $-60^{\circ} \mathrm{F}$ load case. Lateral buckling is reduced significantly, and the magnitude of out-of-plane displacements decreases up to around $90-95 \%$.

Figures 6.8-6.13 show the longitudinal web profiles for Girder $4 \mathrm{~N}$ with the $+90^{\circ} \mathrm{F}$ temperature load applied to the FE model. It is expected that the bridge's response under the $+90^{\circ} \mathrm{F}$ temperature load will be similar to that of the previous $+60^{\circ} \mathrm{F}$ load. 


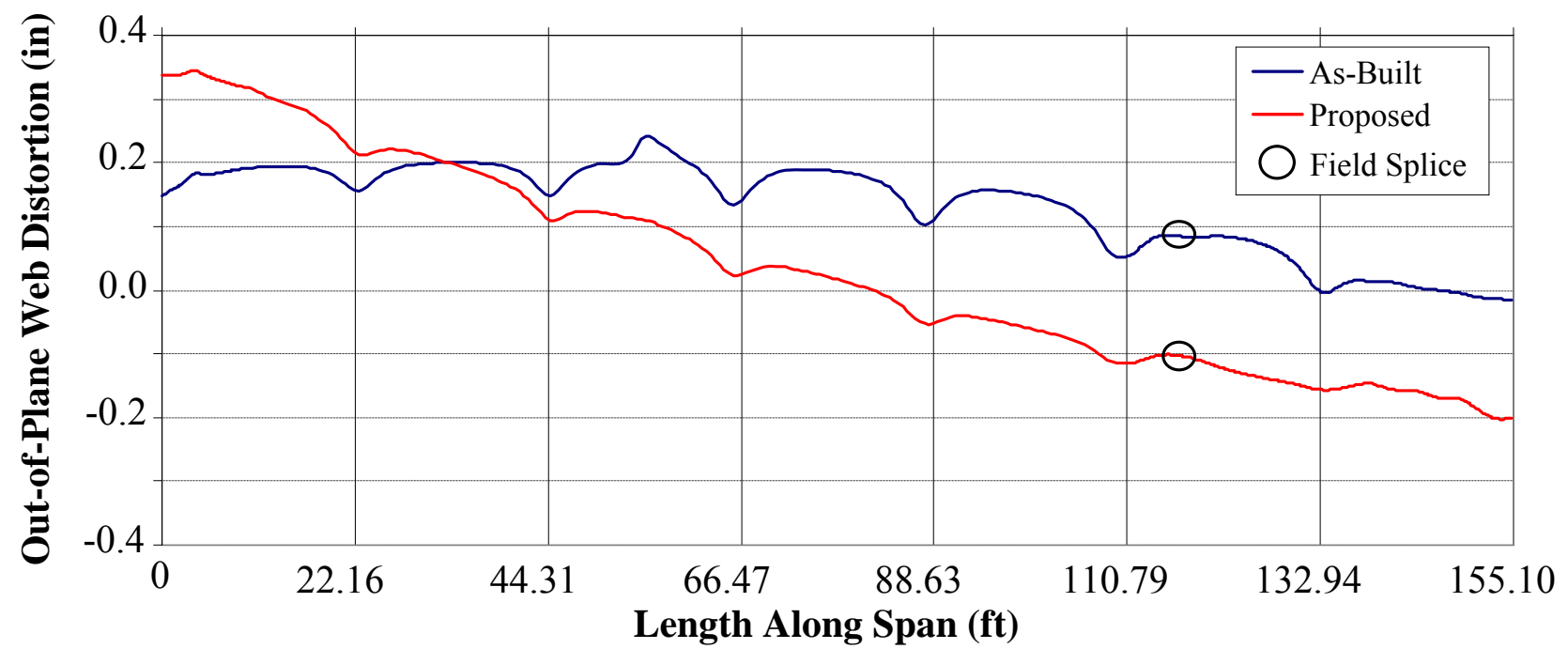

Figure 6.8 Longitudinal Profiles Comparison of Span $7 \mathrm{~N}$ Due to Temp $+90^{\circ} \mathrm{F}$

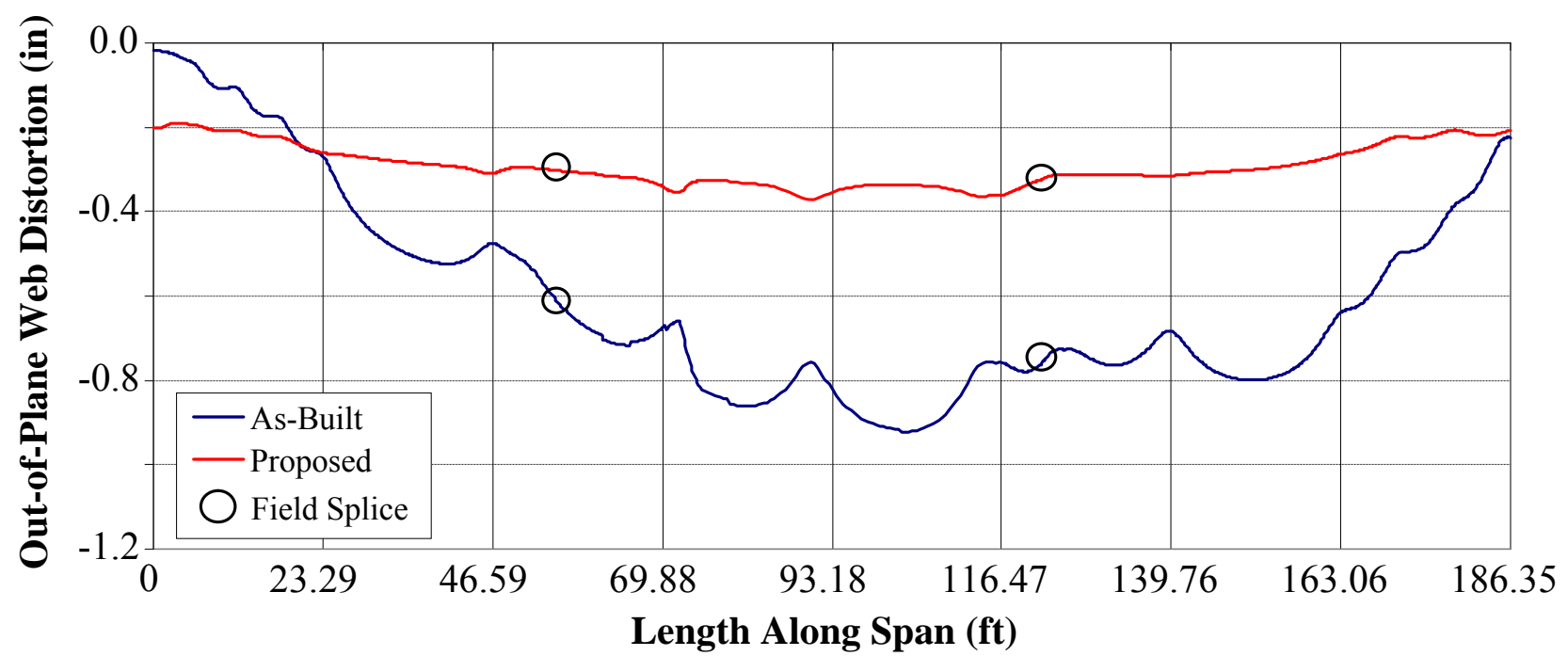

Figure 6.9 Longitudinal Profiles Comparison of Span $8 \mathrm{~N}$ Due to Temp $+90^{\circ} \mathrm{F}$

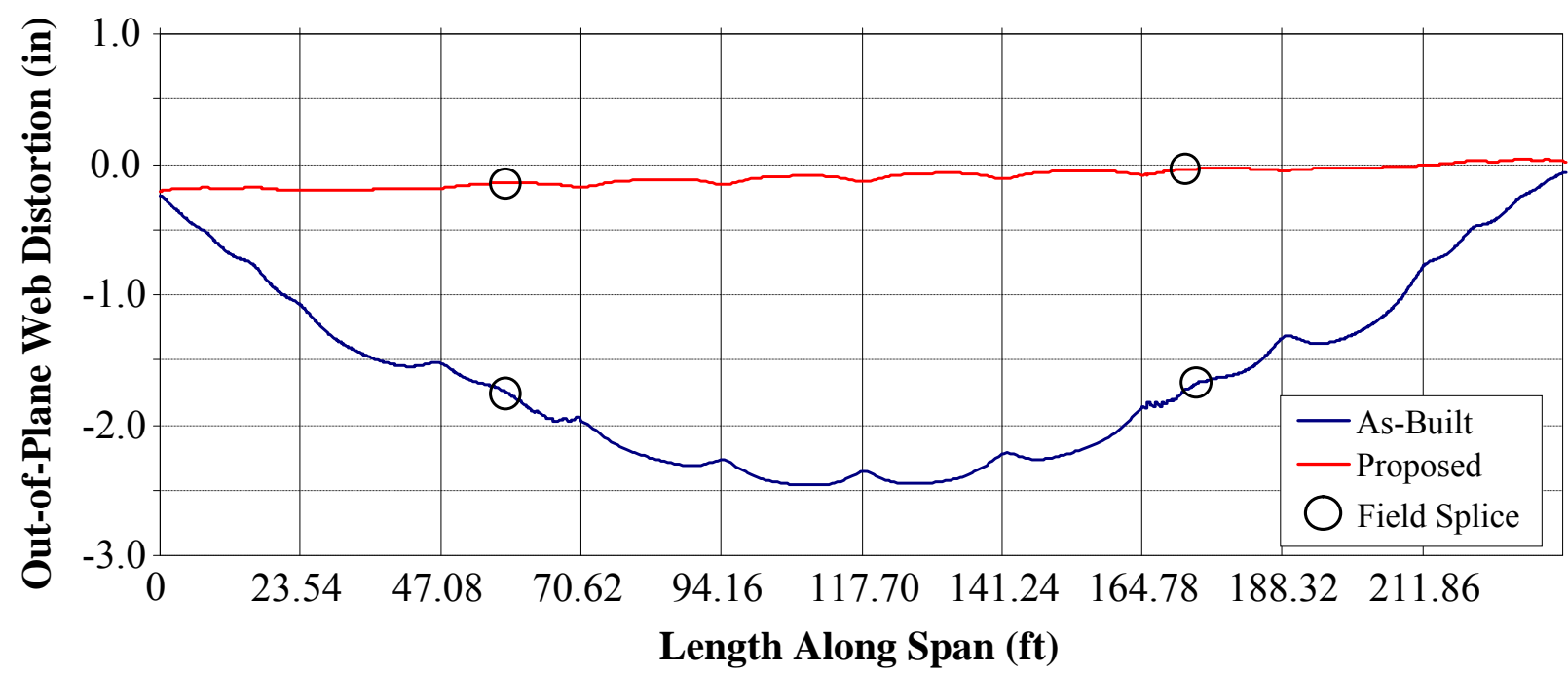

Figure 6.10 Longitudinal Profiles Comparison of Span $9 \mathrm{~N}$ Due to Temp $+90^{\circ} \mathrm{F}$ 


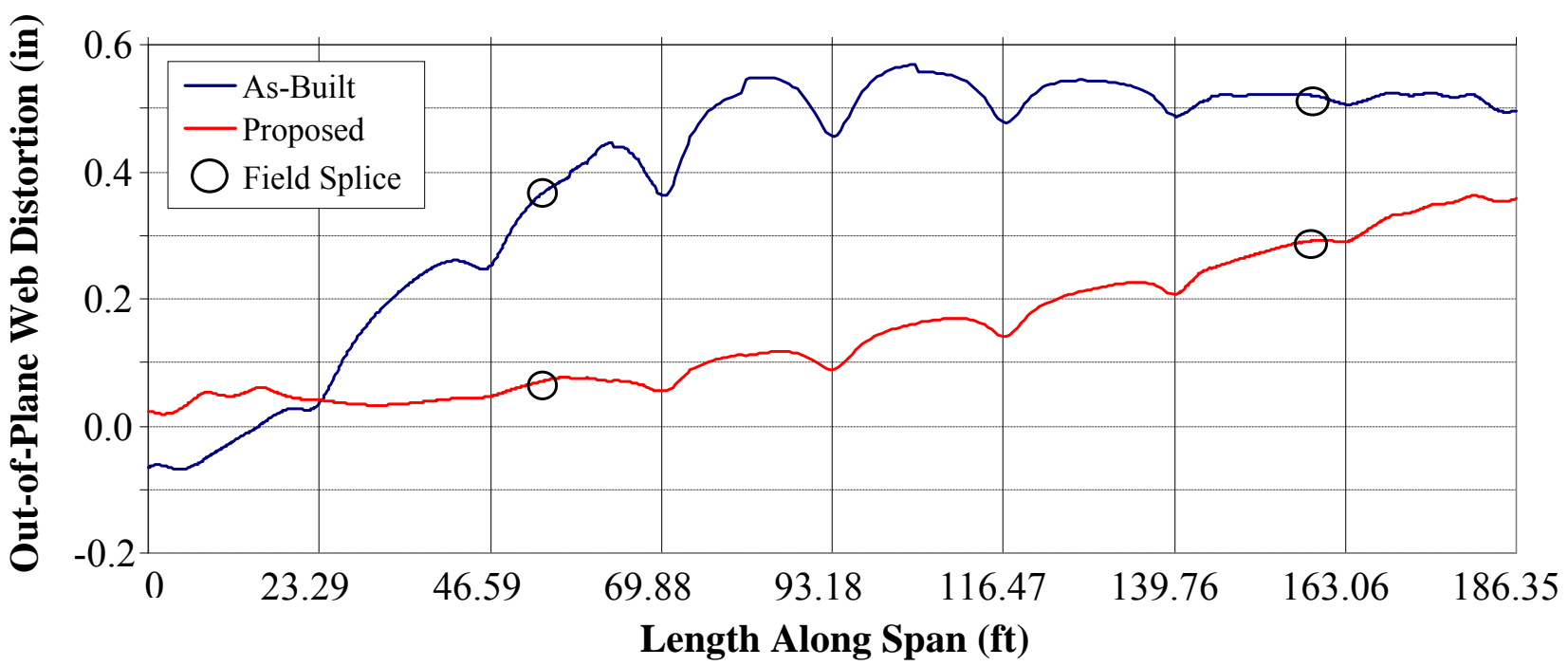

Figure 6.11 Longitudinal Profiles Comparison of Span $10 \mathrm{~N}$ Due to Temp $+90^{\circ} \mathrm{F}$

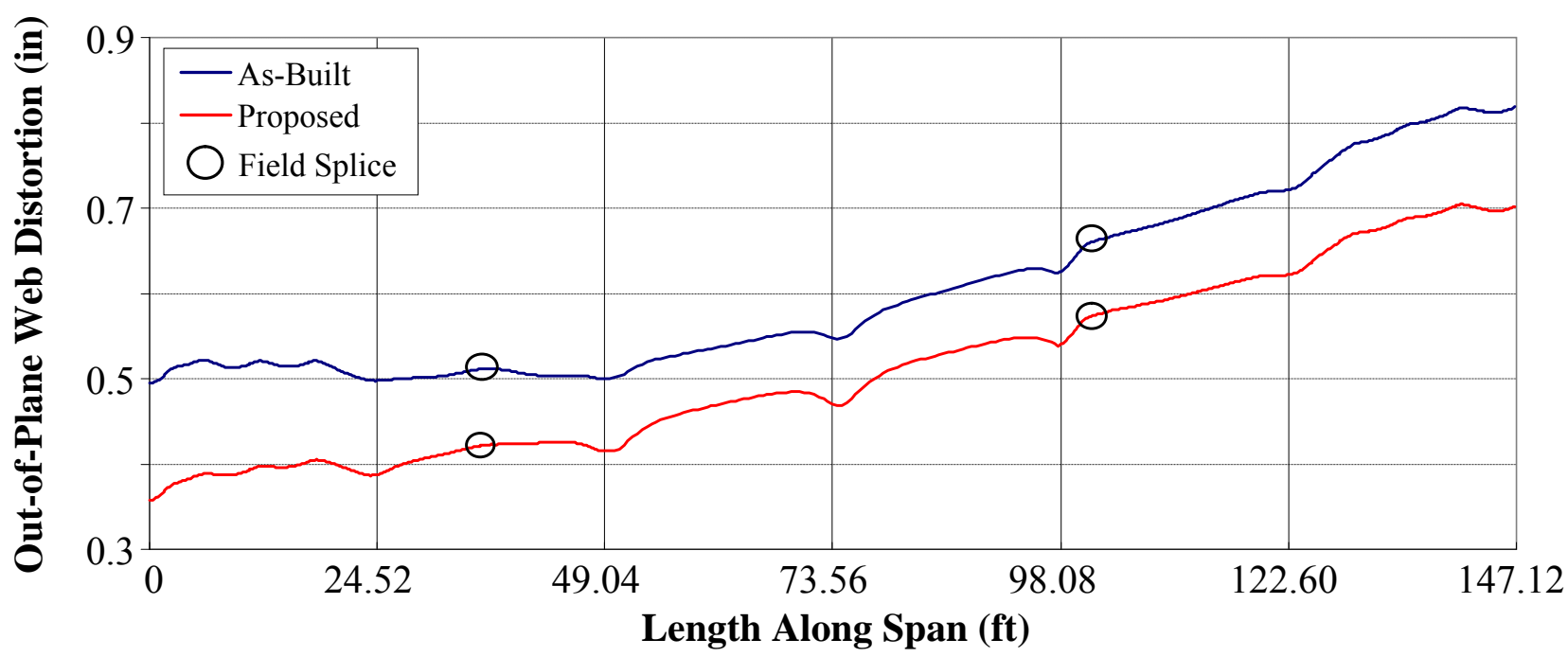

Figure 6.12 Longitudinal Profiles Comparison of Span $11 \mathrm{~N}$ Due to Temp $+90^{\circ} \mathrm{F}$

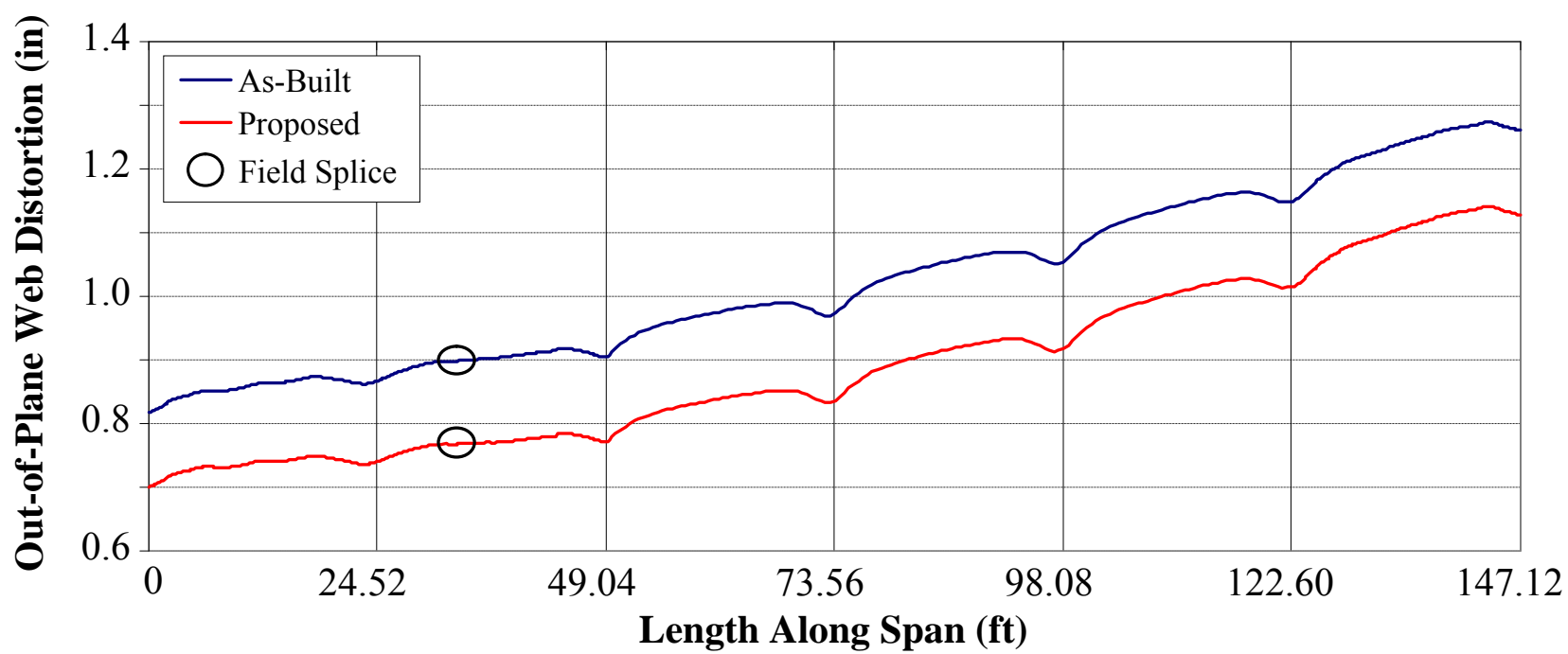

Figure 6.13 Longitudinal Profiles Comparison of Span $12 \mathrm{~N}$ Due to Temp $+90^{\circ} \mathrm{F}$ 
When subjected to the $+90^{\circ} \mathrm{F}$ temperature load, the FE model shows similar behavior to the $+60^{\circ} \mathrm{F}$ load case. The maximum decrease in lateral displacement is again near the midspan of Span 9N, where displacement is reduces from 2.5 in. under the as-built bearing arrangement to approximately $0.125 \mathrm{in}$. under the proposed bearing conditions, a decrease of 95\%. Spans $8 \mathrm{~N}, 9 \mathrm{~N}$, and $10 \mathrm{~N}$ show the largest decreases in overall lateral displacement when compared to the as-built bearing arrangement. Overall, the maximum lateral displacement in each span studied decreased significantly under the new bearing arrangement. The average decrease in displacement was 0.71 in across each span $(7 \mathrm{~N}$ through $12 \mathrm{~N}$ ) for the exterior girder (Girder $4 \mathrm{~N})$. The interior girder (Girder $3 \mathrm{~N}$ ) showed roughly the same results. The maximum out-of-plane displacement in each span for both bearing arrangements is shown in Figures 6.14-6.17.

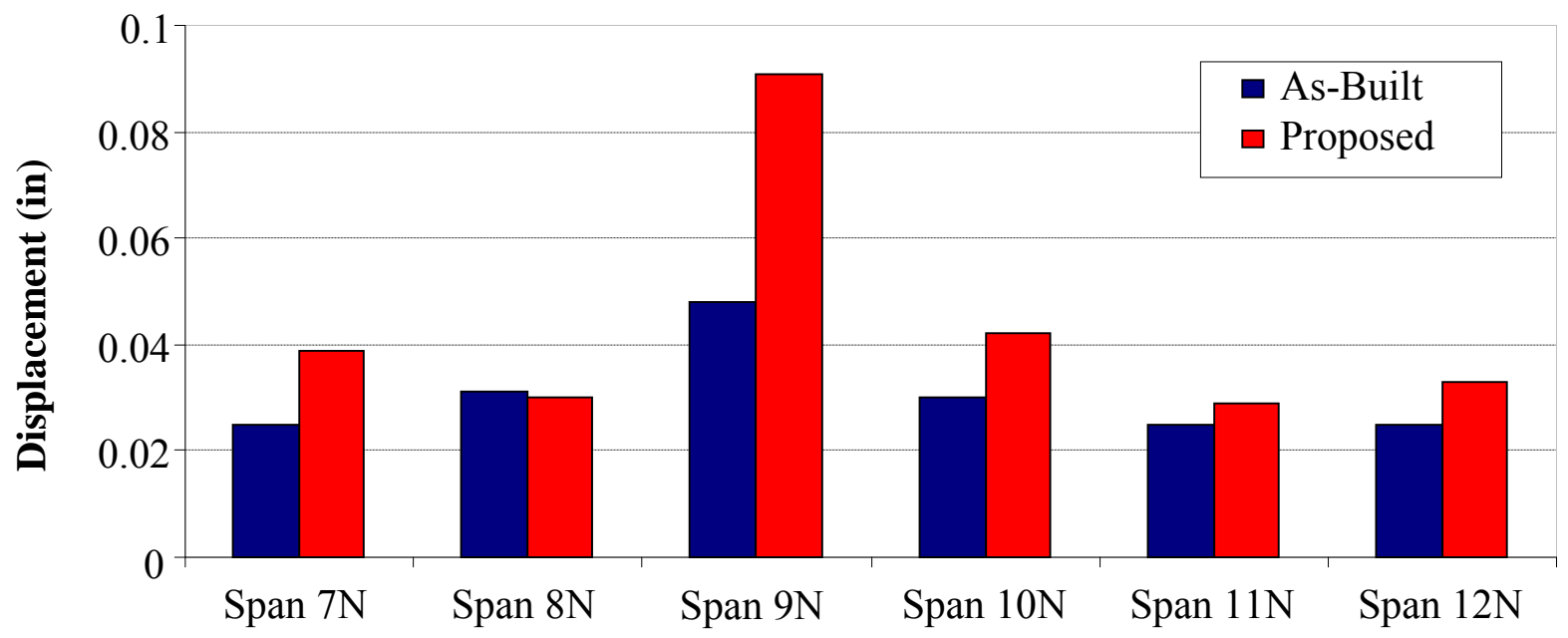

Figure 6.14 Comparison of Maximum Lateral Displacement Due to Self-Weight 


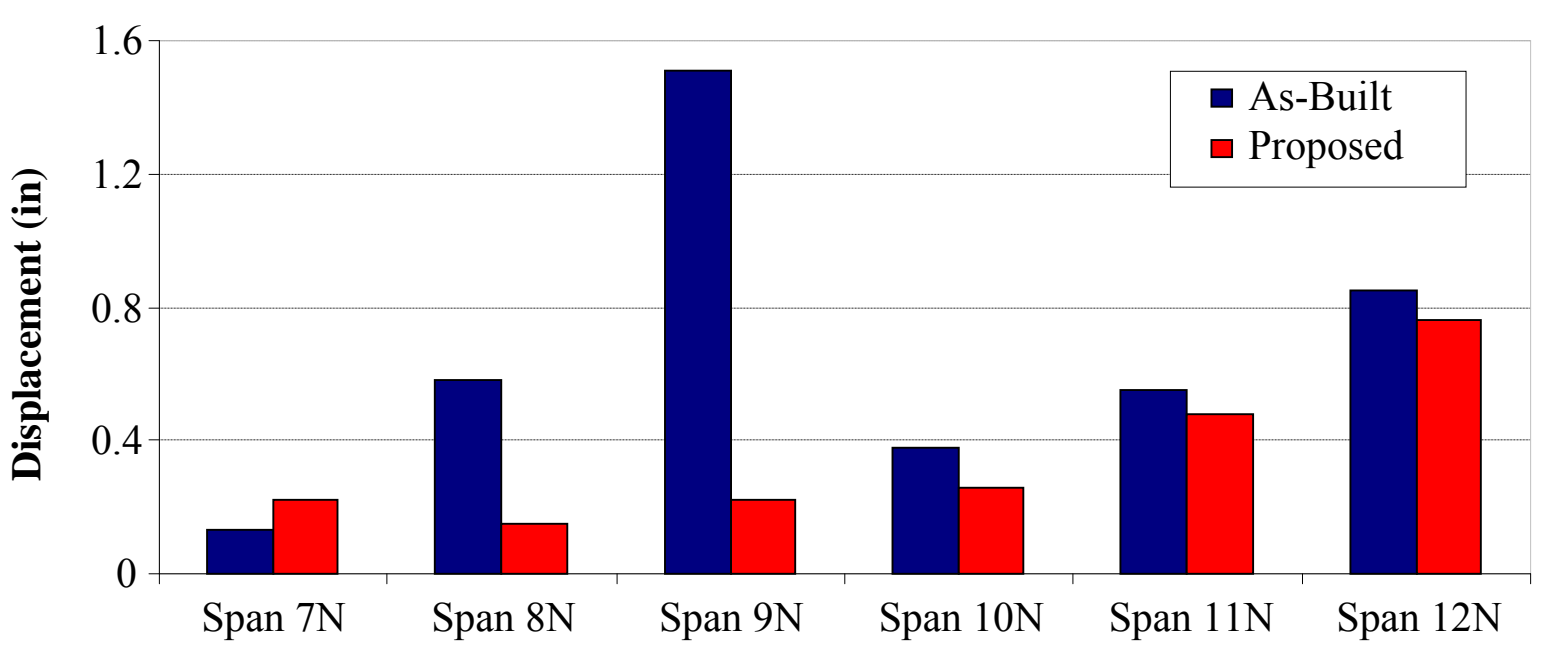

Figure 6.15 Comparison of Maximum Lateral Displacement Due to Temp $-60^{\circ} \mathrm{F}$

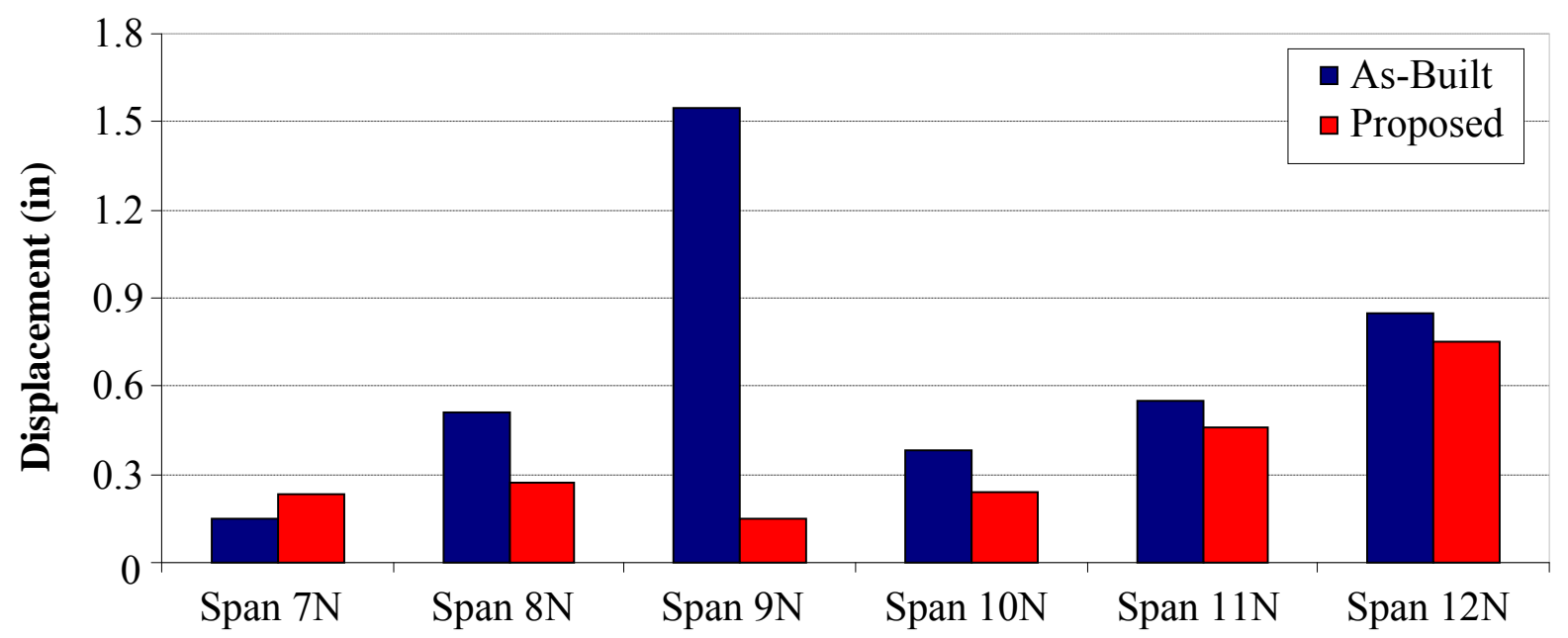

Figure 6.16 Comparison of Maximum Lateral Displacement Due to Temp $+60^{\circ} \mathrm{F}$

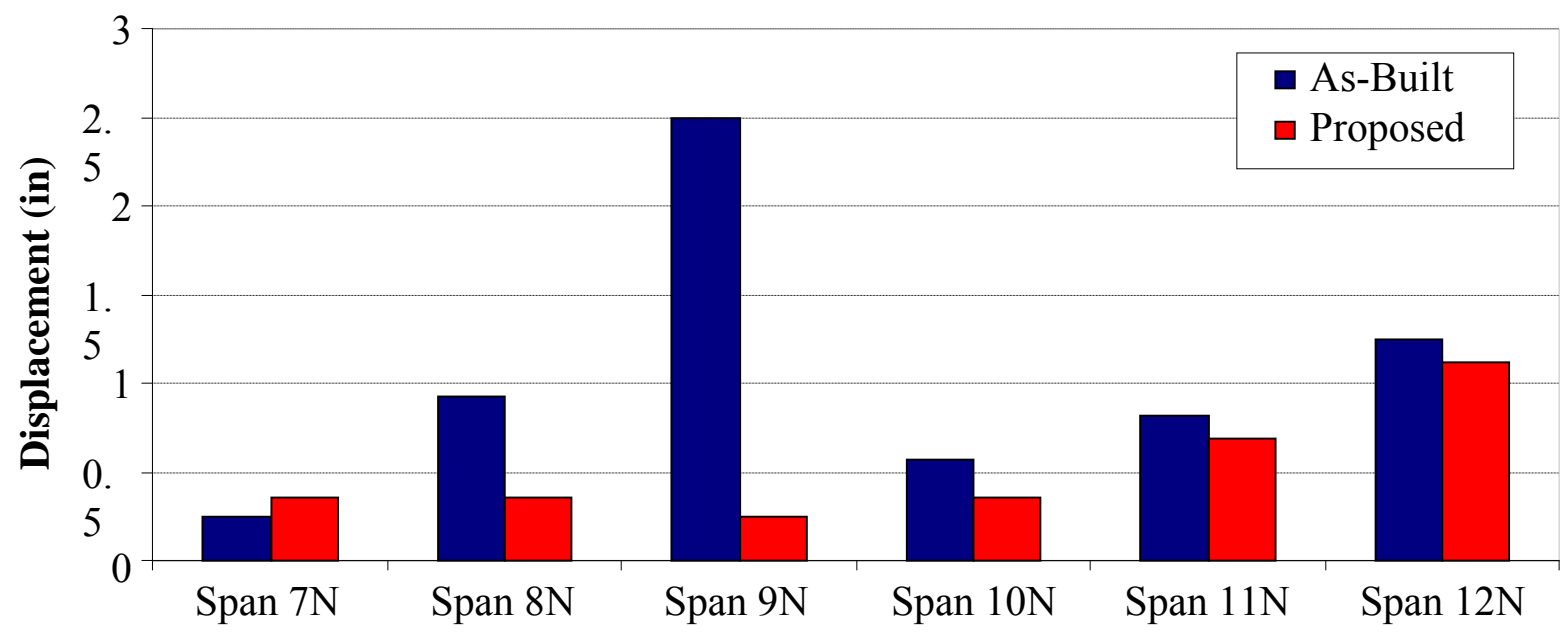

Figure 6.17 Comparison of Maximum Lateral Displacement Due to Temp $+90^{\circ} \mathrm{F}$ 


\subsection{PROPOSED BOUNDARY CONDITIONS - TRANSVERSE WEB PROFILES}

To get a better understanding of the local web buckling behavior under the temperature loads, several cross-sectional profiles are analyzed. Figures 6.14-6.16 present several transverse cross-sections extracted from the FE model at several locations throughout the bridge under each temperature load.

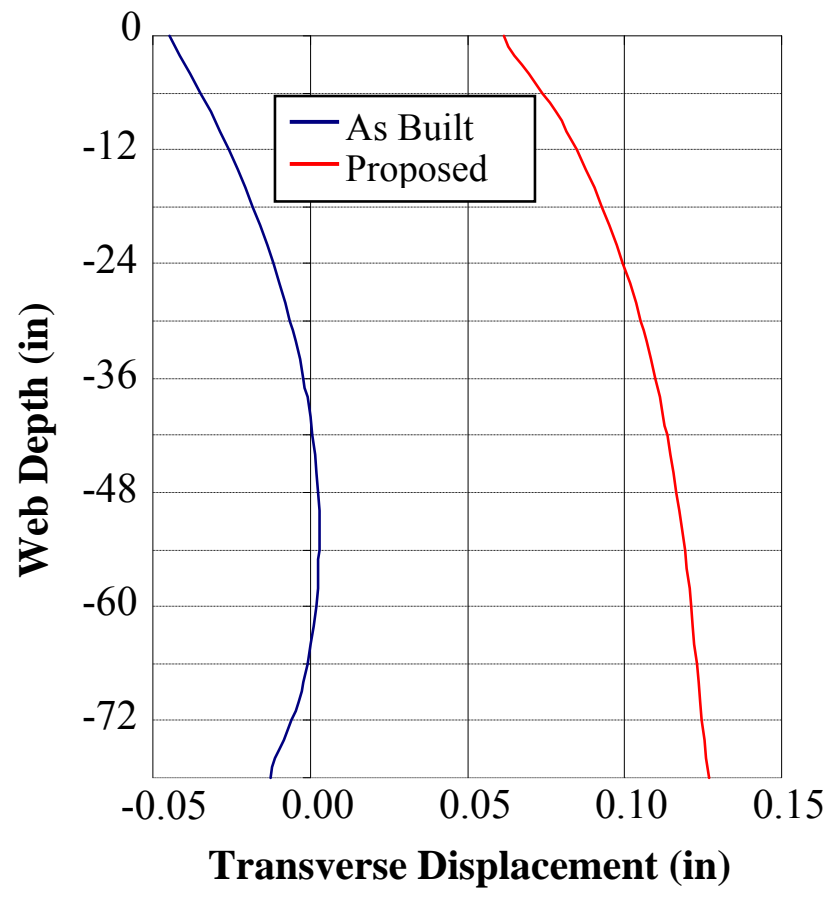

(a) Span $7 \mathrm{~N}$, Girder $4 \mathrm{~N}$

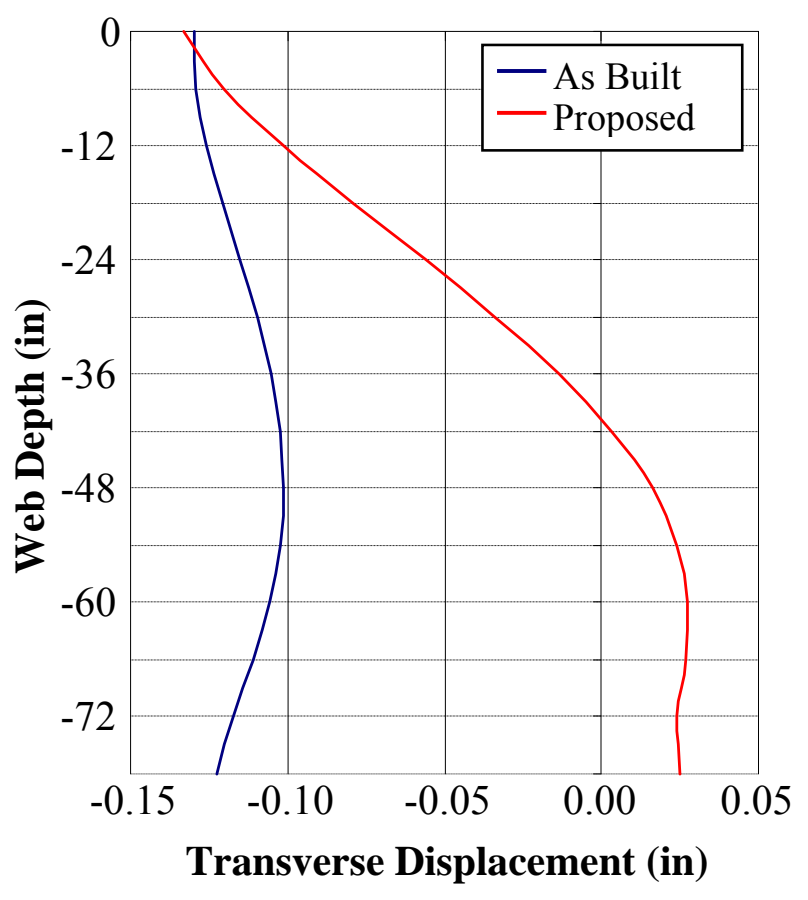

(b) Span $7 \mathrm{~N}$, Girder $1 \mathrm{~N}$ 


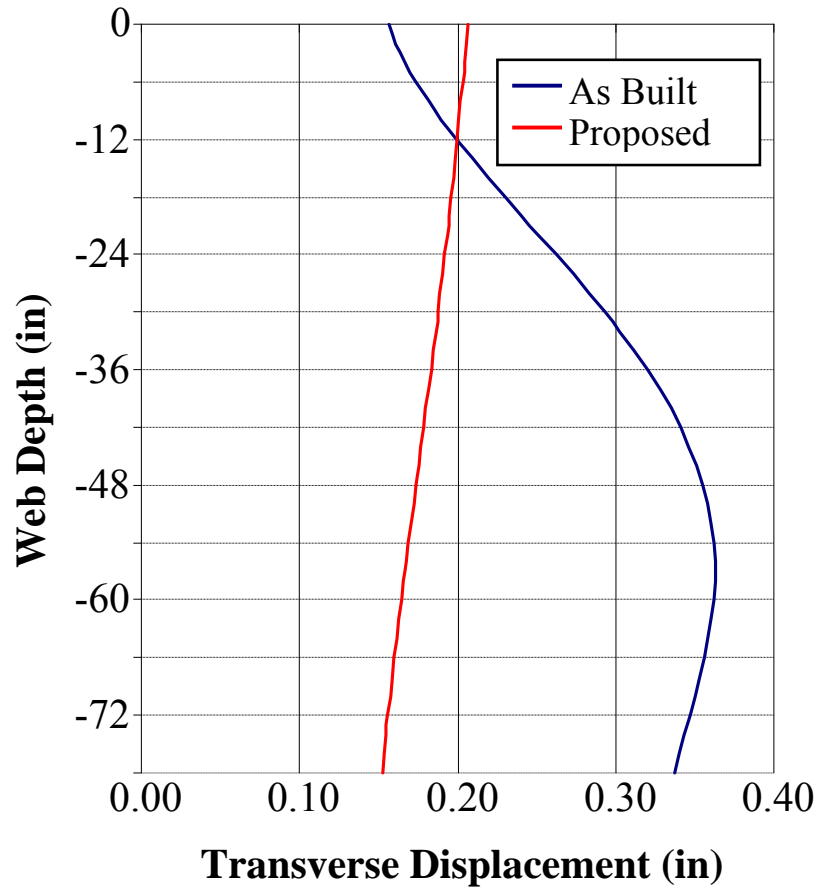

(c) Span $8 \mathrm{~N}$, Girder $4 \mathrm{~N}$

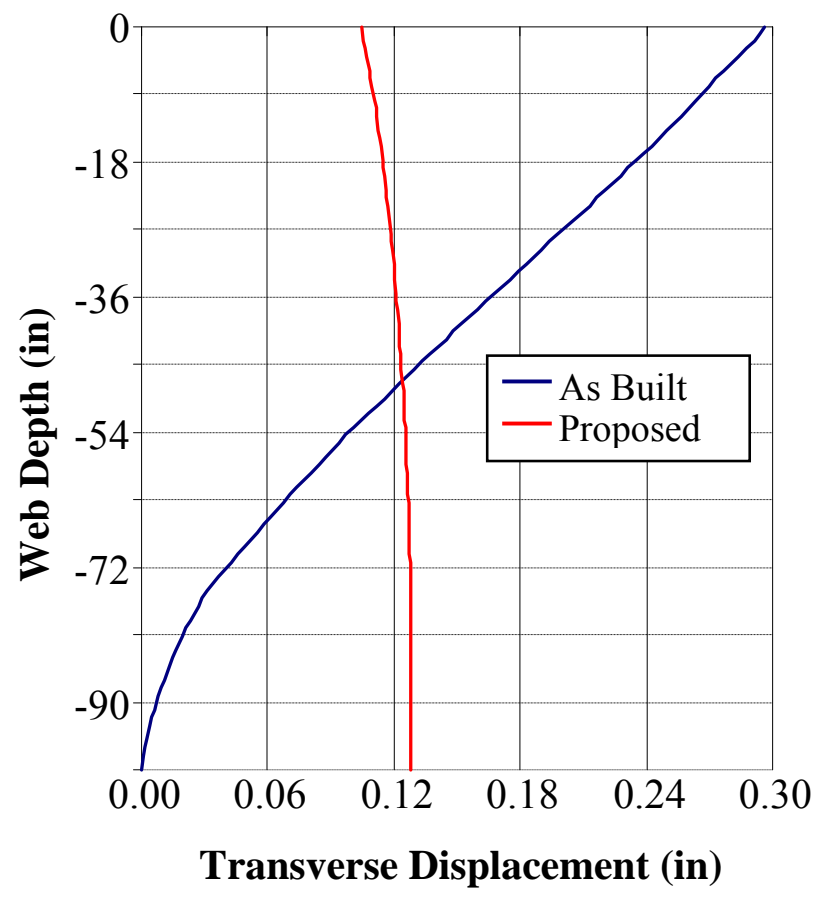

(e) Pier $8 \mathrm{~N}$, Girder $4 \mathrm{~N}$

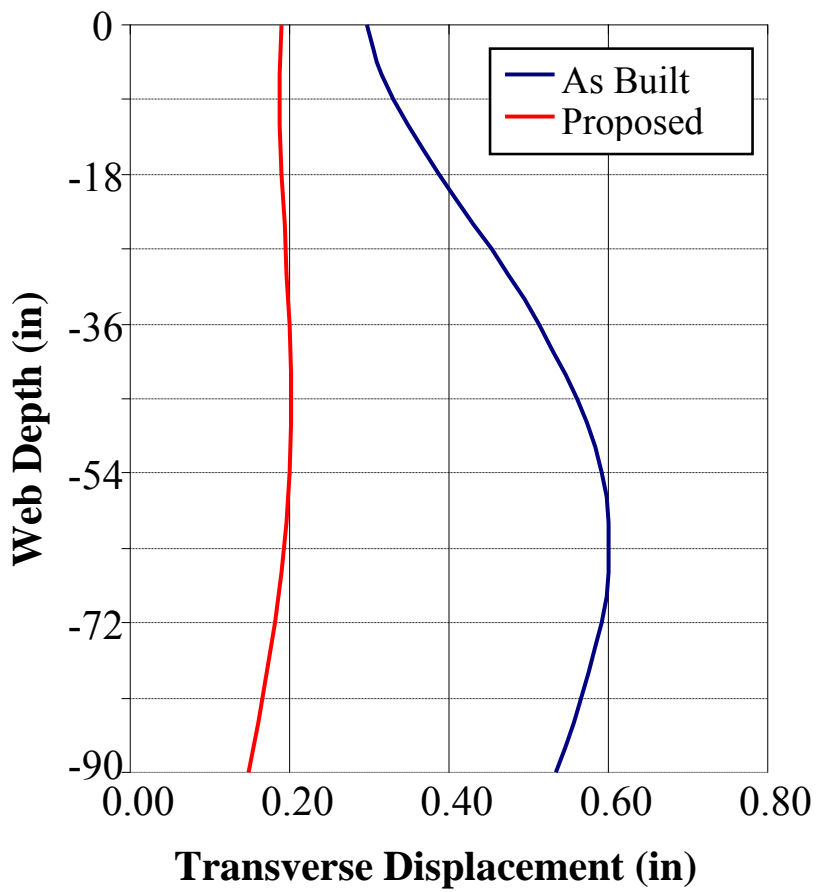

(d) Span $8 \mathrm{~N}$, Girder $1 \mathrm{~N}$

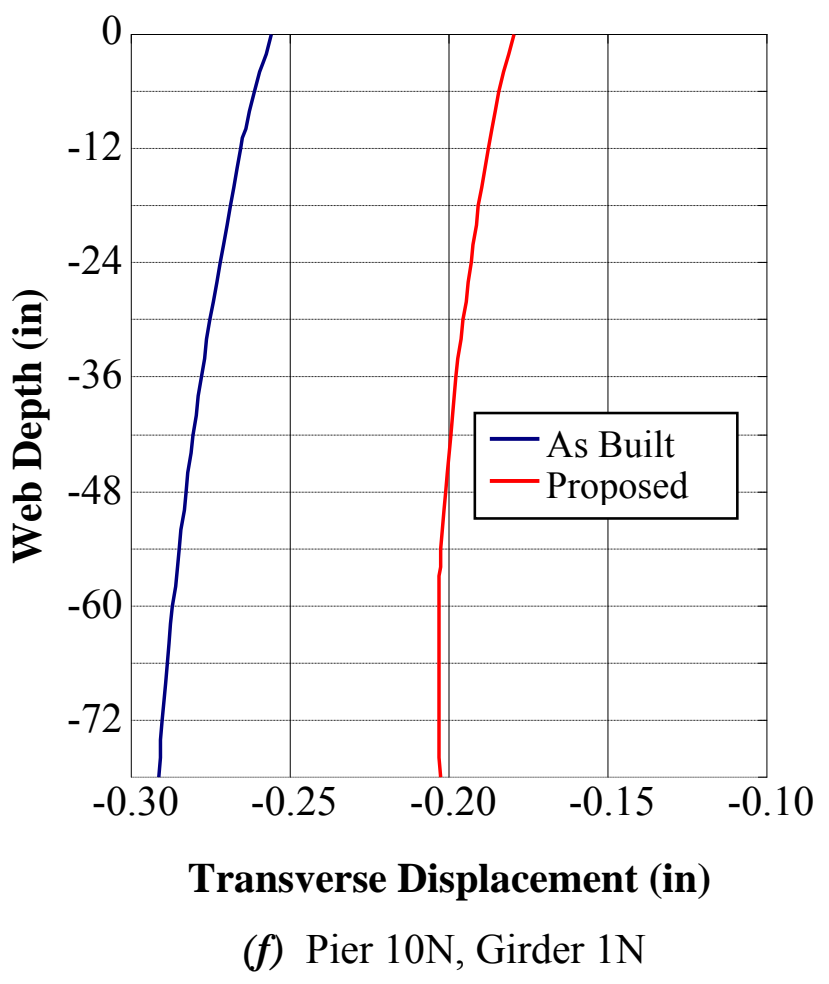

Figure 6.18 Transverse Web Profile Comparisons Under $-60^{\circ} \mathrm{F}$ Temperature Load 
Figure 6.18 presents some very valuable information regarding the bridge's behavior under temperature load. Except for near the midspan of Span 7N (Girder 4N), each location analyzed show a major reduction in local web buckling. Near the midspan on Span $7 \mathrm{~N}$ (Girder $4 \mathrm{~N}$ ), local buckling decreased under the new bearing arrangement, but lateral buckling actually increased. The cross-sections of Span $8 \mathrm{~N}$ show the best improvements in web distortions. The local web buckling is almost eliminated, while lateral buckling is reduced more than $50 \%$. Distortional buckling at Pier $8 \mathrm{~N}$ is significantly reduced as well, mainly due to the replacement of the fixed bearings with expansion bearings. Figure 6.19 presents the transverse web profiles for the $+60^{\circ} \mathrm{F}$ temperature load case.

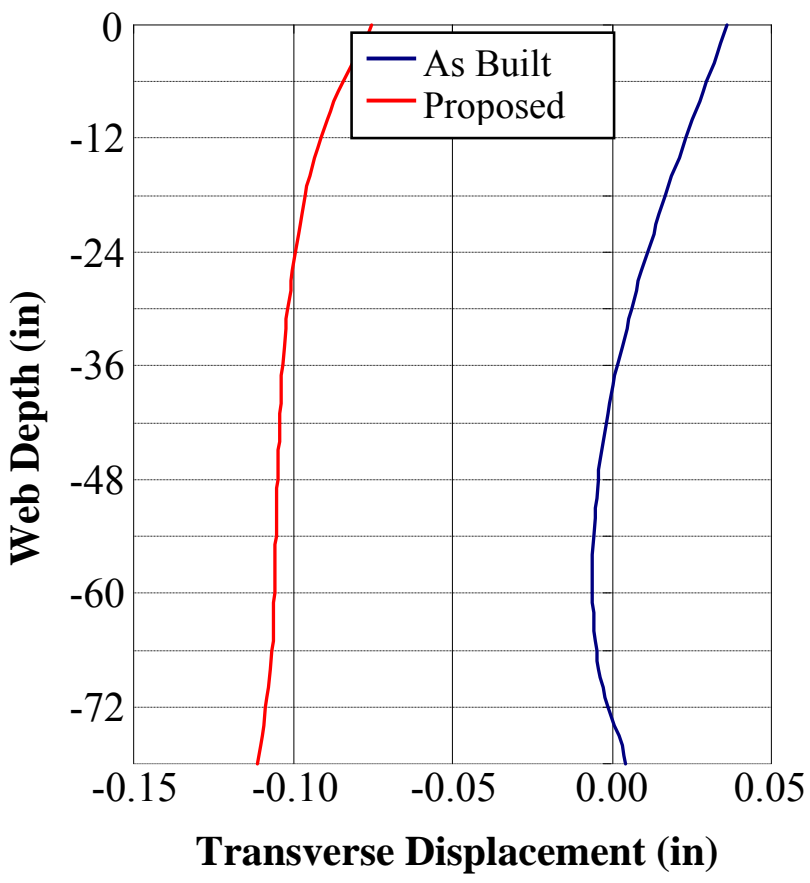

(a) Span $7 \mathrm{~N}$, Girder $4 \mathrm{~N}$

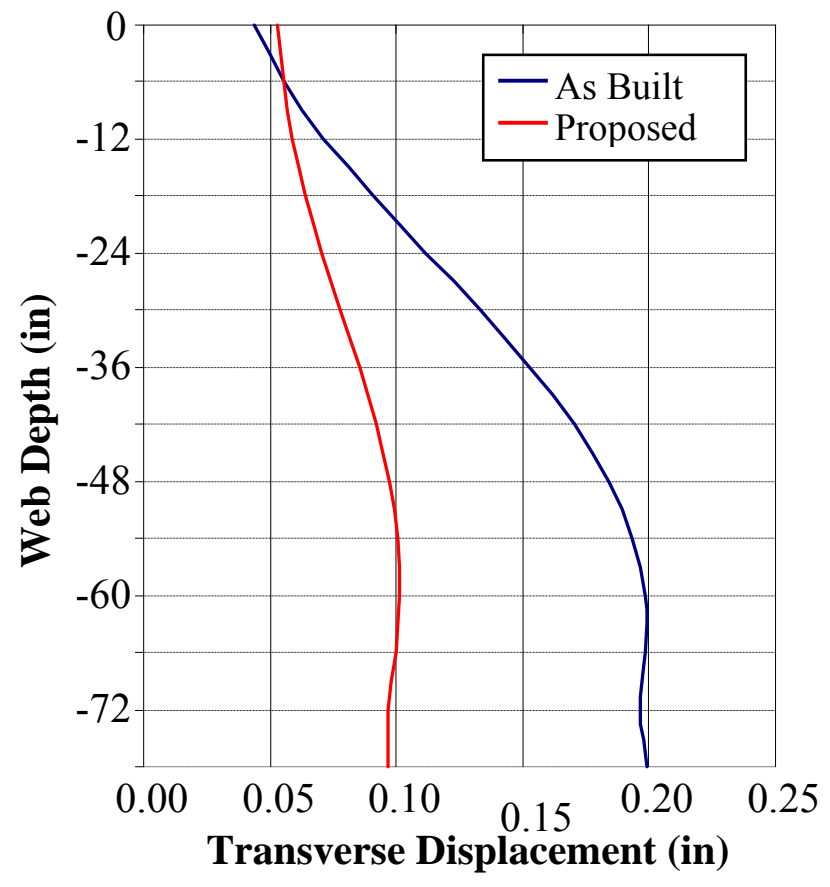

(b) Span $7 \mathrm{~N}$, Girder $1 \mathrm{~N}$ 


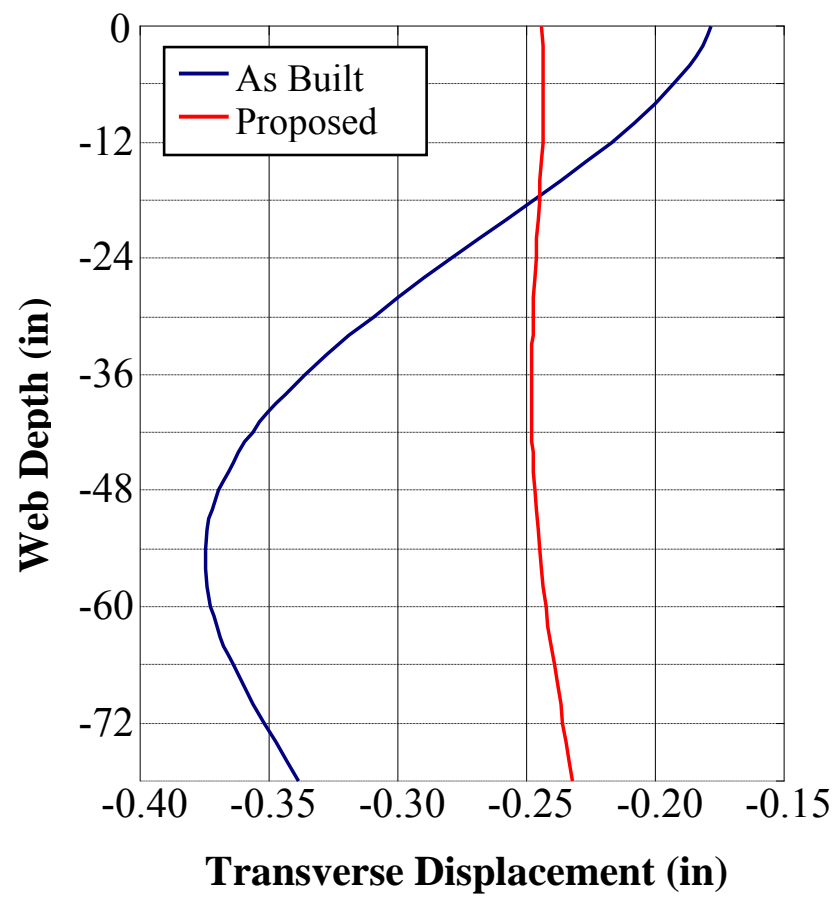

(c) Span $8 \mathrm{~N}$, Girder $4 \mathrm{~N}$

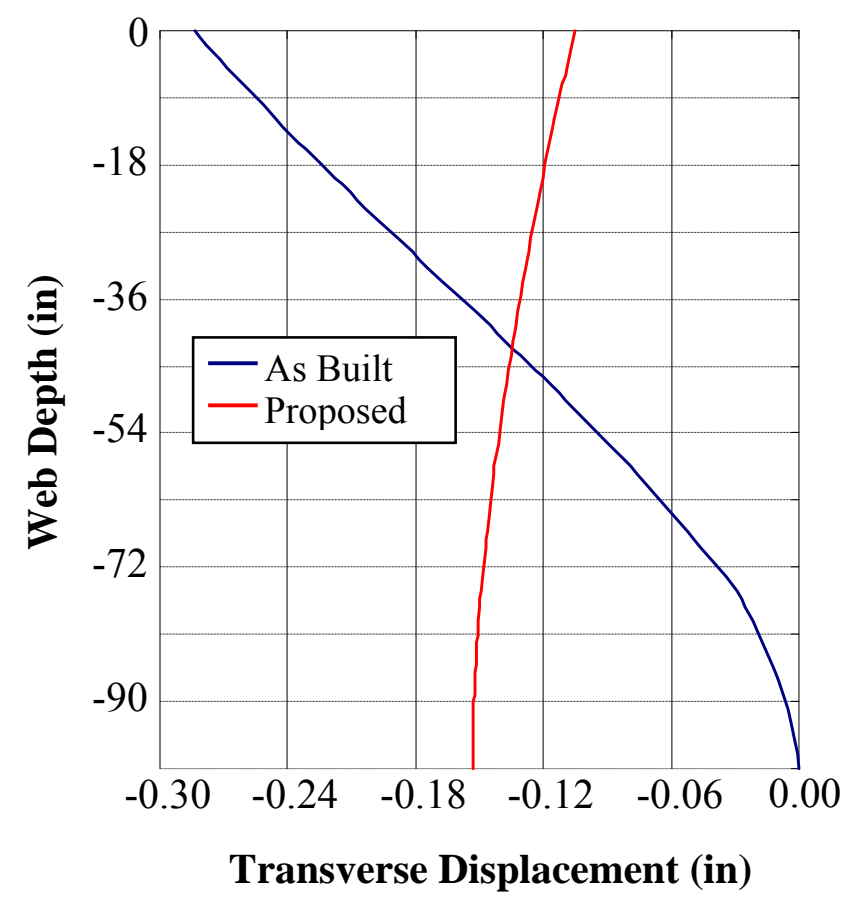

(e) Pier $8 \mathrm{~N}$, Girder $4 \mathrm{~N}$

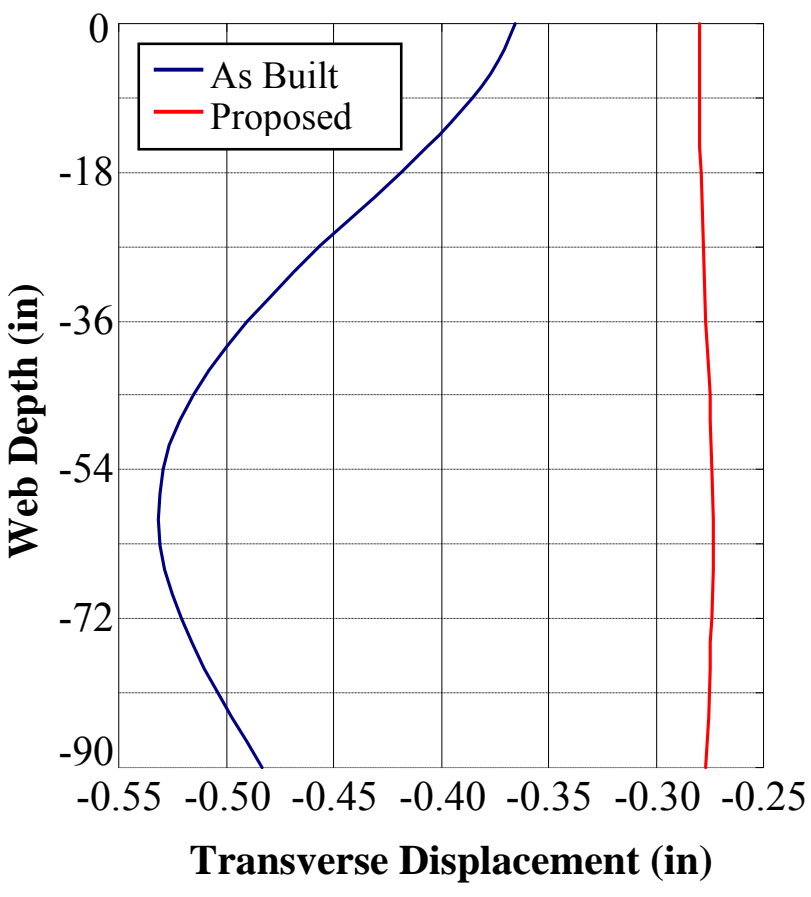

(d) Span $8 \mathrm{~N}$, Girder $1 \mathrm{~N}$

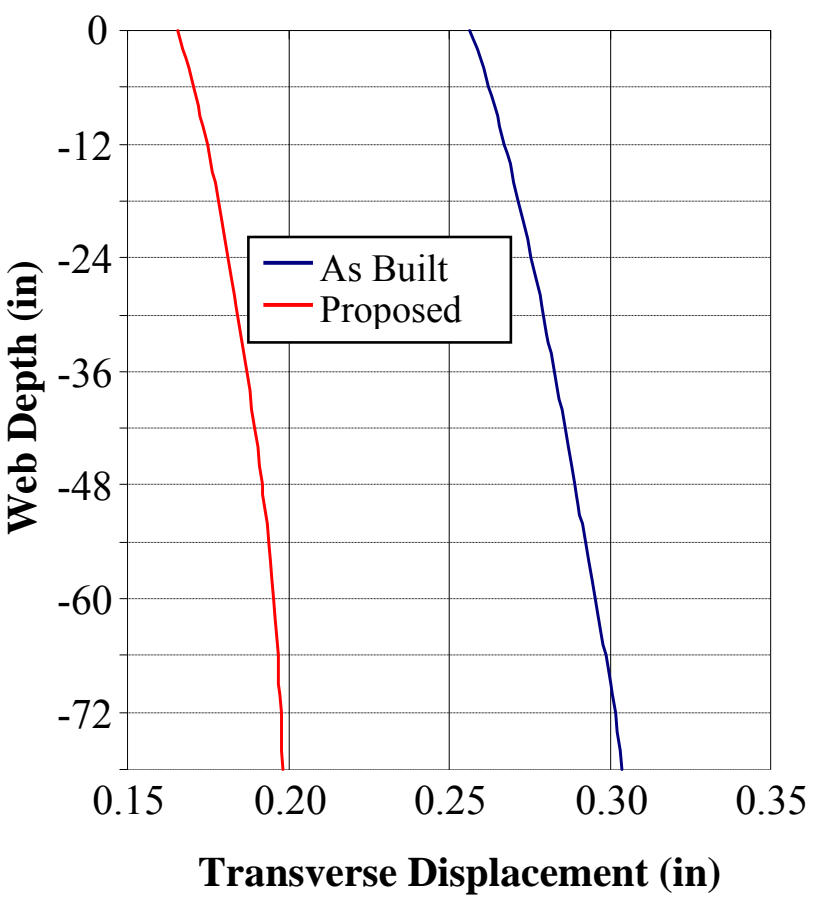

(f) Pier 10N, Girder 1N

Figure 6.19 Transverse Web Profile Comparisons Under $+60^{\circ} \mathrm{F}$ Temperature Load 
In Figure 6.19, all vertical profiles, except for Span 7N (Girder 4N), show a significant reduction in local web buckling and lateral buckling under the new bearing conditions. In Span 7N, local buckling has decreased, but lateral displacement shows an increase at the two locations examined. Local web buckling is more or less eliminated at the cross-sections in Span $8 \mathrm{~N}$, with lateral displacements decreasing more than $50 \%$ at each location, similar to the load case in Figure 6.18. Figure 6.19 presents the transverse web profiles for the $+90^{\circ} \mathrm{F}$ load case.

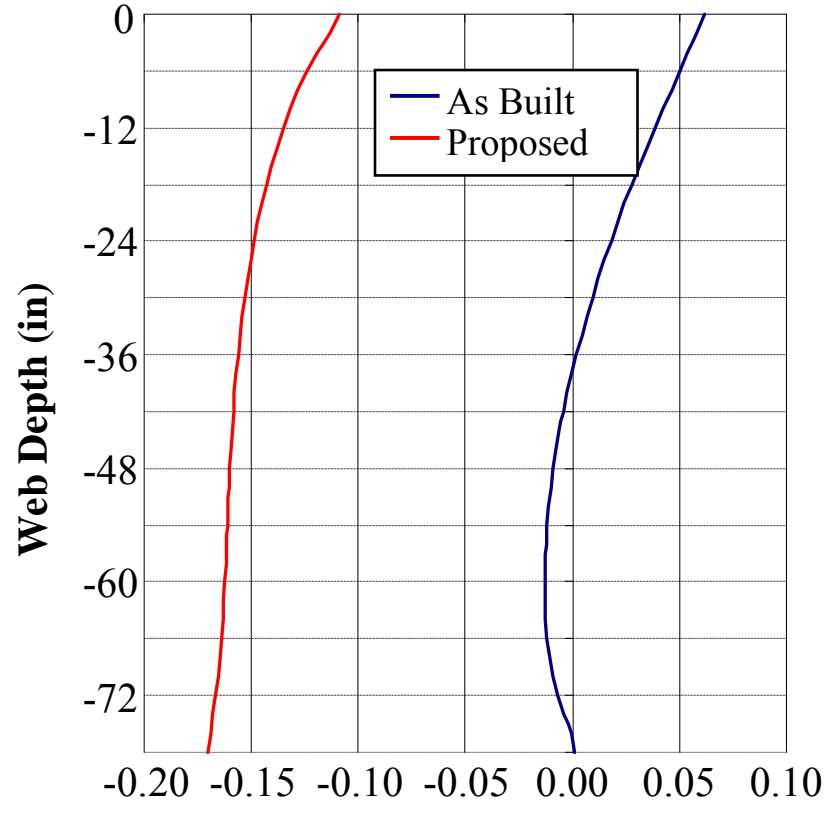

Transverse Displacement (in)

(a) Span $7 \mathrm{~N}$, Girder $4 \mathrm{~N}$

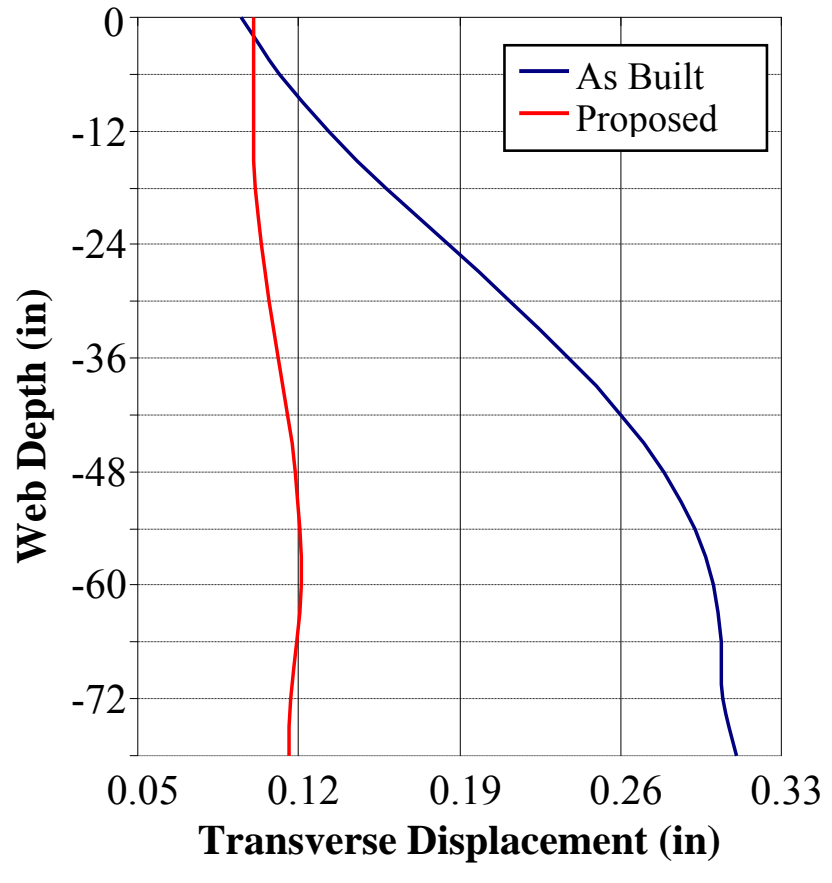

(b) Span 7N, Girder 1N 


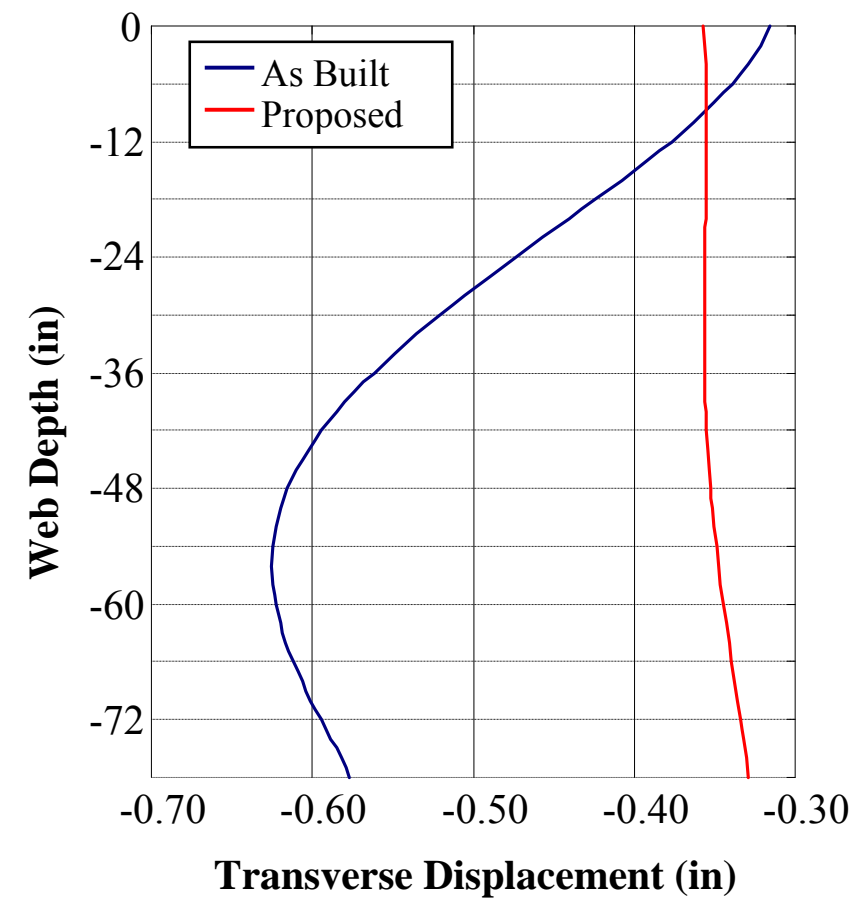

(c) Span $8 \mathrm{~N}$, Girder $4 \mathrm{~N}$

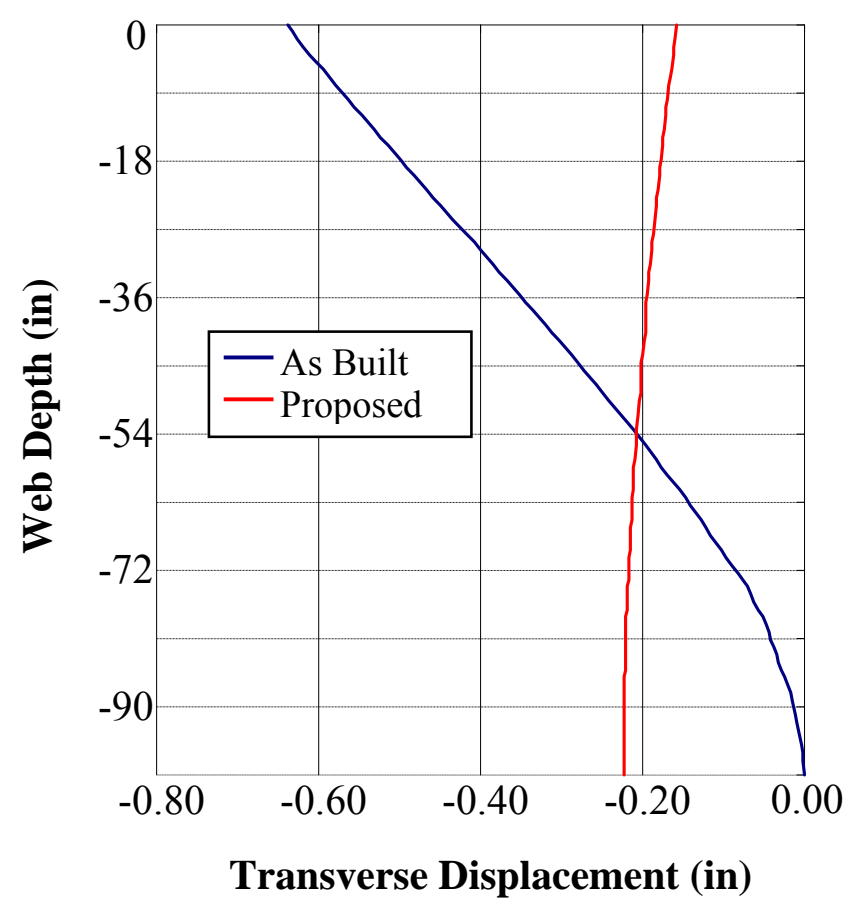

(e) Pier $8 \mathrm{~N}$, Girder $4 \mathrm{~N}$

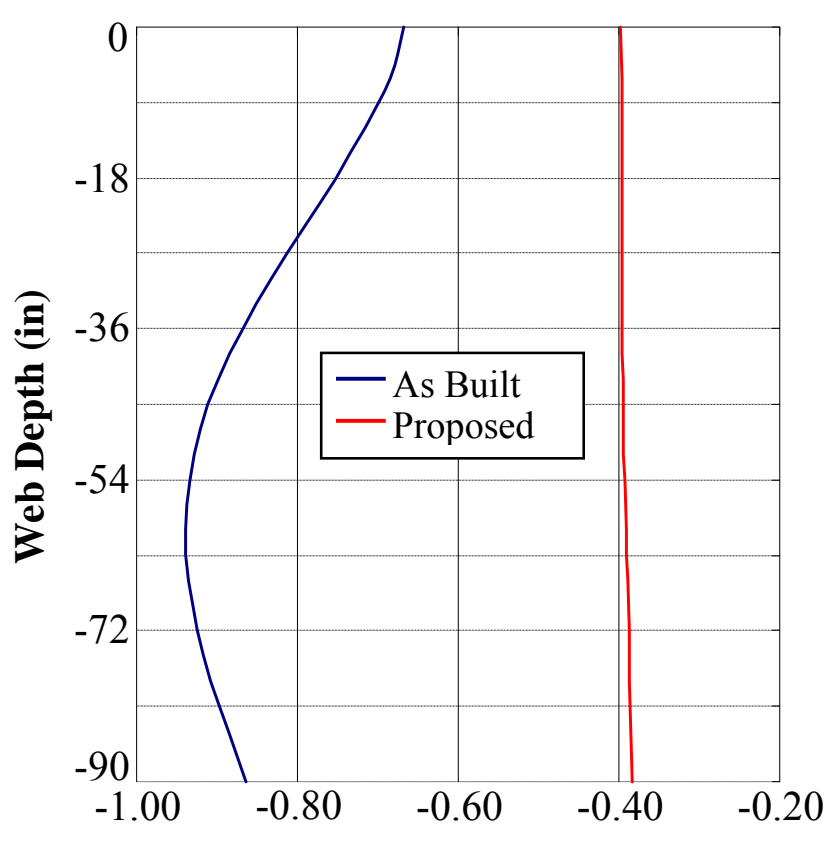

Transverse Displacement (in)

(d) Span $8 \mathrm{~N}$, Girder $1 \mathrm{~N}$

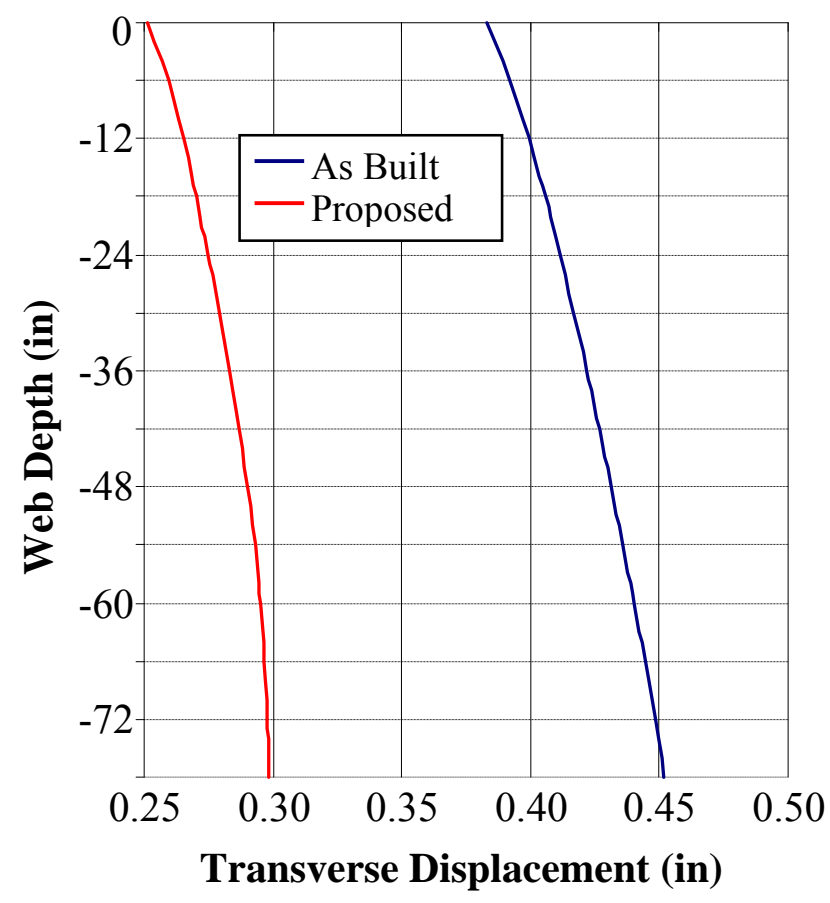

(f) Pier 10N, Girder 1N

Figure 6.20 Transverse Web Profile Comparisons Under $+90^{\circ} \mathrm{F}$ Temperature Load 
The vertical profiles in Figure 6.20 show marked improvement in both local and lateral web buckling under the proposed bearing arrangement. Local web buckling in Span $7 \mathrm{~N}$ Girder $1 \mathrm{~N}(6.20 \mathrm{~b})$ and Span $8 \mathrm{~N}$ cross-sections is nearly eliminated, similar to results shown in Figure 6.19. At Pier 8N, the web distortion is dramatically reduced under the new bearing plan. Replacing the fixed bearing at this location has removed the severe distortions, and only lateral buckling with very small amplitude of local buckling is present. Pier 10N shows a modest decrease in lateral buckling under the proposed bearing arrangement.

\subsection{DISCUSSION AND CONLUSIONS}

This chapter investigated the effects of a newly designed bearing arrangement on the out-of-plane distortion of the steel I-girders. The study found that the magnitude of web outof-plane distortion caused by various temperature loads decreased significantly when compared to the as-built bearing arrangement. The magnitude of local web buckling experienced dramatic reductions, almost being eliminated at several of the locations examined. Lateral buckling also declined. Since the magnitude of web distortion is reduced, the proposed bearing arrangement should have a positive impact on girder capacity and future serviceability. Considering the significant reduction in distortions, the design of the proposed bearing arrangement that was implemented in this chapter is superior to the bearing arrangement currently employed on the bridge. 


\section{CHAPTER SEVEN}

\section{THERMAL STRESSES UNDER PROPOSED BEARING ARRANGEMENT}

\subsection{INTRODUCTION}

It was well documented in Chapter Five that the current bearing arrangement employed on the bridge is the main factor in the development of large thermal stresses in the steel I-girders under the application of uniform temperature loads. The main component of the thermal stress was shown to be large longitudinal stresses, and axial stresses, which negatively influenced bridge capacity. In this chapter, the proposed bearing arrangement from Chapter Six is implemented into the FE bridge model, and the temperature loads are applied in order to investigate the stress levels in the steel bridge girders with the new bearings employed. Since the bridge is much less restrained against thermal movement

under the new bearing conditions, the magnitude of thermal stress that develops in the girders should be much smaller than the stresses produced under the as-built bearing arrangement.

\subsection{EFFECTIVE STRESSES}

Figures 7.1-7.9 present effective stress profiles produced from the FE bridge model with the new bearing arrangement applied. Stresses due to bridge self-weight and the temperature loads are shown and compared for the same cross-sections analyzed in chapter five. Effective stresses are again investigated to establish the overall state of stress in the girders when a uniform thermal load is added to the bridge self-weight dead load. 


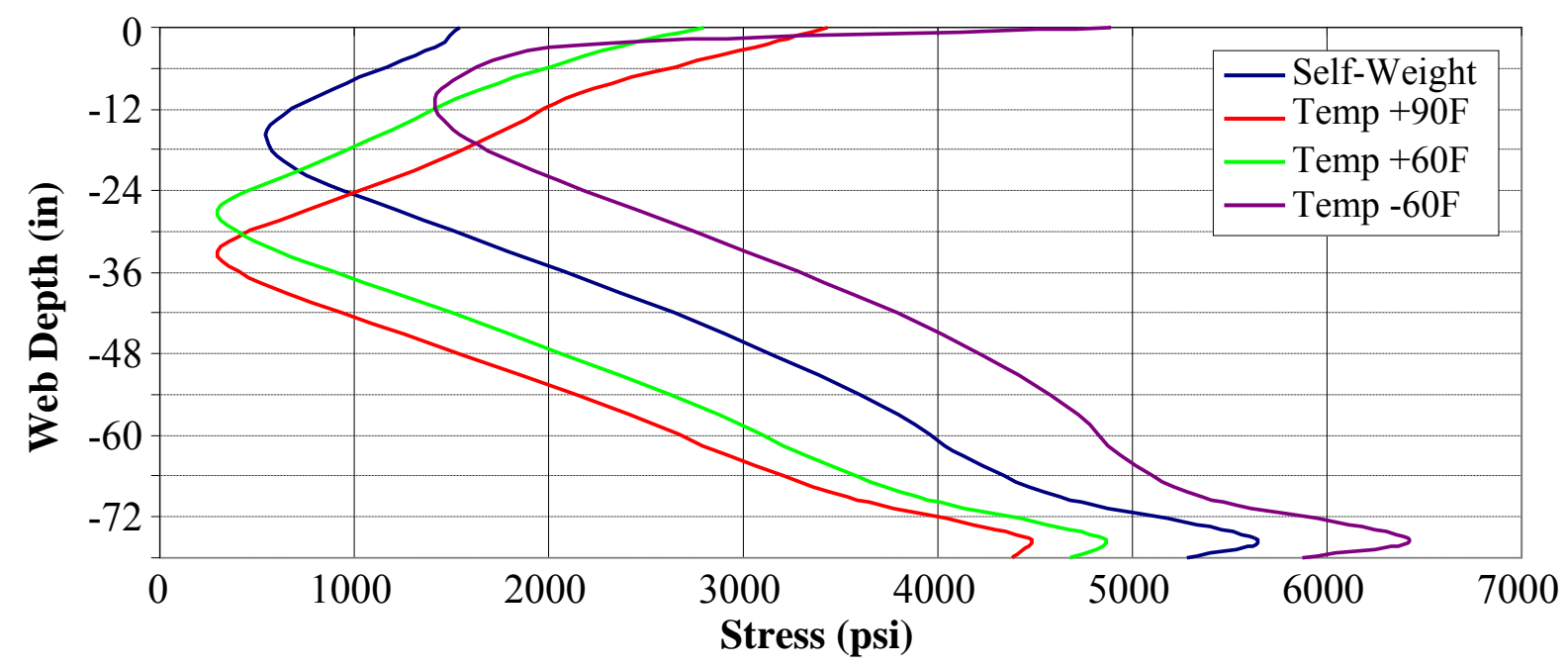

Figure 7.1 New Bearings, Effective Stress Profiles for Span 7N

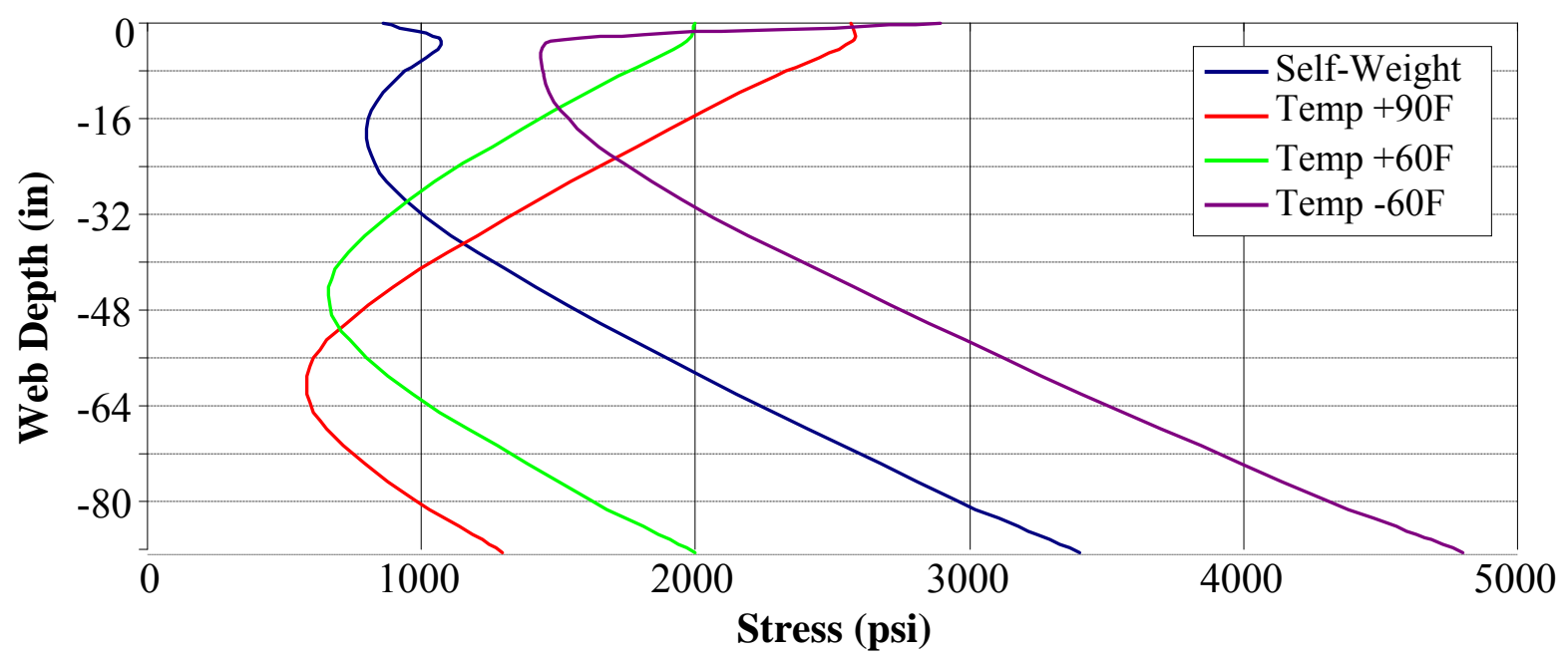

Figure 7.2 New Bearings, Effective Stress Profiles for Span 8N

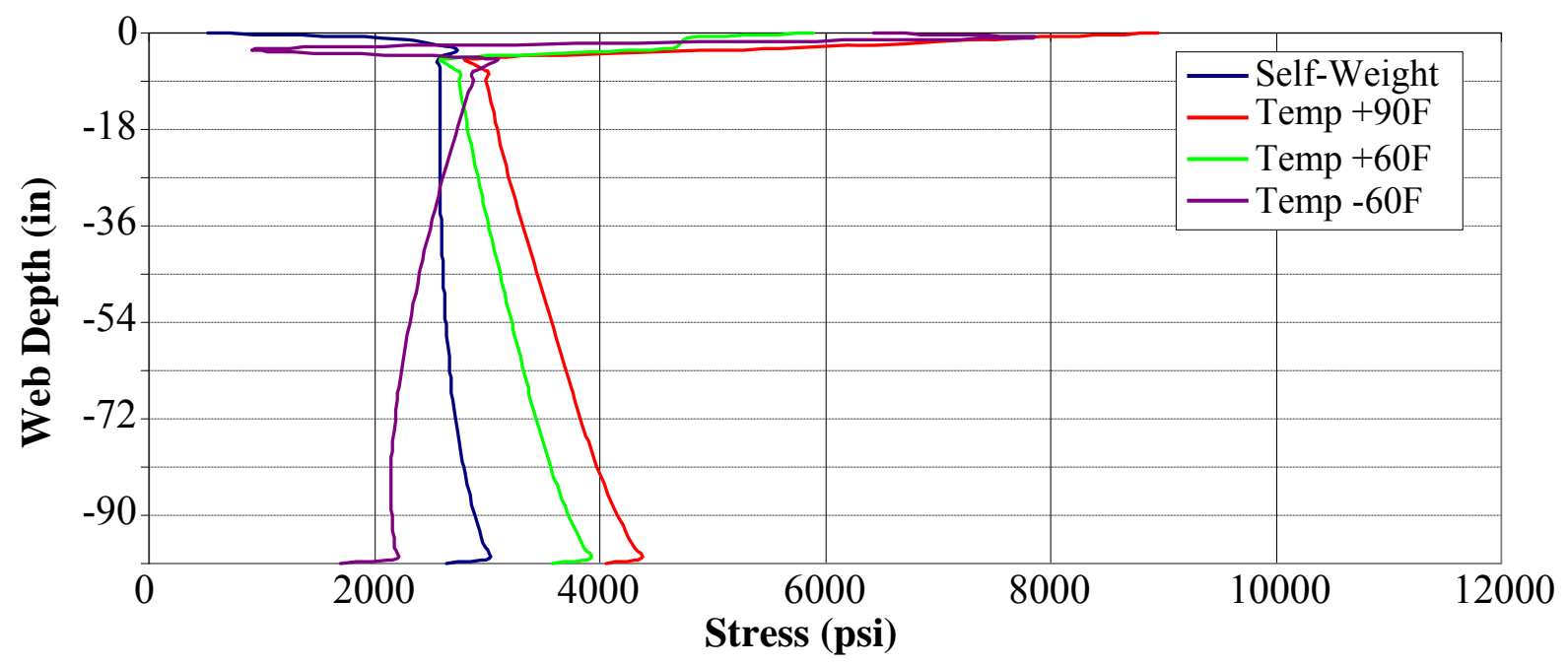

Figure 7.3 New Bearings, Effective Stress Profiles for Span 9N 


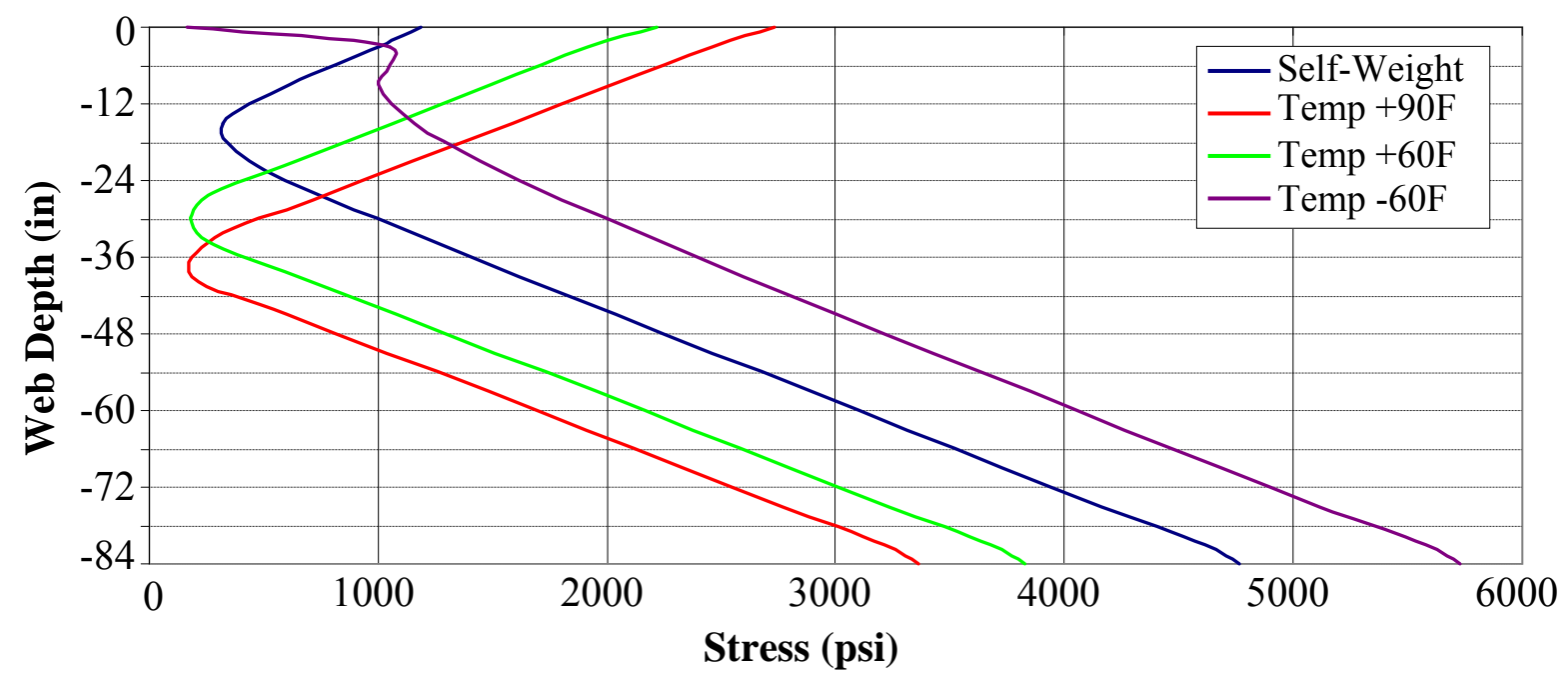

Figure 7.4 New Bearings, Effective Stress Profiles for Span 10N

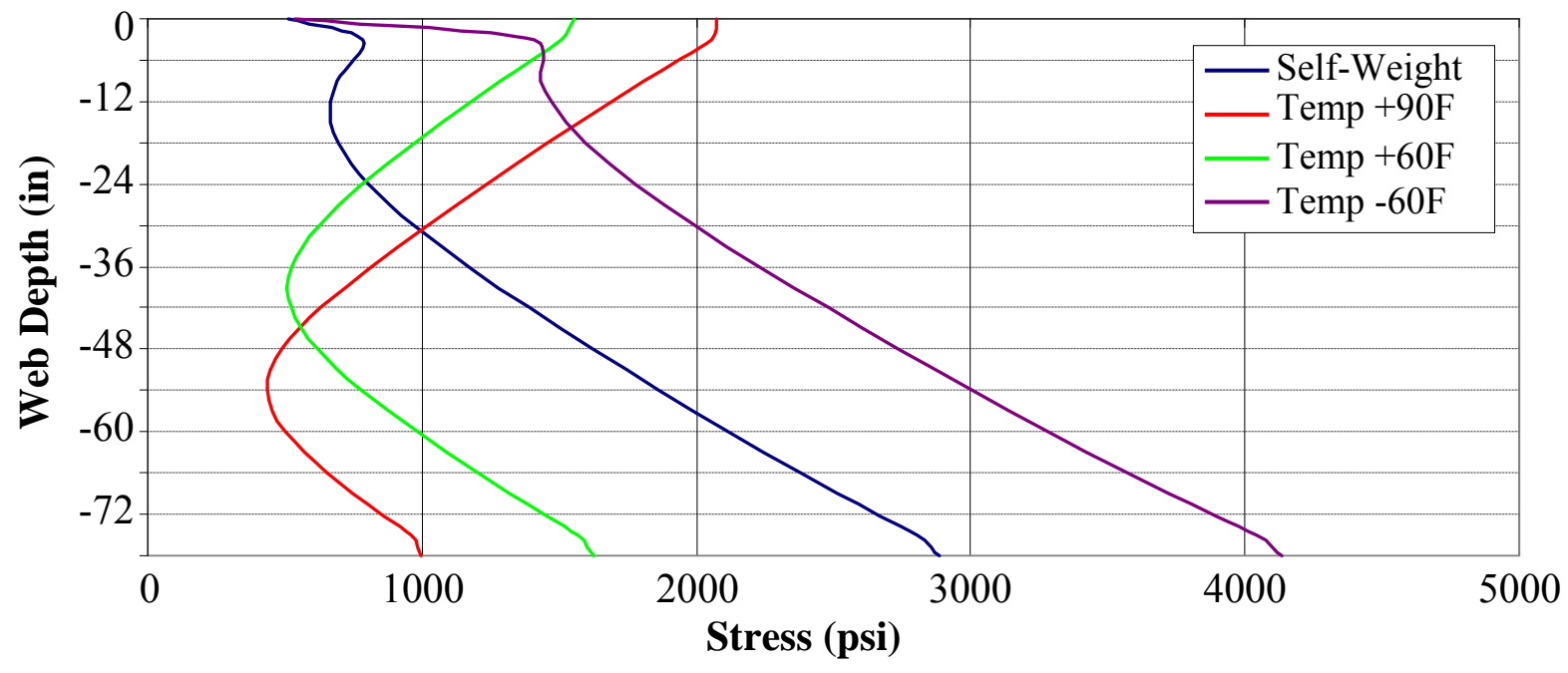

Figure 7.5 New Bearings, Effective Stress Profiles for Span 11N

The effective stress profiles presented in Figure 7.1 indicate mostly similar behavior across all load cases. Noticed first is the parity throughout each load case. Unlike under the as-built bearing arrangement, no single temperature load results in extreme stress levels in the girders. The $-60^{\circ} \mathrm{F}$ temperature load produces the highest effective stress of the four load cases in four of the five spans analyzed. Overall, effective stresses have decreased approximately $50 \%$ in each span. Figures 7.6-7.9 compare the maximum effect stress values 
for the as-built and proposed bearing arrangements at each cross-section analyzed in Figures 7.1-7.5. It is clearly seen that the proposed bearing arrangement, when implemented on the FE bridge model, produces considerably lower effective stresses in the bridge in the cases where a temperature load is present. Under the $+90^{\circ} \mathrm{F}$ temperature load, maximum effective stress in Spans $8 \mathrm{~N}$ and $9 \mathrm{~N}$ decrease $82 \%$ and 56\% respectively. Stress levels in Span $11 \mathrm{~N}$ remain almost unchanged under the new bearing arrangement. Similar results are produced in the $-1+60^{\circ} \mathrm{F}$ load cases. Figures 7.7-7.9 suggest that the as-built bearing arrangement is the main reason for the high stress values recorded in Chapter Five.

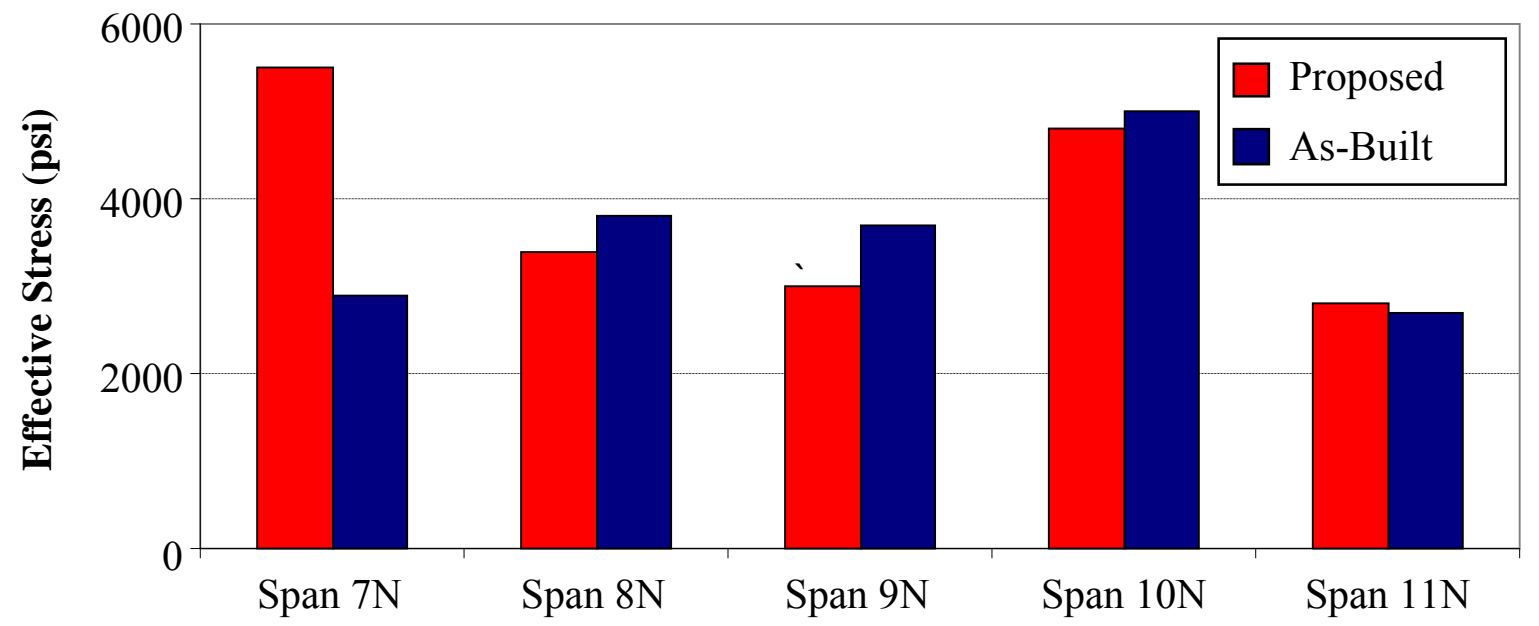

Figure 7.6 As-Built - New Bearings Eff. Stress Comparison Under Self-Weight (Spans)

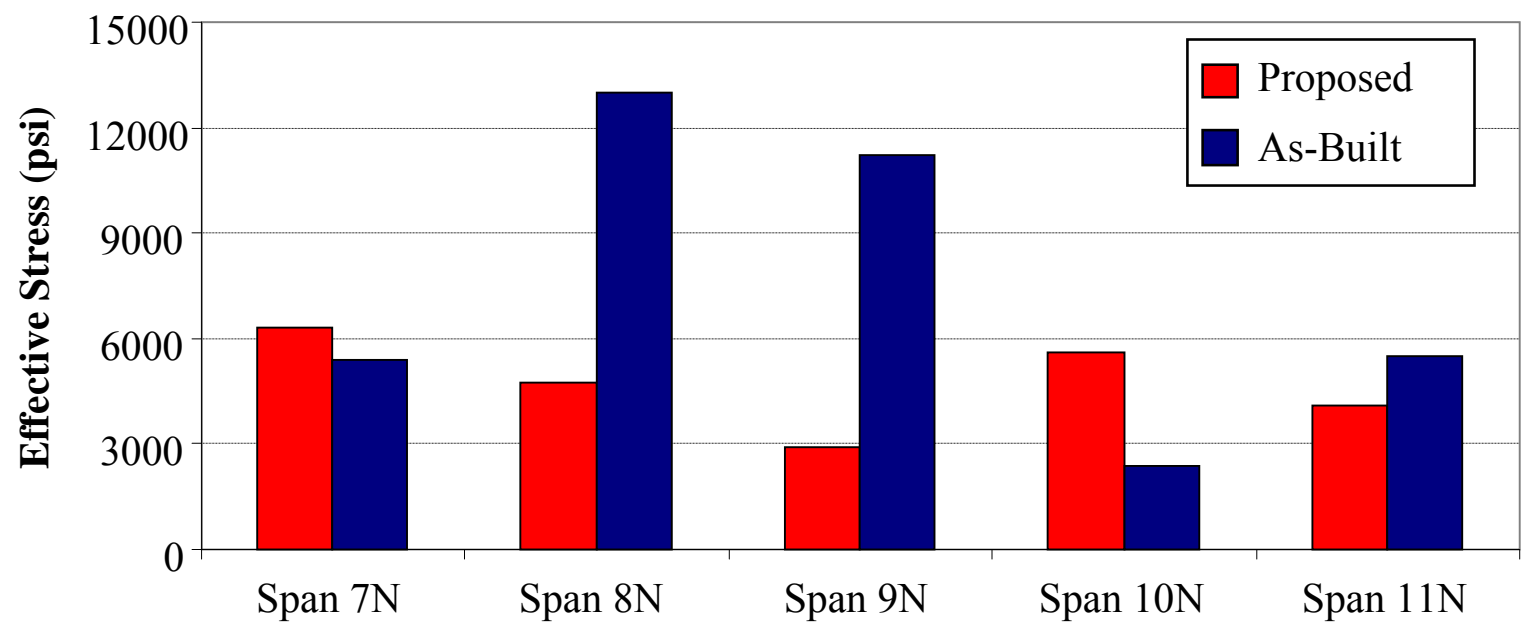

Figure 7.7 As-Built - New Bearings Eff. Stress Comparison Under Temp - $60^{\circ} \mathrm{F}$ (Spans) 


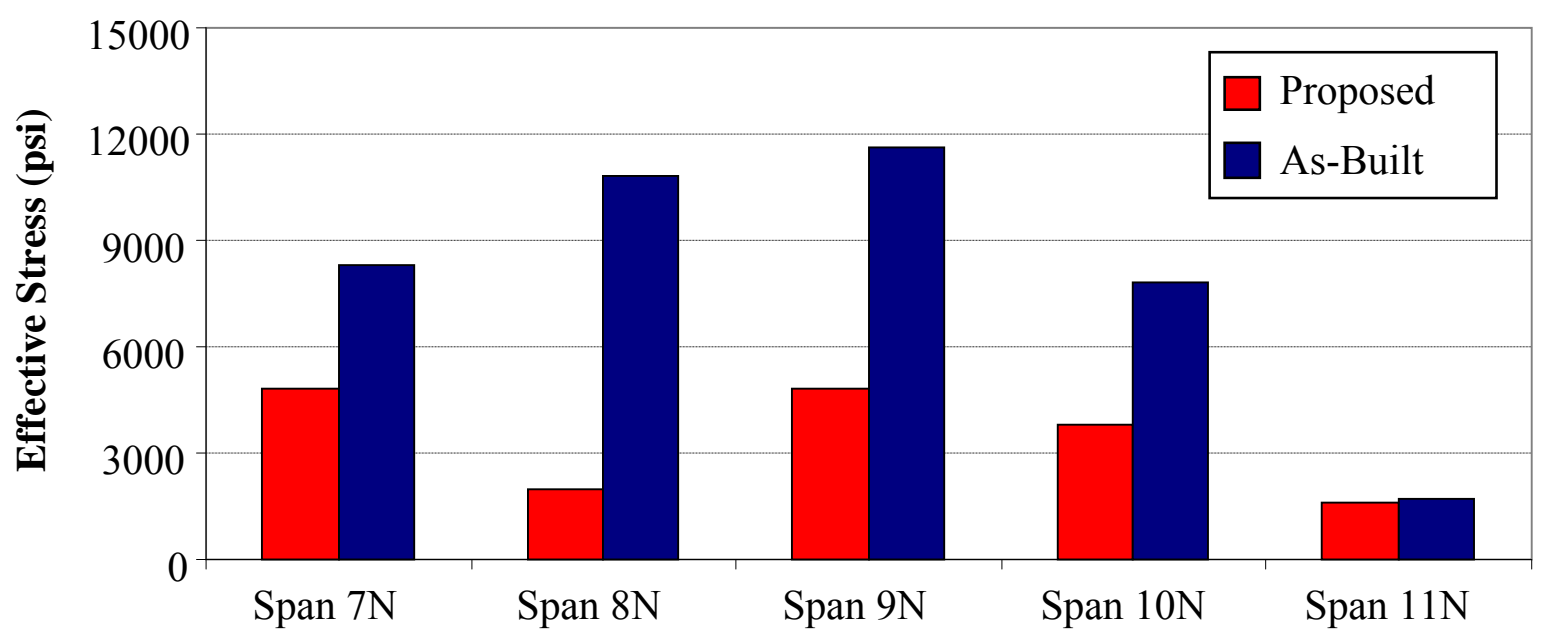

Figure 7.8 As-Built - New Bearings Eff. Stress Comparison Under Temp $+60^{\circ} \mathrm{F}$ (Spans)

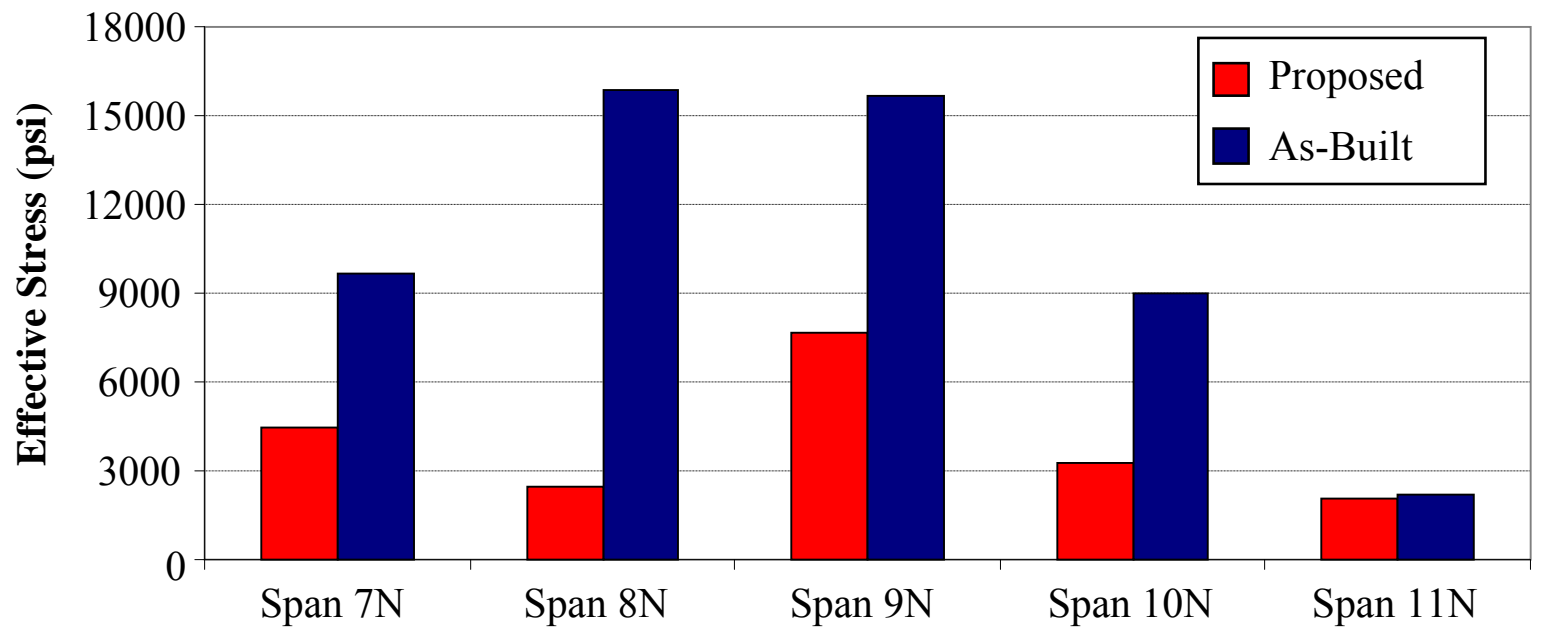

Figure 7.9 As-Built - New Bearings Eff. Stress Comparison Under Temp $+90^{\circ} \mathrm{F}$ (Spans)

Figures 7.10-7.14 shows the effective stress profiles for the pier locations under the proposed bearing arrangement, and Figure 7.15-7.18 compares the maximum effective stress between the as-built and proposed bearing arrangements at these pier locations. 


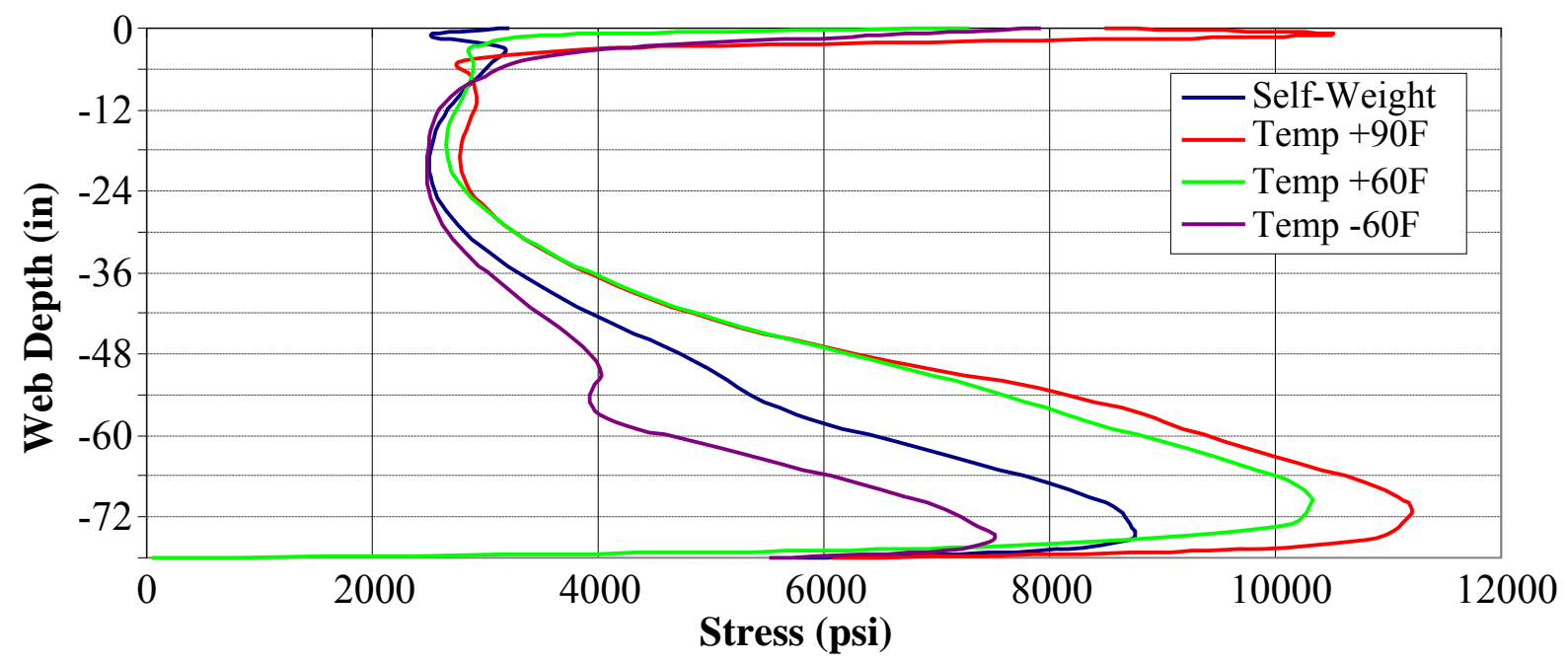

Figure 7.10 New Bearings, Effective Stress Profiles for Pier 7N

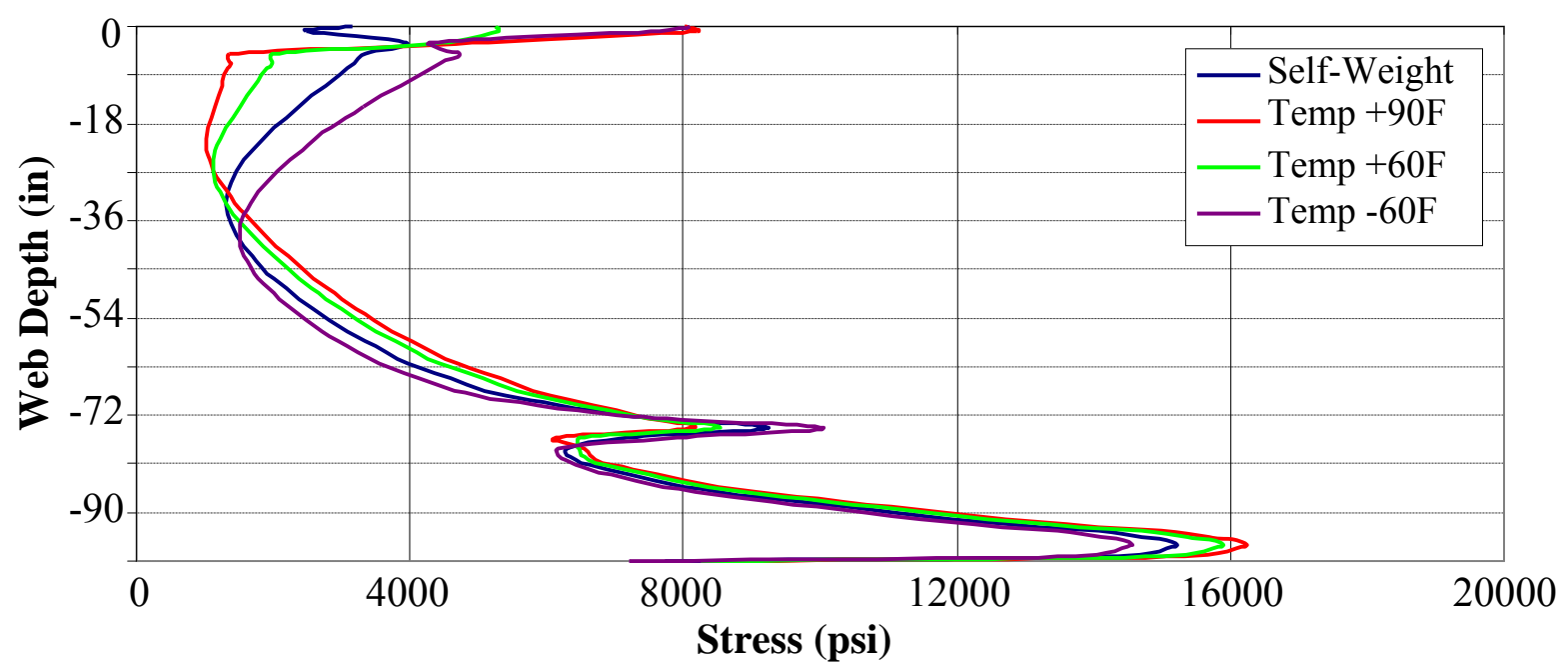

Figure 7.11 New Bearings, Effective Stress Profiles for Pier 8N

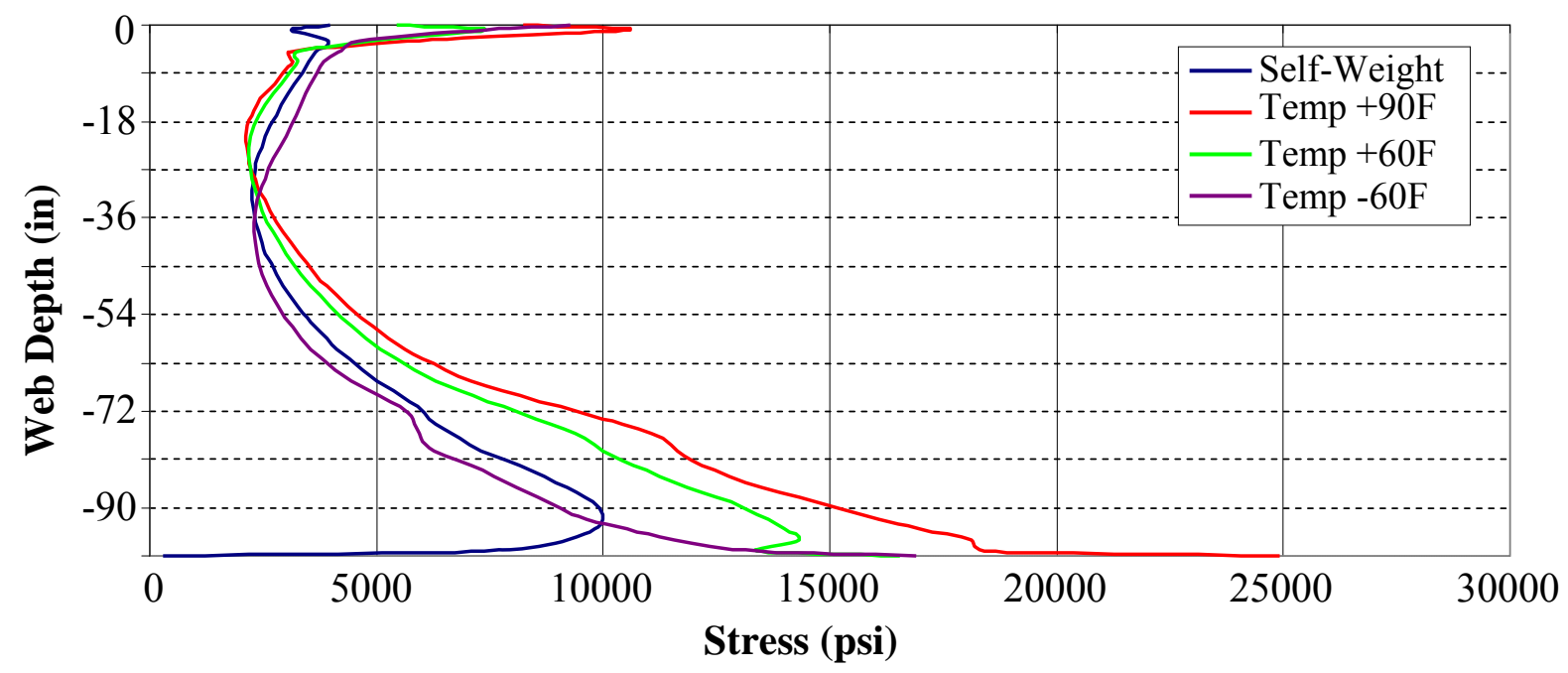

Figure 7.12 New Bearings, Effective Stress Profiles for Pier 9N 


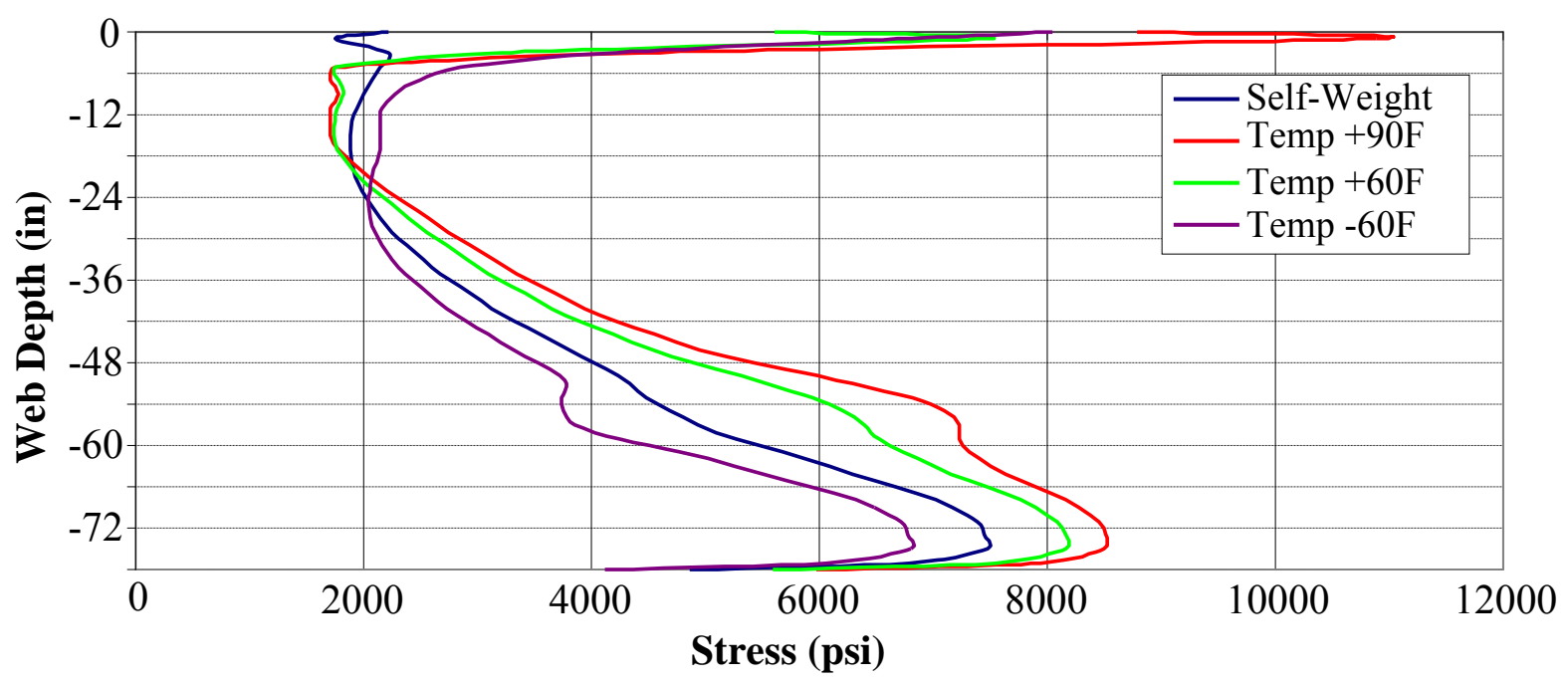

Figure 7.13 New Bearings, Effective Stress Profiles for Pier 10N

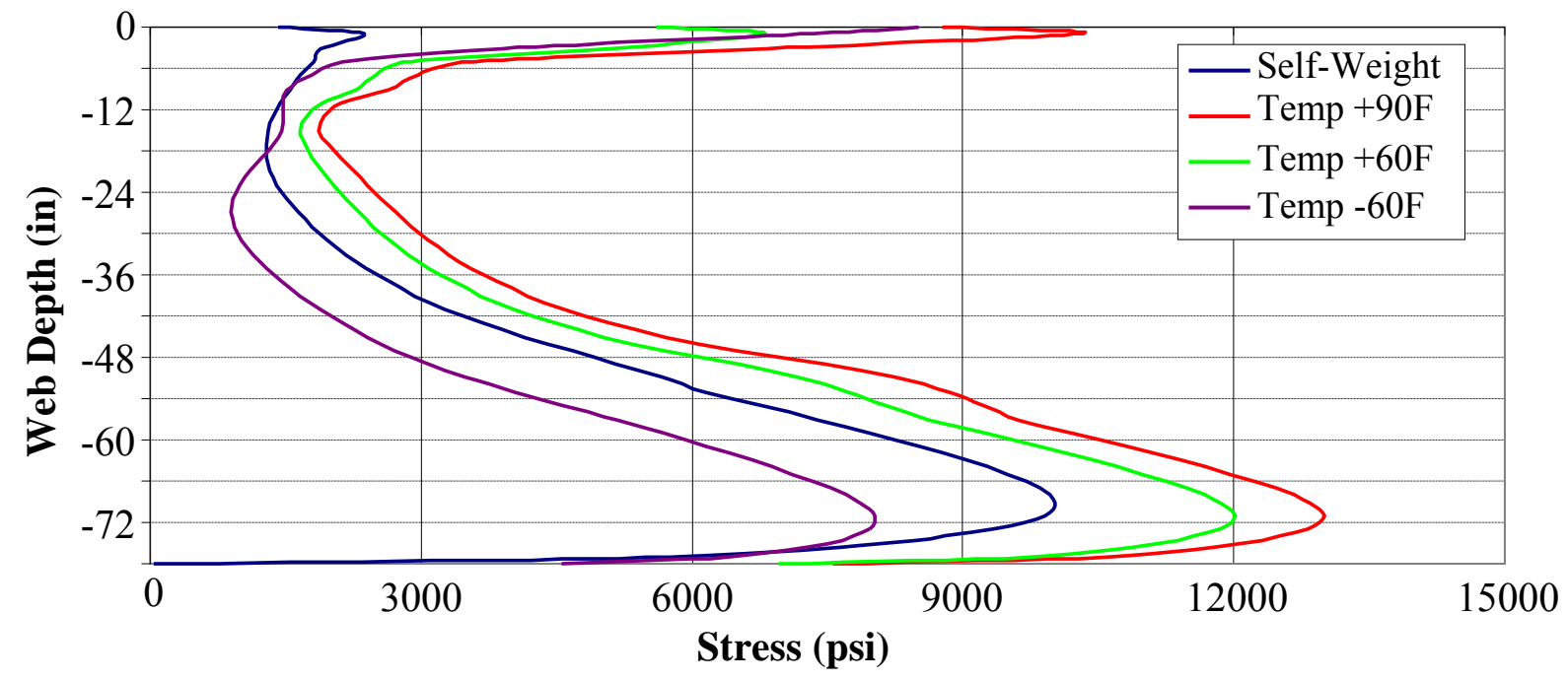

Figure 7.14 New Bearings, Effective Stress Profiles for Pier 11N

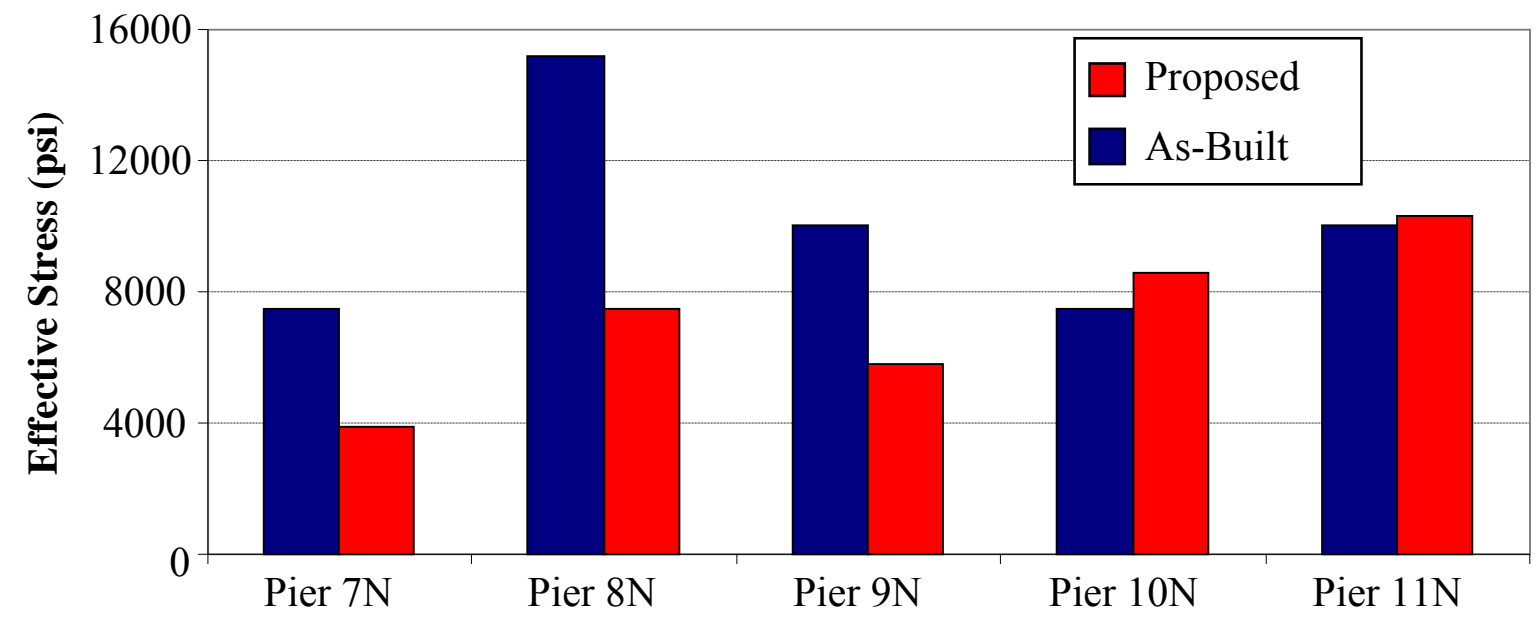

Figure 7.15 As-Built - New Bearings Eff. Stress Comparison Under Self-Weight (Piers) 


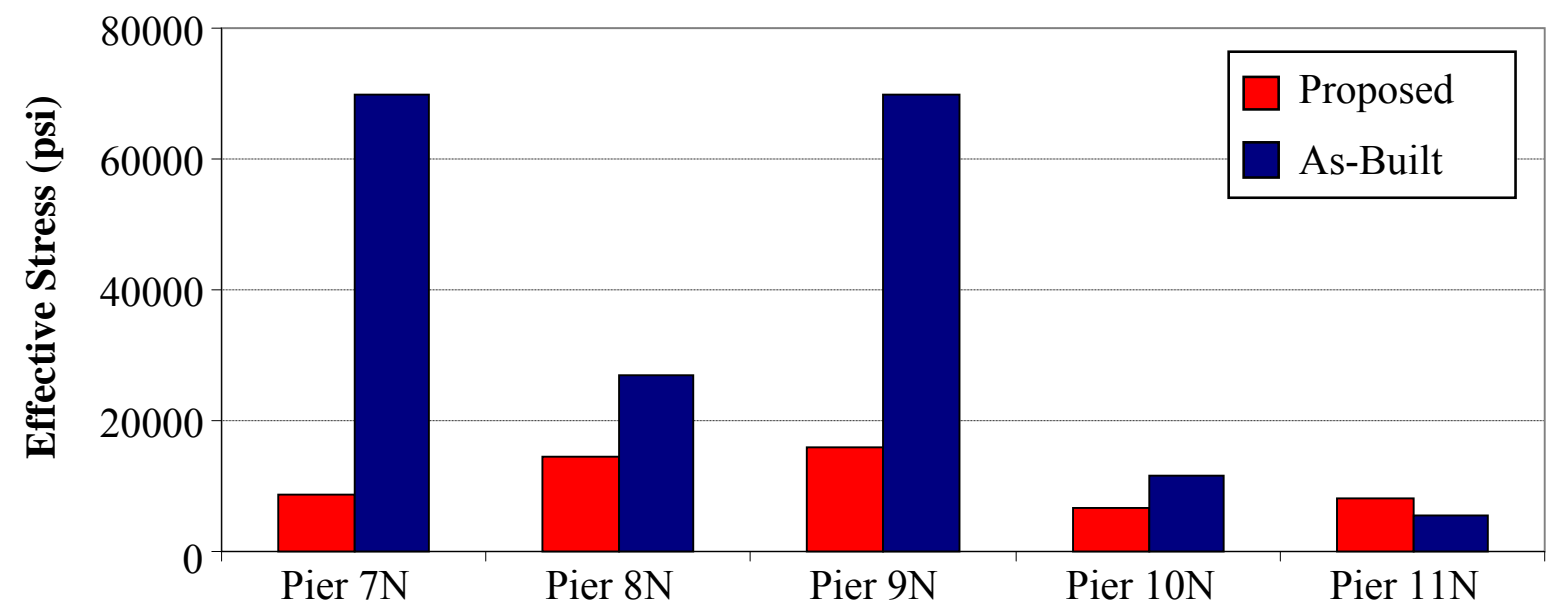

Figure 7.16 As-Built - New Bearings Eff. Stress Comparison Under Temp - $60^{\mathbf{0}} \mathrm{F}$ (Piers)

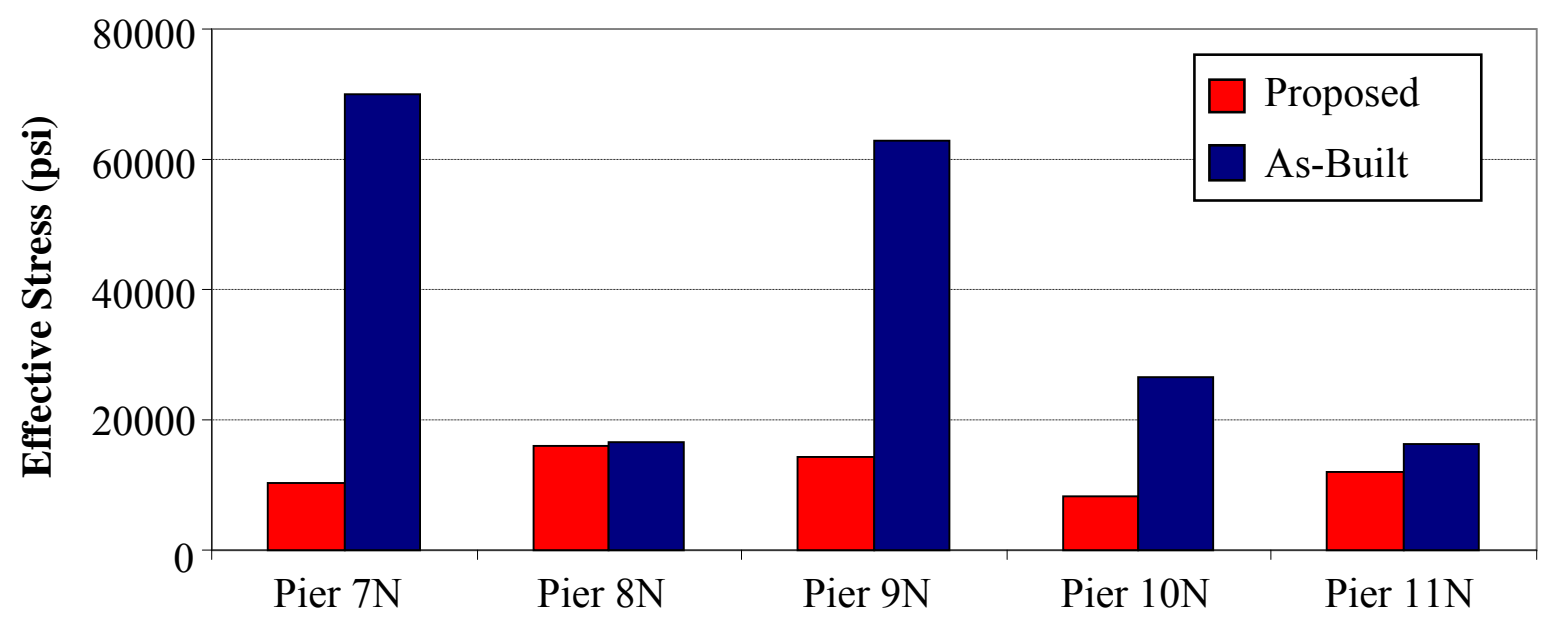

Figure 7.17 As-Built - New Bearings Eff. Stress Comparison Under Temp $+60^{\circ} \mathrm{F}$ (Piers)

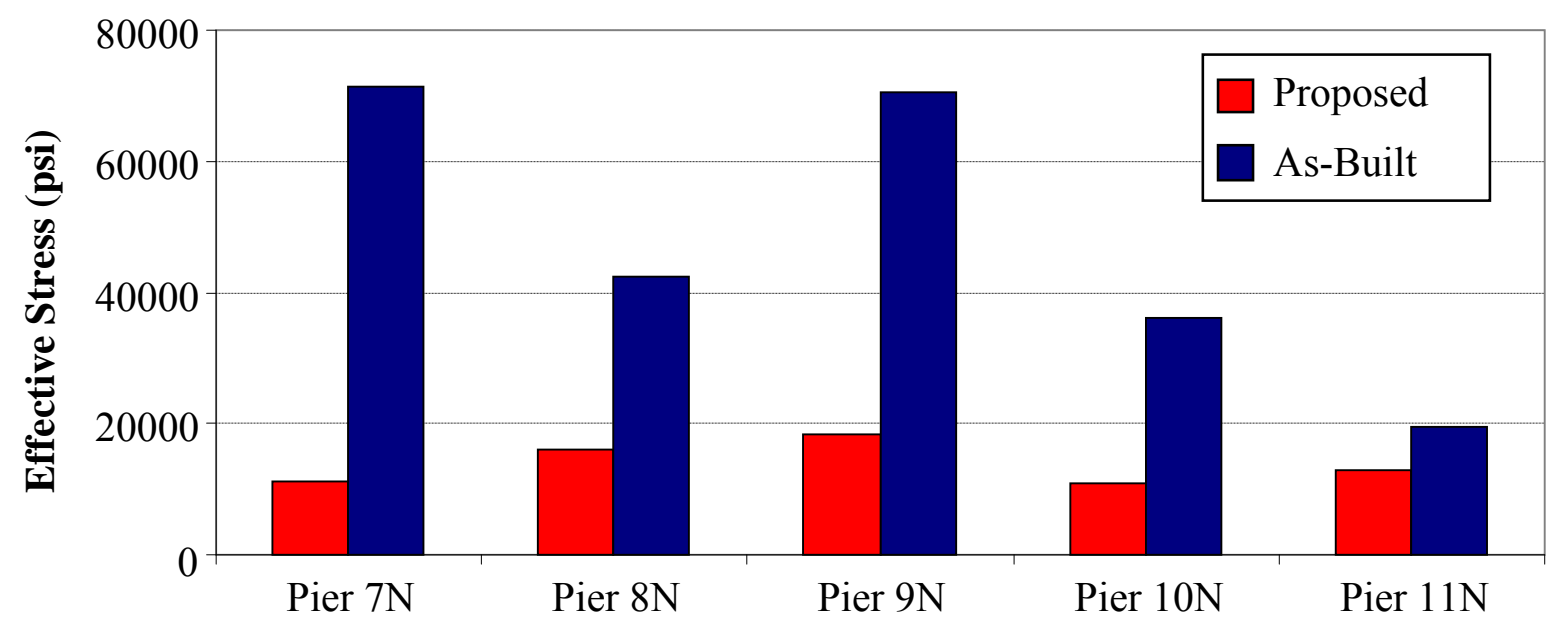

Figure 7.18 As-Built - New Bearings Eff. Stress Comparison Under Temp $+90^{\circ} \mathrm{F}$ (Piers) 
The comparisons given in Figures 7.15-7.18 show a significant reduction in effective stress levels at the pier locations as well, especially at Piers 7N-9N. Overall, the proposed bearing arrangement is a much better alternative as far as effective stress levels are concerned. Comparing the effective stresses for the as-built and proposed bearing arrangements, it is very apparent that the proposed arrangement results in significantly lower magnitudes of stress throughout the FE model. Under each temperature load case, effective stresses at Pier $7 \mathrm{~N}$ are reduced from over $70 \mathrm{ksi}$ to less than $10 \mathrm{ksi}$, an $85 \%$ decrease. At Pier $9 \mathrm{~N}$, a $75 \%$ reduction in stress is recorded. Thermal stress at Pier 10N decreases as well, roughly $50 \%$ for under each temperature load. The only anomaly occurs at Pier $11 \mathrm{~N}$ under the $-60^{\circ} \mathrm{F}$ temperature load, where effective stress increases moderately under the new bearing conditions. These results show that after removing the fixed bearing devices, stress levels experience a dramatic reduction, from larger than yield stress (70 ksi), to less than 20 ksi.

The largest effective stress produced by the FE model is $49.8 \mathrm{ksi}$, near yield, in the web at Abutment 2N, which was unaffected by the change in bearing conditions. Similar stress values are recorded at Pier $6 \mathrm{~N}$ as well. So, there seems to be some peculiar behavior occurring at the expansion joints of the superstructure (Pier $6 \mathrm{~N}$ and Abutment $2 \mathrm{~N}$ ). At the pier support locations, effective stresses average well below $20 \mathrm{ksi}$ which is only $28 \%$ of the yield strength at these locations. Girder yield strength at Pier $6 \mathrm{~N}$ and Abutment $2 \mathrm{~N}$ is only $50 \mathrm{ksi}$. Therefore, the FE model is showing that at these two locations, the yield stress of the girders is almost exceeded. Figures 7.19-7.20 show effective stress contour plots at Pier 9N and Abutment $2 \mathrm{~N}$ respectively, under the $+90^{\circ} \mathrm{F}$ temperature load. The contour plots produced by the FE model show perfectly the stress patterns at their respective locations. The largest effective stresses are found at the bearings and diminish rapidly nearer midspan. 


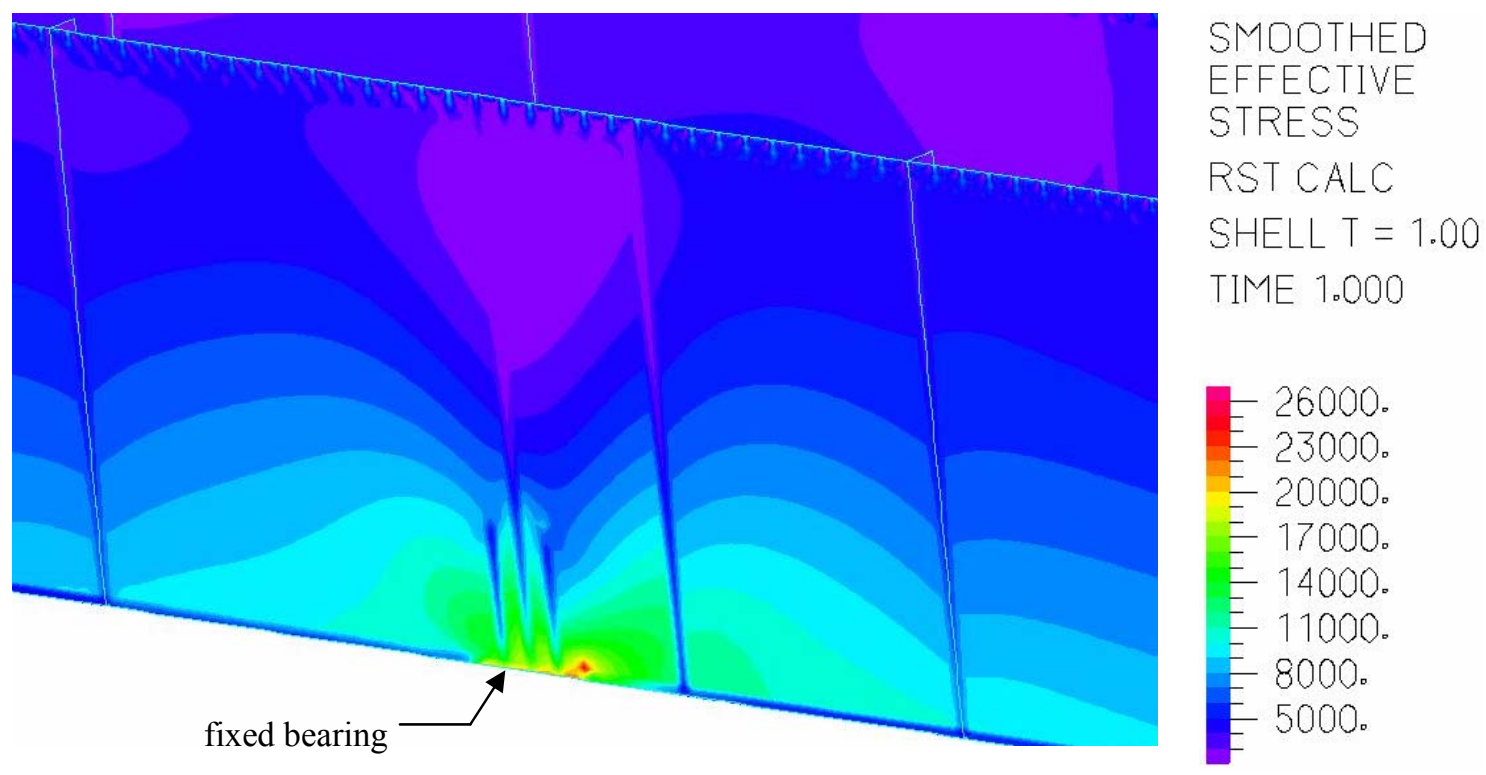

Figure 7.19 Girder 1N, FE Model Effective Stress Contour Plot $\left(+90^{\circ} \mathrm{F}\right.$ Temperature Load, New Bearings)

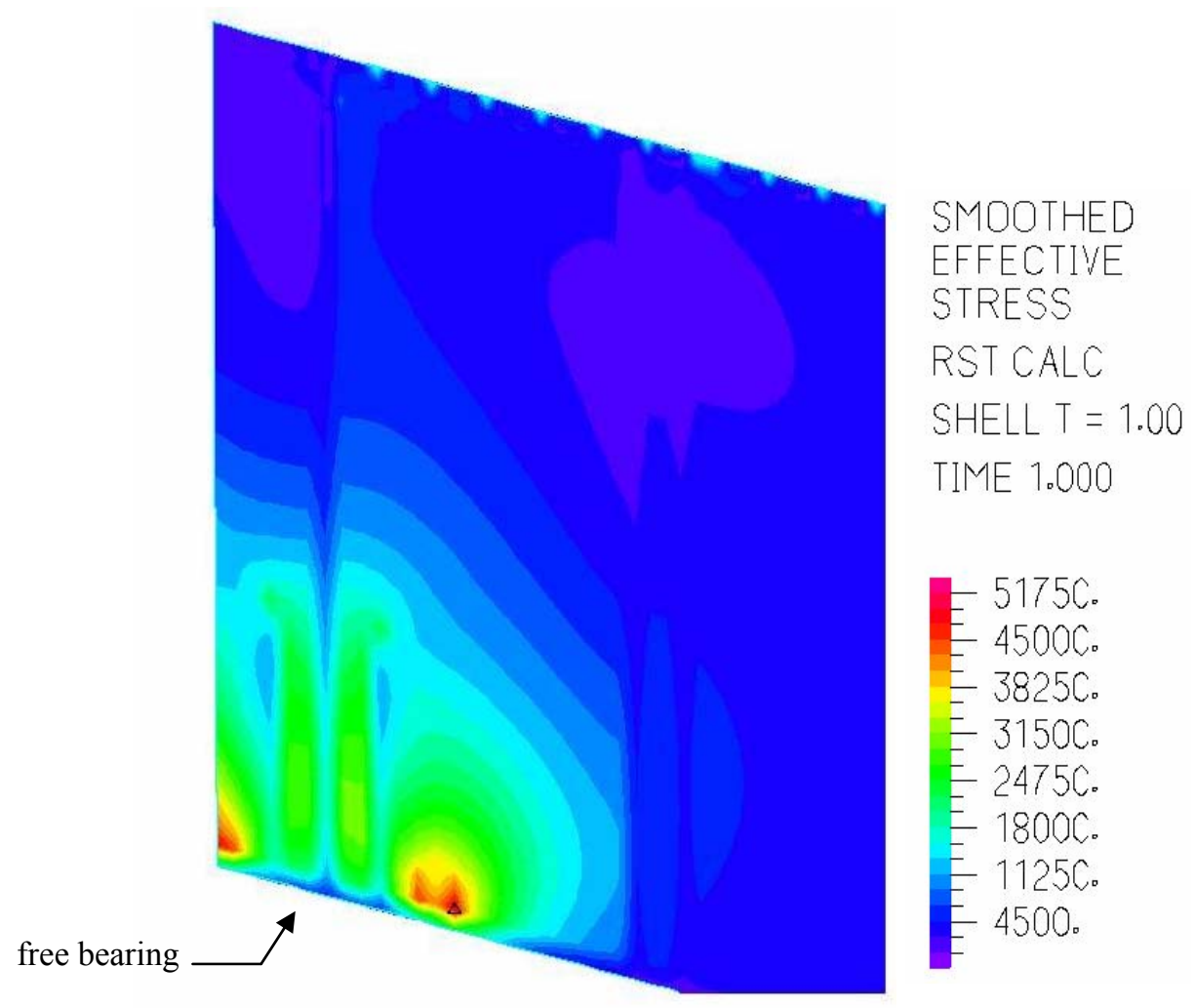

Figure 7.20 Girder 1N, Abutment 2N FE Model Effective Stress Contour Plot $\left(+90^{\circ} \mathrm{F}\right.$ Temperature Load, New Bearings) 


\subsection{LONGITUDINAL STRESSES}

In this section, the longitudinal stresses produced by the FE bridge model under the proposed bearing arrangement are investigated. As done in Chapter Five, longitudinal stress profiles for various cross-sections are constructed from data obtained from the FE model. The longitudinal stress profiles are later decomposed into bending and axial components in order to determine the magnitude of axial stress produced by the different temperature loads under the new bearing arrangement. After analyzing effective stress levels in Section 7.2 and the displacement behavior in Chapter Six, it is expected that axial stresses will be considerably less with the new bearing conditions. Figures 7.21-7.25 show the longitudinal stress profiles for the midspan cross-sections under each loading case.

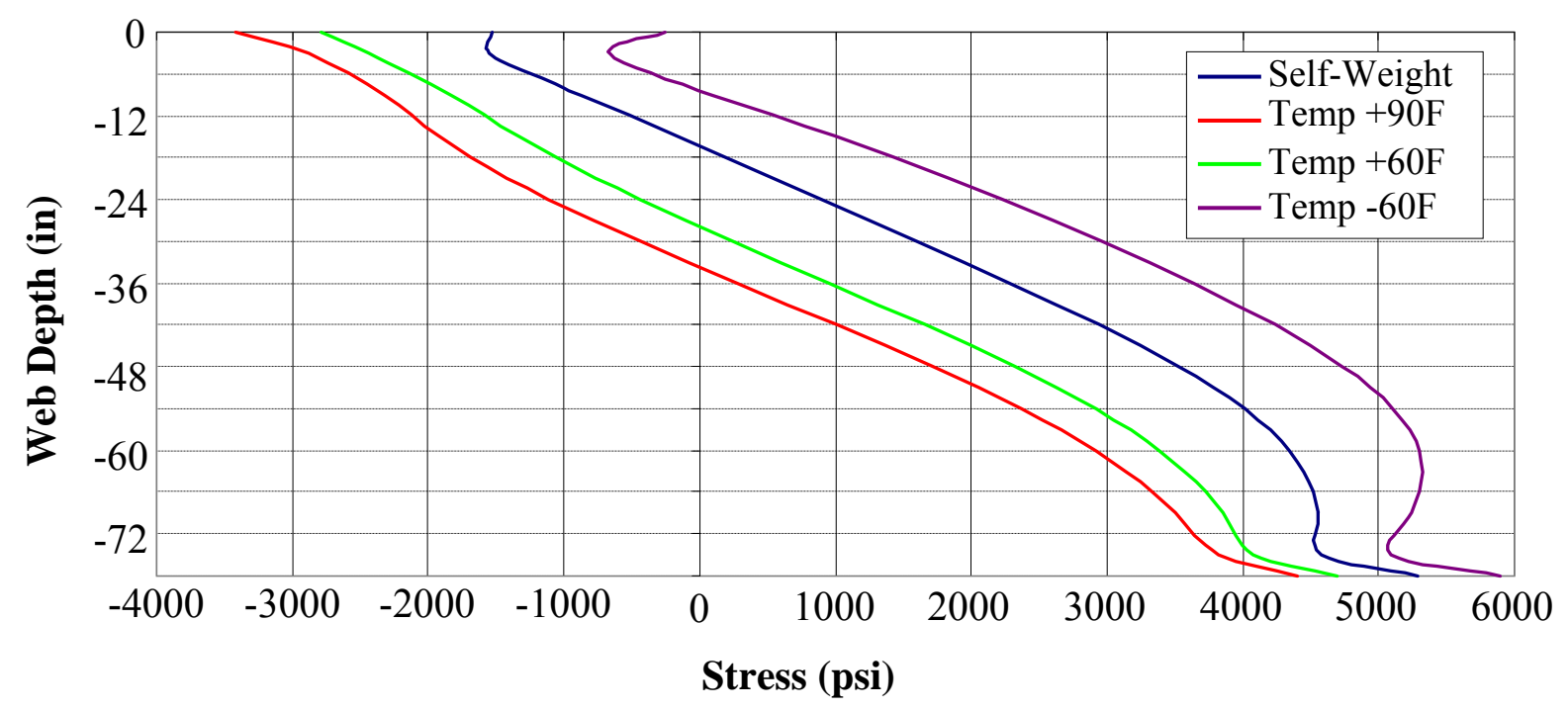

Figure 7.21 New Bearings, Longitudinal Stress Profiles For Span 7N 


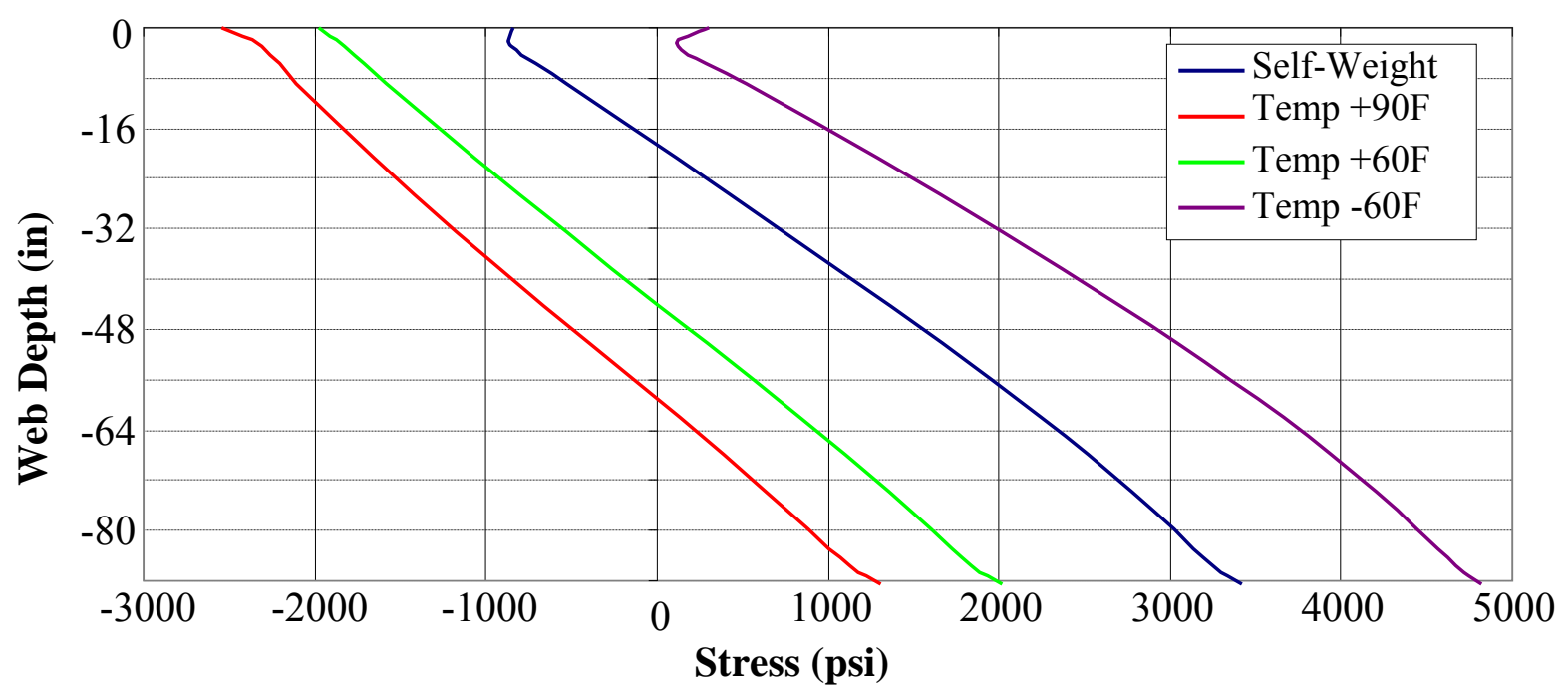

Figure 7.22 New Bearings, Longitudinal Stress Profiles for Span 8N

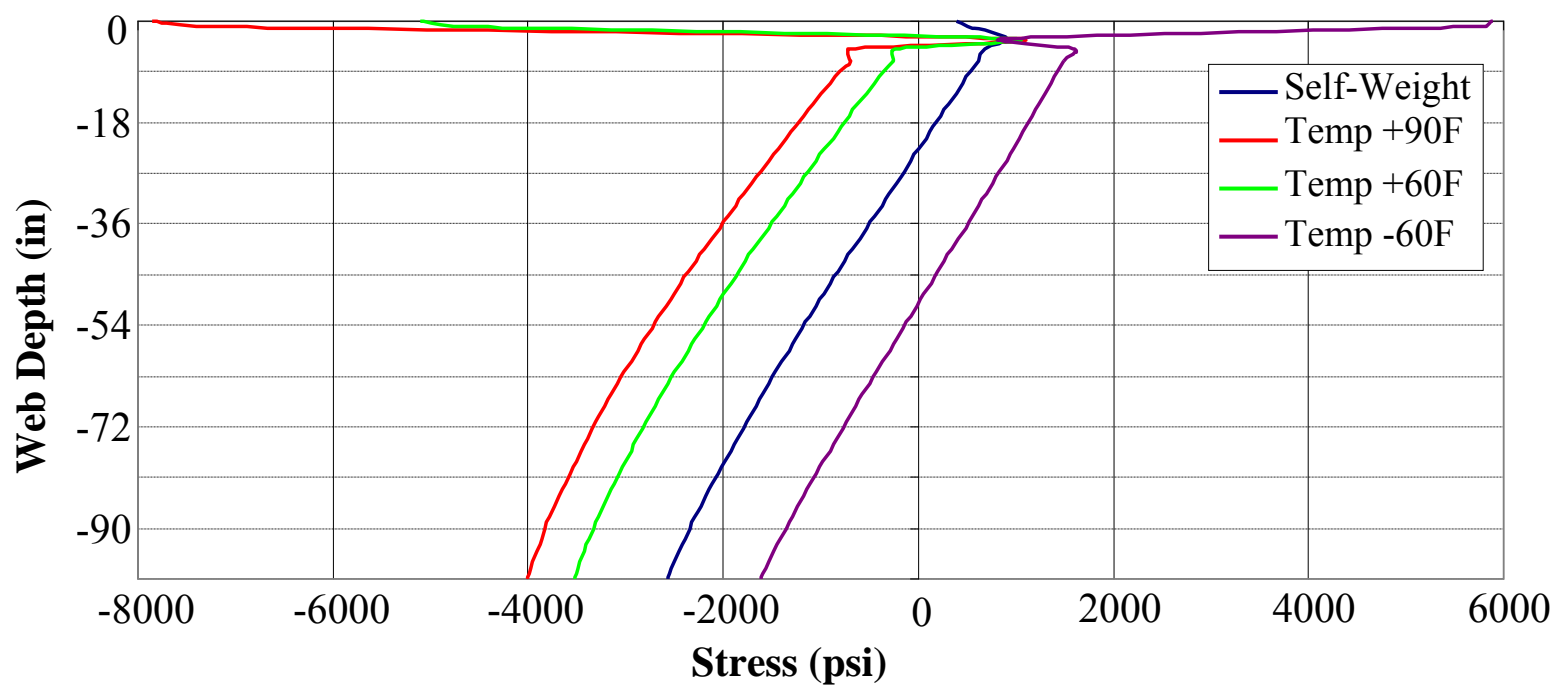

Figure 7.23 New Bearings, Longitudinal Stress Profiles for Span 9N

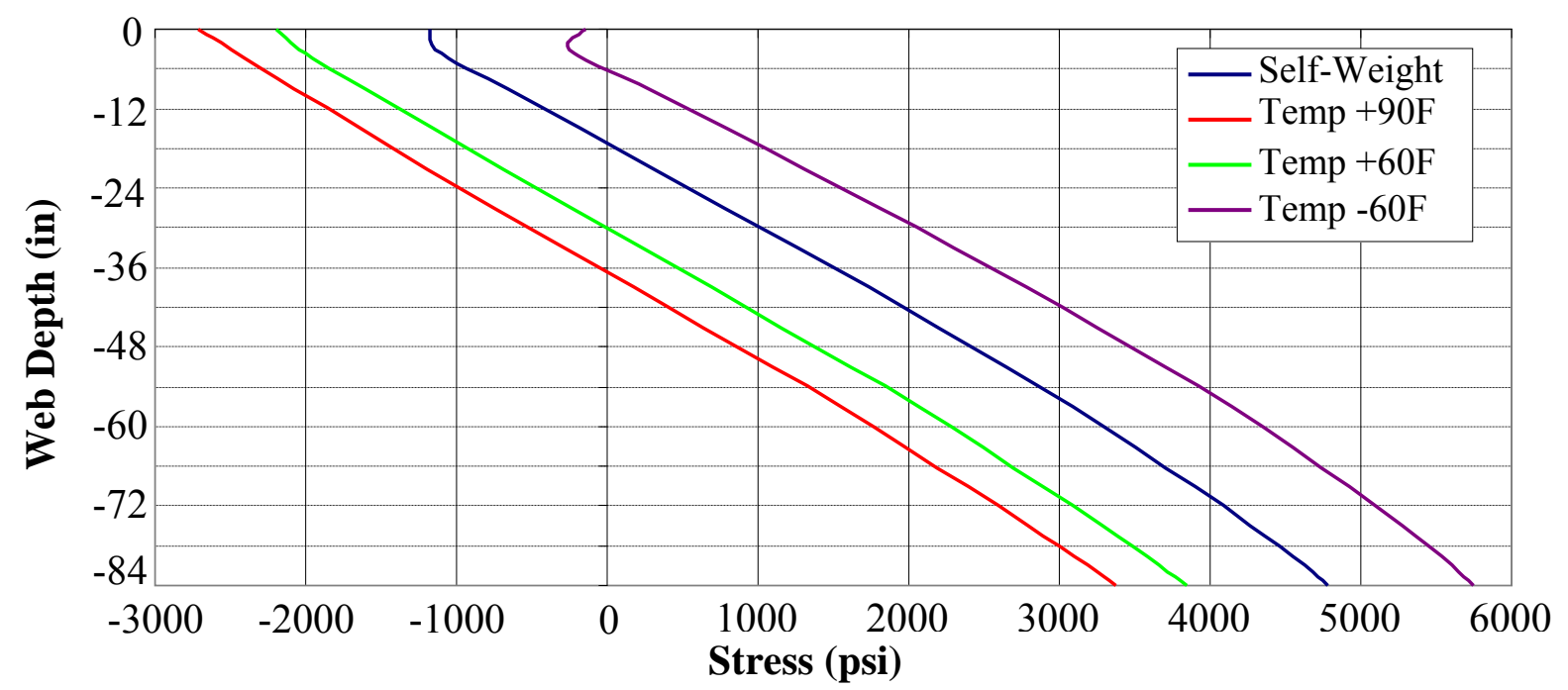

Figure 7.24 New Bearings, Longitudinal Stress Profiles for Span 10N 


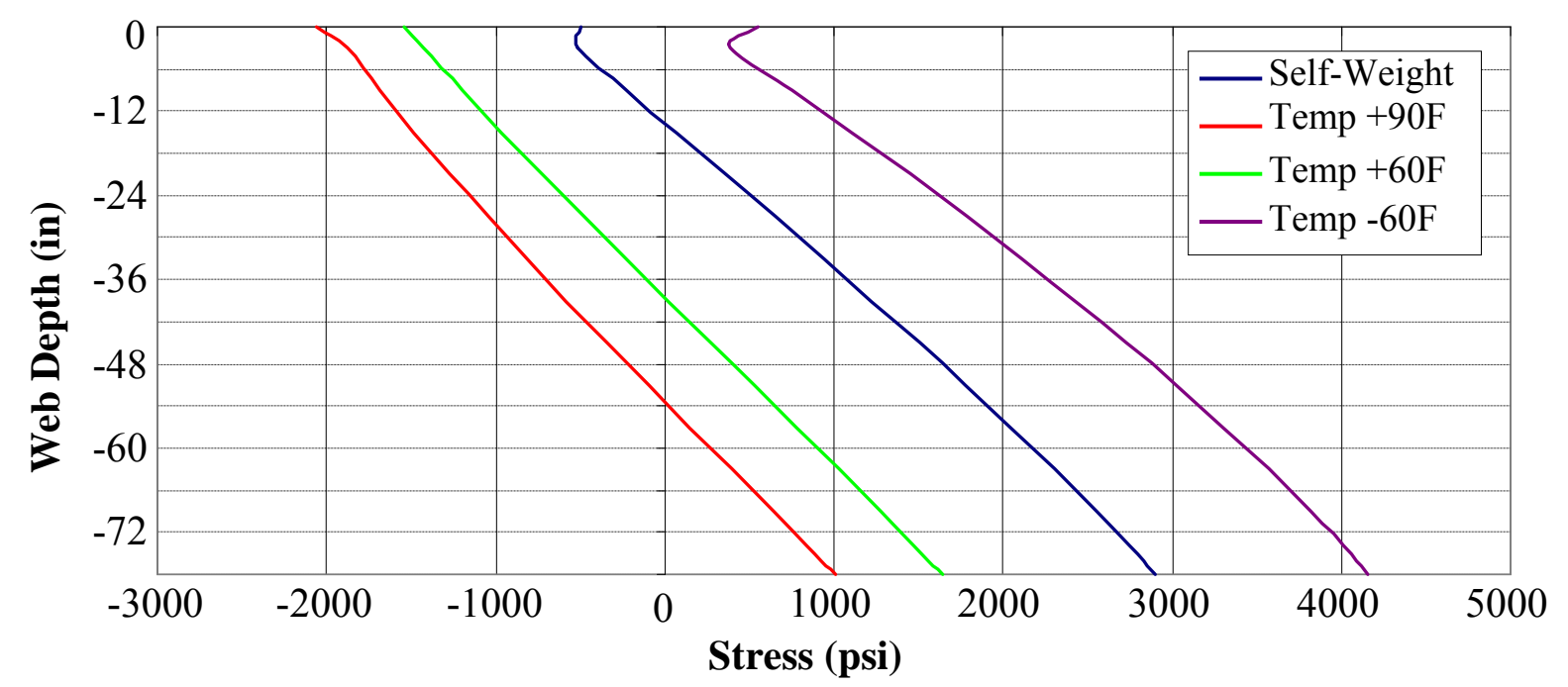

Figure 7.25 New Bearings, Longitudinal Stress Profiles for Span 11N

When the longitudinal stress profiles in Figures 7.21-7.25 are compared to the same stress profiles when the as-built bearing arrangement is applied, several differences are noticed immediately. For the most part, under the new bearing arrangement, the longitudinal stress profiles display almost perfect linear behavior, with the exception of the lower portions of the web ofSpan $7 \mathrm{~N}$ and within the vicinity of the top flange of each span. From the longitudinal profiles in chapter five (as-built bearing arrangement) only the self-weight profiles display linear behavior. Under temperature loads, longitudinal stress was shown to be highly non-linear. This non-linear behavior is substantially reduced, if not eliminated, under the new bearing conditions. Under the new bearing arrangement, all midspan longitudinal stress profiles have a neutral axis located within the web of the girder (near the centroid). This fact alone demonstrates that the axial forces and stresses produced by the temperature loads under the as-built bearing arrangement have been greatly reduced. Under the as-built bearing arrangement, the entire cross-section in Spans $8 \mathrm{~N}$ and $9 \mathrm{~N}$ is under compression. 
The largest longitudinal stress of $5.7 \mathrm{ksi}$ in tension is produced in Span 10N. A maximum compressive longitudinal stress for the positive moment regions of $3 \mathrm{ksi}$ is found in Span 7N. In Span 9N, a maximum compressive longitudinal stress of almost $4 \mathrm{ksi}$ is produced. Figures 7.26-7.28 compare maximum compressive longitudinal stresses between the bearing cases. As seen in Figures 7.26-7.28, the compressive longitudinal stress has decreased drastically in Spans $8 \mathrm{~N}$ and $9 \mathrm{~N}$, which are now only partially restrained against thermal movement. The other locations in Spans $7 \mathrm{~N}, 10 \mathrm{~N}$ and $11 \mathrm{~N}$ show only slight differences in stress levels. Overall, compressive longitudinal stress is significantly reduced throughout the bridge under the new bearing arrangement, which has important implications on critical web stress values. When compared to the critical compressive longitudinal web stress, $F_{c r}$, calculated in Chapter Five, the stress levels produced should be well within limiting critical stress values. The longitudinal stresses at the pier support locations are investigated in Figure 7.29-7.33.

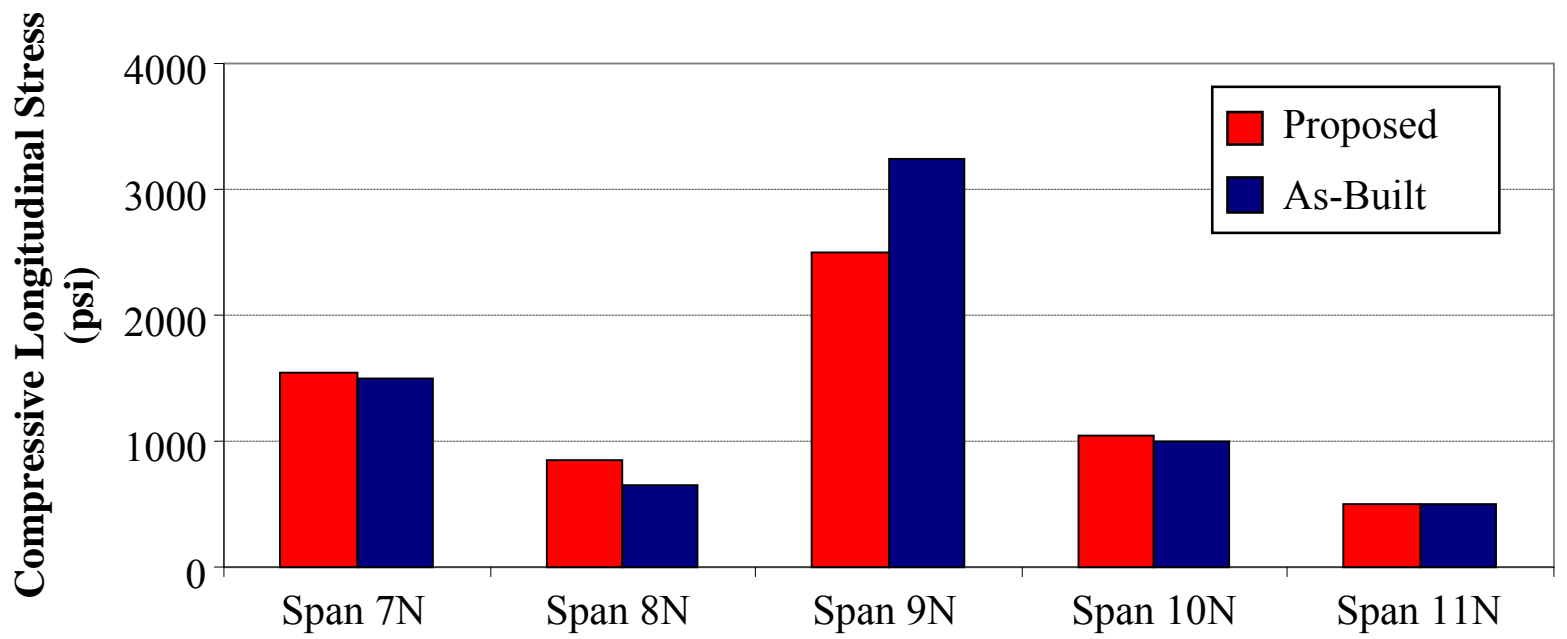

Figure 7.26 As-Built - New Bearings Long. Stress Comparison Under Self-Weight (Spans) 


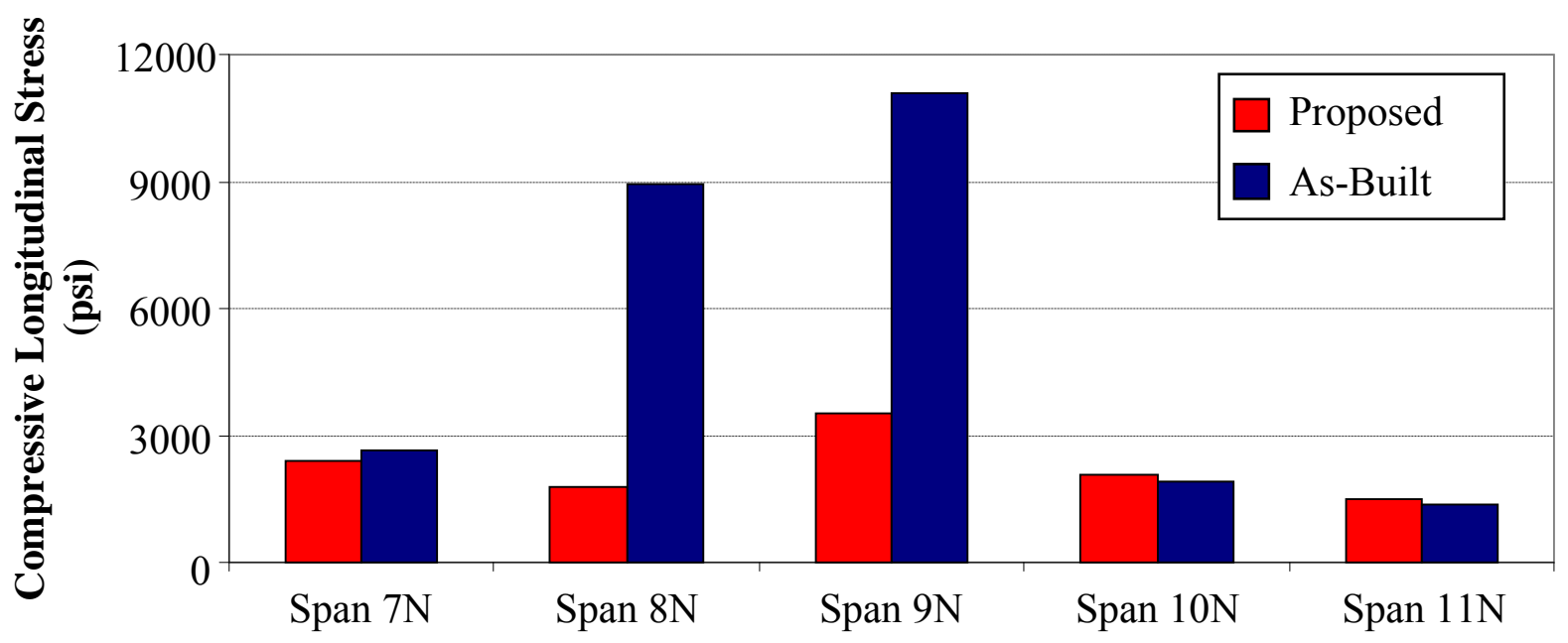

Figure 7.27 As-Built - New Bearings Long. Stress Comparison Under Temp $+60^{\circ} \mathrm{F}$ (Spans)

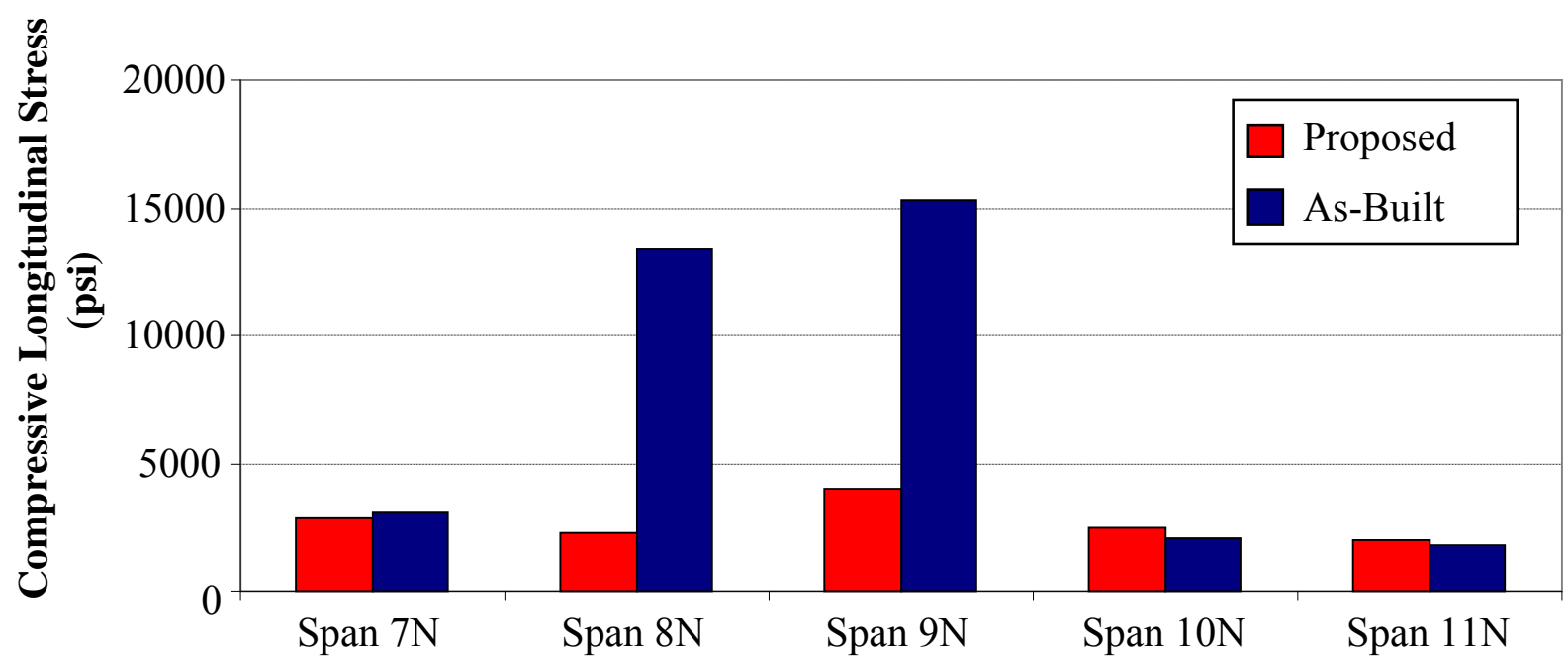

Figure 7.28 As-Built - New Bearings Long. Stress Comparison Under Temp $+90^{\circ} \mathrm{F}$ (Spans) 


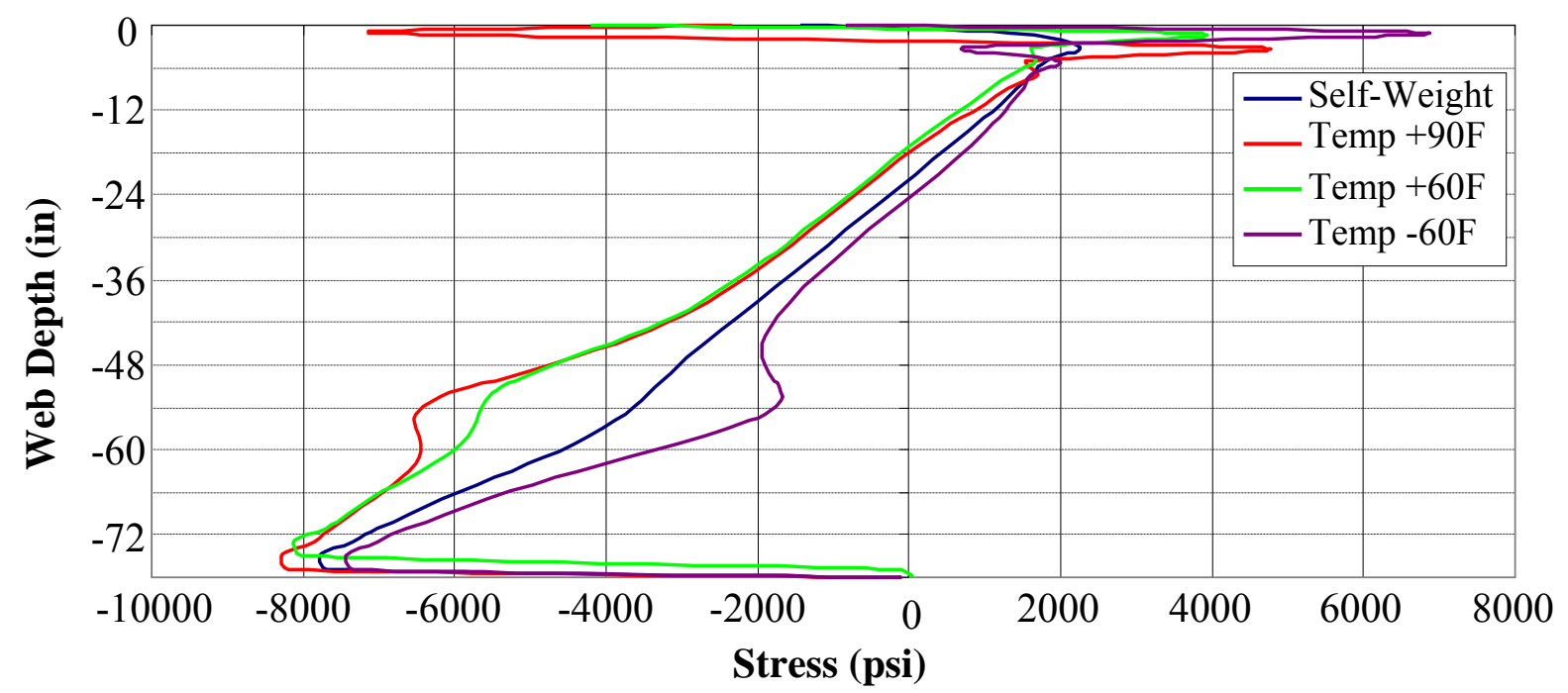

Figure 7.29 New Bearings, Longitudinal Stress Profiles for Pier 7N

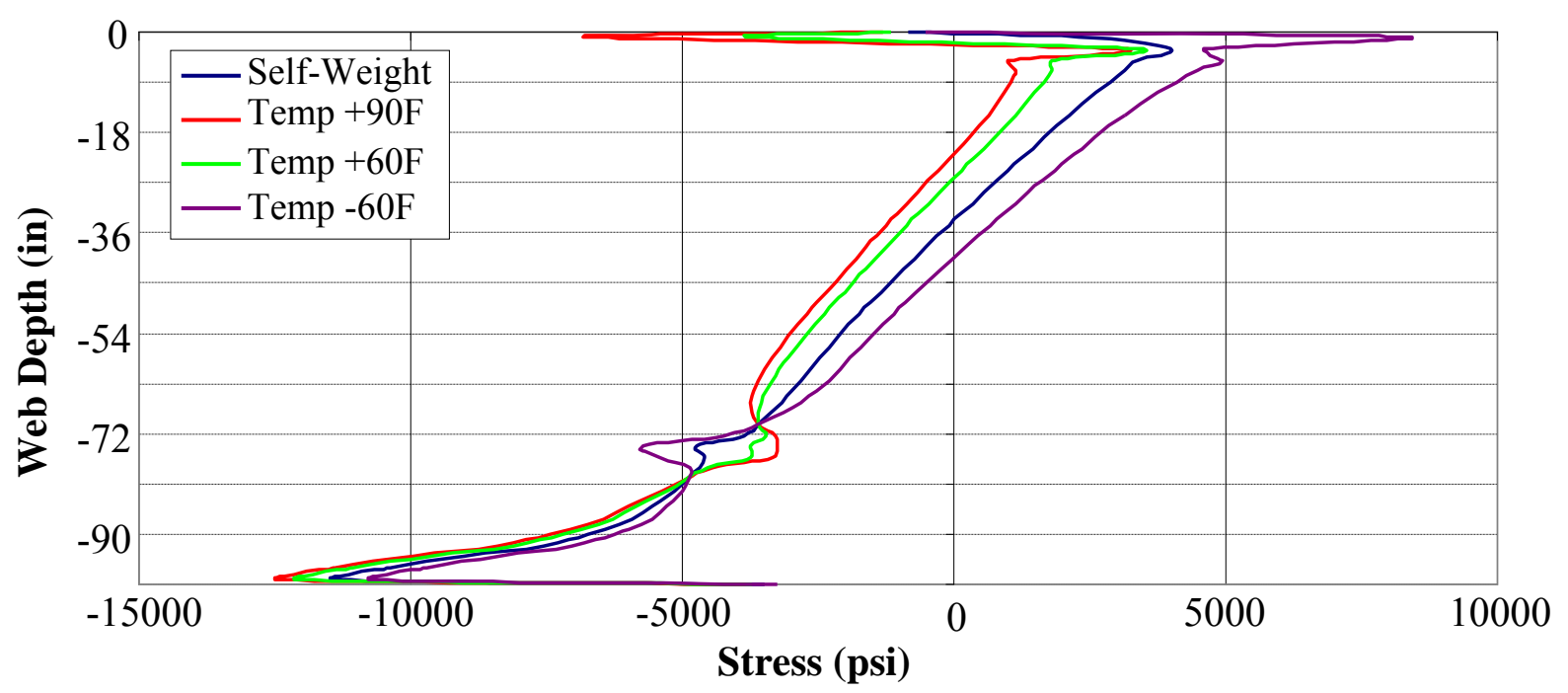

Figure 7.30 New Bearings, Longitudinal Stress Profiles for Pier 8N

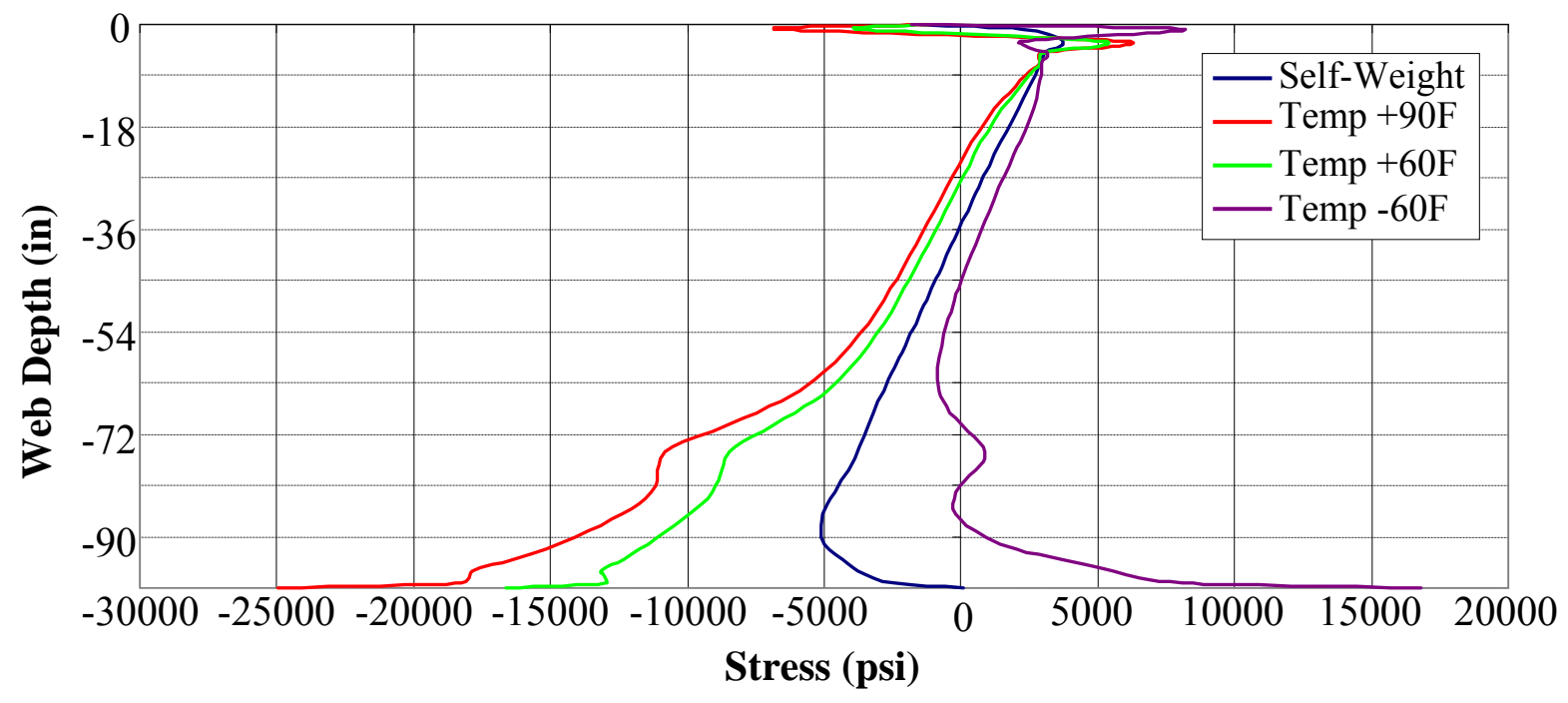

Figure 7.31 New Bearings, Longitudinal Stress Profiles for Pier 9N 


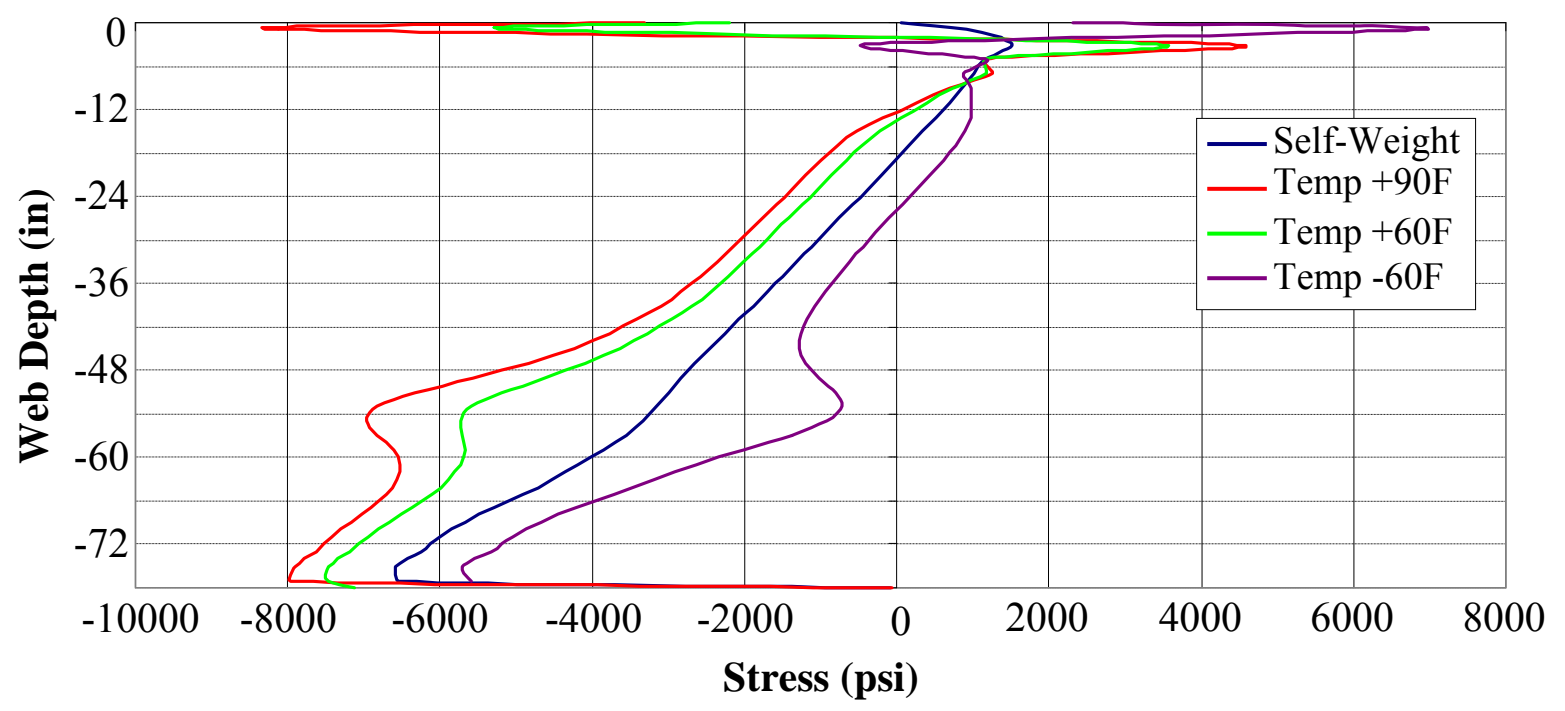

Figure 7.32 New Bearings, Longitudinal Stress Profiles for Pier 10N

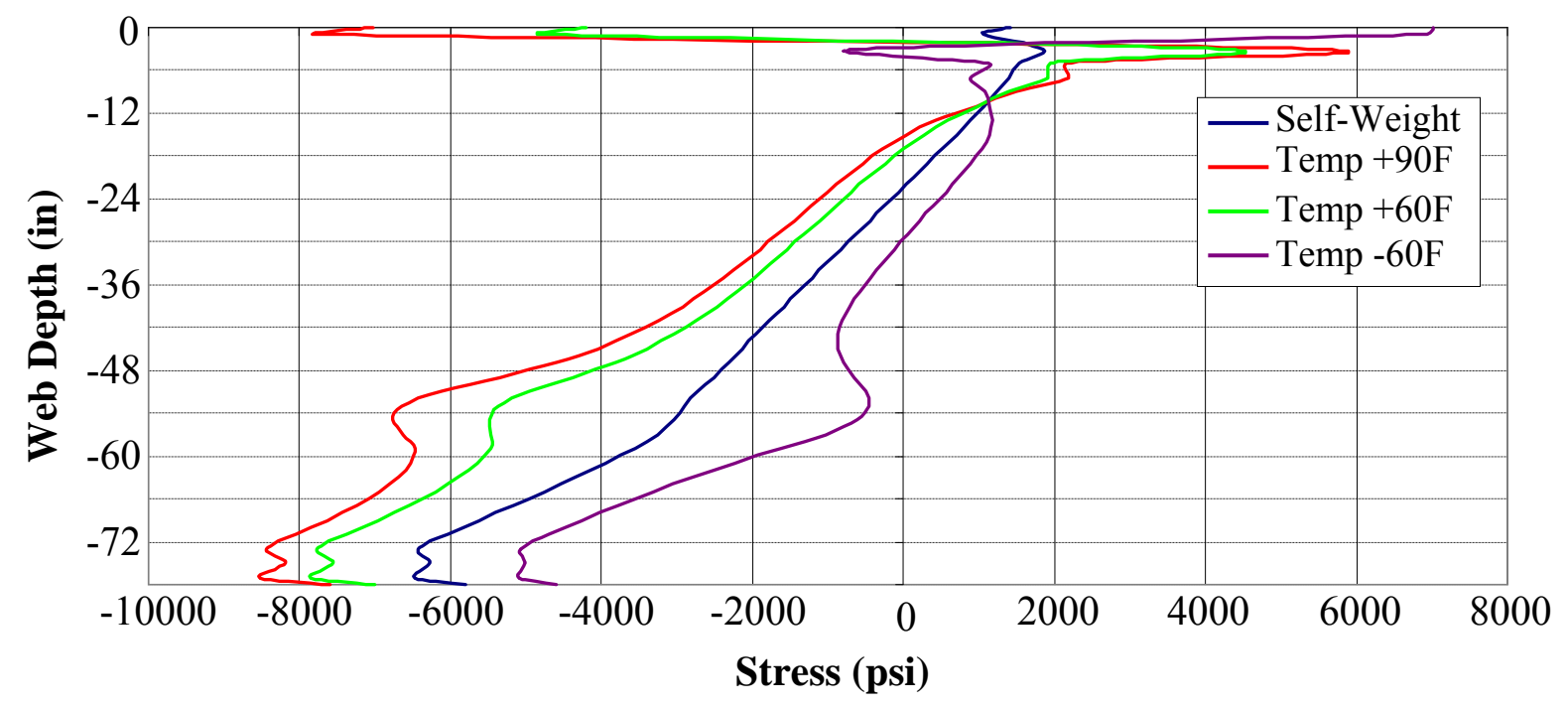

Figure 7.33 New Bearings, Longitudinal Stress Profiles for Pier 11N

When compared to the longitudinal stresses produced under the as-built bearing arrangement, in general the magnitude of longitudinal stress at each pier location has decreased considerably under the new bearing arrangement. The first thing noticed in Figures 7.29-7.31 is the near elimination of the stress concentration created by the 24 " high auxillary stiffeners at Piers $7 \mathrm{~N}-9 \mathrm{~N}$. This is a very significant change in bridge response. The stress concentrations at these locations were the main cause of the large thermal stresses 
under the as-built bearing arrangement, and their absence under the proposed bearing arrangement will have major implications when analyzing critical web stresses. Similar to the midspan locations, the neutral axis of the profiles is located within the girder's web. Thus, the cross-sections are no longer under compression, which will also affect critical web stresses. Figures 7.34-7.36 give a better understanding of the stress comparisons at the piers, by comparing the maximum stress between the as-built and proposed bearing arrangements. The temperature load of $-60^{\circ} \mathrm{F}$ is not shown because under the as-built bearing arrangement each cross-section is predominantly in tension or develops relatively little compressive stress.

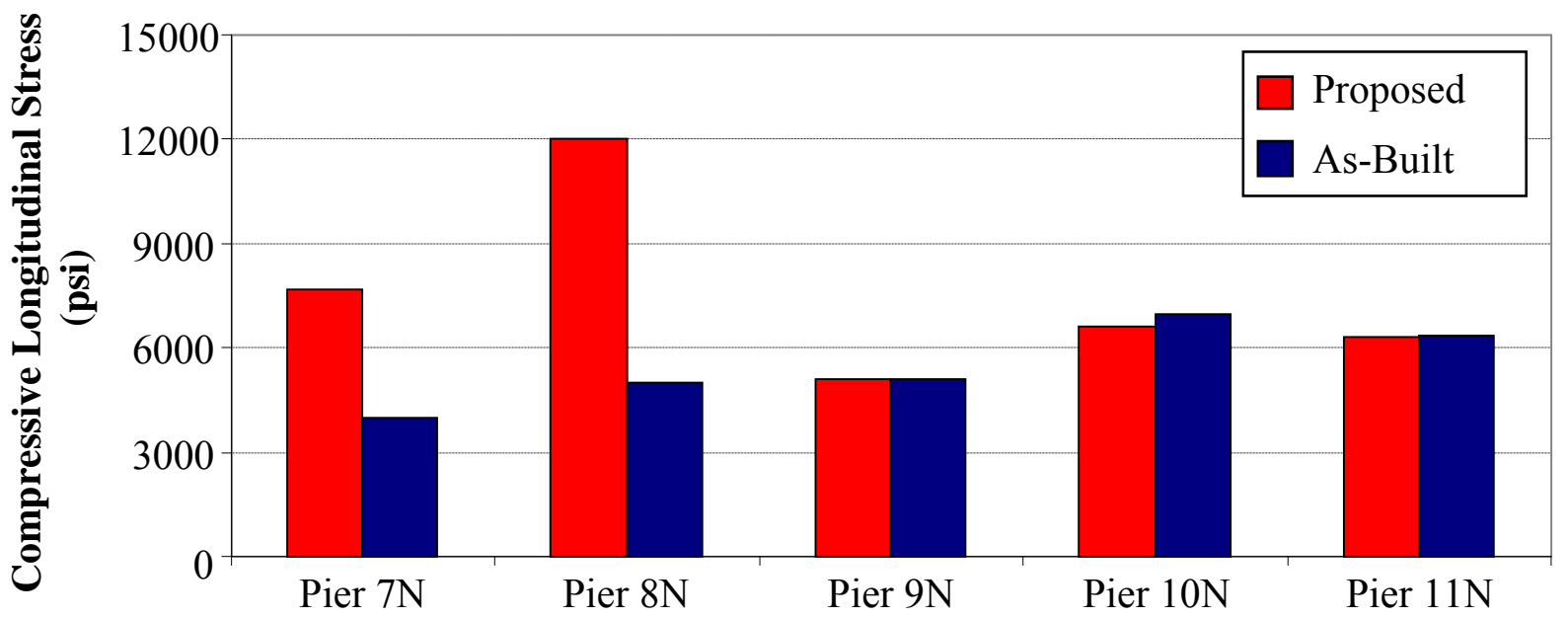

Figure 7.34 As-Built - New Bearings Long. Stress Comparison Under Self-Weight (Piers)

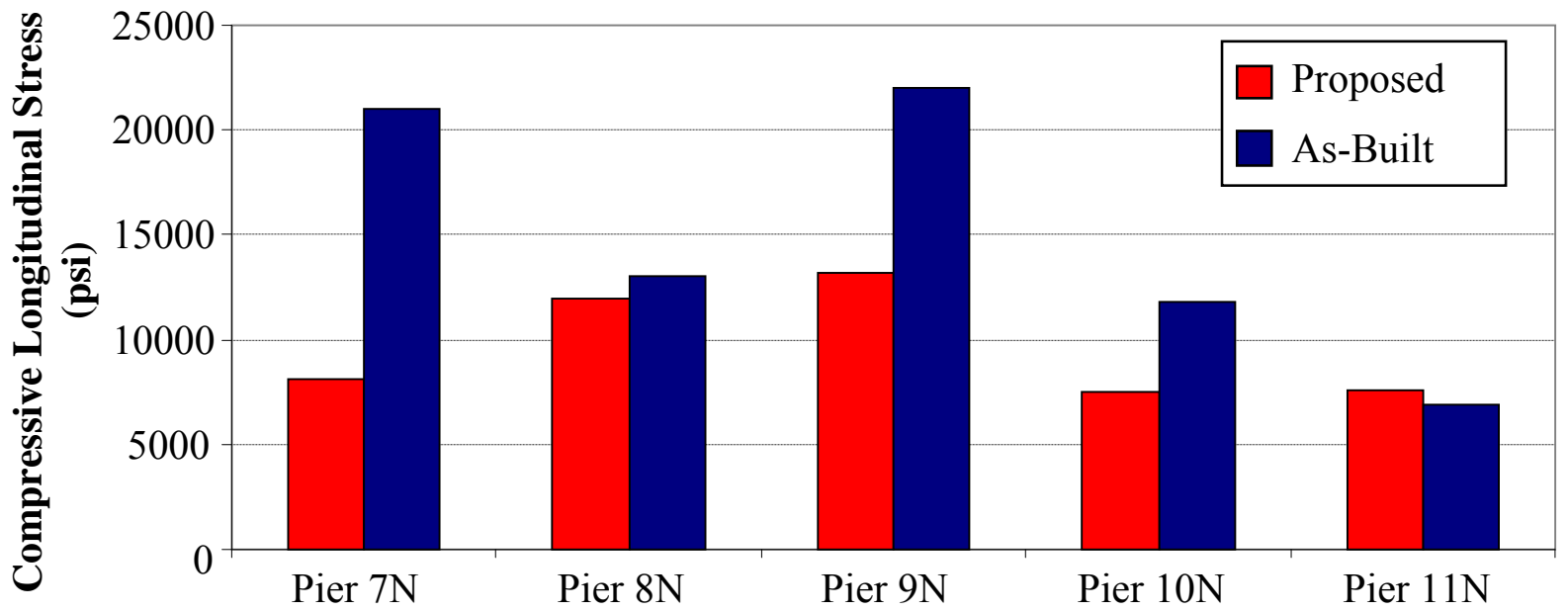

Figure 7.35 As-Built - New Bearings Long. Stress Comparison Under Temp $+60^{\circ} \mathrm{F}$ (Piers) 


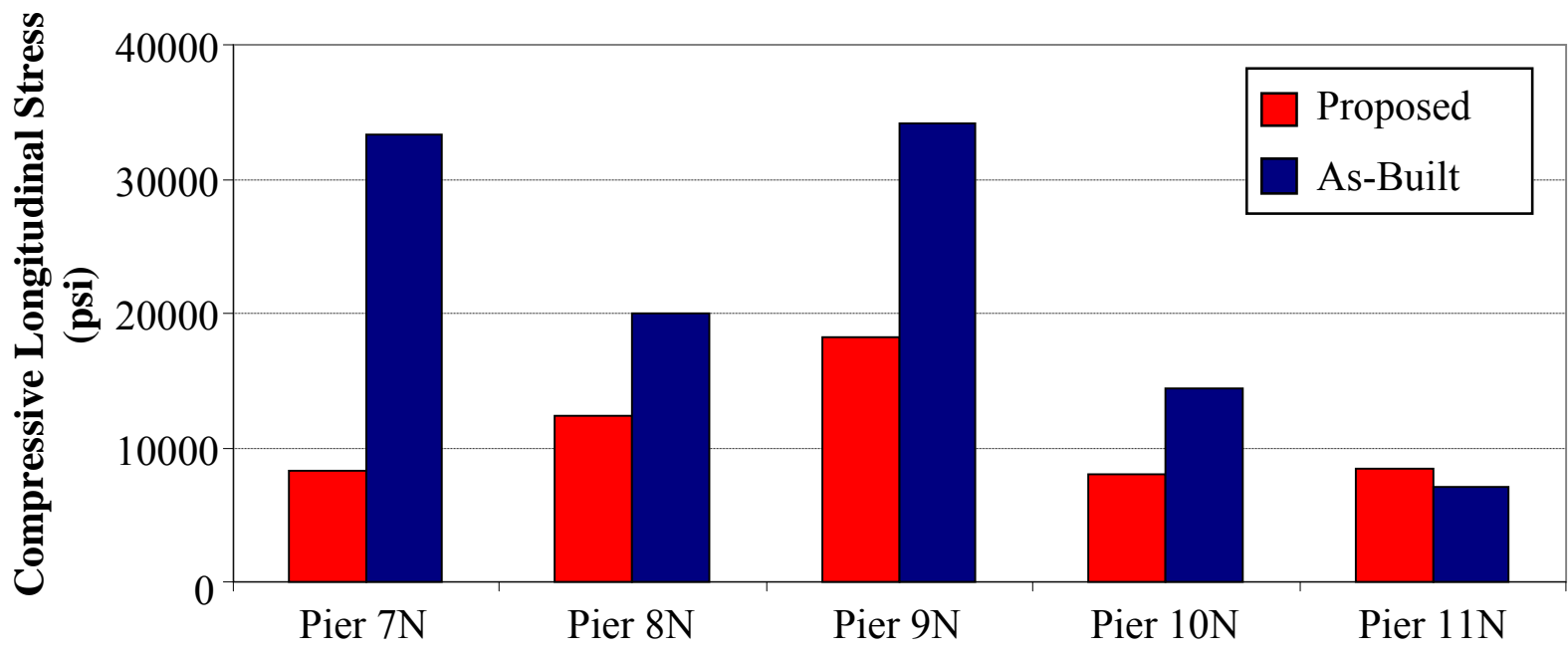

Figure 7.36 As-Built - New Bearings Long. Stress Comparison Under Temp $+90^{\circ} \mathrm{F}$ (Piers)

In Figures 7.34-7.36, it is easily seen that compressive stresses due to the temperature loads have decreased significantly at Piers $7 \mathrm{~N}-10 \mathrm{~N}$. Pier $11 \mathrm{~N}$ shows a slight increase in longitudinal stress. The largest decrease in stress occurs at Piers 7N and 9N. Reductions in longitudinal stress between $62-72 \%$ are recorded for Temp $+60^{\circ} \mathrm{F}$ and Temp $+90^{\circ} \mathrm{F}$ at Pier 7N. At Pier 9N, stresses reduce $40-45 \%$ with new bearings employed.

As seen in the stress band plot in Figure 7.37, the magnitude of longitudinal stress with the new bearings are implemented is dramatically lower throughout the entire structure. The structure behaves in a more typical fashion, even with thermal load applied. In positive moment regions, the bottom fibers of the girders are under tension, while top fibers are in compression, and vice versa for negative moment regions. This contrasts the behavior produced under the as-built bearing conditions, where it was shown that Spans $8 \mathrm{~N}$ and $9 \mathrm{~N}$ were in states of compression throughout their spans when uniform temperature loads were applied. 


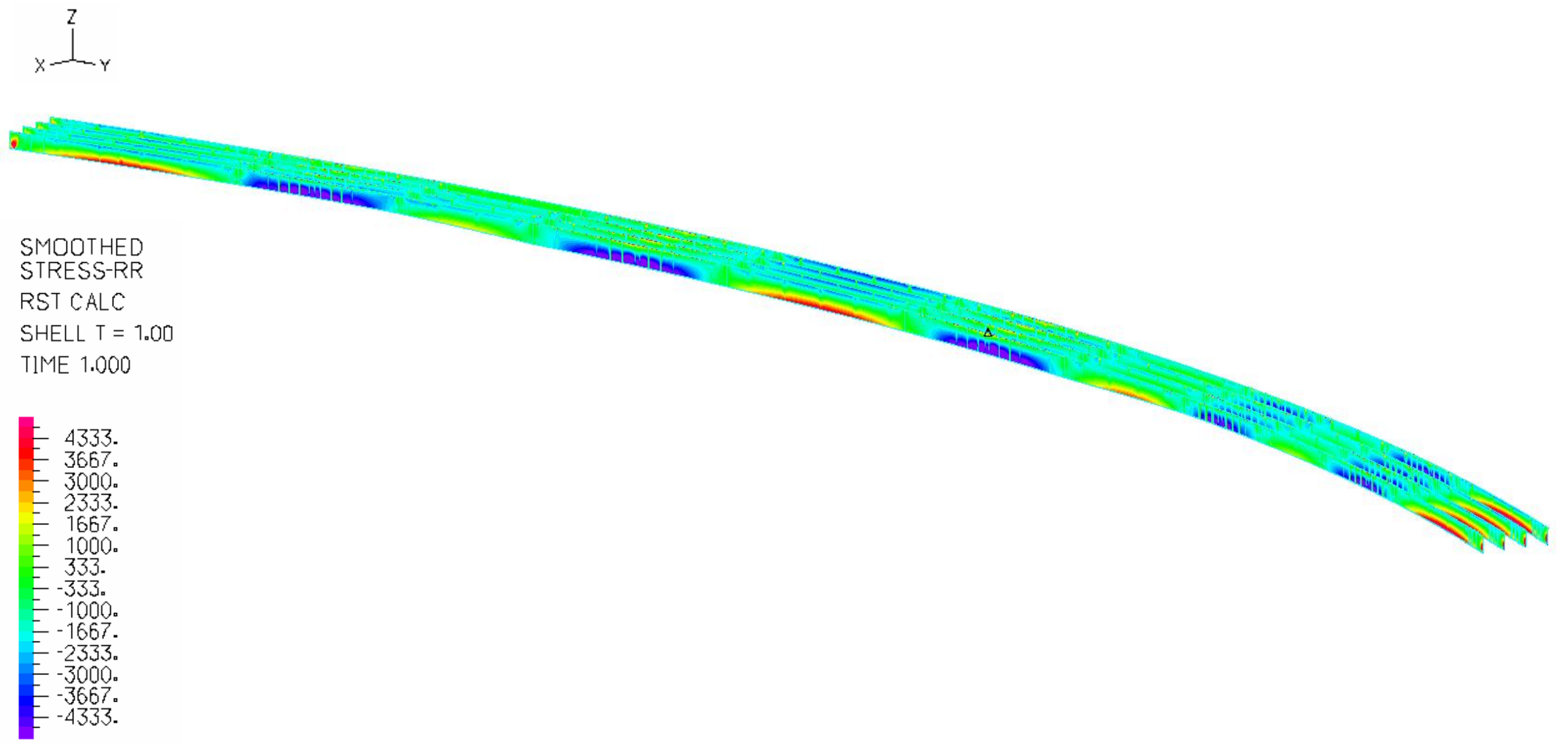

Figure 7.37 FE Model Longitudinal Stress Band Plots for Unit 2 Under Proposed Bearing Arrangement $\left(+90^{\circ} \mathrm{F}\right.$ Temperature Load) 


\subsection{BENDING AND AXIAL STRESSES}

In this section, the longitudinal stress profiles developed in Section 7.3 are decomposed into axial and bending components in order to compare the magnitude of axial stress under each bearing arrangement. After studying the longitudinal stresses and determining the considerable reduction in stress levels, it is highly expected that the magnitude of compressive axial stress will be much lower under the proposed bearing conditions. With lower magnitudes of axial compressive stress, girder stability will improve and a higher percentage of girder capacity will be available for bending resistance. This will have a significant impact on the bridge's ability to carry additional live loads.

Figures 7.38-7.60 show bending and axial stress profiles for the $+60^{\circ} \mathrm{F}$ and $+90^{\circ} \mathrm{F}$ temperature loads under the proposed bearing arrangement. Similar profiles for the selfweight and $-60^{\circ} \mathrm{F}$ load cases are presented in Appendix D. As before, the uniform axial stress is represented by the vertical line shown on each plot. The linear (or nonlinear) plot is the pure bending stress.

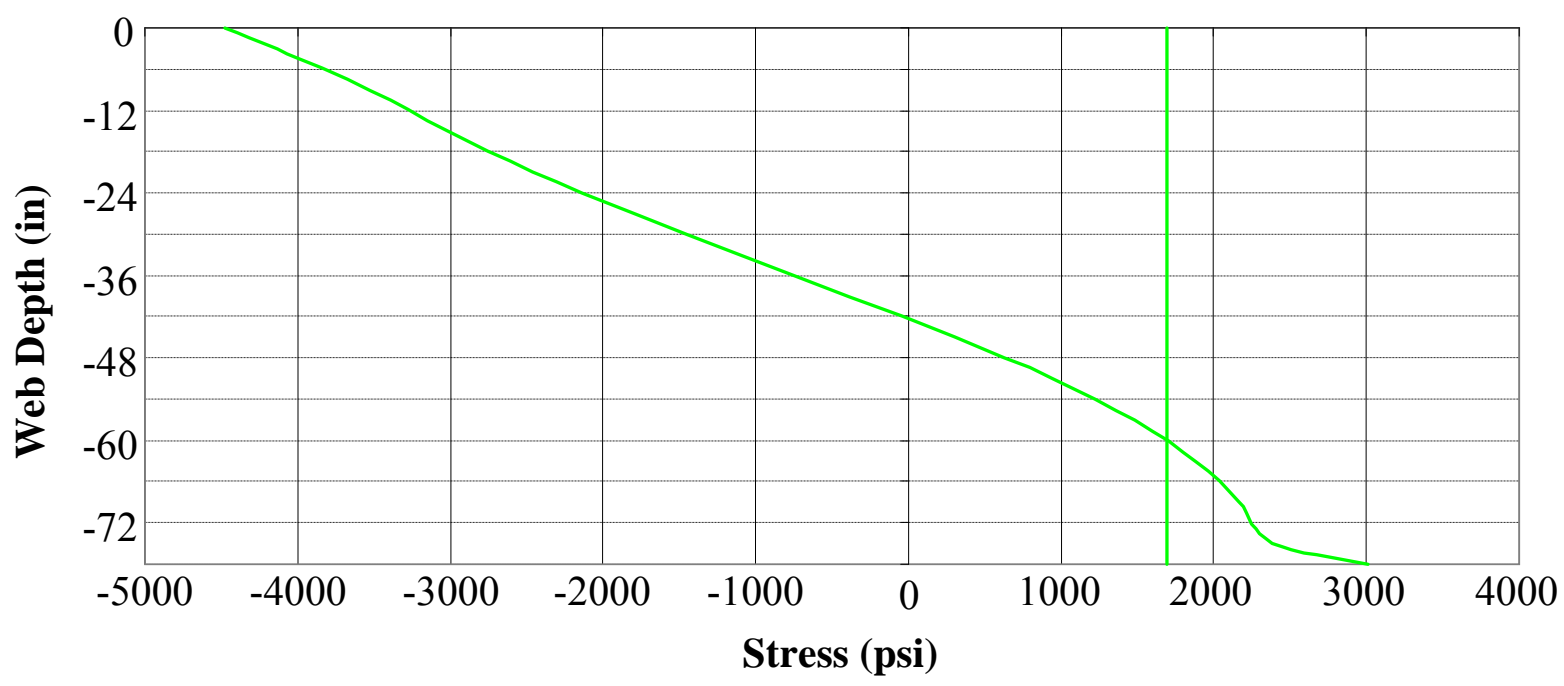

Figure 7.38 New Bearings, Span 7N Bending and Axial Stresses Under Temp $+60^{\circ} \mathrm{F}$ 


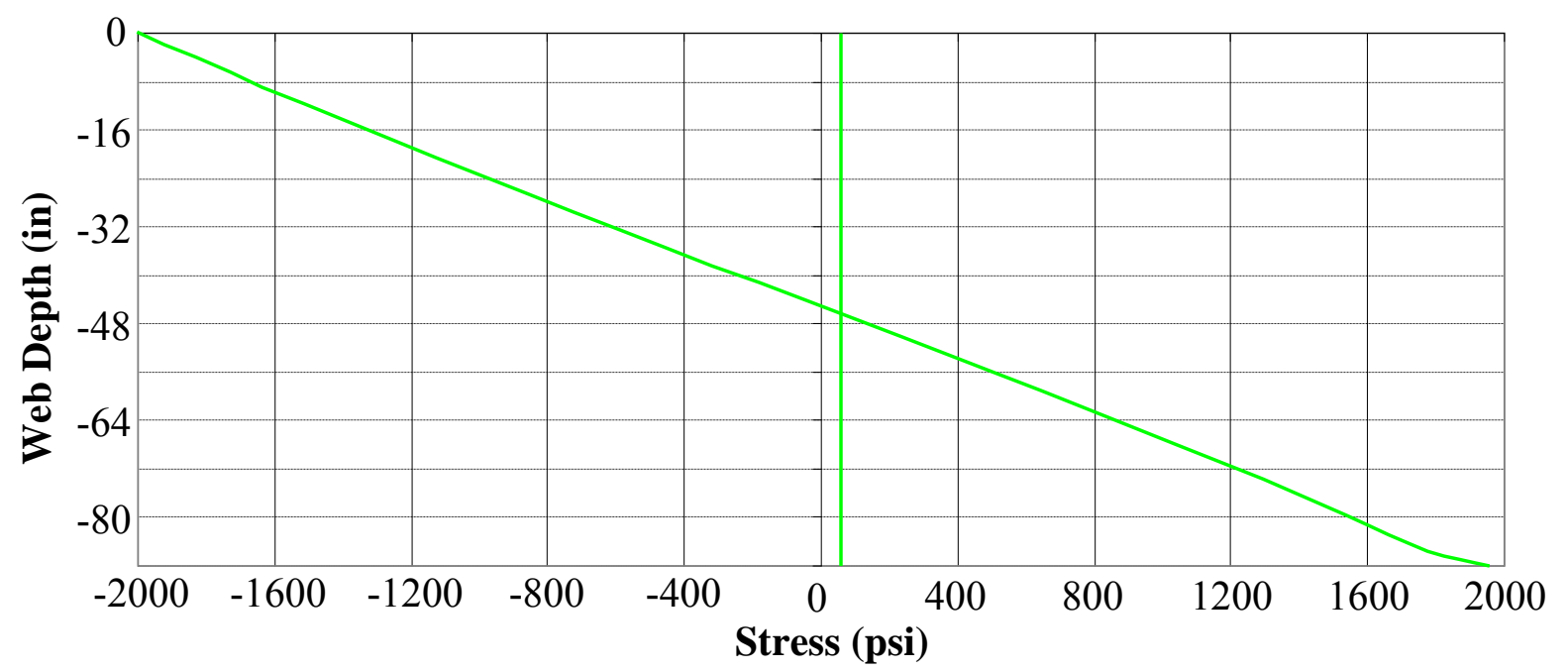

Figure 7.39 New Bearings, Span $8 \mathrm{~N}$ Bending and Axial Stresses Under Temp $+60^{\circ} \mathrm{F}$

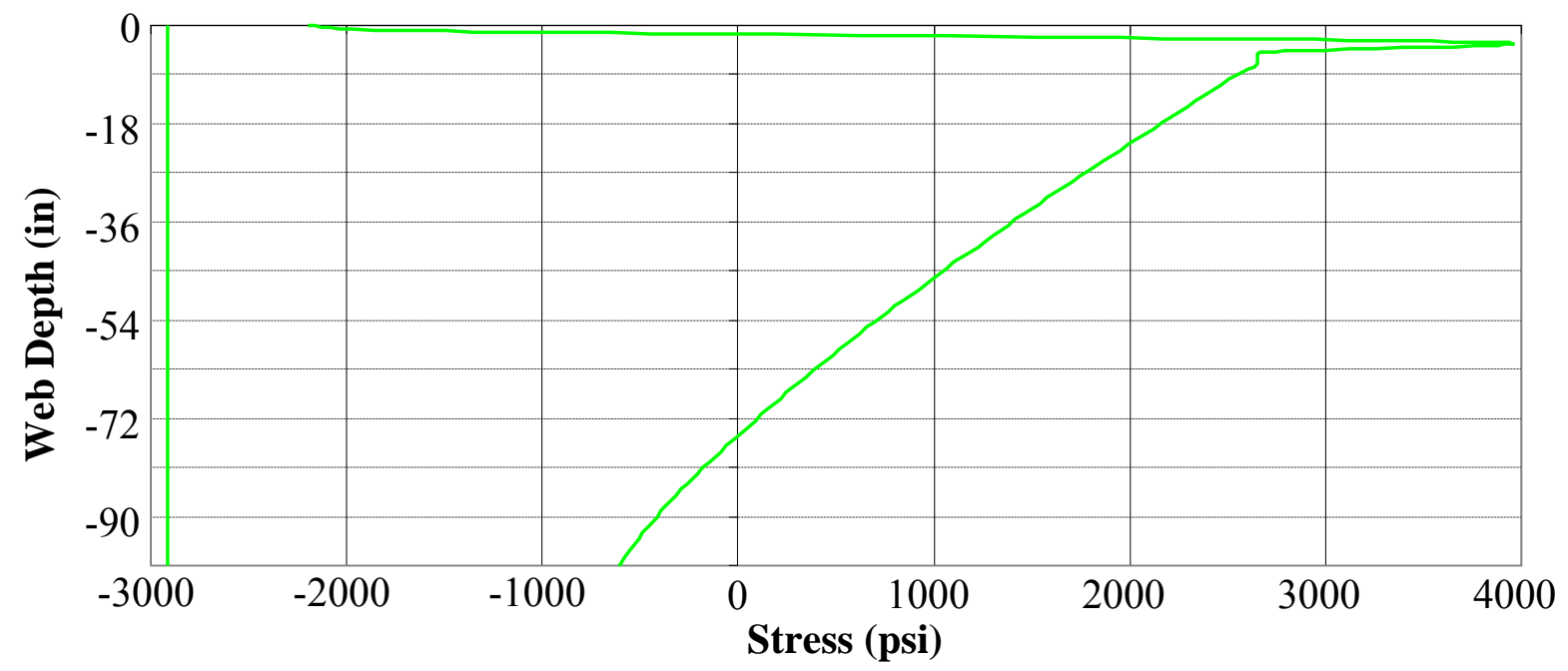

Figure 7.40 New Bearings, Span 9N Bending and Axial Stresses Under Temp $+60^{\circ} \mathrm{F}$

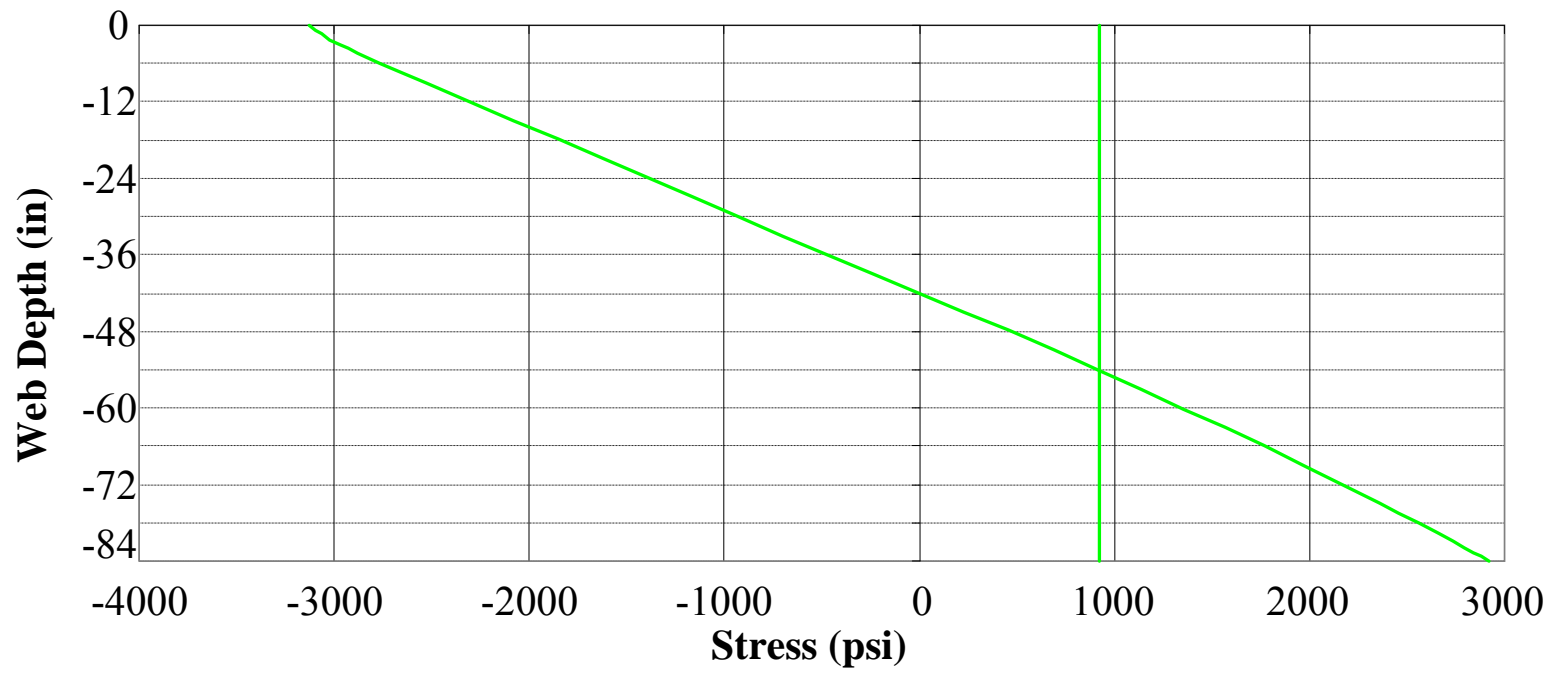

Figure 7.41 New Bearings, Span 10N Bending and Axial Stresses Under Temp $+60^{\circ} \mathrm{F}$ 


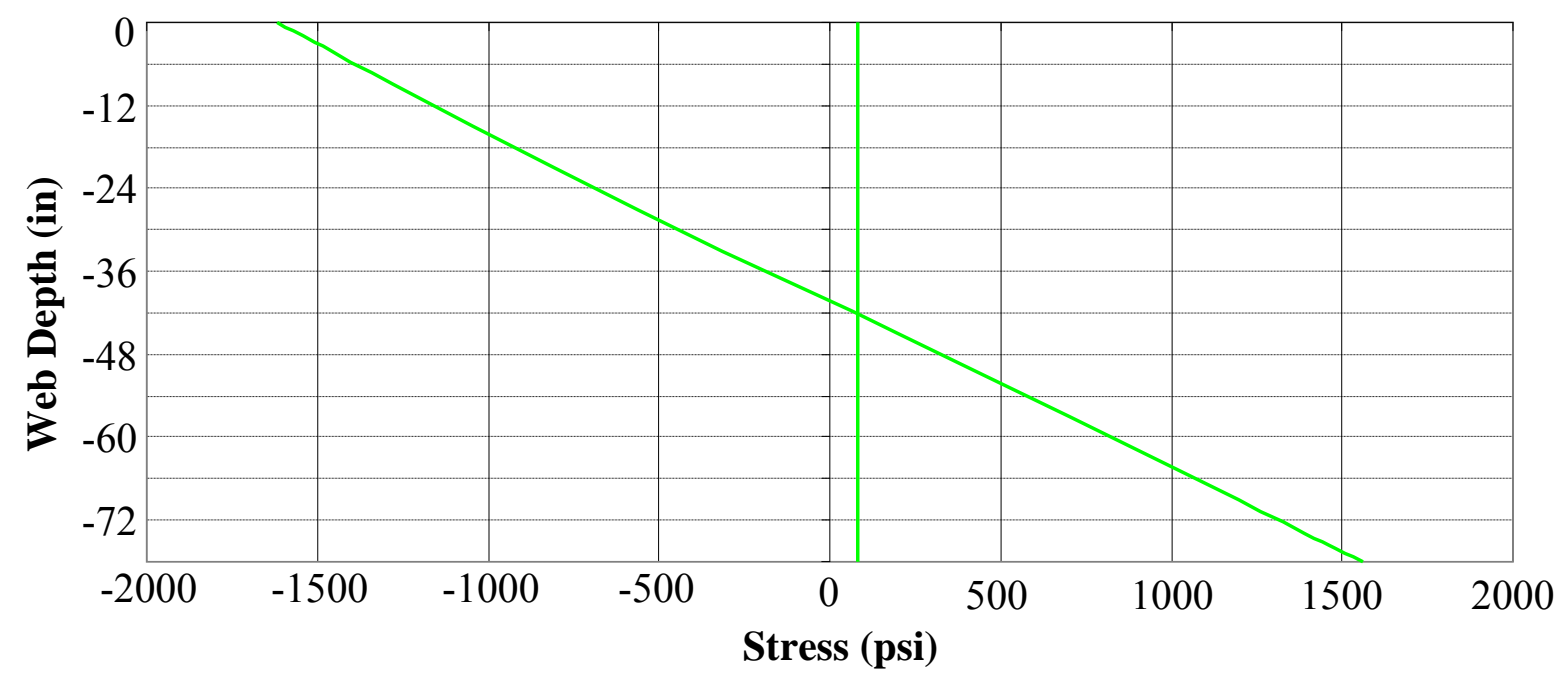

Figure 7.42 New Bearings, Span 11N Bending and Axial Stresses Under Temp $+60^{\circ} \mathrm{F}$

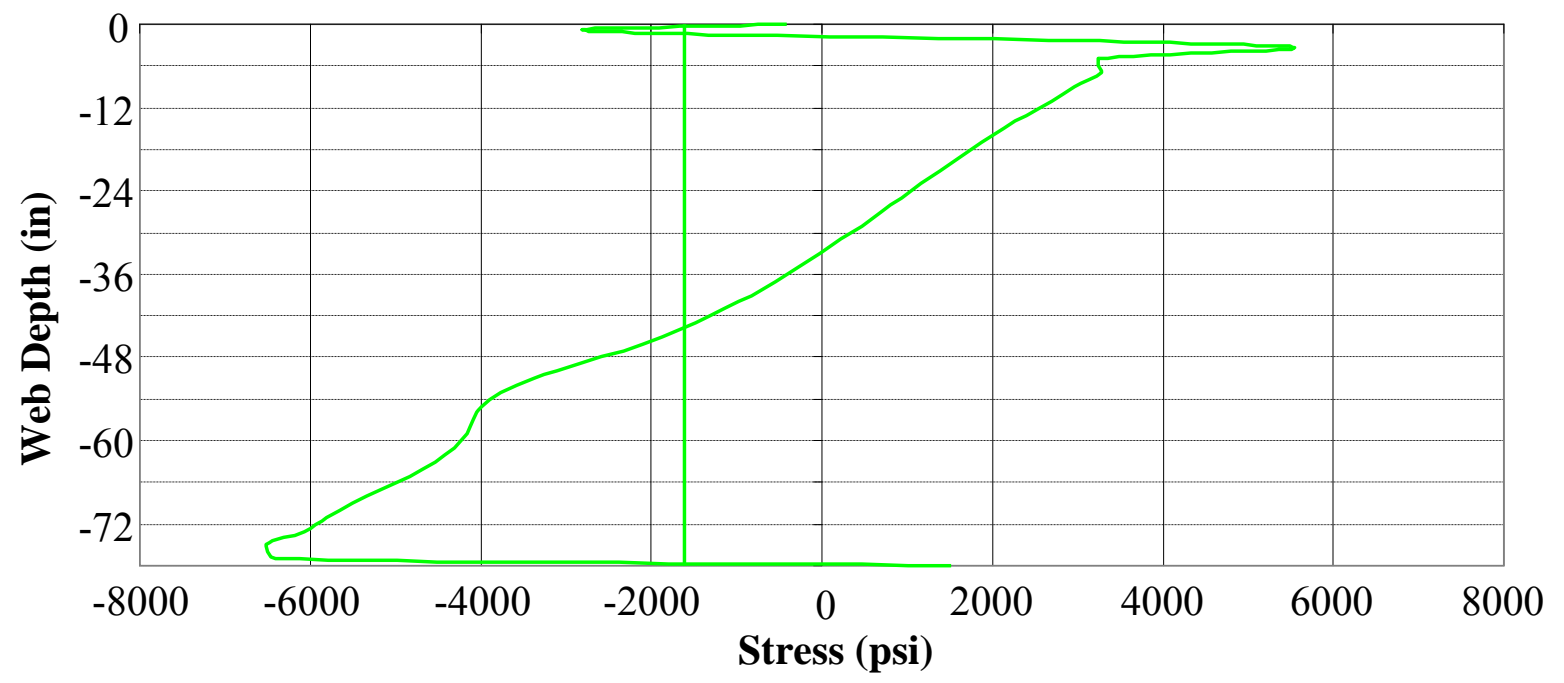

Figure 7.43 New Bearings, Pier 7N Bending and Axial Stresses Under Temp $+60^{\circ} \mathrm{F}$

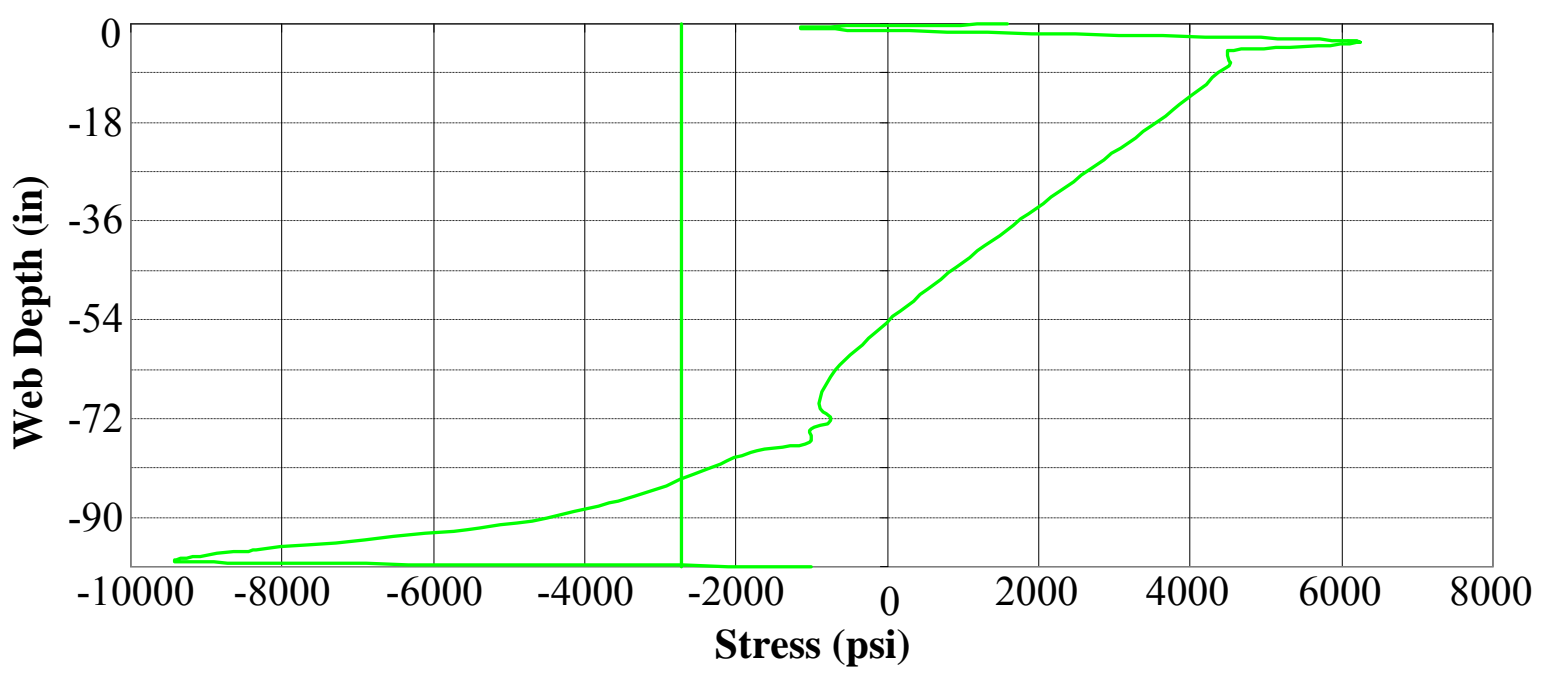

Figure 7.44 New Bearings, Pier 8N Bending and Axial Stresses Under Temp $+60^{\circ} \mathrm{F}$ 


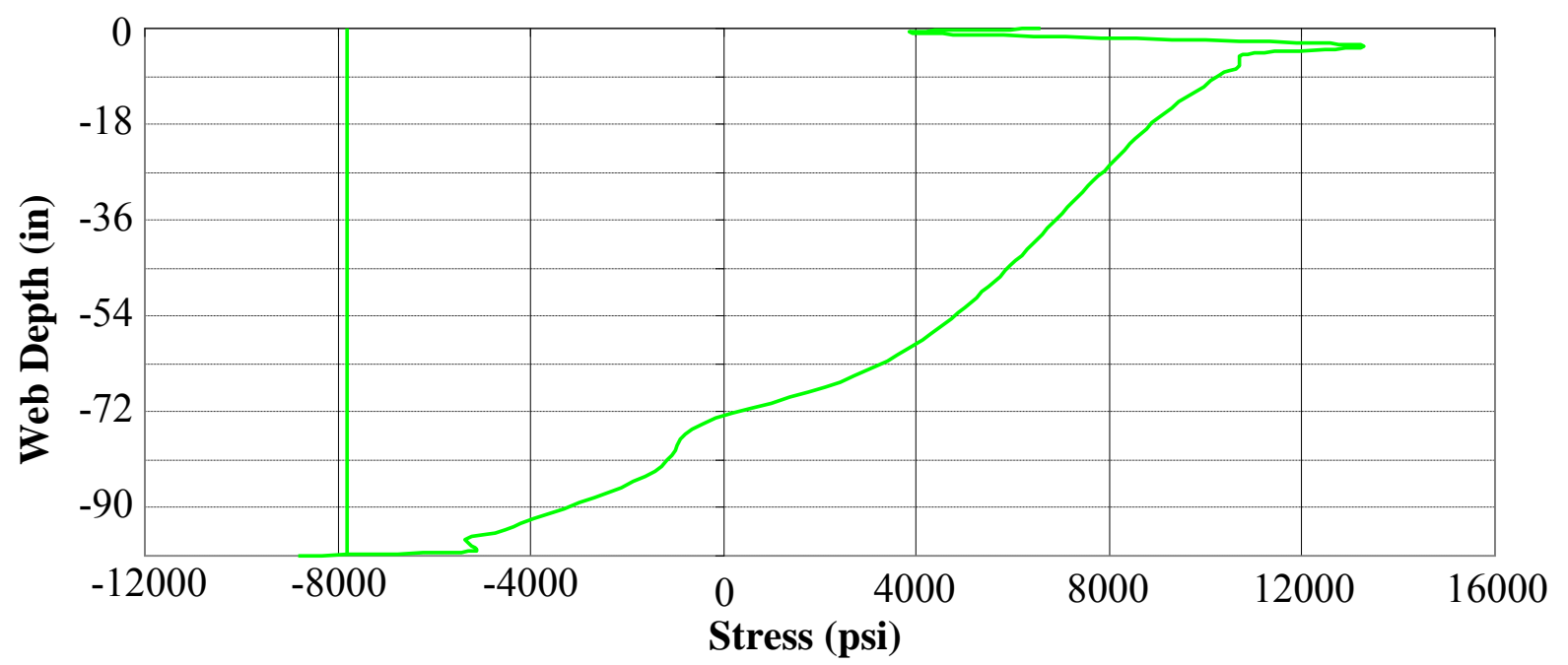

Figure 7.45 New Bearings, Pier 9N Bending and Axial Stresses Under Temp $+60^{\circ} \mathrm{F}$

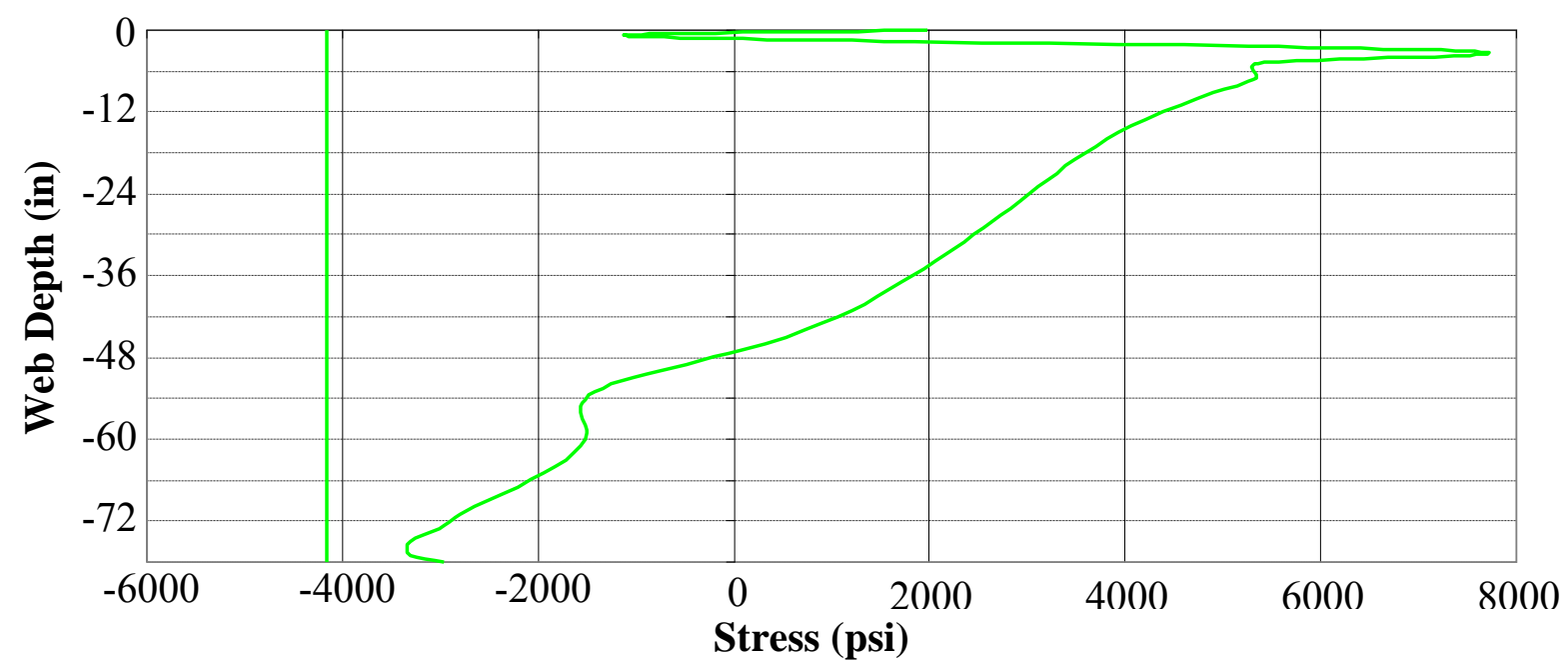

Figure 7.46 New Bearings, Pier 10N Bending and Axial Stresses Under Temp $+60^{\circ} \mathrm{F}$

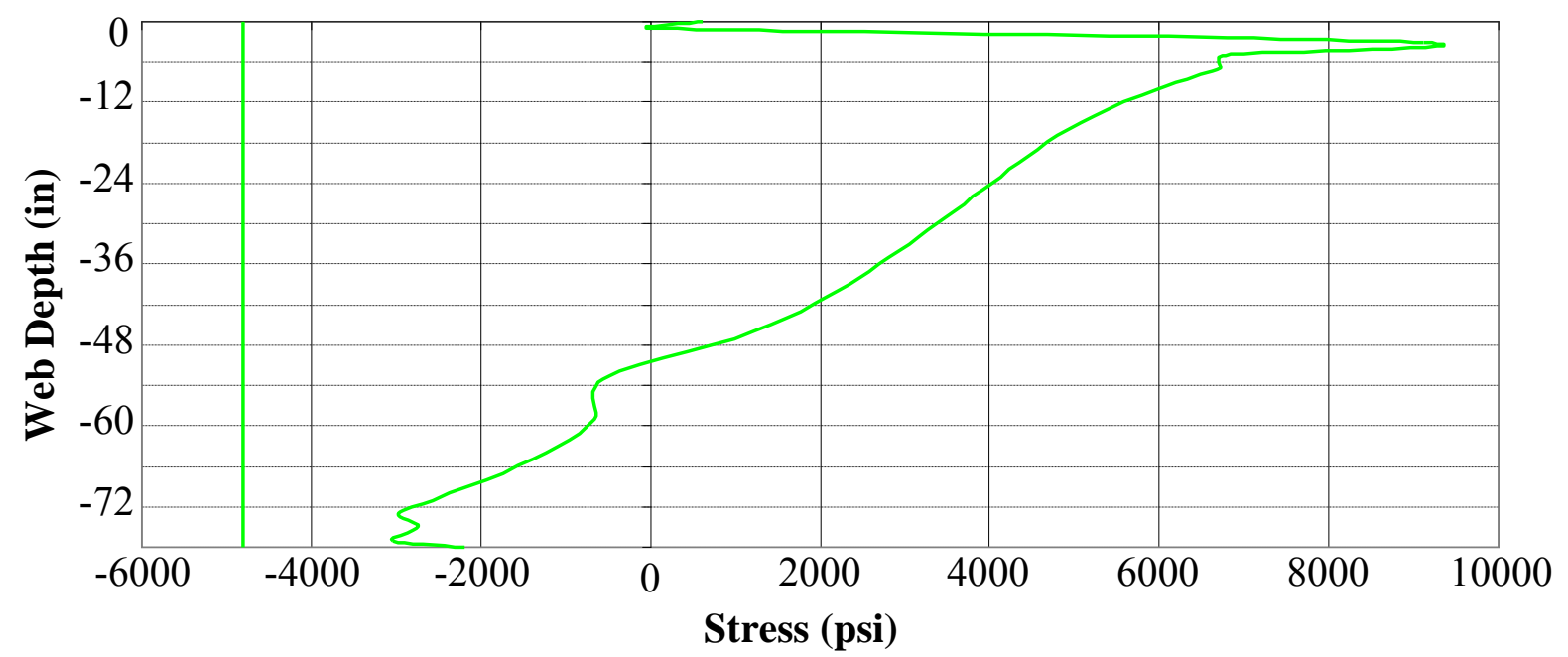

Figure 7.47 New Bearings, Pier 11N Bending and Axial Stresses Under Temp $+60^{\circ} \mathrm{F}$ 


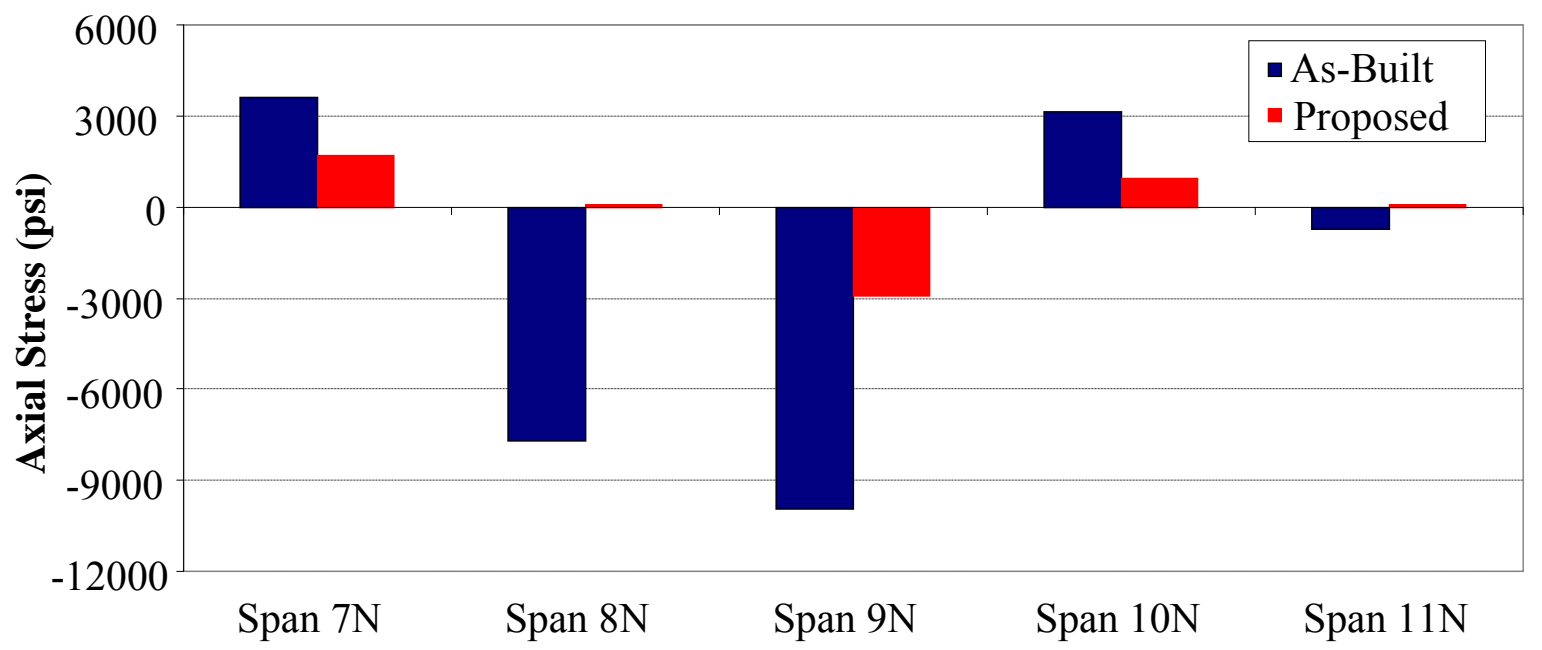

Figure 7.48 As-Built - New Bearings, Axial Stress Comparison Under Temp $+60^{\circ} \mathrm{F}$ (Spans)

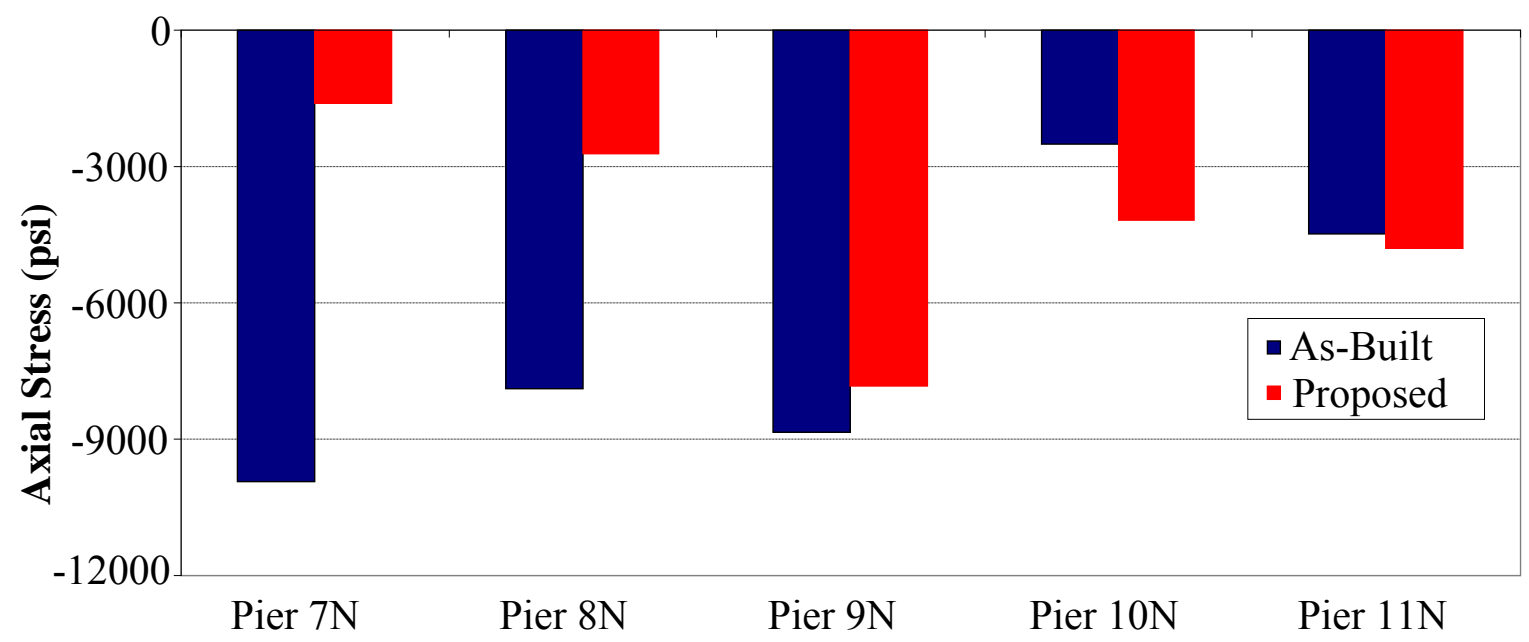

Figure 7.49 As-Built - New Bearings, Axial Stress Comparison Under Temp $+60^{\circ} \mathrm{F}$ (Piers)

Significant decreases in axial compressive stresses are seen in at the midspan crosssections of Spans $8 \mathrm{~N}$ and $9 \mathrm{~N}$ in Figure 7.48. The cross-section in Span $8 \mathrm{~N}$ is nearly free of axial stress under the new bearing conditions after developing a compressive stress of $8 \mathrm{ksi}$ under the as-built bearing arrangement. Compressive stress in Span 9N decreases from 10 ksi to 3 ksi. Tensile stresses in Spans $7 \mathrm{~N}$ and $10 \mathrm{~N}$ reduce to less than 2 ksi under the new bearing arrangement, while the cross-section in Span $11 \mathrm{~N}$ is nearly free of any axial stress. 
Figure 7.49 nicely shows how the proposed bearing arrangement affects the development of axial compressive stress at the support locations. Compressive stress at Pier $7 \mathrm{~N}$ decreases from $10 \mathrm{ksi}$ to approximately $1.7 \mathrm{ksi}$ under the proposed bearing arrangement. At Pier $8 \mathrm{~N}$, compressive axial stress decreases roughly 5 ksi. Pier $9 \mathrm{~N}$ shows a decrease of around $1.0 \mathrm{ksi}$ with the new bearing conditions applied to the FE model. Modest increases in compressive stress are recorded at Piers $10 \mathrm{~N}$ and $11 \mathrm{~N}$. Figures 7.50-7.61 present the bending and axial profiles for the $+90^{\circ} \mathrm{F}$ load case.

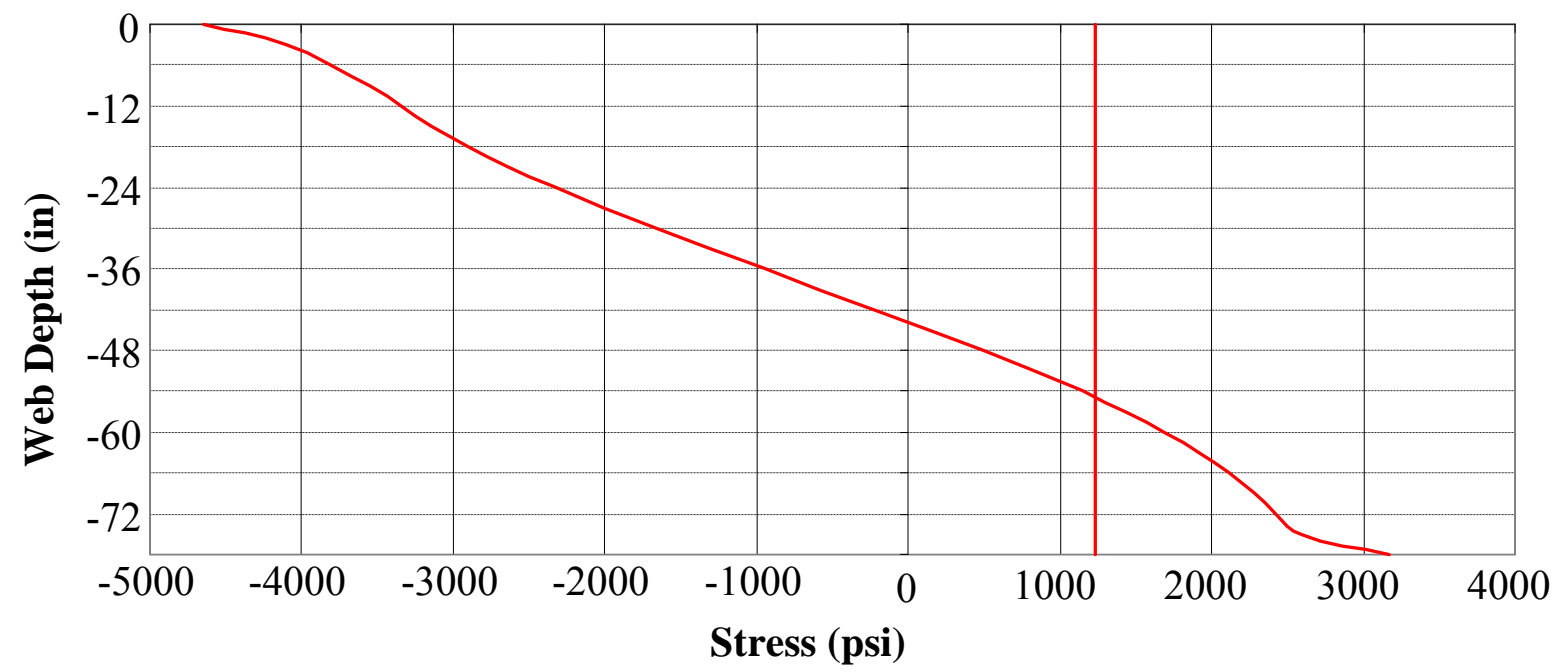

Figure 7.50 New Bearings, Span 7N Bending and Axial Stresses Under Temp $+90^{\circ} \mathrm{F}$

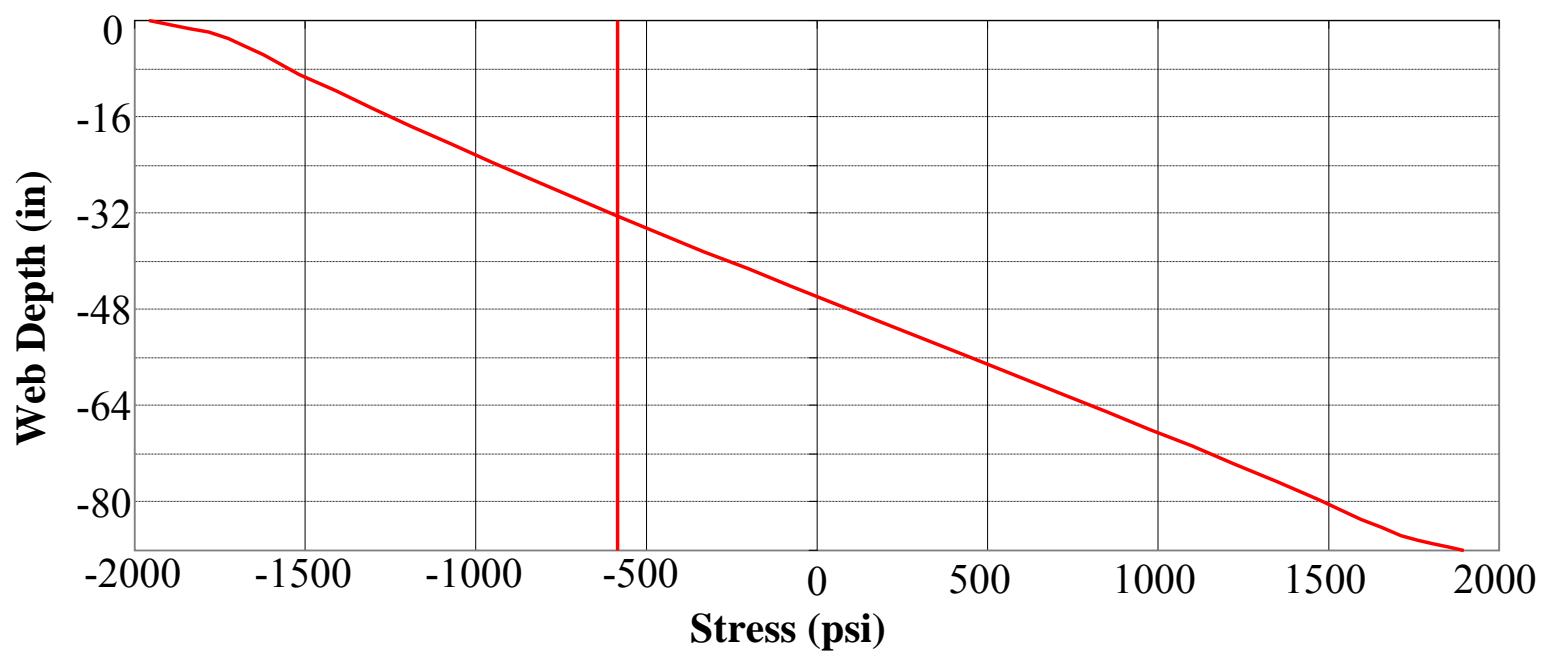

Figure 7.51 New Bearings, Span $8 \mathrm{~N}$ Bending and Axial Stresses Under Temp $+90^{\circ} \mathrm{F}$ 


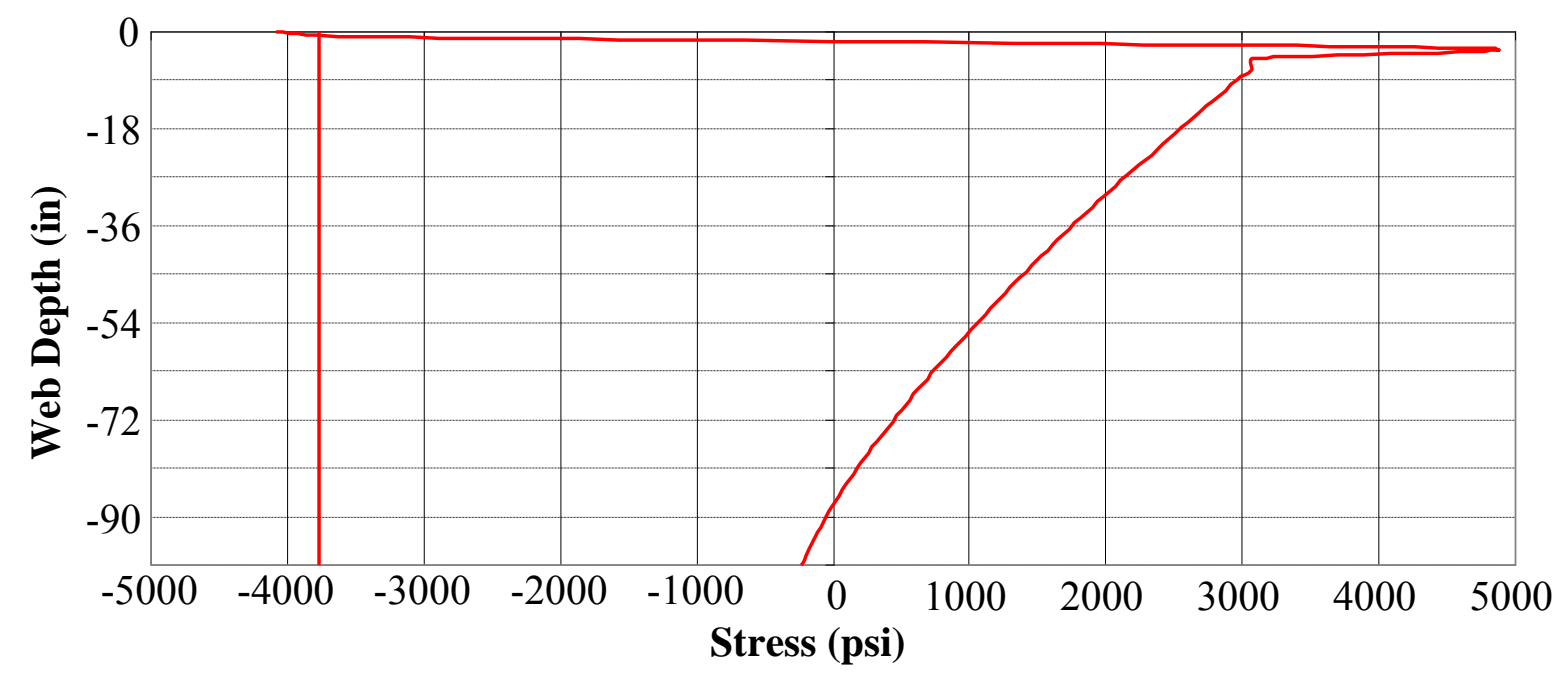

Figure 7.52 New Bearings, Span 9N Bending and Axial Stresses Under Temp $+90^{\circ} \mathrm{F}$

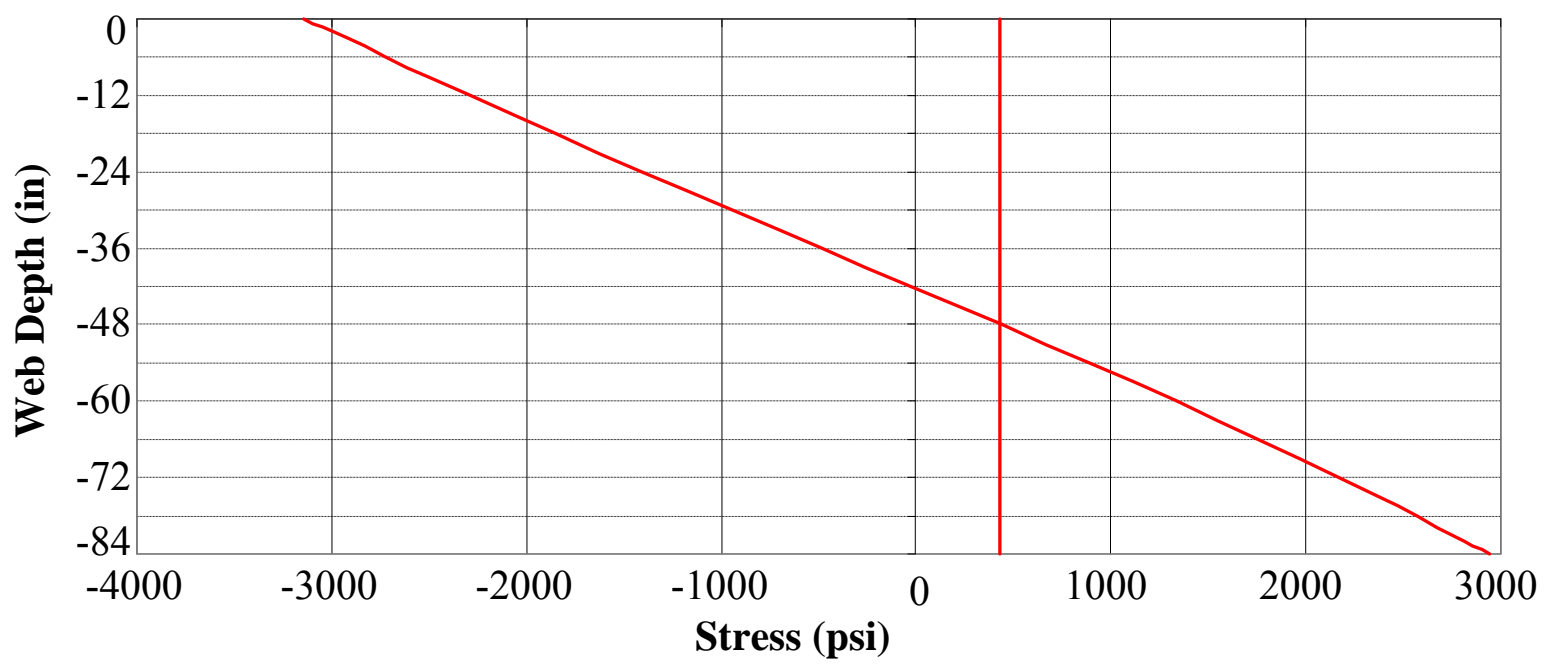

Figure 7.53 New Bearings, Span 10N Bending and Axial Stresses Under Temp $+90^{\circ} \mathrm{F}$

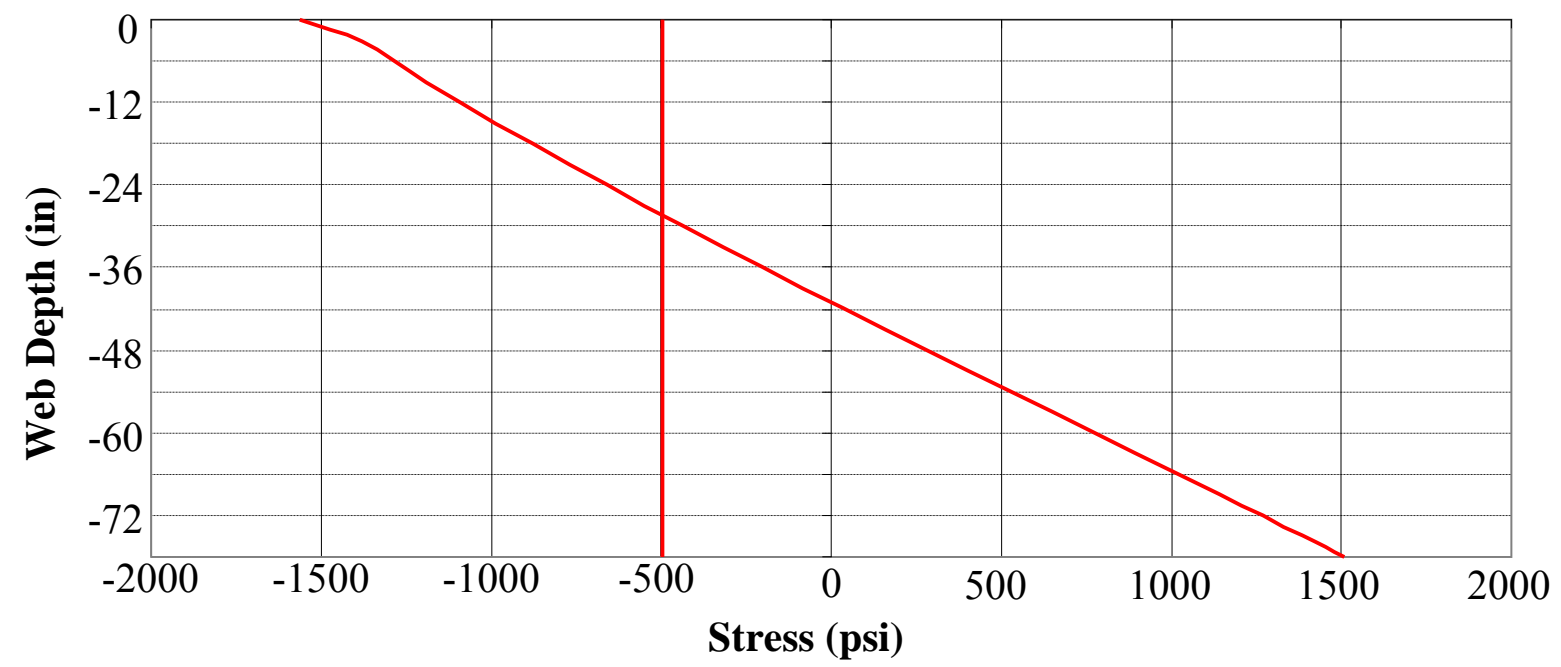

Figure 7.54 New Bearings, Span 11N Bending and Axial Stresses Under Temp $+90^{\circ} \mathrm{F}$ 


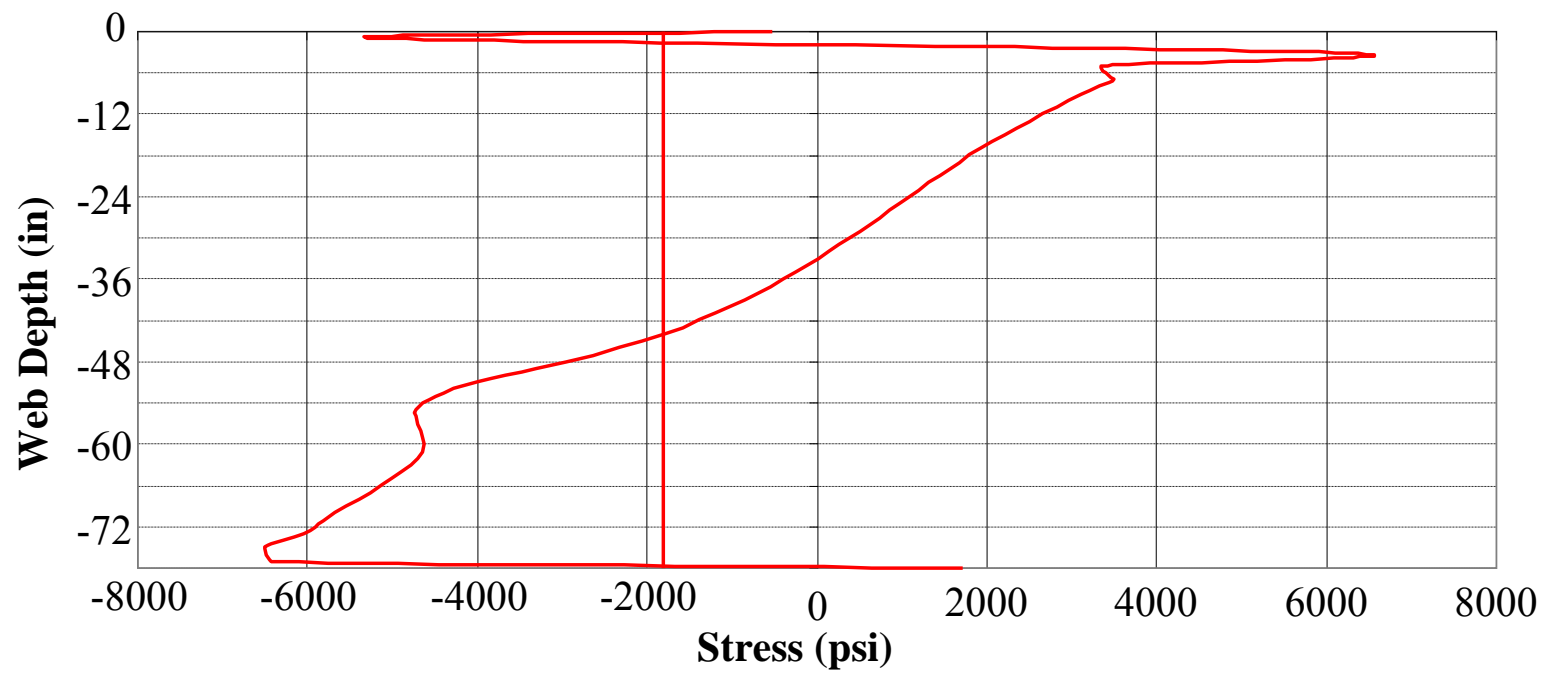

Figure 7.55 New Bearings, Pier 7N Bending and Axial Stresses Under Temp $+90^{\circ} \mathrm{F}$

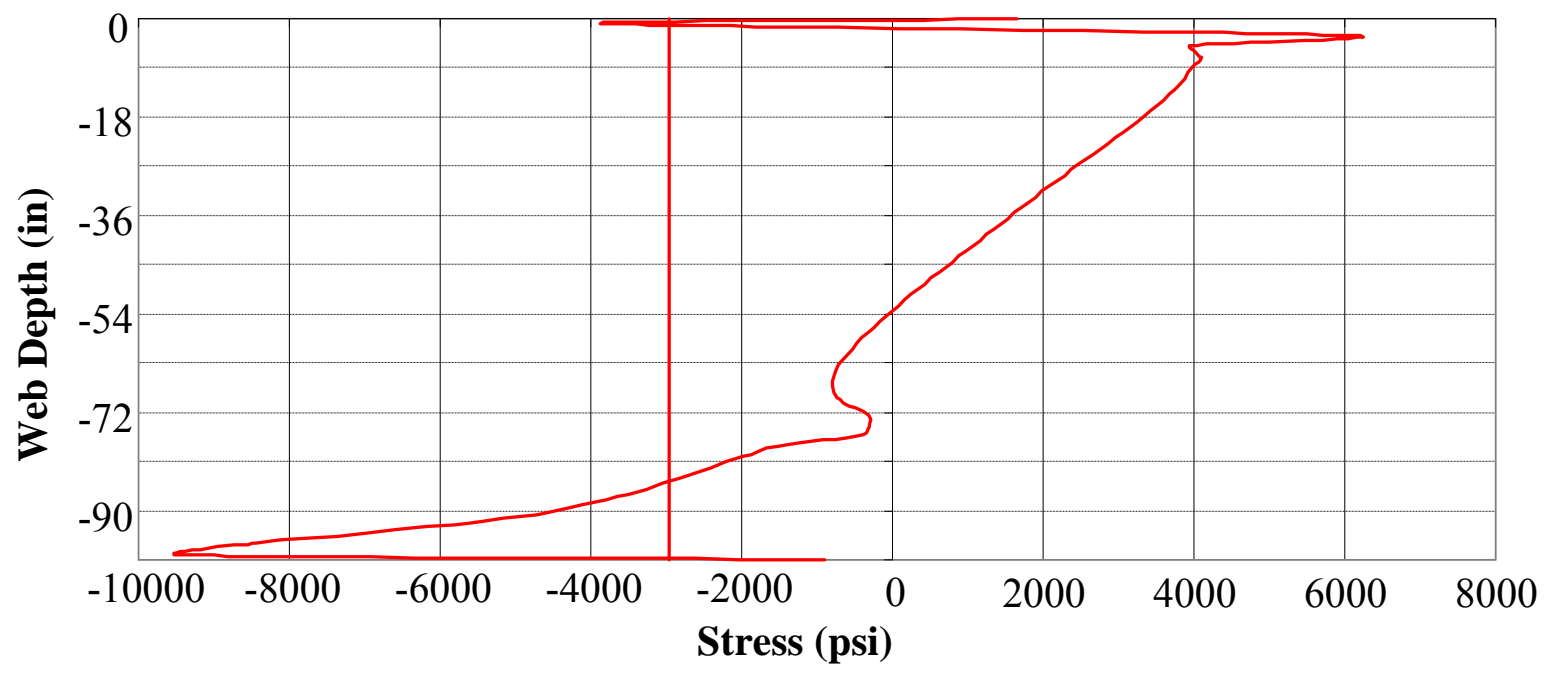

Figure 7.56 New Bearings, Pier 8N Bending and Axial Stresses Under Temp $+90^{\circ} \mathrm{F}$

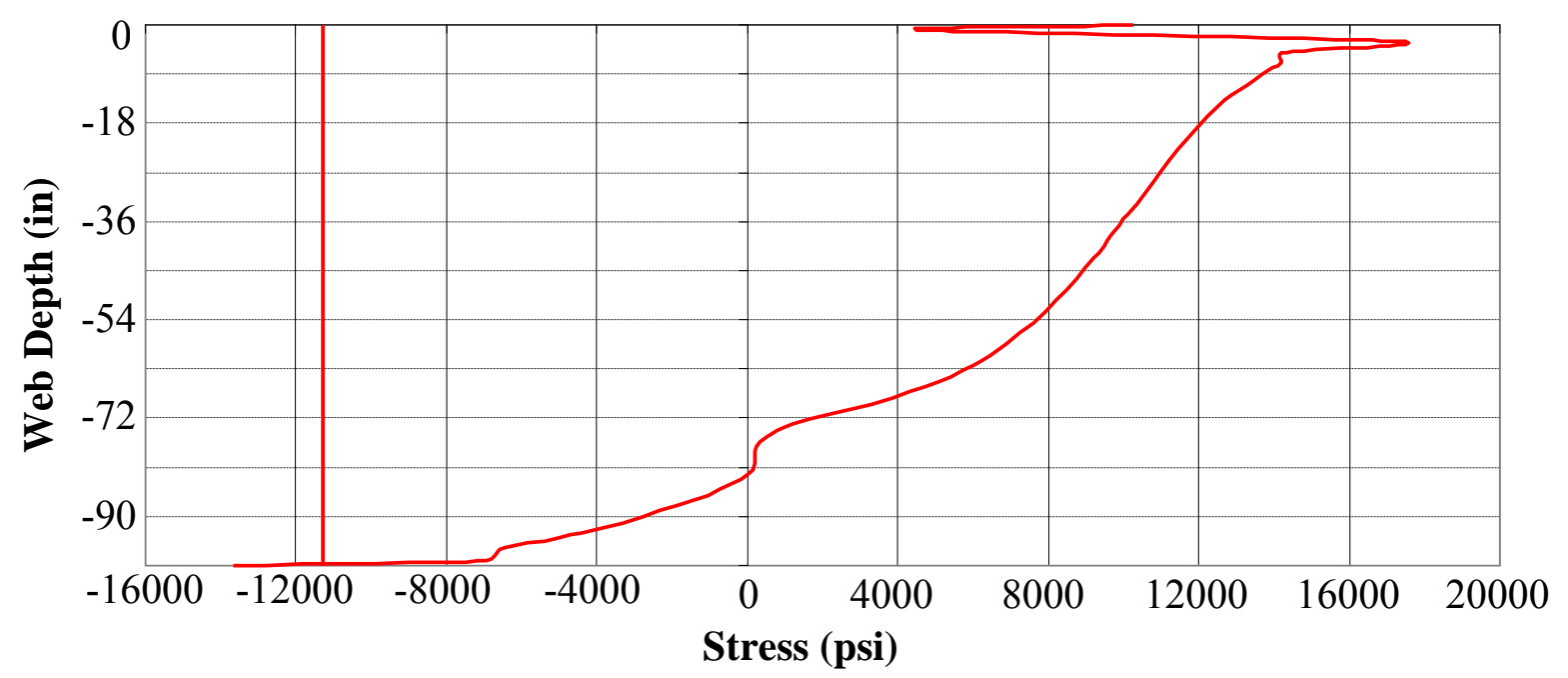

Figure 7.57 New Bearings, Pier 9N Bending and Axial Stresses Under Temp $+90^{\circ} \mathrm{F}$ 


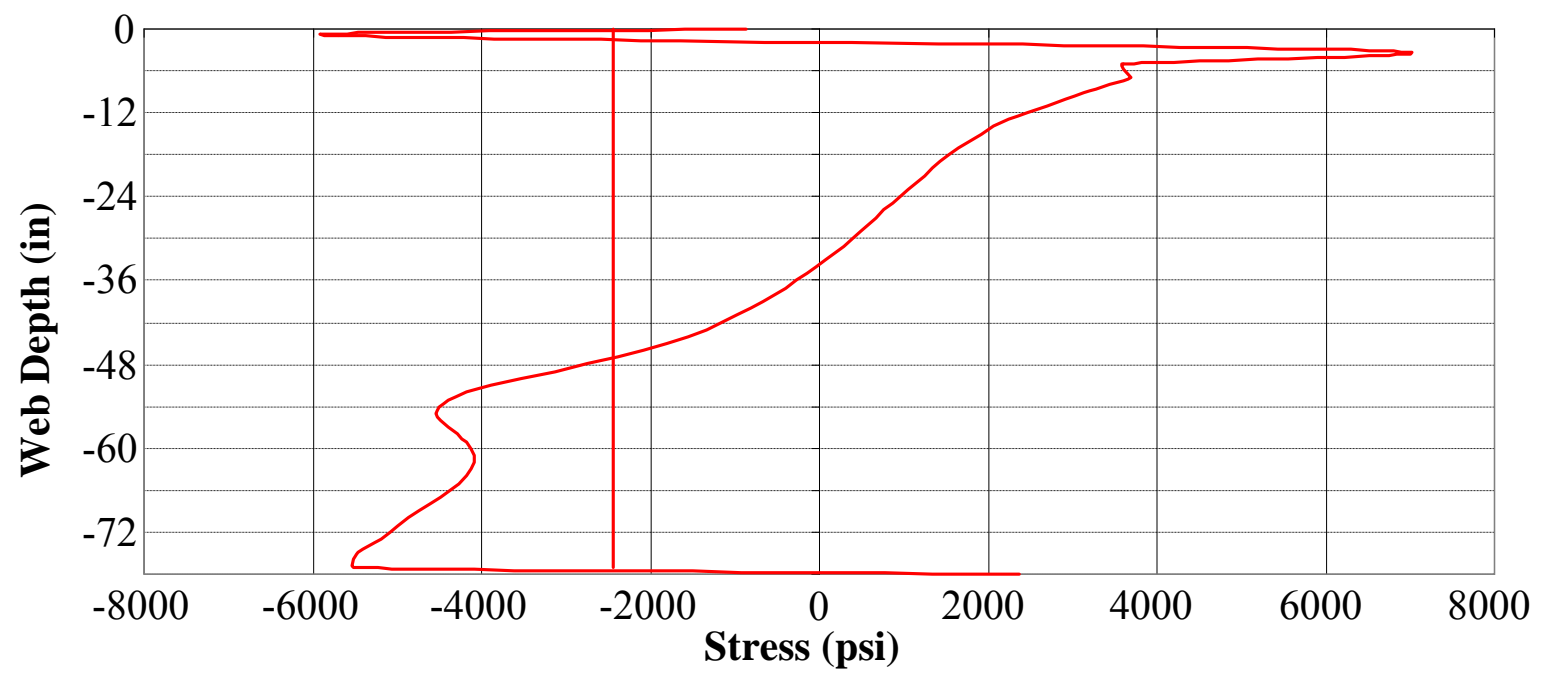

Figure 7.58 New Bearings, Pier 10N Bending and Axial Stresses Under Temp $+90^{\circ} \mathrm{F}$

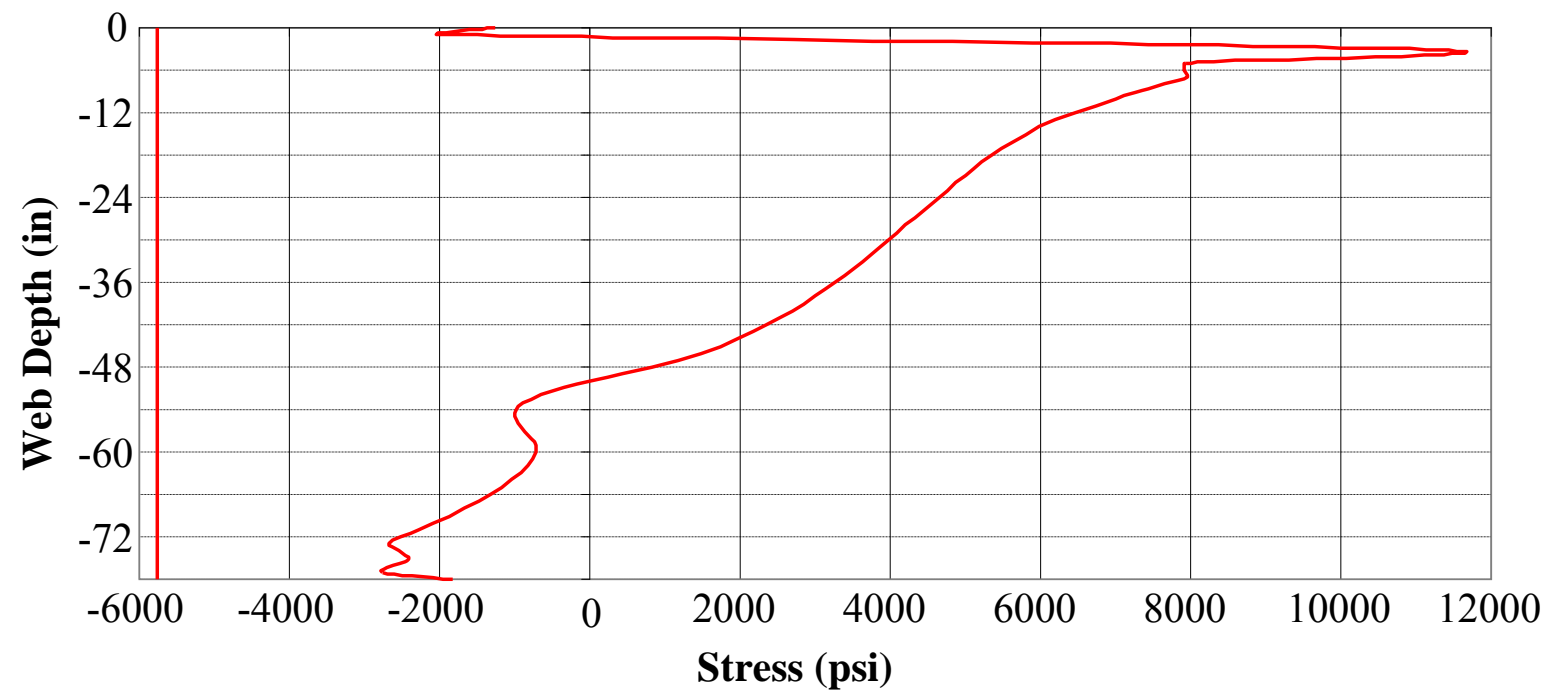

Figure 7.59 New Bearings, Pier 11N Bending and Axial Stresses Under Temp $+90^{\circ} \mathrm{F}$

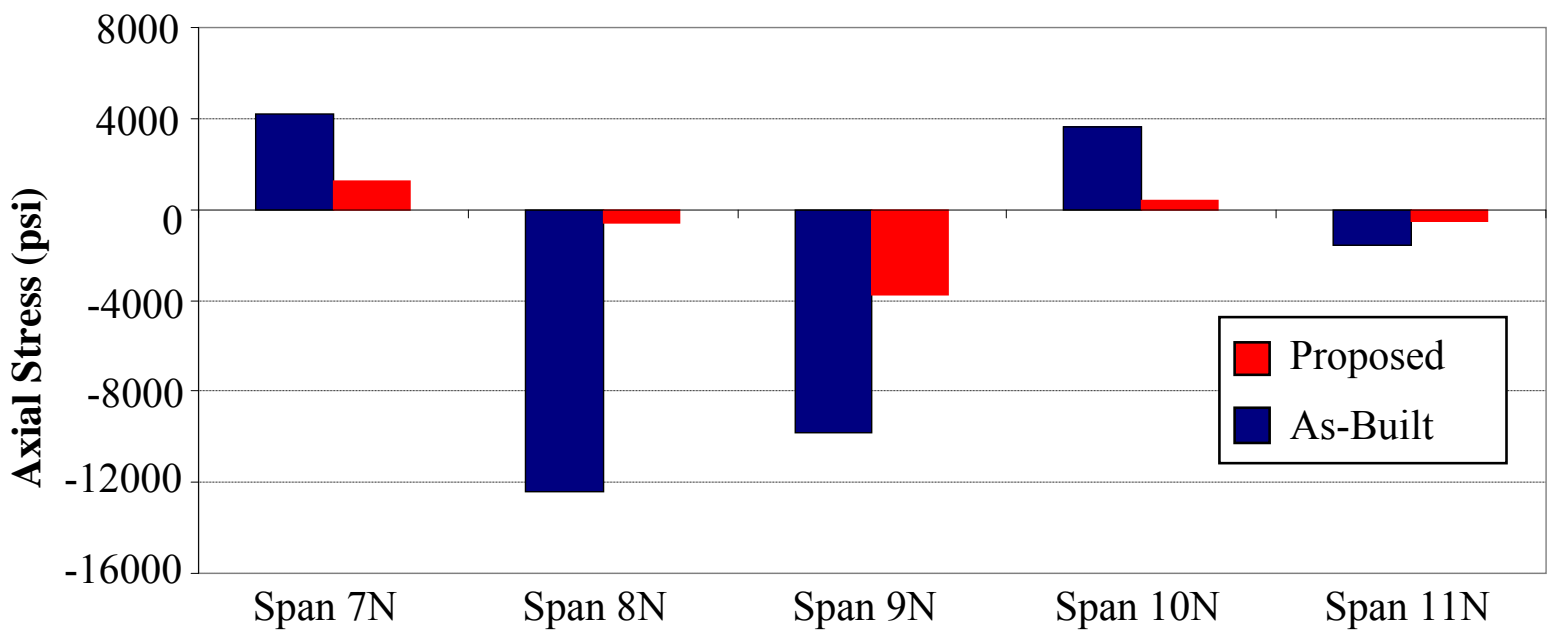

Figure 7.60 As-Built - New Bearings, Axial Stress Comparison Under Temp $+90^{\circ} \mathrm{F}$ (Spans) 


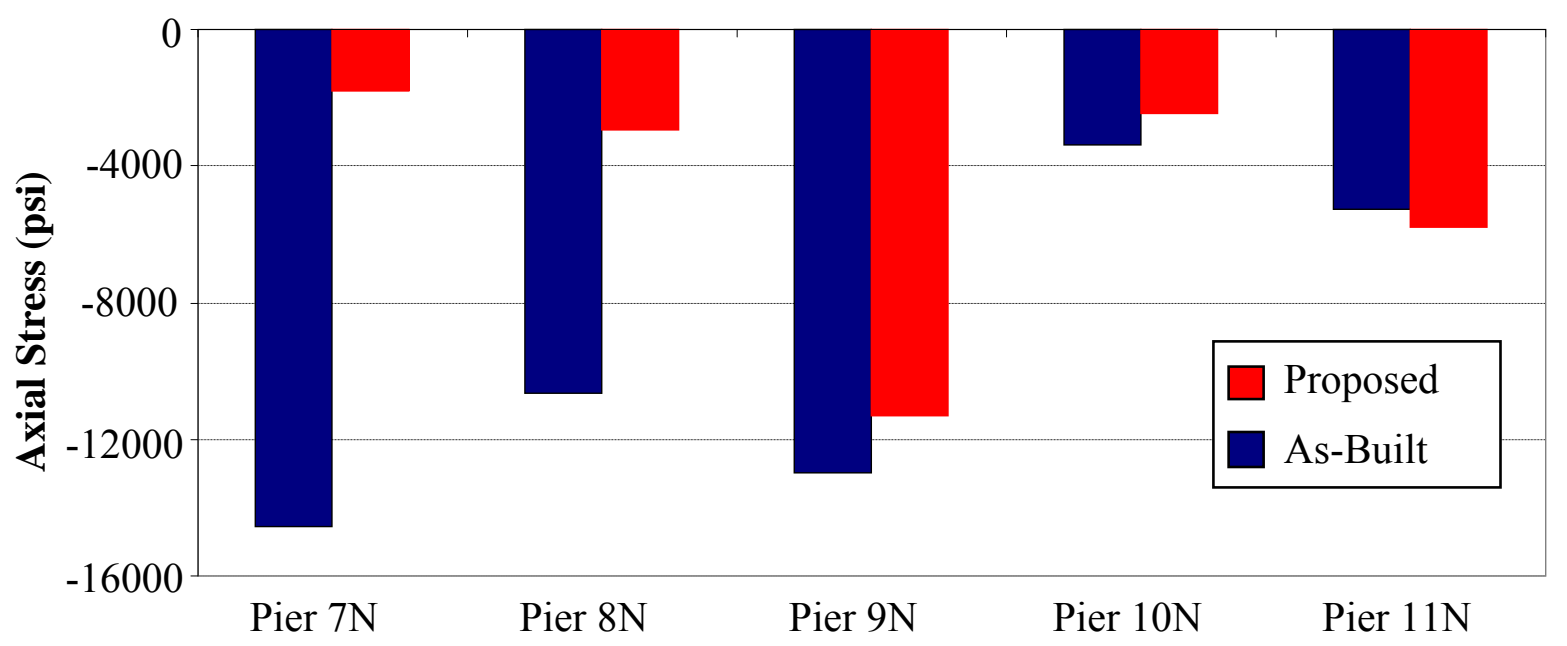

Figure 7.61 As-Built - New Bearings, Axial Stress Comparison Under Temp $+90^{\circ} \mathrm{F}$ (Piers)

Changing the bearing arrangement with the $+90^{\circ} \mathrm{F}$ temperature load applied yields very similar results to the $+60^{\circ} \mathrm{F}$ load case. Large decreases in axial compressive stress are occur at the cross-sections in Spans $8 \mathrm{~N}$ and $9 \mathrm{~N}$ when the proposed bearing arrangement is implemented. Compressive stress in Span 8N decreases approximately 95\%, from $12.4 \mathrm{ksi}$ under the as-built arrangement to $570 \mathrm{psi}$ with the new bearings. Span $9 \mathrm{~N}$ experiences a $61 \%$ decrease in compressive stress when compared to the as-built bearing arrangement. The cross-sections in Spans $7 \mathrm{~N}$ and $10 \mathrm{~N}$ both show a decrease in axial tensile stresses with the new bearing arrangement, which similar behavior as seen with the $+60^{\circ} \mathrm{F}$ temperature load applied. In Spans $10 \mathrm{~N}$ and $11 \mathrm{~N}$, axial stresses are almost fully eliminated under the proposed bearing arrangement.

Figures 7.55-7.61 show that with the new bearing conditions, the compressive stress at each pier support location due to the $+90^{\circ} \mathrm{F}$ temperature load has either reduced or remains roughly unchanged compared to the as-built conditions. Piers $7 \mathrm{~N}$ and $8 \mathrm{~N}$ experience the largest decreases in axial stress under the proposed bearing arrangement, at $87 \%$ and $72 \%$ respectively. Piers $9 \mathrm{~N}$ and $10 \mathrm{~N}$ each show a modest decrease in axial stress, while stress at Pier $11 \mathrm{~N}$ increases slightly. 


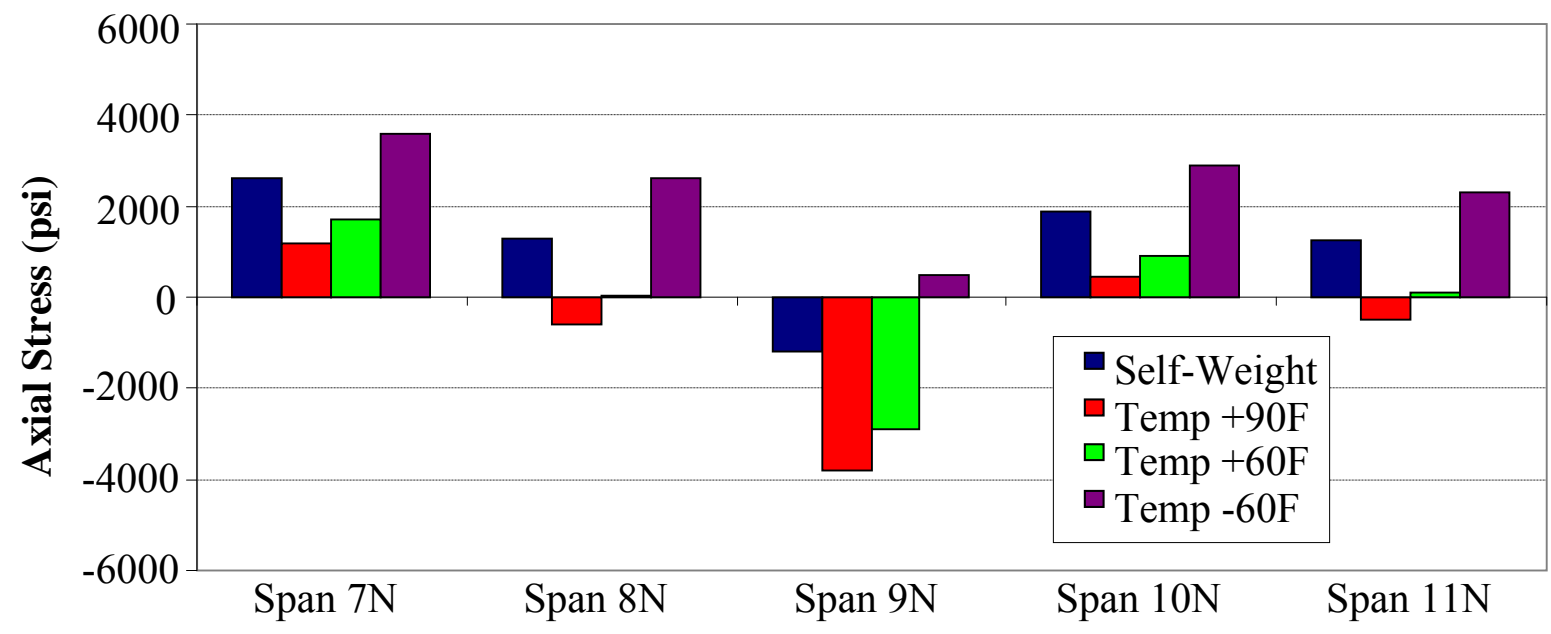

Figure 7.62 New Bearings, Axial Stress Due to Temperature Loads (Spans)

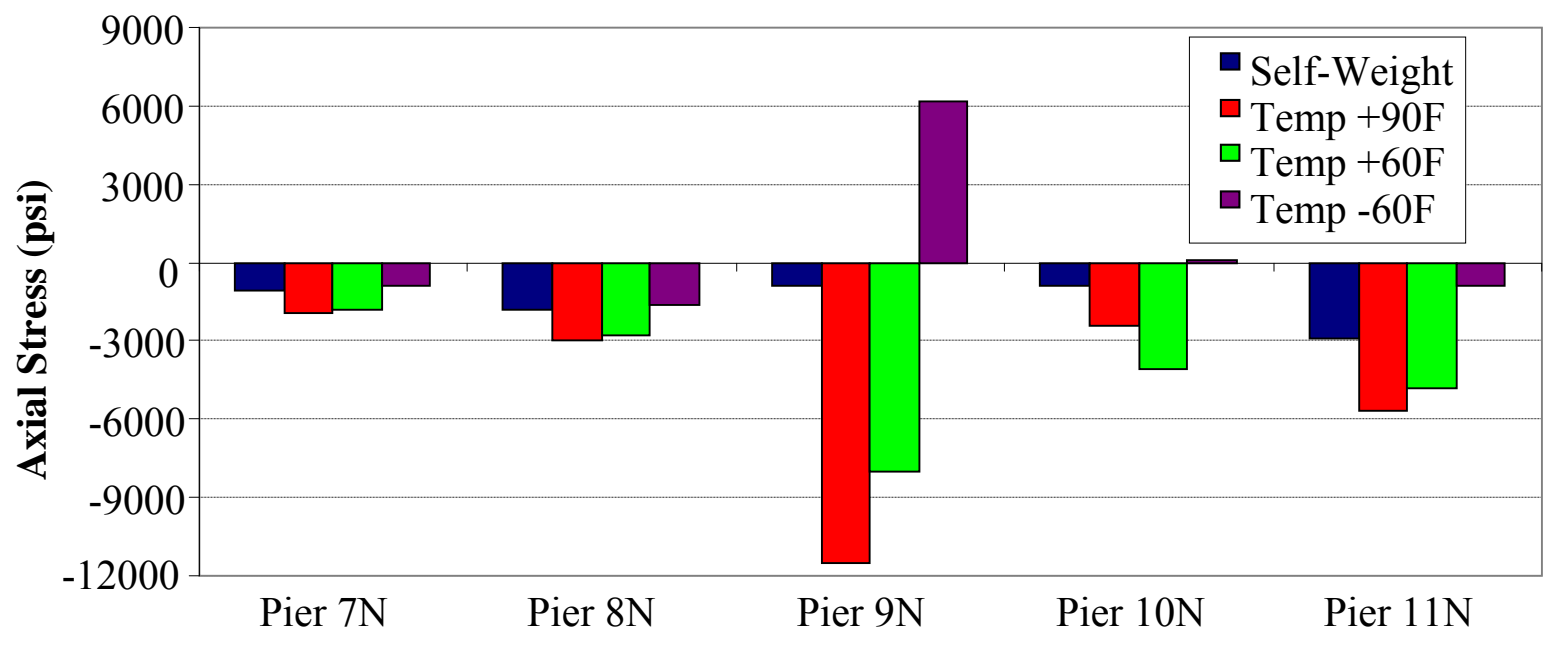

Figure 7.63 New Bearings, Axial Stress Due to Temperature Loads (Piers)

The results presented here show that the proposed bearing arrangement produces highly more favorable levels of stress compared the as-built bearing conditions. With the fixed bearings removed and expansion bearings implemented, axial stress throughout the bridge has diminished. The reduction in stress is a result of the new bearing arrangement better accommodating the thermal expansion of the steel I-girders when subjected to uniform temperature loads. Nevertheless, it is evident that even the expansion bearings are providing a certain level of restraint against the thermal expansion. The curvature of the steel girders is 
complicating their thermal movement; therefore completely eliminating thermal stresses in this structure would be very difficult.

Figures 7.64-7.69 compares the compressive resistance percentages calculated using the axial stresses developed under each bearing arrangement. With the exception of the cross-section at Pier $11 \mathrm{~N}$, when subjected to positive temperature loads, significant reductions in the compressive resistance percentage are recorded with the implementation of the new bearing arrangement. With the new bearings, a much lower magnitude of compressive stress develops in the steel I-girders, resulting in significantly less compressive resistance being consumed. This will have a significant impact on the load-carrying capacity of the girders. If the magnitude of axial stress has reduced, a greater portion of girder capacity will be available to carry bending stresses (from additional live loads).

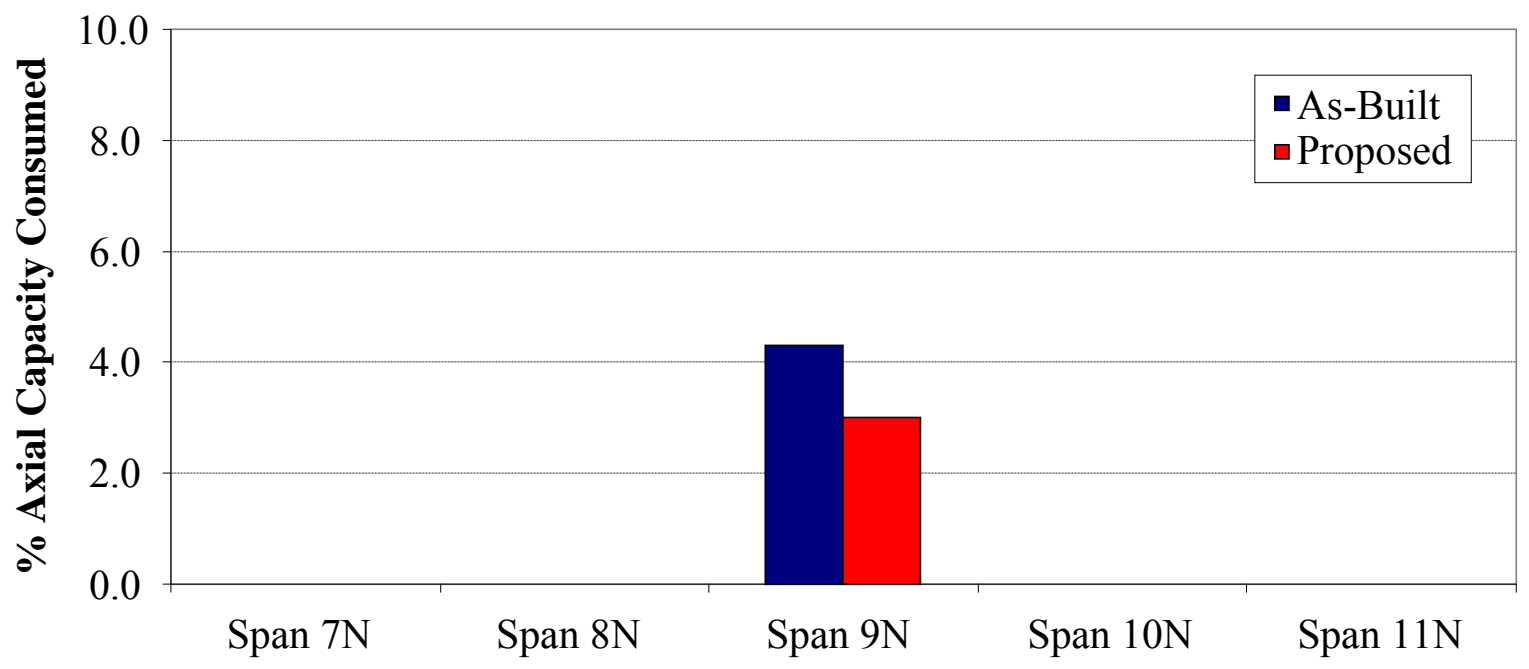

Figure 7.64 Axial Capacity Comparison Under Self-Weight (Spans) 


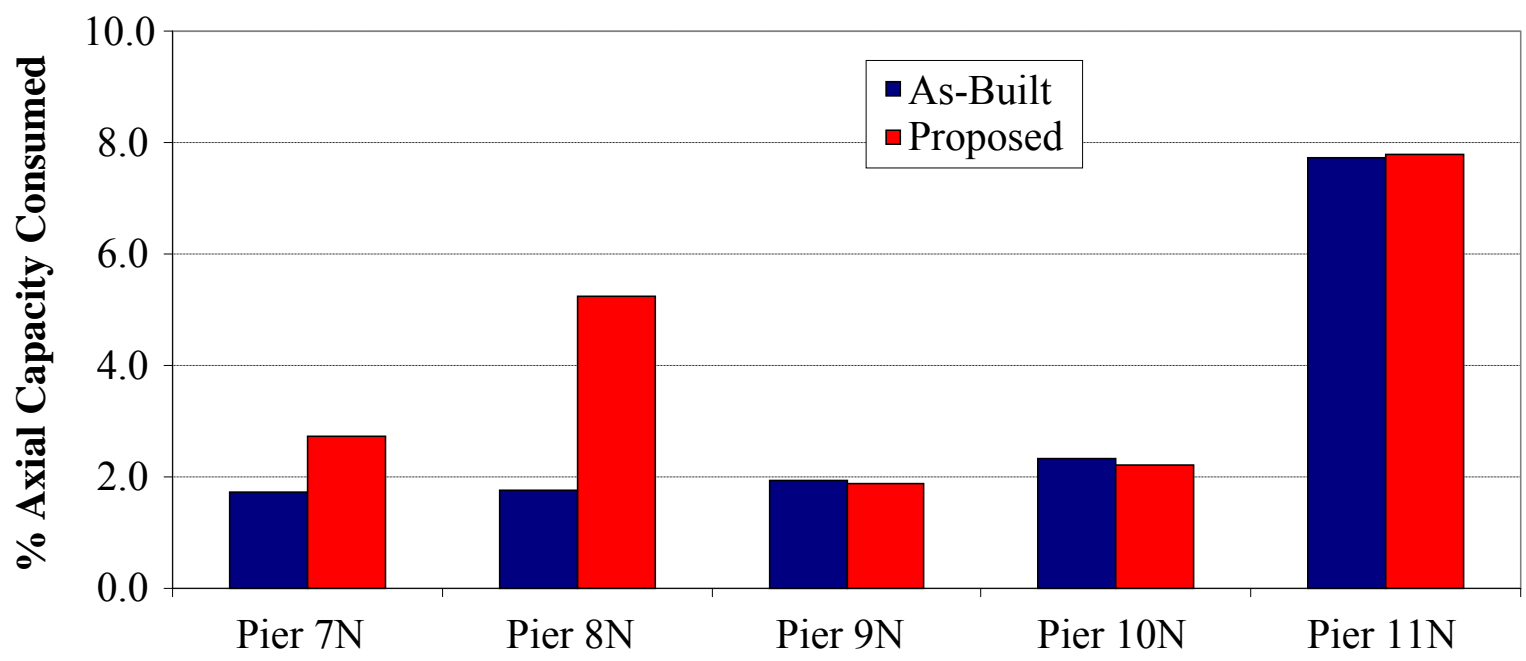

Figure 7.65 Axial Capacity Comparison Under Self-Weight (Piers)

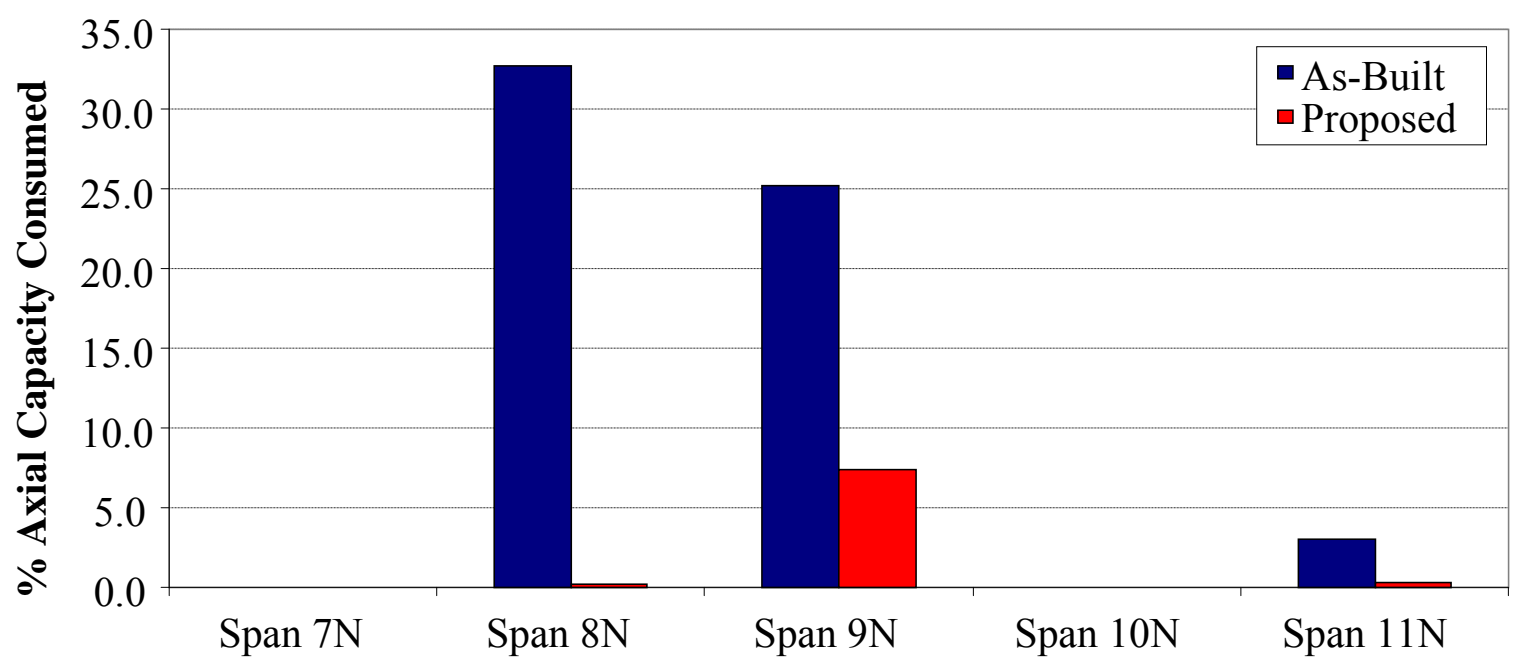

Figure 7.66 Axial Capacity Comparison Under Temp $+60^{\circ} \mathrm{F}$ (Spans)

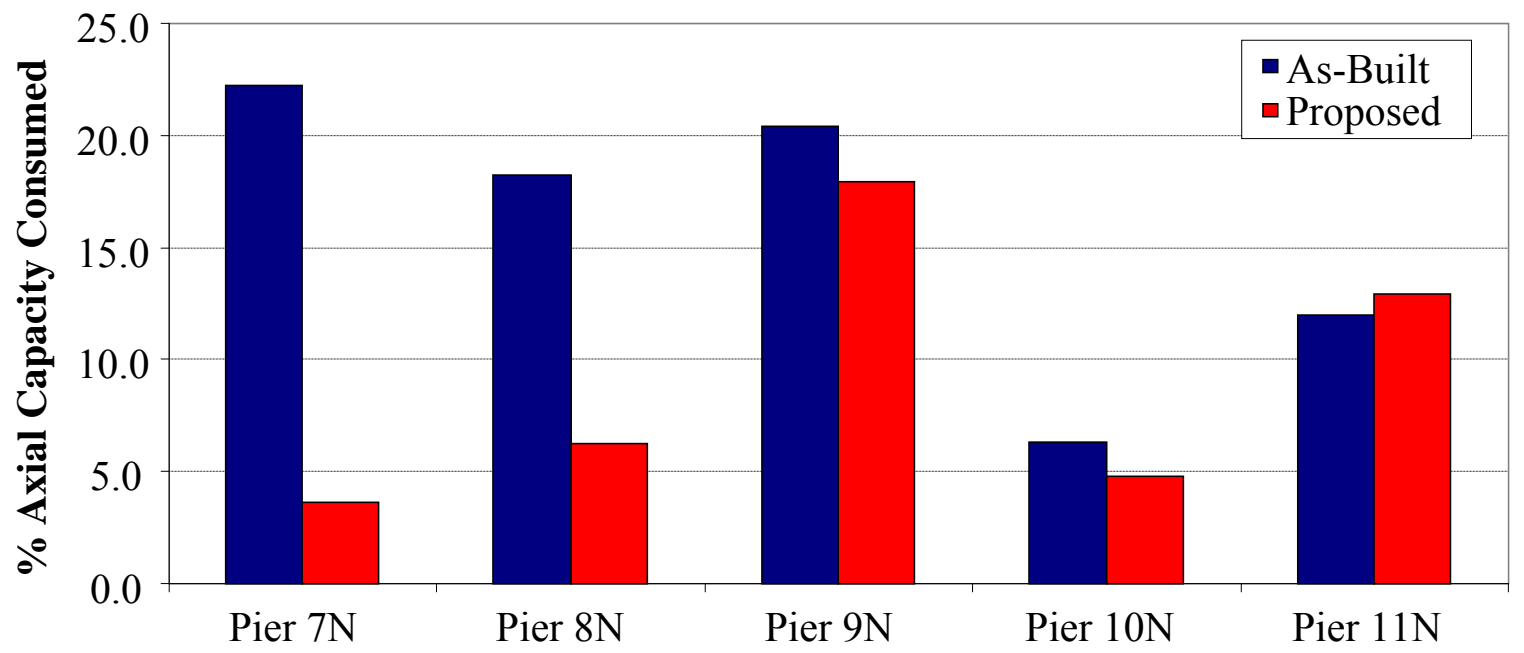

Figure 7.67 Axial Capacity Comparison Under Temp $+60^{\circ} \mathrm{F}$ (Piers) 


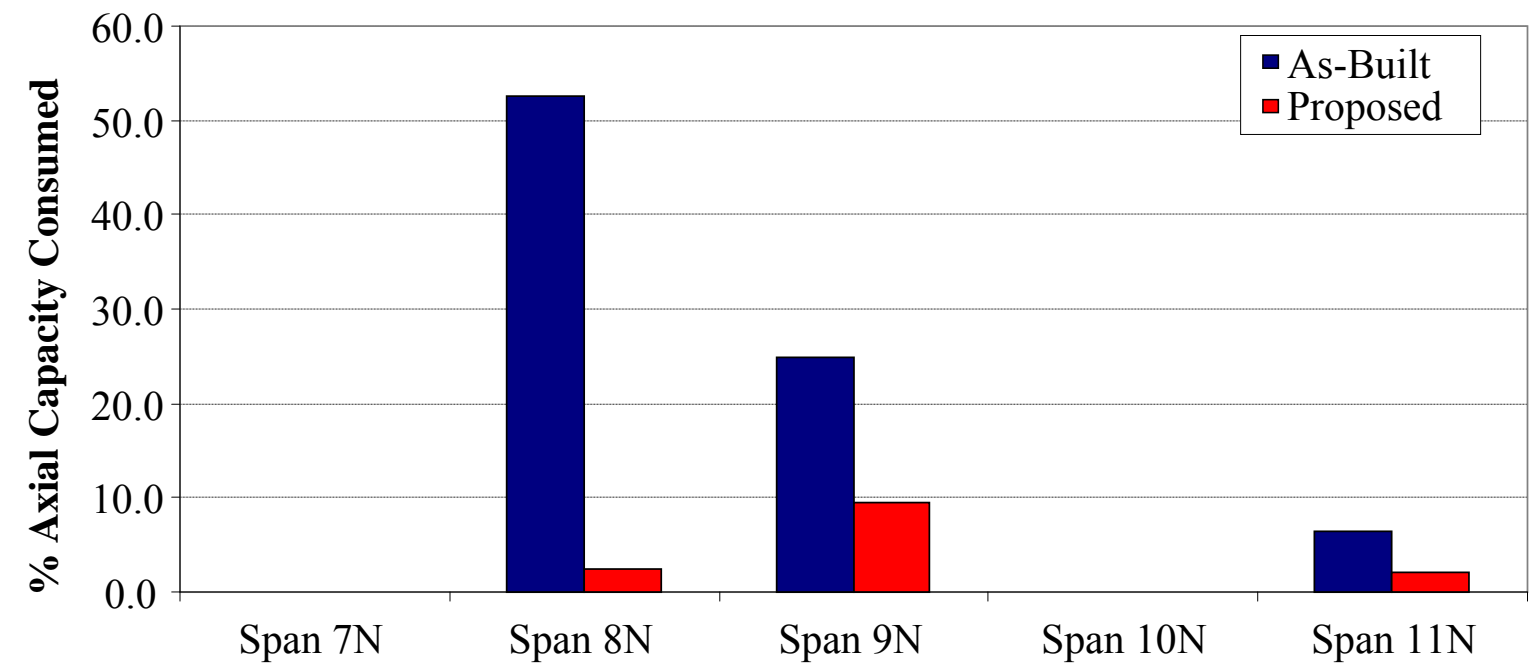

Figure 7.68 Axial Capacity Comparison Under Temp $+90^{\circ} \mathrm{F}$ (Spans)

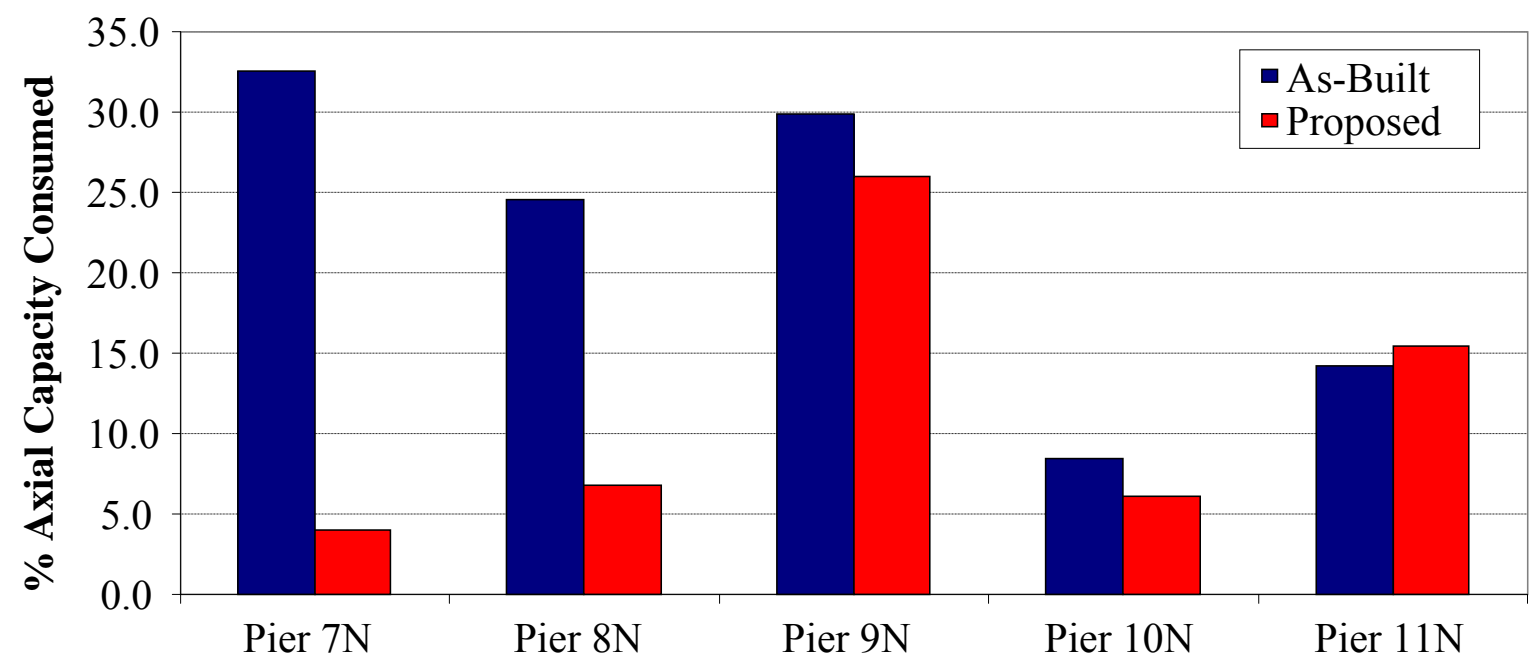

Figure 7.69 Axial Capacity Comparison Under Temp $+90^{\circ} \mathrm{F}$ (Piers) 


\subsection{NEW BEARING CONDITIONS EFFECT ON BRIDGE GIRDER CAPACITY}

Tables 7.1 and 7.2 show the results produced by Equation 5.5 (structural capacity ratio) for the $+60^{\circ} \mathrm{F}$ and $+90^{\circ} \mathrm{F}$ load cases at several cross-sections under the proposed bearing arrangement. Analysis in Tables 7.1 and 7.2 is similar to that performed in Tables 5.1 and 5.2. As seen in Tables 7.1 and 7.2, no cross-section, under either temperature load, is at a stress state exceeding the total capacity of the steel I-girder. The largest percentage of total girder capacity consumed, $53 \%$, occurs at Pier $9 \mathrm{~N}$ under the $+90^{\circ} \mathrm{F}$ load case. This is a substantial improvement over the results produced for the as-built bearing arrangement, where four cross-sections were under stresses that did exceed the total capacity of the steel Igirders.

Table 7.1 Bridge Girder Capacity Analysis (New Bearings, $+60^{\circ} \mathrm{F}$ )

\begin{tabular}{|c|c|c|c|c|c|c|c|}
\hline & $\begin{array}{l}\sigma_{\text {axial }} \\
(p s i)\end{array}$ & $\begin{array}{c}\sigma_{\text {axial allowable }} \\
\text { (psi) }\end{array}$ & $\sigma_{\text {axial/axial allowable }}$ & $\begin{array}{l}\sigma_{\text {bending }} \\
\text { (psi) }\end{array}$ & $\begin{array}{c}\sigma_{\text {bending allowable }} \\
\text { (psi) }\end{array}$ & $\sigma_{\text {bending/bending allowable }}$ & ratio \\
\hline$\overline{S p a n ~ 7 N}$ & & & & 4129 & 50000 & 0.083 & 0.083 \\
\hline Span 8N & 57 & 23516 & 0.002 & 1881 & 57348 & 0.033 & 0.035 \\
\hline Span 9N & 2914 & 39574 & 0.074 & 1851 & 41058 & 0.045 & 0.119 \\
\hline Span $10 \mathrm{~N}$ & & & & 2969 & 50000 & 0.059 & 0.059 \\
\hline Span 11N & & 24911 & & 1506 & 48865 & 0.031 & 0.031 \\
\hline Pier $7 \mathrm{~N}$ & 1611 & 44733 & 0.036 & 6520 & 25488 & 0.256 & 0.292 \\
\hline Pier 8N & 2724 & 43357 & 0.063 & 9324 & 25480 & 0.366 & 0.429 \\
\hline Pier 9N & 7811 & 43453 & 0.180 & 5374 & 25480 & 0.211 & 0.391 \\
\hline Pier 10N & 4162 & 39760 & 0.105 & 3312 & 20964 & 0.158 & 0.263 \\
\hline Pier $11 \mathrm{~N}$ & 4807 & 37225 & 0.129 & 3035 & 25488 & 0.119 & 0.248 \\
\hline
\end{tabular}

Table 7.2 Bridge Girder Capacity Analysis (New Bearings, $+90^{\circ} \mathrm{F}$ )

\begin{tabular}{|c|c|c|c|c|c|c|c|}
\hline & $\begin{array}{l}\sigma_{\text {axial }} \\
\text { (psi) }\end{array}$ & $\begin{array}{l}\sigma_{\text {axial allowable }} \\
\text { (psi) }\end{array}$ & $\sigma_{\text {axial/axial allowable }}$ & $\begin{array}{c}\sigma_{\text {bending }} \\
\text { (psi) }\end{array}$ & $\begin{array}{l}\sigma_{\text {bending allowable }} \\
\text { (psi) }\end{array}$ & $\sigma_{\text {bending/bending allowable }}$ & ratio \\
\hline Span 7N & & & & 4107 & 50000 & 0.082 & 0.082 \\
\hline Span 8N & 586 & 23516 & 0.025 & 1725 & 32998 & 0.052 & 0.077 \\
\hline Span 9N & 3772 & 39574 & 0.095 & 3628 & 27968 & 0.130 & 0.225 \\
\hline Span $10 \mathrm{~N}$ & & & & 2922 & 50000 & 0.058 & 0.058 \\
\hline Span 11N & 498 & 24911 & 0.020 & 1380 & 25478 & 0.054 & 0.074 \\
\hline Pier 7N & 1806 & 44733 & 0.040 & 10380 & 25488 & 0.407 & 0.448 \\
\hline Pier 8N & 2953 & 43357 & 0.068 & 9438 & 23488 & 0.402 & 0.470 \\
\hline Pier 9N & 11308 & 43453 & 0.260 & 6932 & 25480 & 0.272 & 0.532 \\
\hline Pier $10 \mathrm{~N}$ & 2435 & 39760 & 0.061 & 5500 & 20964 & 0.262 & 0.324 \\
\hline Pier 11N & 5769 & 37225 & 0.155 & 2756 & 25488 & 0.108 & 0.263 \\
\hline
\end{tabular}


Figures 7.70-7.73 compare the total capacity ratios under each bearing arrangement for the two temperature load cases presented previously. These figures show the effect that each bearing arrangement has on the load-carrying capability of the steel I-girders. The lower the capacity ratio, the further the girder may be stressed in addition to its current state. When the fixed bearings in the as-built arrangement are replaced with expansion bearings, thermal stresses are significantly reduced, resulting in a much lower state of stress in the girders when subjected to uniform temperature loads. Thus, a larger portion of bride capacity is available for live load force effects.

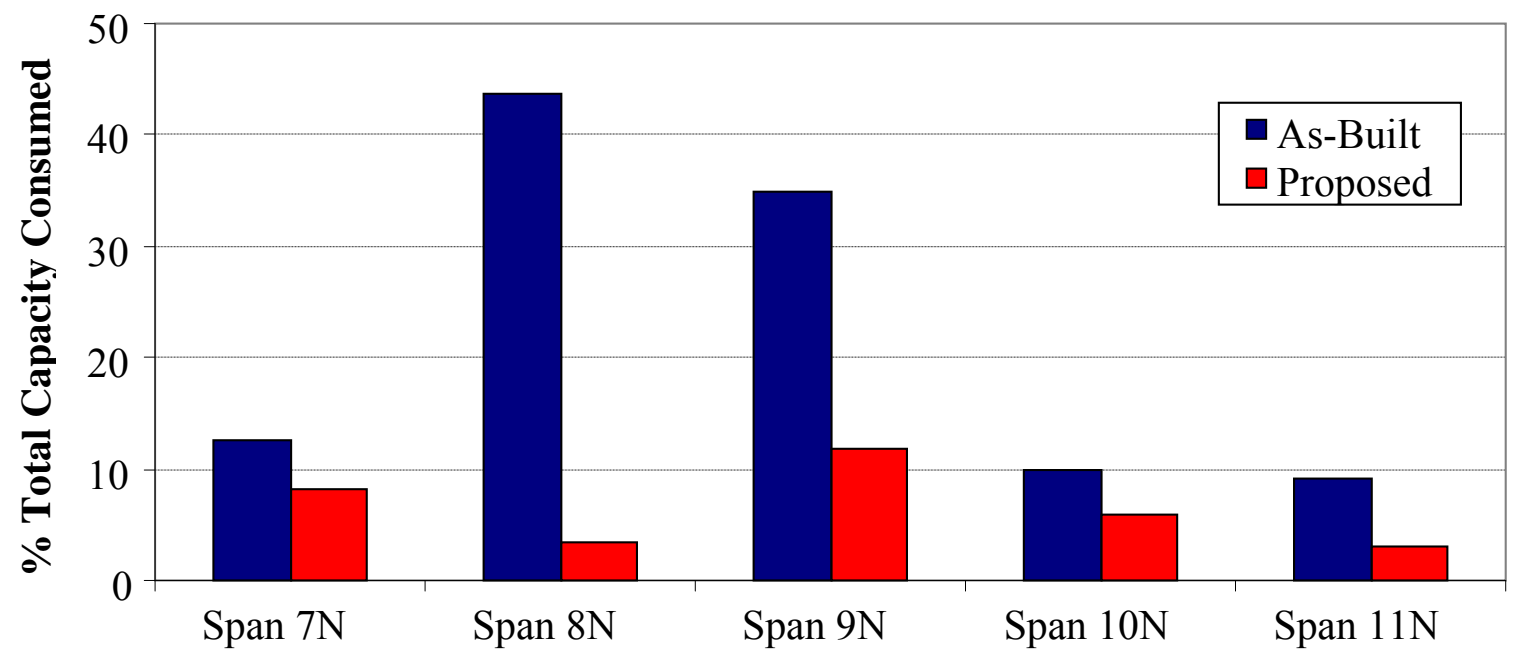

Figure 7.70 As-Built - New Bearings, Total Capacity Comparison (Temp $+60^{\circ} \mathrm{F}$, Spans)

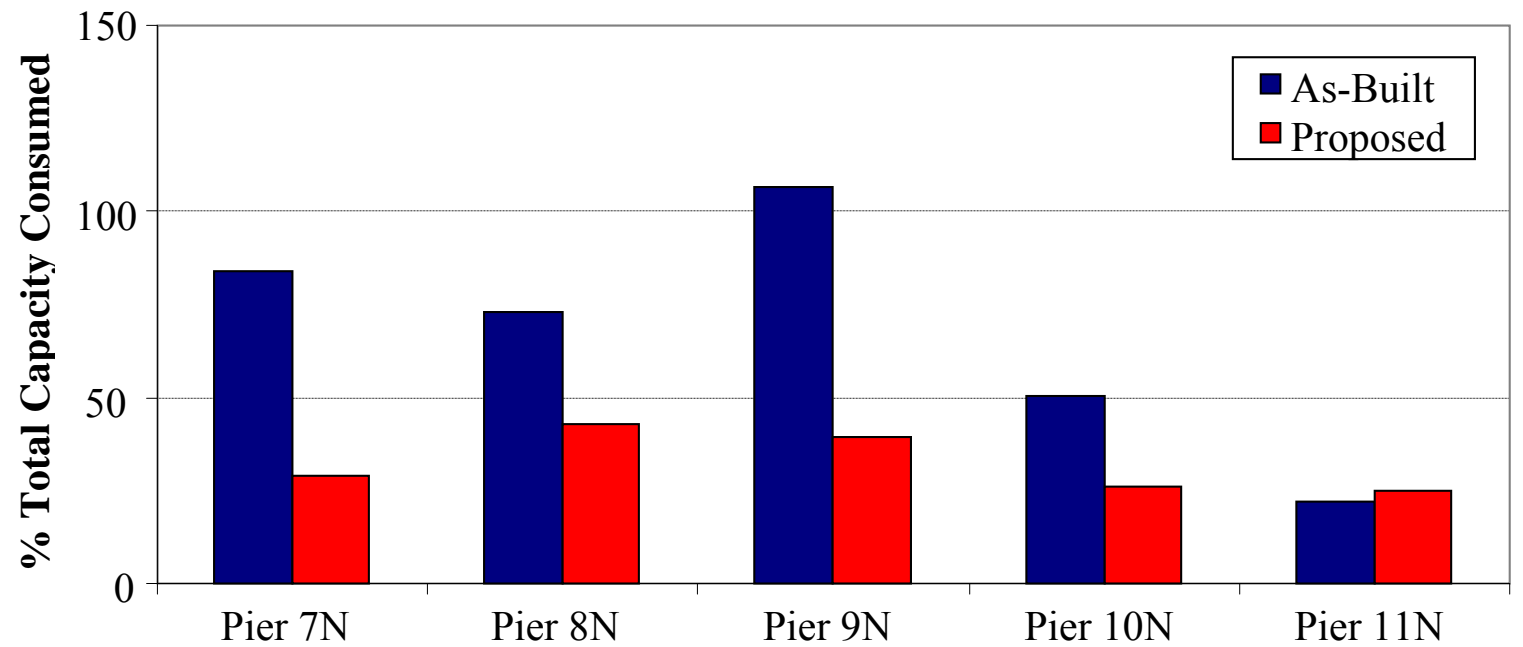

Figure 7.71 As-Built - New Bearings, Total Capacity Comparison (Temp $+60^{\circ} \mathrm{F}$, Piers) 


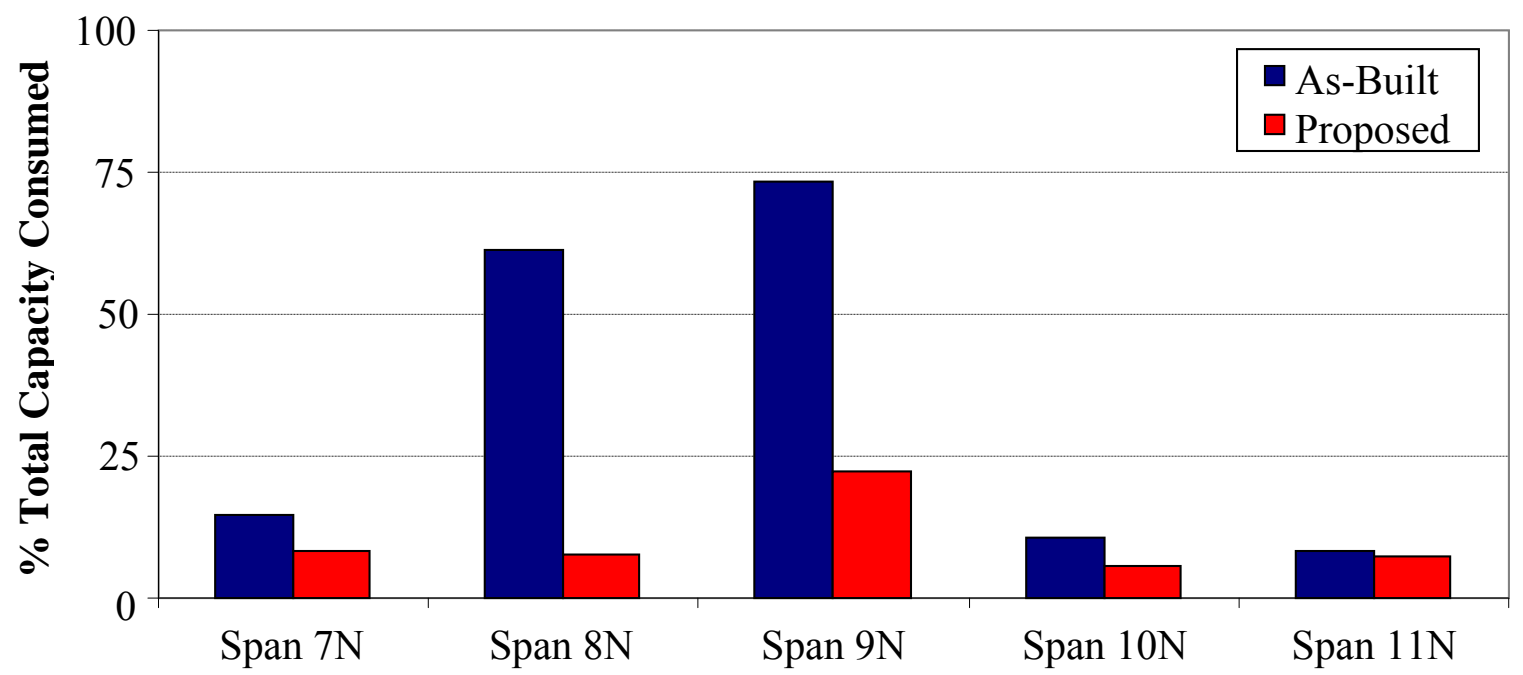

Figure 7.72 As-Built - New Bearings, Total Capacity Comparison (Temp $+90^{\circ} \mathrm{F}$, Spans)

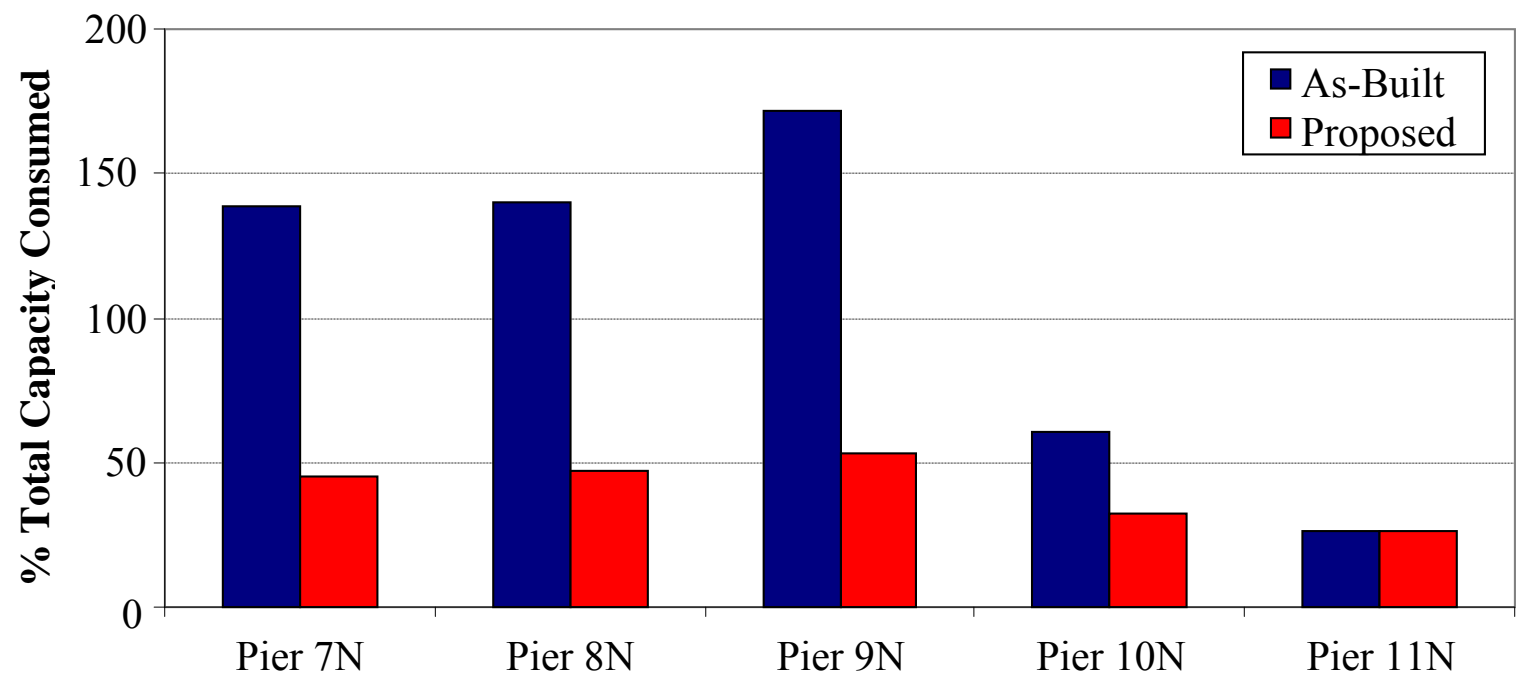

Figure 7.73 As-Built - New Bearings, Total Capacity Comparison (Temp $+90^{\circ} \mathrm{F}$, Piers)

The largest reductions in the capacity ratio occur in Spans $8 \mathrm{~N}-9 \mathrm{~N}$, and at Piers $7 \mathrm{~N}-$ 9N. In Spans $7 \mathrm{~N}-8 \mathrm{~N}$, and at Piers $7 \mathrm{~N}-8 \mathrm{~N}$, decreases in axial stress are mainly responsible for the decrease in the total capacity ratio, where as at Pier 9N, a decrease in bending stresses results in the significant reduction of the total ratio. It is very evident that removing the fixed bearings at Piers $7 \mathrm{~N}$ and $8 \mathrm{~N}$ results in drastic reductions in thermal stress, mainly axial stress, when compared to the as-built bearing arrangement. 


\subsection{DISCUSSION AND CONCLUSIONS}

In this chapter, a new bearing arrangement was designed and implemented into the FE bridge model to study the response of the bridge due to thermal loading. This new bearing plan called for the removal of numerous fixed bearings. The fixed bearing devices at Piers $7 \mathrm{~N}$ and $8 \mathrm{~N}$ were replaced with expansion bearings, leaving Pier $9 \mathrm{~N}$ as the only location where fixed bearings where utilized.

It was found that the new bearing arrangement, when compared to the as-built arrangement, results in a much lower overall state of stress in the bridge superstructure when due to uniform temperature loads. Longitudinal stresses throughout the bridge were reduced dramatically with the implementation of the new bearing plan. Most important, the magnitude of compressive axial stress diminished greatly, as evident when comparing the percentage of axial capacity consumed and the bending and axial stress profiles between the two bearing plans.

Under the new bearing arrangement, a lower percentage of total girder capacity is consumed by thermal stresses, therefore improving girder stability when compared to results obtained under the original bearing plan. The significant reduction in axial compressive stress makes available a higher percentage of girder capacity to resist flexural forces. However, the FE model shows that even with a minimal number of fixed bearings, thermal stresses still develop to some degree throughout the structure. This occurs even though bearing alignment suggestions from literature and AASHTO (2003) were strictly adhered to. Fully mitigating thermal stresses in a horizontally curved steel girder bridge may be an impossible task. Therefore, a certain level of axial stress due to thermal loading should be accounted for during the bridge design process. 


\section{CHAPTER EIGHT}

\section{EFFECT PIER FLEXIBILITY ON WEB DISTORTIONS AND THERMAL STRESSES}

\subsection{INTRODUCTION}

After analyzing the results from the FE bridge model, it was deemed necessary to incorporate the concrete piers at Piers $6 \mathrm{~N}-11 \mathrm{~N}$ in order to determine what role pier flexibility may play with regard to web distortion and thermal stresses. In the original FE model, the concrete piers were not modeled, and boundary conditions were applied directly to the bottom flange where appropriate. This modeling strategy assumes infinitely rigid substructure elements (piers and bearings) and may produce thermal stresses significantly larger than what may actually develop in the structure. The new FE model eliminates this rigidity by including bearing and pier flexibility, while implementing the original bearing arrangement.

\subsection{PIER AND BEARING MODELING}

The concrete pier caps for Piers $6 \mathrm{~N}-11 \mathrm{~N}$ were modeled as 4-noded shell elements, as shown in Figures 8.1-8.3, with elastic material properties representing reinforced concrete. Element thickness at Pier $6 \mathrm{~N}$ is 120 in., while Piers $7 \mathrm{~N}-11 \mathrm{~N}$ have pier cap thicknesses of 90 in., as stated in the bridge design plans. Element mesh size for the majority of the pier caps

is 2 in. Beam elements were selected to model the concrete columns, as shown in Figure 8.1. Appropriate cross-sectional properties were defined using the design plans, and a similar reinforced concrete material model was applied.

Linear spring elements were selected to model the bearing devices. Each node along the bottom flange at pier centerline is connected to a corresponding node on the pier cap 
through linear spring elements. Each degree of freedom, three translational and three rotational, is represented by a separate spring element having a very large stiffness coefficient. A fixed bearing consists of six spring elements per node, while guided bearing and free bearings would consist of five and four spring elements per node respectively. Spring elements, shown in Figure 8.4 (highlighted in green), were chosen because their stiffness can be adjusted to represent different levels of bearing flexibility. For example, actual fully fixed bridge bearings do permit small magnitudes of translation. This behavior was ignored in the original FE model. The stiffness of the spring elements can be adjusted to accurately model this small amount of "play" in the fixed bearing if needed. Figures 8.1-8.2 show the FE model, Unit 2, with the addition of the piers. Figures 8.3-8.4 illustrate the mesh applied to the concrete pier cap shell elements.

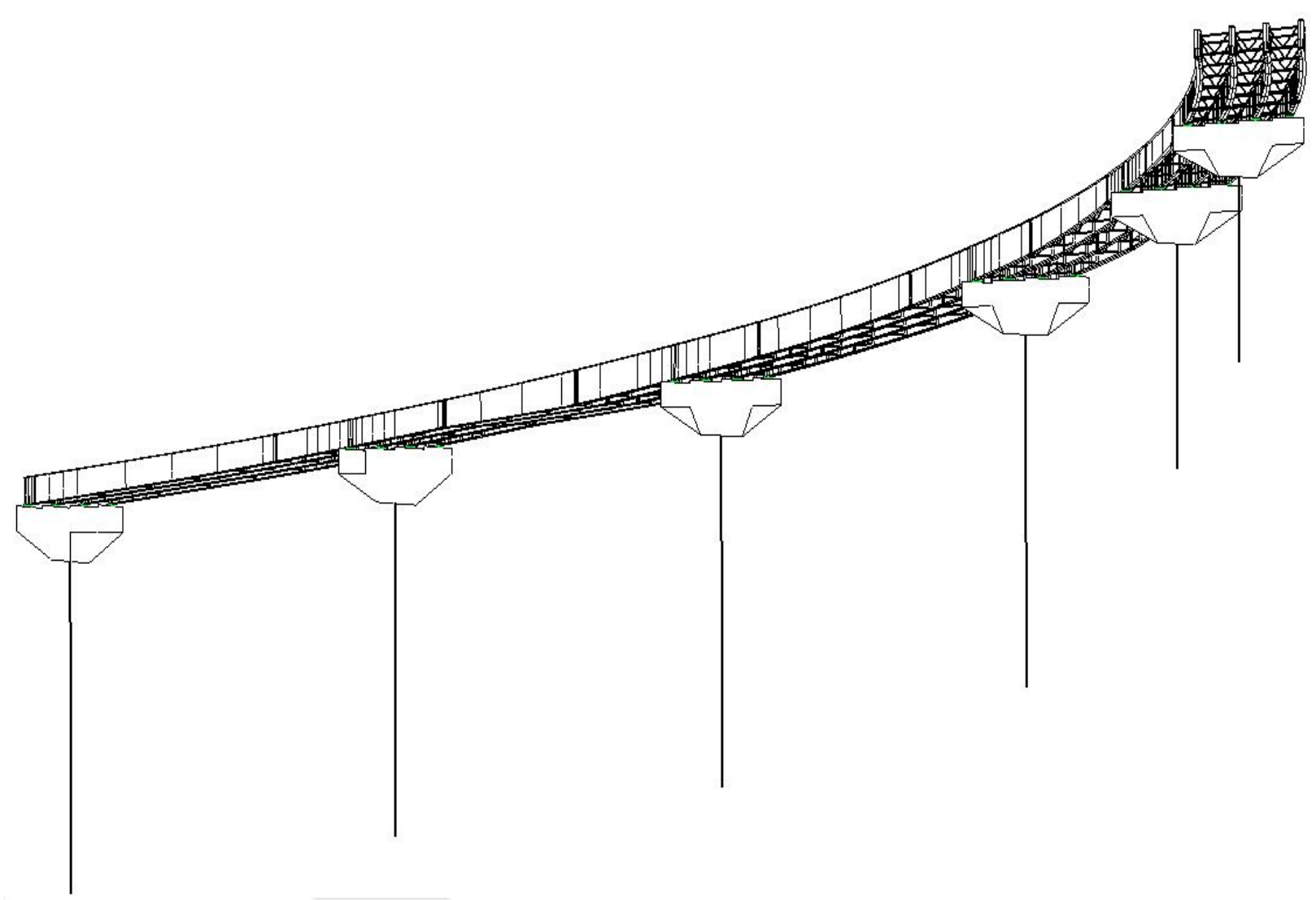

Figure 8.1 Unit 2 FE Model with Piers (iso-view 1) 


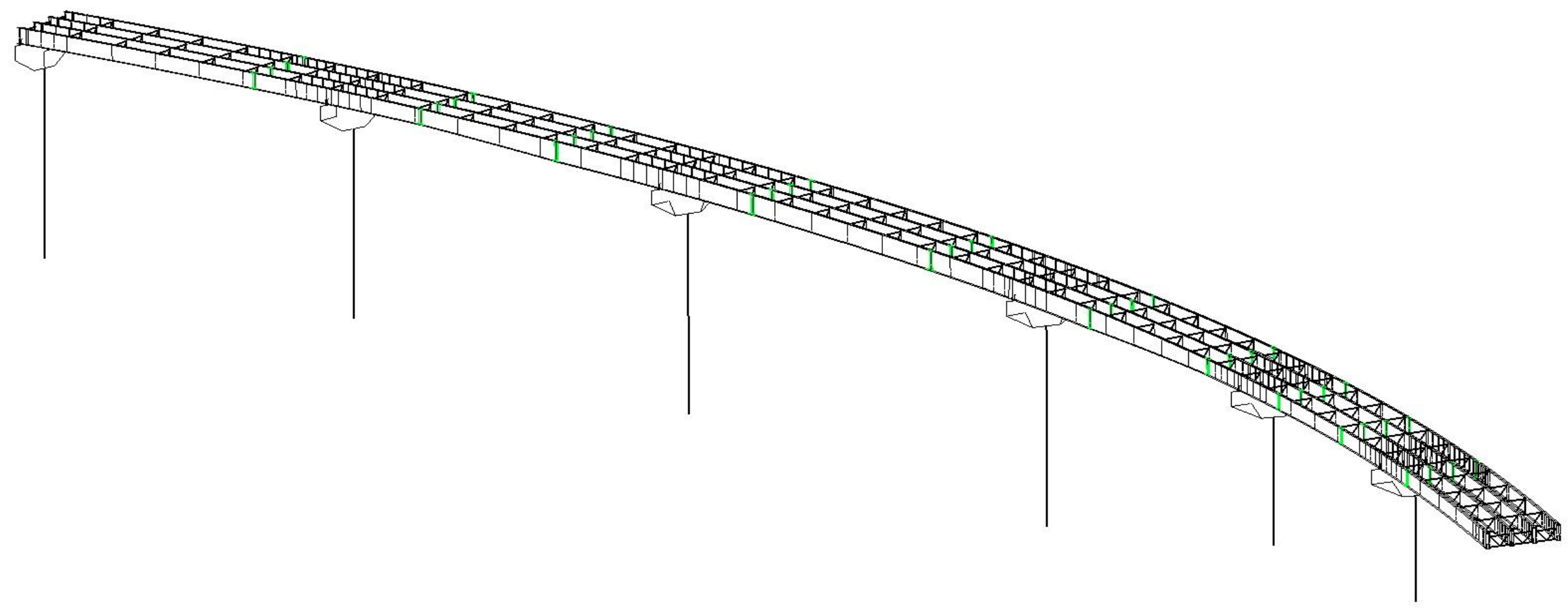

Figure 8.2 Unit 2 FE Model with Piers (iso-view 2) 


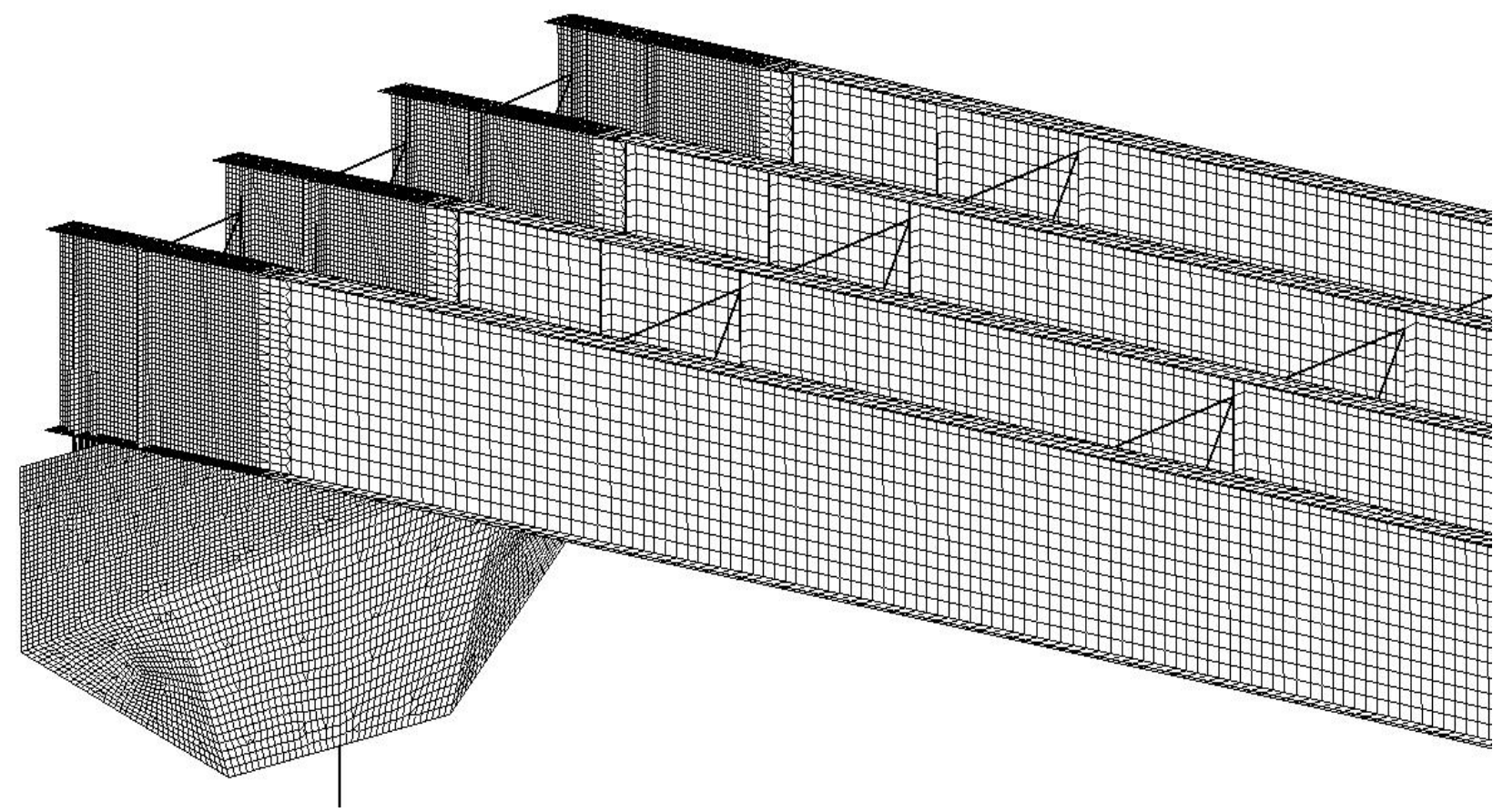

Figure 8.3 Pier 6N, Pier Cap Mesh

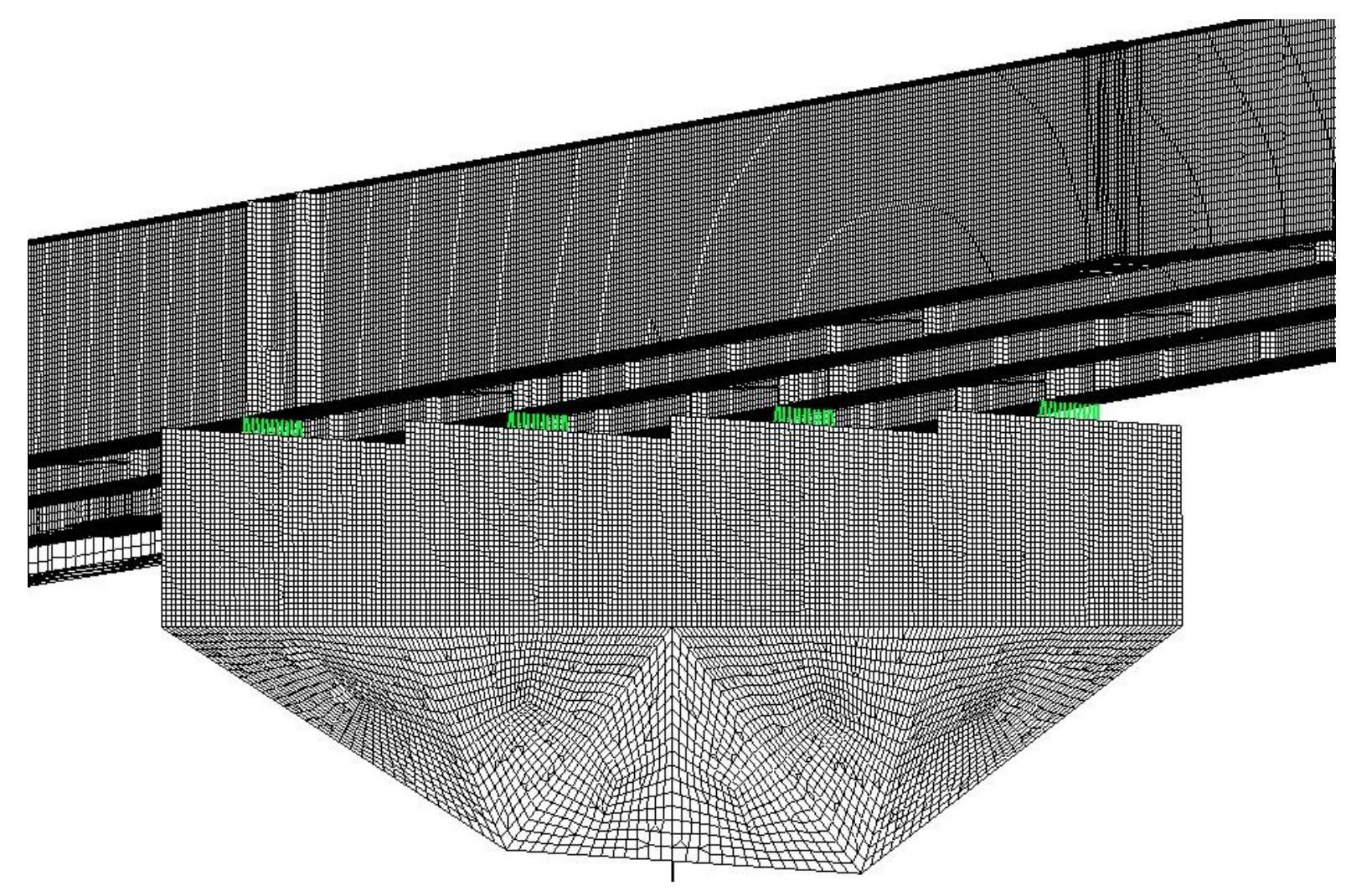

Figure 8.4 Pier 7N, Pier Cap Mesh and Spring Elements 


\subsection{EFFECT OF PIER FLEXIBILITY ON WEB DISTORTIONS}

Figures 8.5-8.22 present horizontal profile comparisons between the original FE model, and the new model that includes the concrete piers. Web distortions in Girder 4N under bridge self-weight, $+60^{\circ} \mathrm{F}$ and $+90^{\circ} \mathrm{F}$ load cases were investigated. Figures 8.5-8.10 show profiles under bridge self-weight.

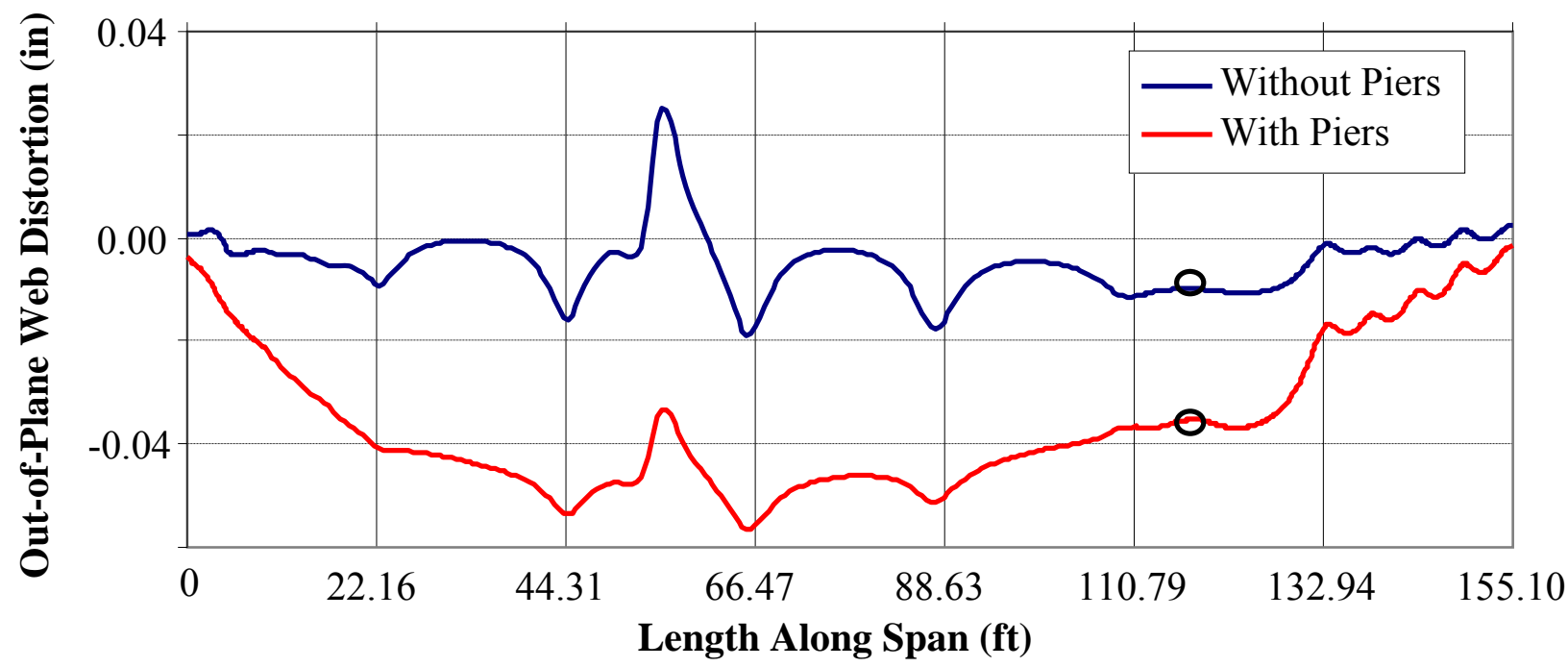

Figure 8.5 Span 7N, Long. Profile Comparison with Addition of Piers (Self-Weight)

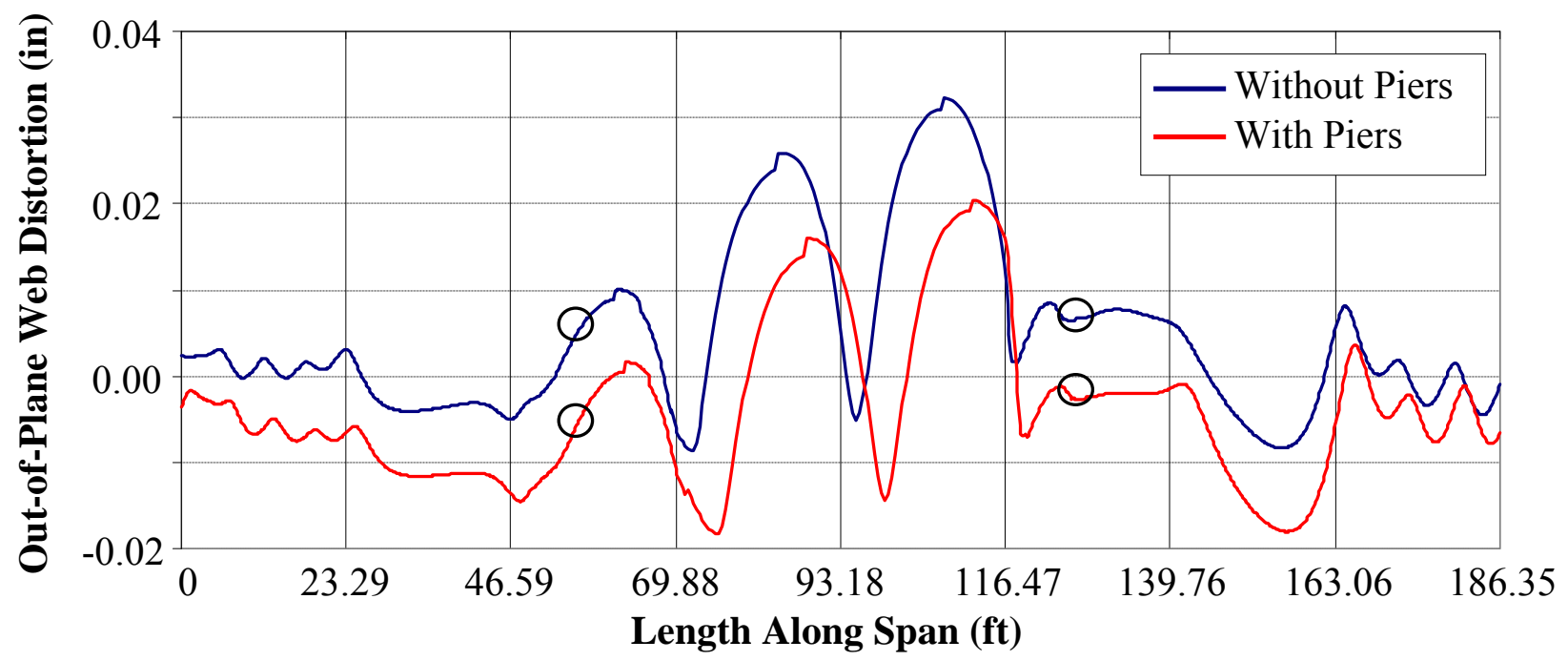

Figure 8.6 Span 8N, Long. Profile Comparison with Addition of Piers (Self-Weight) 


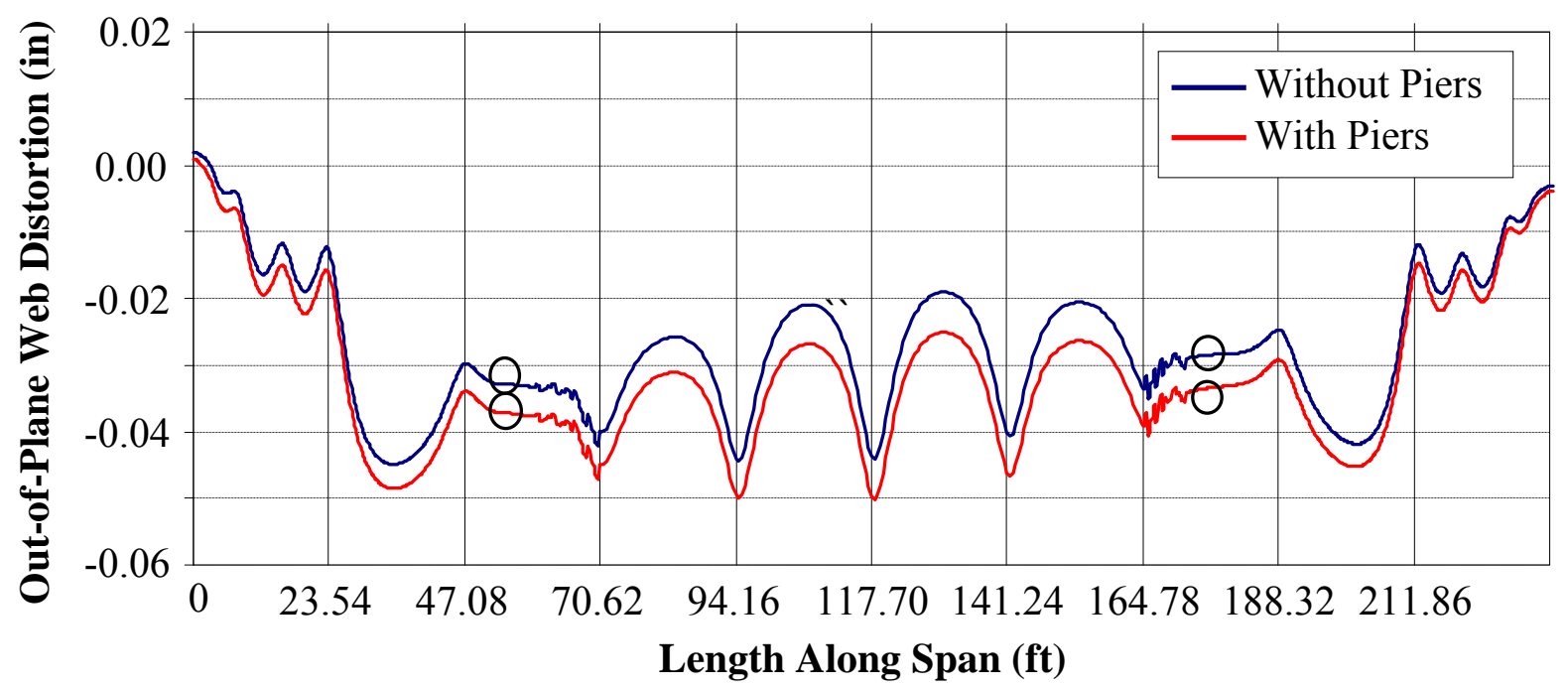

Figure 8.7 Span 9N, Long. Profile Comparison with Addition of Piers (Self-Weight)

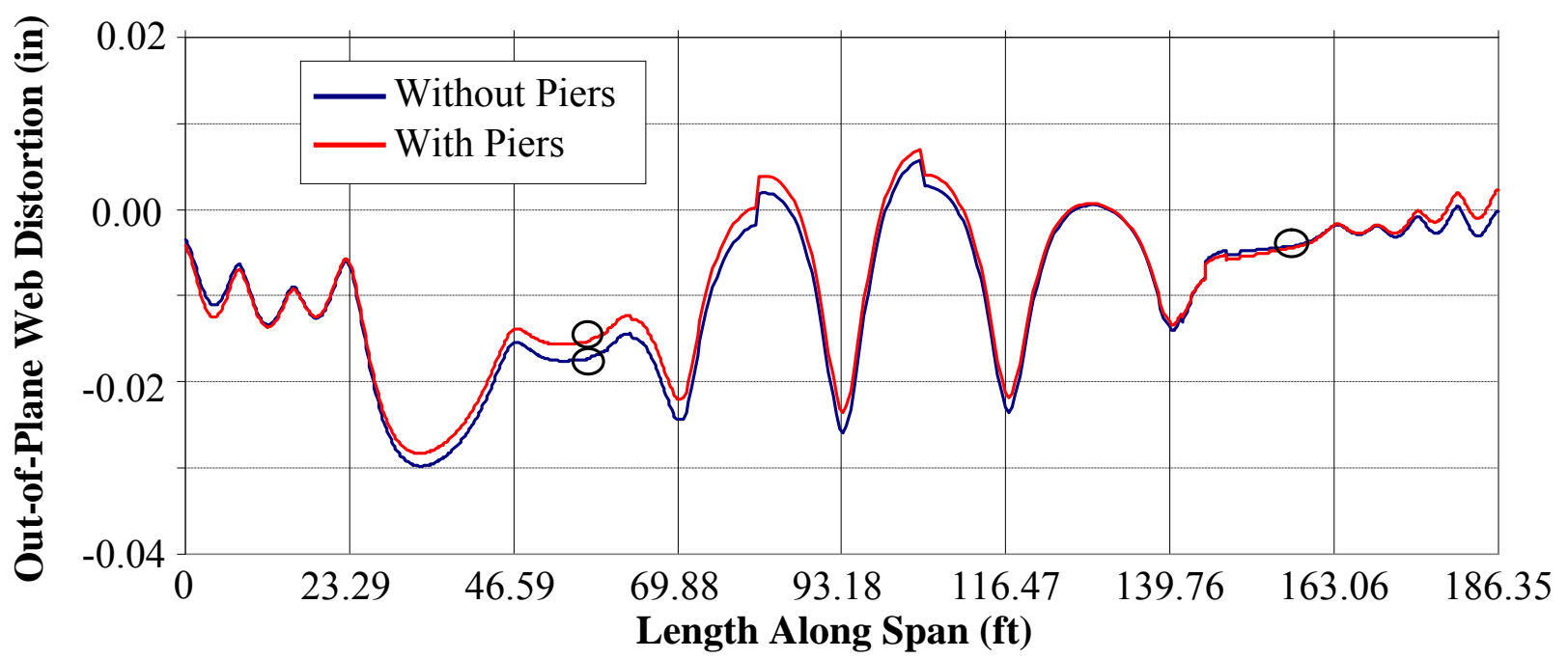

Figure 8.8 Span 10N, Long. Profile Comparison with Addition of Piers (Self-Weight)

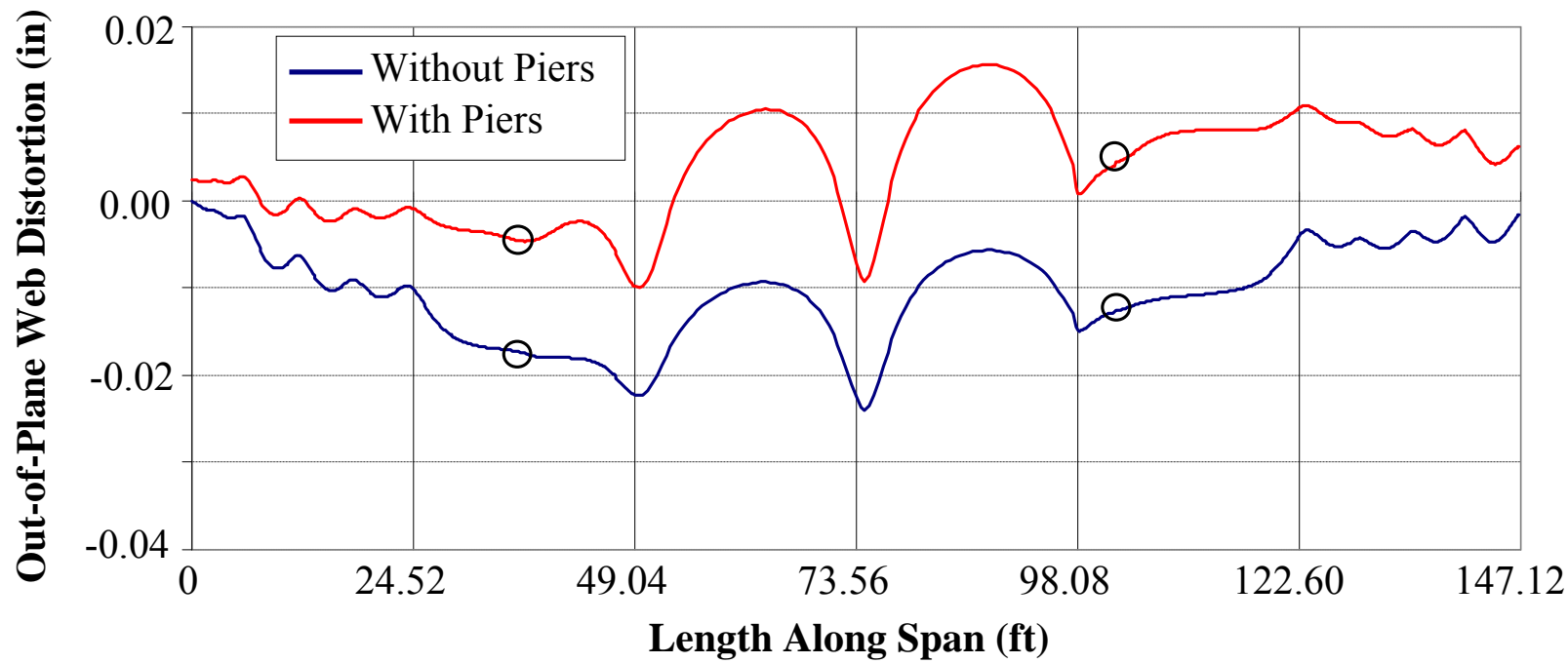

Figure 8.9 Span 11N, Long. Profile Comparison with Addition of Piers (Self-Weight) 


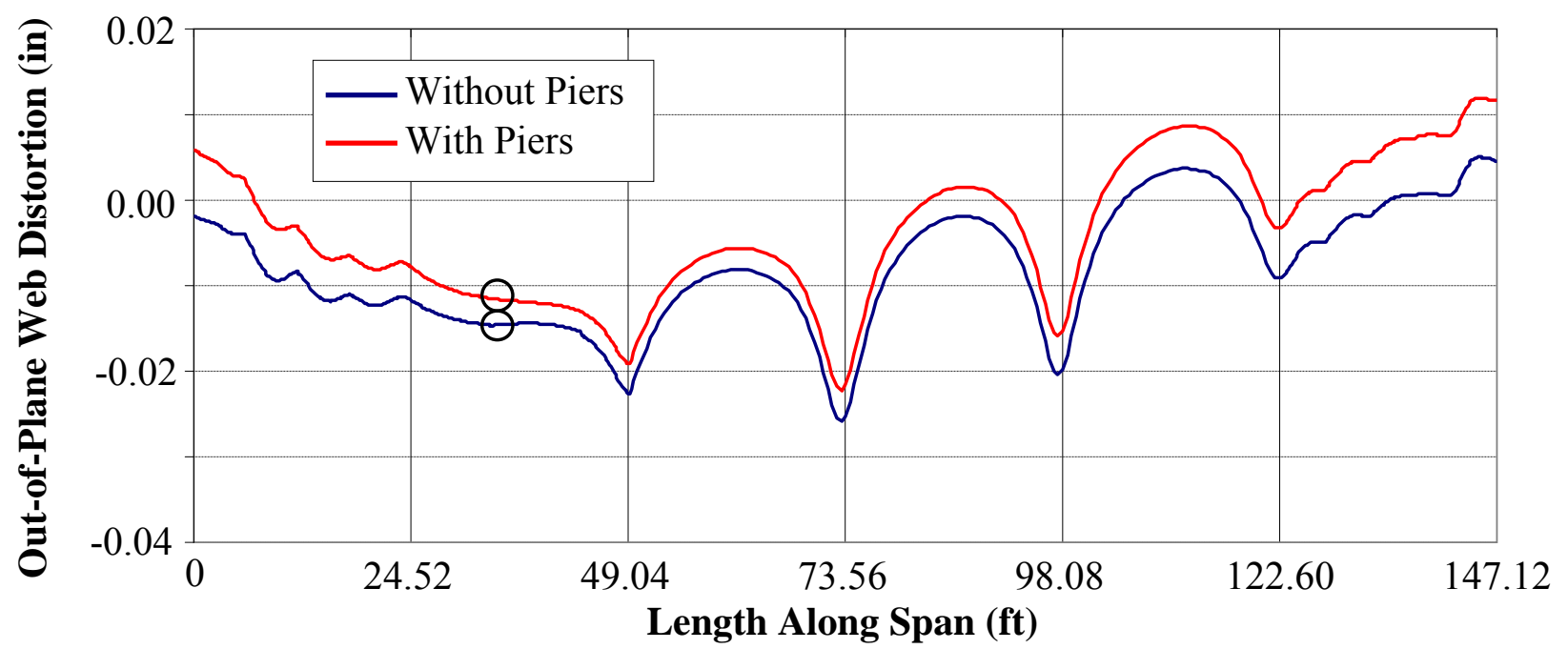

Figure 8.10 Span 12N, Long. Profile Comparison with Addition of Piers (Self-Weight)

Spans $7 \mathrm{~N}$ and $11 \mathrm{~N}$ are most affected by the addition of the piers when subjected to only bridge self-weight loads. Maximum out-of-plane web distortion in Span $7 \mathrm{~N}$ increases from 0.025 in. to $0.055 \mathrm{in}$. at roughly the same location in the span. In Span 11N, maximum web distortion decreases from 0.023 in. to 0.015 in. When compared to the original FE model, the addition the piers does not have a great affect in the other spans. The profile comparisons under the temperature load cases $\left(+60^{\circ} \mathrm{F}\right.$ and $\left.+90^{\circ} \mathrm{F}\right)$ are shown in Figures 8.118.22 .

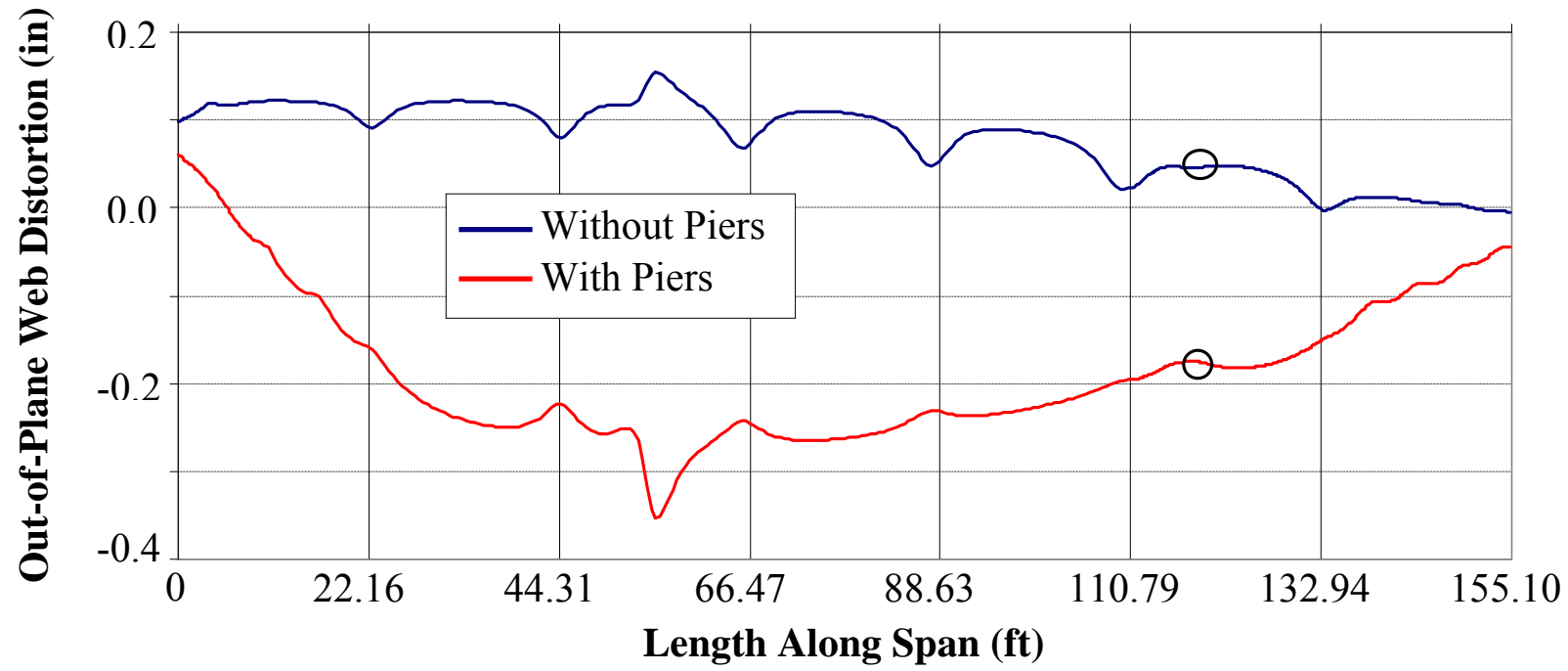

Figure 8.11 Span 7N, Long. Profile Comparison with Addition of Piers $\left(\mathrm{Temp}+60^{\circ} \mathrm{F}\right)$ 


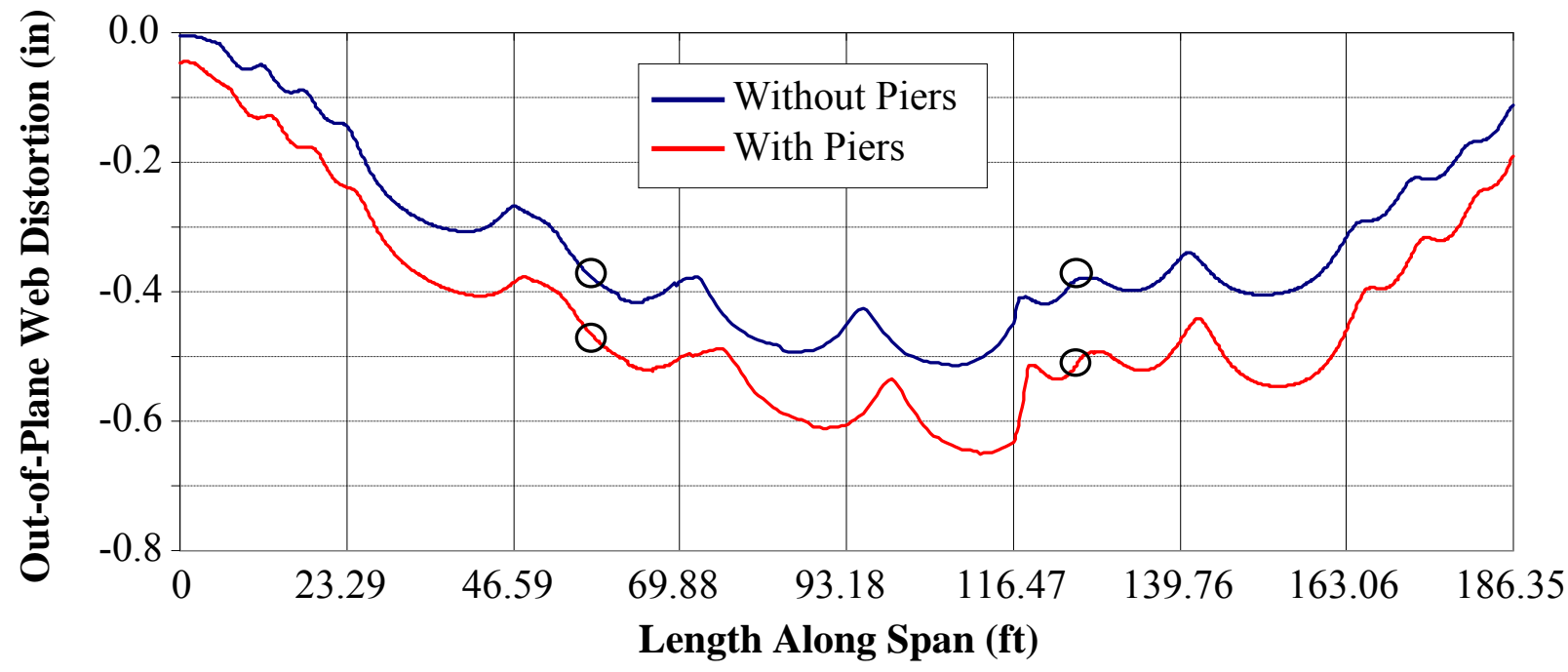

Figure 8.12 Span $8 \mathrm{~N}$, Long. Profile Comparison with Addition of Piers (Temp $\left.+60^{\circ} \mathrm{F}\right)$

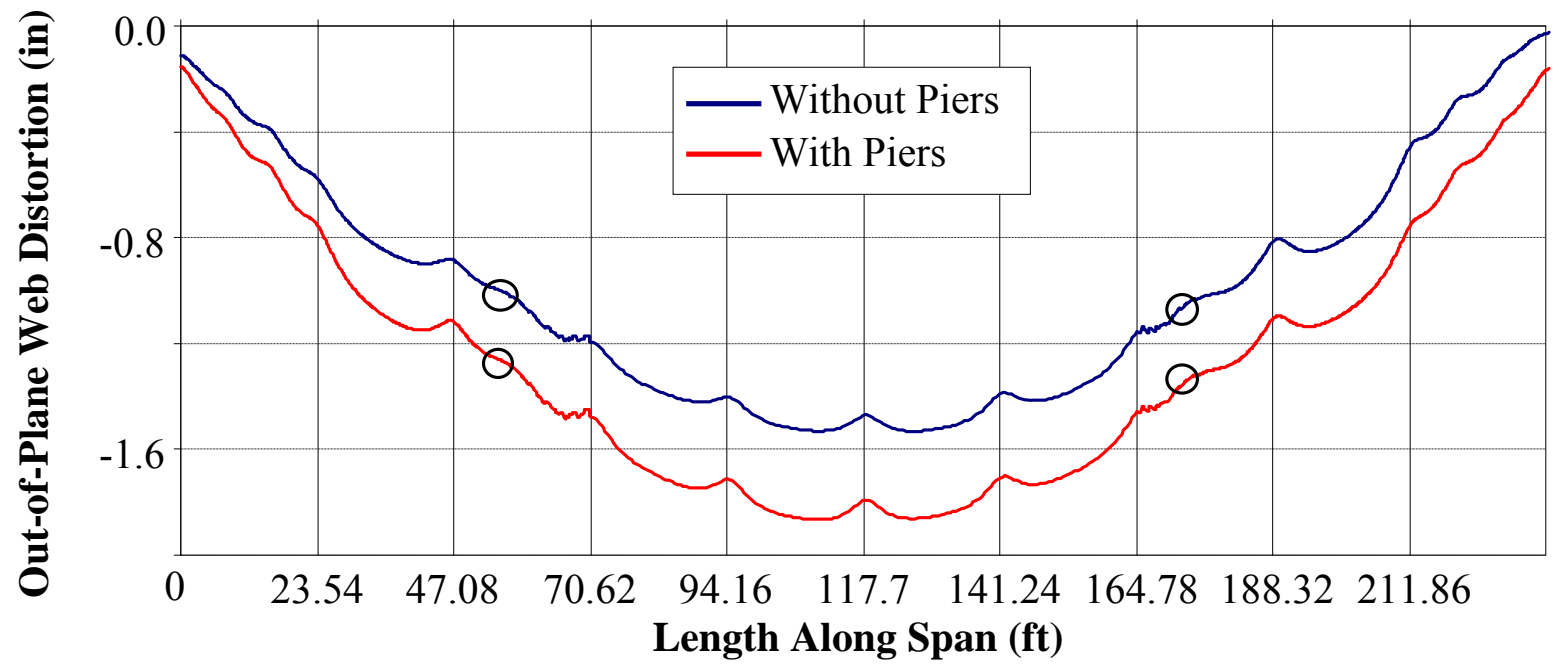

Figure 8.13 Span 9N, Long. Profile Comparison with Addition of Piers $\left(\mathrm{Temp}+60^{\circ} \mathrm{F}\right)$

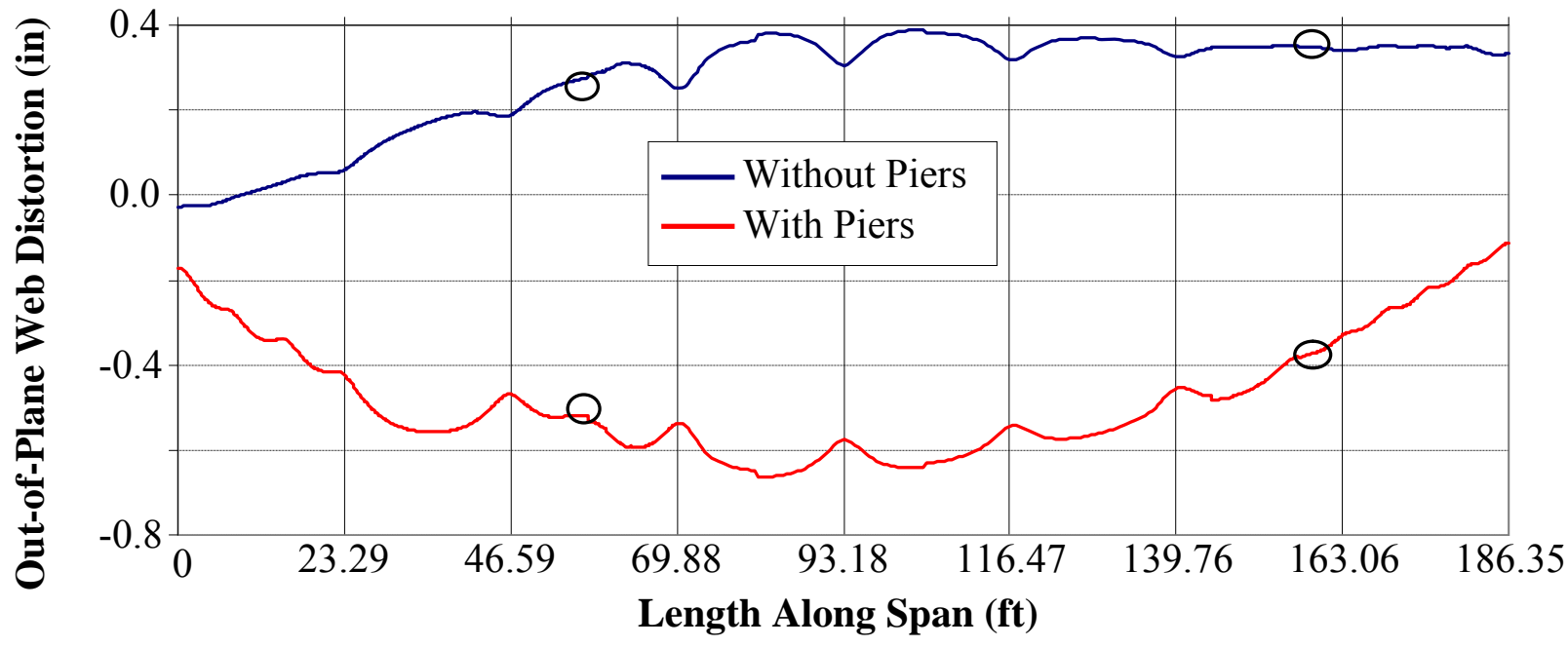

Figure 8.14 Span 10N, Long. Profile Comparison with Addition of Piers (Temp $\left.+60^{\circ} \mathrm{F}\right)$ 


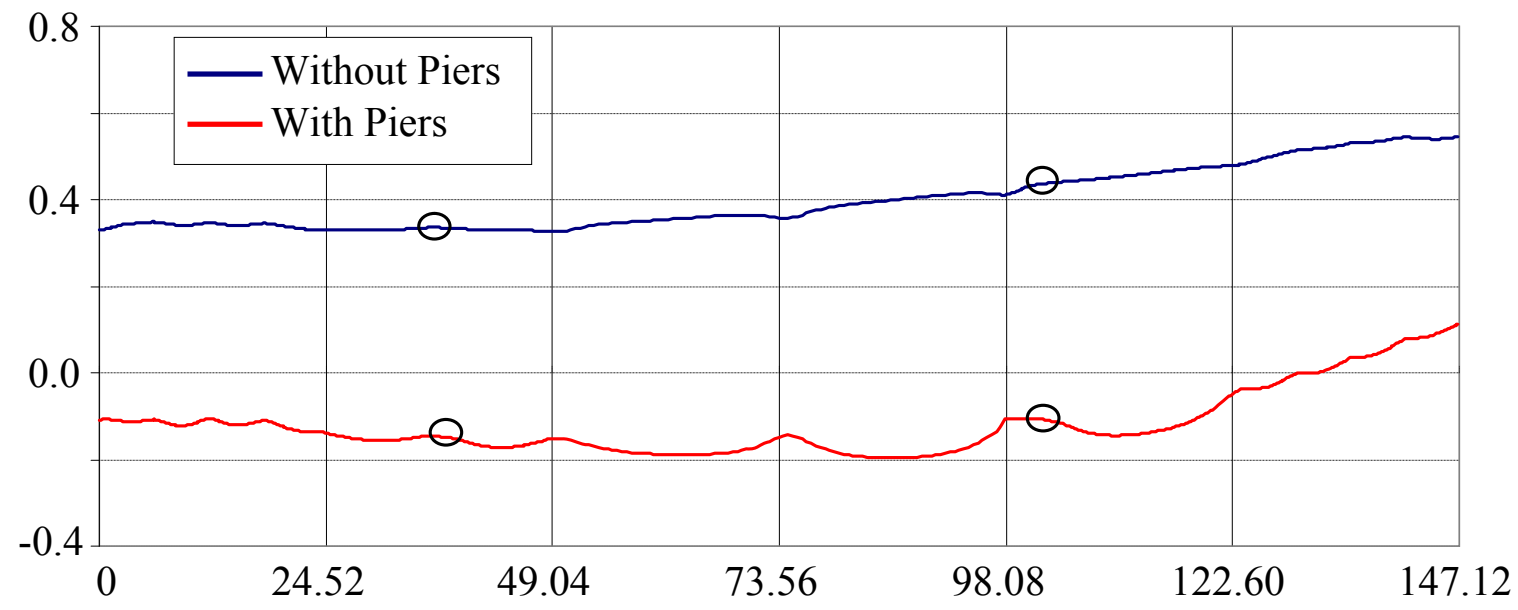

Length Along Span (ft)

Figure 8.15 Span 11N, Long. Profile Comparison with Addition of Piers (Temp $\left.+60^{\circ} \mathrm{F}\right)$

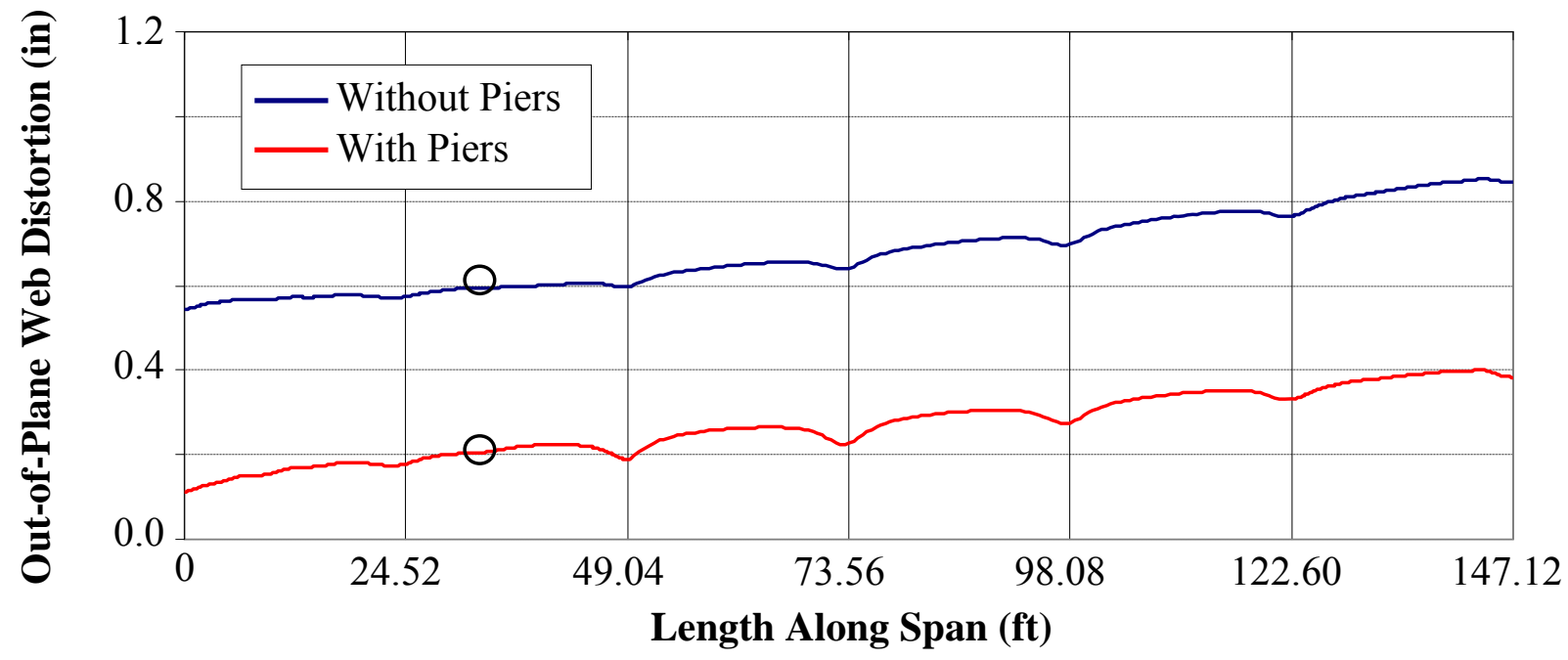

Figure 8.16 Span 12N, Long. Profile Comparison with Addition of Piers $\left(\mathrm{Temp}+60^{\circ} \mathrm{F}\right)$

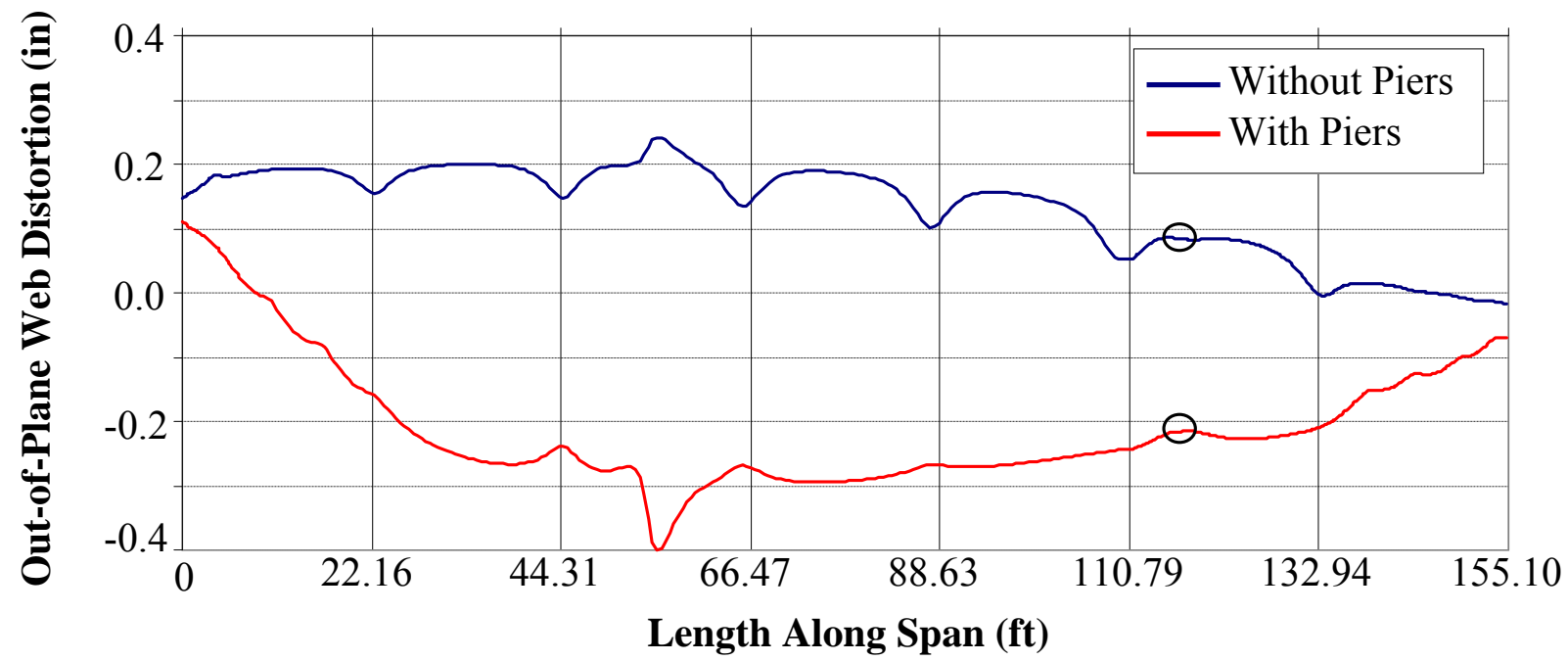

Figure 8.17 Span $7 \mathrm{~N}$, Long. Profile Comparison with Addition of Piers (Temp $\left.+90^{\circ} \mathrm{F}\right)$ 


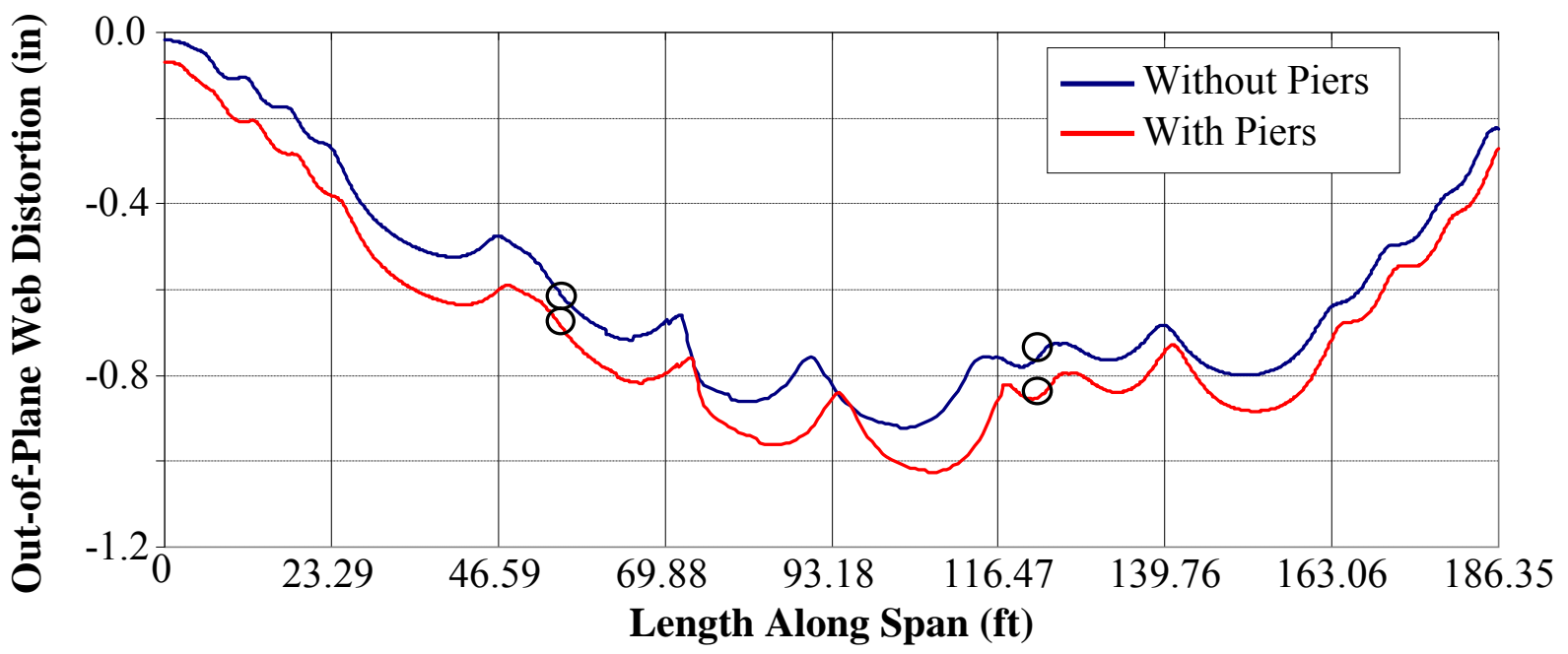

Figure 8.18 Span $8 \mathrm{~N}$, Long. Profile Comparison with Addition of Piers $\left(\mathrm{Temp}+90^{\circ} \mathrm{F}\right)$

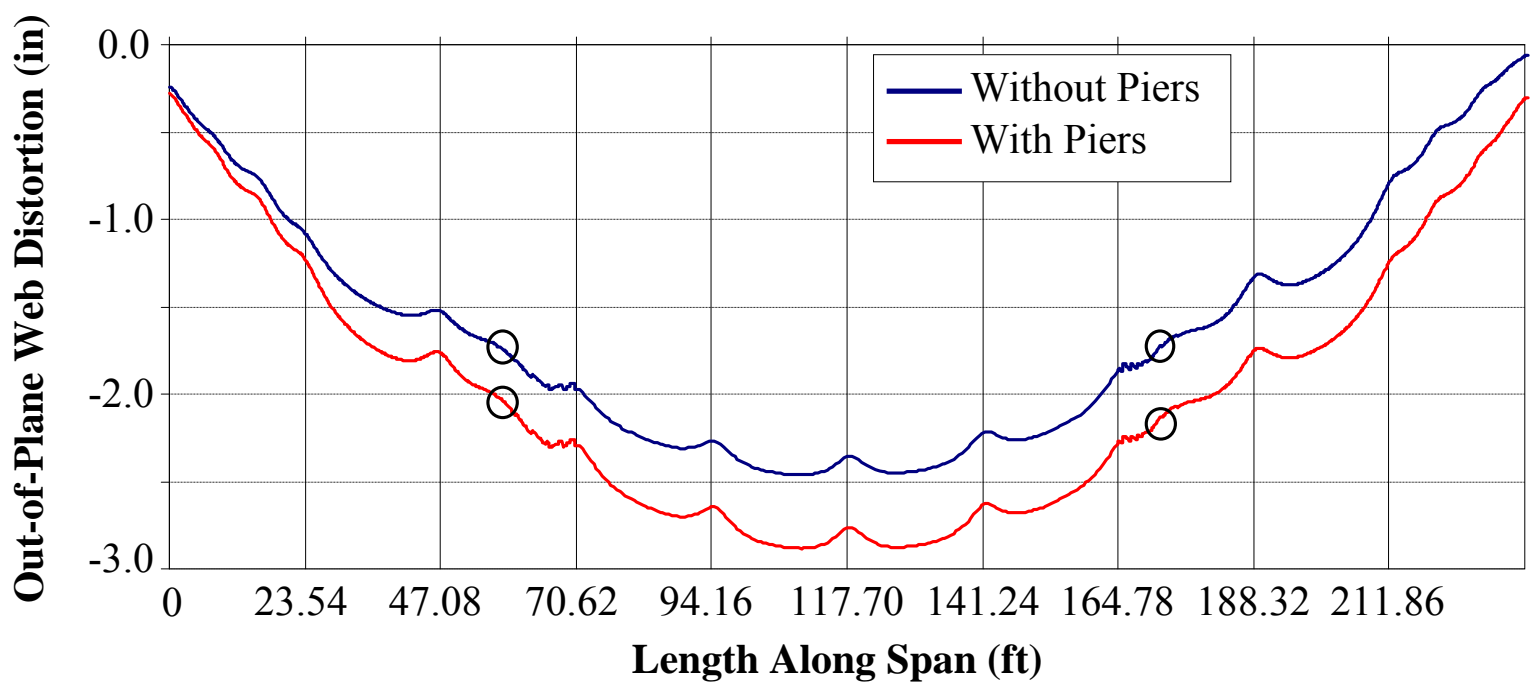

Figure 8.19 Span 9N, Long. Profile Comparison with Addition of Piers (Temp $\left.+90^{\circ} \mathrm{F}\right)$

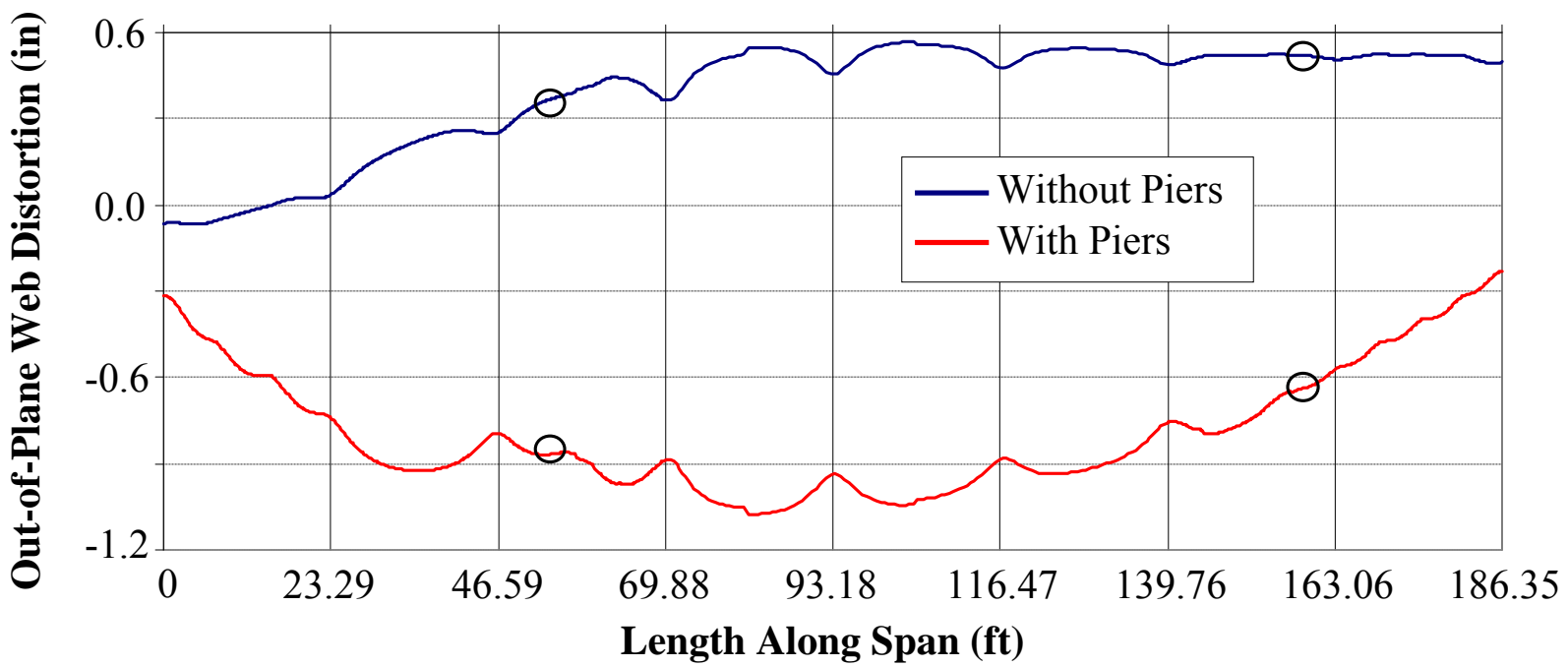

Figure 8.20 Span 10N, Long. Profile Comparison with Addition of Piers $\left(\mathrm{Temp}+90^{\circ} \mathrm{F}\right)$ 


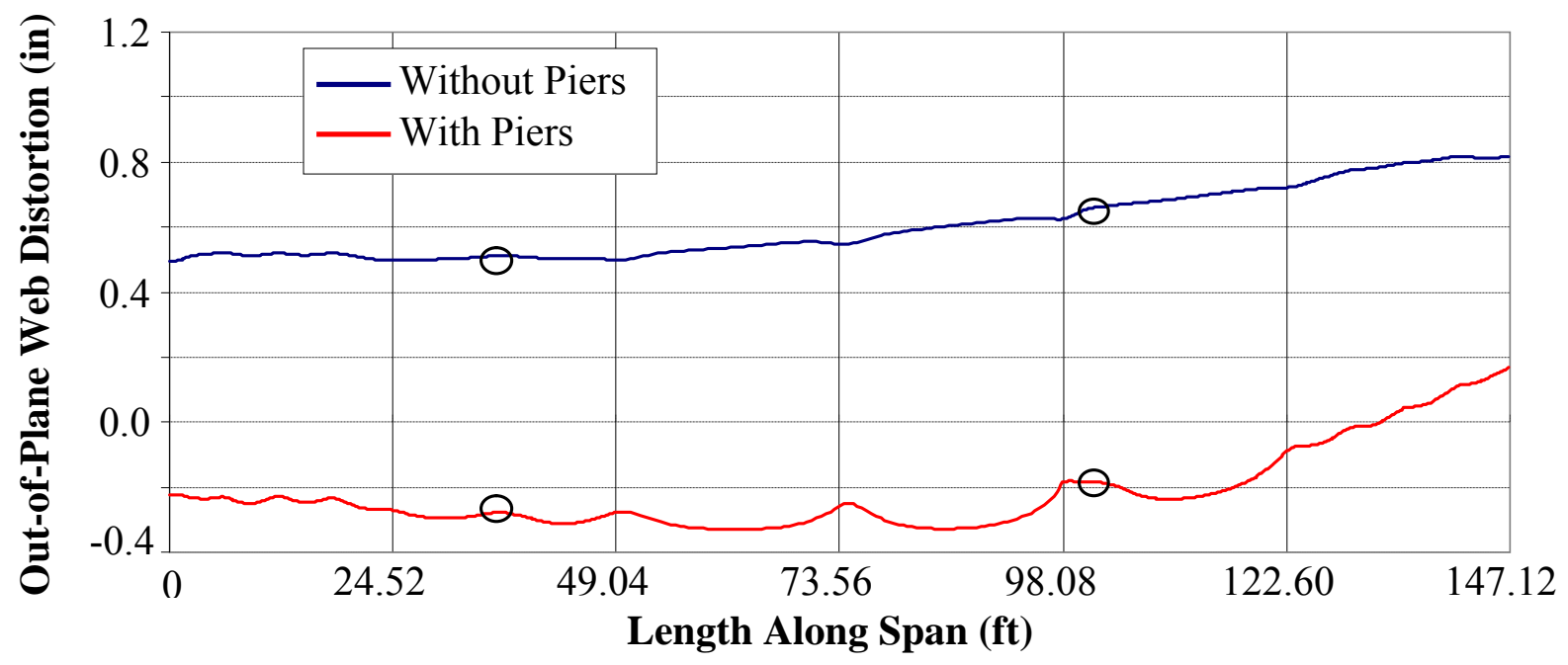

Figure 8.21 Span 11N, Long. Profile Comparison with Addition of Piers (Temp $\left.+90^{\circ} \mathrm{F}\right)$

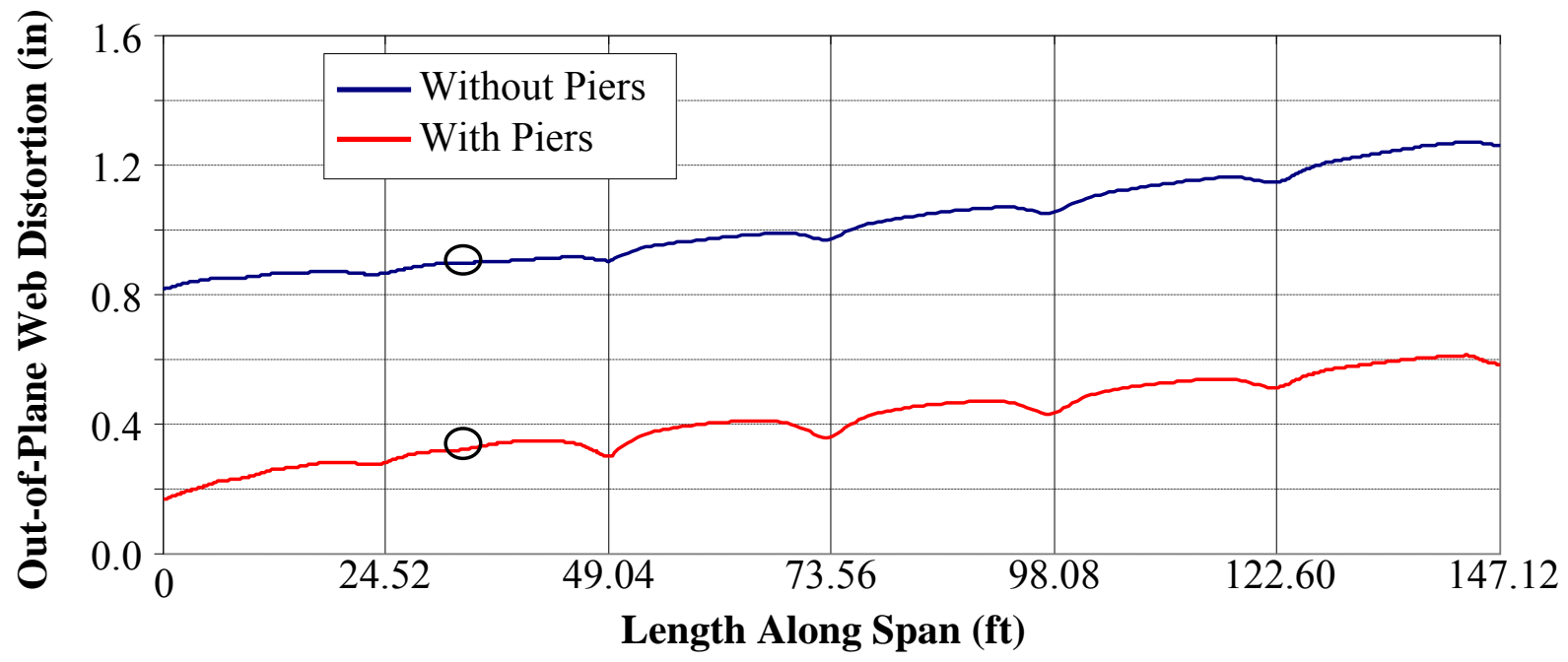

Figure 8.22 Span 12N, Long. Profile Comparison with Addition of Piers (Temp $\left.+90^{\circ} \mathrm{F}\right)$

Overall, inclusion of the piers results in increased magnitudes of out-of-plane web distortion (mainly lateral buckling) throughout Spans $7 \mathrm{~N}-10 \mathrm{~N}$, while Spans $11 \mathrm{~N}-12 \mathrm{~N}$ show reductions in web distortion. The increased web distortions are likely due to the increased overall flexibility of the FE model. Figures 8.23-8.24 compare the maximum out-of-plane distortion for each temperature load case for each FE model. As seen below, the largest increases in web distortion after including the piers in the FE model occur near the midspan of Span 10N. Web distortion near this location increases by roughly $100 \%$ for both 
temperature load cases, while locations in Spans $11 \mathrm{~N}$ and $12 \mathrm{~N}$ show reductions exceeding $50 \%$.

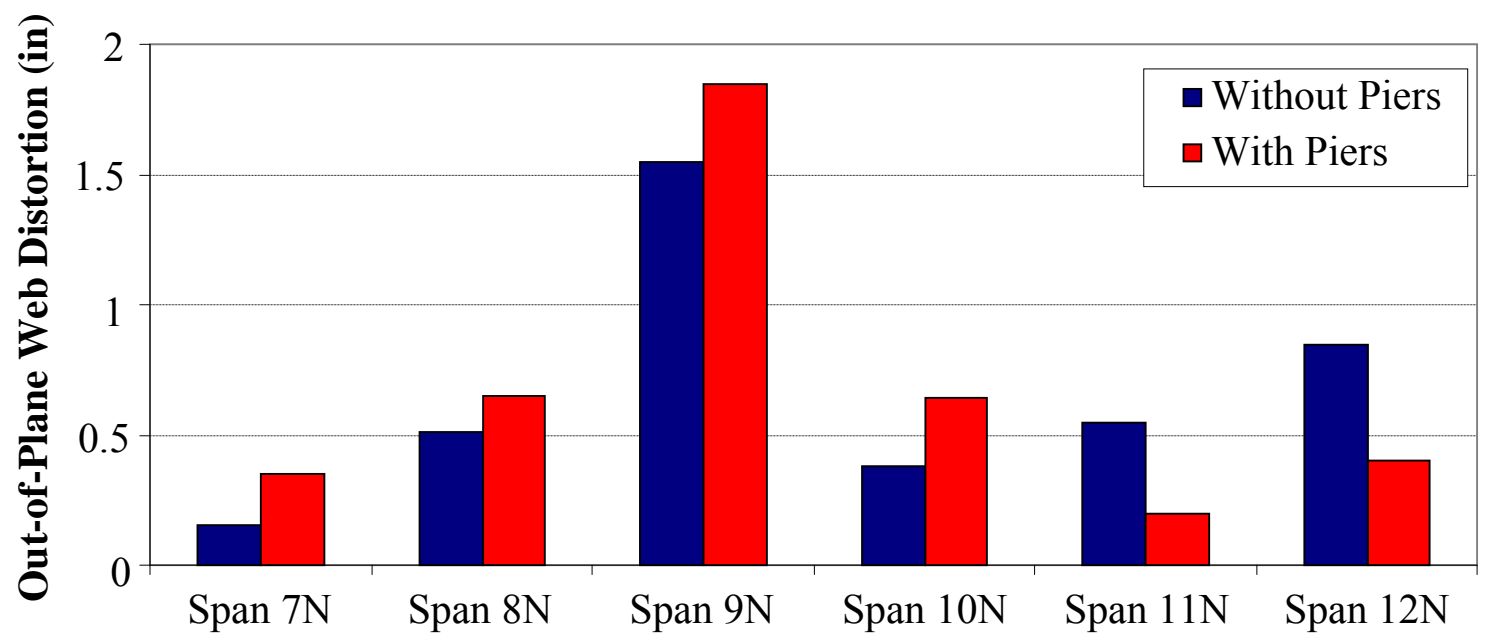

Figure 8.23 Maximum Out-of-Plane Web Distortion Comparison with Piers Modeled $\left(\right.$ Temp $\left.+60^{\circ} \mathrm{F}\right)$

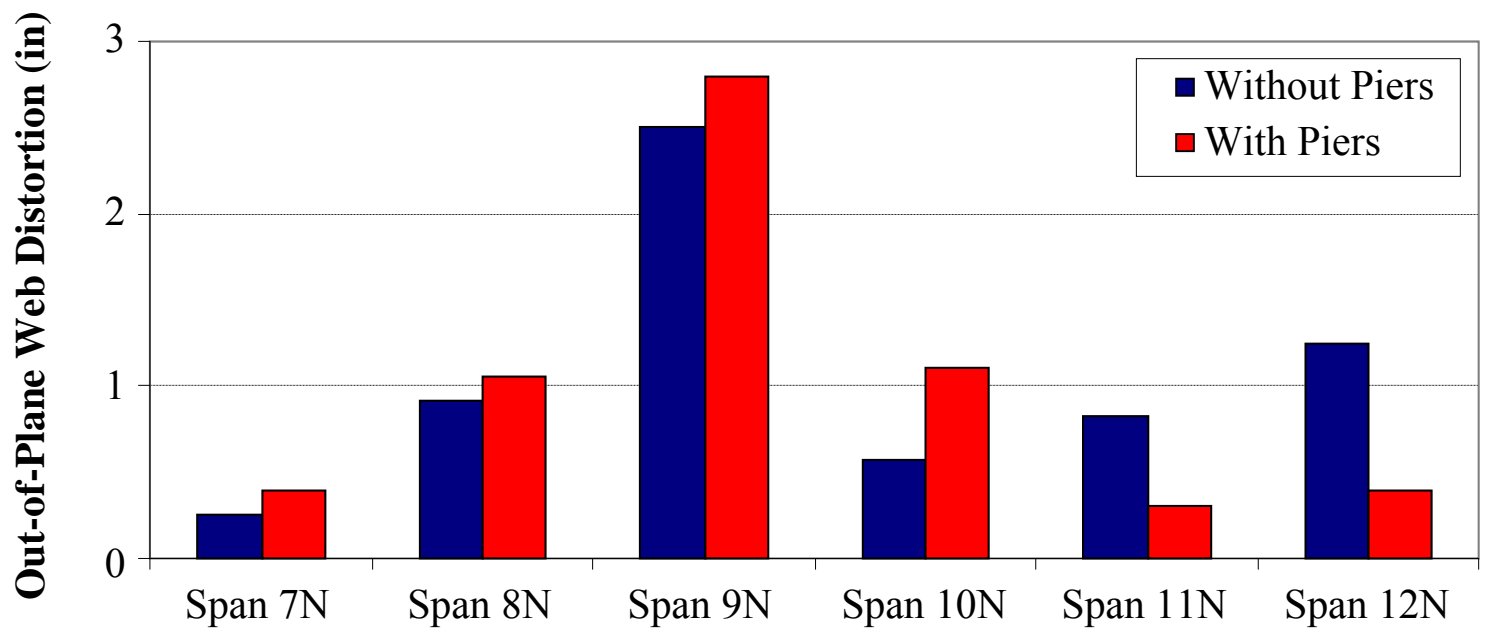

Figure 8.24 Maximum Out-of-Plane Web Distortion Comparison with Piers Modeled $\left(\right.$ Temp $\left.+90^{\circ} \mathrm{F}\right)$ 


\subsection{EFFECT OF PIER FLEXIBILITY ON THERMAL STRESSES}

Accounting for pier flexibility in the FE model will impact the overall state of stress in the steel I-girders. In the original FE model, without pier modeling, all thermal stress caused by uniform temperature loading was imparted into the steel girders. As shown previously, these thermal stresses exceed $F_{y}$ in several locations in the original model. In the new FE model, a certain portion of those thermal stresses will be distributed to the concrete piers through bending and torsional stresses. This pier flexibility will allow the structure to undergo some level of thermal expansion without the incurrence of additional thermal stresses in the steel girders. In this section, effective and longitudinal stresses in the steel Igirder webs are investigated with the $+90^{\circ} \mathrm{F}$ temperature load applied to the FE model with the piers included. These results are then compared to those results presented in Chapter Five. Stresses in the concrete piers are analyzed as well. Figures 8.25-8.36 show effective stress profiles comparing the FE models with and without the modeling of the piers.

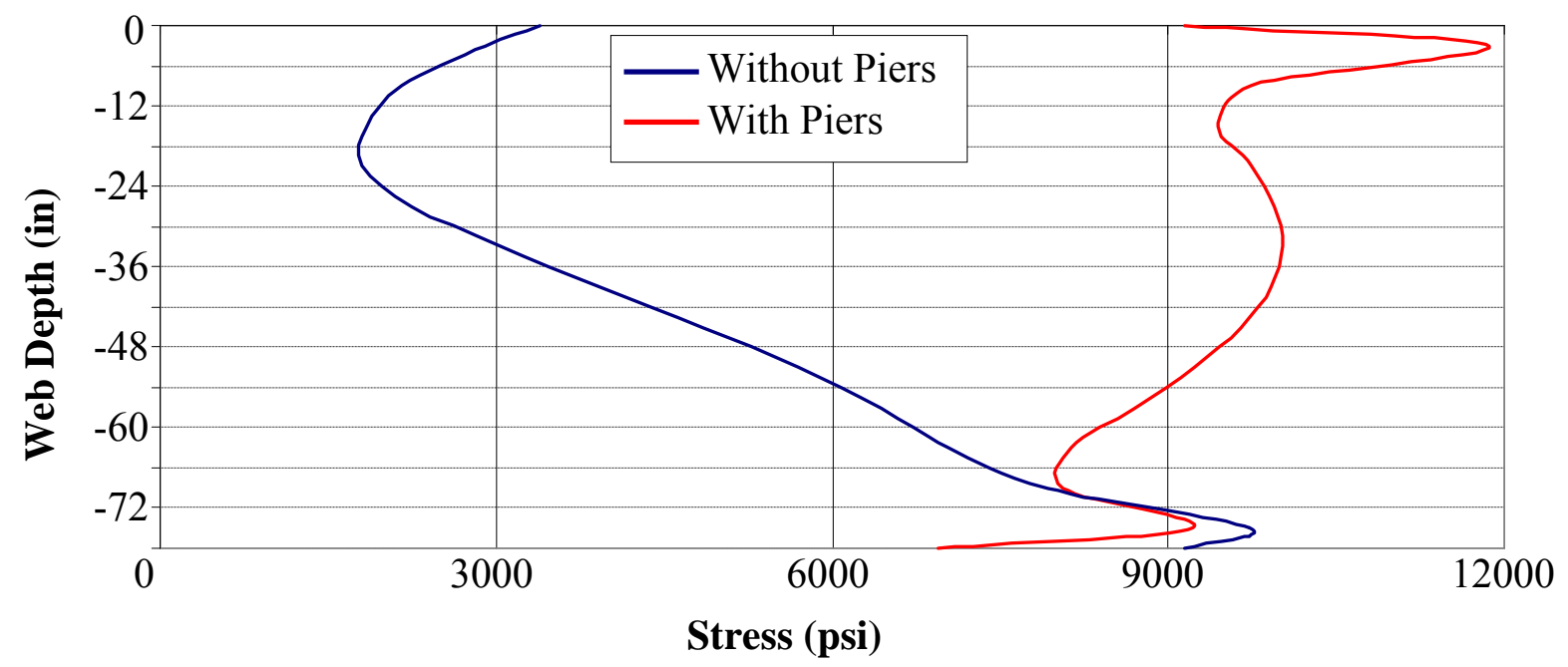

Figure 8.25 Span 7N, Effective Stress Comparison with Addition of Piers (Temp $\left.+90^{\circ} \mathrm{F}\right)$ 


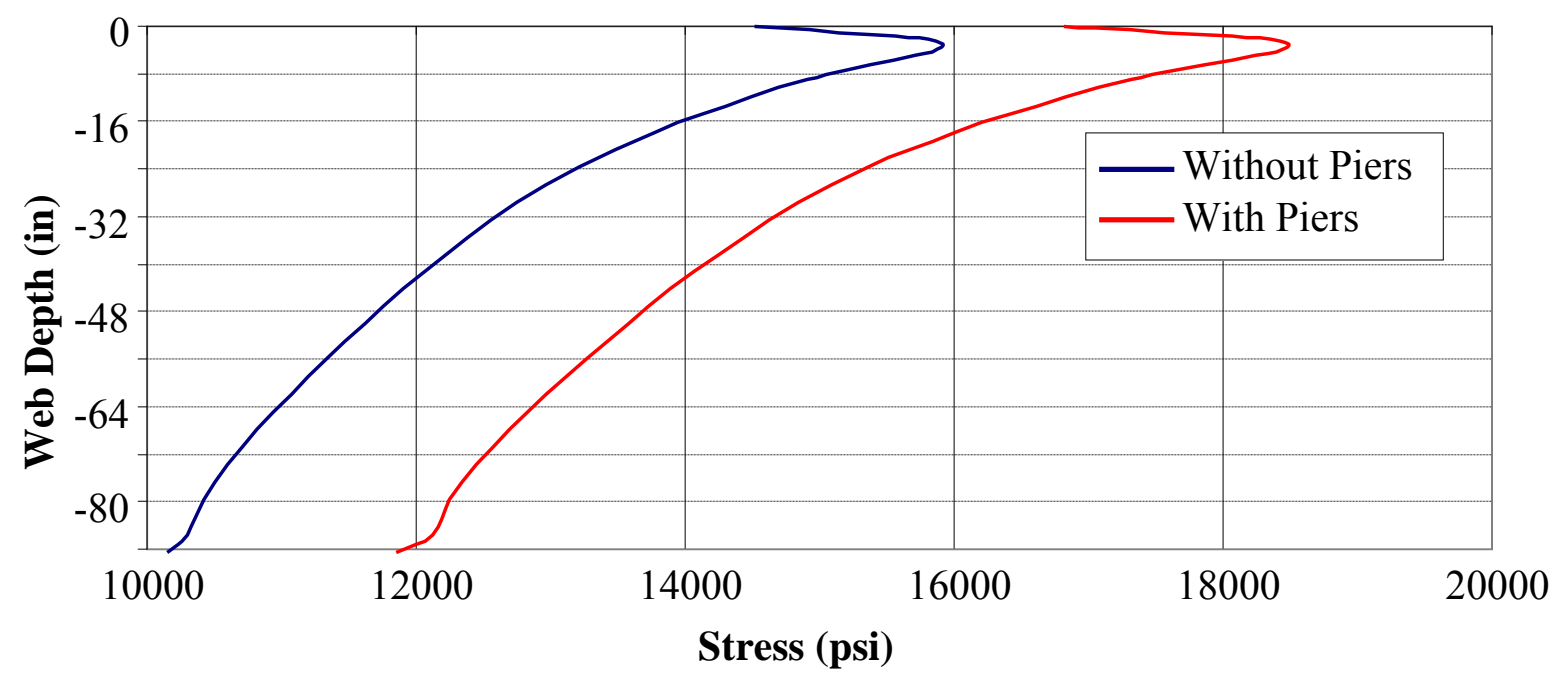

Figure 8.26 Span $8 \mathrm{~N}$, Effective Stress Comparison with Addition of Piers $\left(\mathrm{Temp}+90^{\circ} \mathrm{F}\right)$

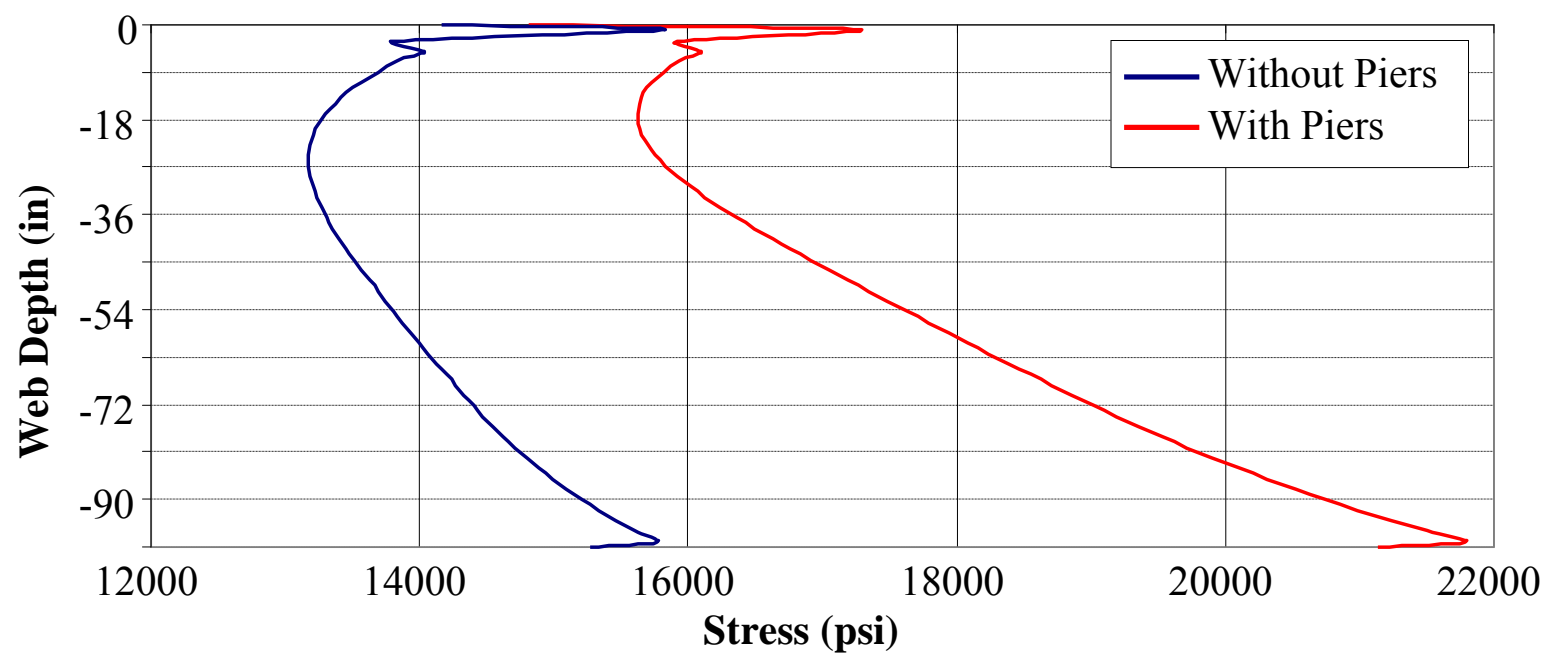

Figure 8.27 Span 9N, Effective Stress Comparison with Addition of Piers $\left(\mathrm{Temp}+90^{\circ} \mathrm{F}\right)$

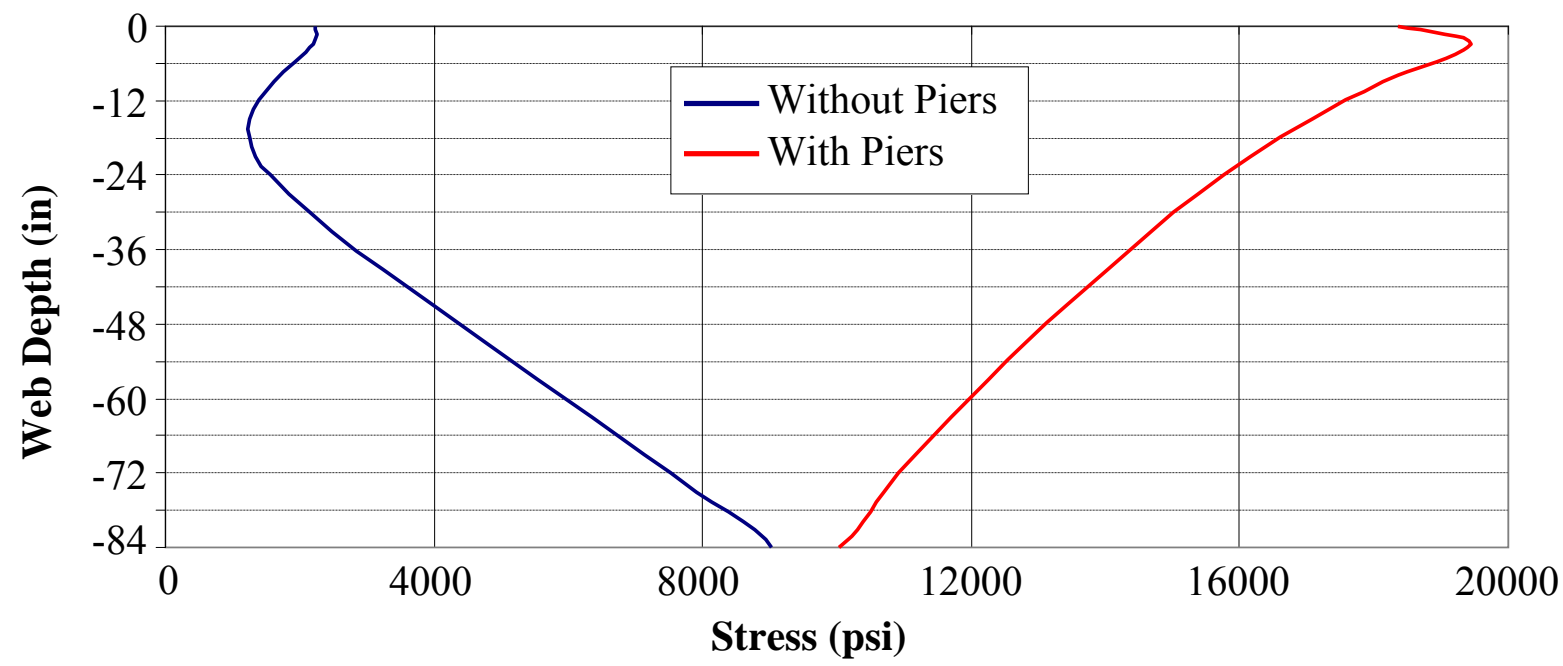

Figure 8.28 Span 10N, Effective Stress Comparison with Addition of Piers $\left(\right.$ Temp $\left.+90^{\circ} \mathrm{F}\right)$ 


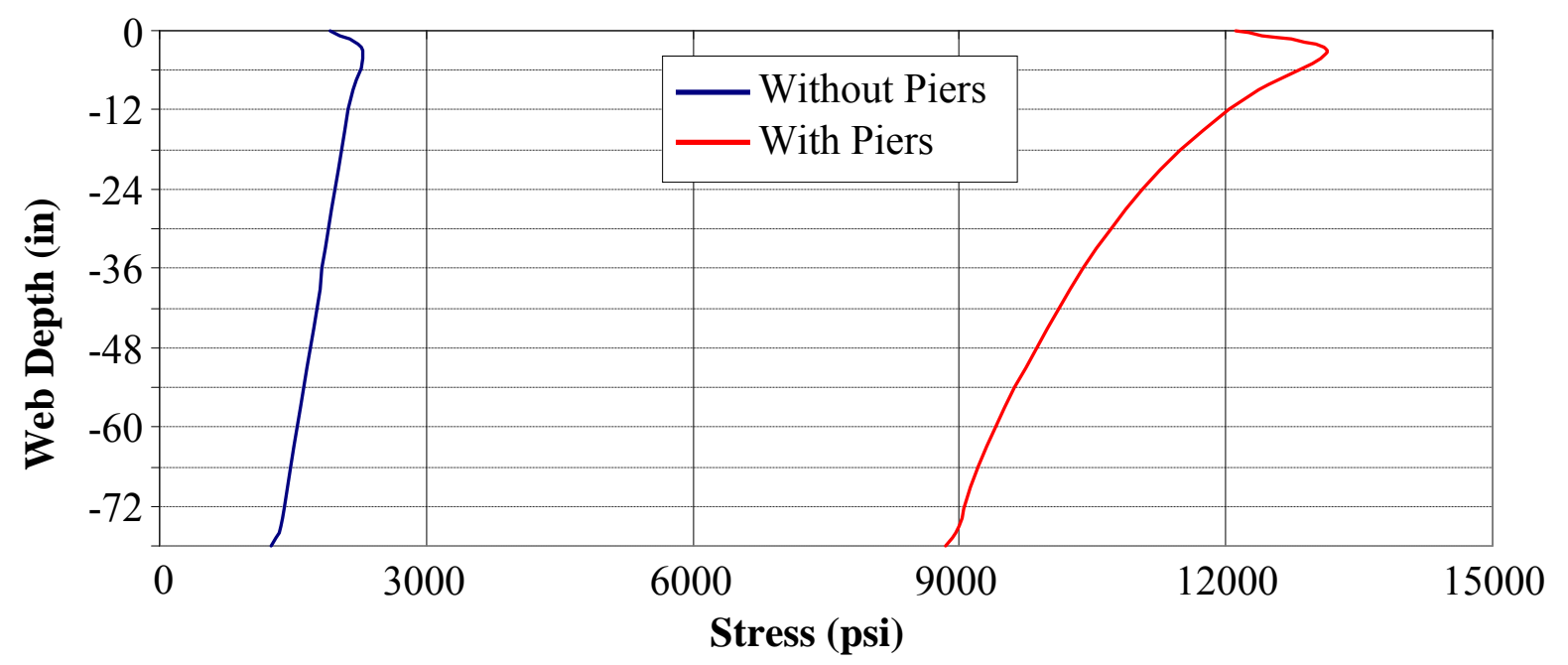

Figure 8.29 Span 11N, Effective Stress Comparison with Addition of Piers $\left(\mathrm{Temp}+90^{\circ} \mathrm{F}\right)$

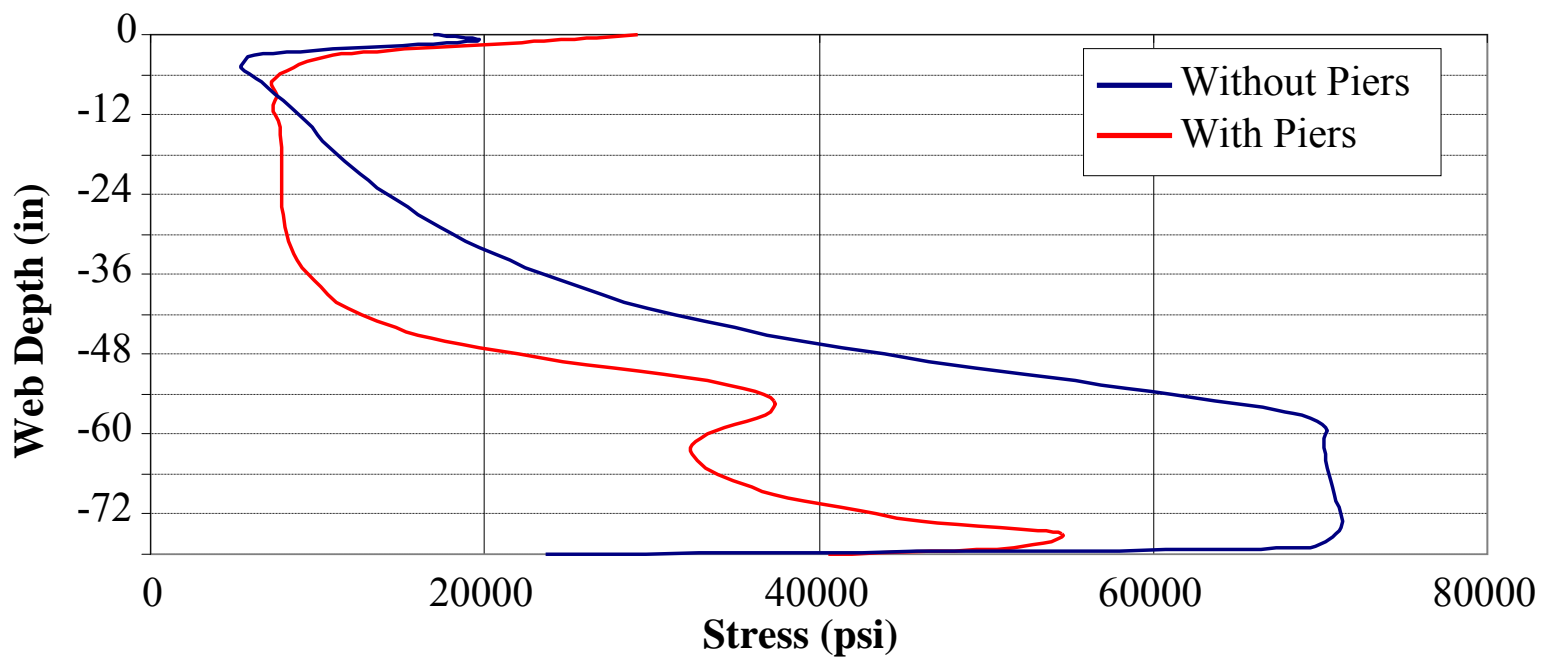

Figure 8.30 Pier 7N, Effective Stress Comparison with Addition of Piers $\left(\mathrm{Temp}+90^{\circ} \mathrm{F}\right)$

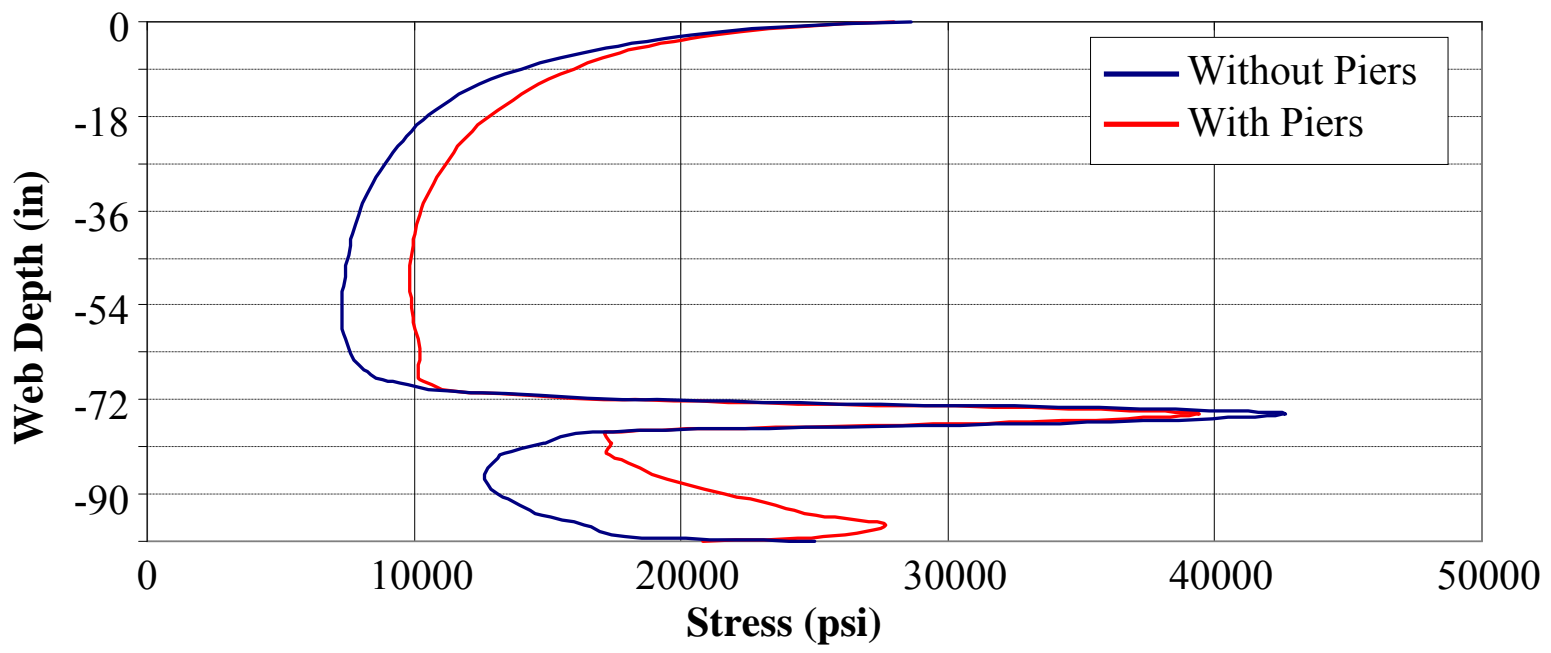

Figure 8.31 Pier 8N, Effective Stress Comparison with Addition of Piers $\left(\mathrm{Temp}+90^{\circ} \mathrm{F}\right)$ 


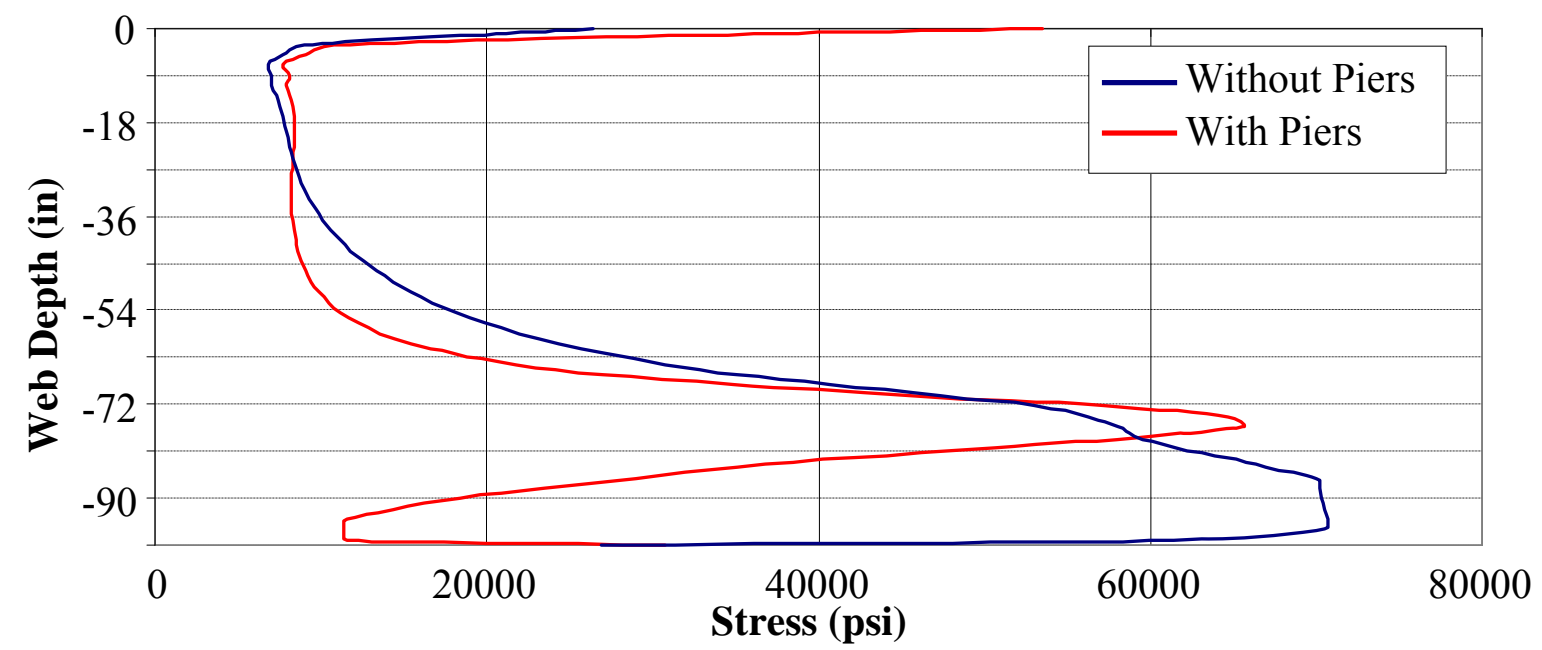

Figure 8.32 Pier 9N, Effective Stress Comparison with Addition of Piers $\left(\mathrm{Temp}+90^{\circ} \mathrm{F}\right)$

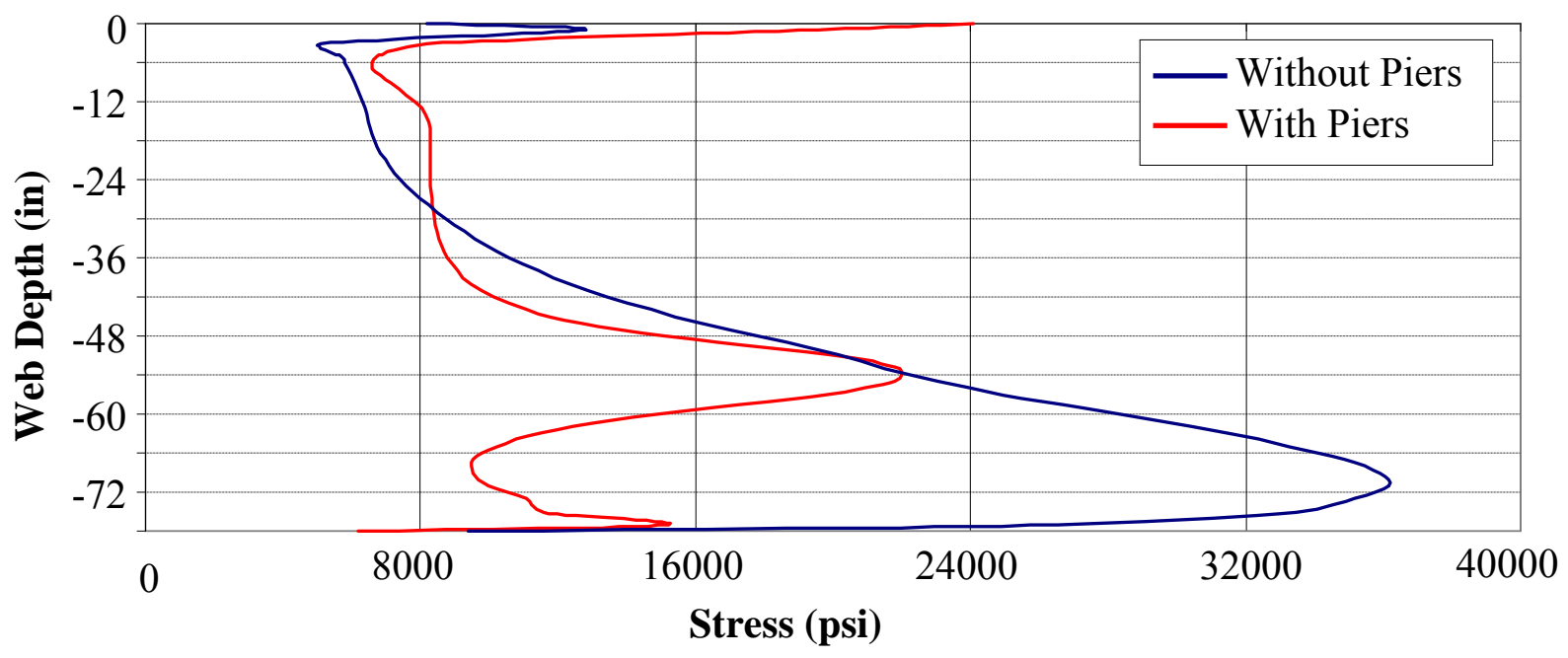

Figure 8.33 Pier 10N, Effective Stress Comparison with Addition of Piers $\left(\mathrm{Temp}+90^{\circ} \mathrm{F}\right)$

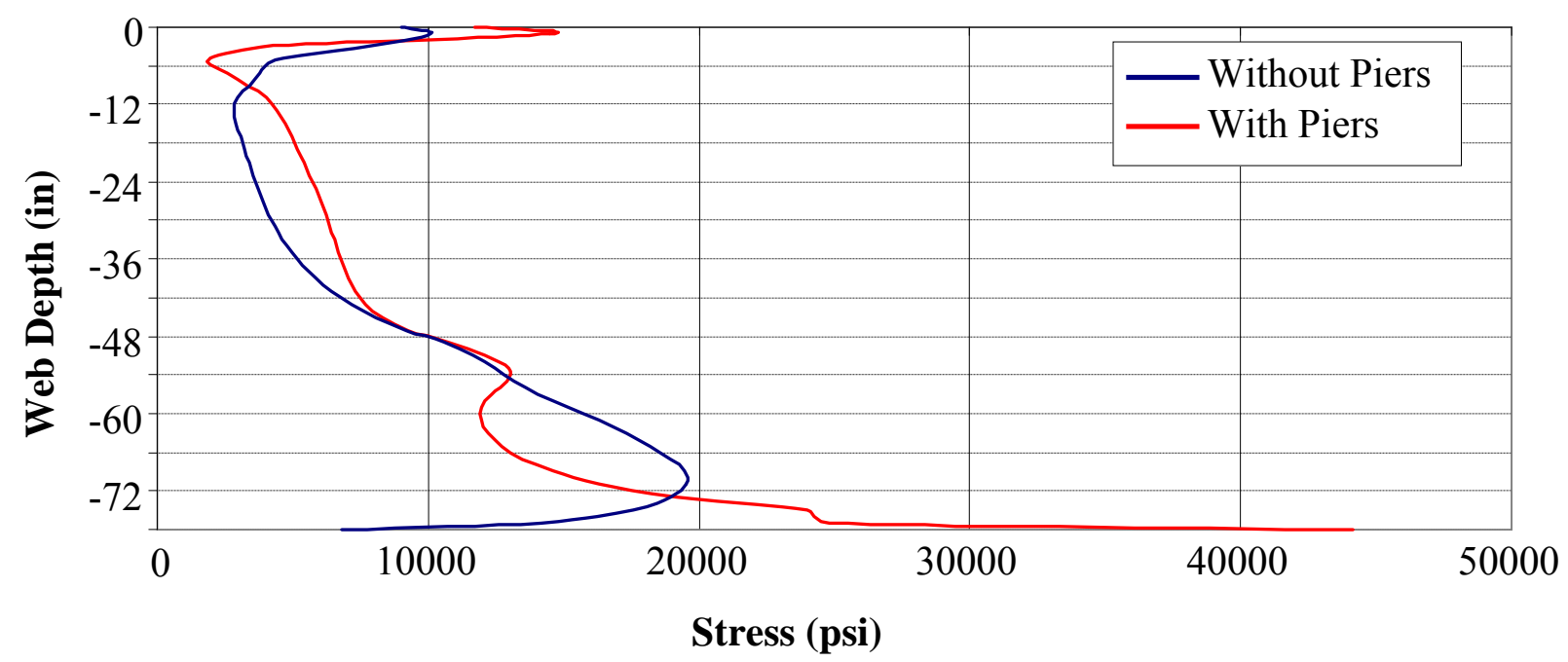

Figure 8.34 Pier 11N, Effective Stress Comparison with Addition of Piers (Temp $\left.+90^{\circ} \mathrm{F}\right)$ 


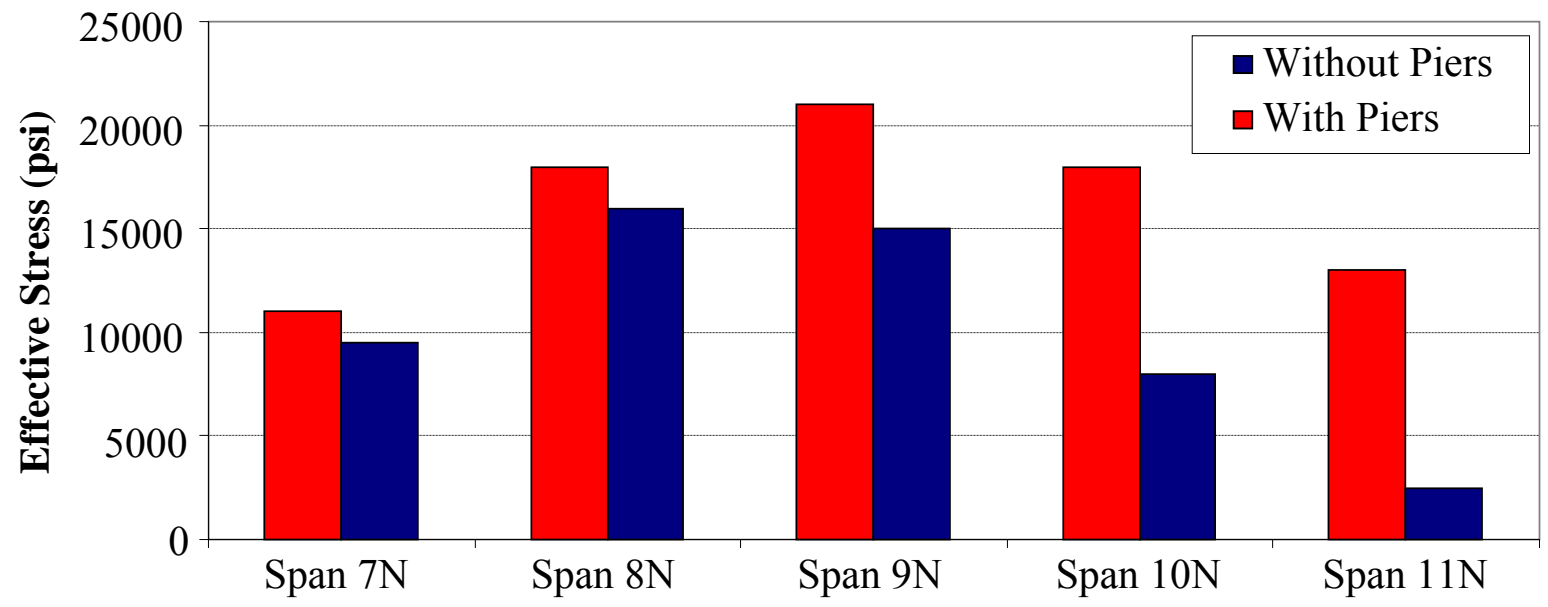

Figure 8.35 Maximum Web Effect Stress Comparisons near Midspans with Piers Modeled $\left(\right.$ Temp $\left.+90^{\circ} \mathrm{F}\right)$

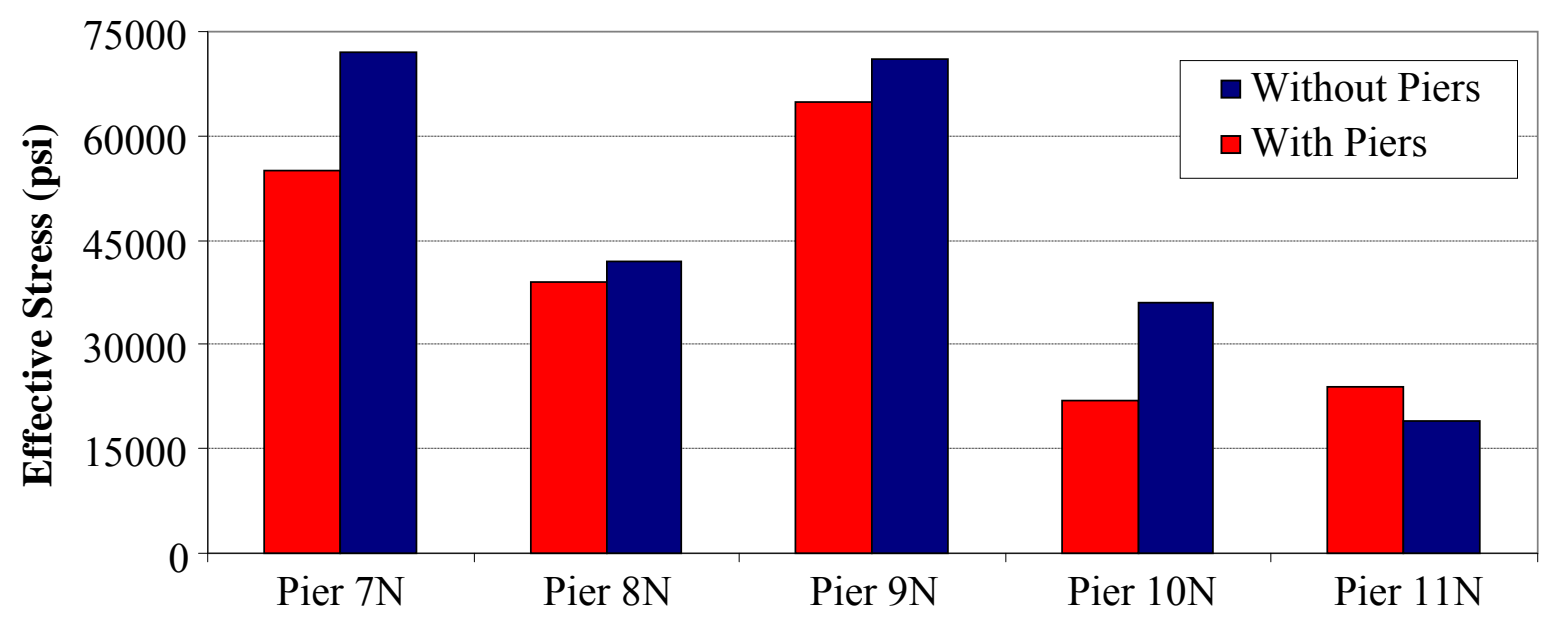

Figure 8.36 Maximum Web Effect Stress Comparisons at Pier Centerlines with Piers Modeled $\left(\mathrm{Temp}+90^{\circ} \mathrm{F}\right)$

As seen is Figures 8.35-8.36, effective stress in the girders near midspan locations has increased with the inclusion of the concrete piers, while stress at pier centerlines has decreased. While effective stress levels increased in areas near the midspans, maximum stress is only around $20 \mathrm{ksi}$ in Span 9N. Effective stress levels for the cross-sections at the pier centerlines have diminished moderately at Piers $7 \mathrm{~N}-10 \mathrm{~N}$. A slight increase occurred at Pier $11 \mathrm{~N}$. The most important result occurs at Piers $7 \mathrm{~N}$ and $9 \mathrm{~N}$, where the magnitude of effective stress has reduced from over $70 \mathrm{ksi}$, to $55 \mathrm{ksi}$ and $65 \mathrm{ksi}$ respectively. The yield 
stress of the steel I-girders is not exceeded, as is the case without the consideration of pier flexibility. It is evident that a certain portion of thermal stress produced in the original FE model, has now been distributed to the piers. Longitudinal stress profile comparisons are presented in Figures 8.37-8.48.

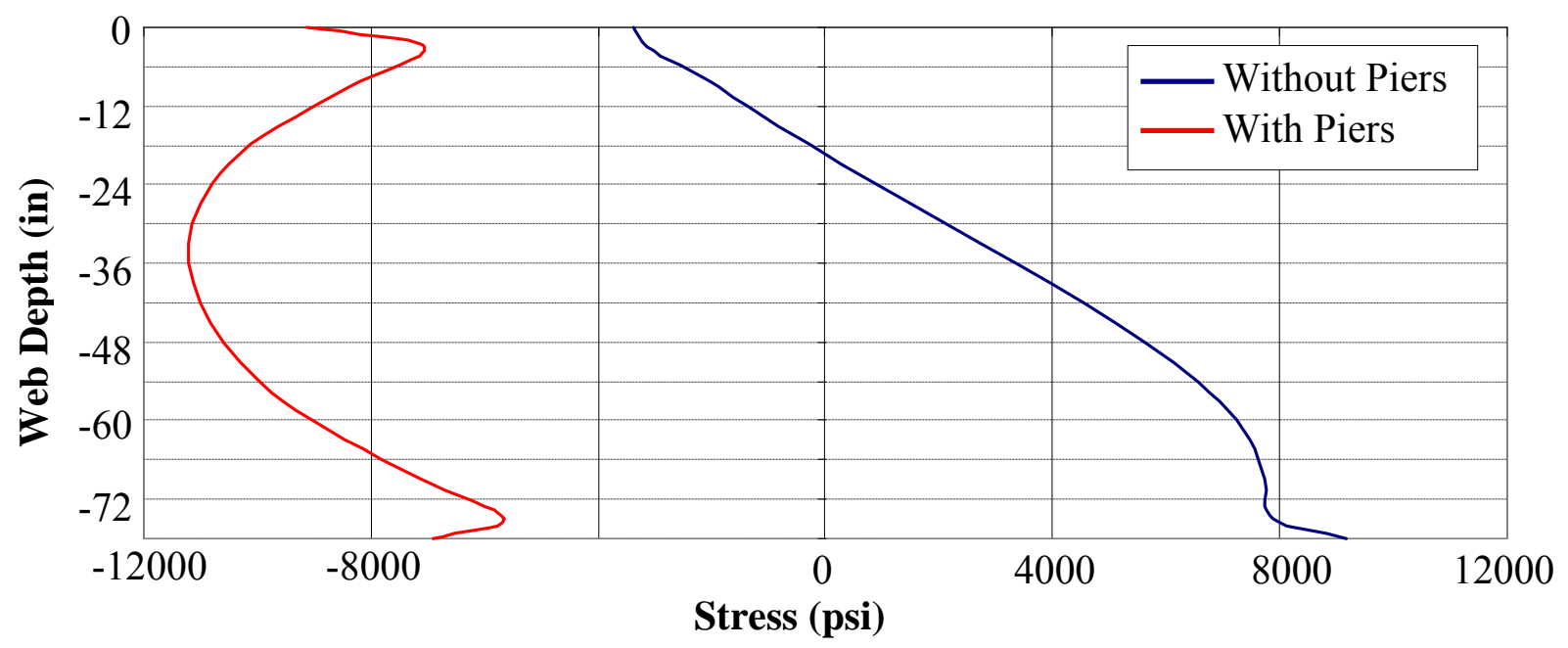

Figure 8.37 Span $7 \mathrm{~N}$, Longitudinal Stress Comparison with Addition of Piers $\left(\mathrm{Temp}+90^{\circ} \mathrm{F}\right)$

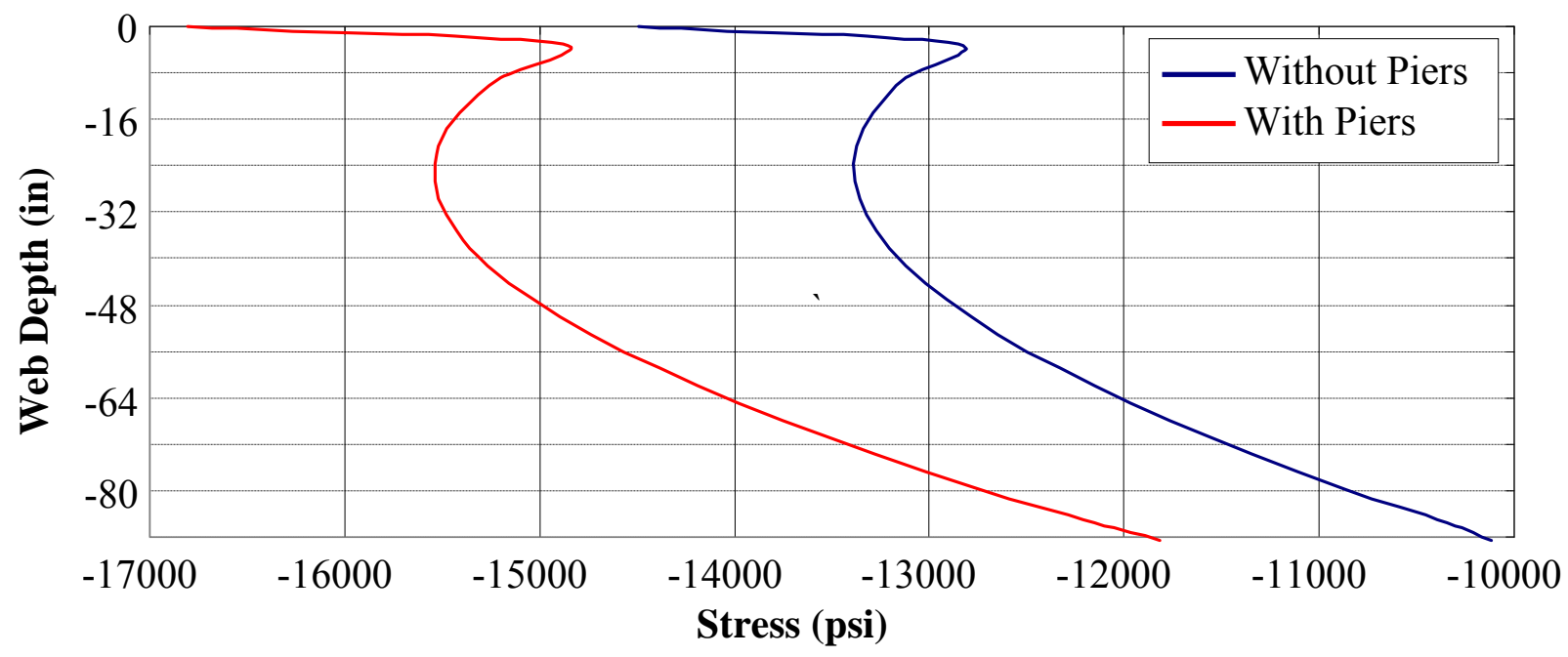

Figure 8.38 Span 8N, Longitudinal Stress Comparison with Addition of Piers $\left(\right.$ Temp $\left.+90^{\circ} \mathrm{F}\right)$ 


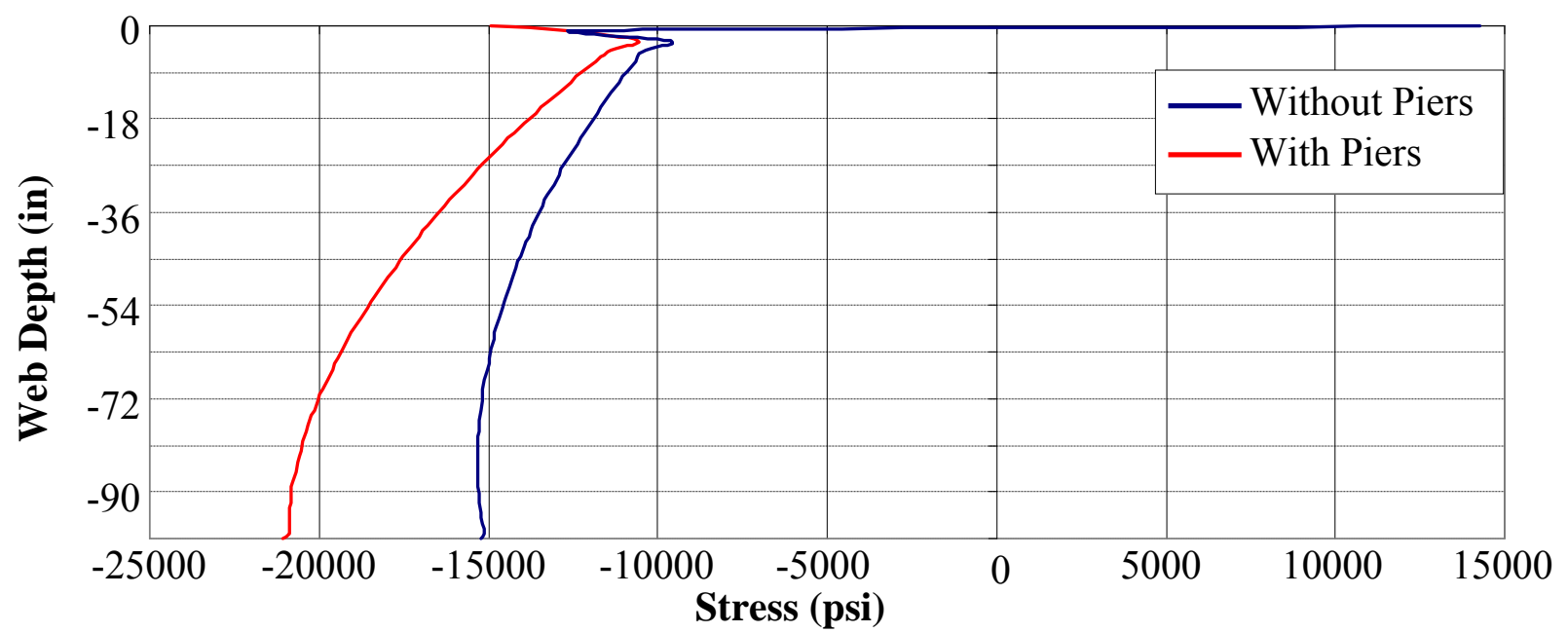

Figure 8.39 Span 9N, Longitudinal Stress Comparison with Addition of Piers (Temp $\left.+90^{\circ} \mathrm{F}\right)$

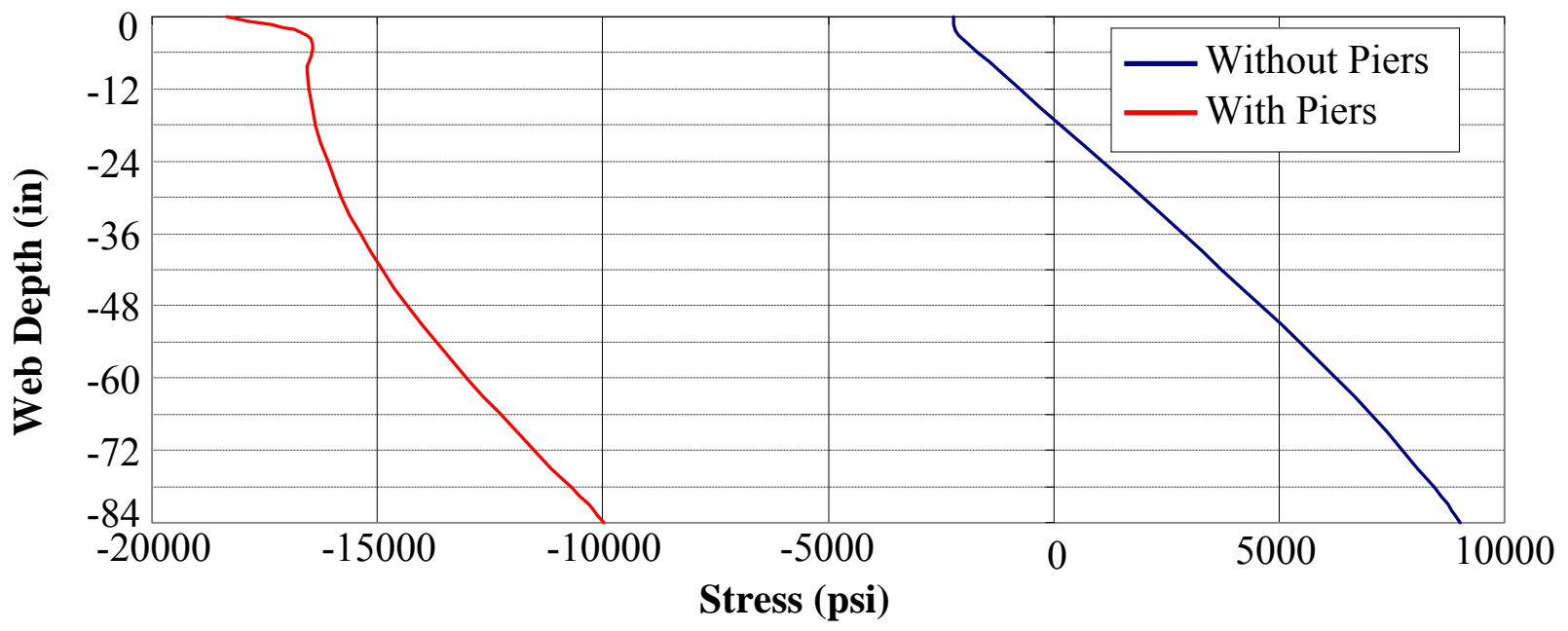

Figure 8.40 Span 10N, Longitudinal Stress Comparison with Addition of Piers (Temp $\left.+90^{\circ} \mathrm{F}\right)$

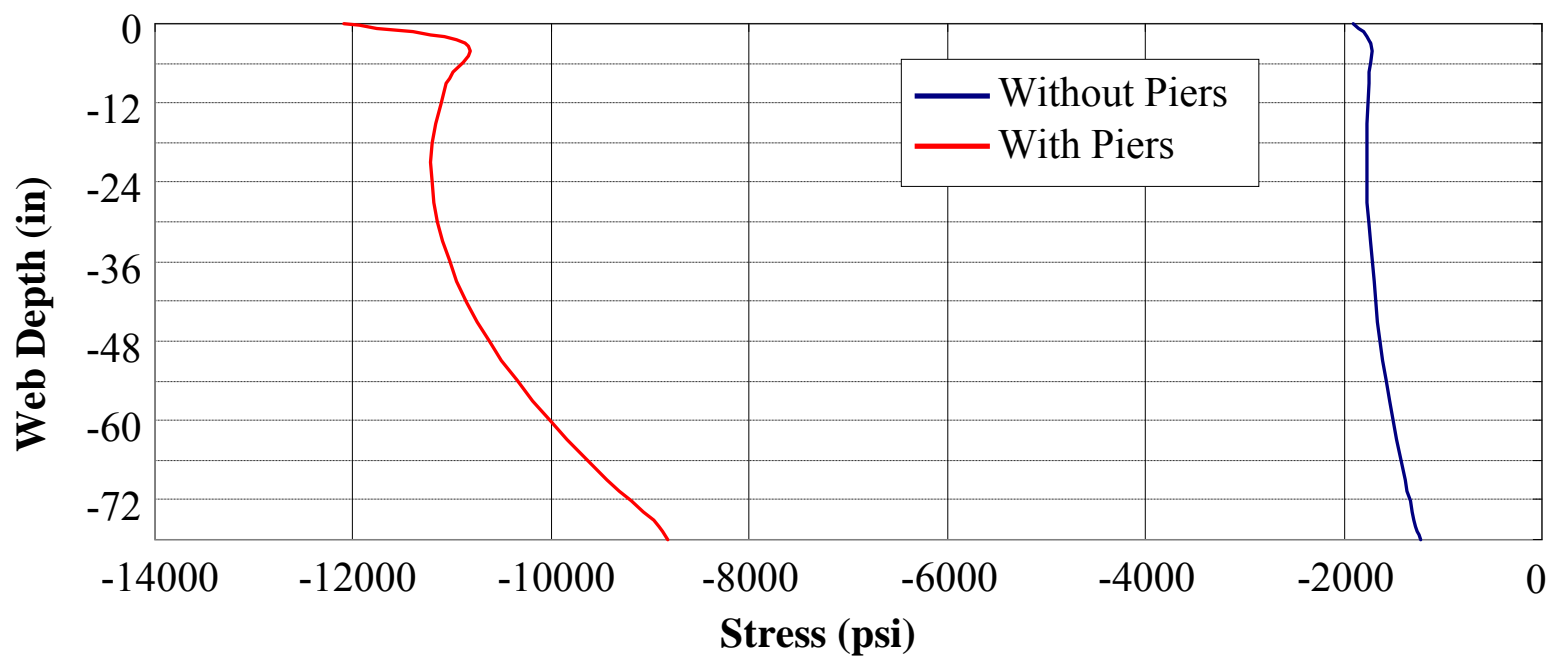

Figure 8.41 Span 11N, Longitudinal Stress Comparison with Addition of Piers (Temp $\left.+90^{\circ} \mathrm{F}\right)$ 


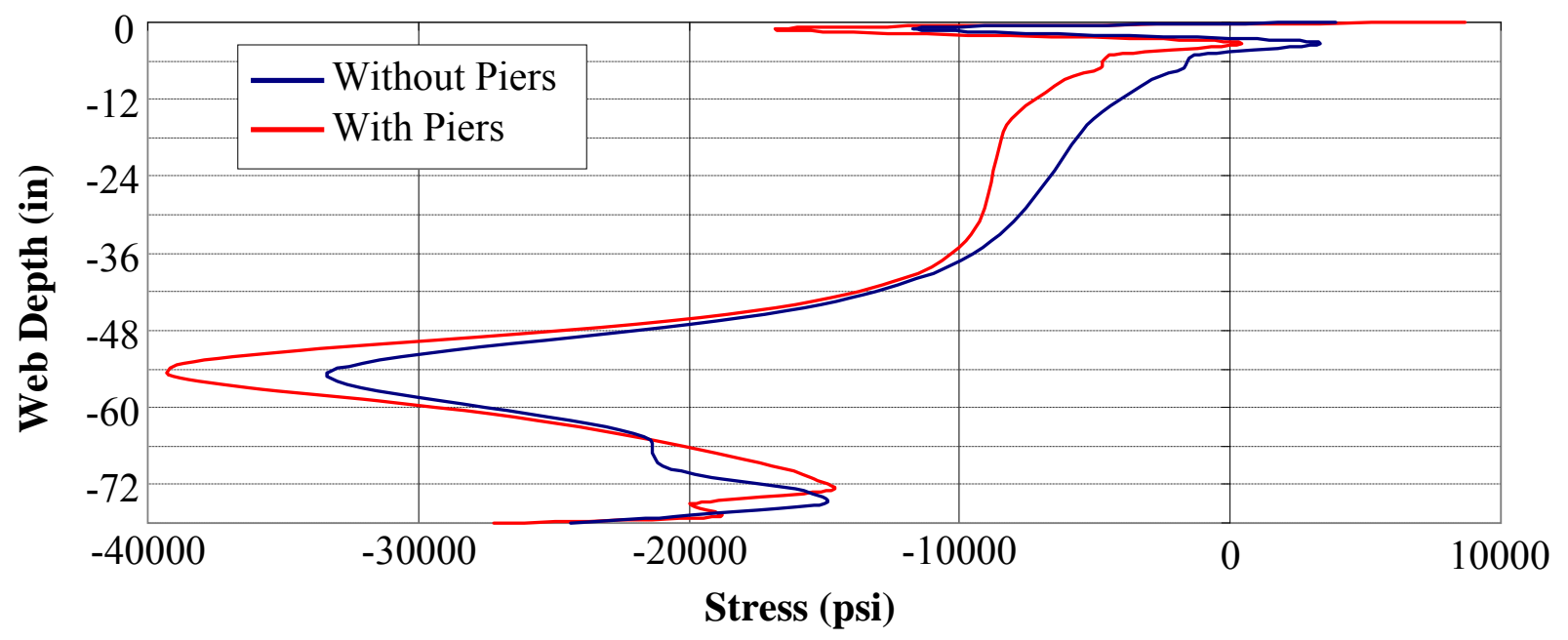

Figure 8.42 Pier 7N, Longitudinal Stress Comparison with Addition of Piers (Temp $\left.+90^{\circ} \mathrm{F}\right)$

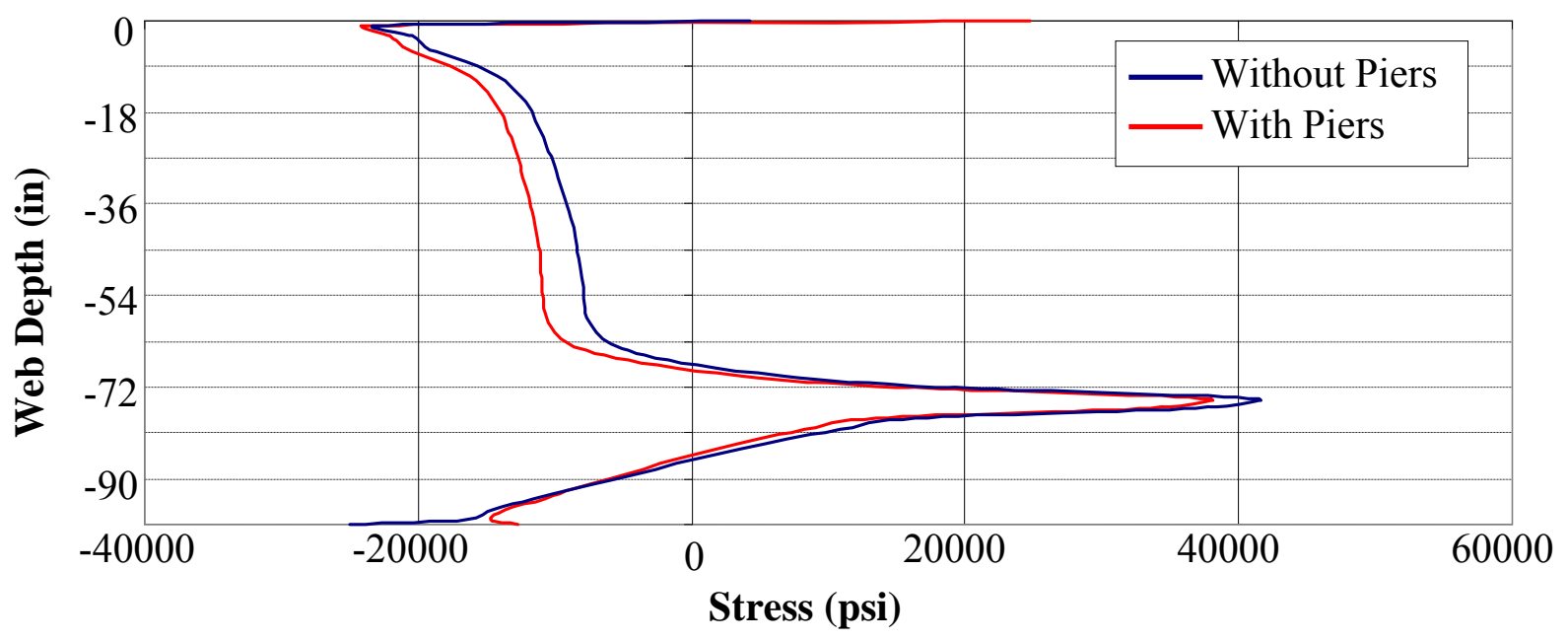

Figure 8.43 Pier $8 \mathrm{~N}$, Longitudinal Stress Comparison with Addition of Piers $\left(\mathrm{Temp}+90^{\circ} \mathrm{F}\right)$

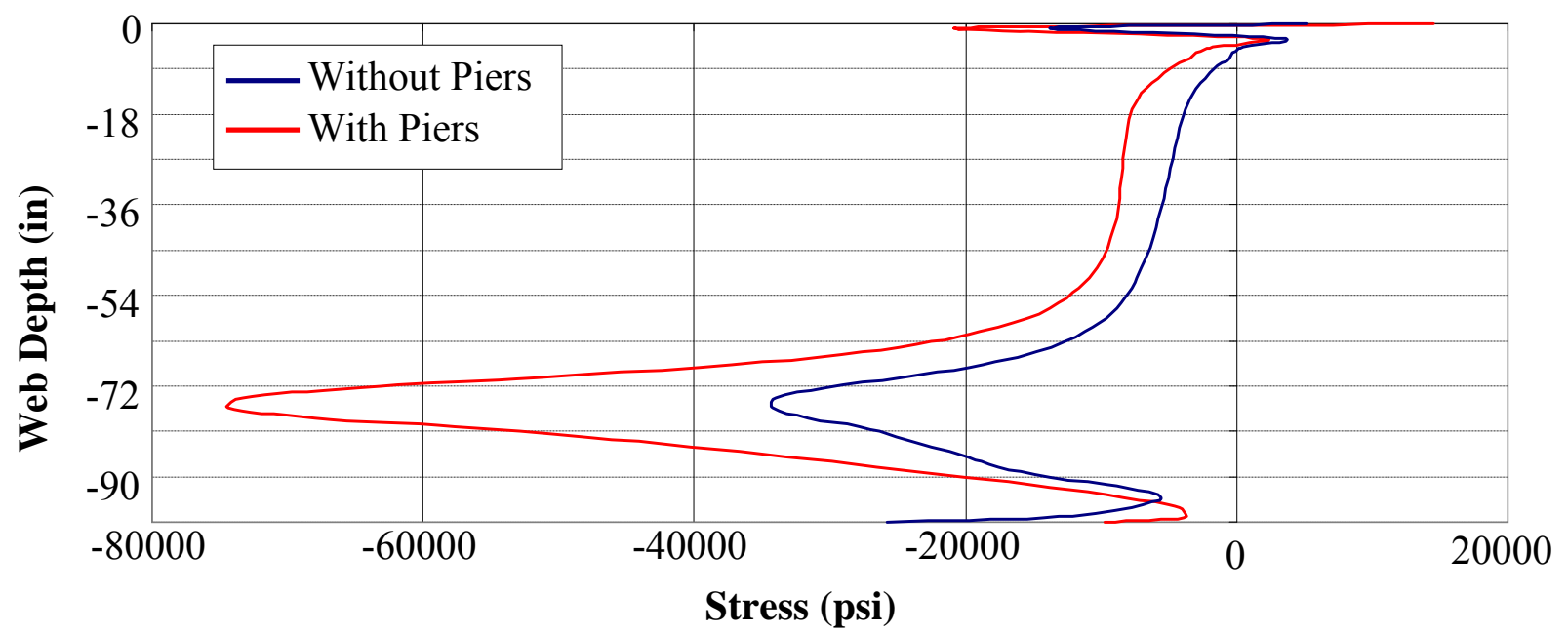

Figure 8.44 Pier 9N, Longitudinal Stress Comparison with Addition of Piers (Temp $\left.+90^{\circ} \mathrm{F}\right)$ 


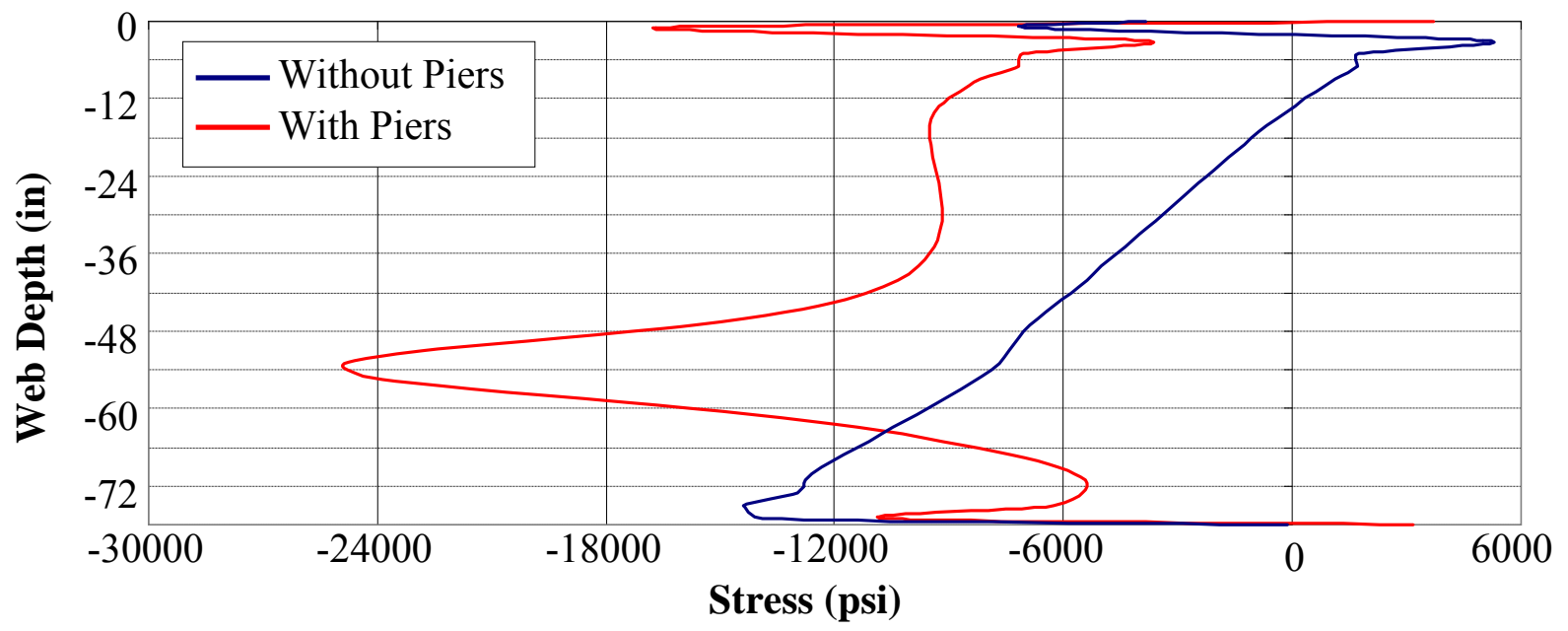

Figure 8.45 Pier 10N, Longitudinal Stress Comparison with Addition of Piers $\left(\mathrm{Temp}+90^{\circ} \mathrm{F}\right)$

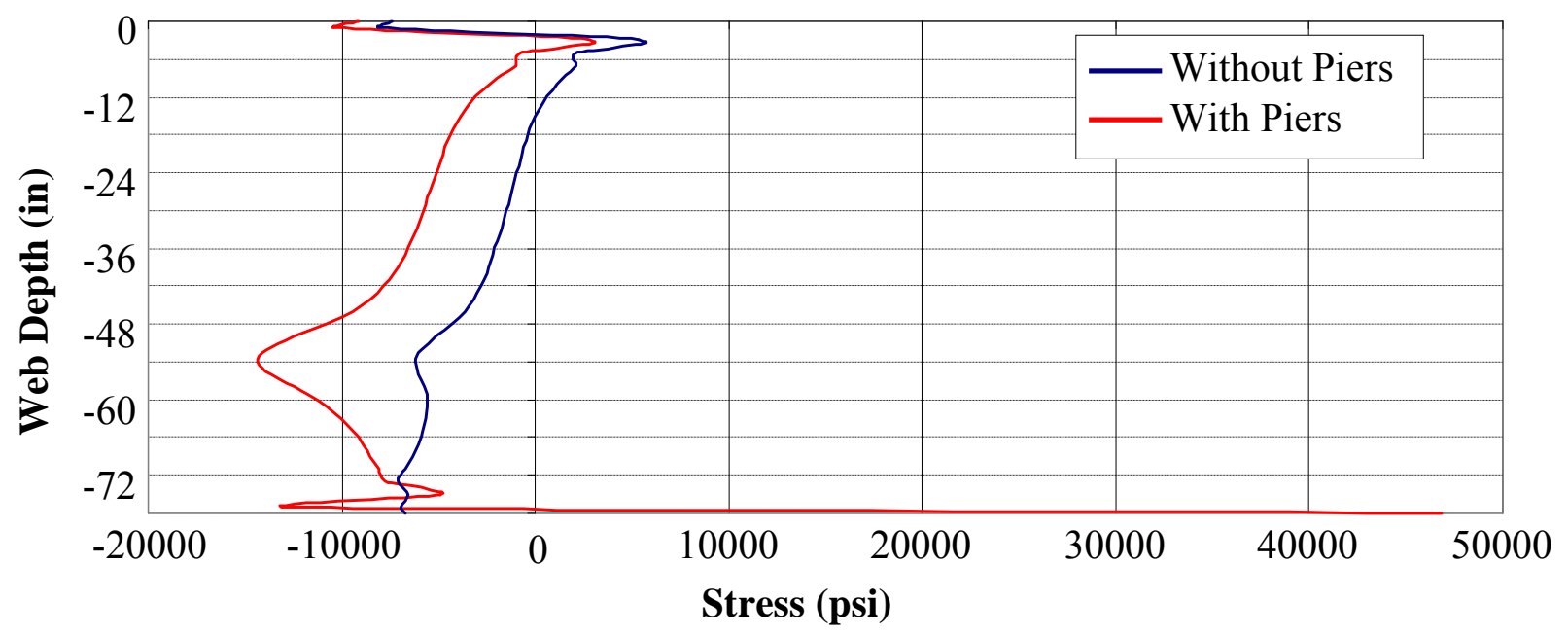

Figure 8.46 Pier 11N, Longitudinal Stress Comparison with Addition of Piers (Temp $\left.+90^{\circ} \mathrm{F}\right)$

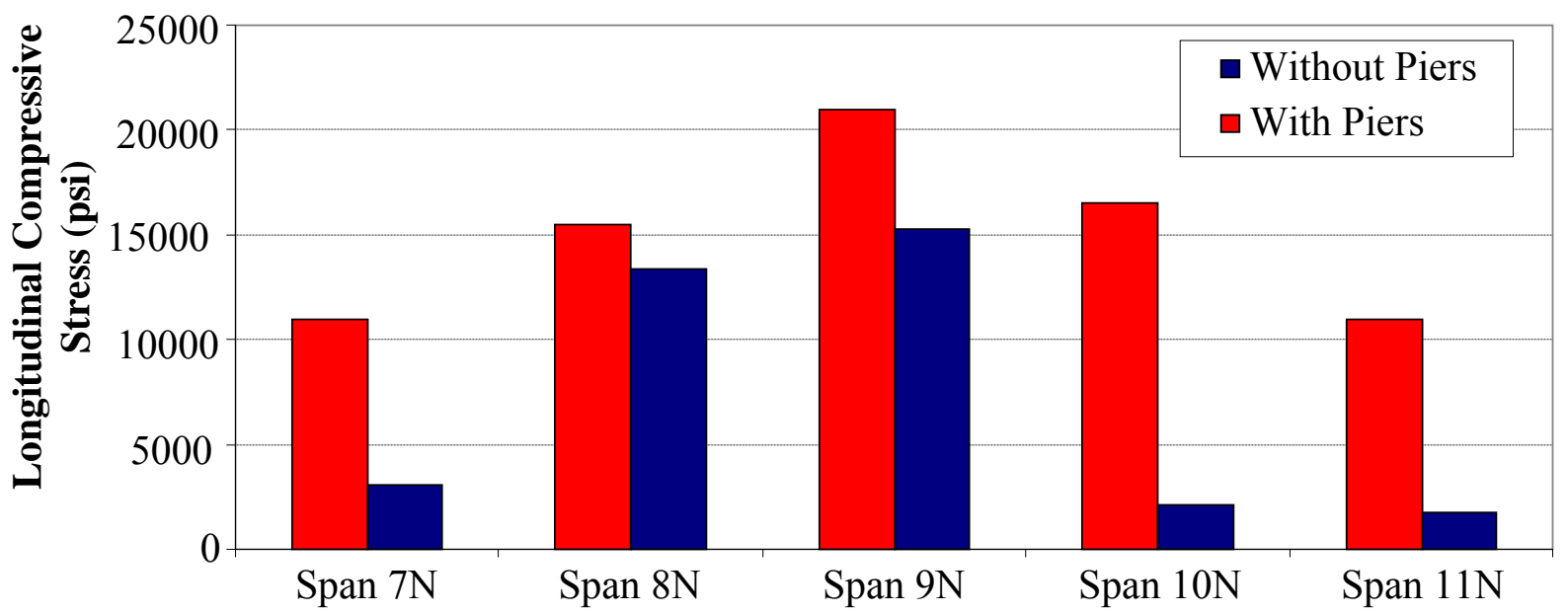

Figure 8.47 Maximum Web Longitudinal Stress Comparisons near Midspans with Piers Modeled $\left(\right.$ Temp $\left.+90^{\circ} \mathrm{F}\right)$ 


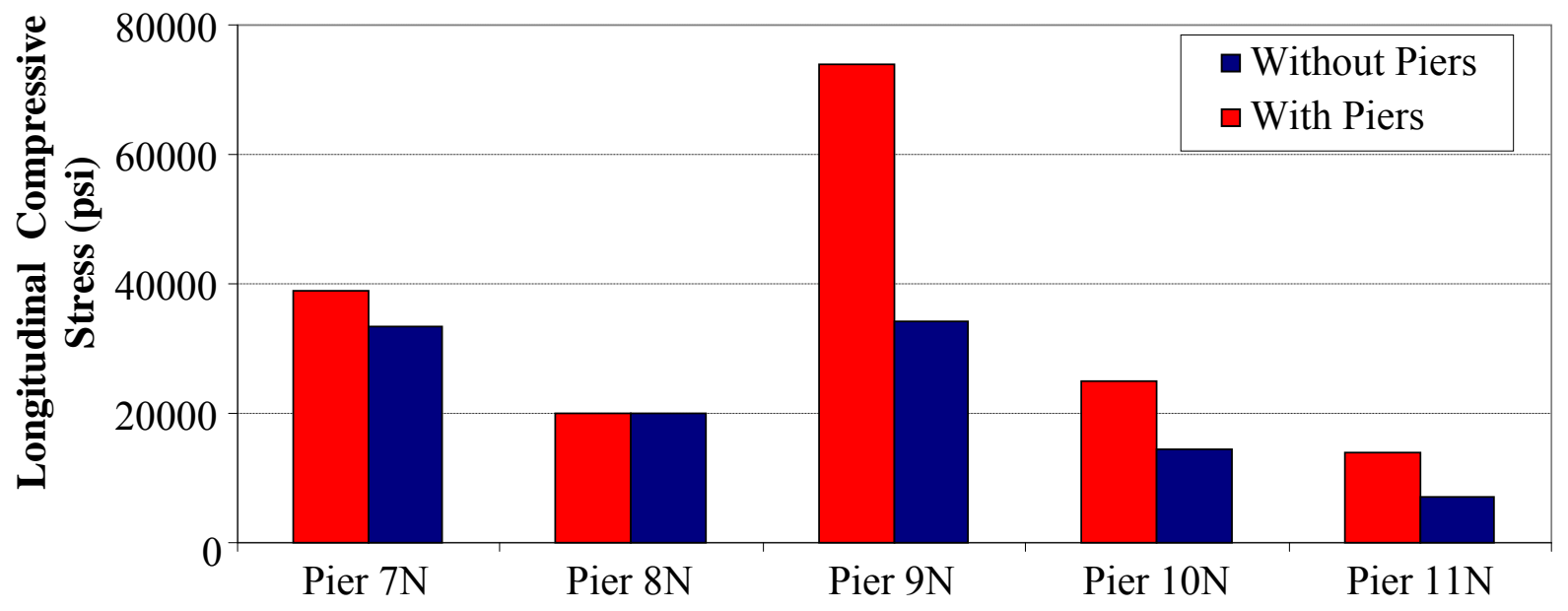

Figure 8.48 Maximum Web Longitudinal Stress Comparisons at Pier Centerlines with Piers Modeled $\left(\mathrm{Temp}+90^{\circ} \mathrm{F}\right)$

By examining the longitudinal stress profiles and Figures $8.47-8.48$, it is very apparent that the inclusion of the piers in the FE model has resulted in a noticeable increase in compressive longitudinal stress throughout the entire structure. The most significant increases in longitudinal stress occur at Pier 9N, and near the midspan of Spans 10N and 11N. Stress in Span 10N increased from 2 ksi to over $15 \mathrm{ksi}$ when the piers were included in the FE model. Stresses in Span 11N and at Pier 9N increased very drastically as well. Longitudinal stress band plots obtained from the FE model including the piers for the $+90^{\circ} \mathrm{F}$ temperature load case is presented in Figure 8.49. When compared to 5.30(a), the increased magnitude of longitudinal stress is clearly seen, especially throughout Spans 10N and 11N. Also, a greater portion of the bridge is under longitudinal compression, which will impact critical web stresses and axial stresses. Axial stress comparisons between the FE models are presented in Figures 8.50 and 8.51. 


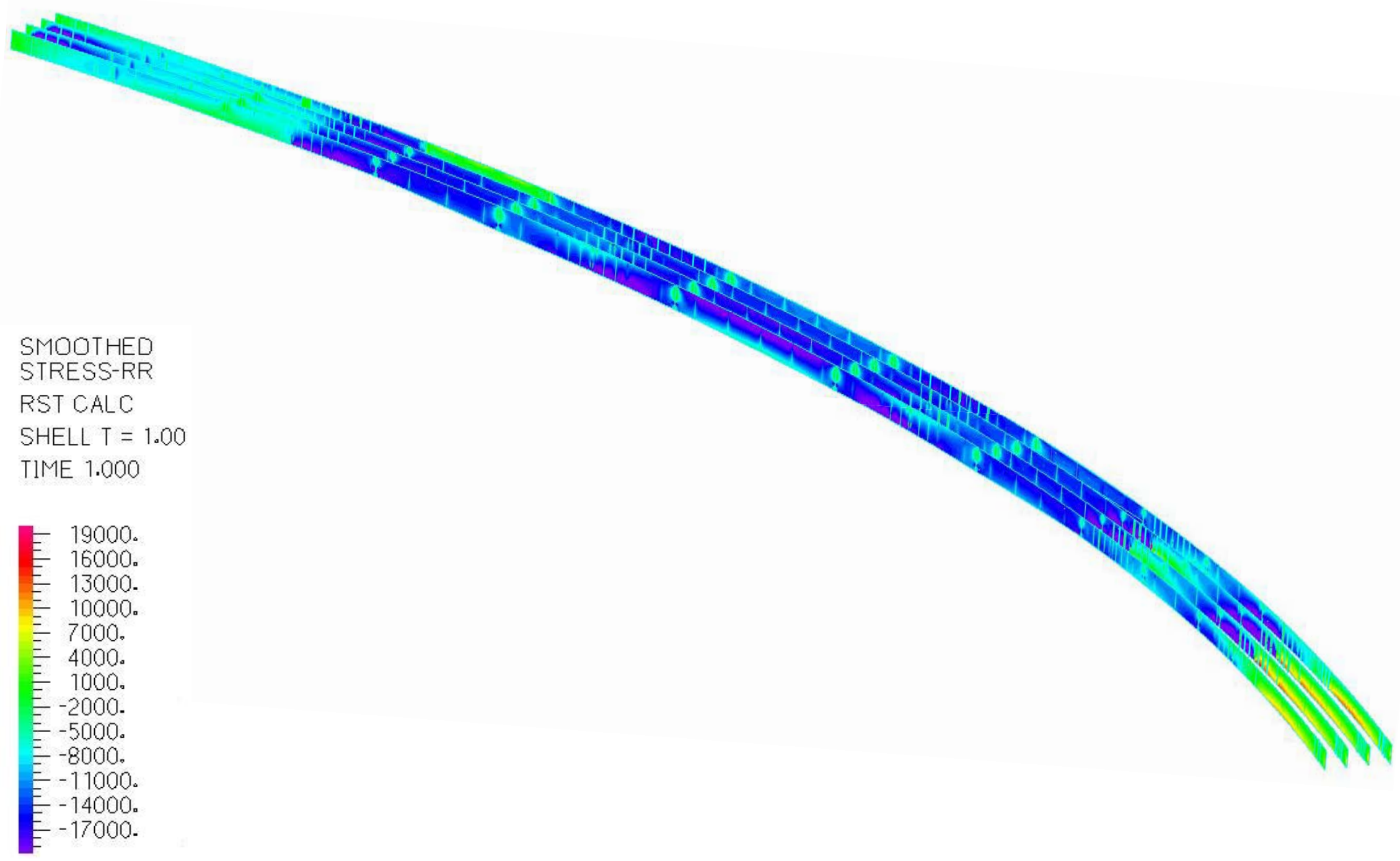

Figure 8.49 FE Model Longitudinal Stress Band Plots for Unit 2 with Addition of Piers $\left(+90^{\circ} \mathrm{F}\right.$ Temperature Load) 


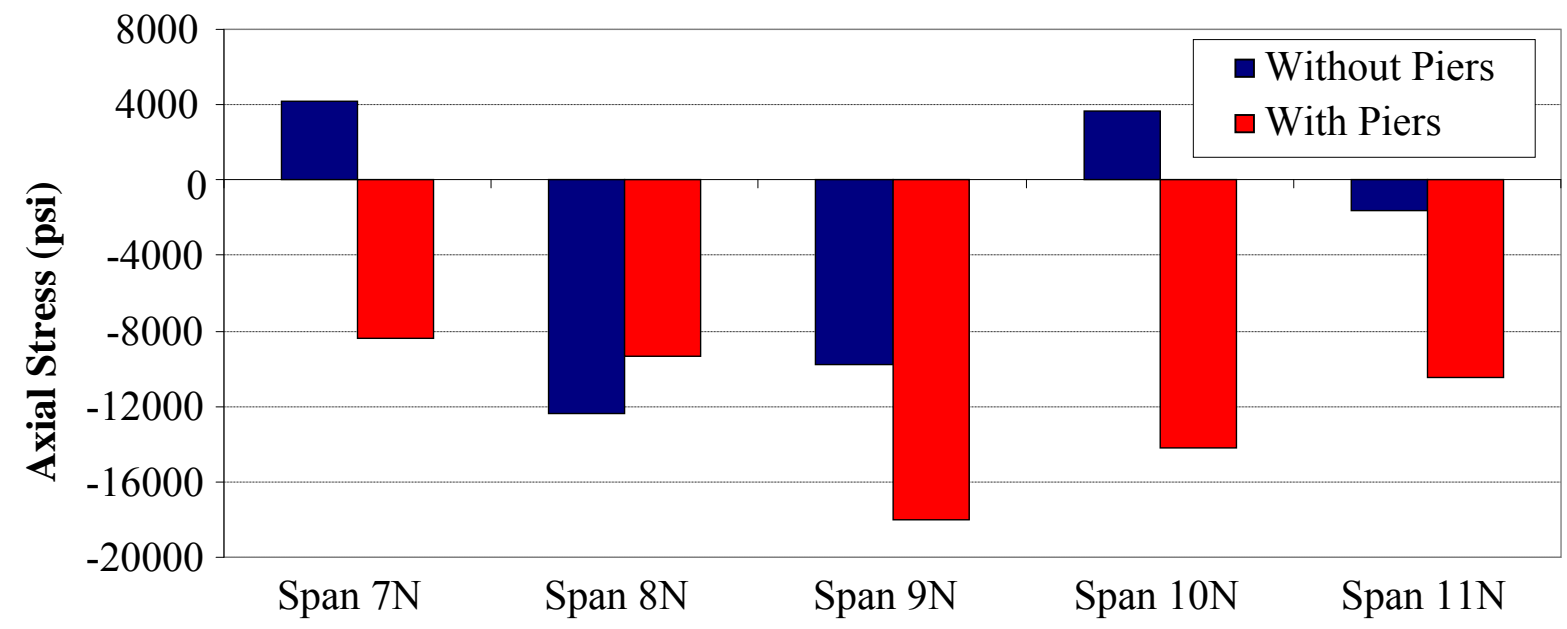

Figure 8.50 Axial Stress Comparisons near Midspans with Piers Modeled $\left(\right.$ Temp $\left.+90^{\circ} \mathrm{F}\right)$

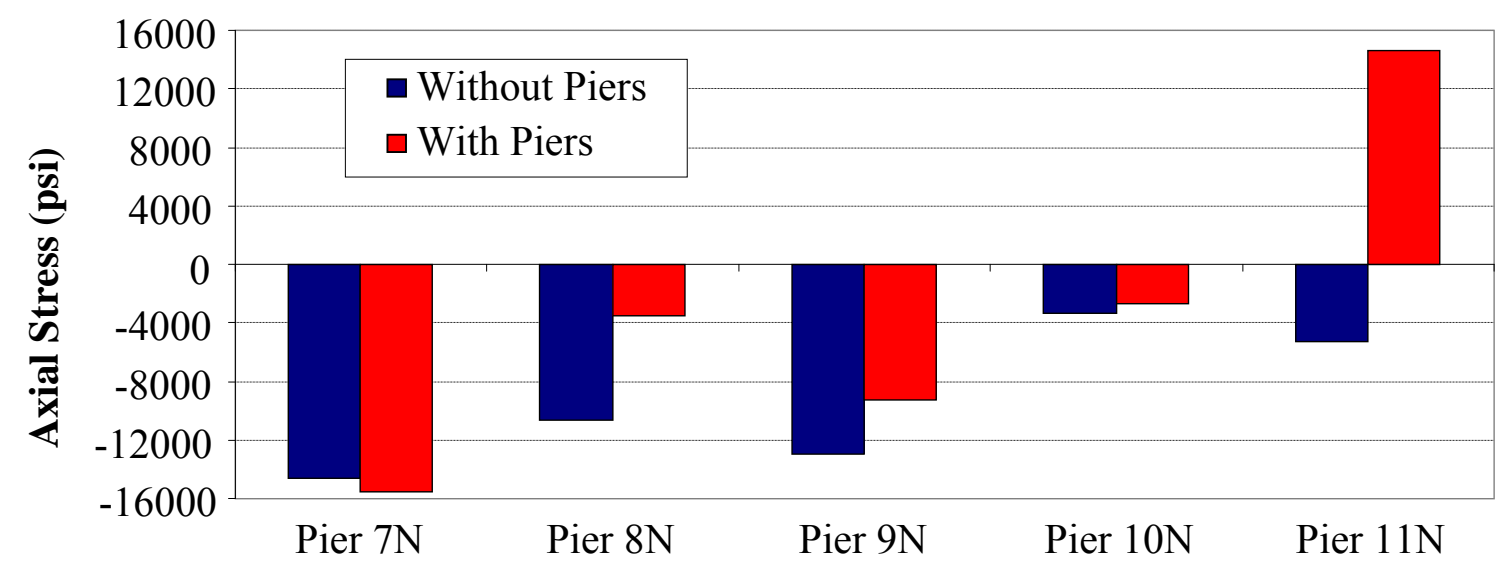

Figure 8.51 Axial Stress Comparisons at Pier Centerlines with Piers Modeled $\left(\right.$ Temp $\left.+90^{\circ} \mathrm{F}\right)$

Figures 8.50-8.51 show that the addition of the piers resulted in a reduction of compressive axial stress in Span $8 \mathrm{~N}$, and at Piers $7 \mathrm{~N}, 8 \mathrm{~N}$ and $10 \mathrm{~N}$. Compressive stress in these areas reduced approximately 24\%-65\%. All other locations examined experience an increase in compressive axial stress. The cross-sections in Spans $7 \mathrm{~N}$ and $10 \mathrm{~N}$, under axial tensile stress in the original FE model, change to a compressive state of stress when pier modeling is completed. The largest increase in compressive stress occurs near the midspan of Span 10N, where stress is $4 \mathrm{ksi}$ in tension originally, but is $9 \mathrm{ksi}$ in compression with the 
addition of the piers. Figures 8.52-8.53 show the percentage of compressive resistance consumed by the axial stresses that develop due to the $+90^{\circ} \mathrm{F}$ temperature load.

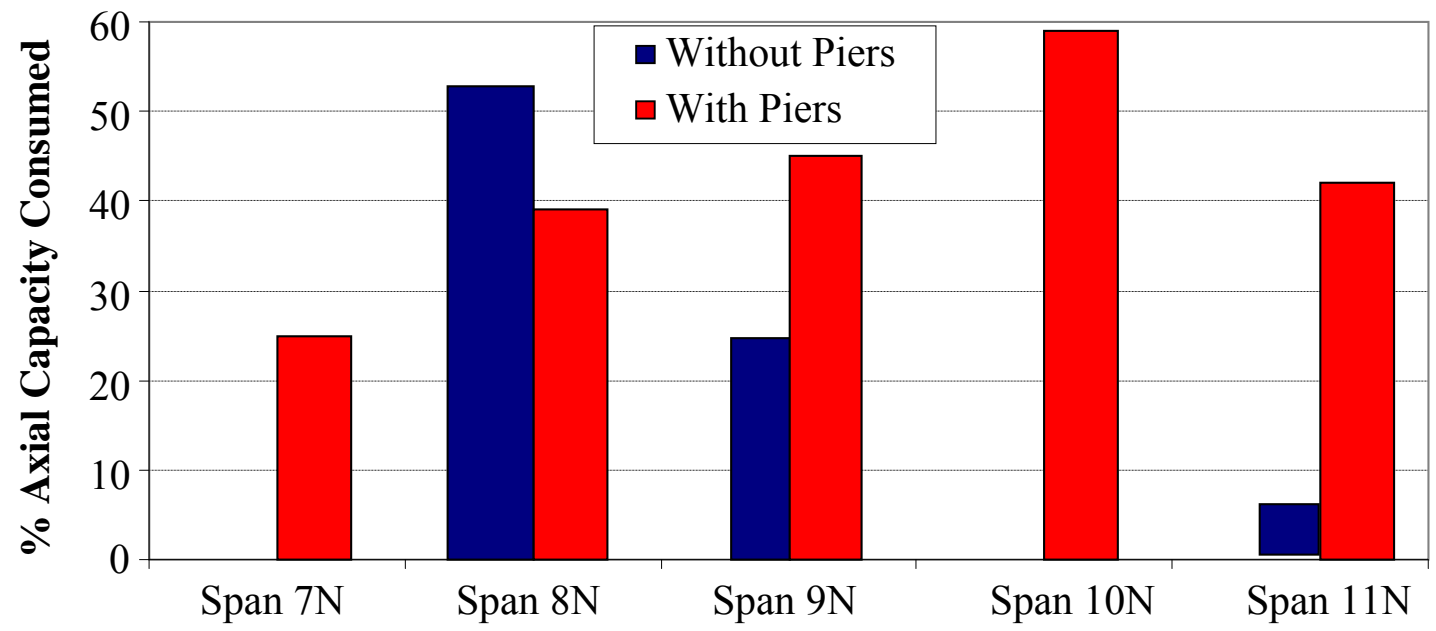

Figure 8.52 Axial Capacity Comparison Near Midspans with Piers Modeled $\left(\right.$ Temp $\left.+90^{\circ} \mathrm{F}\right)$

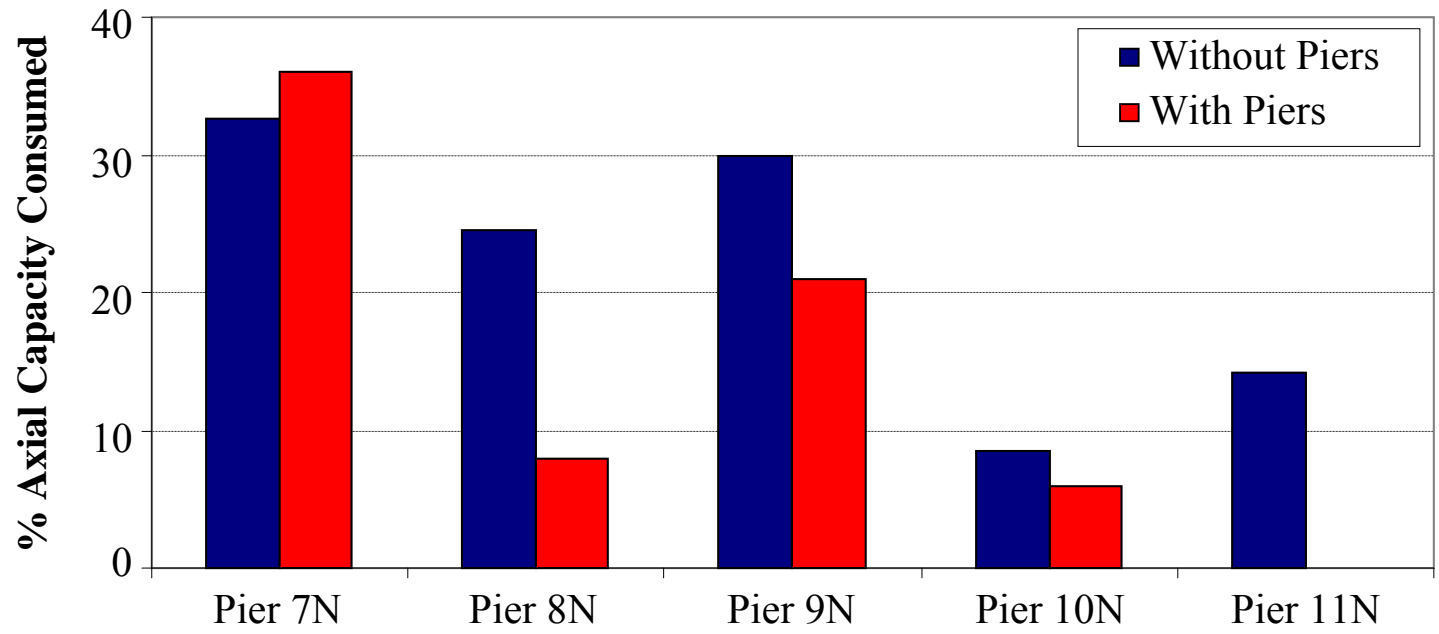

Figure 8.53 Axial Capacity Comparison at Pier Centerlines with Piers Modeled $\left(\right.$ Temp $\left.+90^{\circ} \mathrm{F}\right)$

Figures 8.52-8.53 show how the change in axial compressive stress at each location affects the percentage of axial capacity consumed when the piers are added. In Spans $7 \mathrm{~N}$, and $9 \mathrm{~N}-11 \mathrm{~N}$, axial compressive stress is larger; therefore the percentage of axial compressive capacity consumed increases. As for the pier locations, less compressive axial capacity is 
consumed at Piers $8 \mathrm{~N}-10 \mathrm{~N}$, while more capacity is used at Pier $7 \mathrm{~N}$ with the addition of the piers. The cross-section at Pier $11 \mathrm{~N}$ is in tension, so its effect on capacity is not considered. Table 8.1 shows the effect of including the piers on the total capacity of the steel I-girders. As for Spans $7 \mathrm{~N}$, and $9 \mathrm{~N}-11 \mathrm{~N}$, the increased total capacity ratio is due to the increased axial compressive stress and increased bending stress that developed in the girders, whereas the increased ratio at Piers $8 \mathrm{~N}-10 \mathrm{~N}$ is is due to the dramatic increase in bending stress values. In general, the addition of modeling the piers has negatively influenced the critical web stresses and compressive stresses produced on the bridge. The results found here are opposite to what was predicted if the piers were to be included in the FE model. It was expected that stress levels would fall in between values found for the as-built bearing arrangement and new bearing arrangement applied in Chapters Six and Seven.

Table 8.1 Bridge Girder Capacity Analysis with Piers Added (Temp $\left.+90^{\circ} \mathrm{F}\right)$

\begin{tabular}{|c|c|c|c|c|c|c|c|}
\hline & & & & $M P+90 F$ & & & \\
\hline & $\begin{array}{l}\sigma_{\text {axial }} \\
\text { (psi) }\end{array}$ & $\begin{array}{c}\sigma_{\text {axial allowable }} \\
\text { (psi) }\end{array}$ & $\sigma_{\text {axial/axial allowable }}$ & $\begin{array}{c}\sigma_{\text {bending }} \\
\text { (psi) }\end{array}$ & $\begin{array}{c}\sigma_{\text {bending allowable }} \\
\text { (psi) }\end{array}$ & $\sigma_{\text {bending/bending allowable }}$ & ratio \\
\hline Span 7N & 8400 & 33306 & 0.252 & 2790 & 9773 & 0.285 & 0.538 \\
\hline Span $\mathbf{8 N}$ & 9300 & 23516 & 0.395 & 6200 & 11340 & 0.547 & 0.942 \\
\hline Span 9N & 17990 & 39574 & 0.455 & 7400 & 9063 & 0.817 & 1.271 \\
\hline Span 10N & 14710 & 24017 & 0.612 & 3870 & 11340 & 0.341 & 0.954 \\
\hline Span 11N & 10470 & 24911 & 0.420 & 1500 & 9773 & 0.153 & 0.574 \\
\hline Pier 7N & 15500 & 44733 & 0.347 & 23750 & 12065 & 1.968 & 2.315 \\
\hline Pier 8N & 3546 & 43357 & 0.082 & 41293 & 10785 & 3.829 & 3.910 \\
\hline Pier 9N & 9286 & 43453 & 0.214 & 65000 & 10785 & 6.027 & 6.241 \\
\hline Pier 10N & 2680 & 39760 & 0.067 & 22198 & 12065 & 1.840 & 1.907 \\
\hline Pier 11N & & 37225 & & 28800 & 12065 & 2.387 & 2.387 \\
\hline
\end{tabular}




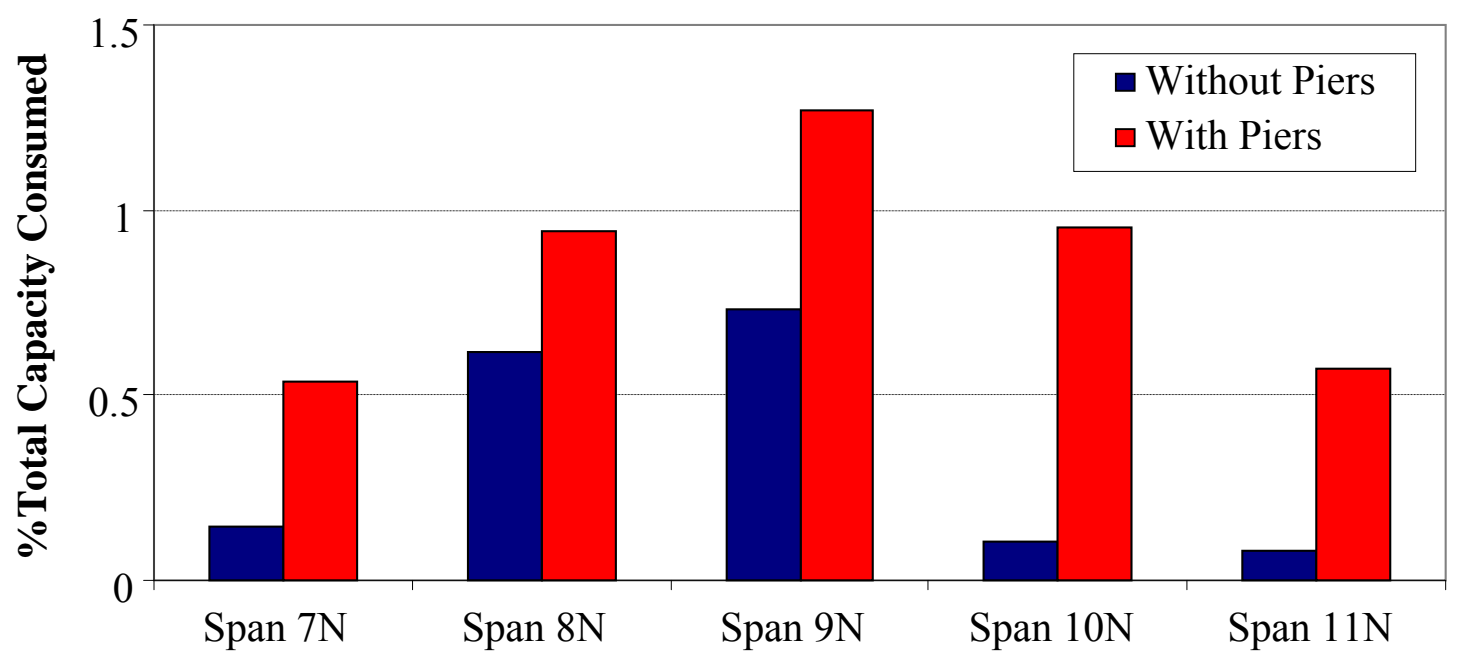

Figure 8.54 Total Capacity Comparison near Midspans with Piers Modeled $\left(\right.$ Temp $\left.+90^{\circ} \mathrm{F}\right)$

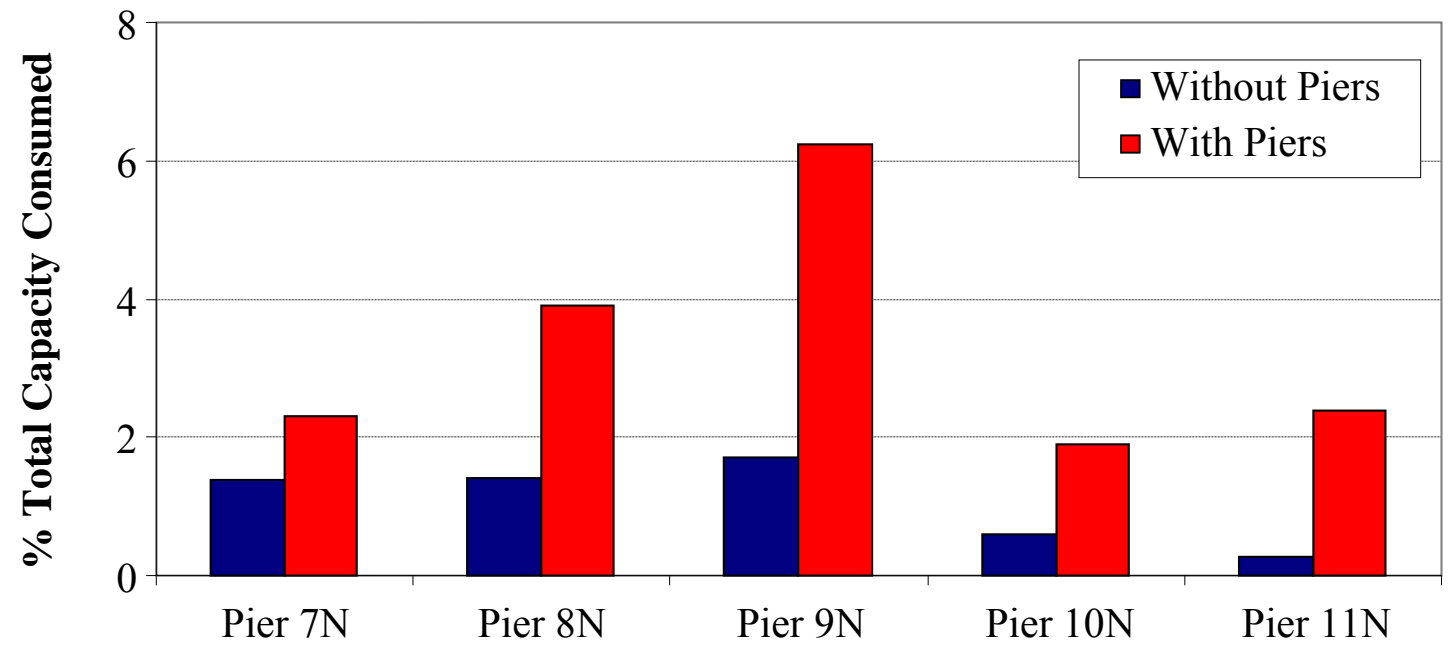

Figure 8.55 Total Capacity Comparison at Pier Centerlines with Piers Modeled $\left(\mathrm{Temp}+90^{\circ} \mathrm{F}\right)$ 


\subsection{PIER STRESSES DUE TO TEMPERATURE LOAD}

This section investigates the stresses in the concrete piers as a result of the thermal loading on the bridge superstructure. Forces imparted to the pier due to the thermal loads will result in bending and torsional moments in the pier columns. Stresses in several pier caps are also studied.

Figures 8.56-8.58 show FE model effective stress band plots of the pier caps for Piers $8 \mathrm{~N}-10 \mathrm{~N}$. Analyzing the plots in Figures 8.56-8.58, it is apparent that a large stress concentration has developed at the base of the pier cap, at the location where the column is attached. It is likely that this concentration is a result of the modeling strategy (beam-shell connection). Nonetheless, a certain pattern of stress is common for all three pier caps shown here. The highest levels of stress occur through the center portion of the pier, with areas directly under the bearings showing larger stresses as well. Throughout the center of pier caps, tensile stresses along the S-axis, shown in Figures 8.56-8.58, reach approximately 100 psi, and stresses under the bearings are around 200-250 psi. The tensile strength of the concrete used for the pier caps is 474 psi, therefore, due only to temperature load and selfweight, stresses in the pier caps reach $53 \%$ of the nominal strength of the concrete. The development of tensile stresses directly under the bearings raises the notion that the thermal loading applied to the superstructure may be resulting in an "uplift" force effect on the bearings. This uplifting force could be detrimental to the pier caps, and the bearing devices themselves, putting unforeseen stress on substructure elements such as anchor bolts. 
SMOOTHED

EFFECTIVE

RST CALC

SHELL T $=1.00$

TIME 1.000

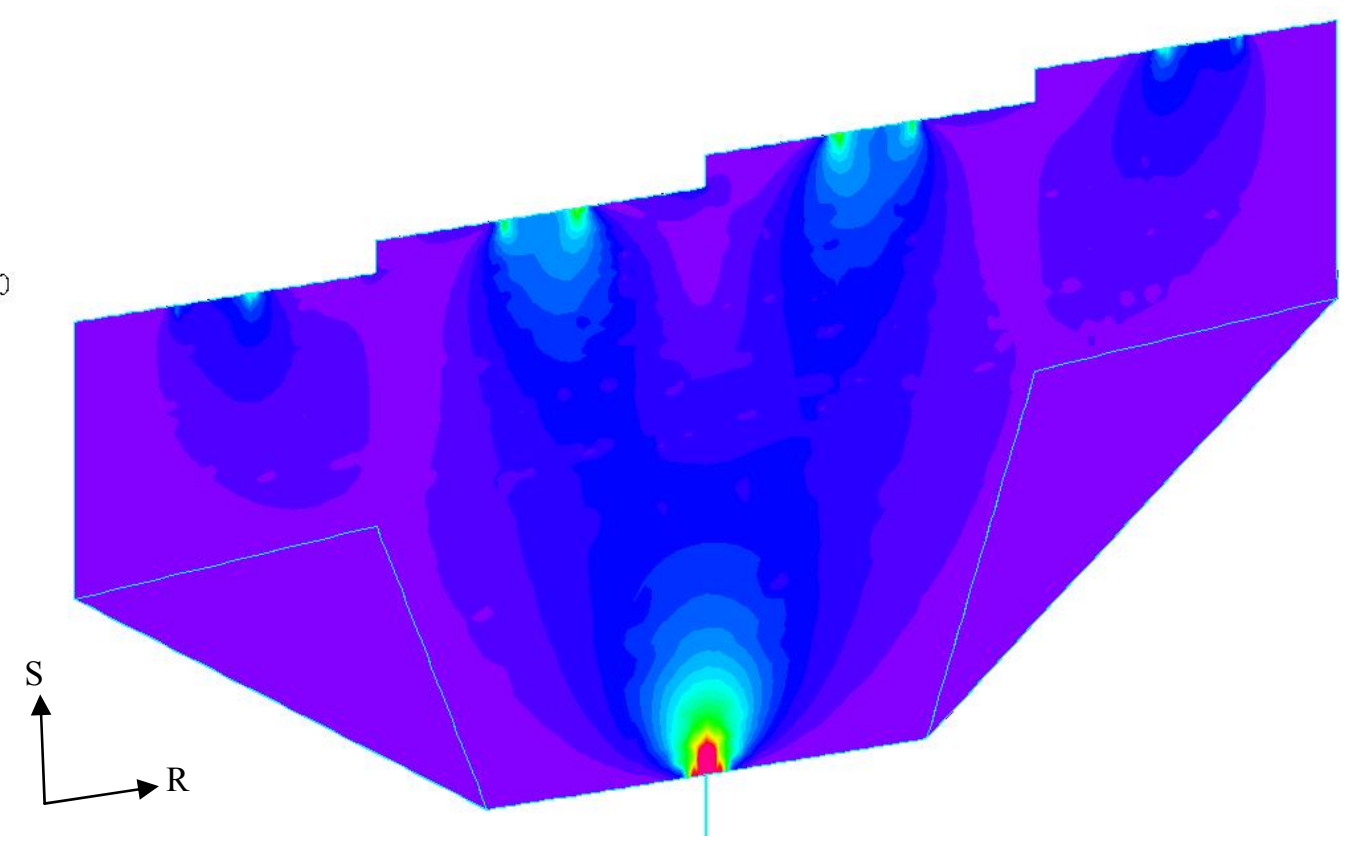

Figure 8.56 Effective Stress in Pier $8 \mathrm{~N}$ Pier Cap due to Temp $+90^{\circ} \mathrm{F}$ load case

SMOOTHED
EFFECTIVE

STRESS

RST CALC

SHELL T $=1.00$

TIME 1.000
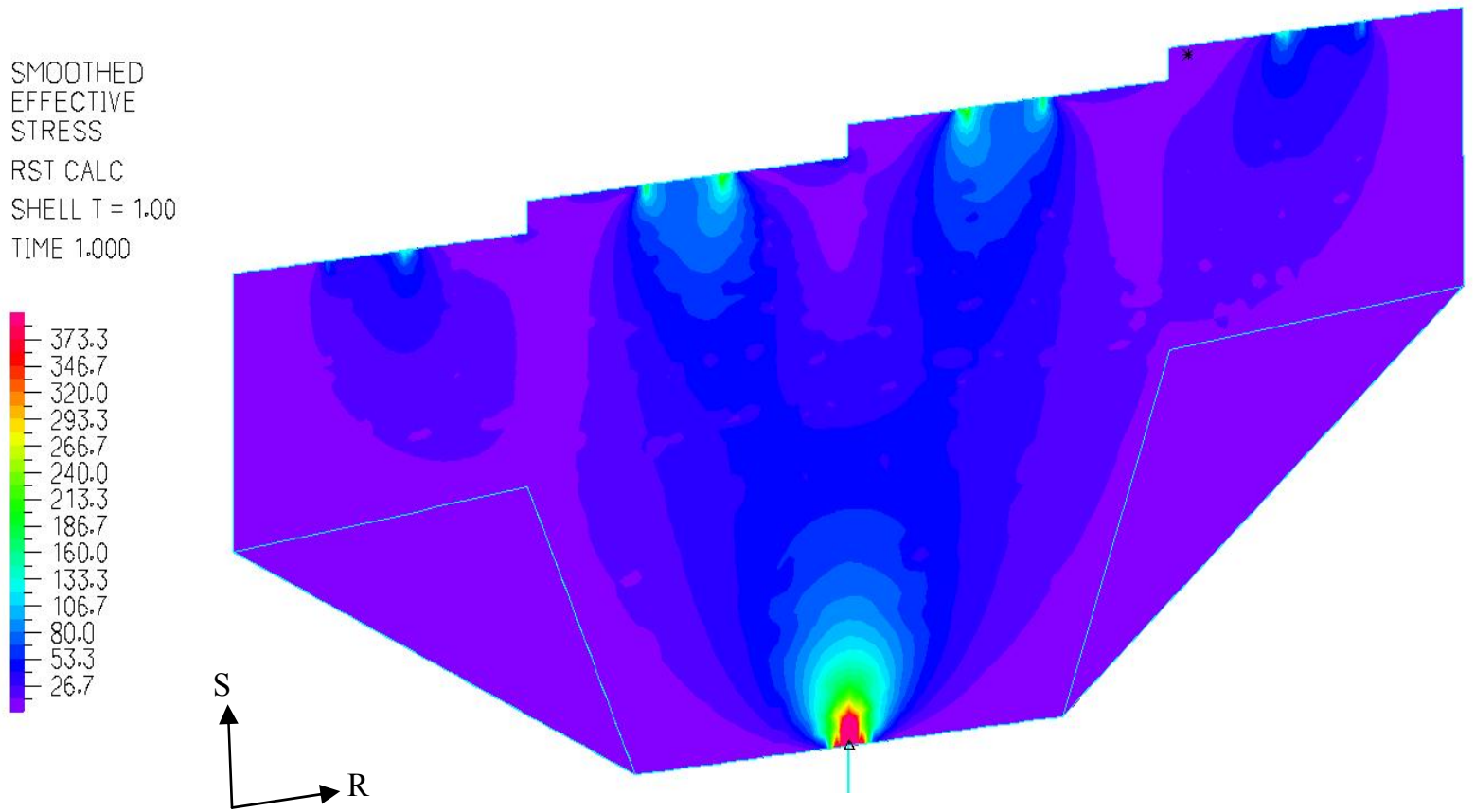

Figure 8.57 Effective Stress in Pier 9N Pier Cap due to Temp $+90^{\circ} \mathrm{F}$ load case 


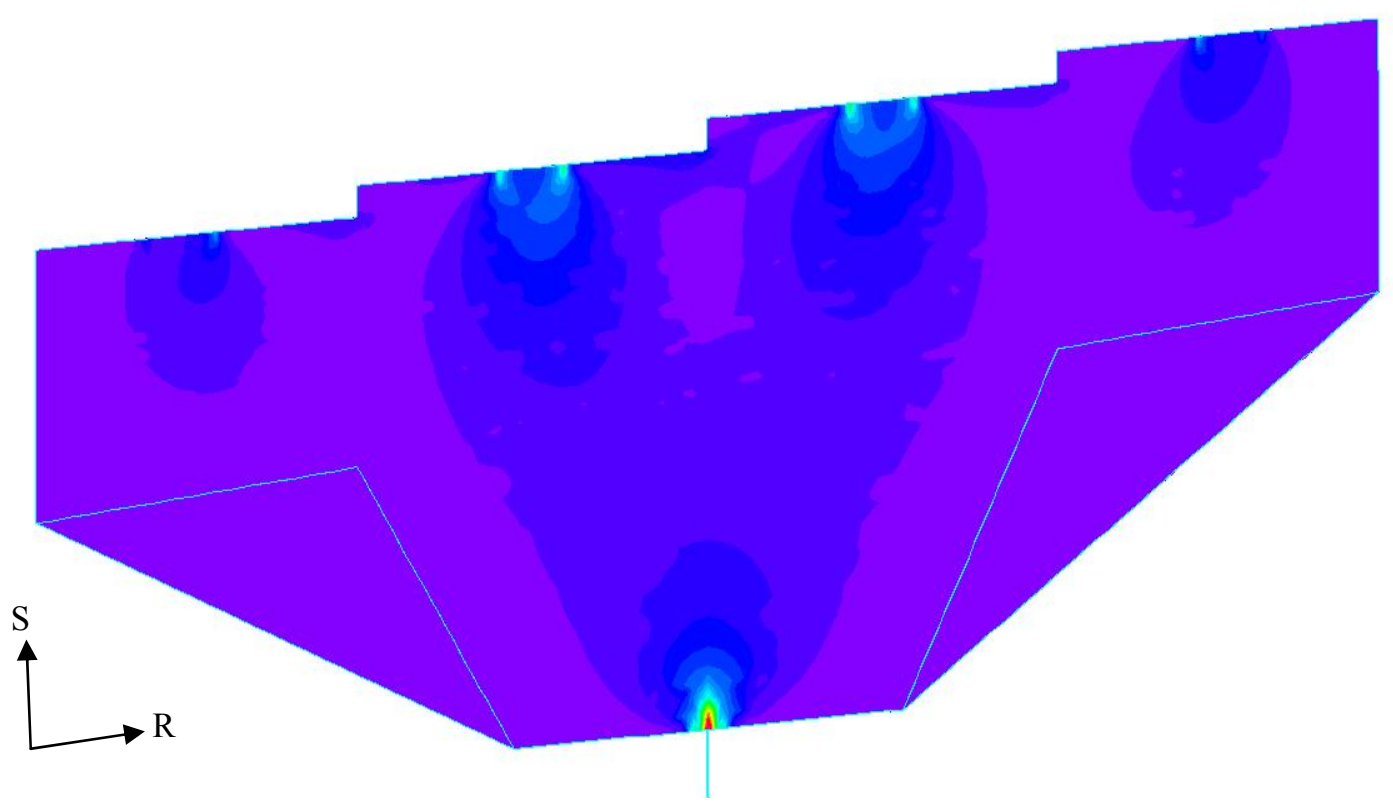

Figure 8.58 Effective Stress in Pier 10N Pier Cap due to Temp $+90^{\circ} \mathrm{F}$ load case

Bending and torsional moments developed in the pier columns are shown in Figures 8.59-8.60. Pier flexibility plays a significant role in bridge behavior, especially under thermal loading and certain bearing arrangements. Thermal expansion of the bridge superstructure will produce bending moments in the pier columns, especially if fixed bearing devices are employed. This bending of the piers will absorb a portion of stress that would otherwise be imparted to the steel I-girders. Bending stress and shear stress (due to torsion) is calculated for each pier column shown Figures 8.59 and 8.60. The bending stress in Piers $7 \mathrm{~N}-9 \mathrm{~N}$ is approximately $0.0429 \mathrm{psi}$. The pier columns are found to be in a very low state of stress. The largest shear stress due to torsion of roughly $0.0307 \mathrm{psi}$ is found in Piers $10 \mathrm{~N}-$ $11 \mathrm{~N}$. Considering bending and torsional moments, the pier columns are in a very low overall state of stress. 


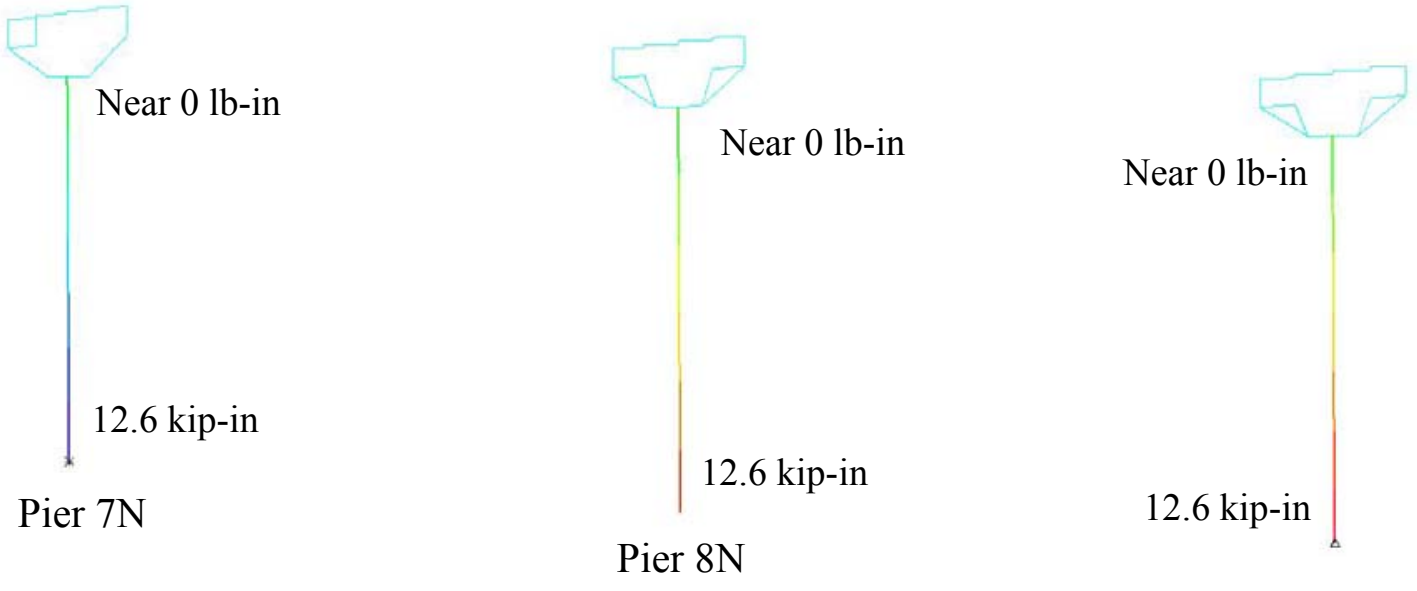

Pier 9N

Figure 8.59 Pier Bending Moments (Piers 7N-9N)

TORSIONAL MOMENT

TIME 1.000

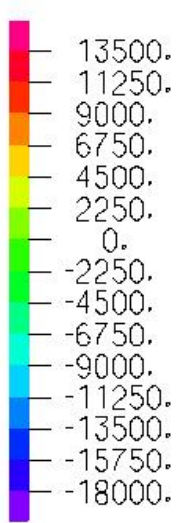

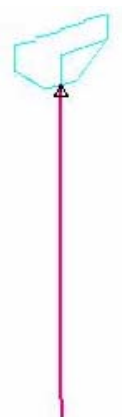

Pier $6 \mathrm{~N}$

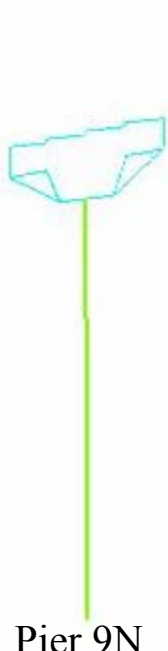

Pier 9N

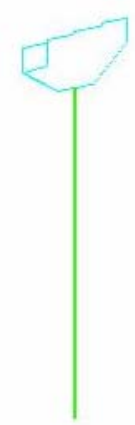

Pier $7 \mathrm{~N}$

Pier $8 \mathrm{~N}$

Figure 8.60 Pier Torsional Moments (Piers 6N-11N) 


\subsection{DISCUSSION and CONCLUSIONS}

This chapter investigated the effects of pier flexibility on the FE bridge model. The concrete pier caps and pier columns were modeled as given in the bridge design drawings. The reasoning to model the piers was to determine approximately how much thermal stress the piers and bearing devices would absorb, and how the superstructure would be affected. The affect of pier flexibility on web distortions was also investigated.

Modeling of the piers resulted in increased magnitudes of out-of-plane web distortion when the FE model is subjected to positive temperature loads. Lateral buckling was most affected, with Spans 7N-10N showing increases in out-of-plane distortion, while Spans 11N12 showed decreases. The increased web distortions are likely due to the increased overall flexibility of the FE model when the piers are included.

Stress levels due to thermal loading were significantly affected by including the piers in the FE model. Effective stress near the midspan of each span increased slightly, while at the support locations effective stress levels decreased moderately. In the original FE model, cross-sections at Piers $7 \mathrm{~N}$ and $9 \mathrm{~N}$ were roughly $72 \mathrm{ksi}$, but these stresses decreased to $55 \mathrm{ksi}$ and $65 \mathrm{ksi}$ respectively when the piers were modeled. At Piers $7 \mathrm{~N}-10 \mathrm{~N}$, effective stress levels decreased, while longitudinal stresses increased, meaning that shear stress at these support locations has decreased with the inclusion of the piers in the FE model. Longitudinal compressive stress increased throughout the bridge, while axial compressive stress decreased at Piers $8 \mathrm{~N}-10 \mathrm{~N}$. However, at these locations (Piers $8 \mathrm{~N}-10 \mathrm{~N})$, maximum bending stresses increased dramatically, causing the critical web stresses to exceed allowable values by $600 \%$ (at Pier 9N).

Bending stress and shear stress due to torsion in the pier columns are very low, at 0.0429 psi and 0.0307 psi respectively. Maximum tensile stress in the concrete pier caps is 
roughly $53 \%$ of the nominal tensile strength of concrete. Therefore, it seems that the piers included in the FE model did not absorbed very large amounts of thermal stress, as evident in the low states of stress in the pier caps and columns. 


\section{CHAPTER NINE}

\section{CONCLUSIONS AND FUTURE RESEARCH}

\subsection{CONCLUSIONS}

This study focused on the affects of thermal loading on out-of-plane web distortion and thermal stress development in a horizontally curved steel I-girder bridge. Out-of-plane web distortions and thermal stresses were investigated using a highly detailed 3D FE model, which was verified using field measurements obtained by TOPCON Imaging Station. Three separate FE models were developed according to the design plans of the bridge in this study. The first model employed the actual bearing arrangement from the design drawings, while a new bearing plan was implemented in the second model. Third, the concrete piers were modeled with the original bearing arrangement applied to study the influence of pier flexibility on web distortions and thermal stresses. The following conclusions can be generated based on the analyses performed during this research:

1. Web slenderness and transverse stiffener spacing throughout the positive moment regions of the bridge fails to meet AASHTO (2003) specifications.

2. Small magnitudes of out-of-plane web distortion are present in the bridge under self-weight dead load alone.

3. Under the as-built bearing arrangement, thermal loading significantly magnifies the web distortions experienced due to bridge self-weight. A maximum out-ofplane displacement on Girder $4 \mathrm{~N}$ of approximately 2.5 in. was produced at the midspan of Span $9 \mathrm{~N}$ under the $+90^{\circ} \mathrm{F}$ temperature load. Lateral web buckling is the major component of the increased web distortion under temperature loads. 
4. It was found that the FE model behaves in an elastic manner when the magnitude of the uniform temperature load is between $-/+60^{\circ} \mathrm{F}$. Temperature loads in excess of these values initiate plastic behavior in the steel bridge girders.

5. The addition of the AASHTO HL-93 live load increased out-of-plane web distortion at lower temperature loads. When applied to the FE model with the $+60^{\circ} \mathrm{F}$ thermal load, the AASHTO truck load results in a $33 \%$ increase in out-ofplane distortion. An $8 \%$ increase is recorded when the truck load is added to the $+90^{\circ} \mathrm{F}$ temperature load.

6. The severity of out-of-plane distortions produced by the FE model generates concerns over the short and long-term serviceability of the bridge.

7. Due to the lack of thermal movement allowed under the as-built bearing arrangement, large magnitudes of thermal stress (axial compressive stress) develop in the bridge at several locations. In several cases, the magnitude of axial stress in the girder webs is greater than the bending stress.

8. Longitudinal compressive stress at five cross-sections (Span 8N, Span 9N, Pier $7 \mathrm{~N}$, Pier $8 \mathrm{~N}$, and Pier $9 \mathrm{~N})$ exceed critical web stress $\left(F_{c r}\right)$ values set forth by AASHTO specifications. This is due in part to axial compressive stresses that develop at these locations.

9. Axial compressive stresses attributable solely to thermal loading consume roughly $25-30 \%$ of the overall capacity of the girder at the five locations mentioned in (7). Near the midspan of Span $8 \mathrm{~N}, 52 \%$ of the girder's capacity is consumed up by compressive stresses, making less than $50 \%$ of the girder's total capacity available to resist flexural loads. 
10. A new bearing arrangement implemented on the FE model significantly decreased out-of-plane web distortions throughout the bridge. The 2.5 in web distortion near the midspan of Span $9 \mathrm{~N}$ is reduced to approximately $0.25 \mathrm{in}$. The maximum out-of-plane displacement recorded under the new bearing conditions is roughly $1.12 \mathrm{in}$. at Abutment $2 \mathrm{~N}$.

11. Under the new bearing arrangement, the magnitude of lateral web buckling experienced the most significant reduction. While local web buckling is almost eliminated at the cross-sections examined, the decrease in lateral buckling seems to be a more important factor when analyzing total web distortion.

12. Implementing the new bearing arrangement significantly reduces the magnitude of axial compressive stress that develops in the bridge girders. The greatest reduction occurred in Span $8 \mathrm{~N}$, where a 95\% decrease in compressive stress is recorded. Under the new bearing plan, a much larger percentage of the total structural capacity of the bridge girders is available for flexural load resistance.

13. Four of the six spans experienced increased out-of-plane distortion when the piers were modeled. Average increases were around 20\% in Spans $8 \mathrm{~N}-10 \mathrm{~N}$, while near the midspan of Span $7 \mathrm{~N}$ showed an increase of roughly $100 \%$. Spans $11 \mathrm{~N}-12 \mathrm{~N}$ showed average decreases in web distortion of $50 \%$ and $80 \%$ respectively.

14. Effective stress levels decreased significantly at Piers $7 \mathrm{~N}, 9 \mathrm{~N}$, and $11 \mathrm{~N}$ when the piers included in the FE model. At Piers $7 \mathrm{~N}$ and $9 \mathrm{~N}$, effective stress decreased from near $72 \mathrm{ksi}$, to $55 \mathrm{ksi}$ and $65 \mathrm{ksi}$ respectively. Effective stress near midspans increased, with Span 9N showing the largest stress at $21 \mathrm{ksi}$. 
15. Longitudinal stress increased throughout the bridge with the inclusion of pier flexibility. Maximum longitudinal stress near the midspans is around $21 \mathrm{ksi}$ in Span 9N. Maximum longitudinal stress at the pier locations increased as well, with the largest value of $65 \mathrm{ksi}$ occurring at Pier 9N. All other locations are showing stresses less than $40 \mathrm{ksi}$.

16. Axial compressive stress increased at most midspans locations, while reducing at most pier support locations. Spans $7 \mathrm{~N}$ and $10 \mathrm{~N}-11 \mathrm{~N}$ were in axial tension in the original FE model, but produced compressive stress when the piers were included. The largest compressive stresses occur in Span 9N and at Pier 7N. Compressive stress at these locations is $18 \mathrm{ksi}$ and $16 \mathrm{ksi}$ respectively.

17. In Spans $7 \mathrm{~N}-11 \mathrm{~N}$, a greater percentage of total capacity is consumed by axial compressive stress, while less capacity is consumed at Piers $8 \mathrm{~N}-10 \mathrm{~N}$. At the midspan locations, $25-60 \%$ of axial capacity is consumed, while at the pier locations $0-35 \%$ is consumed.

18. While axial stress at the pier locations decreased, the total percentage of girder capacity consumed increased dramatically as a result of pier modeling. Calculations showed an increase of over $600 \%$ (at Pier 9N). Therefore, the inclusion of the piers significantly increased bending stresses throughout the bridge.

19. After analyzing the results from this study, it is apparent that axial stresses should not be ignored during the bridge design process. As shown here, axial stress can be comparable or exceed bending stress levels.

20. Lastly, web distortions and residual stresses due to fabrication, erection, and transportation errors were neglected in the FE models. Any additional 
distortions or stresses due to these errors would negatively influence the results found in this study. Therefore, the predictions made using the FE model underestimate the actual conditions on the bridge.

\subsection{FUTURE RESEARCH and RECOMMENDATIONS}

1. AASHTO (2003) recognizes that temperature change within a bridge is not uniform, as applied in this research, but in general, bridges are designed with an assumed uniform temperature change. It is well-known that a temperature gradient develops between the deck and steel girders, and through the depth of the girders due to environmental temperature fluctuations. A similar study to the one presented in this research could be performed with a temperature gradient applied to determine its effect on the development of thermal stresses and web distortions in the steel I-girders.

2. Studies into several different bearing arrangements and orientations could be performed to maximize the accommodation of thermal movement.

3. Efforts could be made to more accurately investigate the effects of the AASHTO truck load on stresses in the steel girders.

4. The thickness of the web plates in the FE model should be increased so as to be in accordance with web slenderness requirements in AASHTO (2003). Afterward, an investigation into the out-of-plane web distortions of the girders should be completed to determine the effect of increased web thicknesses.

5. Transverse stiffeners could be installed throughout the FE model at the spacing calculated by AASHTO (2003) to determine whether or not the lack of stiffeners influences the out-of-plane distortion observed on the bridge. 
6. It needs to be verified whether or not detailing inconsistencies and other construction issues, such as web out-of-plumbness, occurred during steel erection. If so, the magnitude of residual stresses would need to be determined and introduced into the FE model to create a more accurate depiction of the actual stress condition on the bridge.

7. Strength reduction equations that take into account residual stresses due to thermal loading need to be developed.

8. Design standards need to be developed that take into account thermal stresses. The standard should recognize that the magnitude of thermal stresses may be equal to or greater than those stresses produced by flexural forces due to bridge self-weight dead load.

9. The majority of this study focused on the behavior of Unit 2 (Spans $7 \mathrm{~N}-12 \mathrm{~N}$ ) of the bridge. The FE model of Unit 1 (Spans 1N-6N) was not heavily utilized because several modifications are needed in order to create a model comparable in detail to Unit 2. Future tasks will include adding the field splices and concrete piers to the FE model of Unit 1. 


\section{REFERENCES}

1. American Association of State Highway and Transportation Officials (2003). AASHTO Guide Specifications for Horizontally Curved Steel Girder Highway Bridges, Washington D.C.

2. American Association of State Highway and Transportation Officials (2007). AASHTO LRFD Bridge Design Specifications, $4^{\text {th }}$ ed., Washington D.C.

3. AASHTO-NSBA Steel Bridge Collaboration (2004). Steel Bridge Bearing Design and Detailing Guidelines, Washington D.C.

4. Abdel-Sayed, G. (1973). Curved Webs Under Combined Shear and Normal Stresses. Journal of the Structural Division, vol. 99, no. 3, pp. 45-53.

5. AISC Steel Construction Manual (2005). American Institute of Steel Construction Inc., $13^{\text {th }}$ ed.

6. AISI Steel Bridge Bearing Selection and Design Guide. American Iron and Steel Institute, Highway Structures Design Handbook, vol. 2, chap. 4.

7. Baber, T.T. and Lydzinski, J.C. (2008). Finite Element Analysis of the Wolf Creek Mutlispan Curved Girder Bridge. University of Virginia Research Rep. No. FHWA/VTRCO8-CR6, Univ. of Virginia, Charlottesville, VA.

8. Bathe, K.J. (2009). ADINA Theory and Modeling Guide, Volume 1. ADINA R\&D Inc., 71 Elton Ave., Watertown, MA 02472.

9. Bradford, M.A. (1988). Buckling of Elastically Restrained Beams With Web Distortions, Thin-Walled Structures, vol. 6, pp. 287-304. 
10. Chavel, B. W. and Earls, C. J. (2003). Investigation of Construction Issues and Inconsistent Detailing in Horizontally Curved Steel I-Girder Bridge, Journal of the Transportation Research Board. Transportation Research Board, Washington D.C.

11. Culver, C.G. (1972). Web Slenderness Requirements For Curved Girders, Journal of the Structural Division, vol. 99, no. 3, pp. 417-430.

12. Davidson, J. S., Ballance, S. R., and Yoo, Chai H. (1999). Analytical Model of Curved IGirder Web Panels Subject to Bending, Journal of Bridge Engineering, vol. 4, no. 3, pp. 204-212.

13. Davidson, J. S., Ballance, S. R., and Yoo, Chai H. (2000). Behavior of Curved I-Girder Web Panels Subjected to Combined Bending and Shear, Journal of Bridge Engineering, vol. 5, no. 2, pp. 165-170.

14. Davidson, J. S., Keller, M. A., and Yoo, Chai H. (1996). Cross-Frame Spacing and Parametric Effects in Horizontally Curved I-Girder Bridges, Journal of Structural Engineering, vol. 122, no. 9, pp. 1089-1096.

15. Davidson, J. S. and Yoo, Chai H. (2002). Stability of Horizontally Curved I-Girder Web Panels

16. Davidson, J. S. and Yoo, Chai H. (2003). Effects of Distortion on Strength of Curved I-Shaped Bridge Girders, Transportation Research Record, vol. 1845, Transportation Research Board, Washington D.C.

17. Goodier and Barton (1944). The Effects of Web Deformation on the Torsion o I Beams. Journal of Applied Mechanics. 
18. Grubb, M.A., Yadlosky, J.M., and Duwadi, S.R. (1996). Construction Issues in Steel Curved-Girder Bridges, Transportation Research Record, vol. 1544, Transportation Research Board, Washington D.C.

19. Howell, T.D. and Earls, C.J. (2007). Curved Steel I-Girder Bridge Response During Construction Loading: Effects of Web Plumbness, Journal of Bridge Engineering, vol. 12, no. 5, pp. 485-493.

20. Kala, Z., Kala, J., Skaloud, M., and Teply, B. (2005). Sensitivity Analysis of the Effect of Initial Imperfections on the i) Ultimate Load and ii) Fatigue Behavior of Steel Plate Girders, Journal of Civil Engineering and Management, vol. 11, no. 2, pp. 99-107.

21. Kim, S.H., Lee, Y.S., and Cho, K.Y. (2005). Analysis of Horizontal Reactions Due to Moving Vehicle Loads in Curved Bridges With Varied Support Conditions, Advances $\quad$ in Structural Engineering, vol. 8, no. 5, pp. 529-545.

22. Kim, Y.D., Jung, S., and White, D.W. (2007). Transverse Stiffener Requirements in Straight and Horizontally Curved Steel I-Girder Bridges, Journal of Bridge Engineering, vol. 12, no. 2, pp. 174-183.

23. Lee, Sung C. and Yoo, Chai H. (1999). Strength of Curved I-Girder Web Panels Under Pure Shear, Journal of Structural Engineering, vol. 125, no. 8, pp. 847-853.

24. Linzell, D., Hall, D., and White, D. (2004). Historical Perspective on Horizontally Curved I-Girder Bridge Design in the United States, Journal of Bridge Engineering, vol. 9, no. 3, pp. 218-229.

25. Madhavan, M. and Davidson, J.S. (2009). Theoretical Evaluation of Flange Local Buckling for Horizontally Curved I-Girders, Journal of Bridge Engineering, v ol. 14 , no. 6 , pp. 424-435. 
26. Mariani, N., Mozer, J.D., Dym, C.L., and Culver, C.G. (1973). Transverse Stiffener Requirements for Curved Webs, Journal of the Structural Division, vol. 99, no. 4, pp. 757-771.

27. McBride, Kevyn (2005). Thermal Stresses in the Superstructure of Integral Abutment Bridges. MS Thesis. West Virginia University, Morgantown, 2005.

28. Moorty, S. and Roeder, C.W. (1990). Thermal Movements in Bridges, Transportation Research Record, vol. 1290, Transportation Research Board, Washington D.C.

29. Moorty, S. and Roeder, C.W. (1992). Temperature-Dependent Bridge Movements, Journal of Structural Engineering, vol. 118, no. 4, pp. 1090-1105.

30. Moulton, L.K. (1983). Observations of Highway Bridge Movements and Their Effects on Joints and Bearings, Transportation Research Record, vol. 903, Transportation Research Board, Washington D.C.

31. Samaan, M., Sennah, K., and Kennedy, J.B. (2002). Positioning of Bearings for Curved Continuous Spread-Box Girder Bridges, Canadian Journal of Civil Engineering, vol. 29, pp. 641-652.

32. SITE-Blauvelt Engineers (2004). West Virginia Division of Highways (WVDOH) Engineering Division: Bridge Design Manual, $1^{\text {st }}$ ed.

33. Thatcher, W.M. (1967). Horizontally Curved Steel Girders: Fabrication and Design, AISC National Engineering Conference, San Francisco, CA, pp. 107-112. 
34. White, W.D. and Jung, S. (2007). Effect of Web Distortion on the Buckling Strength of Noncomposite Discretely-Braced Steel I-Section Members, Journal of Engineering Structures, vol. 29, pp. 1872-1888.

35. Yoo, C.H. and Littrell, P.C. (1986). Cross-Bracing Effects in Curved Stringer Bridges, Journal of Structural Engineering, vol. 112, no. 9, pp. 2127-2140.

36. Zurieck, A., Linzell, D. Leon,R.T., and Burrell, J. (2000). Curved Steel I-Girder Bridges: Experimental and Analytical Studies, Journal of Engineering Structures, vol. 22, no. 2, pp. 180-190. 


\section{APPENDIX A}

\section{AS-BUILT LONGITUDINAL WEB PROFILES - GIRDER 3N}

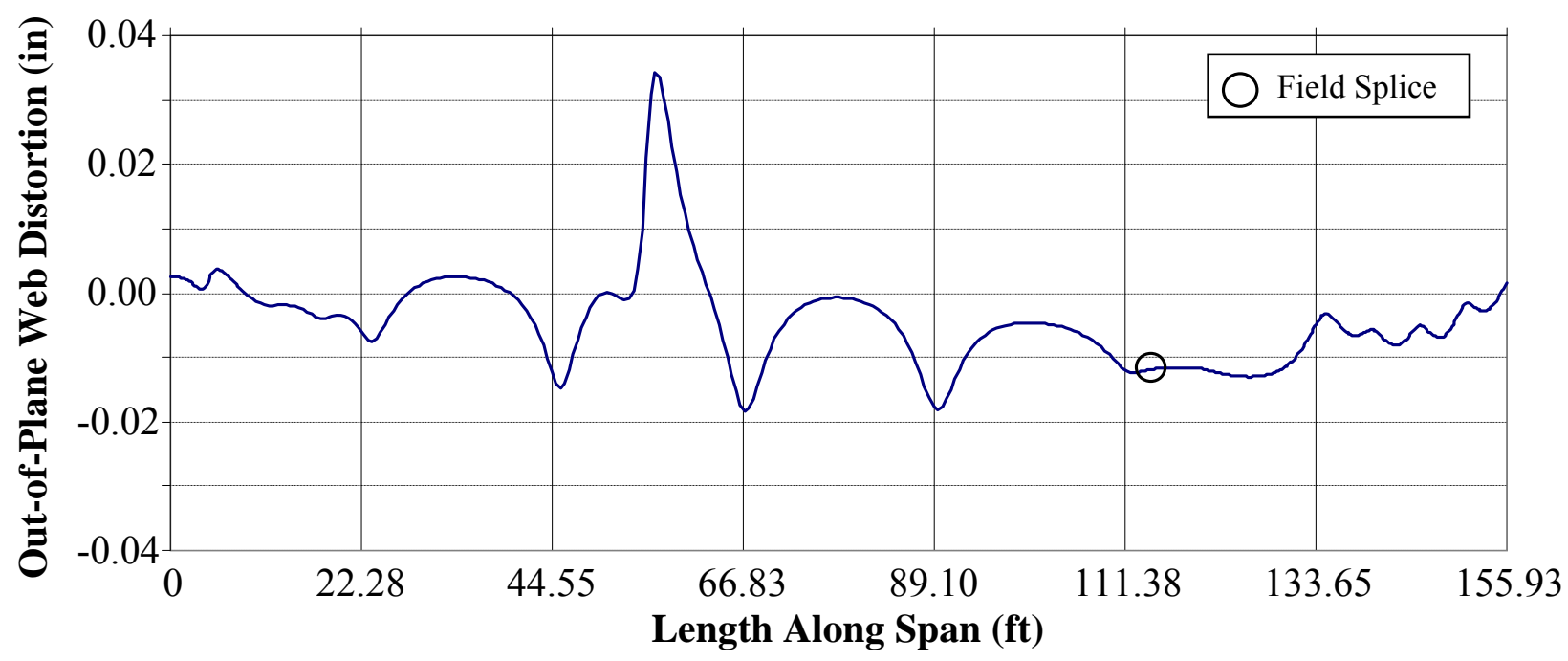

Figure A.1 Span 7N, Girder 3N Longitudinal Web Profile (Self-Weight)

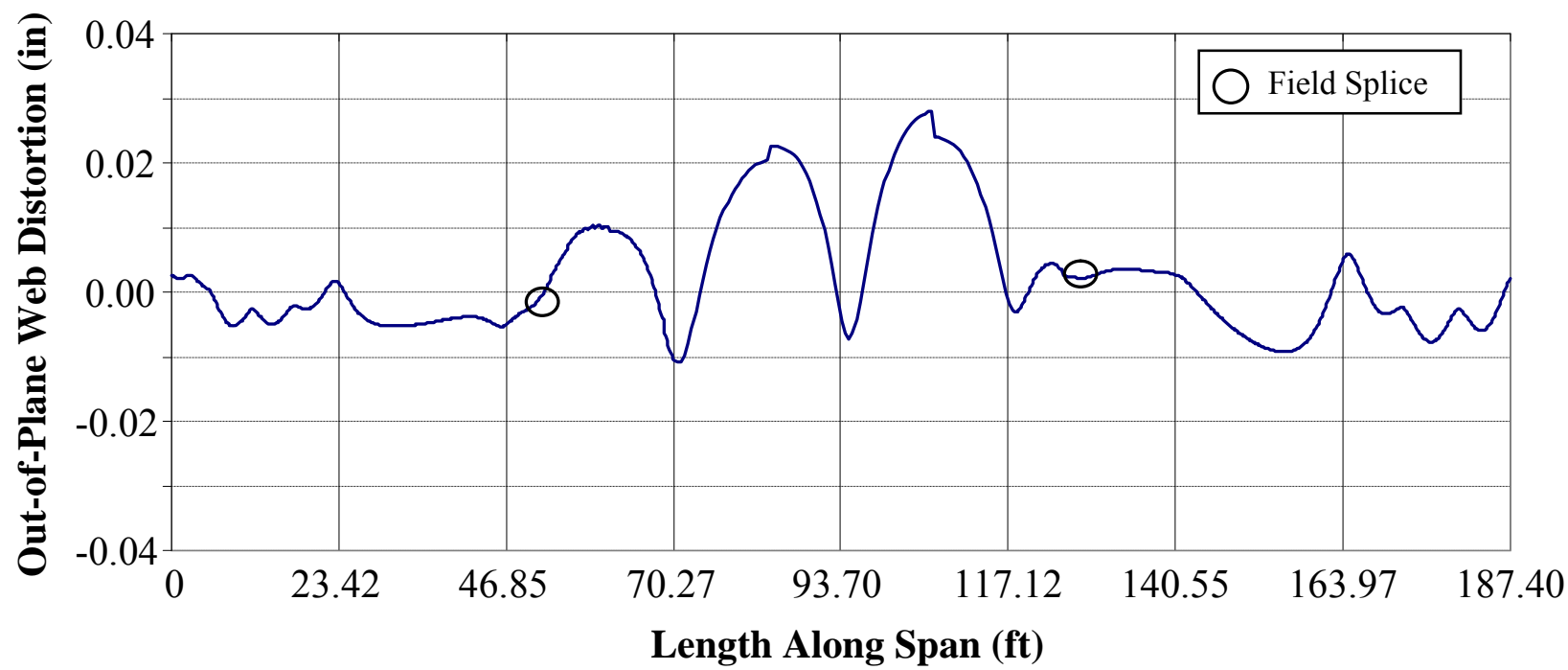

Figure A.2 Span 8N, Girder 3N Longitudinal Web Profile (Self-Weight) 


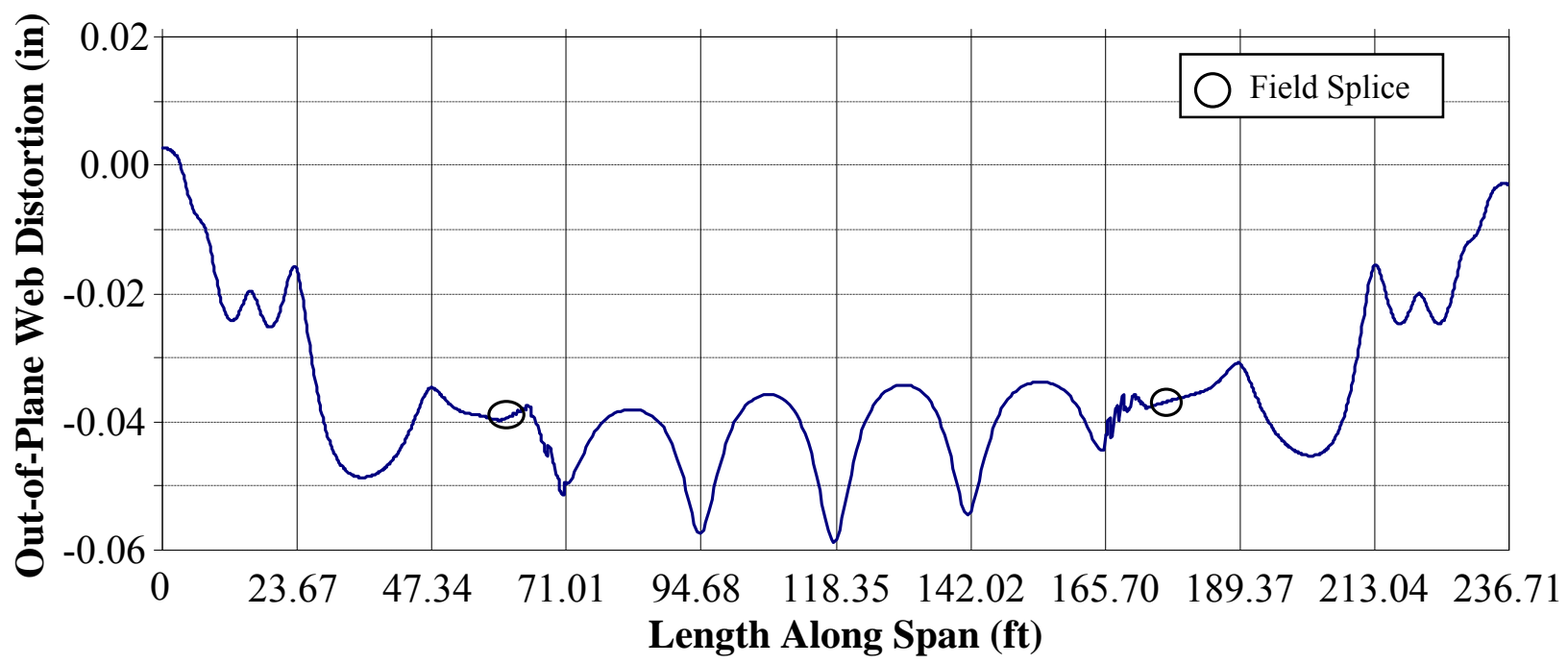

Figure A.3 Span 9N, Girder 3N Longitudinal Web Profile (Self-Weight)

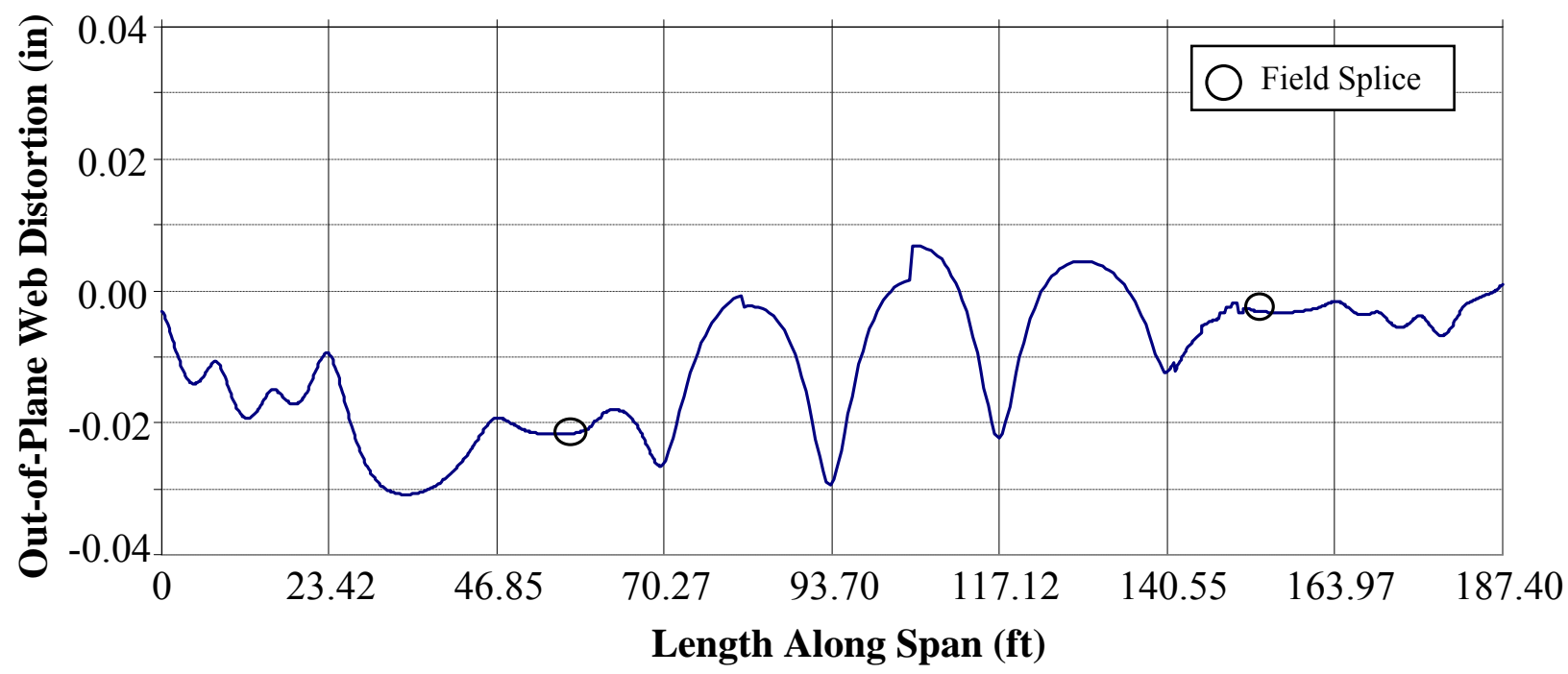

Figure A.4 Span 10N, Girder 3N Longitudinal Web Profile (Self-Weight)

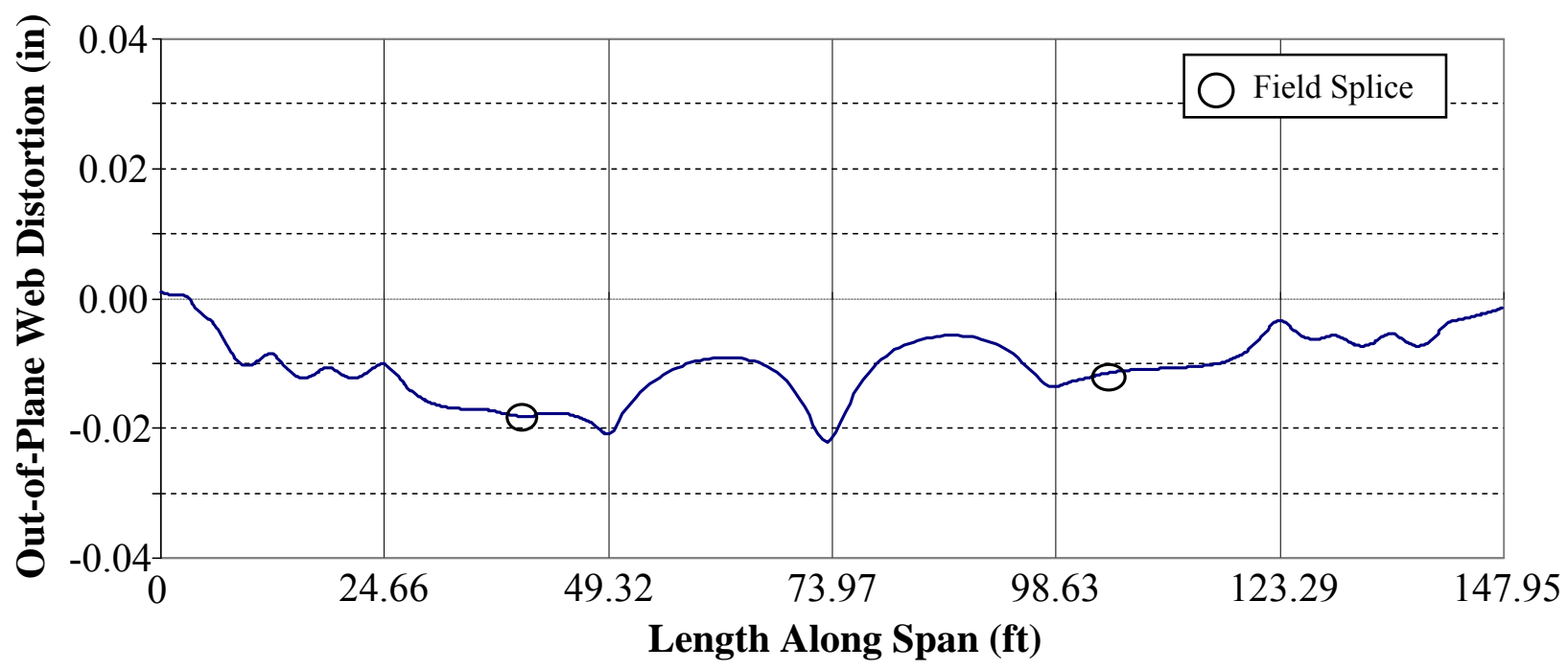

Figure A.5 Span 11N, Girder 3N Longitudinal Web Profile (Self-Weight) 


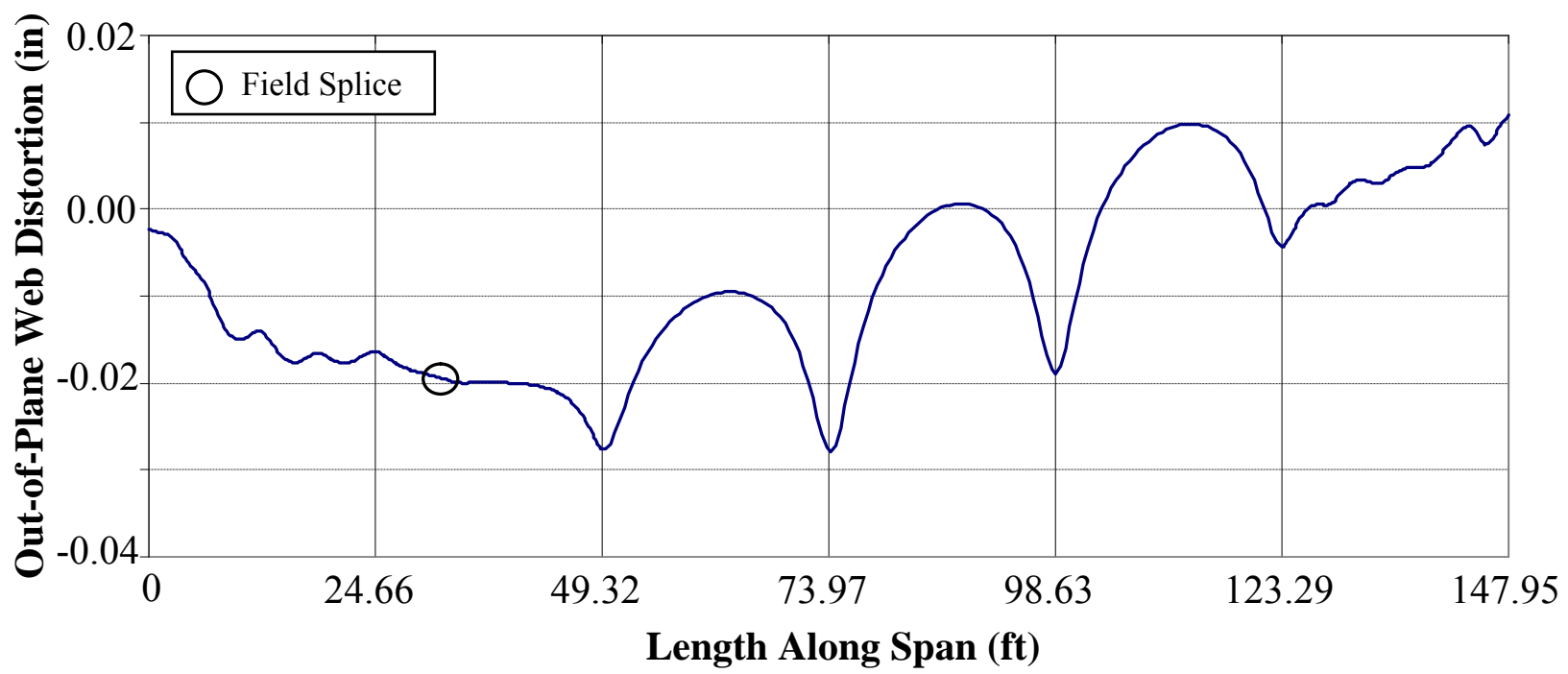

Figure A.6 Span 12N, Girder 3N Longitudinal Web Profile (Self-Weight)

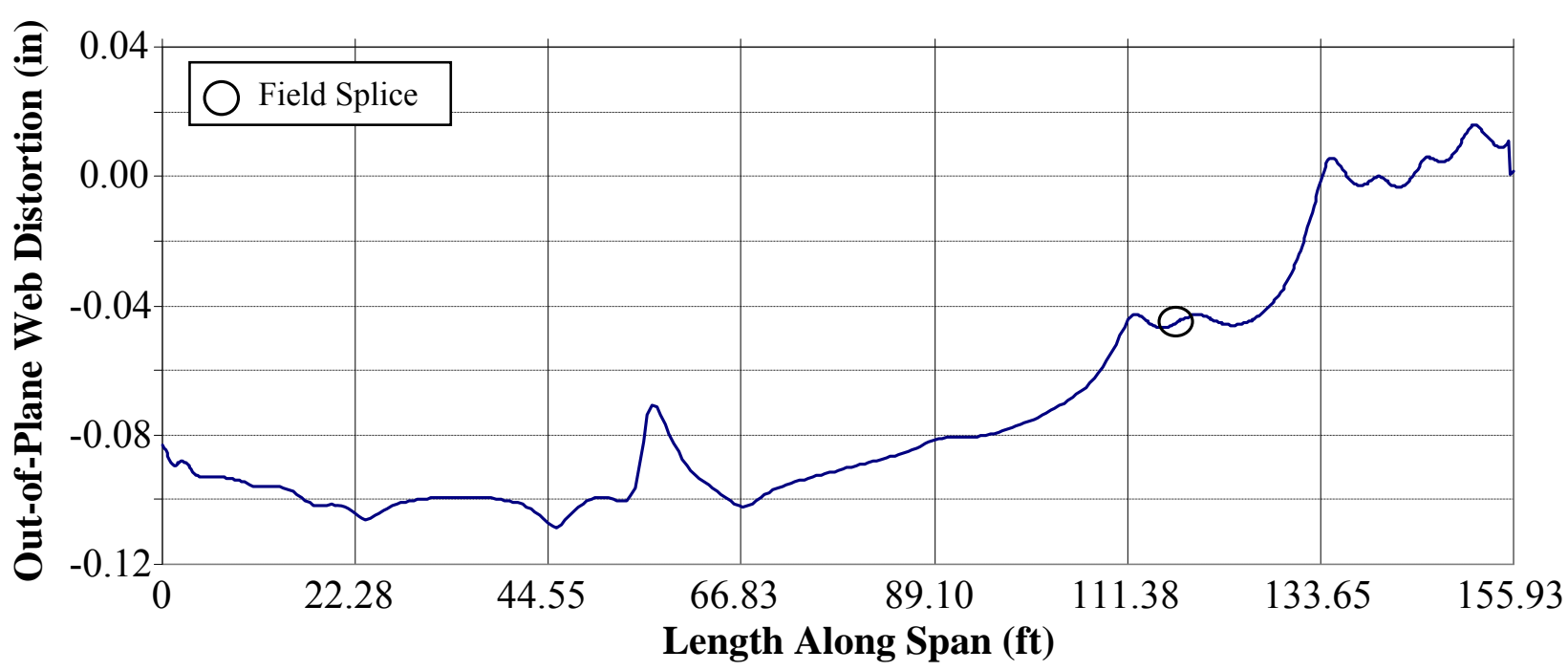

Figure A.7 Span 7N, Girder 3N Longitudinal Web Profile (Temp $-60^{\circ} \mathrm{F}$ )

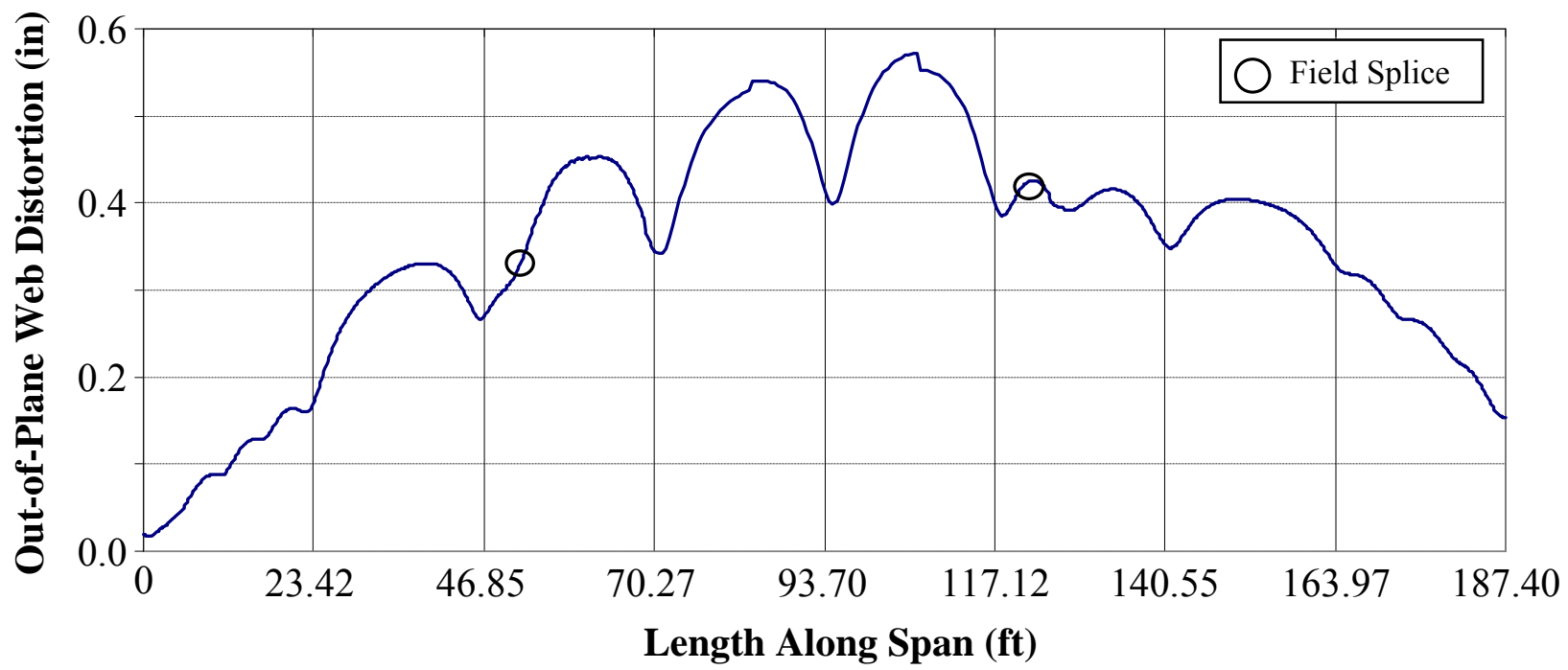

Figure A.8 Span 8N, Girder 3N Longitudinal Web Profile (Temp $-60^{\circ} \mathrm{F}$ ) 


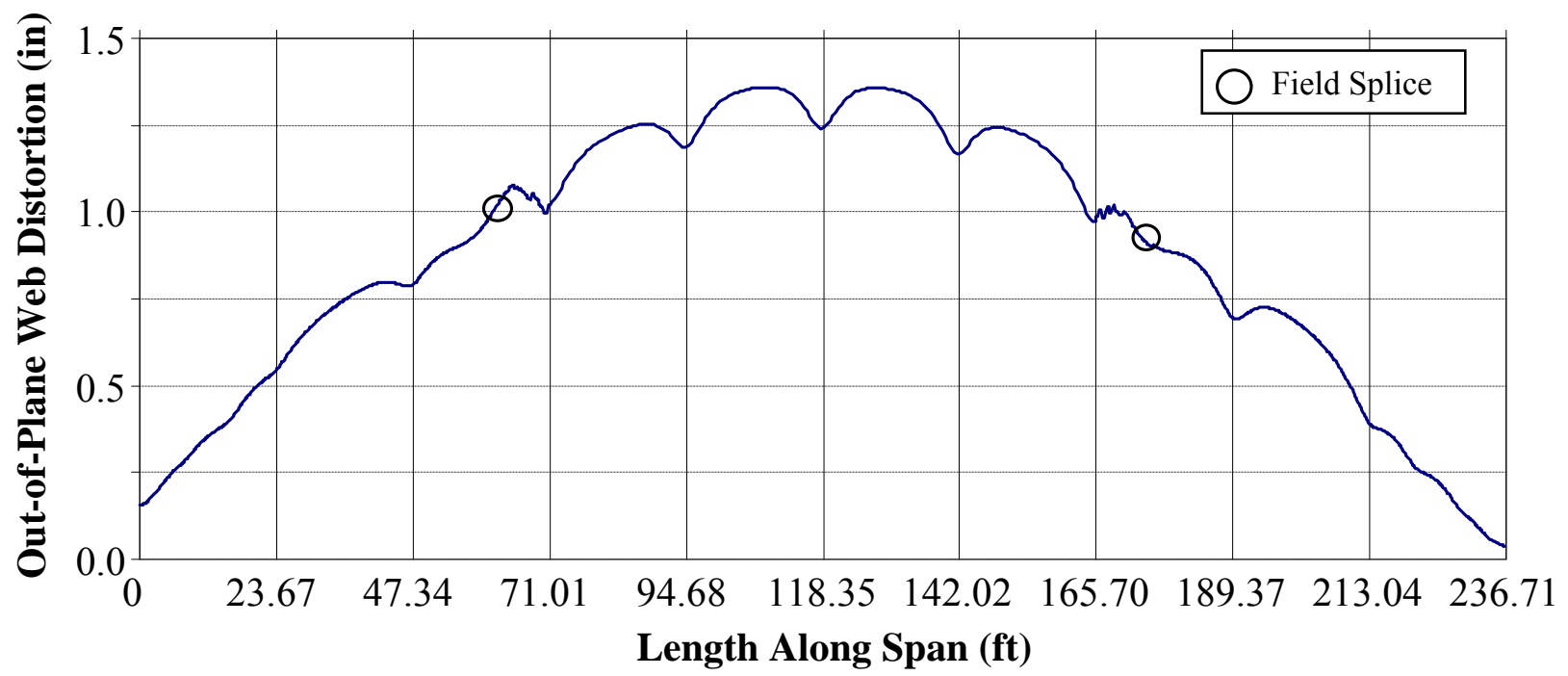

Figure A.9 Span 9N, Girder 3N Longitudinal Web Profile (Temp $-60^{\circ} \mathrm{F}$ )

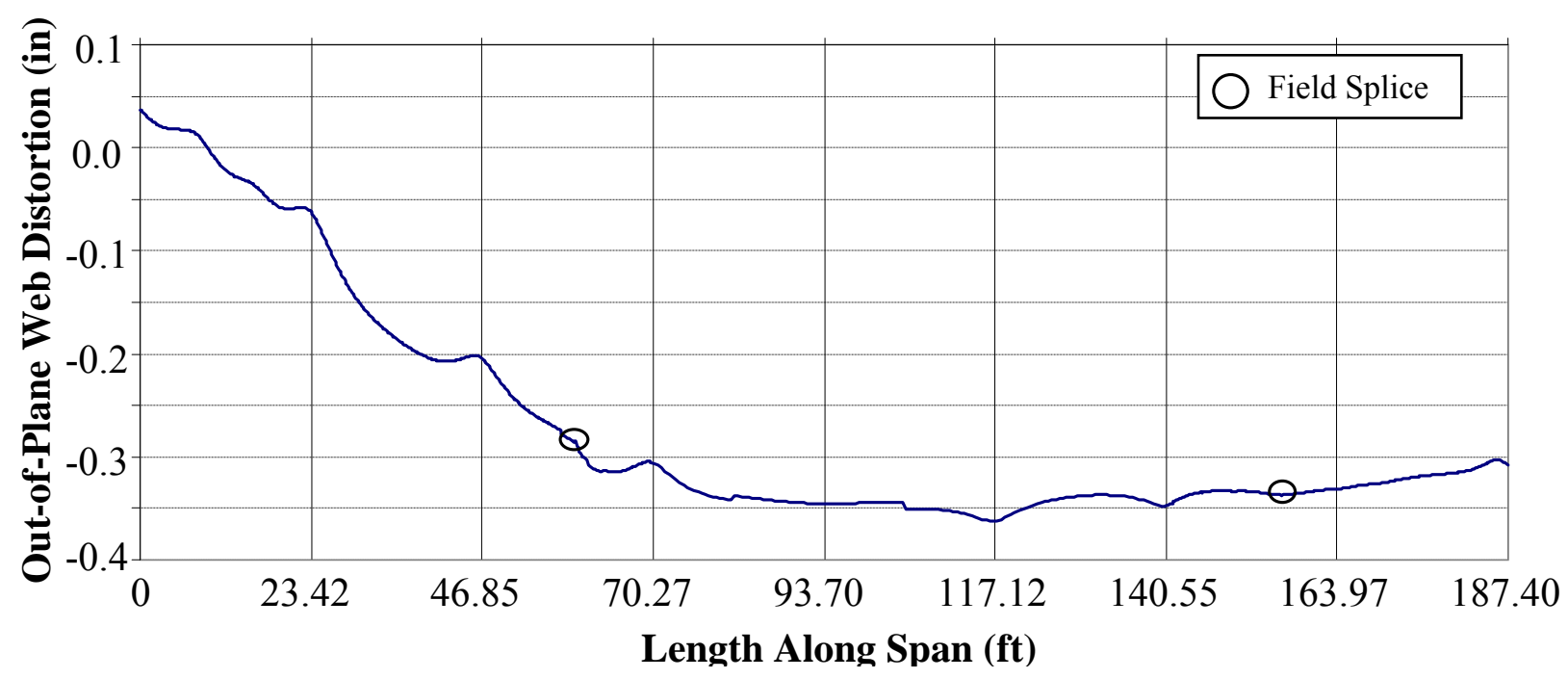

Figure A.10 Span 10N, Girder 3N Longitudinal Web Profile (Temp $-60^{\circ} \mathrm{F}$ )

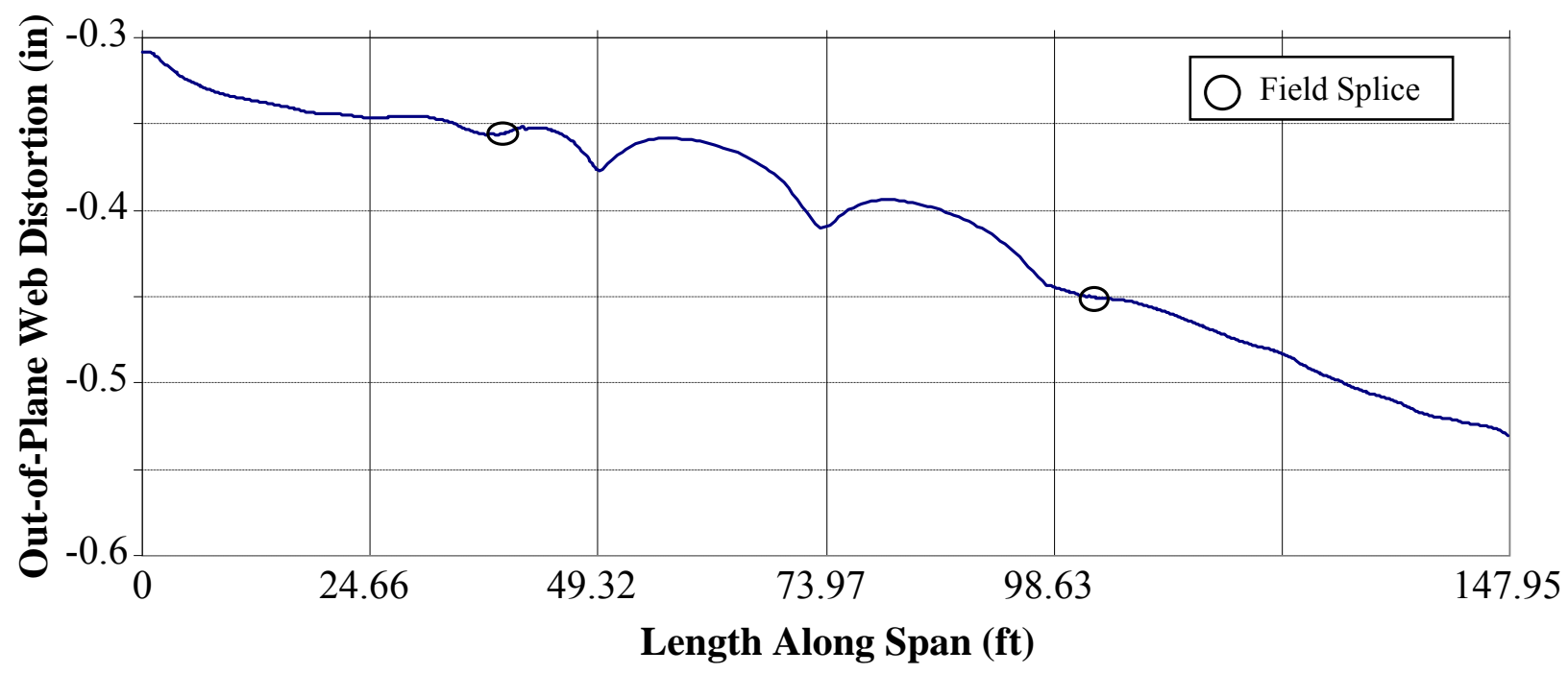

Figure A.11 Span 11N, Girder 3N Longitudinal Web Profile (Temp $-60^{\circ} \mathrm{F}$ ) 


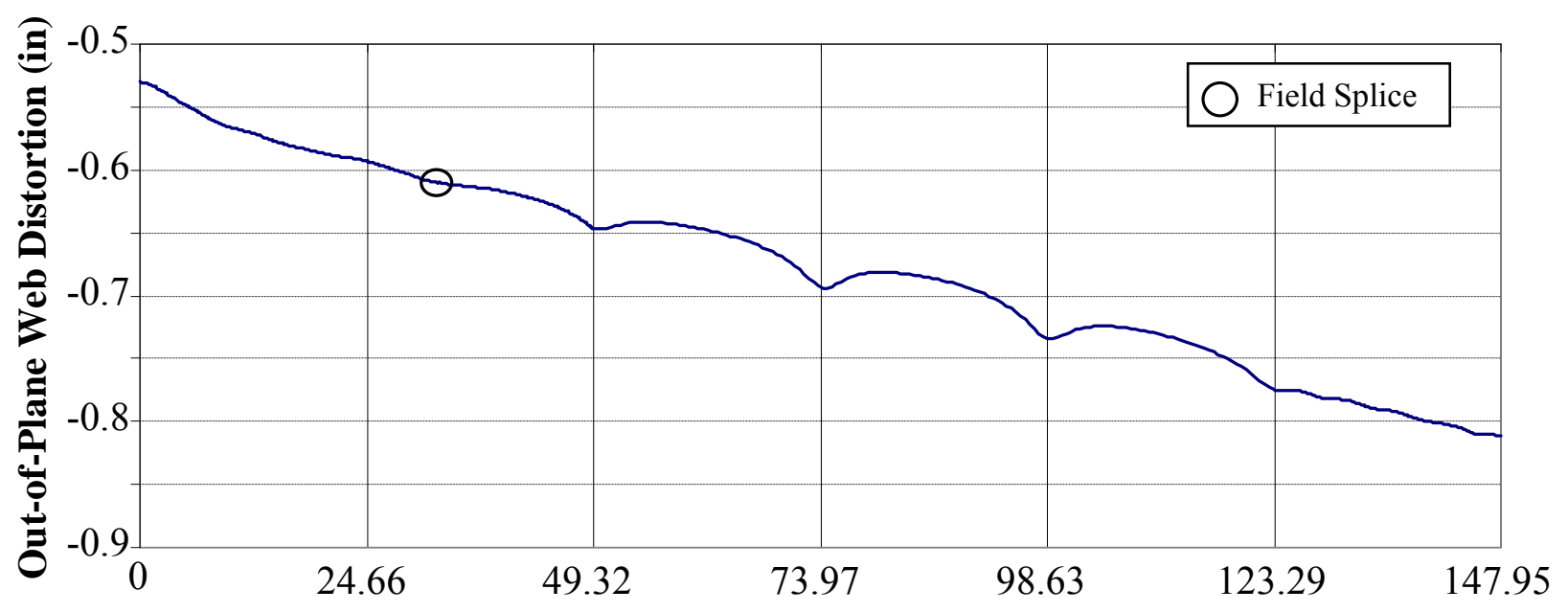

\section{Length Along Span (ft)}

Figure A.12 Span 12N, Girder 3N Longitudinal Web Profile (Temp $-60^{\circ} \mathrm{F}$ )

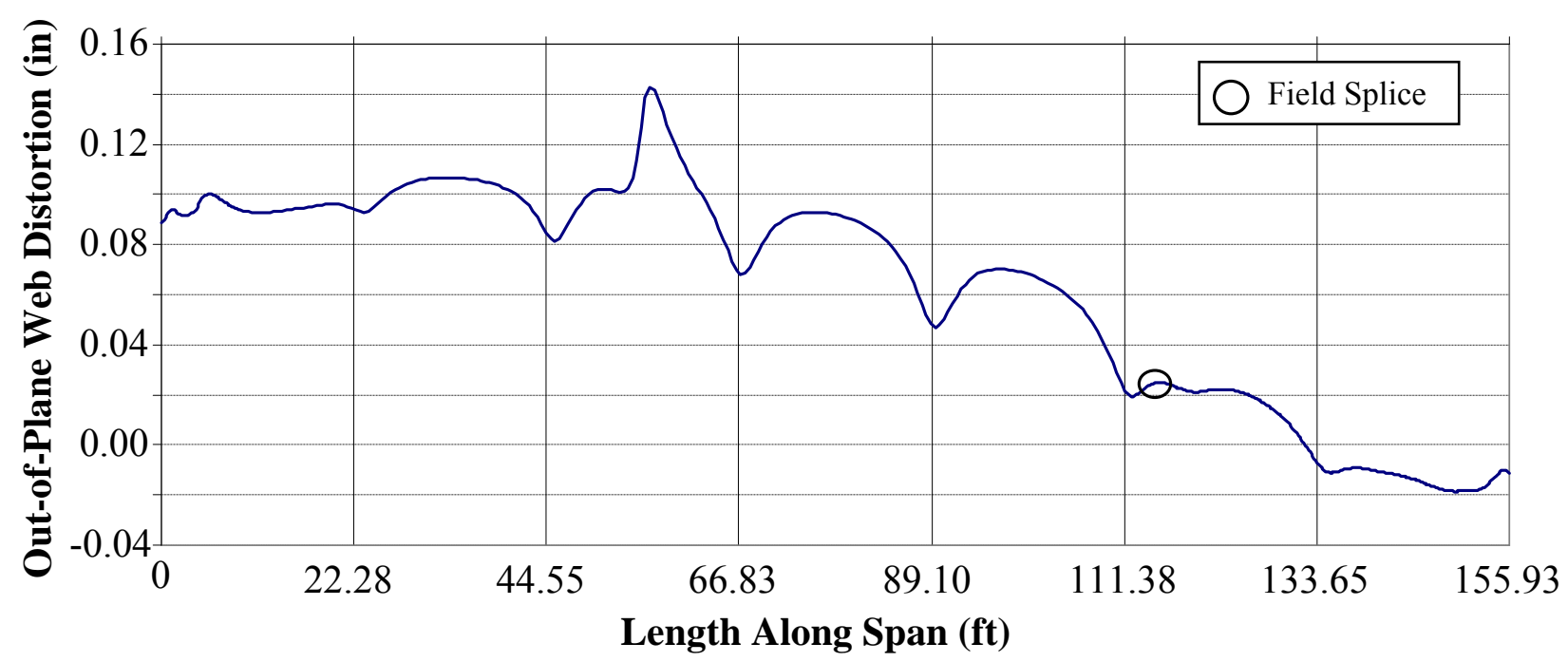

Figure A.13 Span 7N, Girder 3N Longitudinal Web Profile $\left(\mathrm{Temp}+60^{\circ} \mathrm{F}\right)$

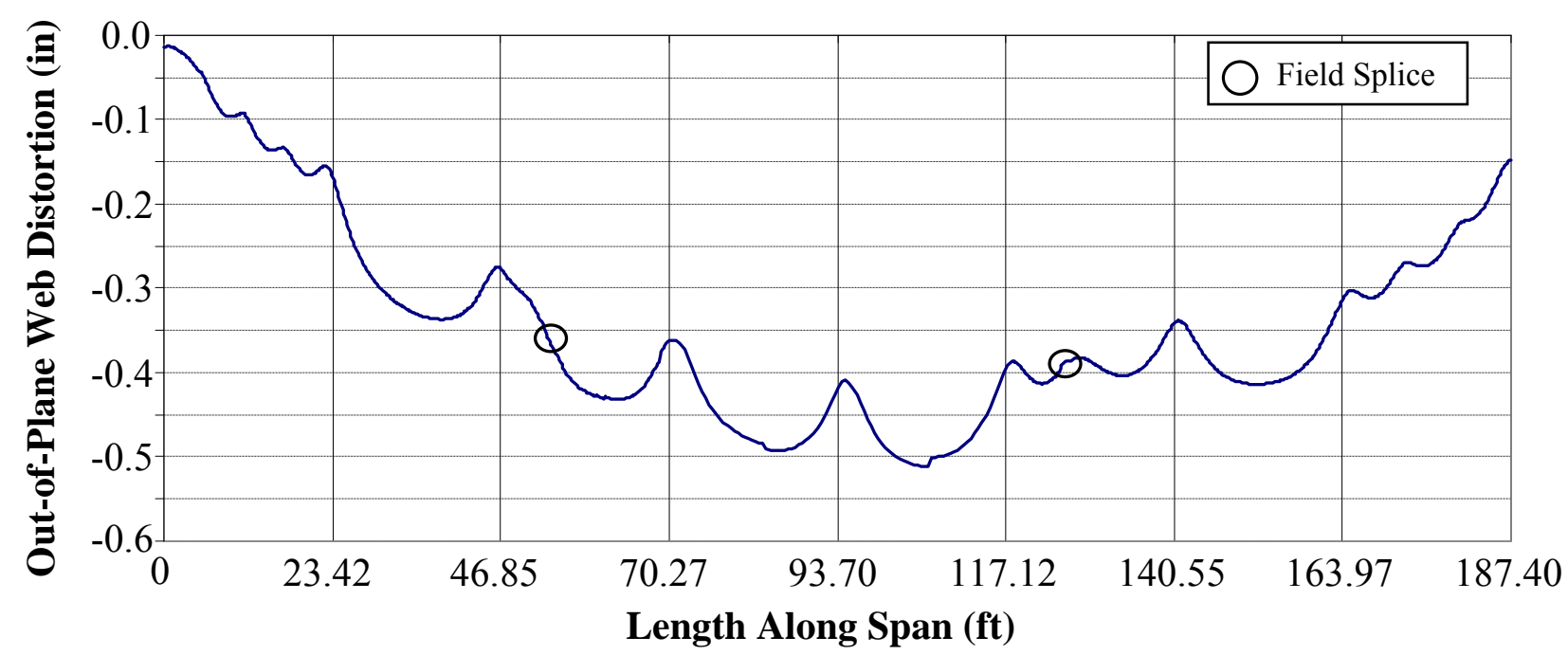

Figure A.14 Span 8N, Girder 3N Longitudinal Web Profile (Temp $+60^{\circ} \mathrm{F}$ ) 


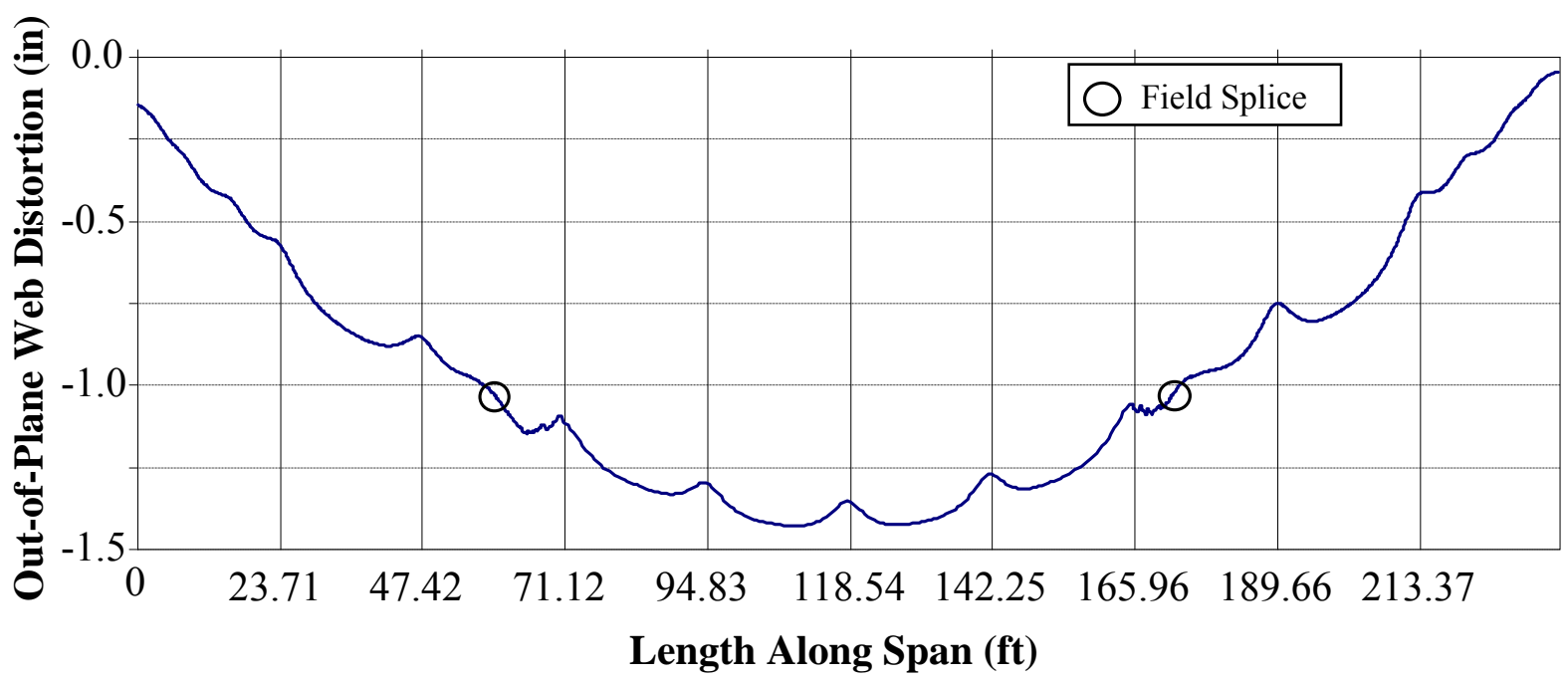

Figure A.15 Span 9N, Girder 3N Longitudinal Web Profile (Temp $\left.+60^{\circ} \mathrm{F}\right)$

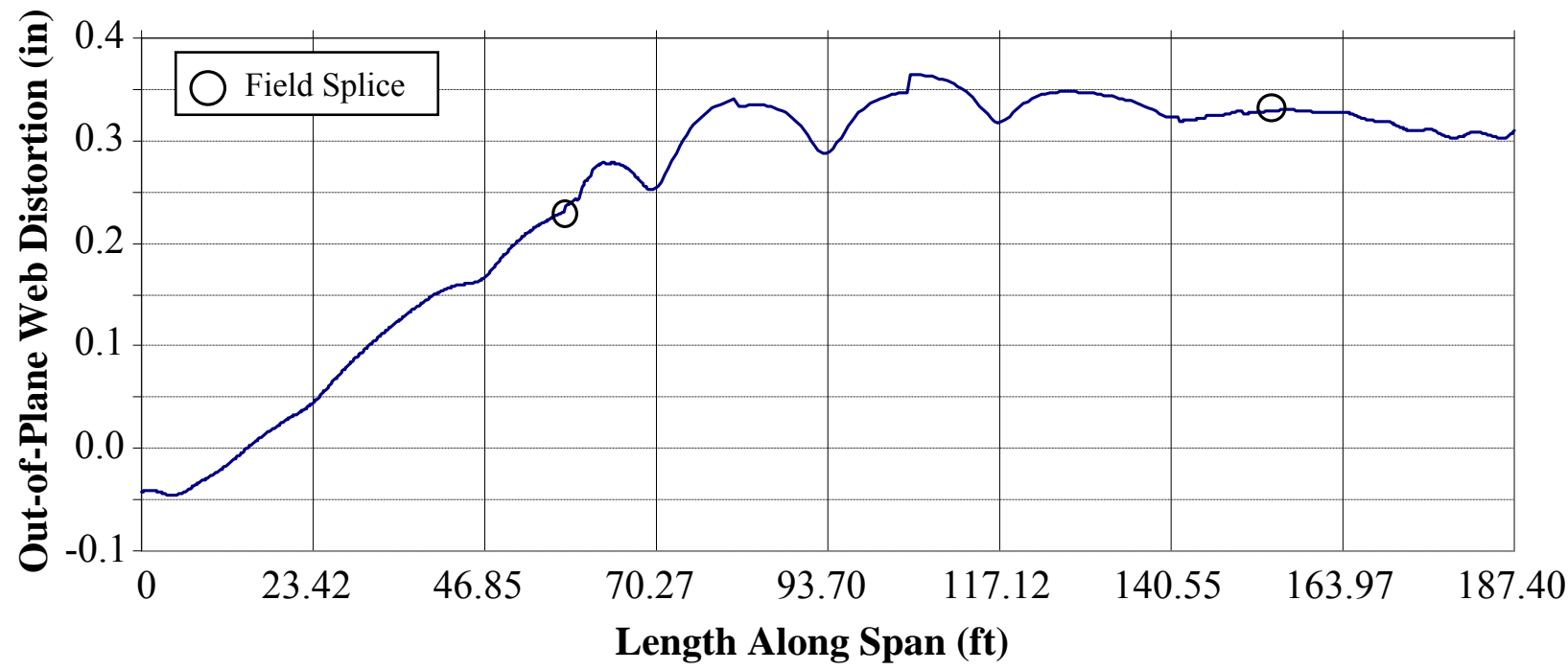

Figure A.16 Span 10N, Girder 3N Longitudinal Web Profile $\left(\right.$ Temp $\left.+60^{\circ} \mathrm{F}\right)$

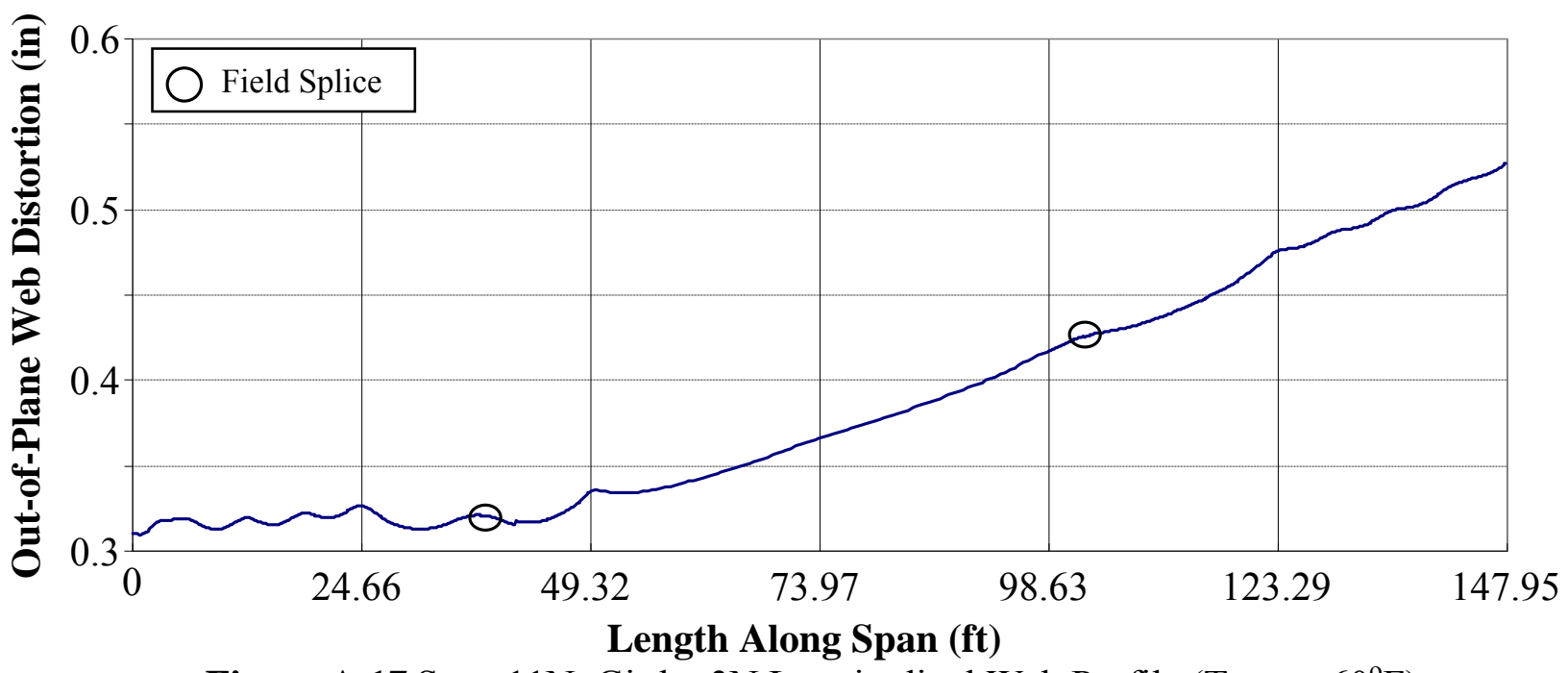

Figure A.17 Span 11N, Girder 3N Longitudinal Web Profile $\left(\mathrm{Temp}+60^{\circ} \mathrm{F}\right)$ 


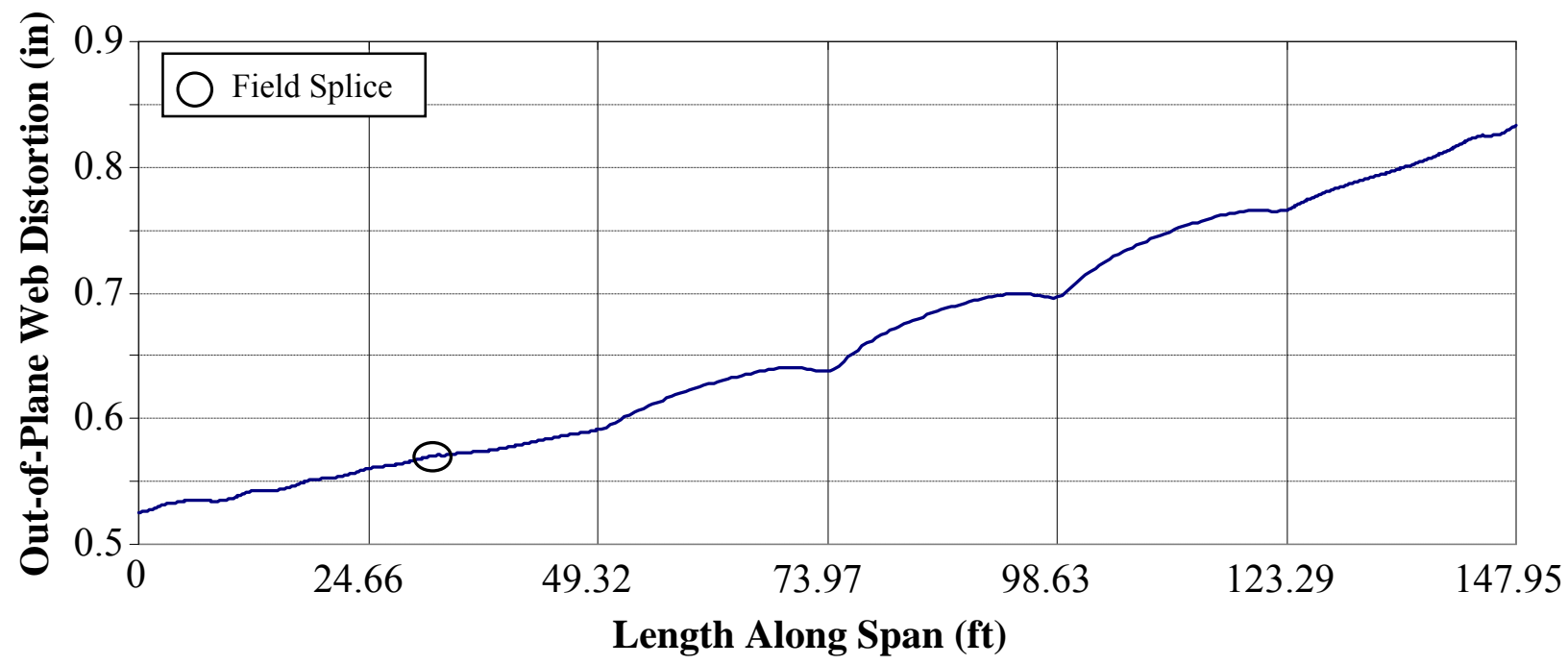

Figure A.18 Span 12N, Girder 3N Longitudinal Web Profile (Temp $\left.+60^{\circ} \mathrm{F}\right)$

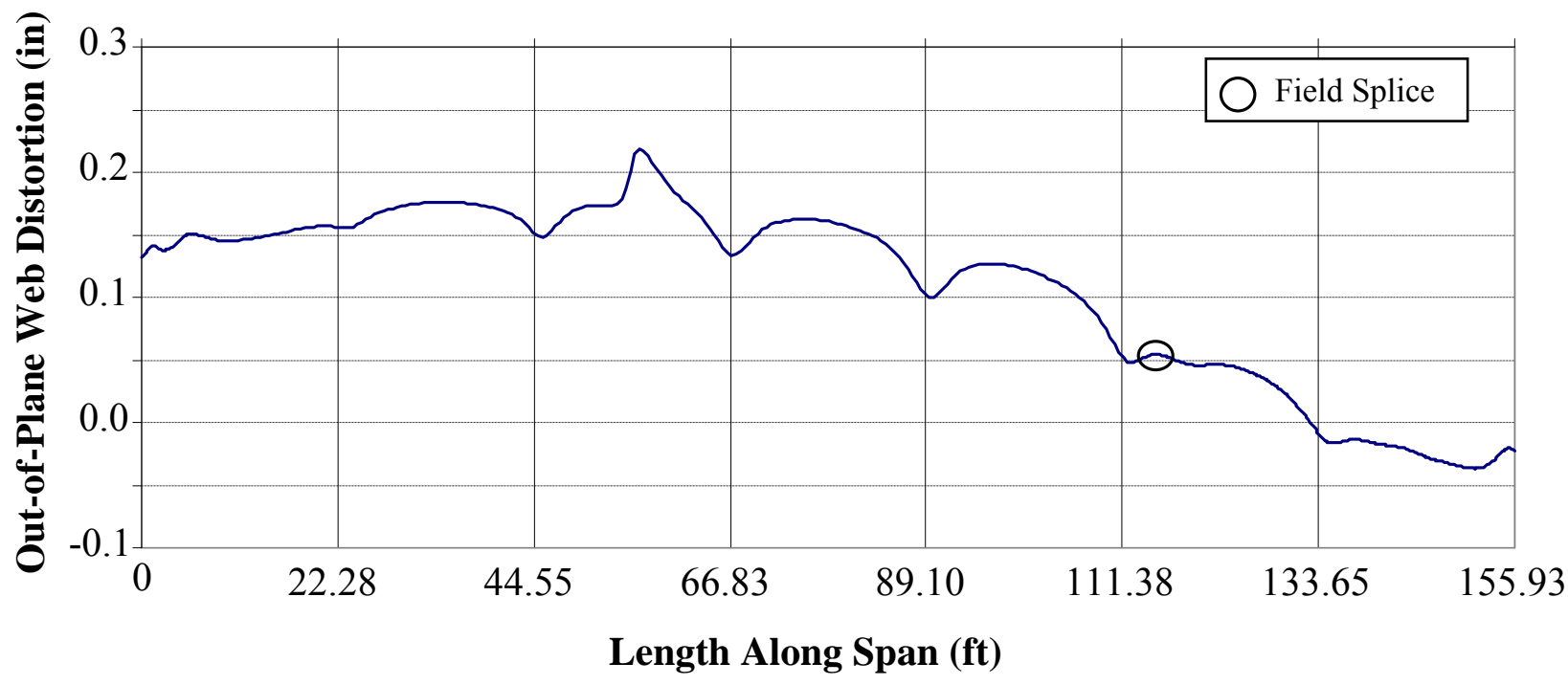

Figure A.19 Span $7 \mathrm{~N}$, Girder $3 \mathrm{~N}$ Longitudinal Web Profile $\left(\mathrm{Temp}+90^{\circ} \mathrm{F}\right)$

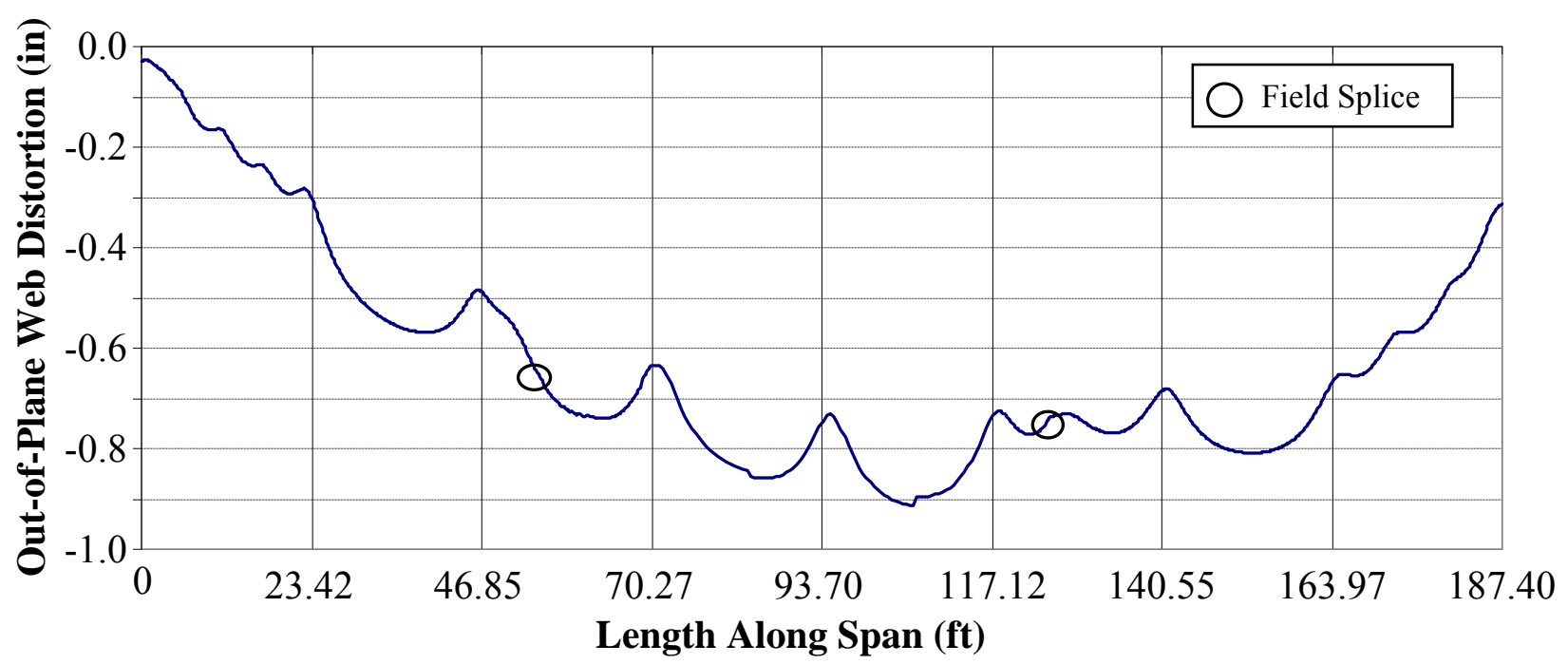

Figure A.20 Span 8N, Girder 3N Longitudinal Web Profile (Temp $\left.+90^{\circ} \mathrm{F}\right)$ 


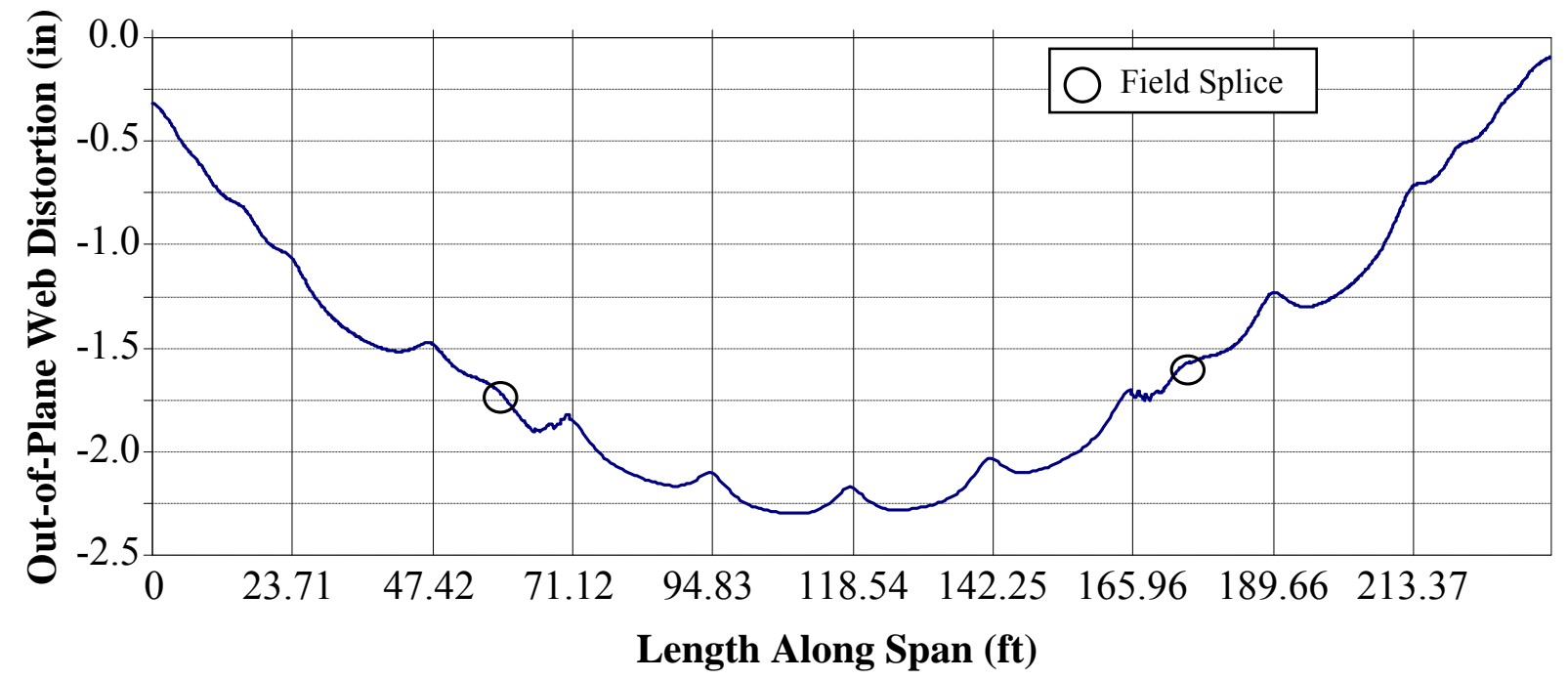

Figure A.21 Span 9N, Girder 3N Longitudinal Web Profile $\left(\mathrm{Temp}+90^{\circ} \mathrm{F}\right)$

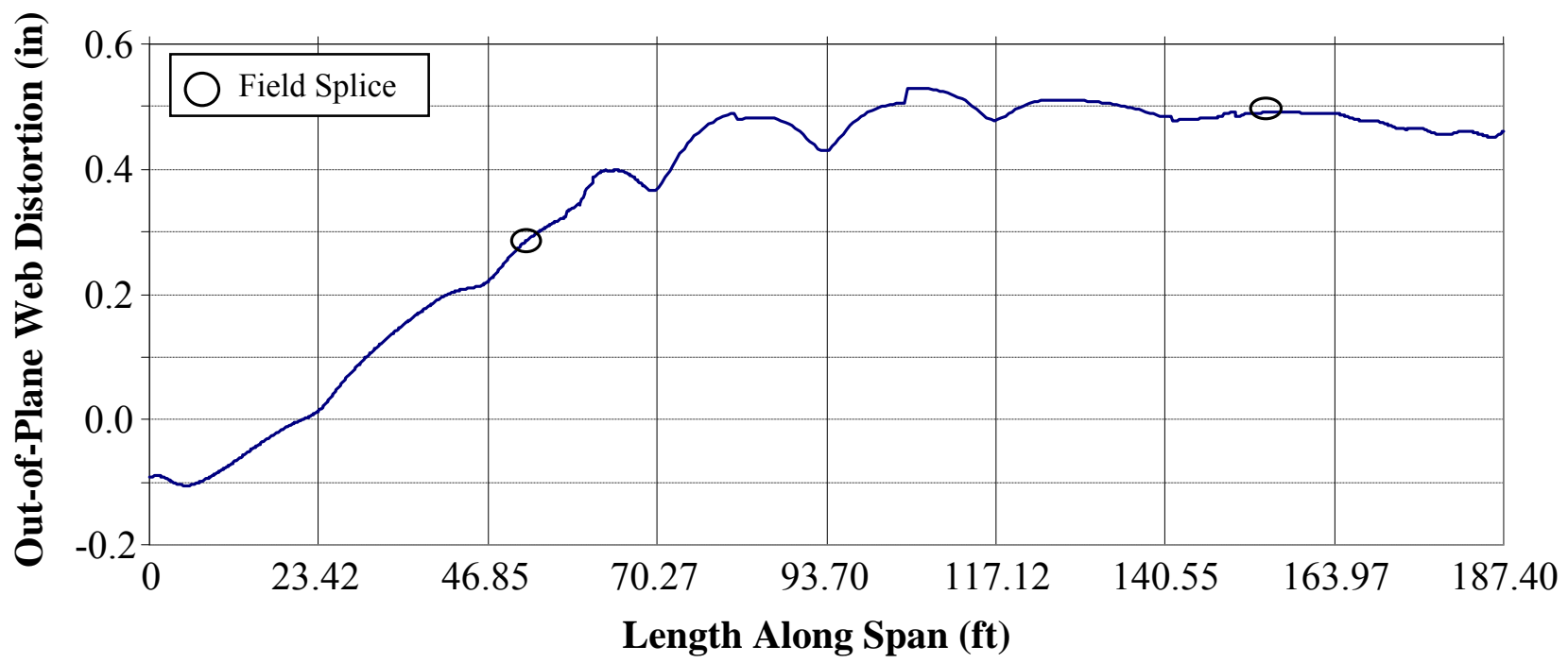

Figure A.22 Span 10N, Girder 3N Longitudinal Web Profile (Temp $\left.+90^{\circ} \mathrm{F}\right)$

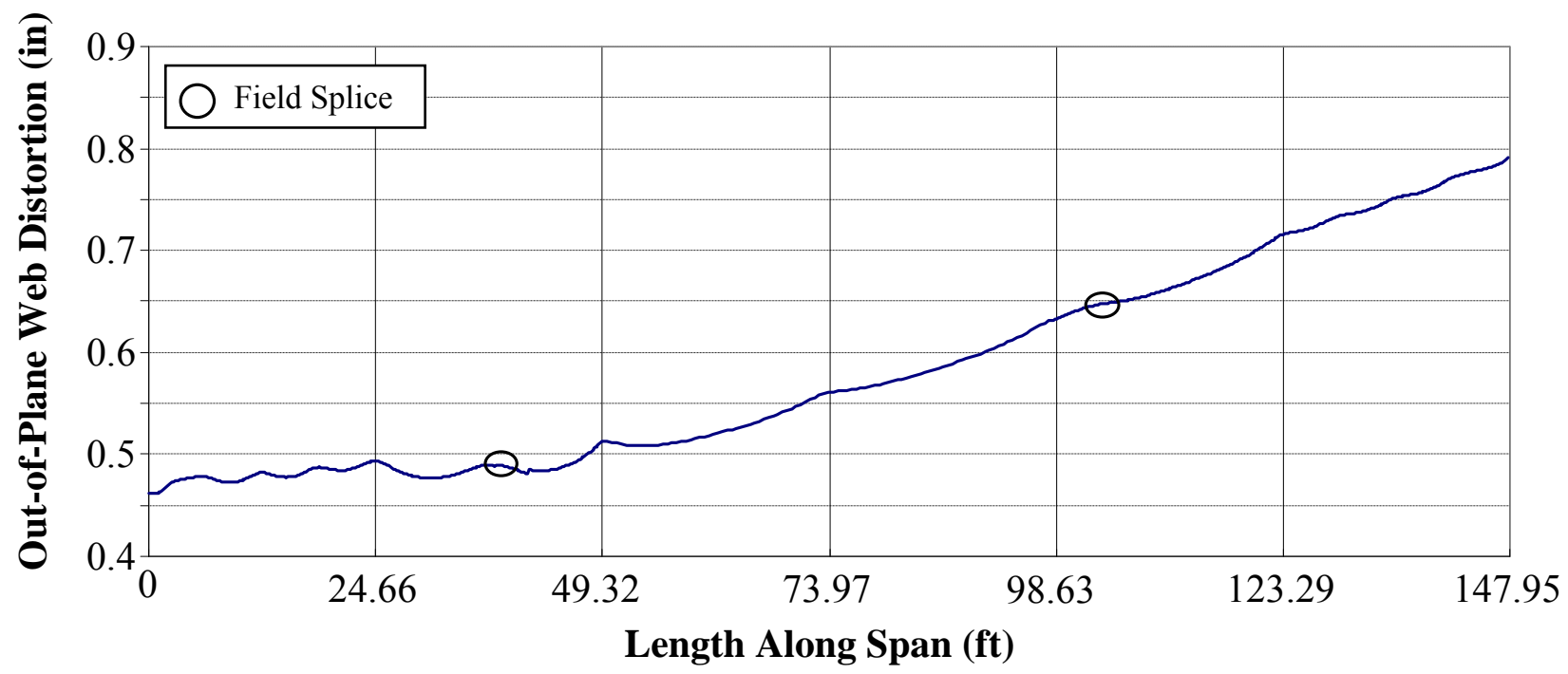

Figure A.23 Span 11N, Girder 3N Longitudinal Web Profile (Temp $\left.+90^{\circ} \mathrm{F}\right)$ 


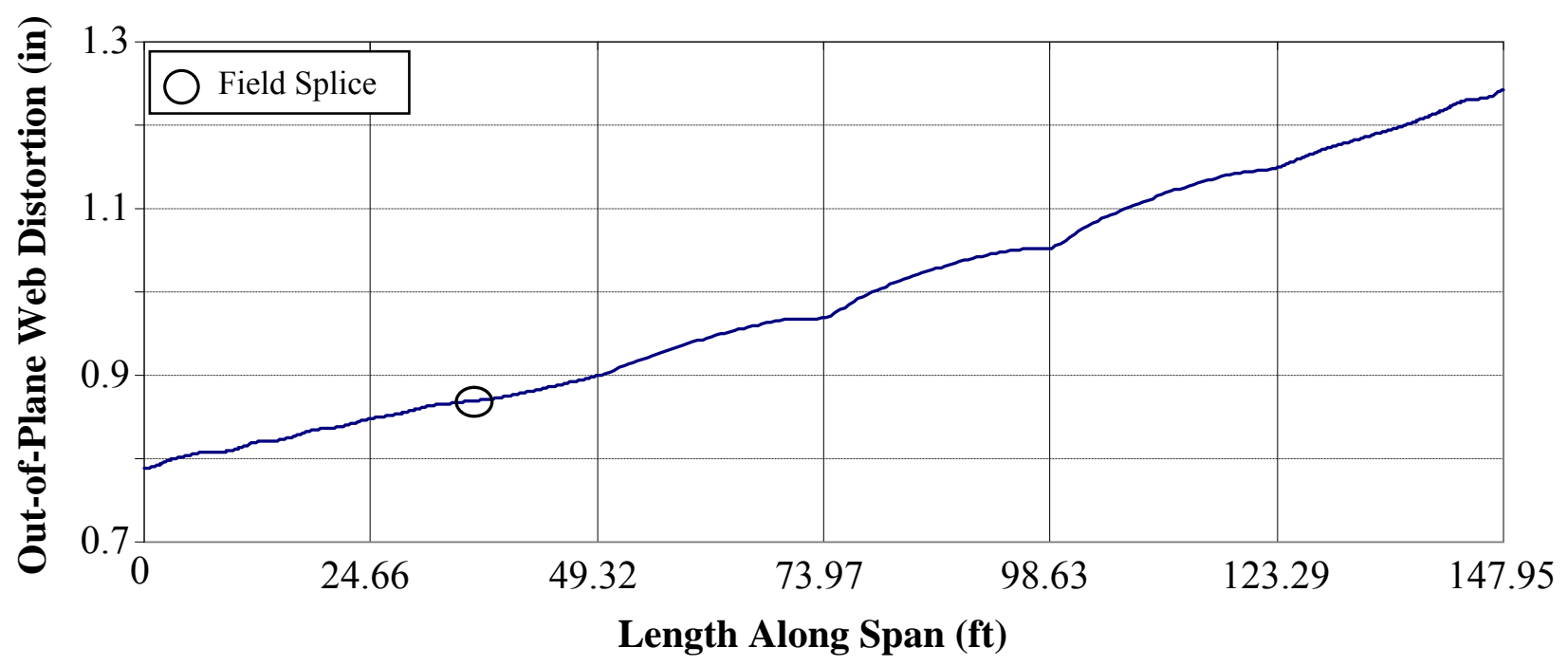

Figure A.24 Span 12N, Girder 3N Longitudinal Web Profile $\left(\mathrm{Temp}+90^{\circ} \mathrm{F}\right)$ 


\section{APPENDIX B}

\section{AS-BUILT BENDING AND AXIAL STRESS PROFILES - TEMP $-/+60^{\circ} \mathrm{F}$}

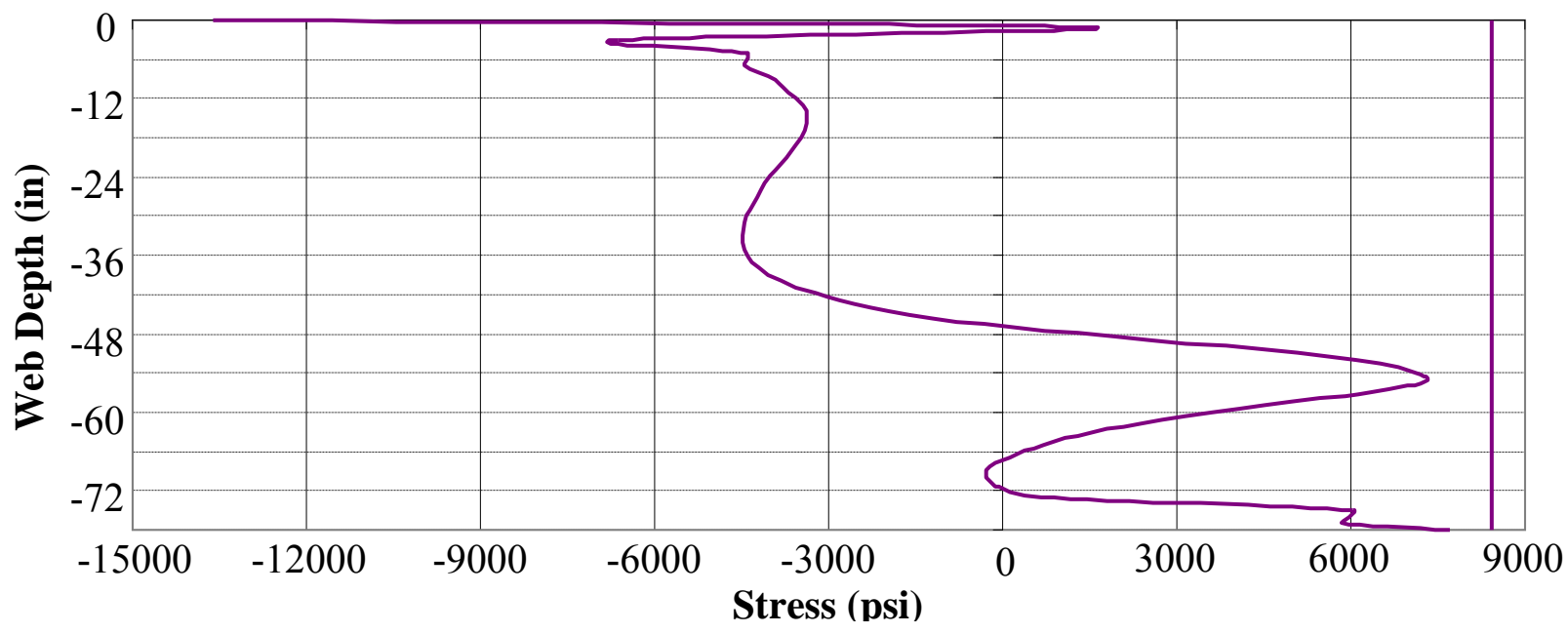

Figure B.1 Pier 7N, Bending and Axial Stress Profiles (Temp $\left.-60^{\circ} \mathrm{F}\right)$

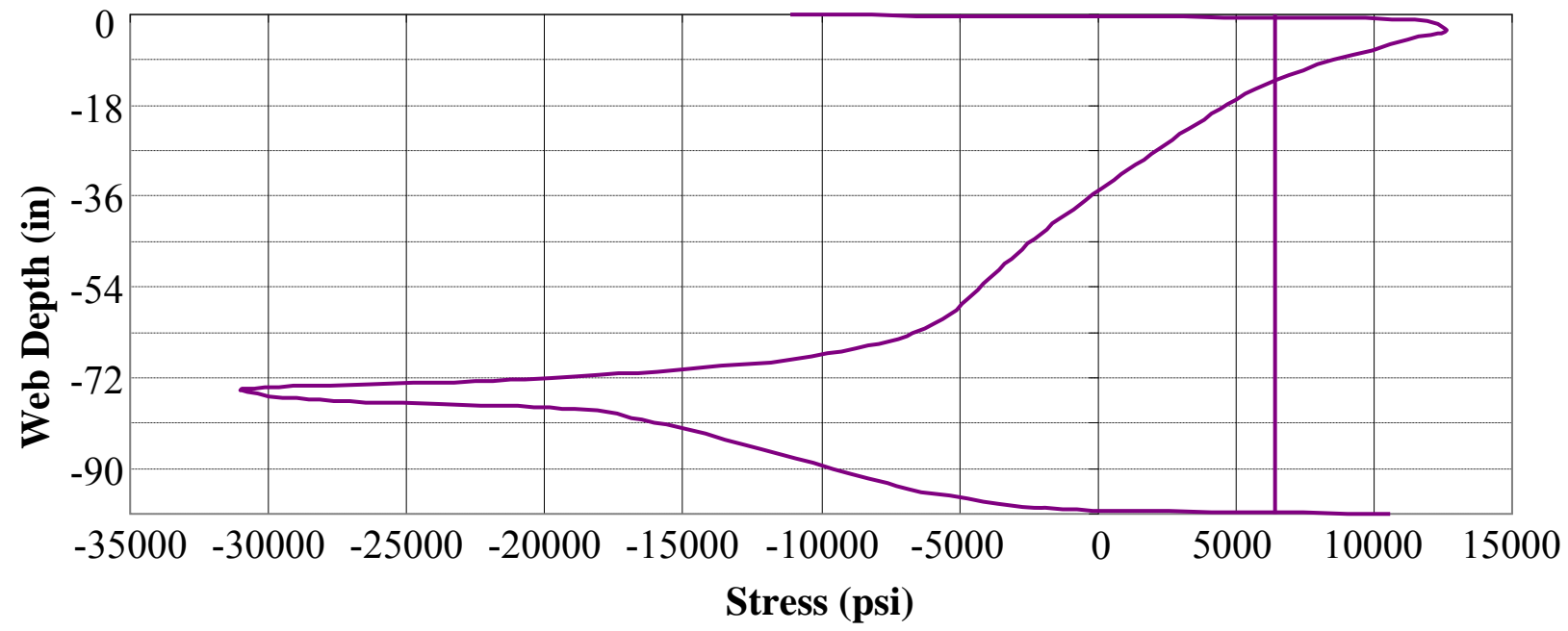

Figure B.2 Pier 8N, Bending and Axial Stress Profiles (Temp $-60^{\circ} \mathrm{F}$ ) 


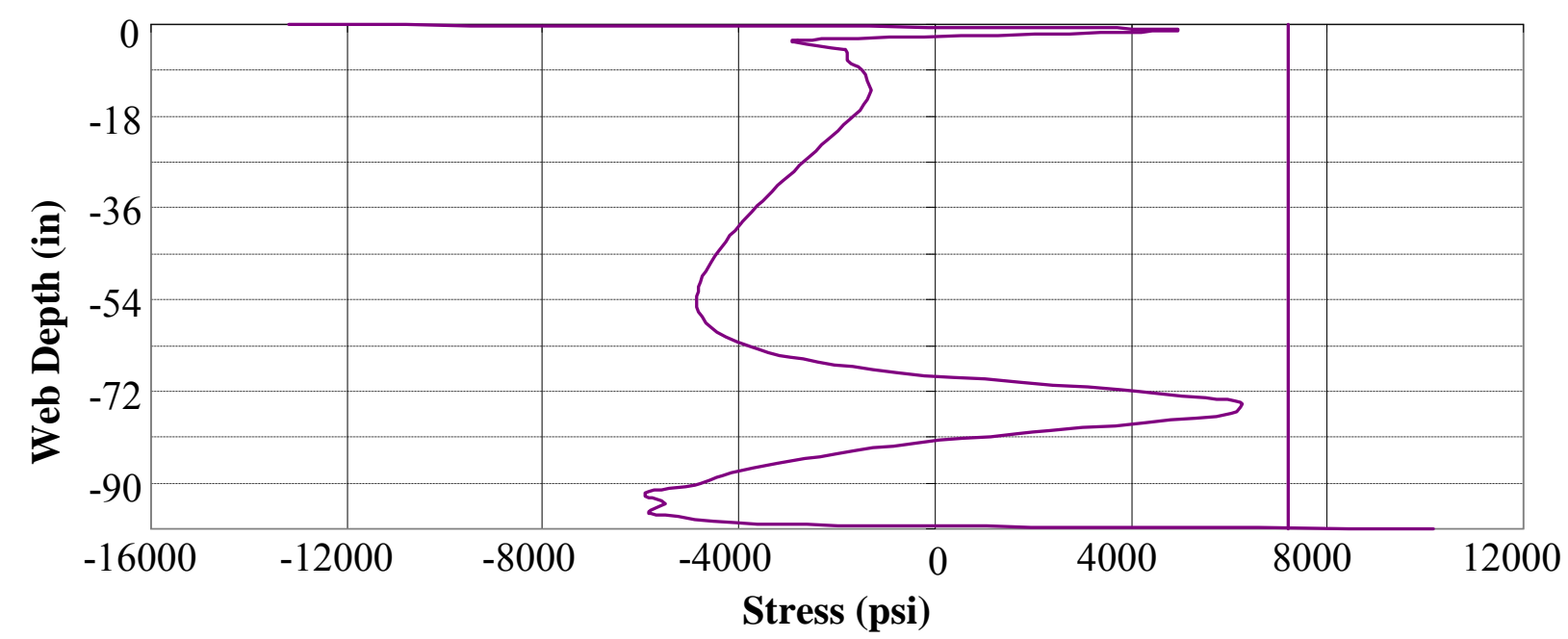

Figure B.3 Pier 9N, Bending and Axial Stress Profiles (Temp $-60^{\circ} \mathrm{F}$ )

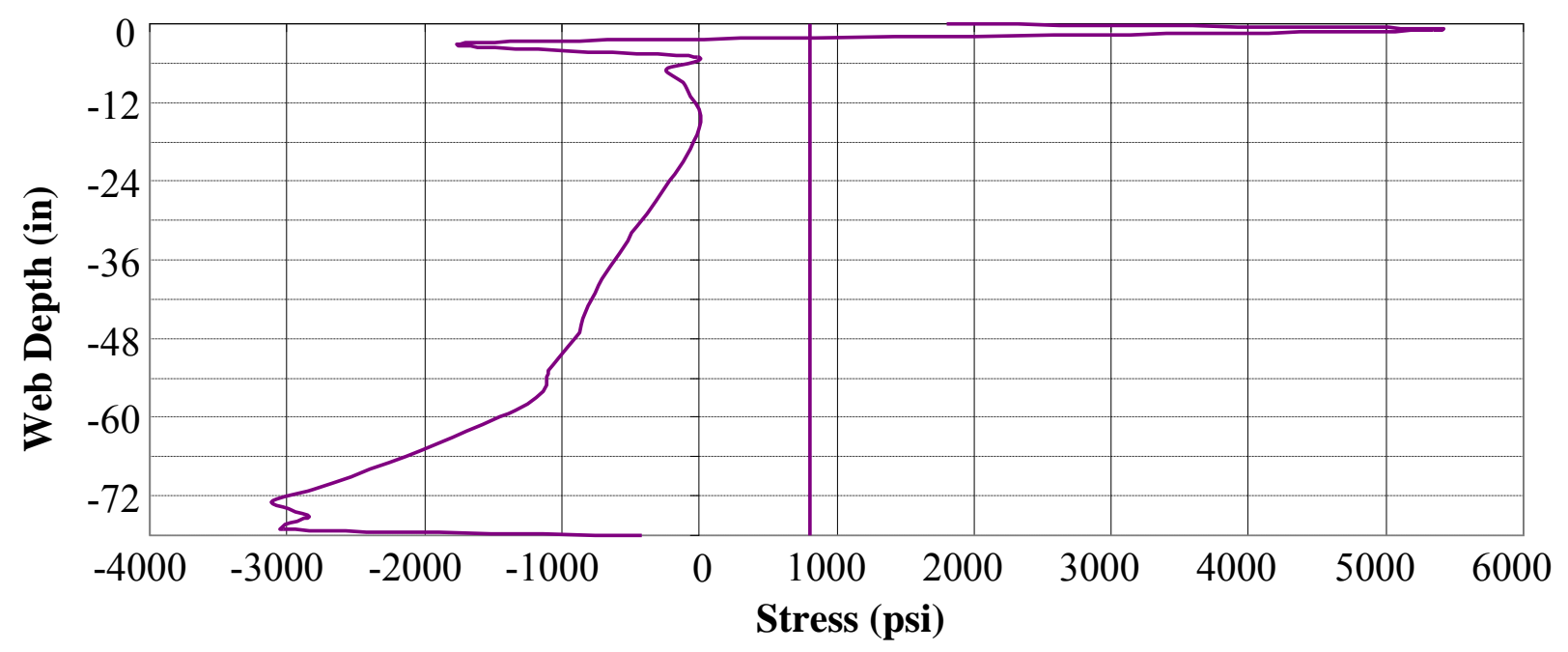

Figure B.4 Pier 10N, Bending and Axial Stress Profiles (Temp $-60^{\circ} \mathrm{F}$ )

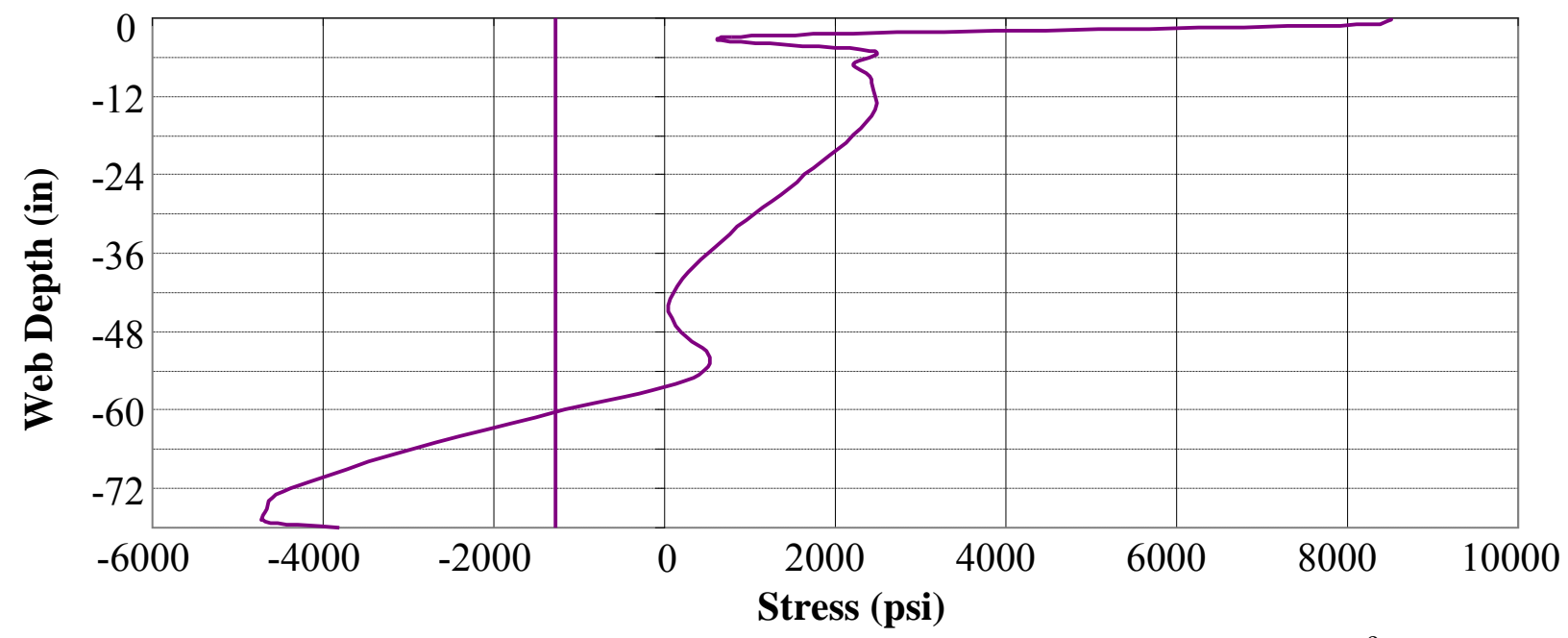

Figure B.5 Pier 11N, Bending and Axial Stress Profiles (Temp $-60^{\circ} \mathrm{F}$ ) 


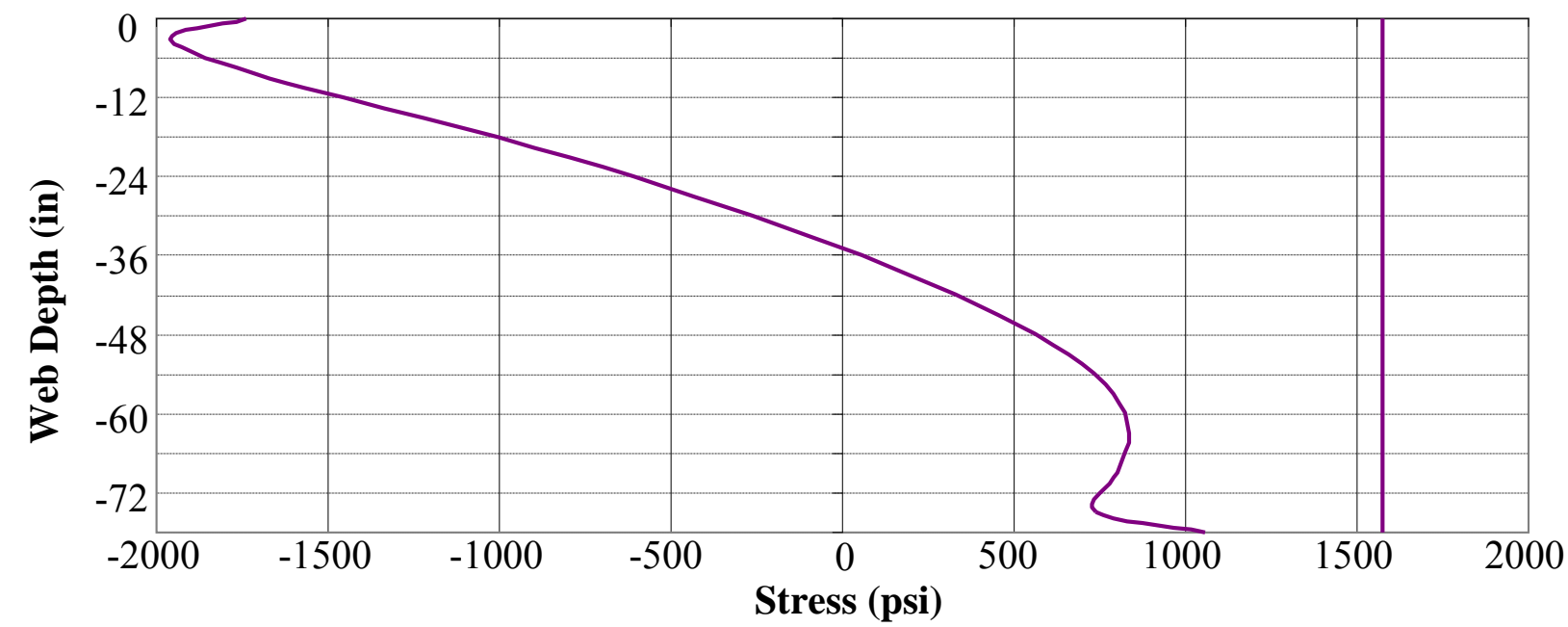

Figure B.6 Span 7N, Bending and Axial Stress Profiles (Temp - $60^{\circ} \mathrm{F}$ )

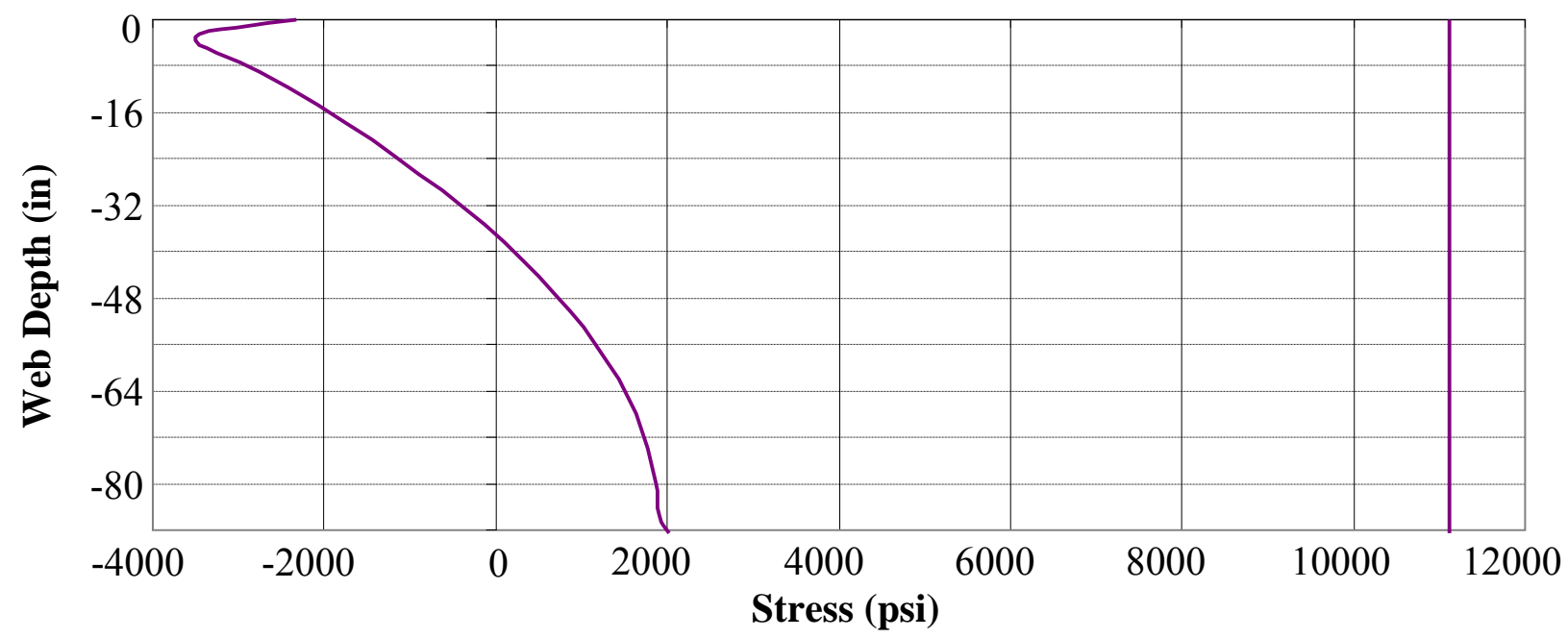

Figure B.7 Span 8N, Bending and Axial Stress Profiles (Temp $-60^{\circ} \mathrm{F}$ )

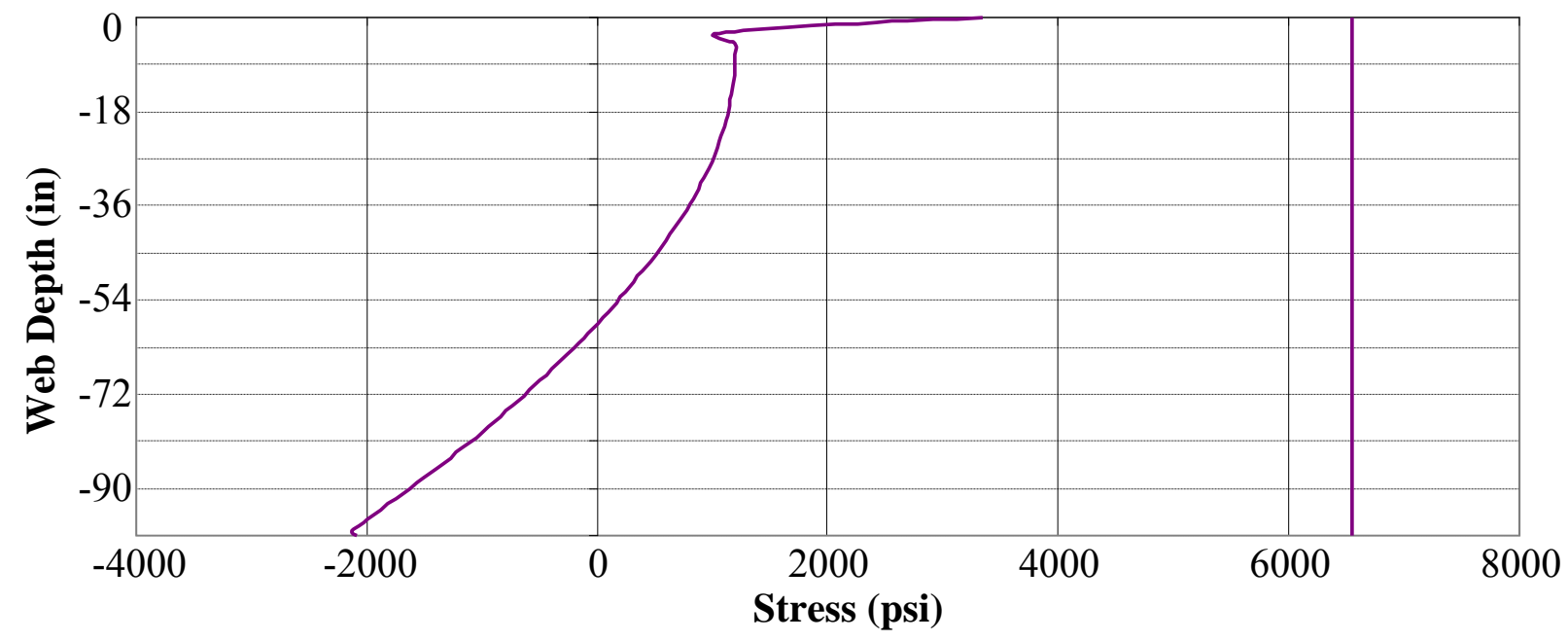

Figure B.8 Span 9N, Bending and Axial Stress Profiles (Temp $-60^{\circ} \mathrm{F}$ ) 


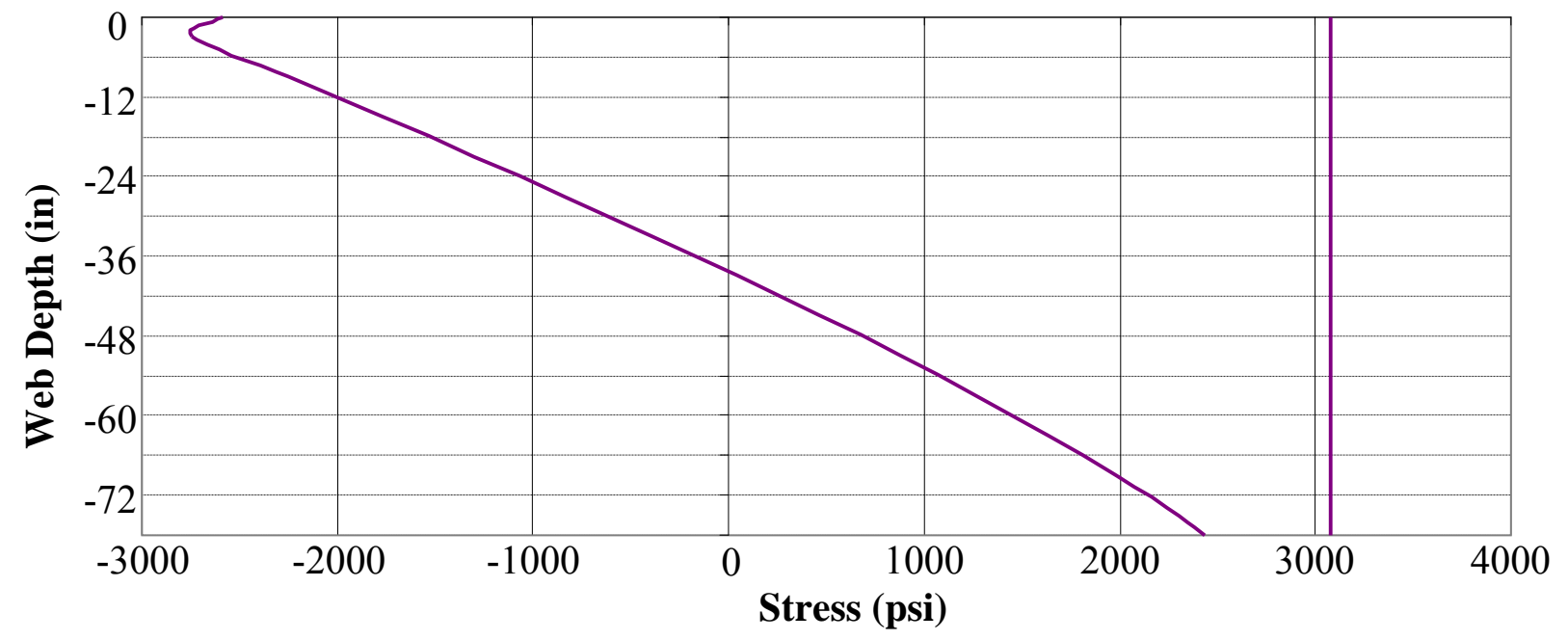

Figure B.9 Span 10N, Bending and Axial Stress Profiles (Temp $\left.-60^{\circ} \mathrm{F}\right)$

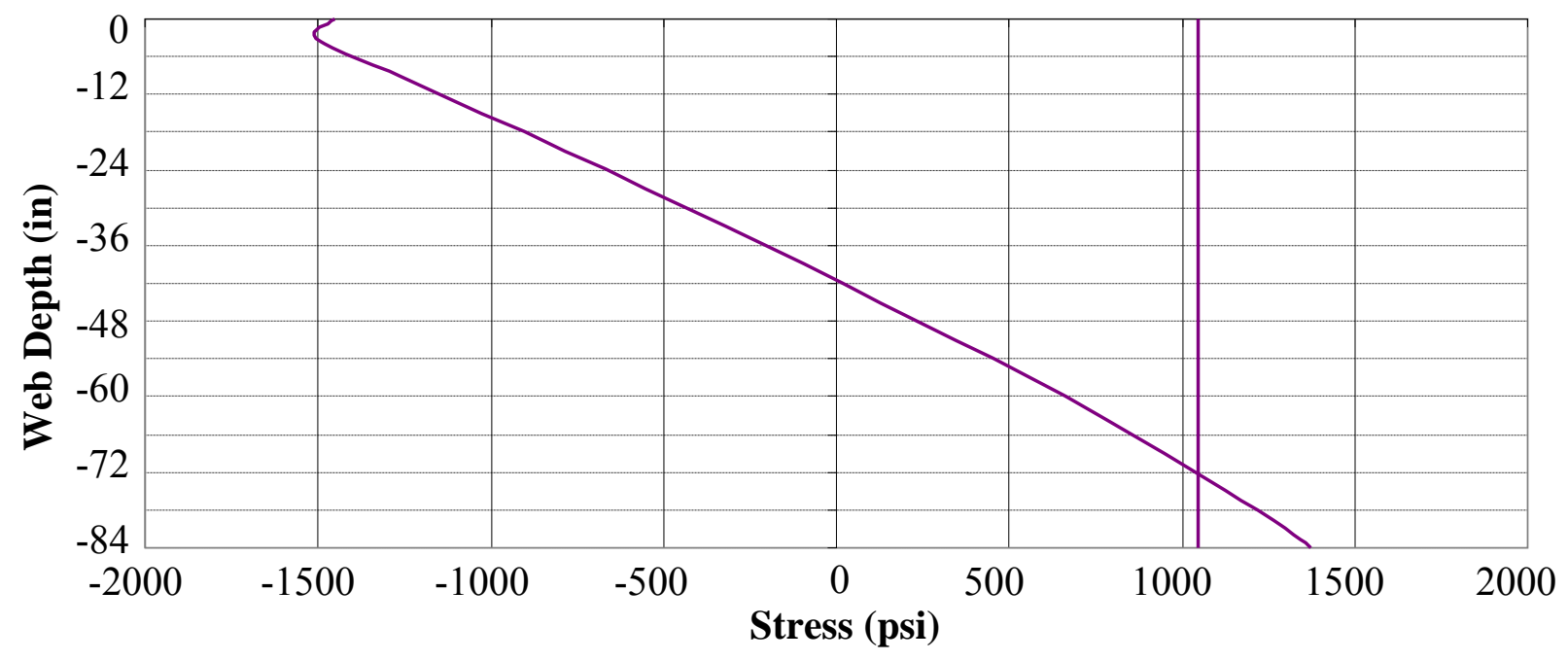

Figure B.10 Span $11 \mathrm{~N}$, Bending and Axial Stress Profiles (Temp $-60^{\circ} \mathrm{F}$ ) 


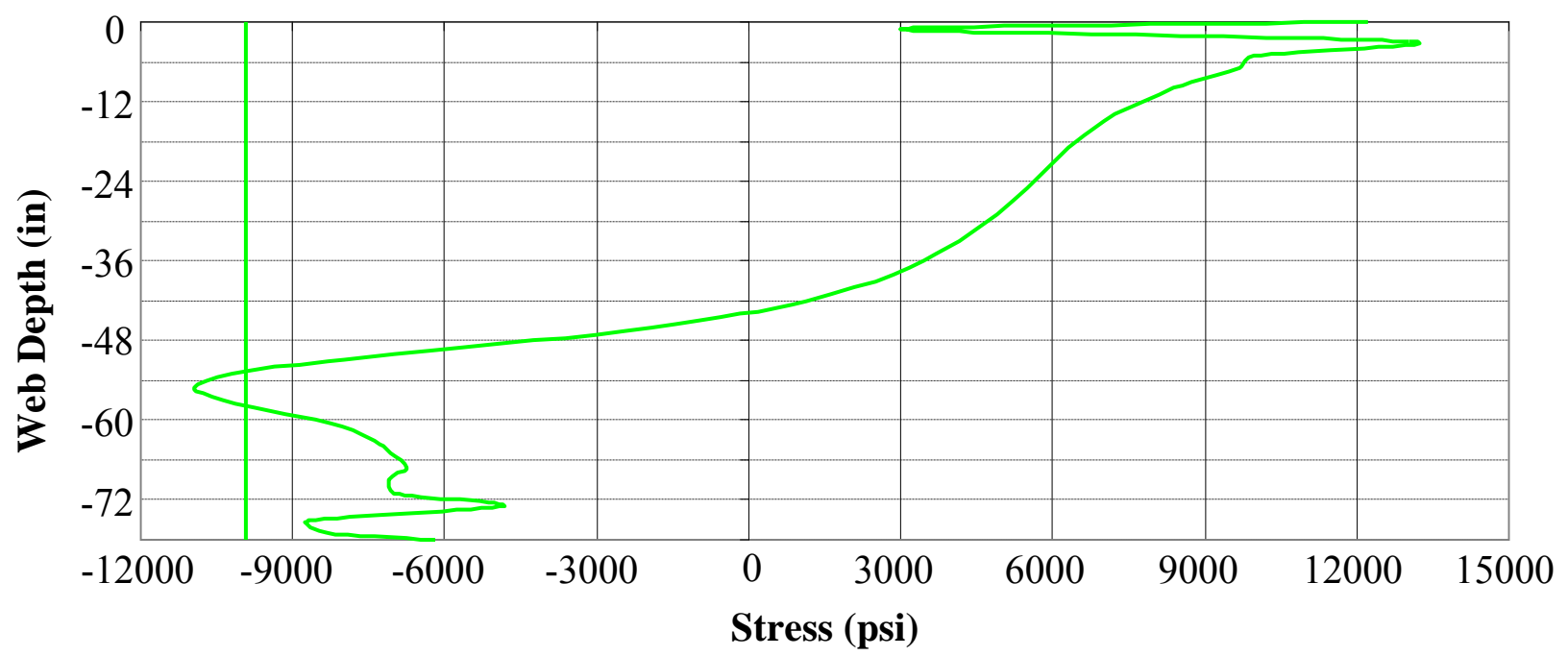

Figure B.11 Pier 7N, Bending and Axial Stress Profiles (Temp $+60^{\circ} \mathrm{F}$ )

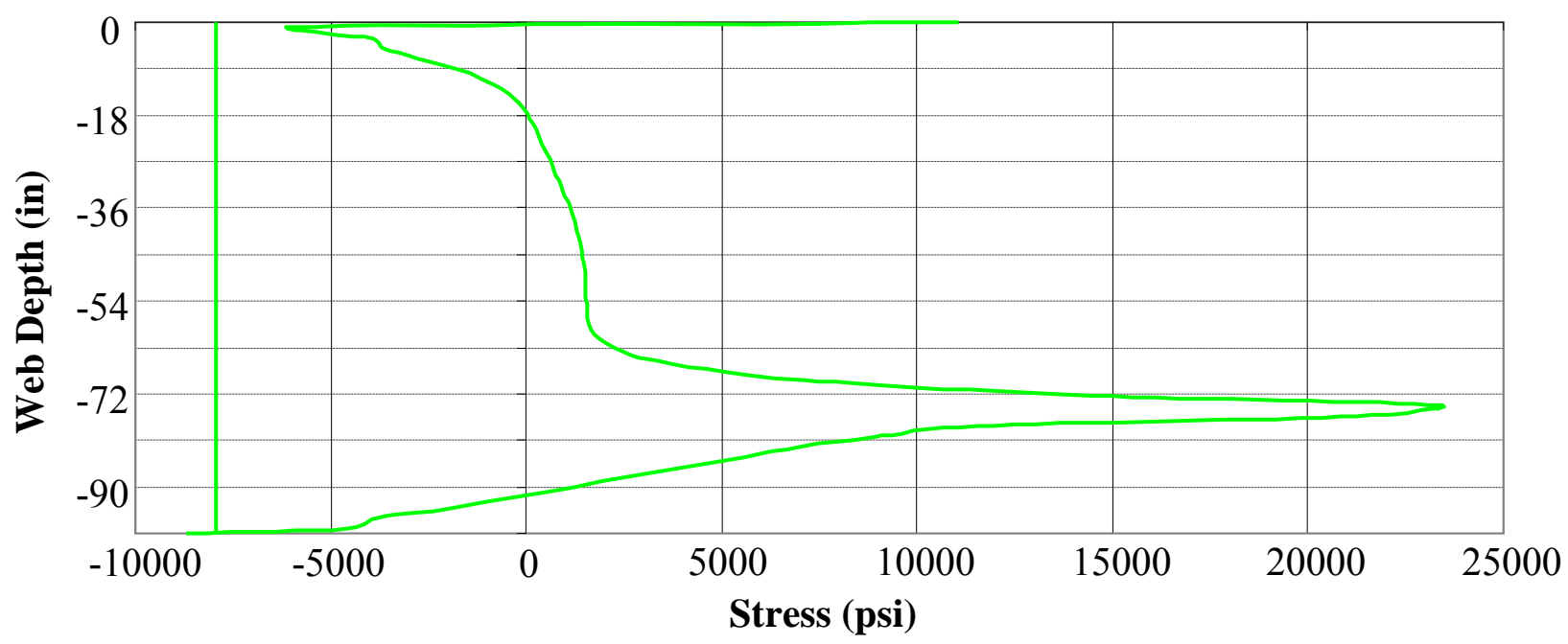

Figure B.12 Pier 8N, Bending and Axial Stress Profiles (Temp $\left.+60^{\circ} \mathrm{F}\right)$

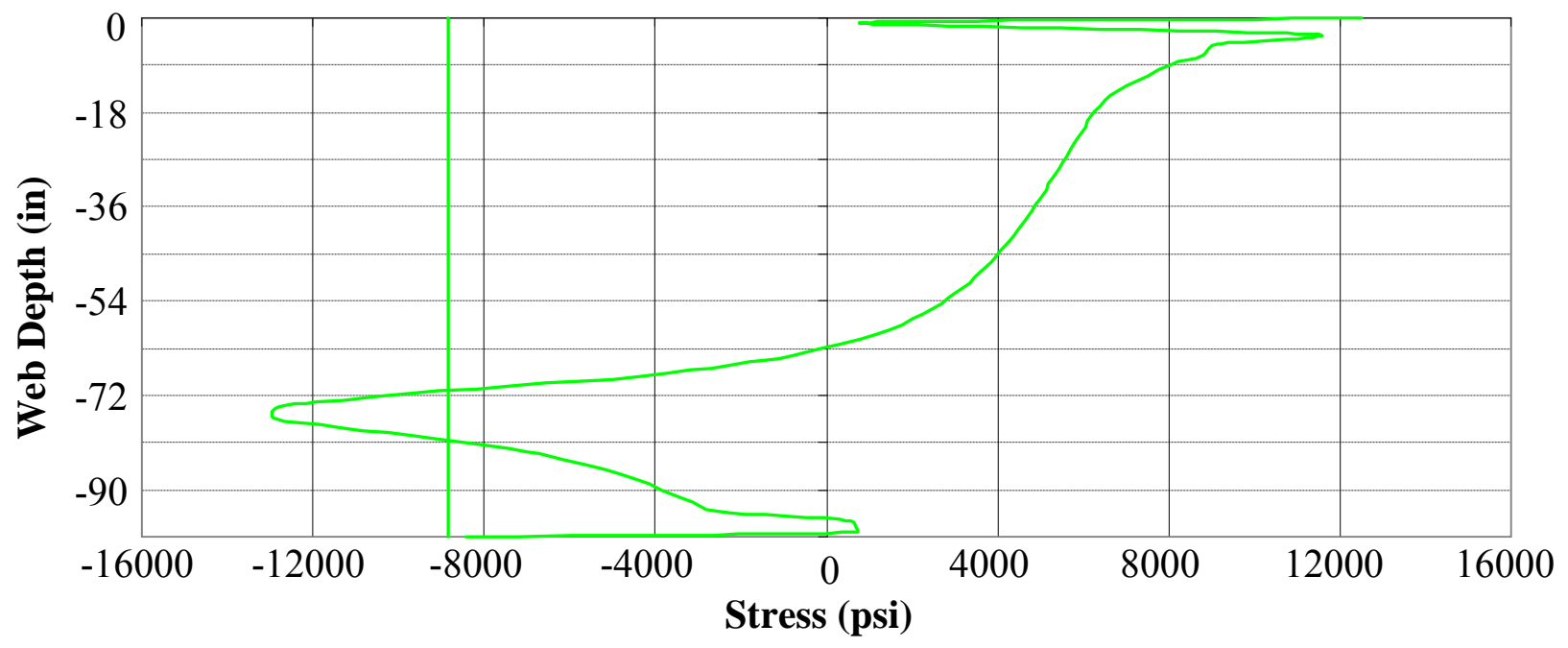

Figure B.13 Pier 9N, Bending and Axial Stress Profiles (Temp $\left.+60^{\circ} \mathrm{F}\right)$ 


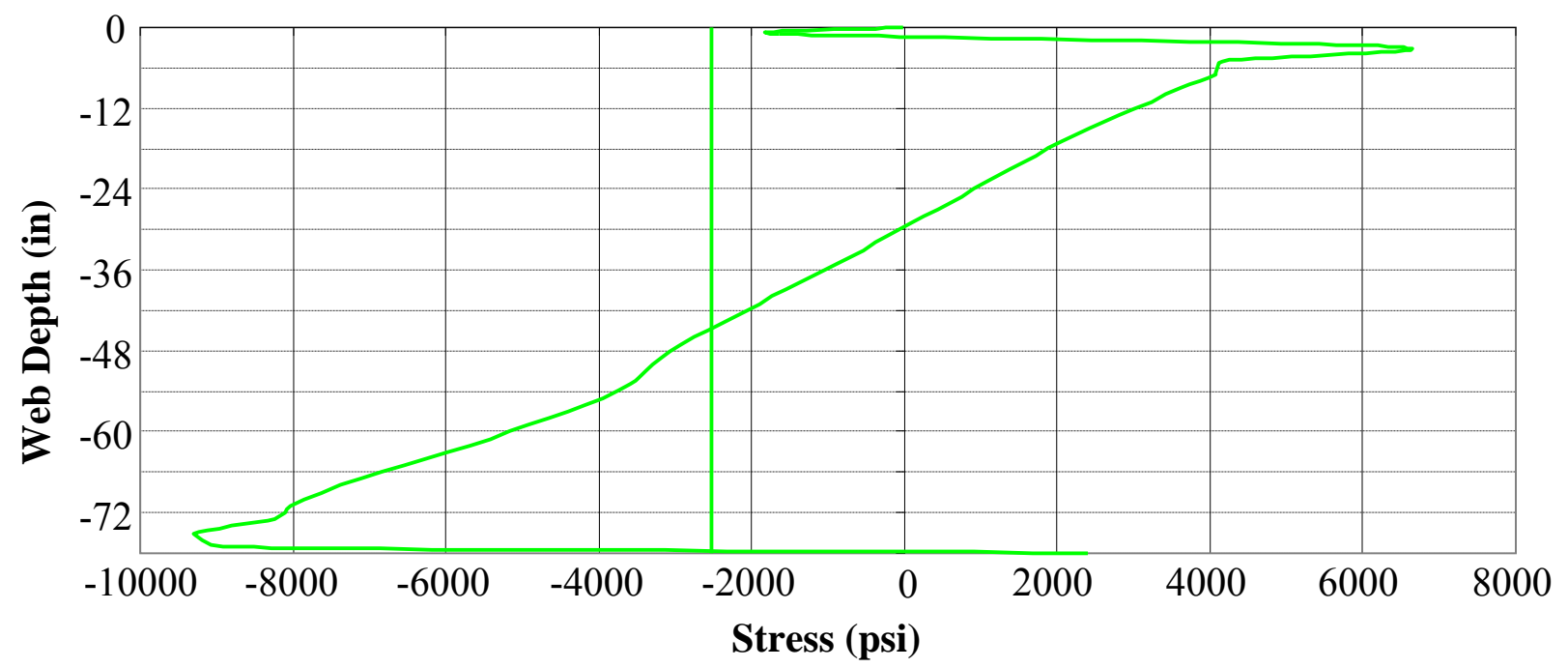

Figure B.14 Pier 10N, Bending and Axial Stress Profiles (Temp $\left.+60^{\circ} \mathrm{F}\right)$

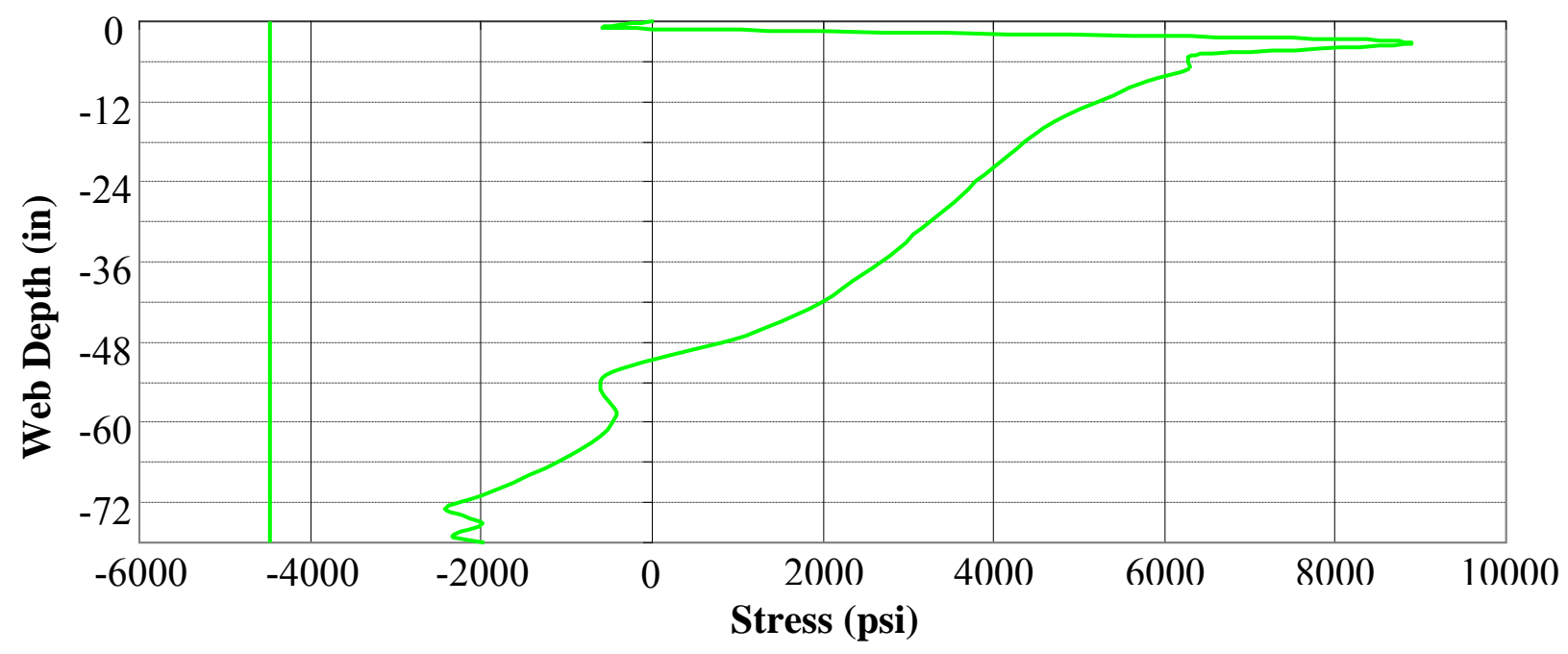

Figure B.15 Pier 11N, Bending and Axial Stress Profiles (Temp $\left.+60^{\circ} \mathrm{F}\right)$ 


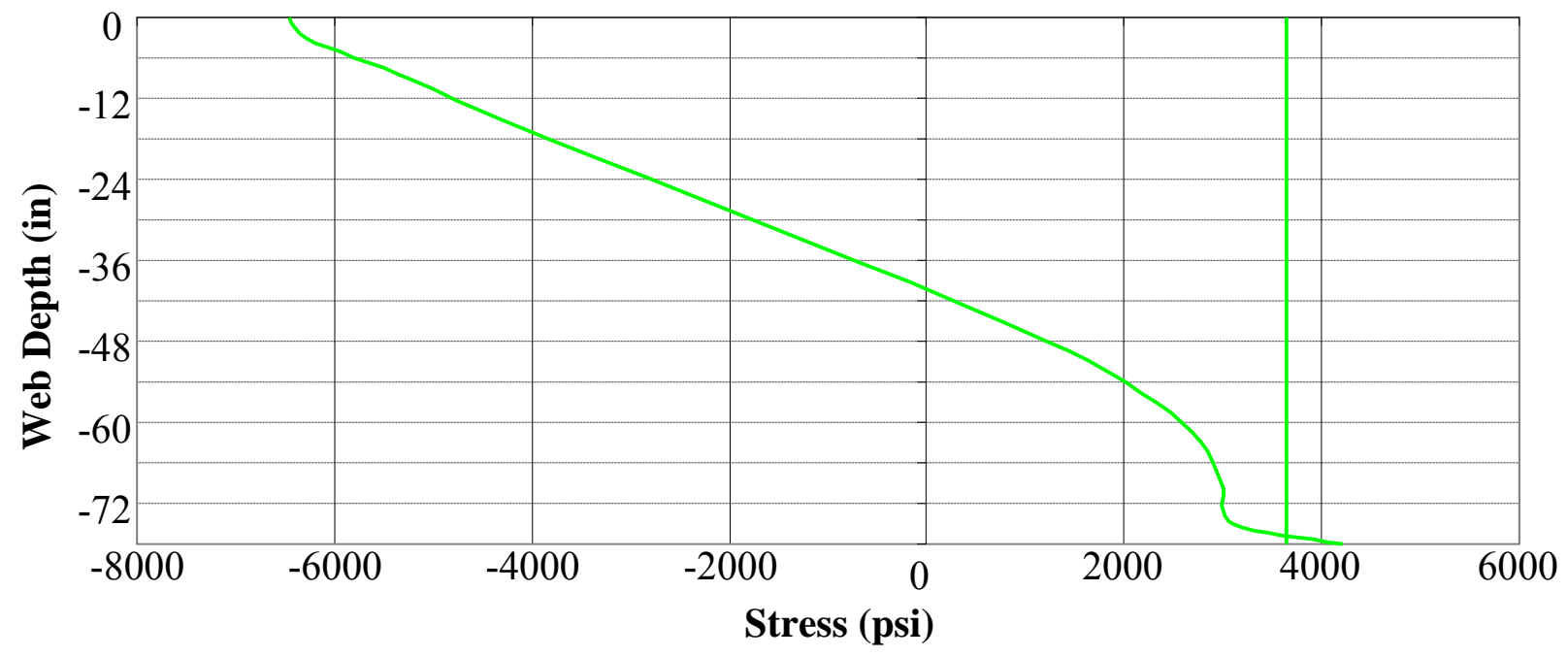

Figure B.16 Span 7N, Bending and Axial Stress Profiles (Temp $\left.+60^{\circ} \mathrm{F}\right)$

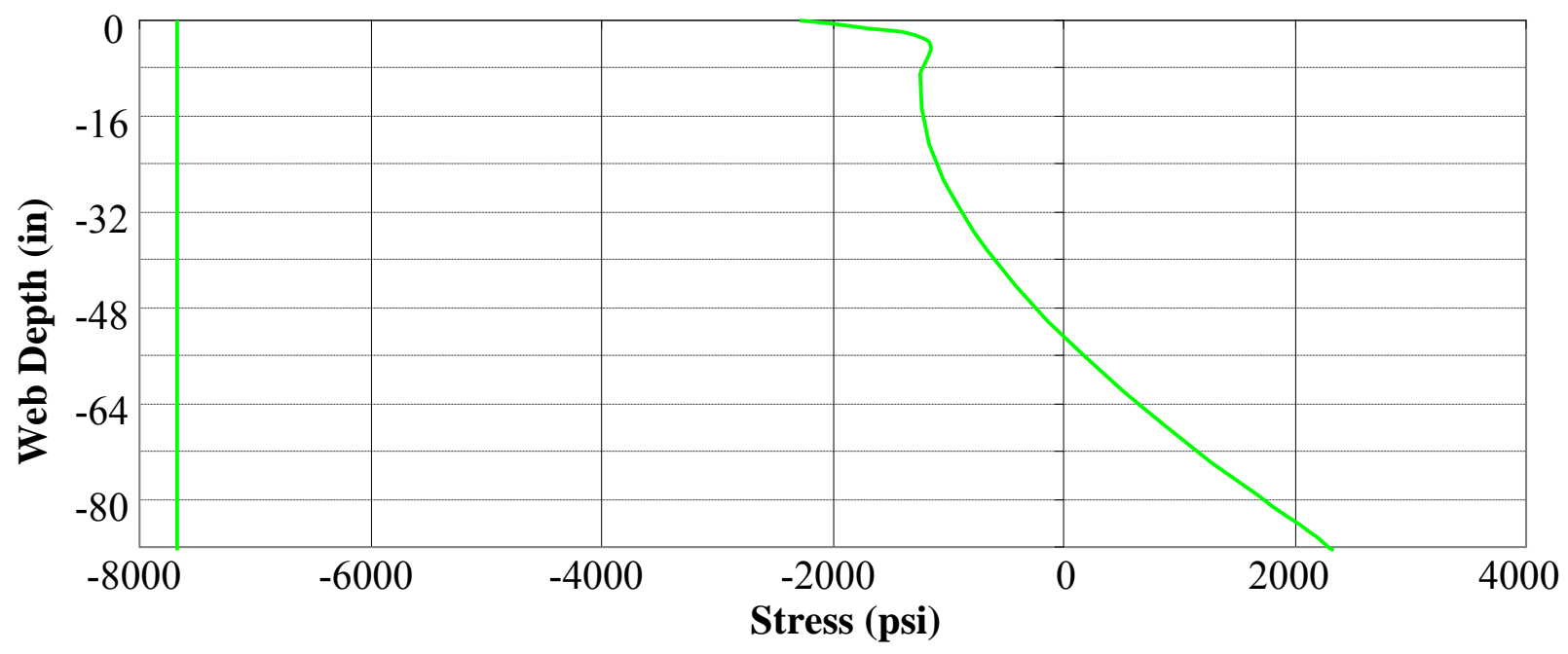

Figure B.17 Span $8 \mathrm{~N}$, Bending and Axial Stress Profiles (Temp $\left.+60^{\circ} \mathrm{F}\right)$

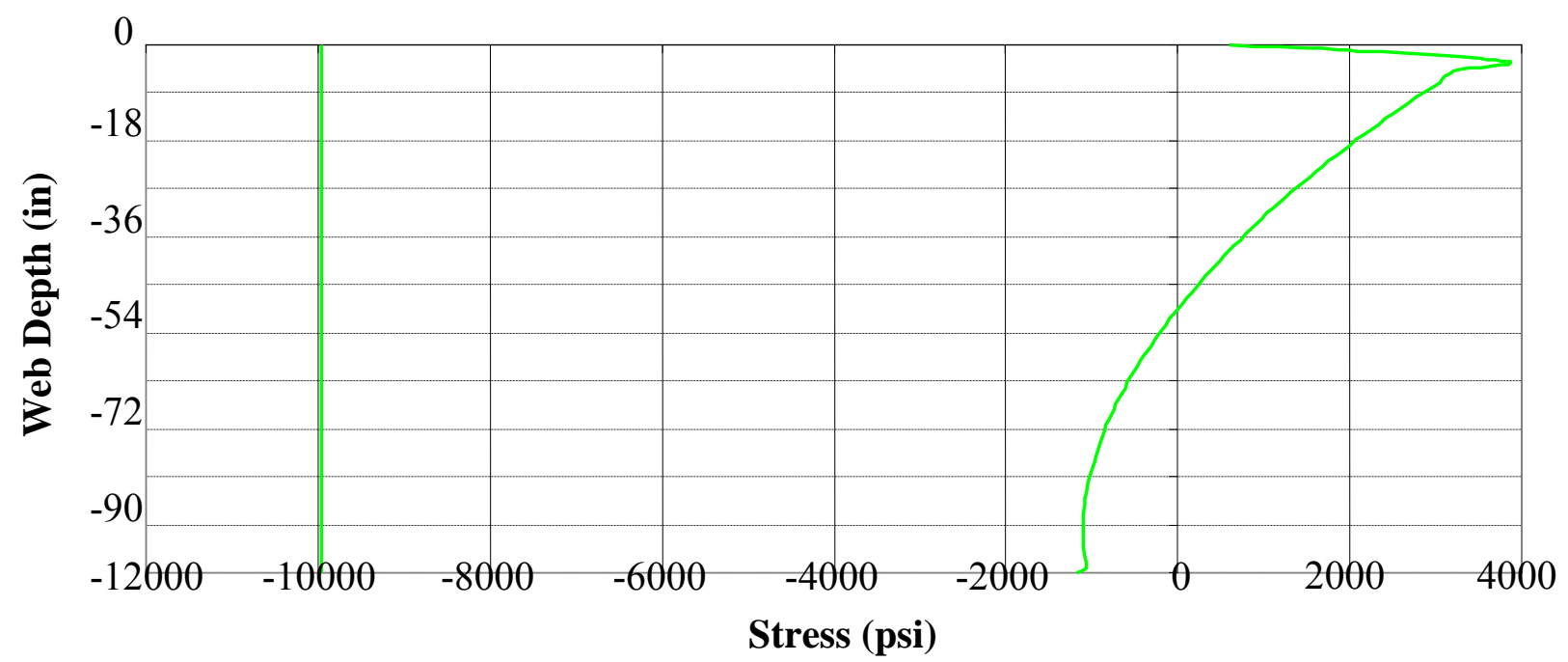

Figure B.18 Span 9N, Bending and Axial Stress Profiles (Temp $\left.+60^{\circ} \mathrm{F}\right)$ 


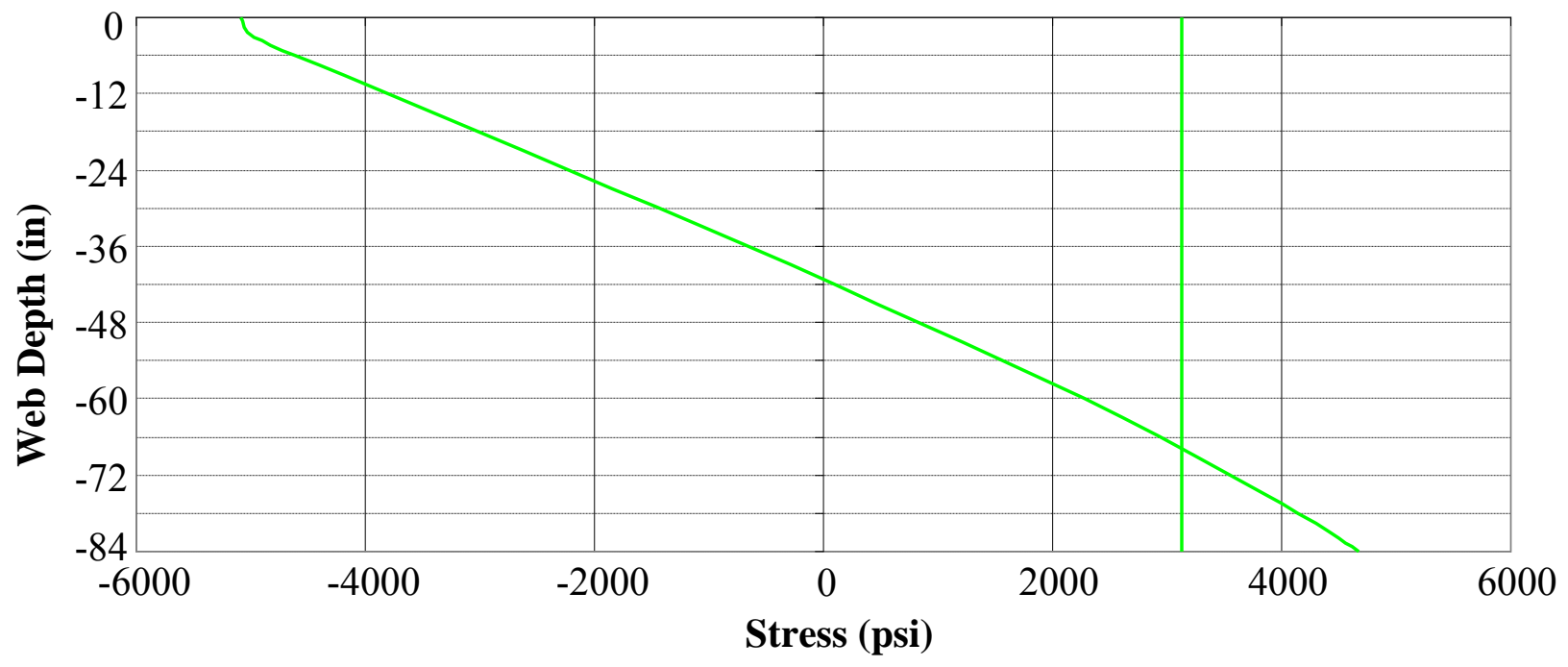

Figure B.19 Span 10N, Bending and Axial Stress Profiles (Temp $\left.+60^{\circ} \mathrm{F}\right)$

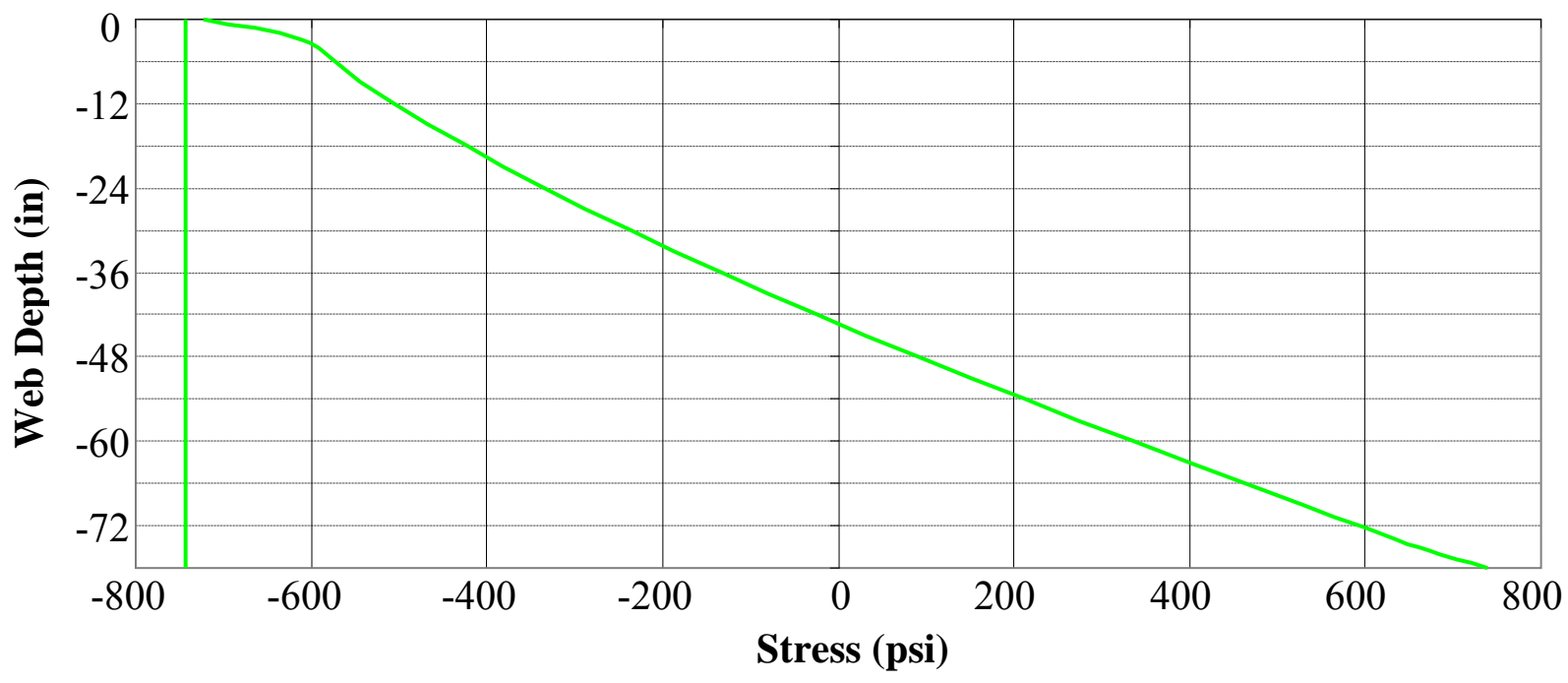

Figure B.20 Span 11N, Bending and Axial Stress Profiles (Temp $\left.+60^{\circ} \mathrm{F}\right)$ 


\section{APPENDIX C}

\section{LONGITUDINAL WEB PROFILE COMPARISONS - GIRDER 3N}

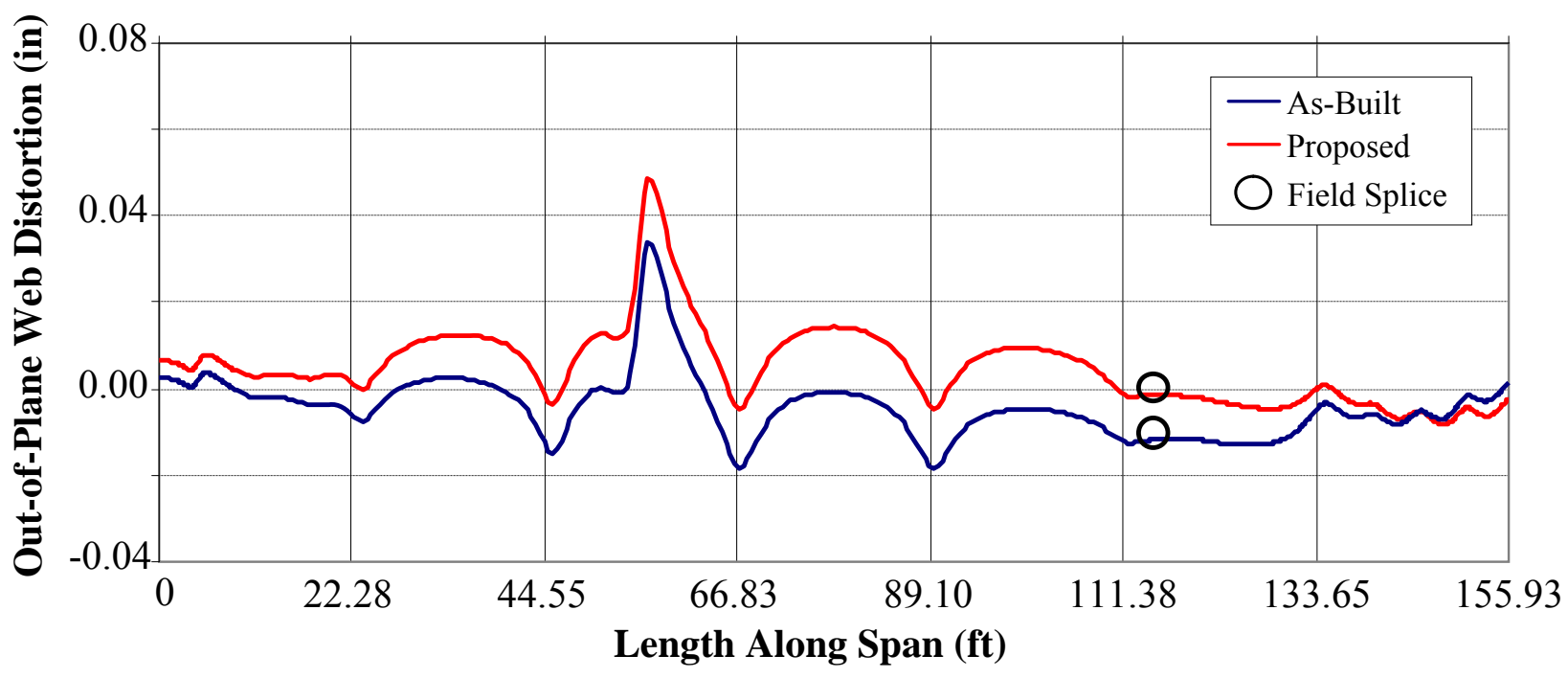

Figure C.1 Longitudinal Profiles Comparison of Span 7N Due to Self-Weight

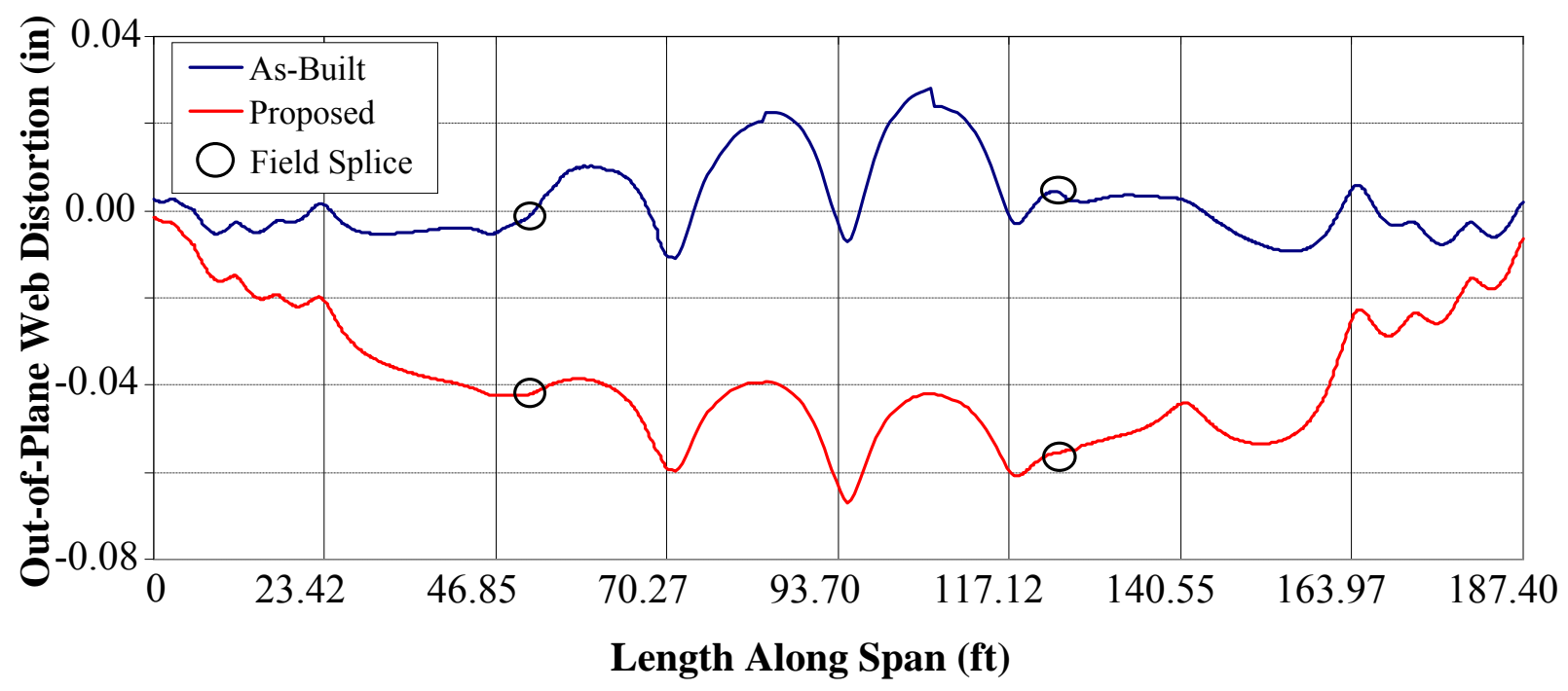

Figure C.2 Longitudinal Profiles Comparison of Span 8N Due to Self-Weight 


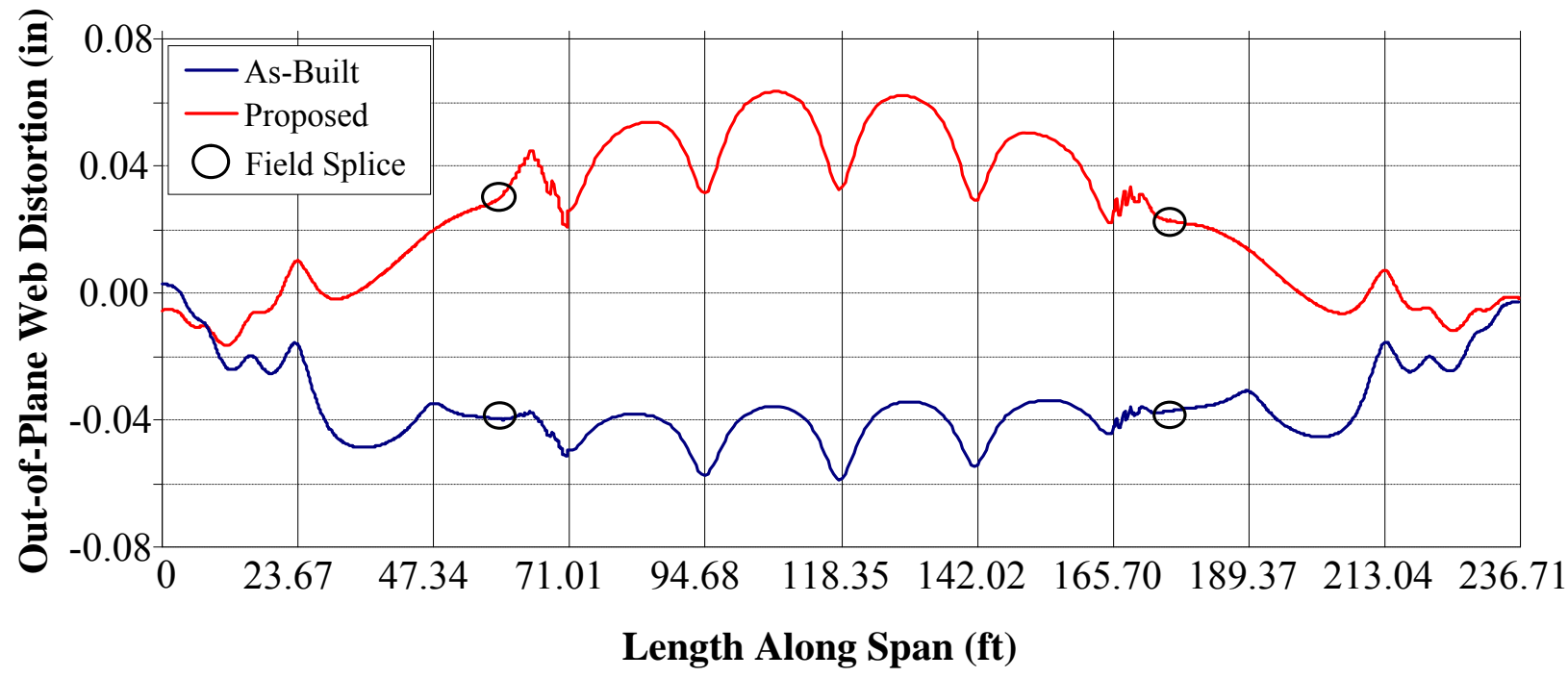

Figure C.3 Longitudinal Profiles Comparison of Span 9N Due to Self-Weight

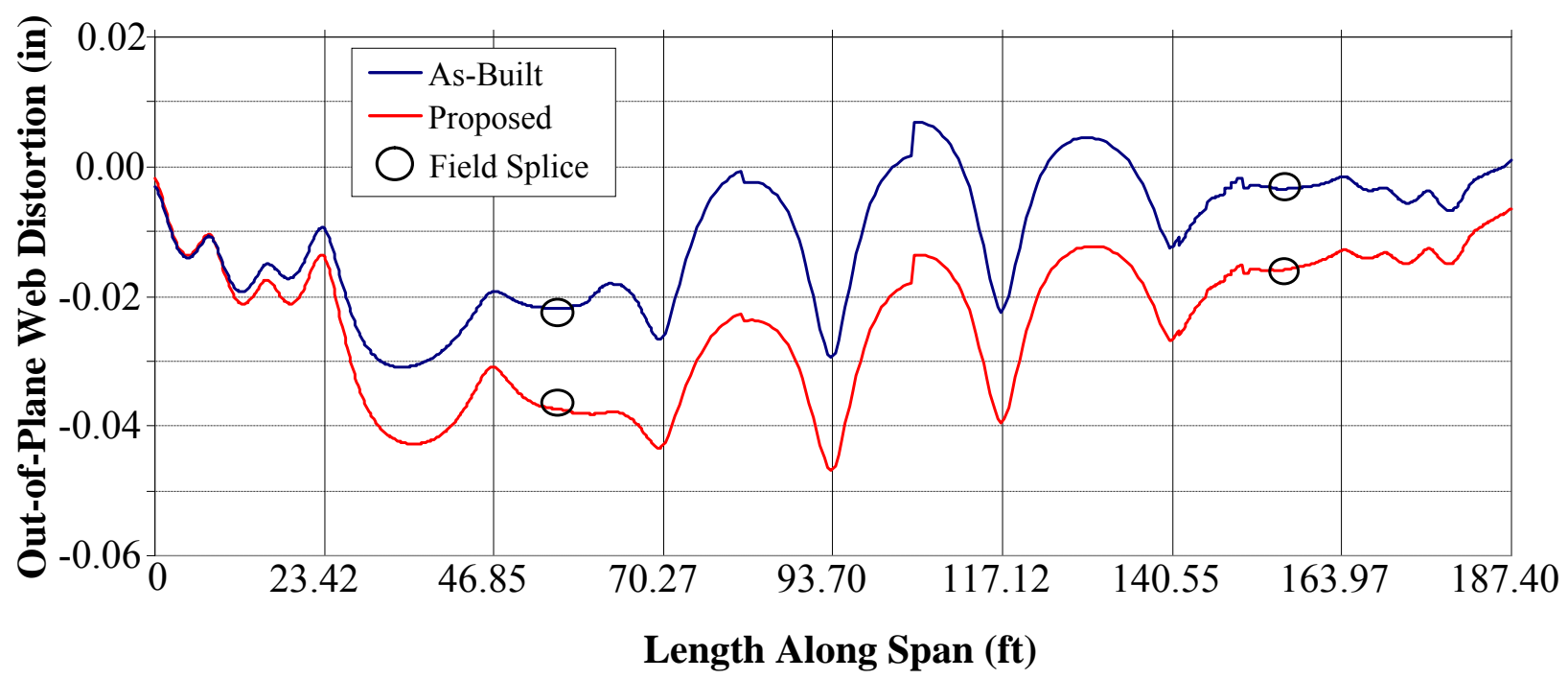

Figure C.4 Longitudinal Profiles Comparison of Span 10N Due to Self-Weight

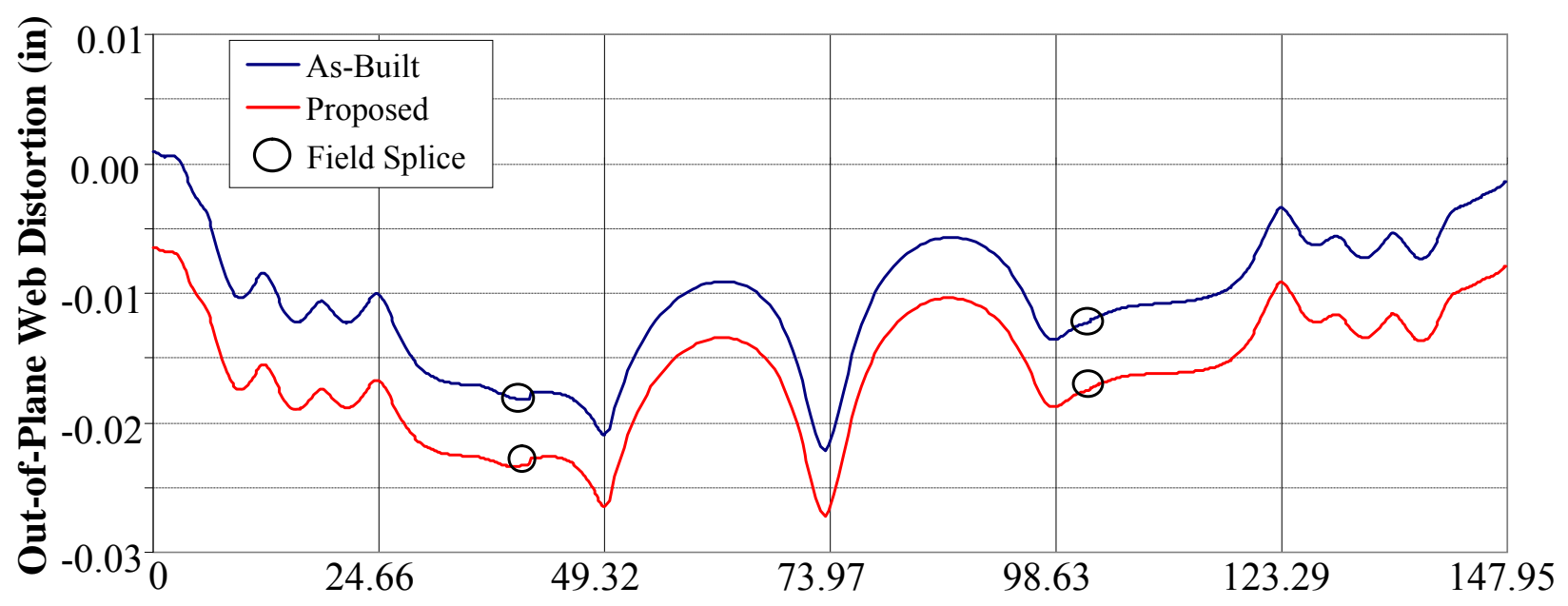

\section{Length Along Span (ft)}

Figure C.5 Longitudinal Profiles Comparison of Span 11N Due to Self-Weight 


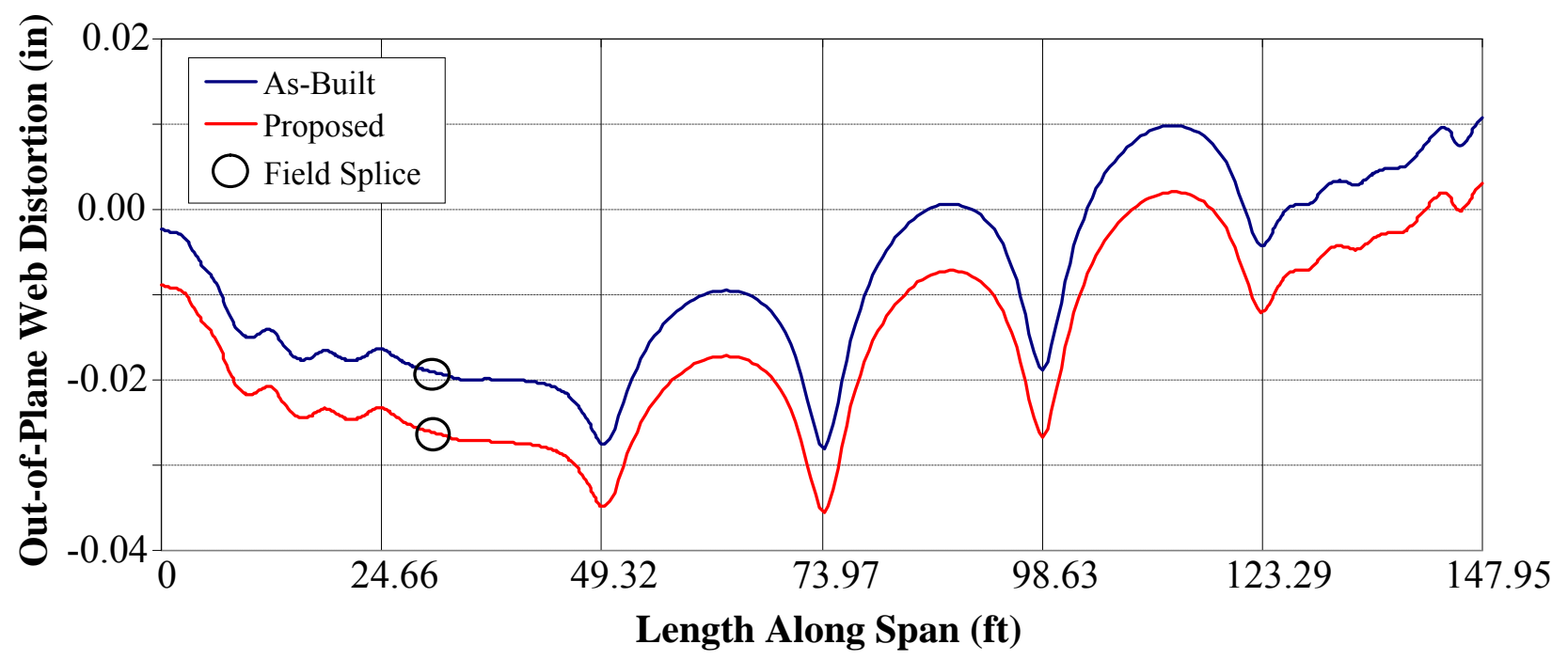

Figure C.6 Longitudinal Profiles Comparison of Span 12N Due to Self-Weight

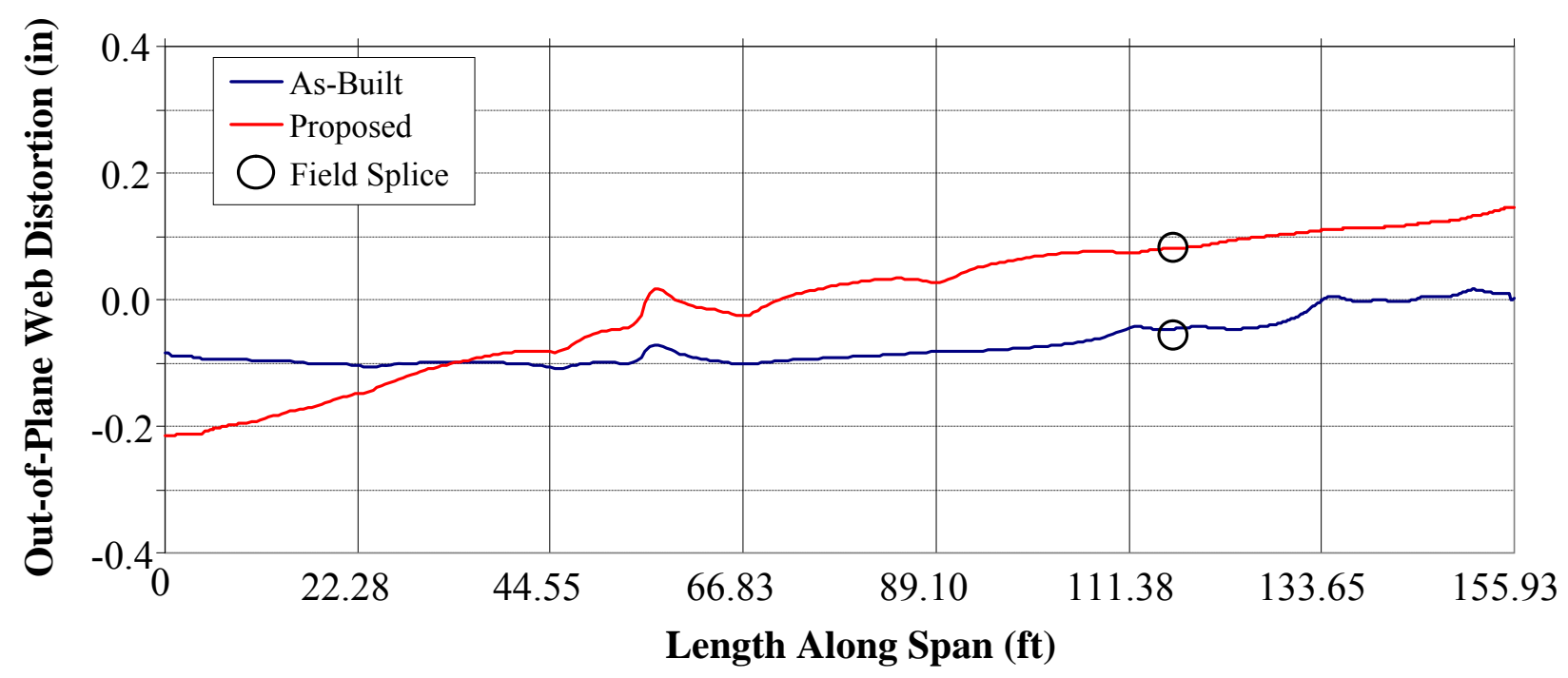

Figure C.7 Longitudinal Profiles Comparison of Span $7 \mathrm{~N}$ Due to Temp $-60^{\circ} \mathrm{F}$

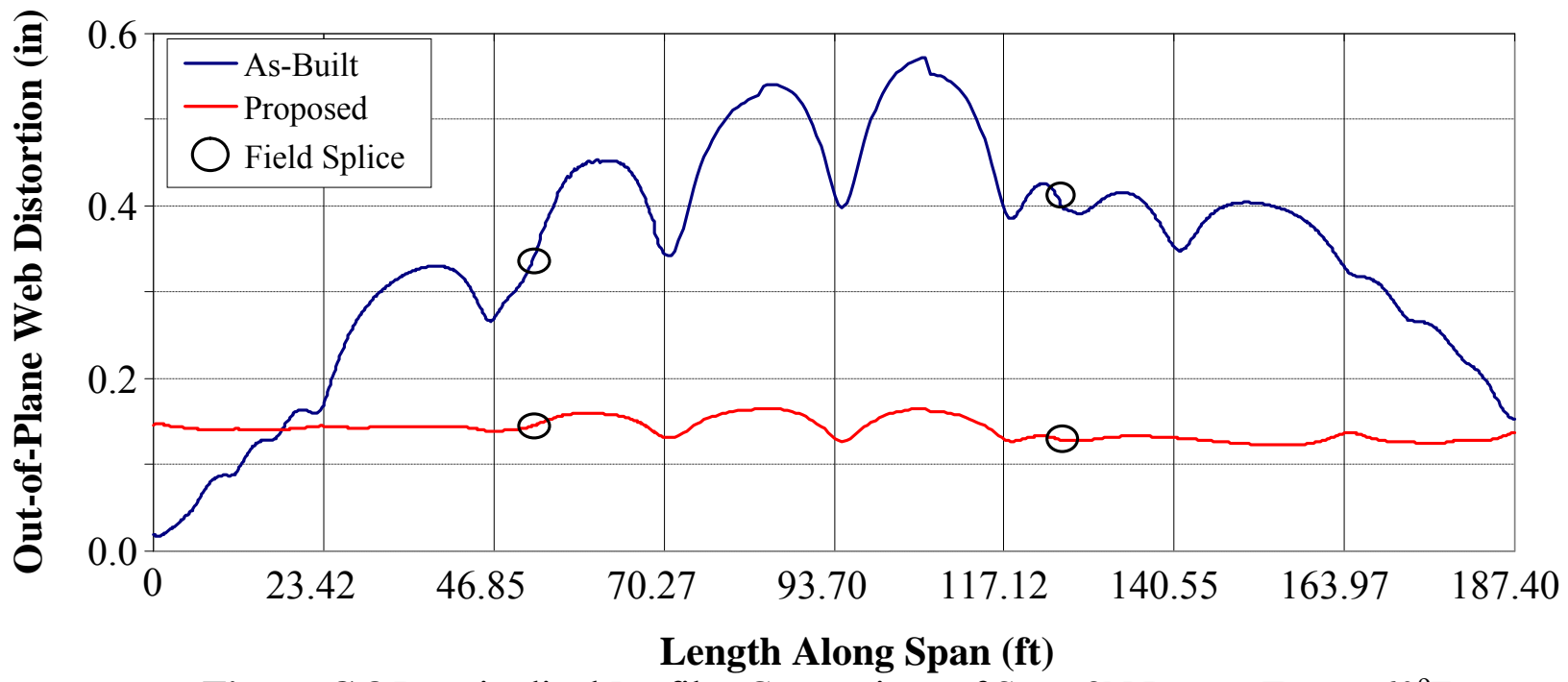

Figure C.8 Longitudinal Profiles Comparison of Span $8 \mathrm{~N}$ Due to Temp $-60^{\circ} \mathrm{F}$ 


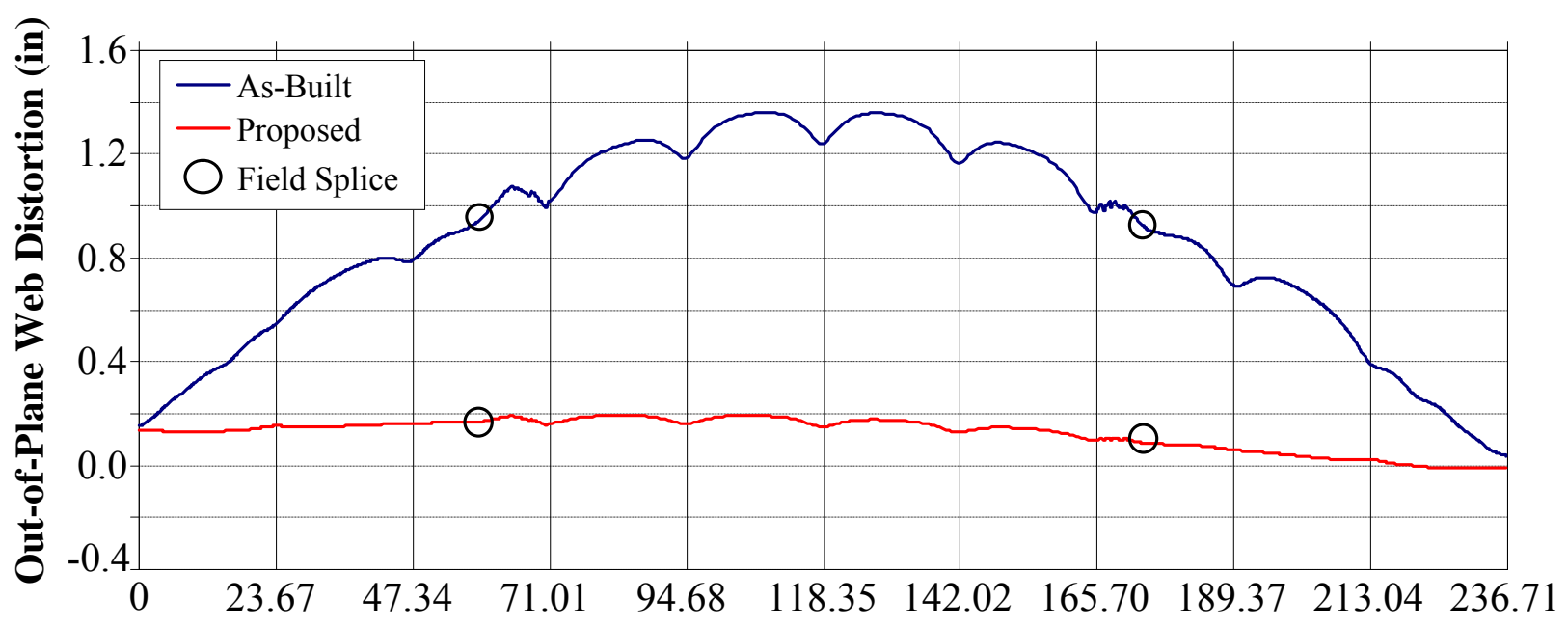

\section{Length Along Span (ft)}

Figure C.9 Longitudinal Profiles Comparison of Span 9N Due to Temp $-60^{\circ} \mathrm{F}$

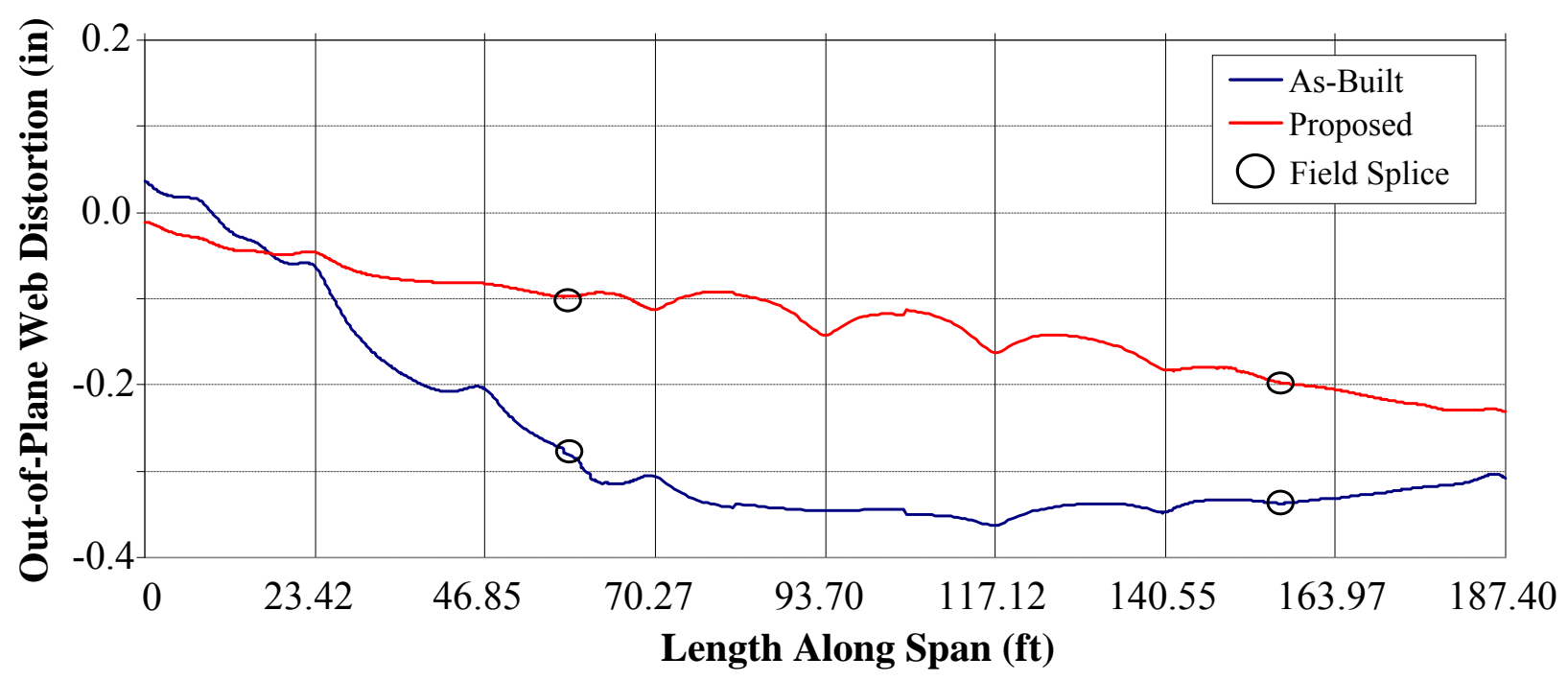

Figure C.10 Longitudinal Profiles Comparison of Span 10N Due to Temp $-60^{\circ} \mathrm{F}$

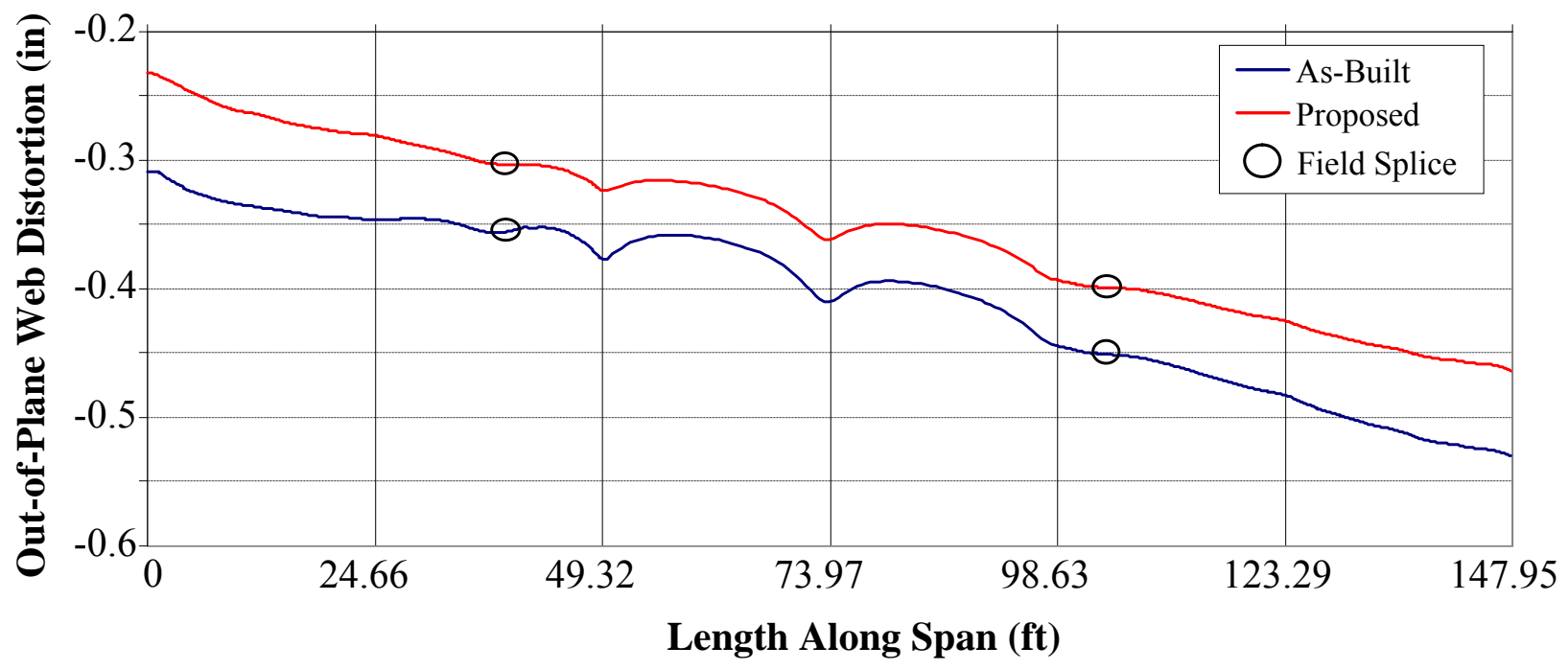

Figure C.11 Longitudinal Profiles Comparison of Span $11 \mathrm{~N}$ Due to Temp $-60^{\circ} \mathrm{F}$ 


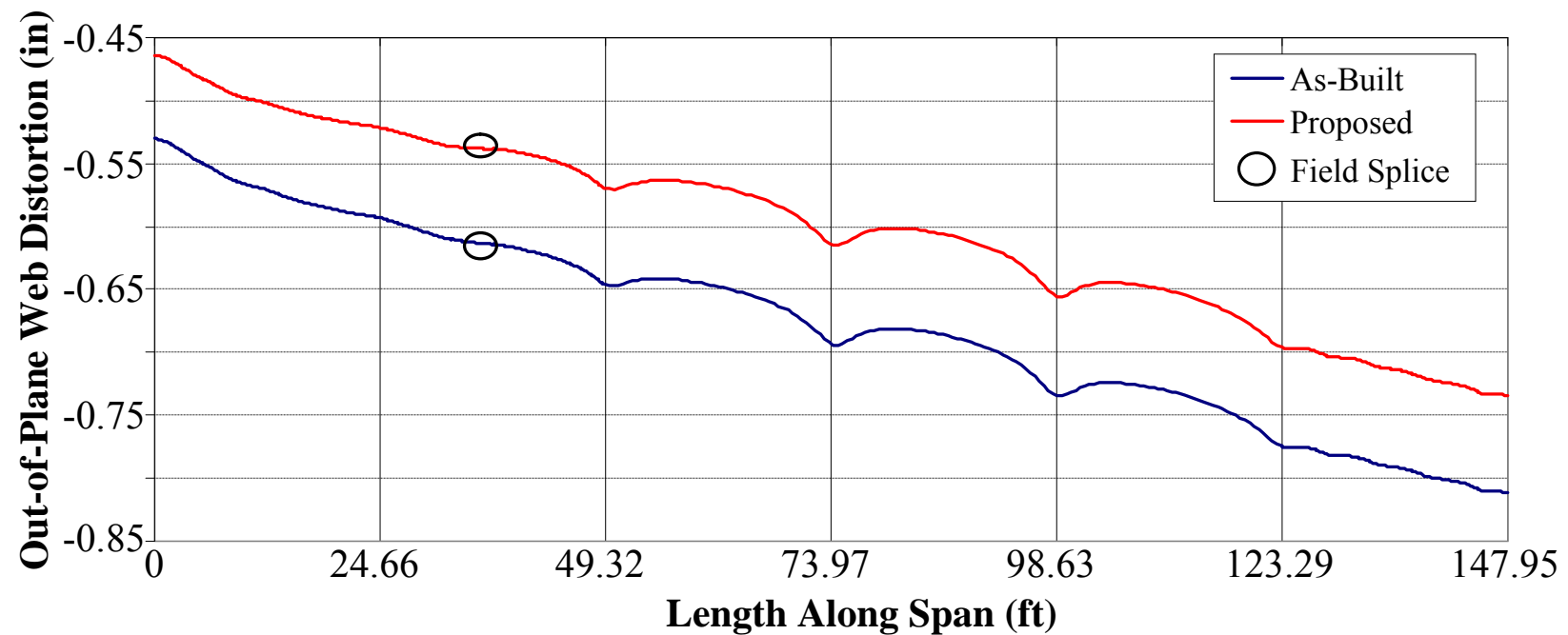

Figure C.12 Longitudinal Profiles Comparison of Span $12 \mathrm{~N}$ Due to Temp $-60^{\circ} \mathrm{F}$

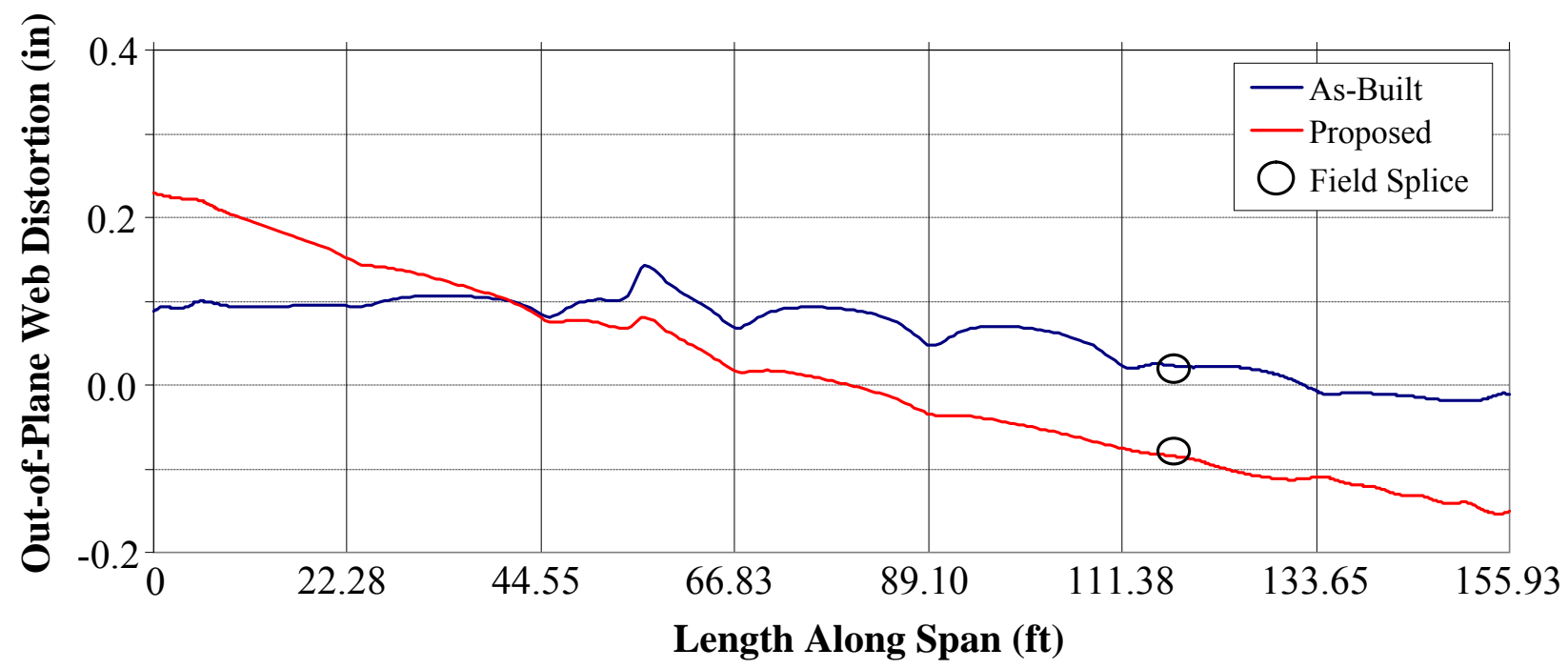

Figure C.13 Longitudinal Profiles Comparison of Span $7 \mathrm{~N}$ Due to Temp $+60^{\circ} \mathrm{F}$

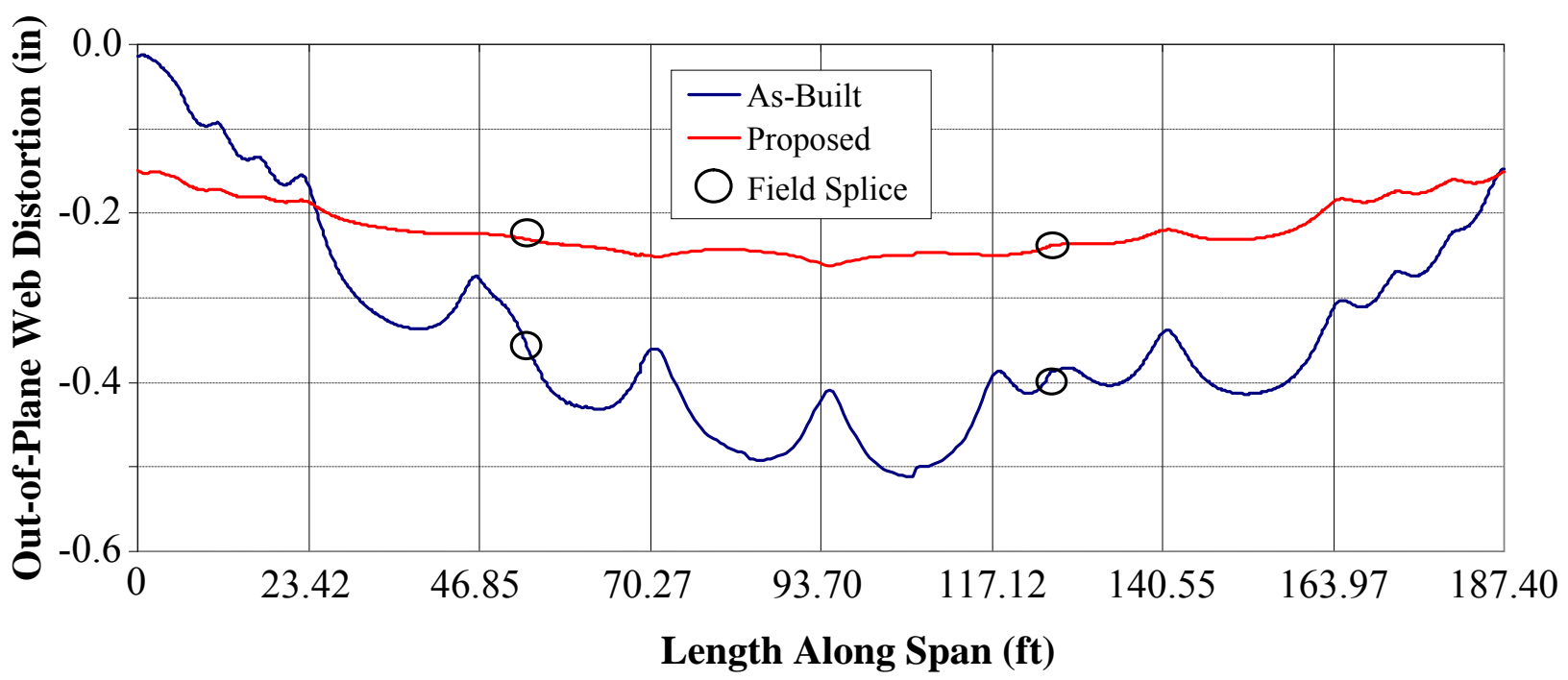

Figure C.14 Longitudinal Profiles Comparison of Span $8 \mathrm{~N}$ Due to Temp $+60^{\circ} \mathrm{F}$ 


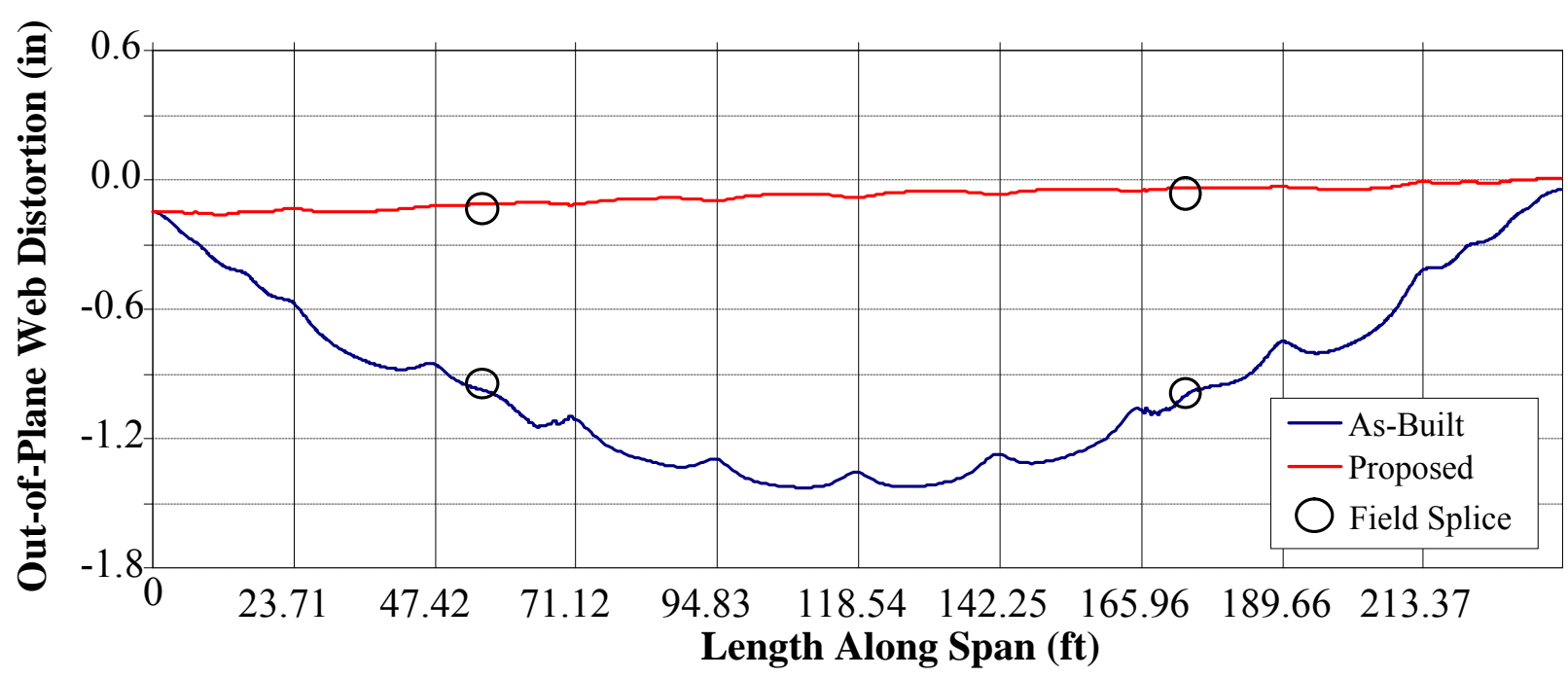

Figure C.15 Longitudinal Profiles Comparison of Span 9N Due to Temp $+60^{\circ} \mathrm{F}$

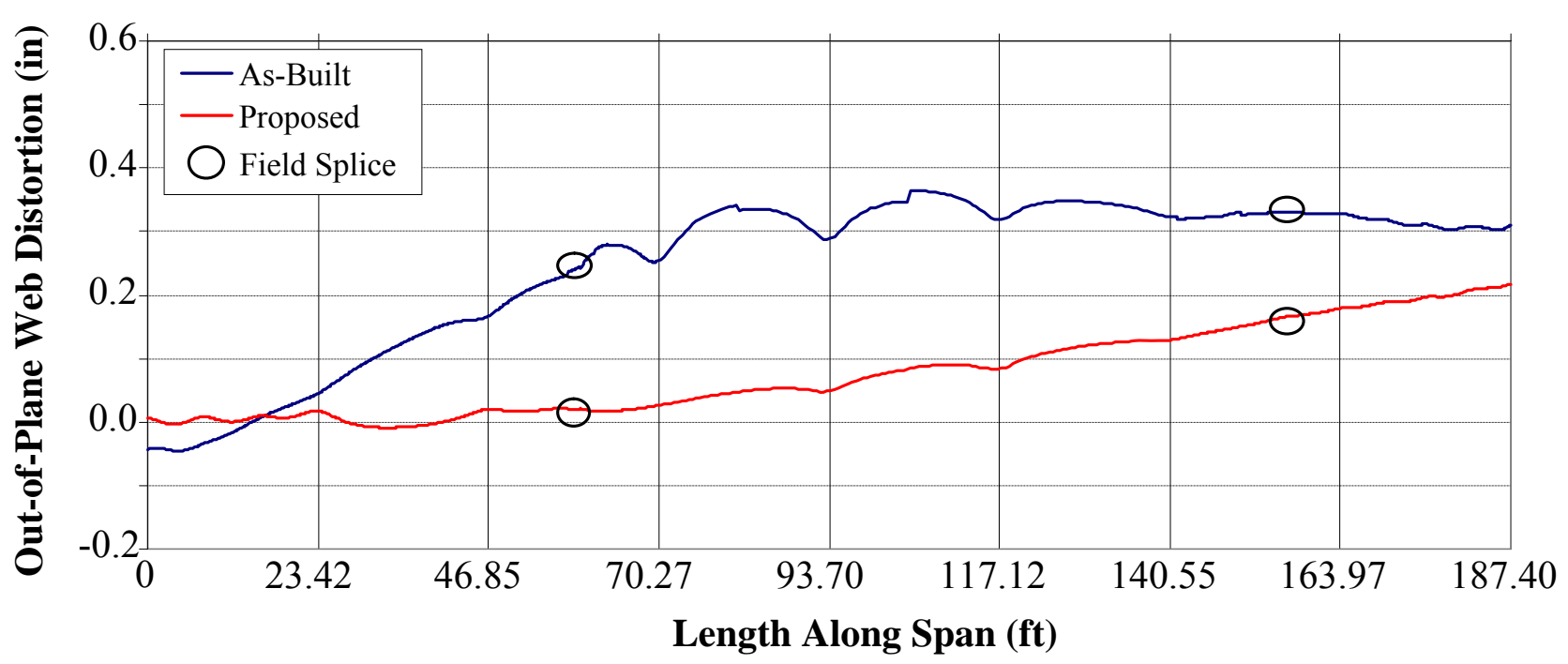

Figure C.16 Longitudinal Profiles Comparison of Span 10N Due to Temp $+60^{\circ} \mathrm{F}$

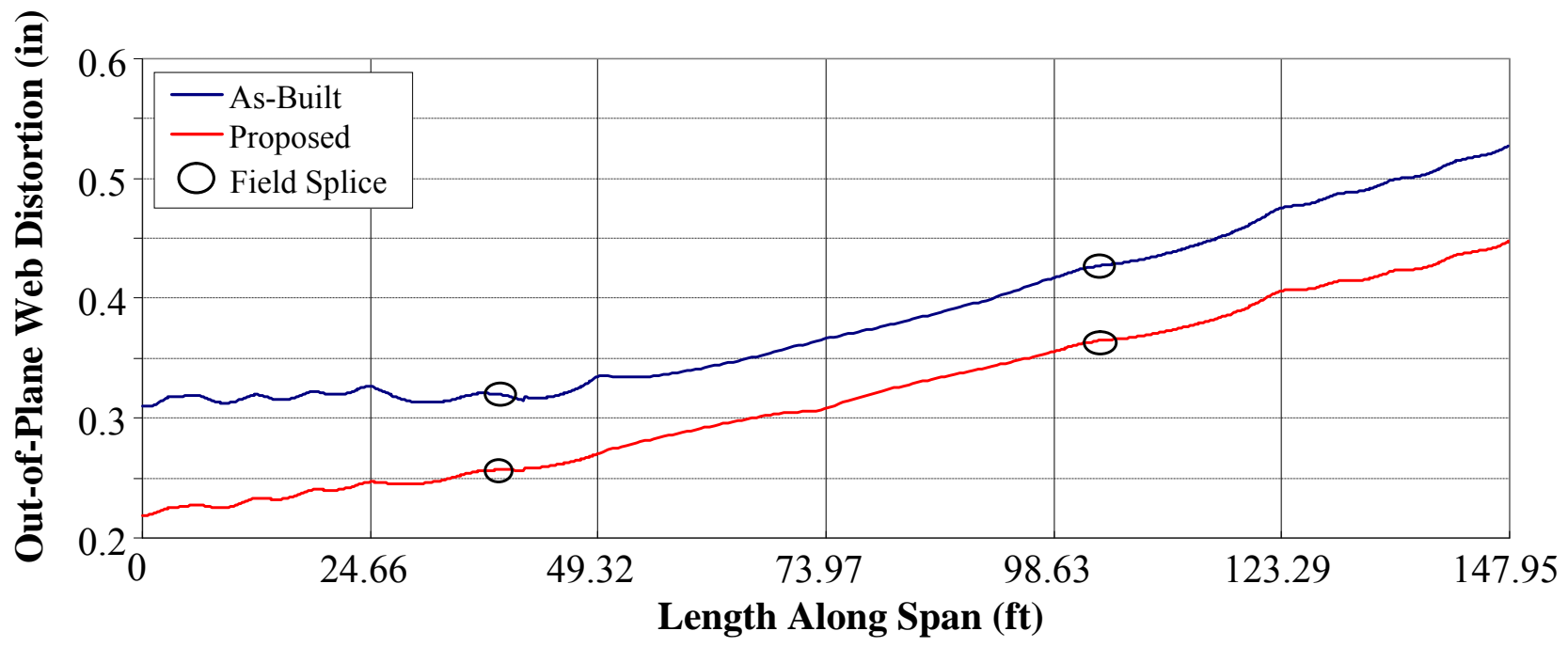

Figure C.17 Longitudinal Profiles Comparison of Span $11 \mathrm{~N}$ Due to Temp $+60^{\circ} \mathrm{F}$ 


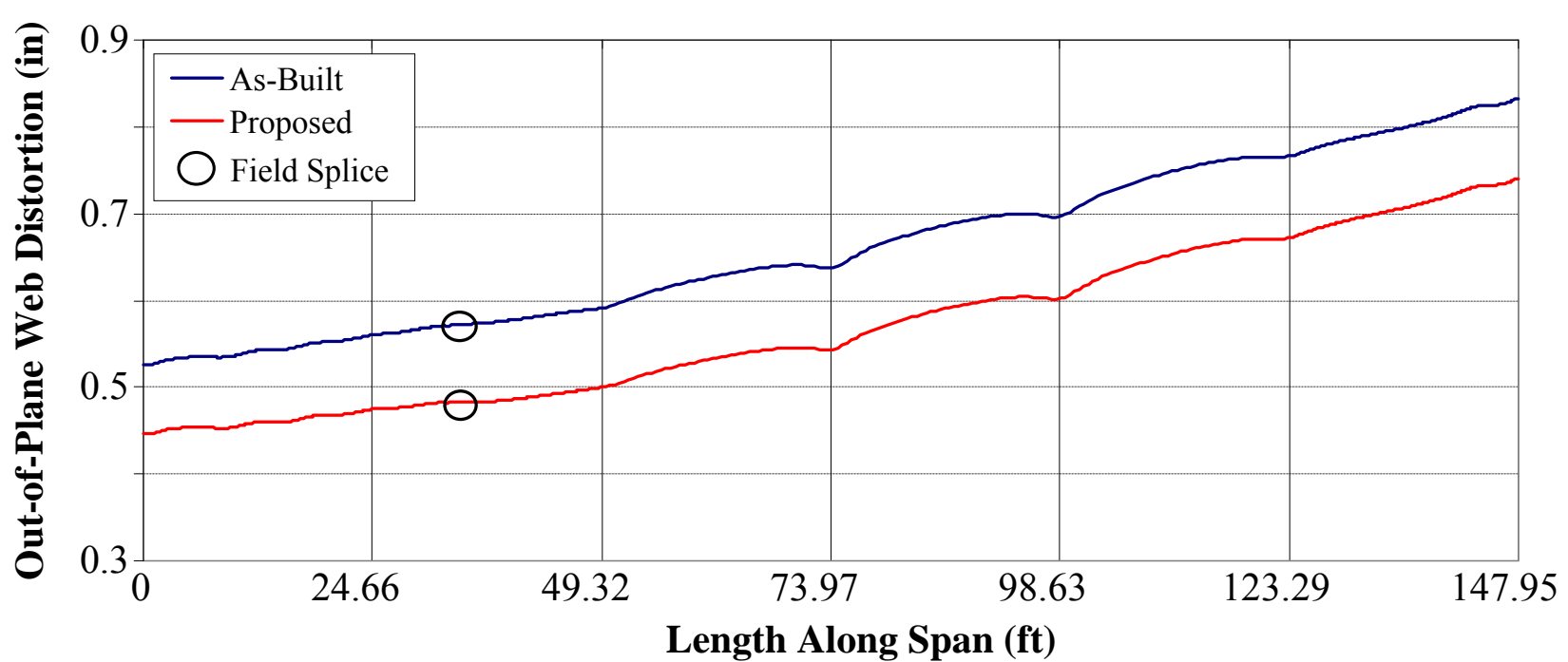

Figure C.18 Longitudinal Profiles Comparison of Span $12 \mathrm{~N}$ Due to Temp $+60^{\circ} \mathrm{F}$

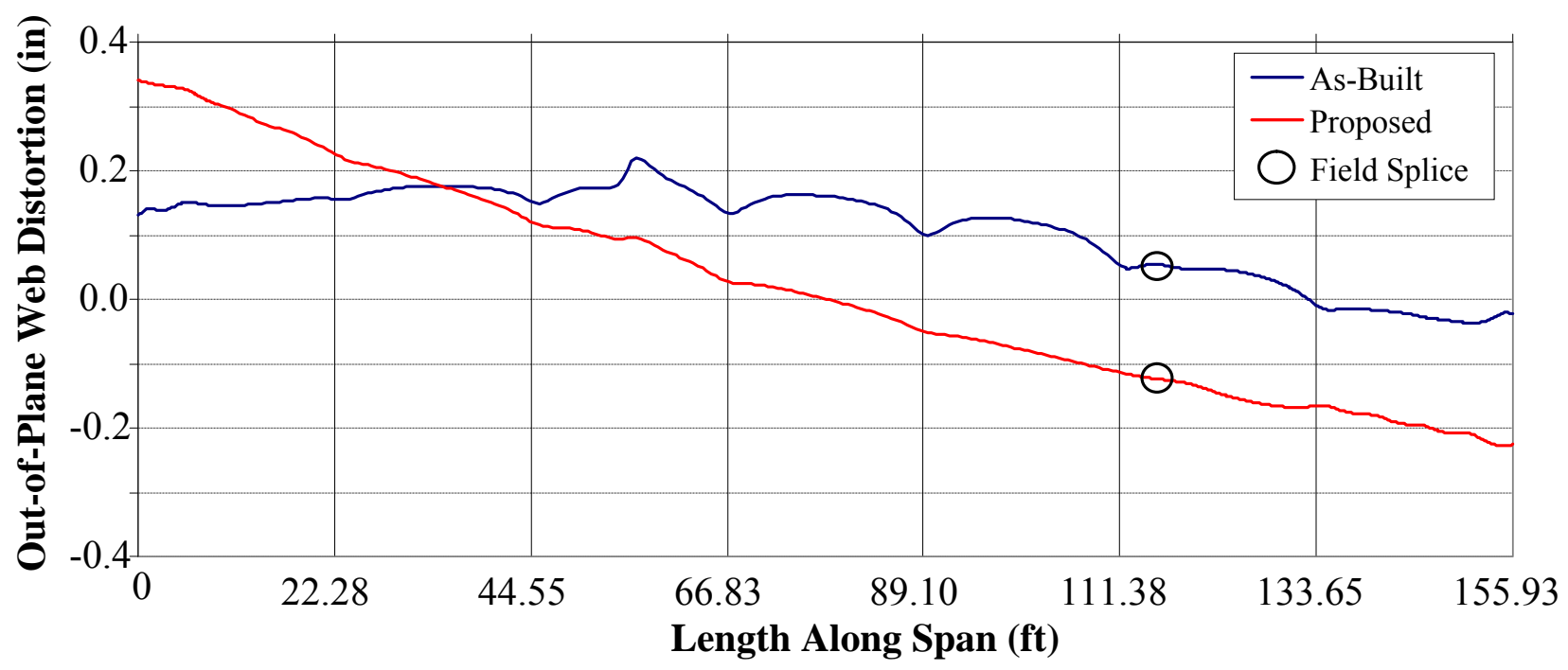

Figure C.19 Longitudinal Profiles Comparison of Span $7 \mathrm{~N}$ Due to Temp $+90^{\circ} \mathrm{F}$

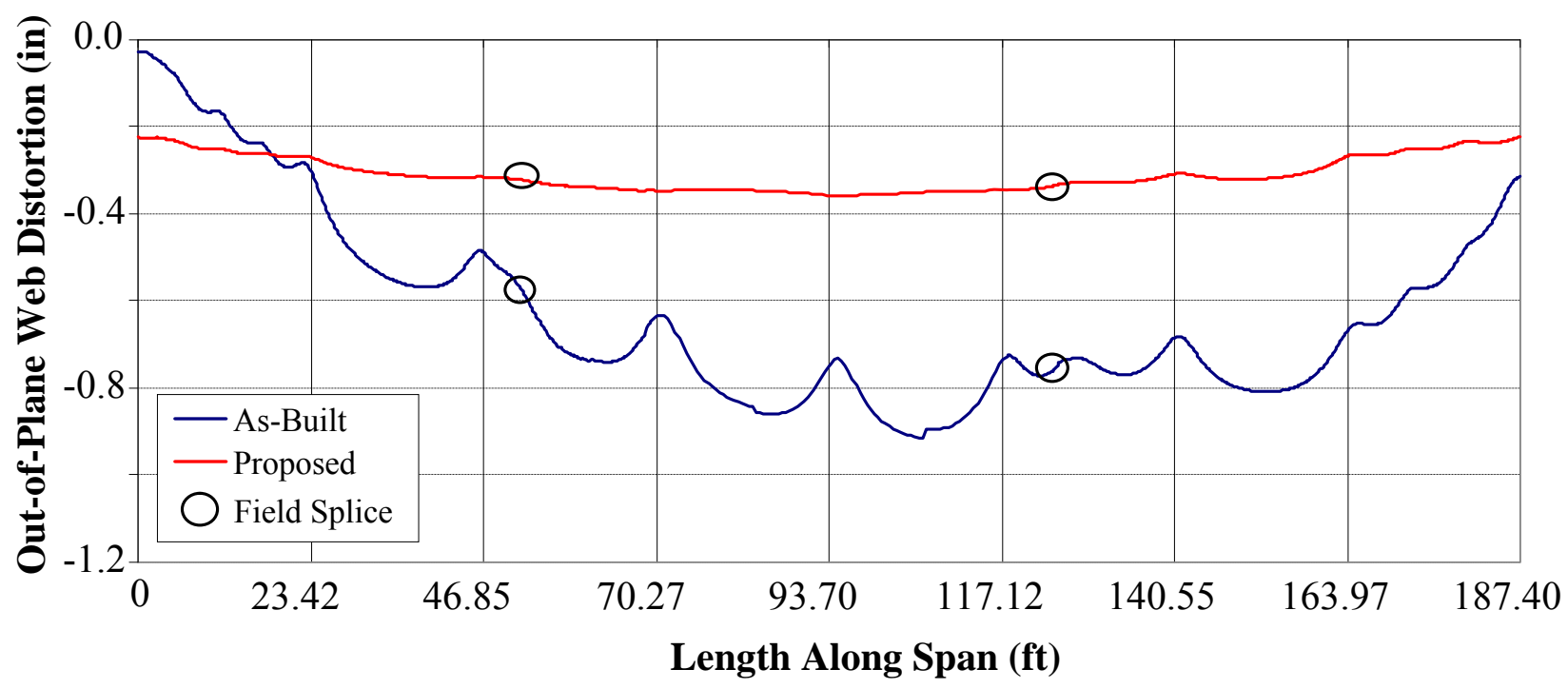

Figure C.20 Longitudinal Profiles Comparison of Span $8 \mathrm{~N}$ Due to Temp $+90^{\circ} \mathrm{F}$ 


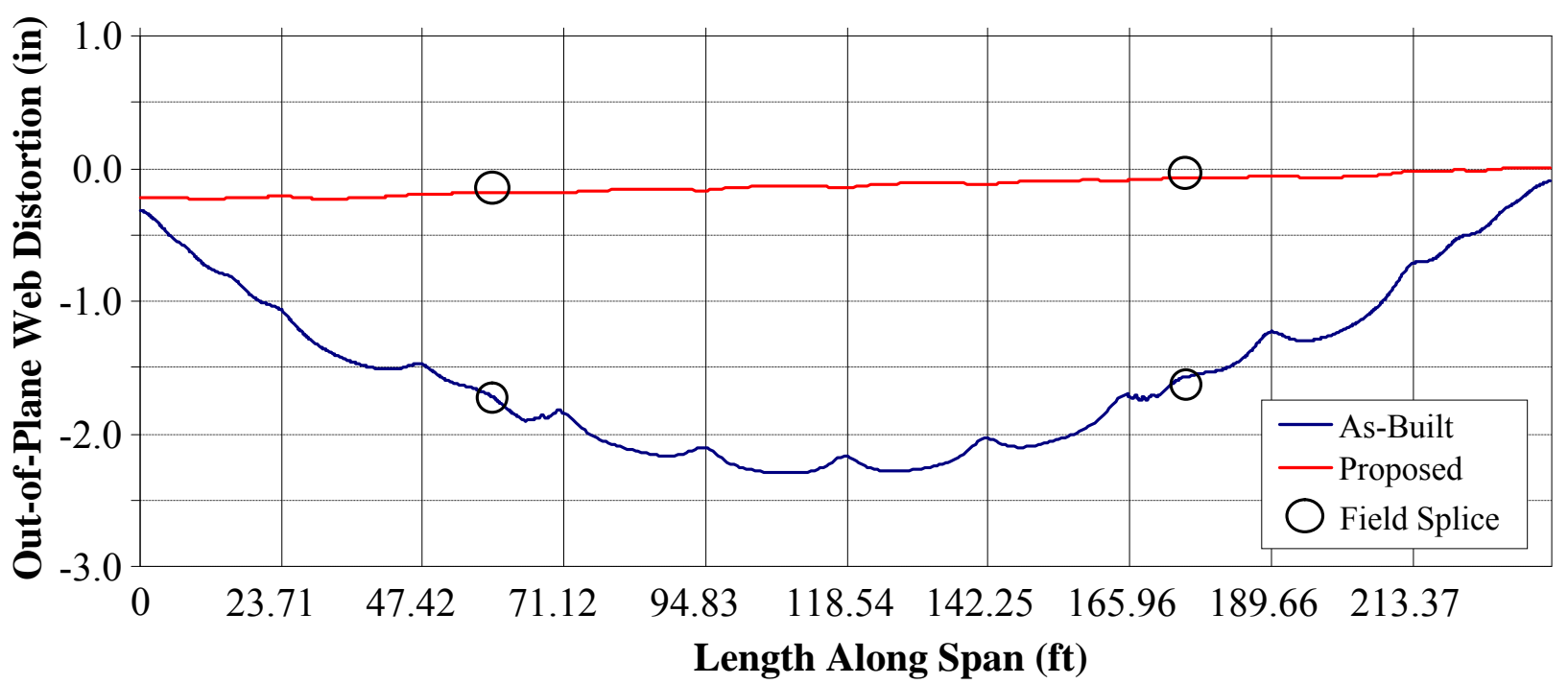

Figure C.21 Longitudinal Profiles Comparison of Span 9N Due to Temp $+90^{\circ} \mathrm{F}$

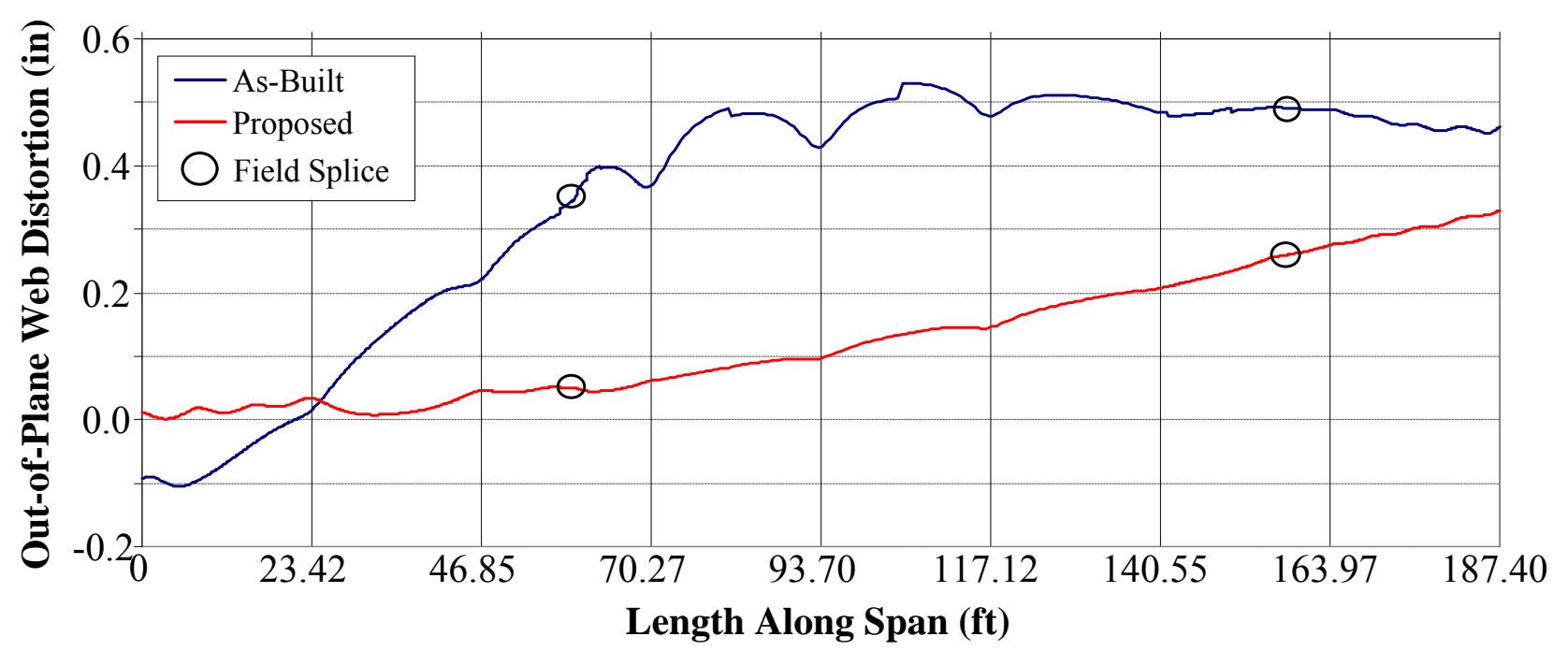

Figure C.22 Longitudinal Profiles Comparison of Span 10N Due to Temp $+90^{\circ} \mathrm{F}$

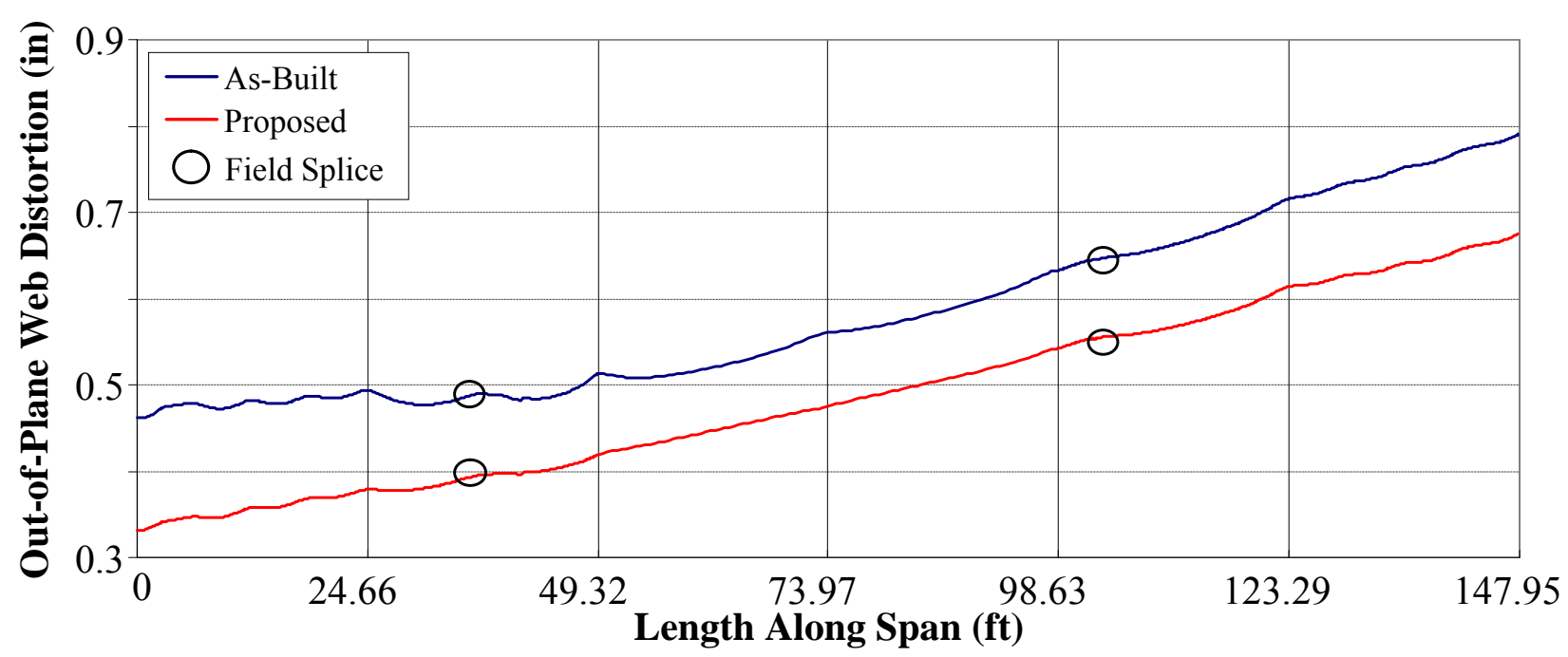

Figure C.23 Longitudinal Profiles Comparison of Span $11 \mathrm{~N}$ Due to Temp $+90^{\circ} \mathrm{F}$ 


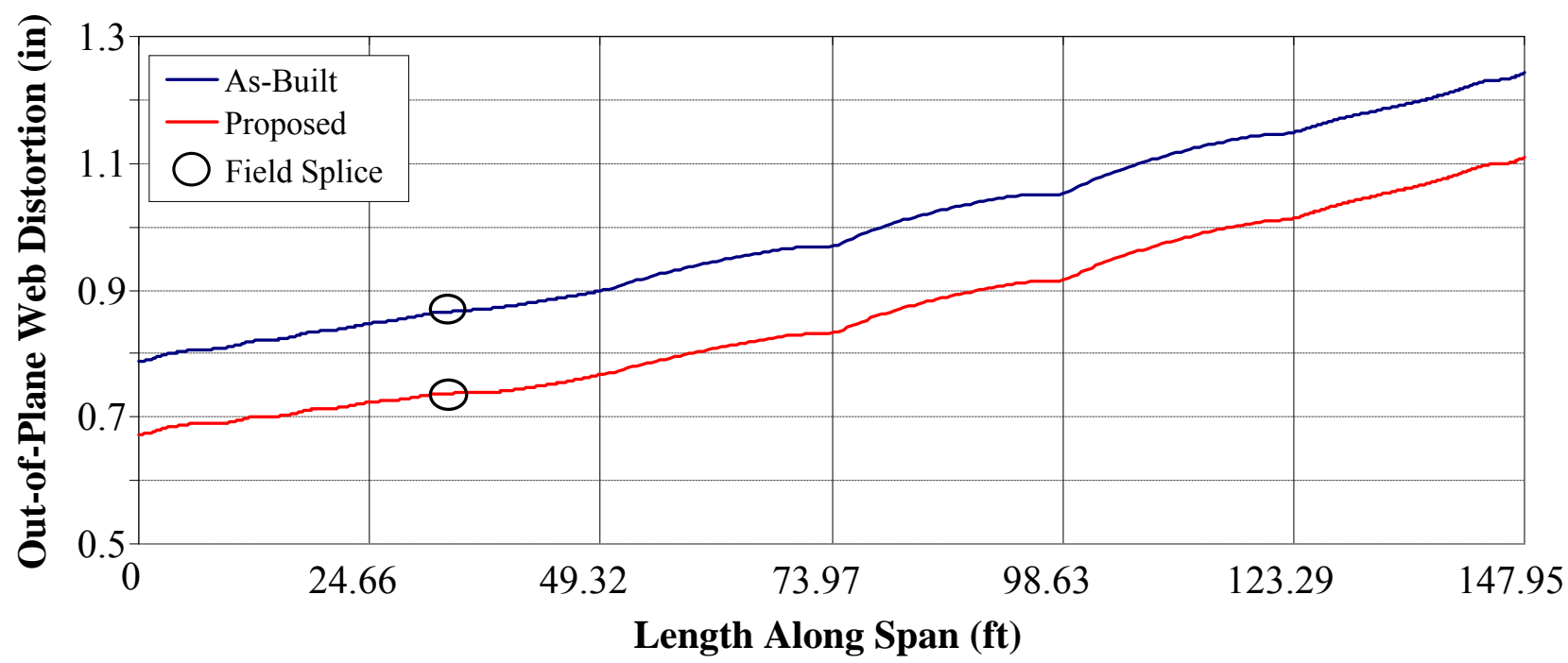

Figure C.24 Longitudinal Profiles Comparison of Span $12 \mathrm{~N}$ Due to Temp $+90^{\circ} \mathrm{F}$ 


\section{APPENDIX D}

NEW BEARINGS BENDING AND AXIAL STRESS PROFILES - Self-Weight and

Temp $-60^{\circ} \mathrm{F}$

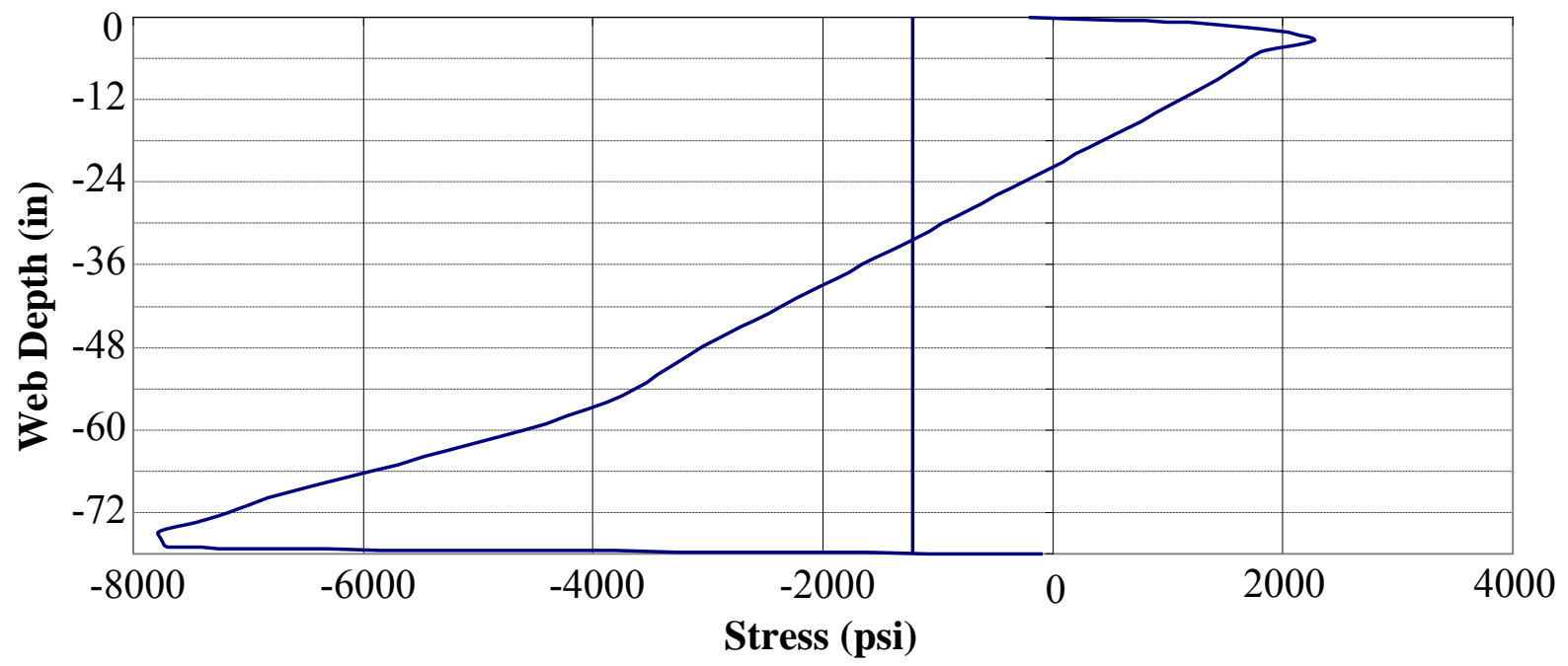

Figure D.1 Pier 7N, Bending and Axial Stress Profiles (Self-Weight)

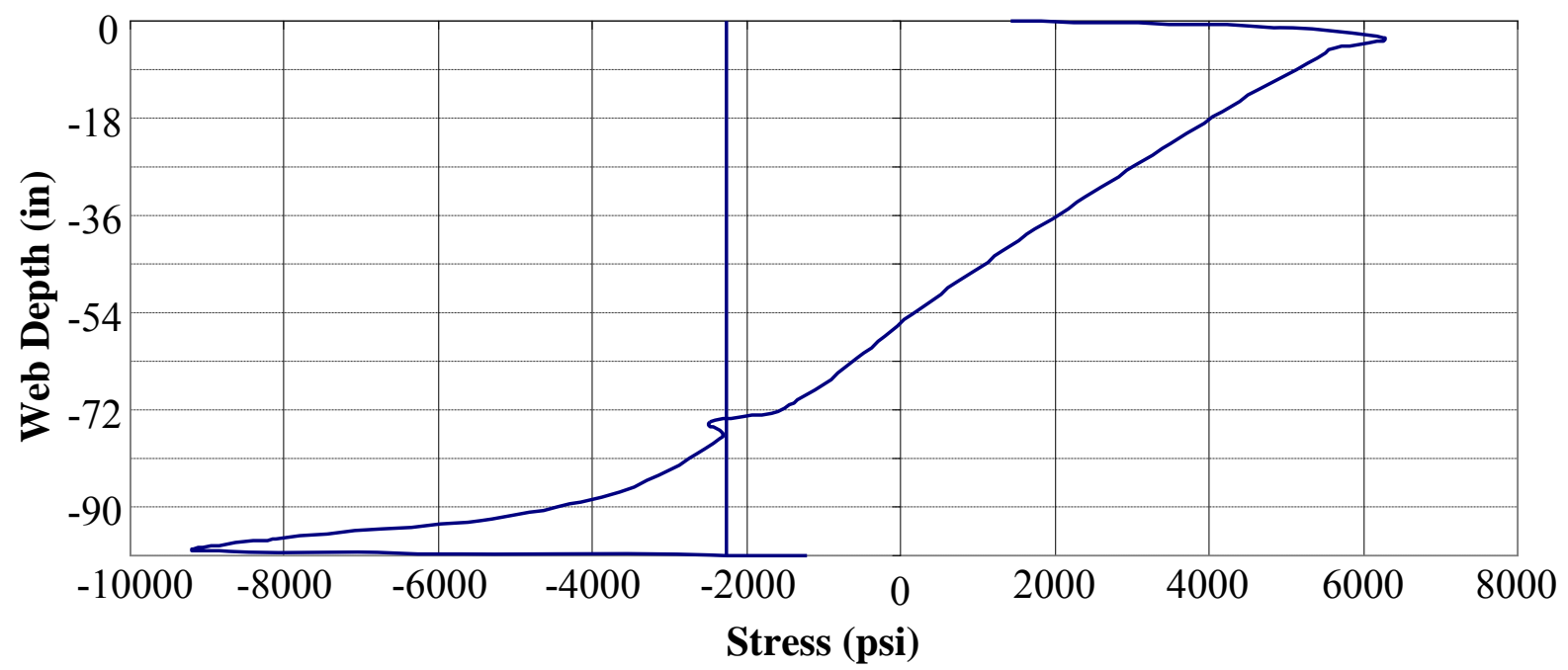

Figure D.2 Pier 8N, Bending and Axial Stress Profiles (Self-Weight) 


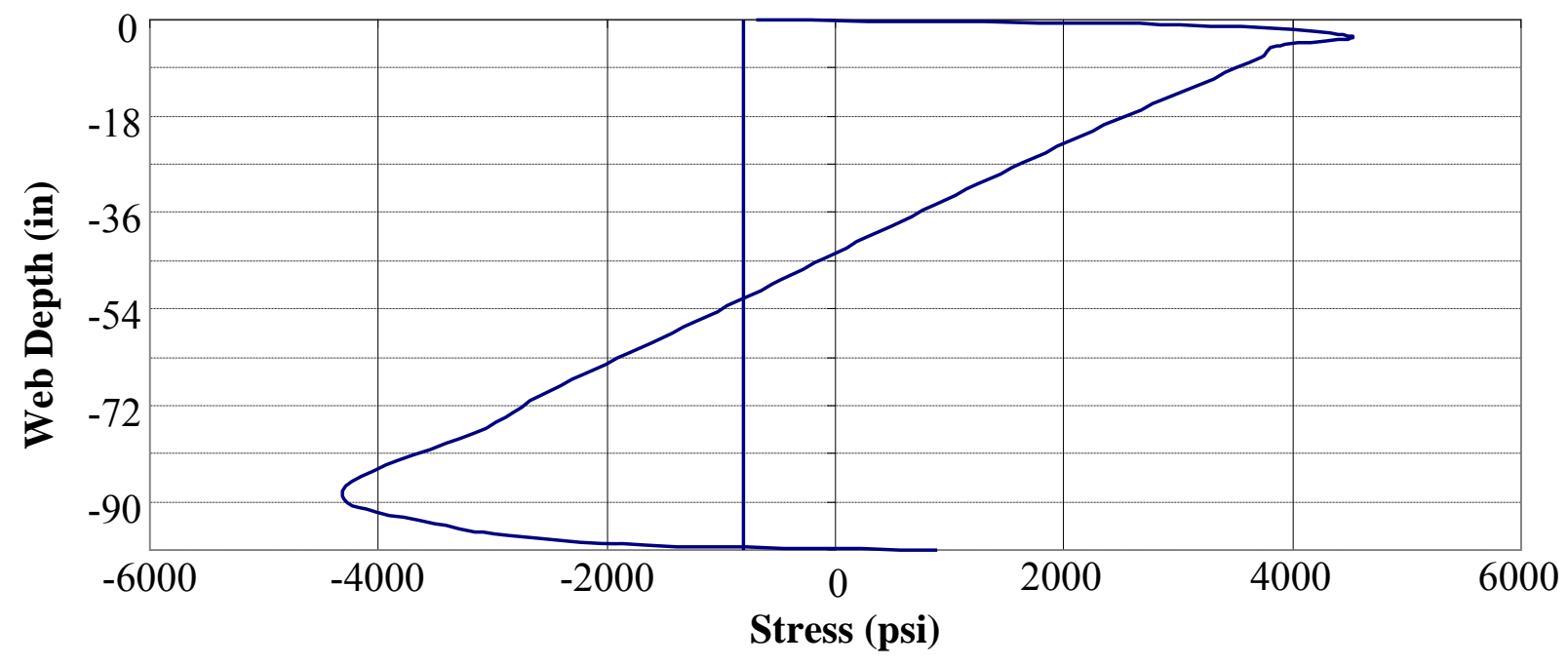

Figure D.3 Pier 9N, Bending and Axial Stress Profiles (Self-Weight)

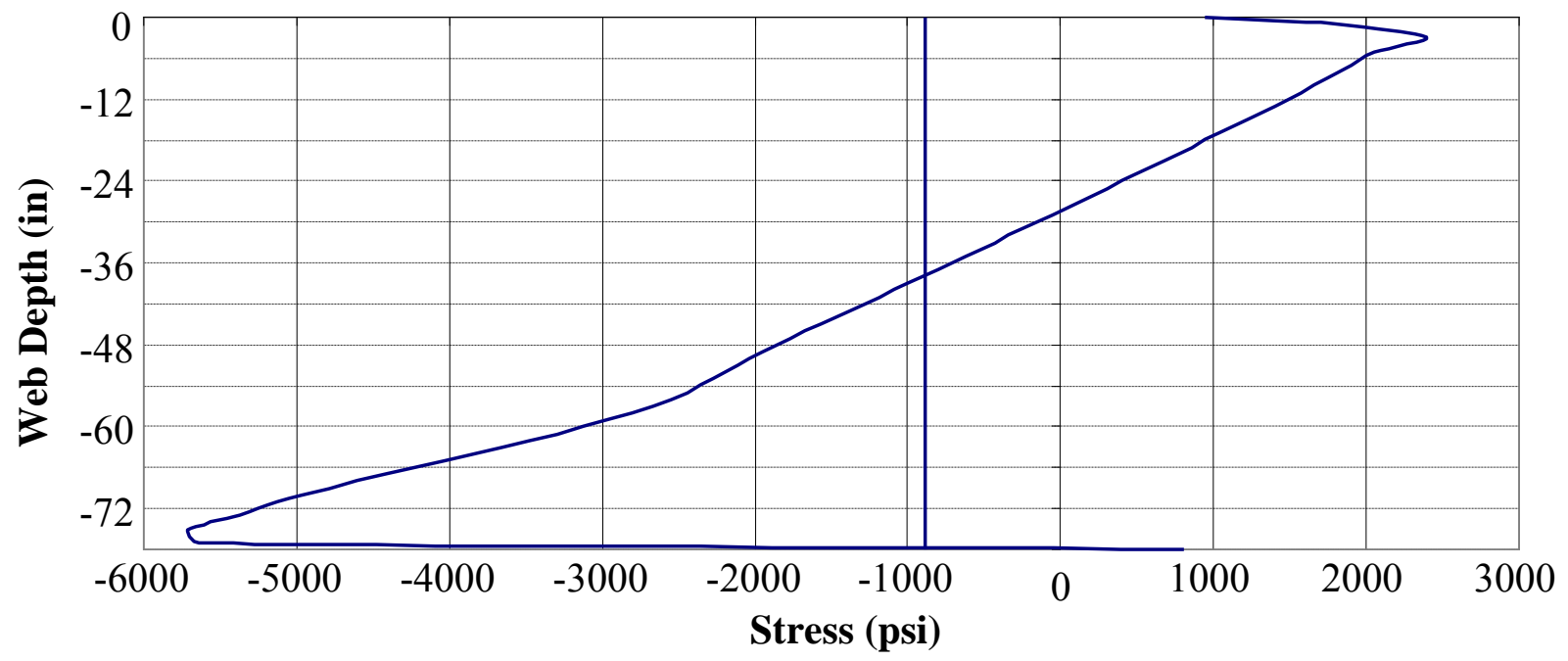

Figure D.4 Pier 10N, Bending and Axial Stress Profiles (Self-Weight)

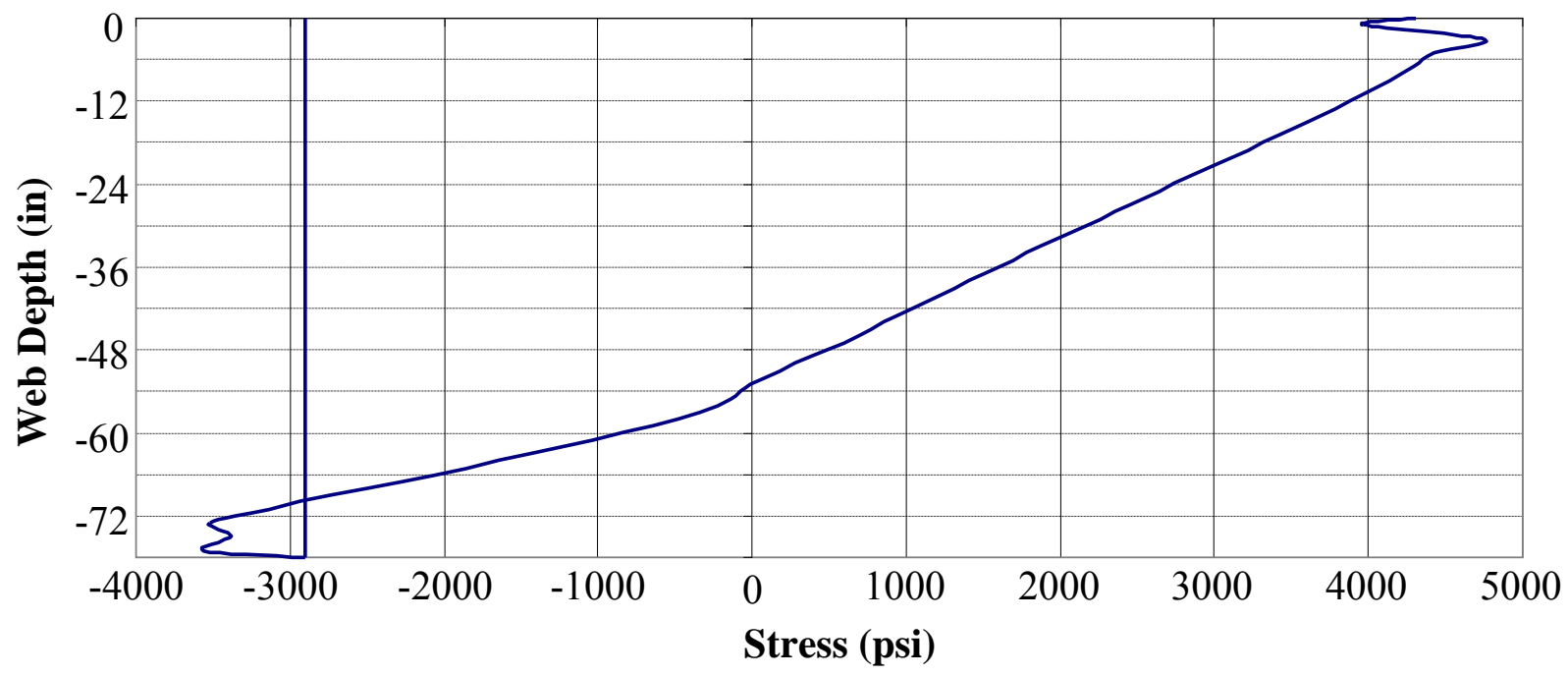

Figure D.5 Pier 11N, Bending and Axial Stress Profiles (Self-Weight) 


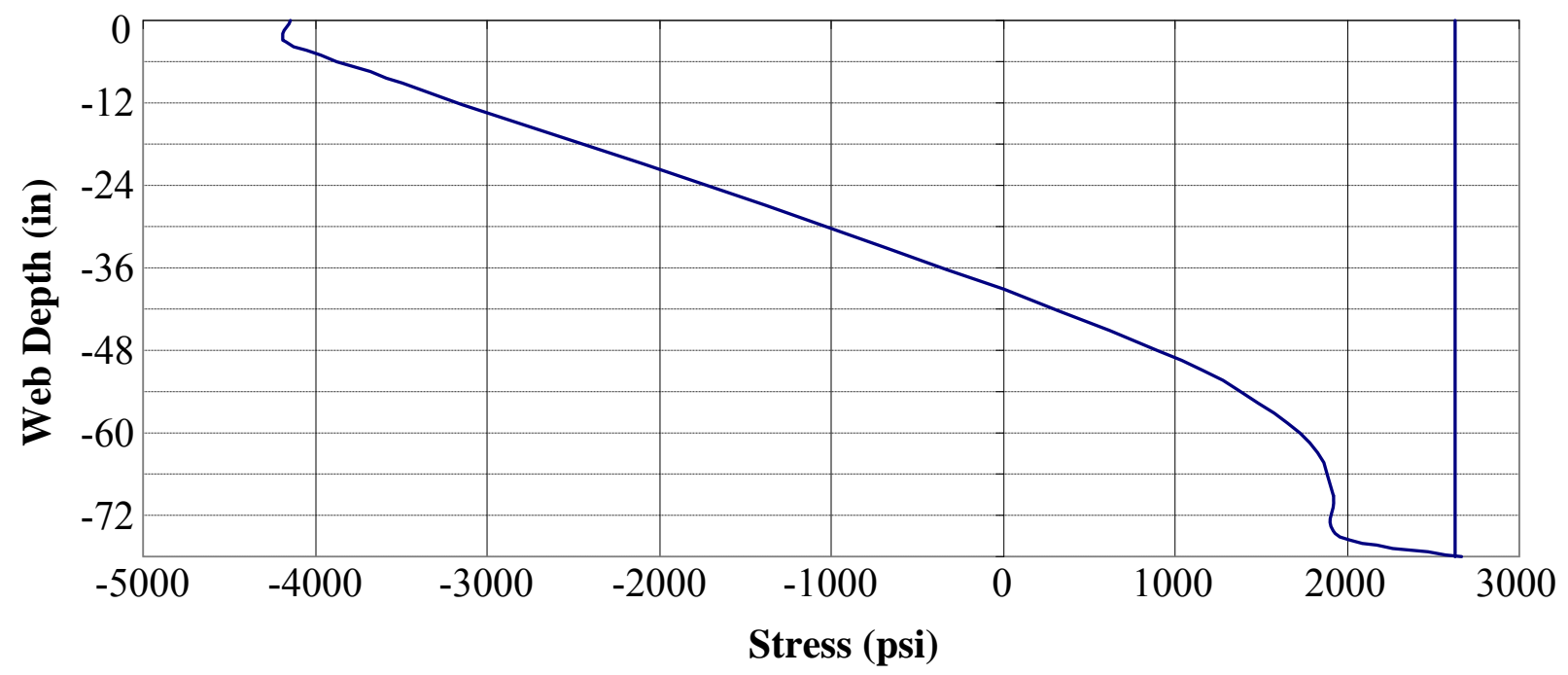

Figure D.6 Span 7N, Bending and Axial Stress Profiles (Self-Weight)

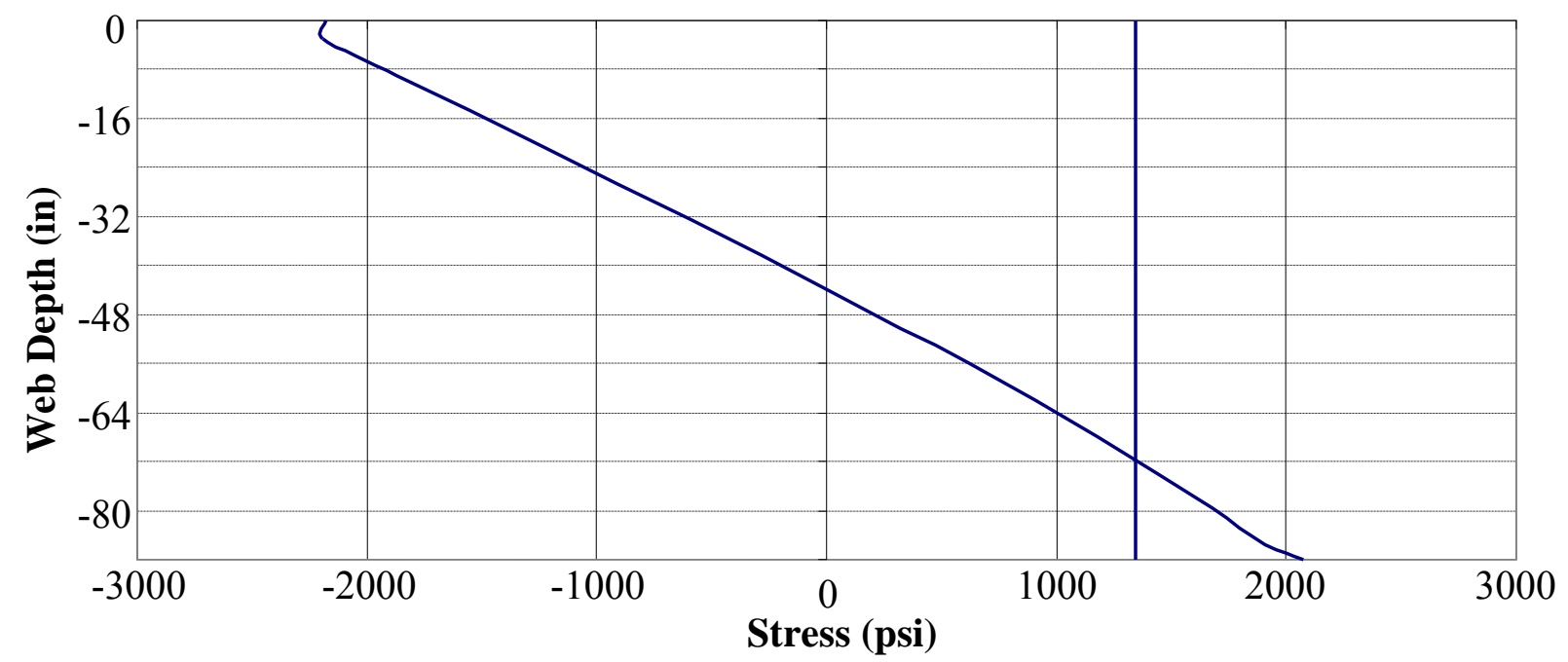

Figure D.7 Span 8N, Bending and Axial Stress Profiles (Self-Weight)

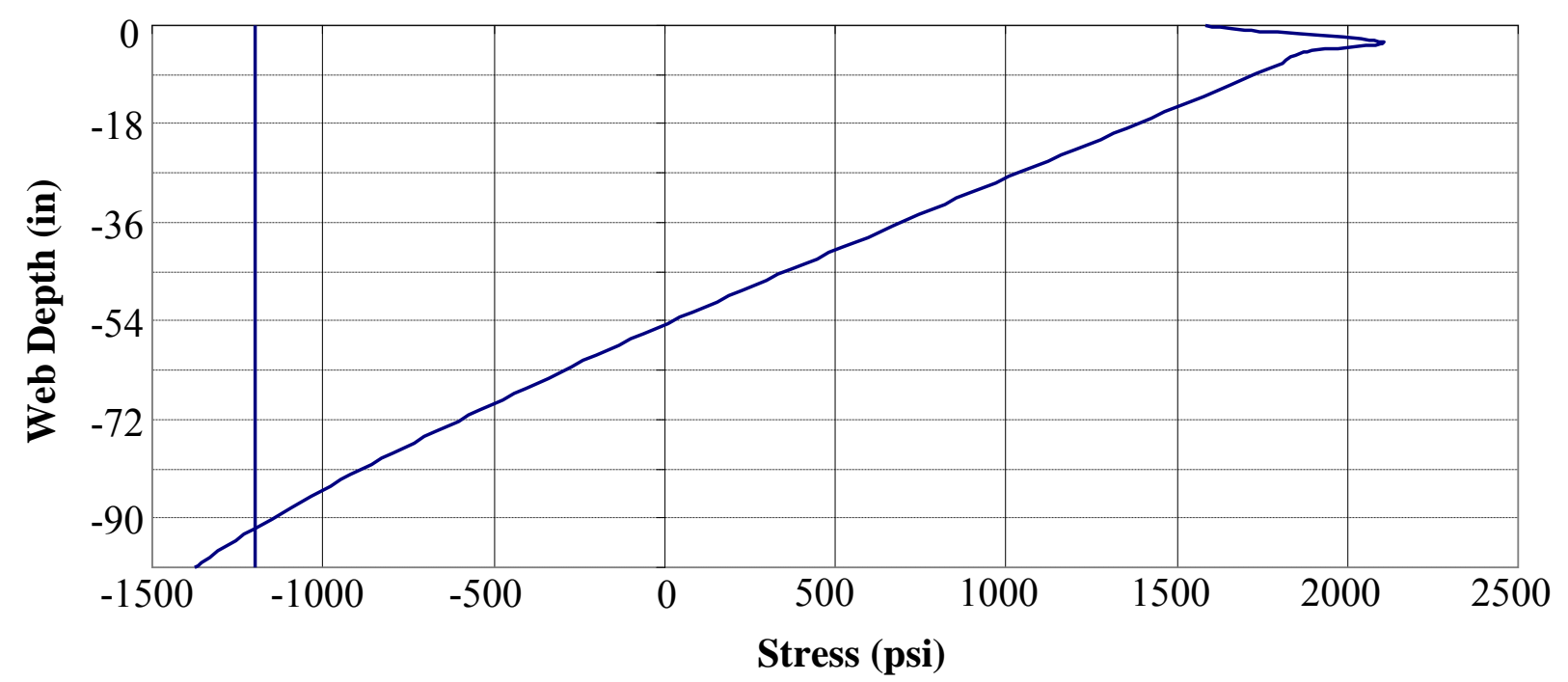

Figure D.8 Span 9N, Bending and Axial Stress Profiles (Self-Weight) 


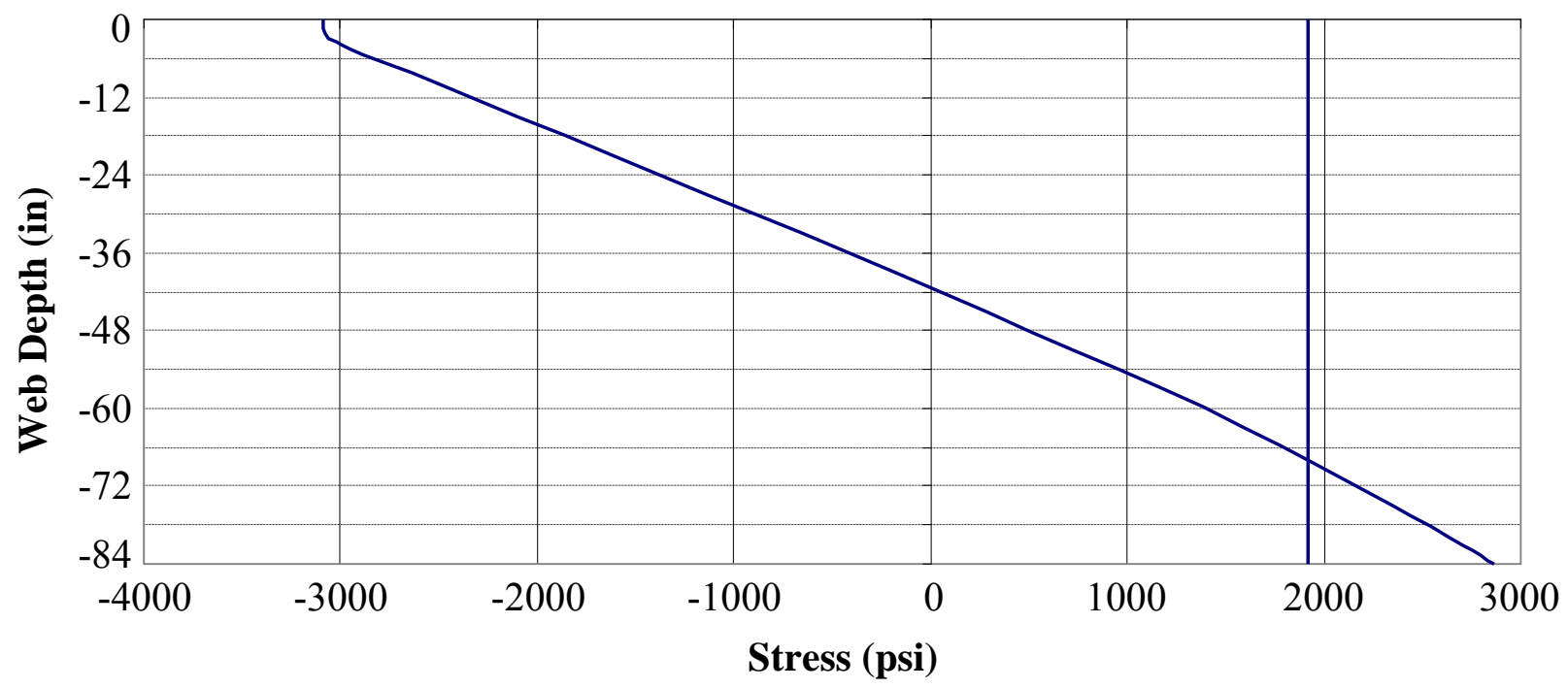

Figure D.9 Span 10N, Bending and Axial Stress Profiles (Self-Weight)

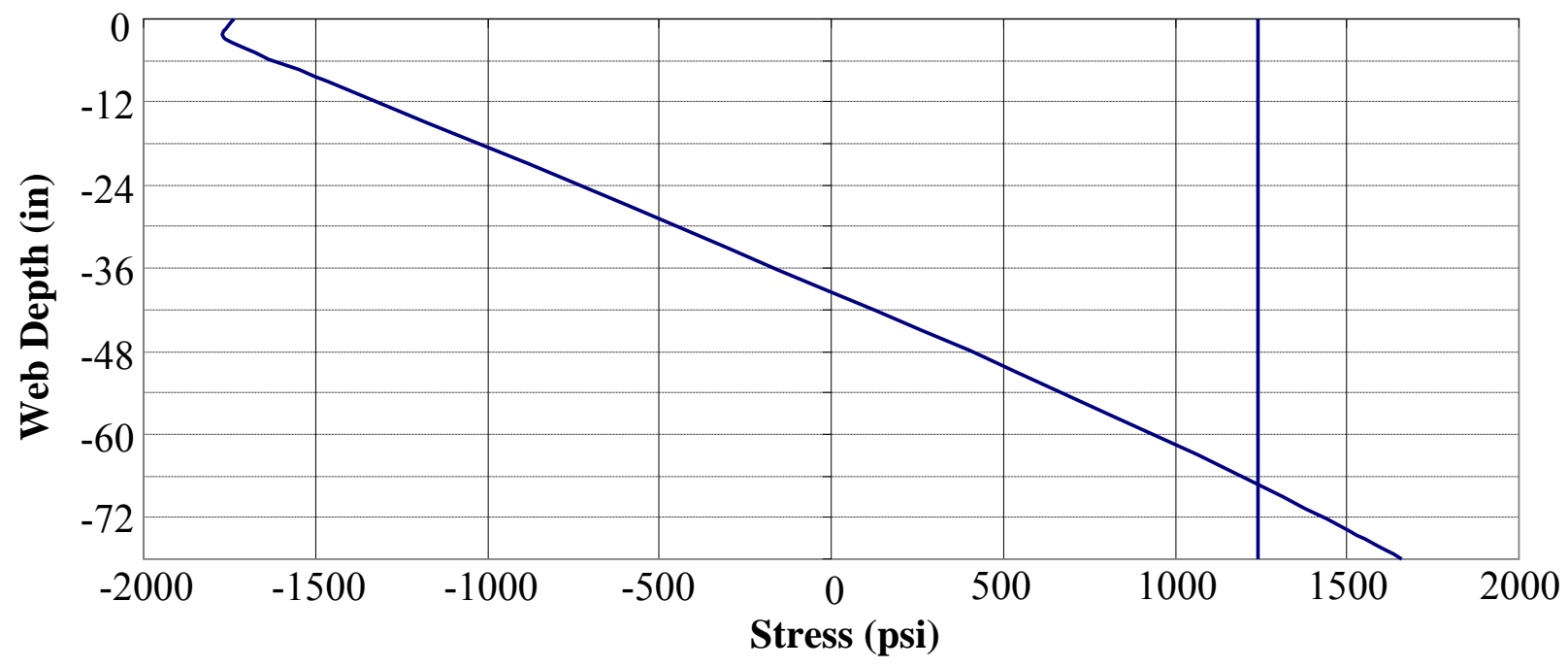

Figure D.10 Span 11N, Bending and Axial Stress Profiles (Self-Weight) 


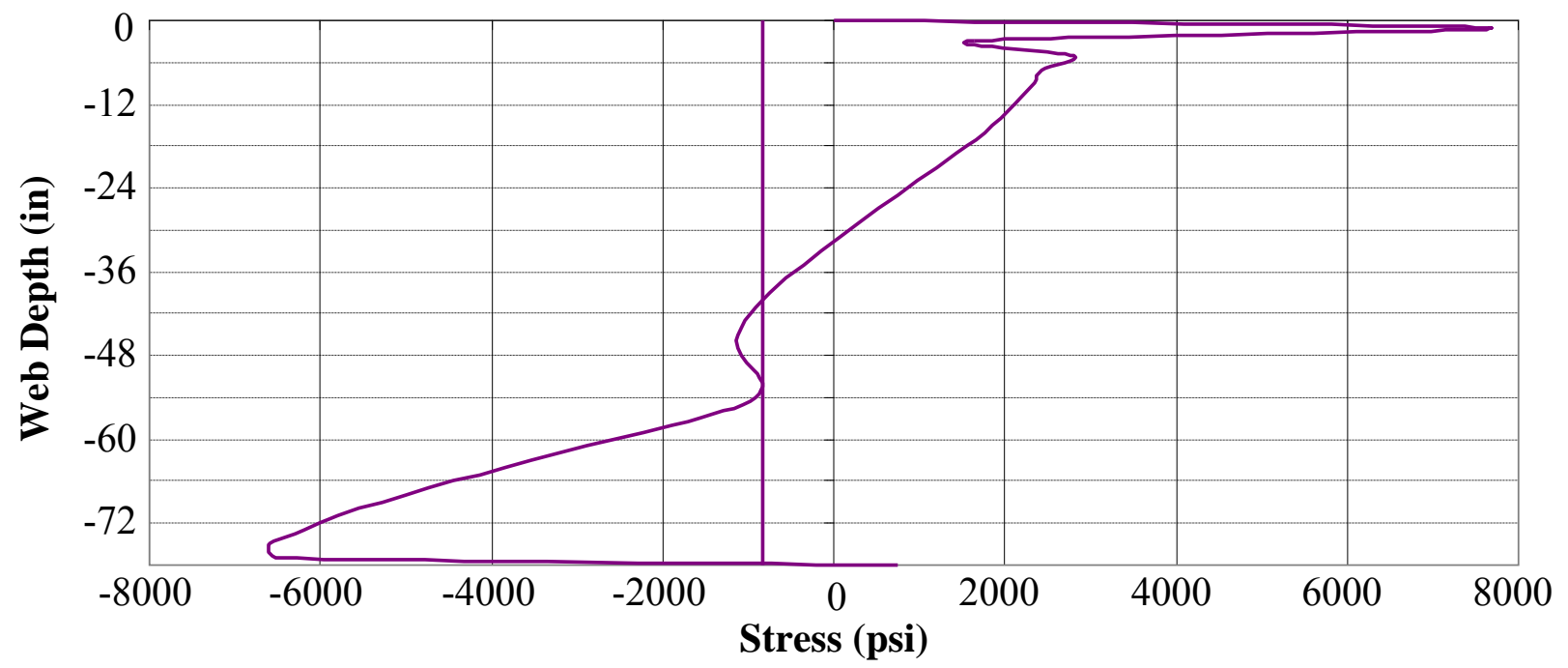

Figure D.11 Pier 7N, Bending and Axial Stress Profiles (Temp $-60^{\circ} \mathrm{F}$ )

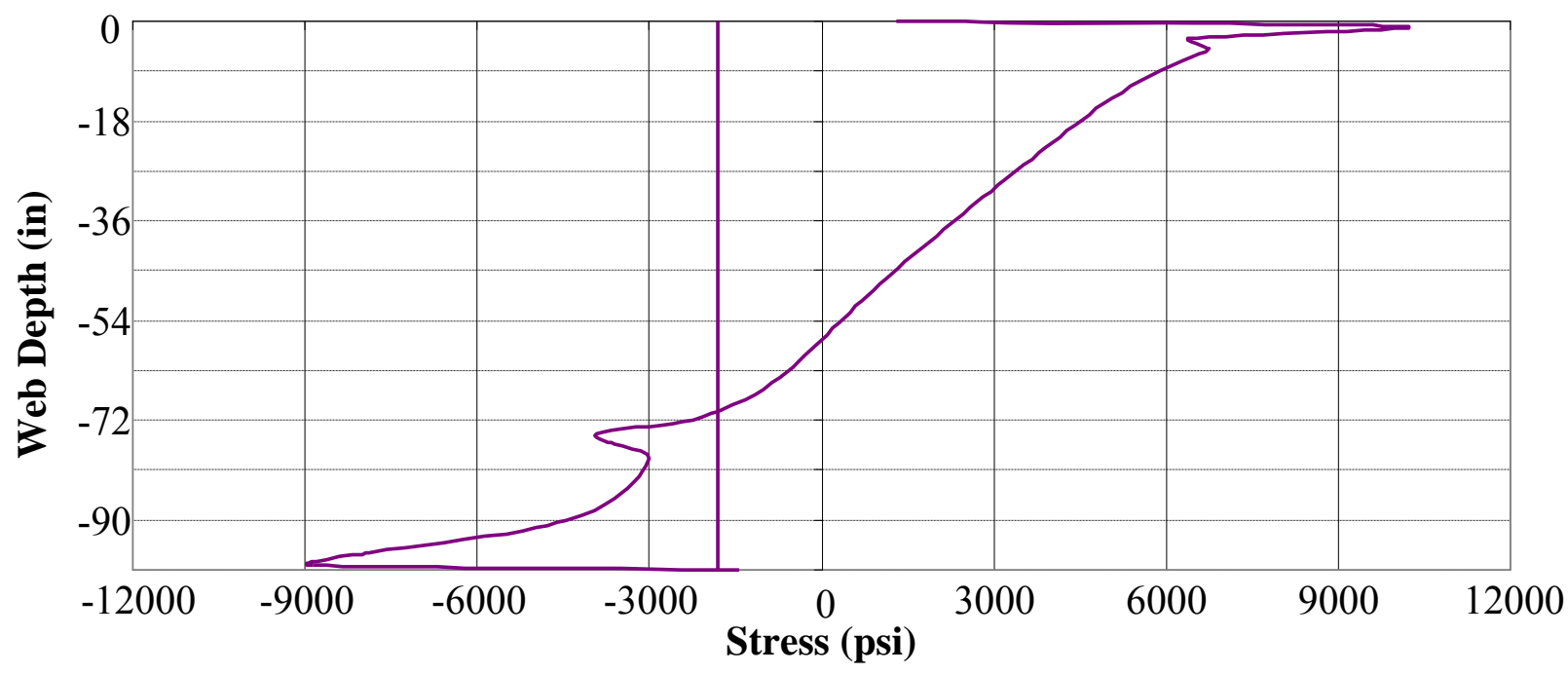

Figure D.12 Pier 8N, Bending and Axial Stress Profiles (Temp $\left.-60^{\circ} \mathrm{F}\right)$

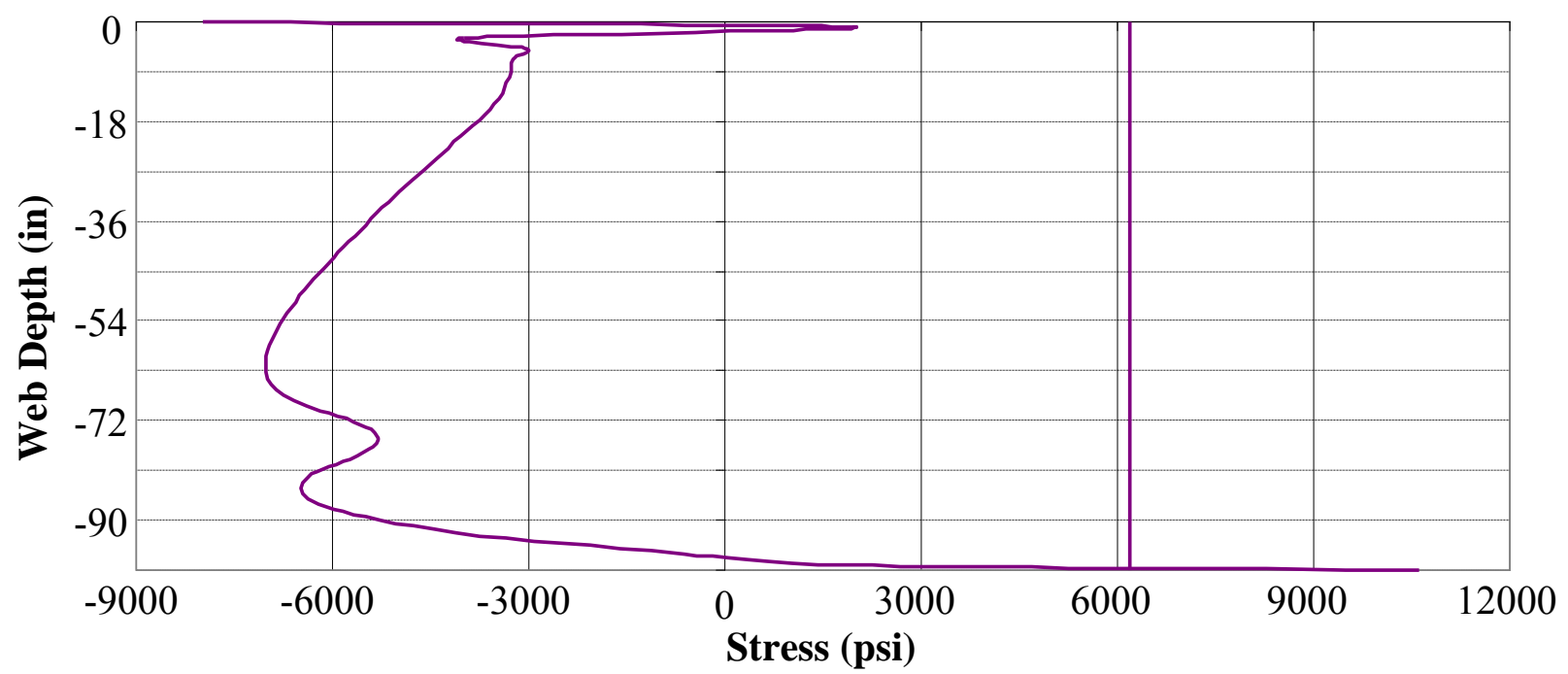

Figure D.13 Pier 9N, Bending and Axial Stress Profiles (Temp $\left.-60^{\circ} \mathrm{F}\right)$ 


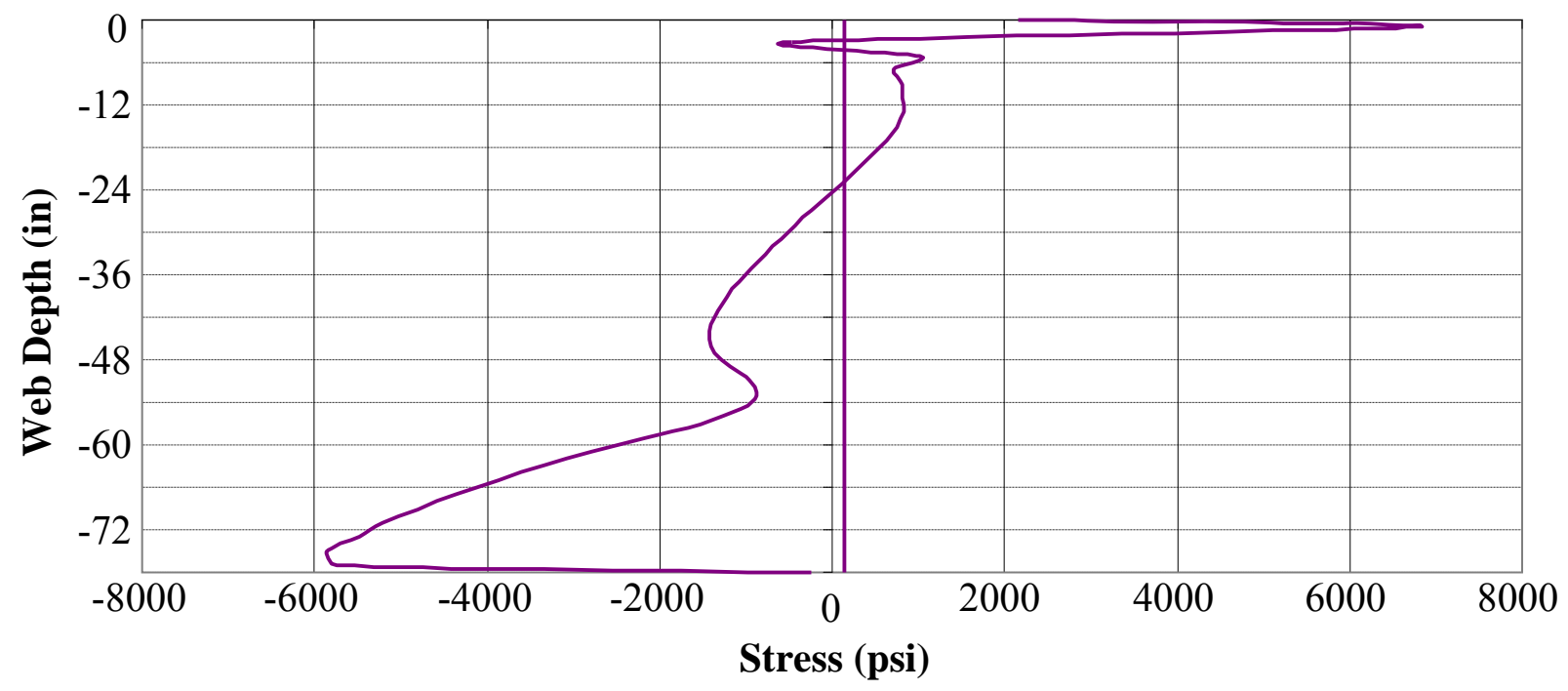

Figure D.14 Pier 10N, Bending and Axial Stress Profiles (Temp $-60^{\circ} \mathrm{F}$ )

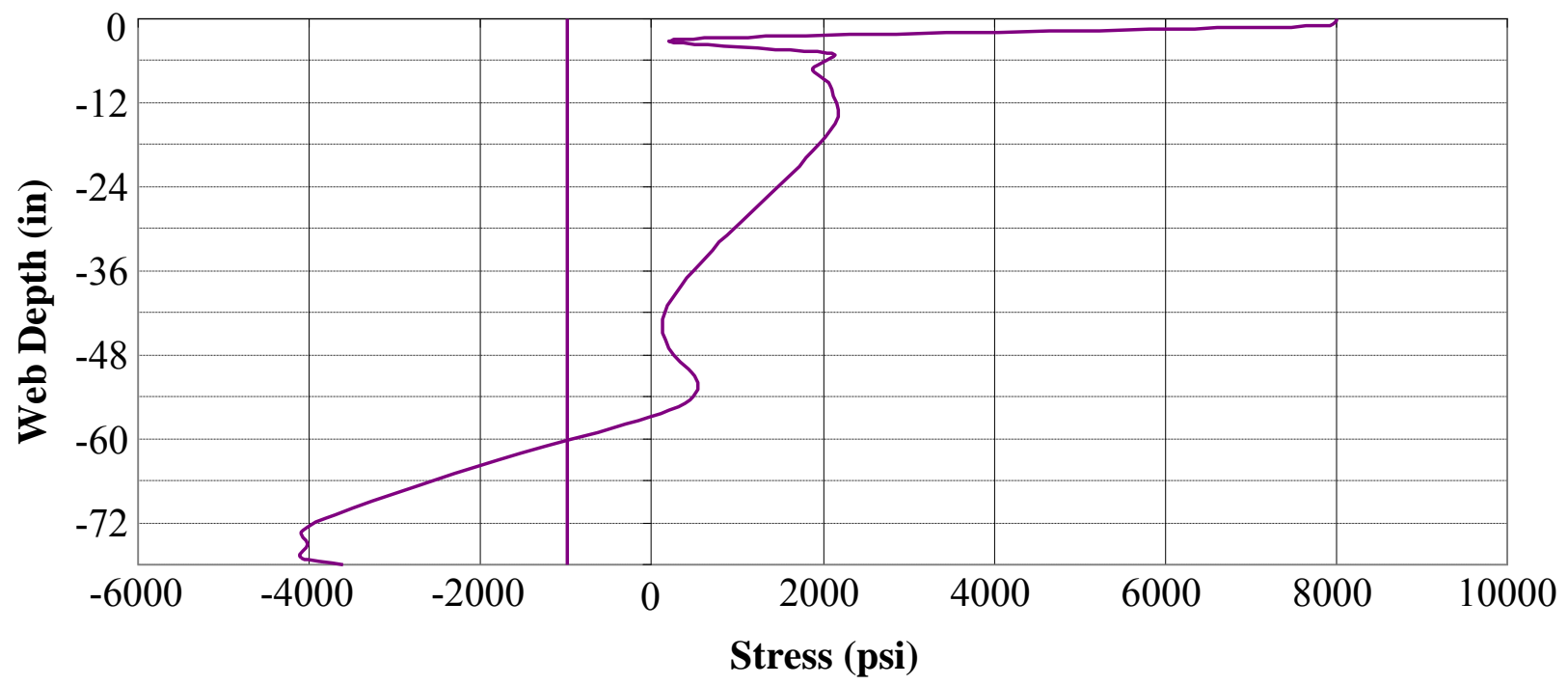

Figure D.15 Pier 11N, Bending and Axial Stress Profiles (Temp $-60^{\circ} \mathrm{F}$ ) 


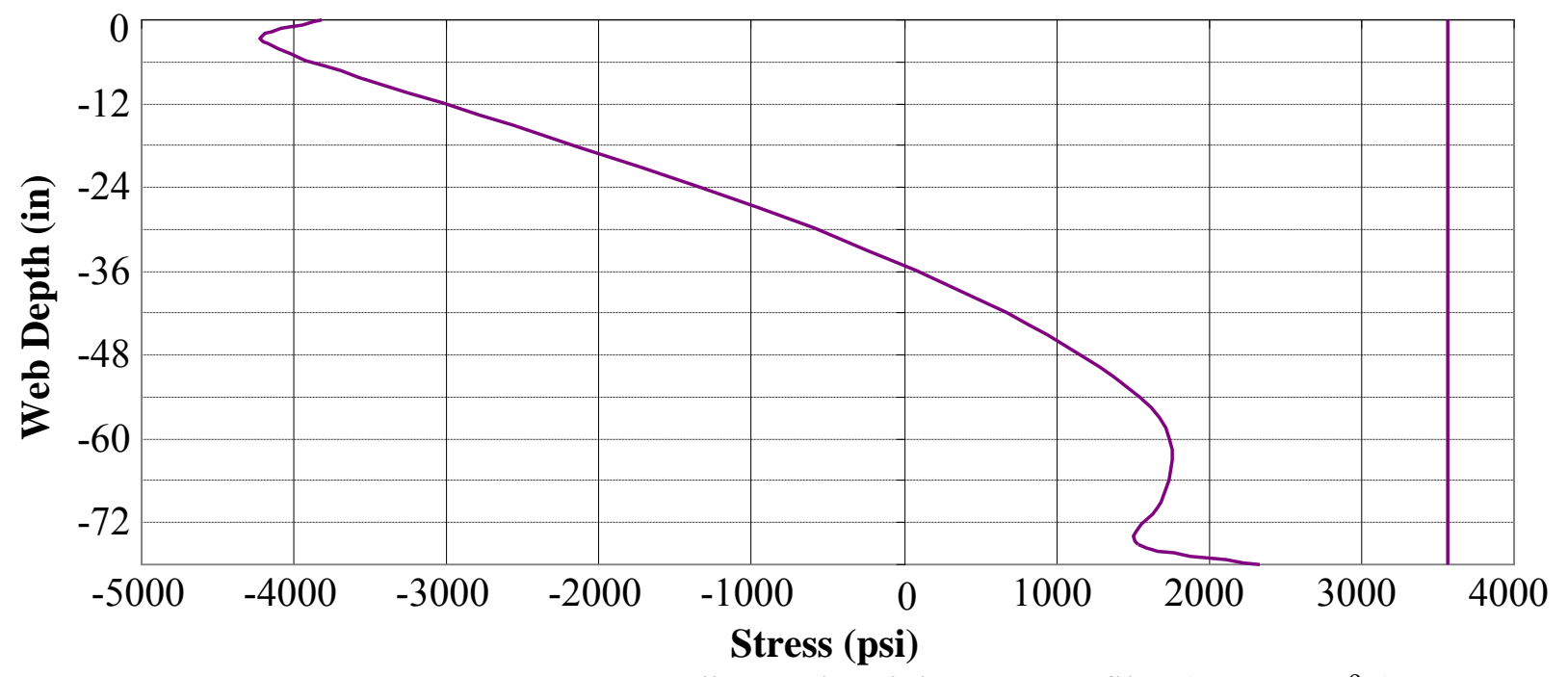

Figure D.16 Span 7N, Bending and Axial Stress Profiles (Temp $-60^{\circ} \mathrm{F}$ )

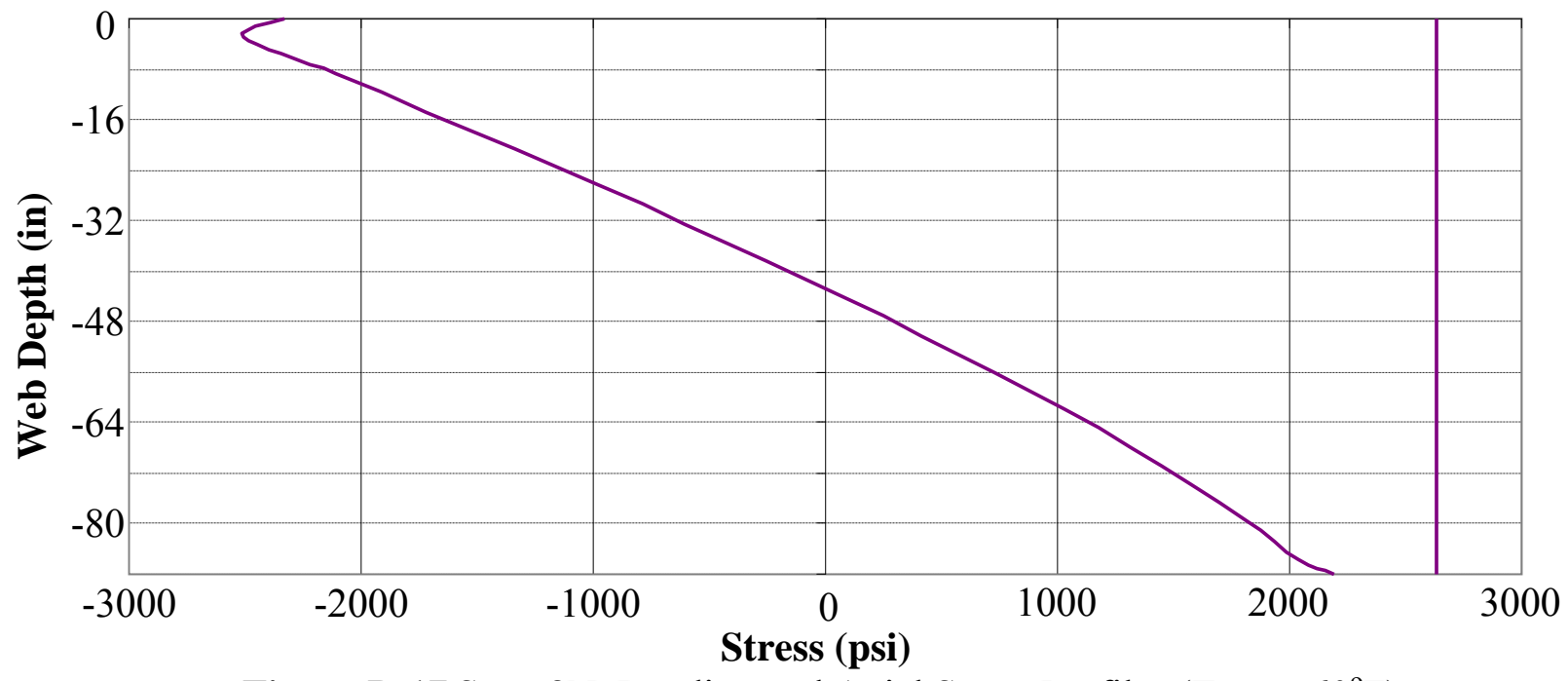

Figure D.17 Span 8N, Bending and Axial Stress Profiles (Temp $-60^{\circ} \mathrm{F}$ )

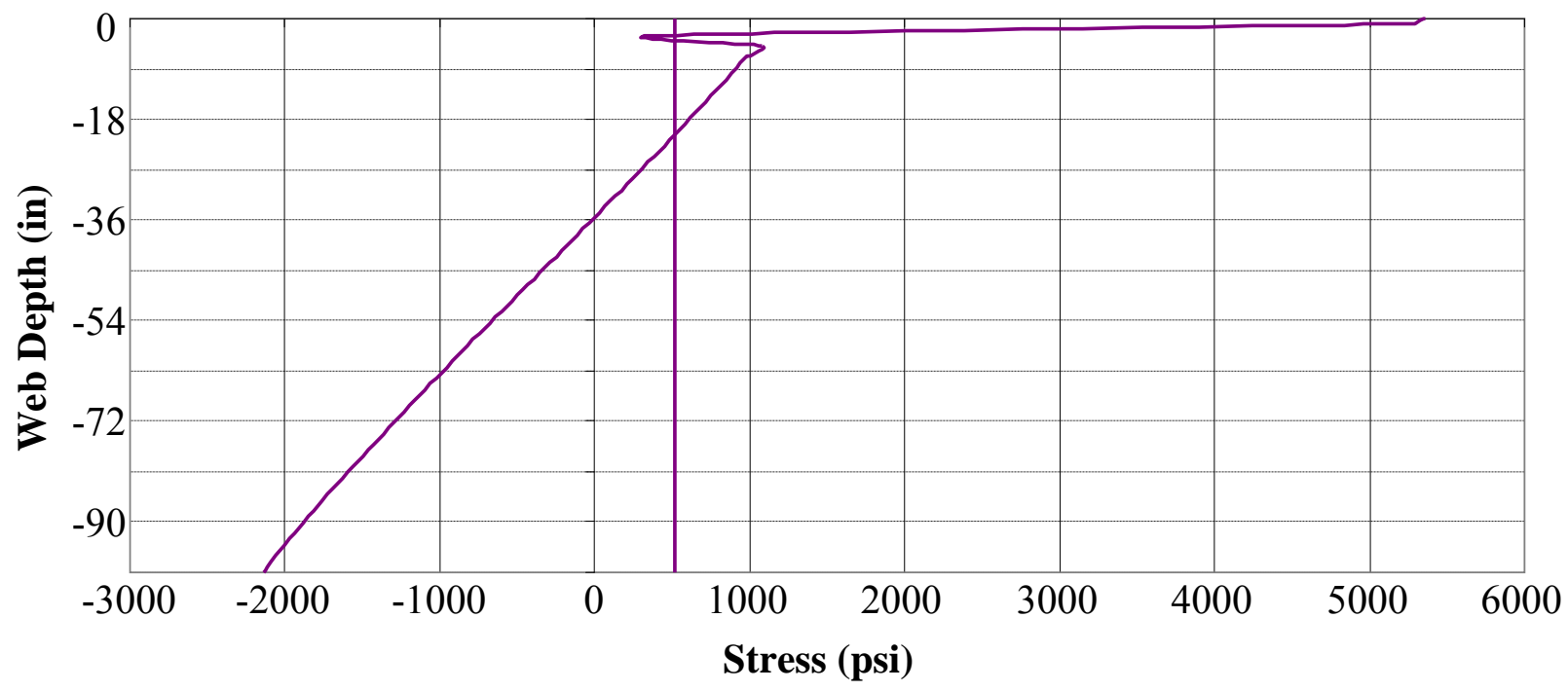

Figure D.18 Span 9N, Bending and Axial Stress Profiles (Temp $-60^{\circ} \mathrm{F}$ ) 


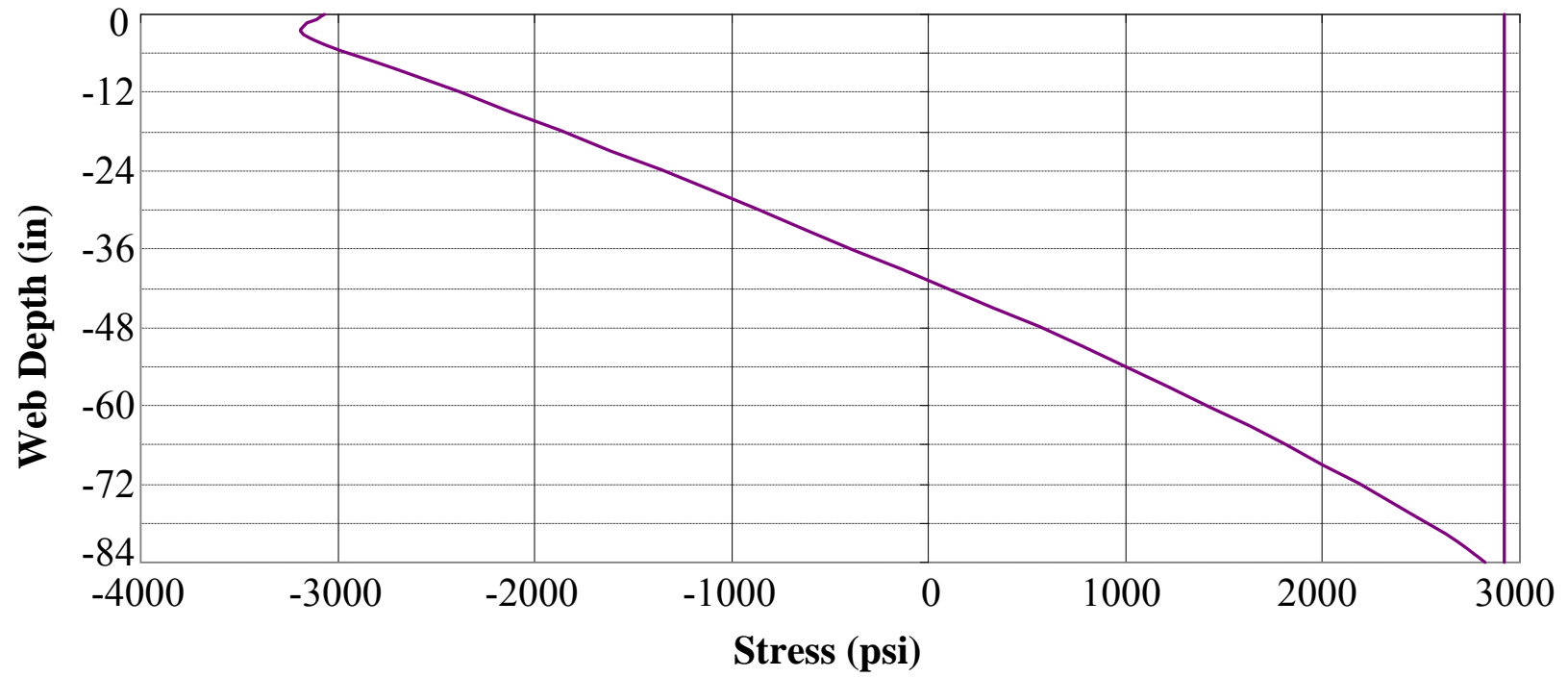

Figure D.19 Span 10N, Bending and Axial Stress Profiles (Temp $-60^{\circ} \mathrm{F}$ )

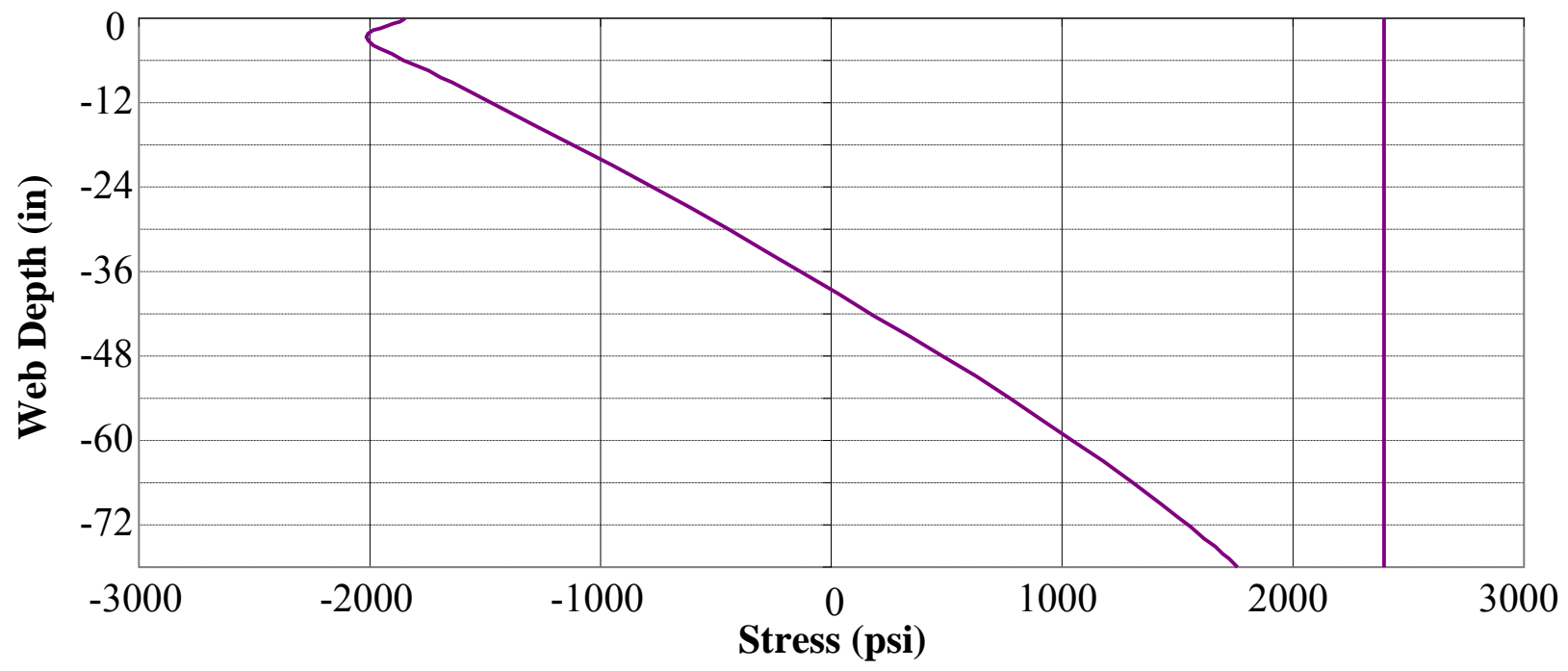

Figure D.20 Span 11N, Bending and Axial Stress Profiles (Temp $-60^{\circ} \mathrm{F}$ ) 